


\section{LIBRARY OF THE HORTICULTURISTS' LAZY-CLUB. CORNELL UNIVERSITY.}

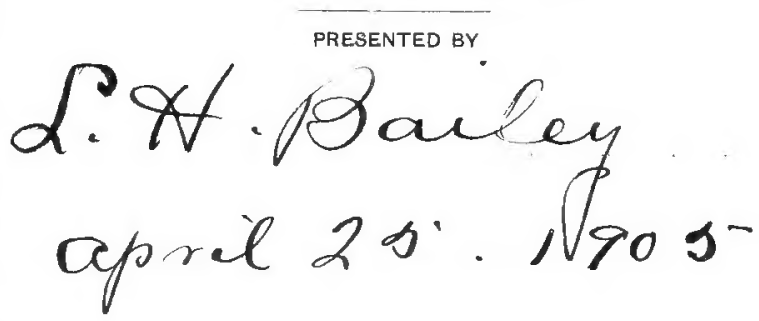

N. B.-Inscribe the date, post-office address, course of study, and the like. 
Cornell University Library

QK 47.085

Experiments with plants,

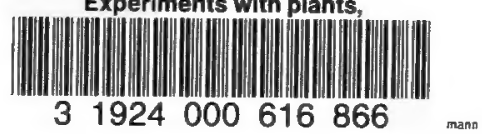




\section{Cornell University Library}

The original of this book is in
the Cornell University Library.

There are no known copyright restrictions in the United States on the use of the text.

http://www.archive.org/details/cu31924000616866 


\section{EXPERINENTS WITH PLANTS}




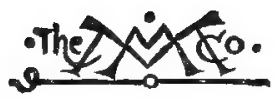




\section{EXPERIMENTS WITH PLANTS}

BY

IV. J. T. OSTERHOUT, Рн.D.

ASSISTANT PROFESSOR OF BOTANY IN TEE UNIVERSITY OF CALFORNIA

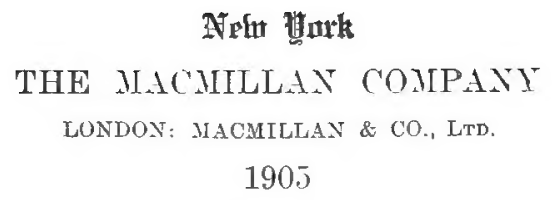

All rights reserved 
Copraight, 1905

BY 'FHE MACMILLAN IOMI'ANY

Set up aud electrotyped Apxil 1905 


\section{PREFACE BI L. H. BAILEY}

My plan for a series of popular botanical texts contemplated three books, - "Lessons with Plants," primarily for the teacher; "Botany," for the school; and "Experiments with Plants," to suggest and explain simple ways by which the pupil could be set at the working out of real problems in the growth and behavior of plants. The first two books have appeared. When I was working on the third, I chanced to visit the laboratory of $\mathrm{Mr}$. Osterhout at the University of California, at a time when he was instructing a class of teachers. I saw at once that he was better fitted than I to write the book; and, finding that he was contemplating a similar text, I gave up my enterprise and offered him the title of the proposed volume. It was at first intended that I collaborate in the preparation of the book, but insistent duties have interposed, and I have given it no personal attention; moreover, I did not feel that I could add to its usefulness; and again, a book made by two persons working so far apart, and one of them not now actively engaged in teaching, would be likely to lack homogeneity.

The introduction of laboratory work has been the great contribution of natural science to pedagogy. The laboratory sets the pupil at work with a personal and concrete problem; it develops the creative and active 
faculties, rather than the receptive; it asks the pupil what he has found out, rather than what he rememlers. The school is now reaching out to the larger problems of the environment, and to the affairs of men; for it is to touch life at every point. In this movement the labmatory is concerned; "onswantly, the laboratory is developing away from me object-teaching and mere piece-work, into a vital and genuine touch with phemomena as they occur under wholly natural or normal conditions; and there is also a tendeney toward the development of simple apparatus, in order that the pupil in even the humblest school may be reached. W $W^{*}$ now see that object-lesson teaching with natural history objects, and the giving of information about nature, are not nature-study: we must study the olyjects and phenomena in their natural relations. The schools are now ready for this point of view. They are growing planti in windows when they have no laboratories adapterl to the purpose; some of them are establishing school-gardens; they are appropriating the arljacent fields; and they are even drawing on private gurlus and farms.

The ideal plant teaching, it seems to me, begins always with function and essential life relations, even with young children. I like thr titles of Professor Osterhout's chapters, - the "work" of roots and leaver and flowers; and I am glad that he relates the subject to the affairs of men ly including a dismssion of plantlinesuling.

(GLLFGE OF AGRICULTURF

L. H. BAILEY,

('ORNGl, University, IthacA, N. Y. 


\section{INTRODUCTION}

THE numerous questions which young people ask about plants are best answered by themselves. No other inethod gives vital knowledge so quickly and satisfactorily; in no other way is a real grasp of the subject obtained. To put them in the way of doing this so far as possible is the object of this book. To this end familiar plants have been chosen, familiar utensils used in the construction of apparatus and the conditions simplified as far as may be. The book may be used by both teacher and pupil: the order of topics rnay be followed or not, as seems best under the circumstances.

In order that the knowledge gained in the classroom and out of it may be organized, notes should be kept: lut the note-taking should not be made a burden. The following outline of work has been found successful.

1. The Question: this, it may be said, should be a real one in which the class as a whole takes an interest, not a formal affair in the nature of an imposed task. 
2. The Method: i. e., how the question is to be answered, by observation or by experiment. In the latter case a simple sketch of the apparatus should be made.

3. The Material: i. e., what plants are to be used, how many and in what condition.

4. Times of observation of the experiment, e. g., every hour, every day, etc.

5. Precautions and sources of Error: these should be discussed as fully as possible before starting the experiment. Such discussion provokes thought, criticism and lively interest. Never forget to have control experiments.

6. Results: these should be presented concisely and clearly, in tabular form when possible.

7. Conclusions: distinguish between what is proven and what is indicated or rendered probable. Discordant results should be given full consideration: they often suggest a new experiment or a repetition under modified conditions.

8. Practical Applications and Related Matters: under this head the general knowledge and the miscellaneous observations of the class may be organized and crystallized into something definite. Information should be obtained from farmers, gardeners and other practical men, the discussion of which will provoke now questions and experiments.

Notes may be made under each of these heads, 
It is advisable to use a separate loose sheet for each question or experiment. The drawings should be inked with India ink; this can be lone outside the class room: a drawing pen is not necessary - any sood fine pen will do. A single bottle of India ink will supply a class, as very little is used.

Where each experiment is to be done by each individual, a laboratory is necessary: where each is to be done by a group or section of the class, only a limited space is needed: where each is done by the class as a whole, a single shelf in front of a window and a drawer beneath to hold the utensils will suffice. For most of the experiments such plants have been suggested as will grow even with poor light and under discouraging conditions. This is an especially important consideration, in view of the fact that the average schoolroom is a very poor place to grow plants.

While the microscopic work suggested is of the simplest kind, it may often be necessary to restrict it to demonstrations only or to omit it altogether.

The principle involved is the thing of prime importance in all the experiments. Exact quantitative results are not necessary, nor is it desirable at this stage to spend much time or effort in trying to obtain them.

It may be added that practically all the experiments have been successfully tried in the schools, many of them in the lower grades. 
It gives me much pleasure to make acknowledgement for helpful criticisms to Prof. W. A. Setchell, Prof. L. H. Bailey, Prof. R. A. Harper, and Prof. E. W. Hilgard. For Figs. $88 \alpha$ and 151 I am indebted to Prof. R. H. Loughridge; for Figs. 3.) and 36 to Prof. L. H. Bailey; for Fig. $148 a$ to $\mathrm{Mr}$. C. K. Tuttle; for Fig. 103 to $\mathrm{Mr}$. N. L. Gardner' for Figs. 23a, 201 and $2(1)$ to Mr. L. E. Hunt; for Figs. 92, 93, and 94 to Prof. E. W. Hilgard; for Figs. 231 to 236 and :40 to 24.5 to Mr. Luther Burbank, and for Figs. 249, 250, 2.5 and 2.5.3 to Prof. Hugo de Vries. A few figures have been redrawn from English or European sources. The line drawings are, with few exceptions, the work of Mr. H. N. Bagley, and the photographs, except "' noted above, are by Mr. B. F. White.

BEREELFE, ('A I IV. J. I. OSTERHOUT.

January, 1905. 


\section{CONTENTS}

CHAPTER

PARt

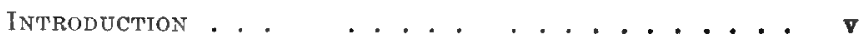

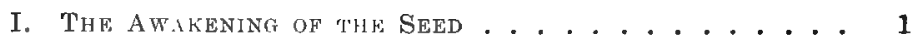

1I. Getting Established ............... 69

III. The Work uF Roots. .............. . 87

IV, The Work of Leaves ............... . 163

V. The Work (fF SteMs. ........... . . 224

VI. The Work of Flowers . . . . . . . 286

VII. THE WORK (IF FrUITS . . . . . . . 312

Viti. How Plants are Influenced by Their Sitrobolndings . . 326

fX. Plants Whir'h Cause Decay, Fromentation and Disease o 361

X. Making New Kinds of Plants ......... . . 406

INDEX .................. . . . 455 



\section{LIST OF ILLUSTRATIONS}

Fig.

FAGE

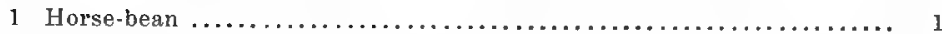

2 Horse-bean opened $\ldots \ldots \ldots \ldots \ldots \ldots \ldots \ldots \ldots \ldots \ldots \ldots \ldots \ldots \ldots \ldots \ldots \ldots$

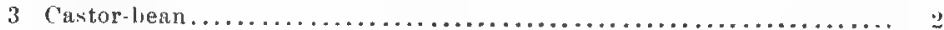

4 Castor-lean openerl $\ldots \ldots \ldots \ldots \ldots \ldots \ldots \ldots \ldots \ldots \ldots \ldots \ldots \ldots \ldots \ldots$

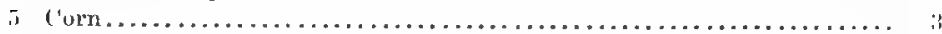

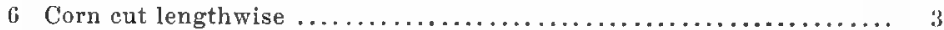

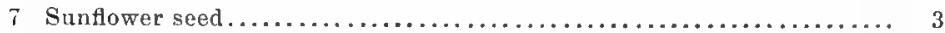

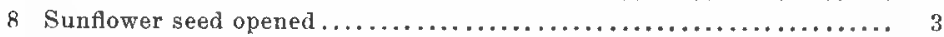

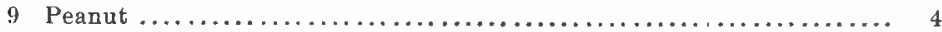

10 Peanut opener......................................... 4

11 Arrangement for keeping seeds on ice................... 5

12 A bottle containing seeds, flled with water and corked air-tight..... 5

13 A method of determining whether air-dry seeds contain water ........ 7

14 A bean placed in water, showing successive stages in the process of wrinkling ........................................... 8

15 A method of determining whether openings exist in the seed-covers... 8

16 An arrangement for holding seeds while under water............. 9

17 A home-made balance constructed of umbrela wire.............. 13

18 A modification of the balance ............................ 14

19 A method of keeping seeds balf-submerged, in order to discover how

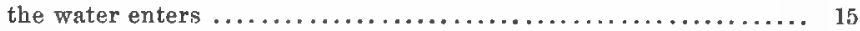

20 Seed-covers floating on water .......................... 16

¿1 Modification of the experiment shown in Fig. $20 \ldots \ldots \ldots \ldots \ldots \ldots \ldots \ldots .19$

22 Searlet Runner Bean opened, showing the pocket into which the caulicle

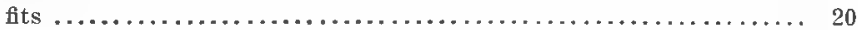

23 Seeds half-submerged in wet sand, to determine how the water enters., 21

$23 a$ Three rows of corn planted at the same time, each grain being halfburied in the moist soil..............................

24 Walnut divided in half, showing the wick-like central strand ....... 23

25 Seeds placed in a saturated atmosphere $\ldots \ldots \ldots \ldots \ldots \ldots \ldots \ldots \ldots \ldots . \ldots$

$\because 6$ Another method of keeping seeds in a saturated atmosphere ......... 27

27 Method of maintaining a saturated atmosphere and a constant waterlevel........................................ $\boldsymbol{q} 7$

28 Method of testing the permeability of the seed-cover to air........ 30 
29 Seeds on wet sand with different amounts of air at their disposal.....

30 Apparatus for determining whether germinating seeds produce carbon

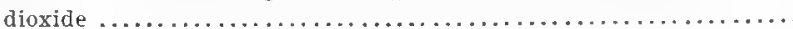

31 Method of measuring the amount of carbon dioxide produced by ger-

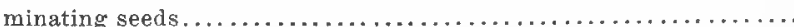

32 Method of measuring the temperature of germinating seeds...........

33 Method of determining whether air exists in the soil..............

34 Apparatus for determining how deep seeds should be planted.........

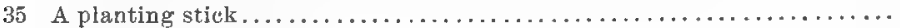

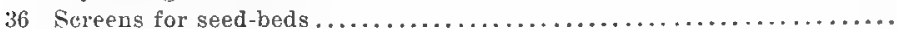

37 Method for testing the permeability of the seed-cover to heat .........

38 Arrangement for testing the swelling power of a single seed .........

39 Arrangement for testing the swelling power of a mass of seerix .......

40 Apparatus for demonstrating that swelling seeds exert pressure ......

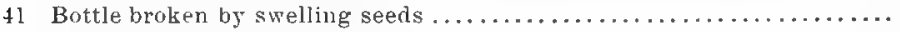

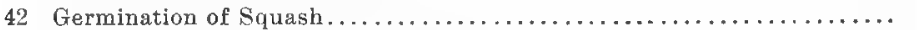

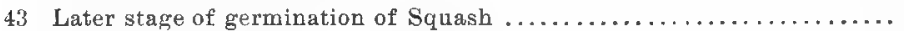

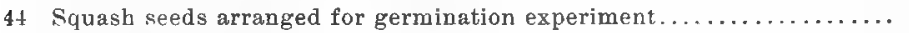

45 Germinating Cocoanut cut lengthwise ......................... 5

46 Buckeye cut open ....................................

47 Buckeye. Plumule emerging from between elongated stalks of seed-

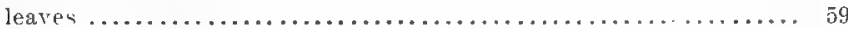

48 Buckeye. A later stage.................................. 59

4!) Buckeye. A still later stage ........................... 60

50 Scarlet Runner Bean germinating ....................... 60

51 Apparatus for demonstrating that osmosis exerts pressure .........61

52 Alparatus for measuring pressure due to osmosis ............... 62

53 Section of a bit of the seed-leaf of the Horse-bean ................. 65

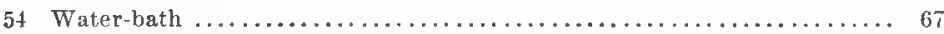

ij Filaree seeds burrowing into cotton ........................ 70

56 Corn making its way above ground $\ldots \ldots \ldots \ldots \ldots \ldots \ldots \ldots \ldots \ldots \ldots \ldots$

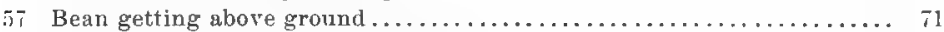

58 Castor-bean twisting itself into a loop $\ldots \ldots \ldots \ldots \ldots \ldots \ldots \ldots \ldots \ldots$ is

59 Apparatus for measuring the foree of the upward growth of the plant.. $7:$;

60 Modification of apparatus shown in Fig. $59 \ldots \ldots \ldots \ldots \ldots \ldots \ldots \ldots \ldots$ it

61 Arrangement for weighting an upward-growing sten ............ i.

62 Modification of arrangement shown in Fig. $61 \ldots \ldots \ldots \ldots \ldots \ldots \ldots \ldots . \ldots . \ldots . \ldots$

6.) Bean with stem marked to determine region of greatest growth...... i

(04 Contrivance for marking stems in manner shown in Fig. 63........ 78

(i.) Scarlet Runner Bean with top (terminal bud) removed ............ 79

66. Radish seedlings growing upward along the glass side of a box ...... 7 ?

67 Sunflower seedlings penetrating the soil...................

68 Squash reedlings endeavoring to penetrate the soil............. 81 
FIG.

69 Apparatus for determining bow much forct thr wot txerts in growing

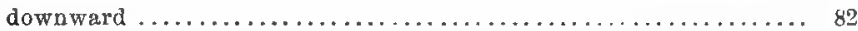

70 Apparatus for determining force of growth of a root............. 84

71 Root marked in order to determine the region of greatest growth .... 85

72 Plant attached to support ready to have root cut off.............. 87

73 Seeds pinned to corks which are floating on water ............. 88

It Seeds arranged with caulicles resting on mereury ............... 89

75 Arrangement for causing germinating seeds to revolve slowly ...... 91

76 Water-wheel for making germinating seerls revolve rapidly ........ 93

77 Arrangement for testing effect of moisture on direction of growth of roots ......................................... 95

78 Arrangement to test behavior of roots in moist air.............. 96

79 Arrangement for ascertaining whether roots grow in the direction of

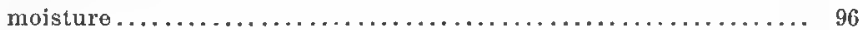

80 Apparatus for observing behavior of roots as they encounter ohstacles, 97

81 Apparatus designed to test behavior of side roots under the influence

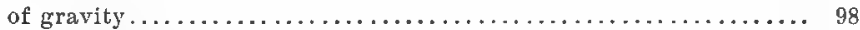

82 Modification of apparatus shown in Fig. $80 \ldots \ldots \ldots \ldots \ldots \ldots \ldots \ldots \ldots . . . . \ldots 9$

83 Radish stedlings showing root-hairs..................... 100

84 Root-hairs of Radish.................................. 101

85 Cutting of Wandering Jew in water, showing root-hairs . . . . . . . 102

86 Apparatus for measuring rate of evaporation from a saturated soil... 114

s. Method of supplying water to apparatus shown in Fig. 86 .......... I]4

88 Four lamp-chimneys filled with soil for the purpose of studying the

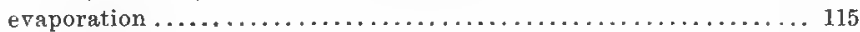

$88 a$ New growth on cultirated and uncultivated Apricot trees.......... 11i

89 Diagram of fairly dry soil showing relations of root-bair to surround-

ing particles . . . . . . . . . . . . . . . . . . . . . . . . . 119

90 Cross-section of a root as it grows in the soil................ 120

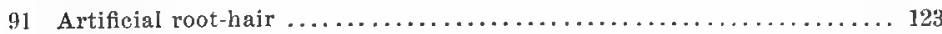

9:2 Diagram to illustrate effect of ideal plowing................ 126

9.3 Part of furrow slice (of Fig. 92) magnified to show flocenles or soil.

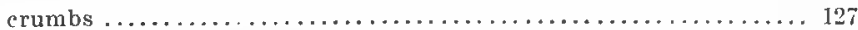

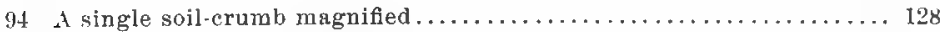

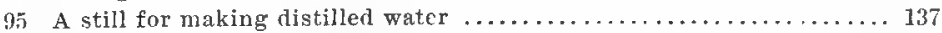

96 The result of a water culture of Wandering Jew................ 140

97 Apparatus to determine whether the root excretes acid . . . . . . . 143

98 Tubercles on roots of Clover ............................ 149

99 Two Scarlet Runner Beans of the same aye, from one of which the seerl-leaves were removed shortly after germination............ 163

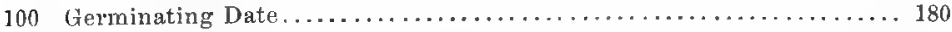

101 Leaf of English Ivy deprived of starch and placed in water........ 182

10. Arrangement for excluding light from a part of the leaf ........... 182 


\section{xvi LIST OF ILLISTRATIOYS}

FIG. PAGH

103 Two lots of Squash seedlings of the same age, one grown in light, the other in darkness..................................... 184

104 A seedling of Castor-bean ................................ 186

105 Apparatus for the decomposition of starch . . . . . . . . . . . . . . 186

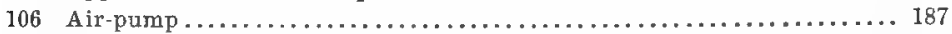

107 Details of piston of air-pump........................... 188

108 Air-pump with automatic arrangement to prevent piston from slipping back .............................................. 190

109 Details of piston of air-pump........................... 190

110 Arrangement for investigating the power of a leaf to "restore" air which has been "vitiated" by a burning candle ............... 191

111 Arrangement for collecting gas given off by a water-plant in sunlight 192

112 Apparatus for growing a leaf in air deprived of carbon dioxide....... 193

113 Section of leaf of common wild Yellow Mustard ................. 198

114 Section of leaf of Iris . ................................. 199

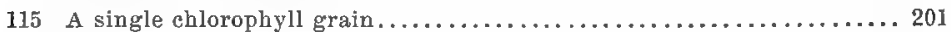

116 A single cell of a leaf with chlorophyll grains .................. 202

117 Arrangement for determining whether leaves give off water vapor.... 203

118 Method of inserting a leaf-stalk air-tight in a rubber stopper ........ 205

119 Apparatus for measuring transpiration of a leaf $\ldots \ldots \ldots \ldots \ldots \ldots \ldots . \ldots 206$

120 Diagram showing in section and surface view the form and position of guard-cells when elosed and open.................... 208

121 Guard-cells and neighboring cells of epidermis . . . . . . . . . . . . . 209

122 Artifieial stoma and guard-cells .......................... 210

123 Modification of part of apparatus shown in Fig. 12. . . . . . . . . . 211

124 Acacia leaf, night or sleep position ....................... 218

125 Acacia leaf, day position ..................................... 218

126 Leaf mosaic of Iry Geranium .......................... 219

127 Leaf mosaic of Chestnut .............................. 219

128 Upright branch of Periwinkle ........................... 220

129 Same branch seen from above ........................... 220

130 Horizontal (trailing) branch from same plant .................. 221

131 Diagram of cross-section of Squash stem ....................... 224

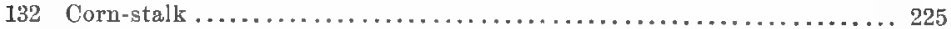

133 Stem of Squash (microscopic structure) ................... 227

134 Cross-section of a bundle of Corn .......................... 231

135 Oak branch (microseopic structure) ....................... 232

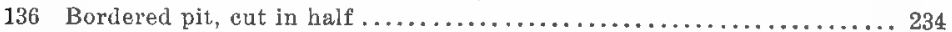

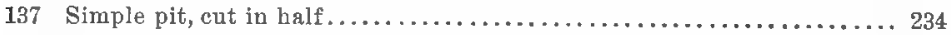

138 Pine branch (microscopic structure) ....................... 236

139 Method of injecting a twig by means of the air-pump ........... 237

140 Arrangement for forcing water through a branch . . . . . . . . . . . . 238

141 Modification of arrangement shown in Fig. $140 \ldots \ldots \ldots \ldots \ldots \ldots \ldots . . . .240$ 
142 Method of measuring the amount of bleeding from a stump (root pres-

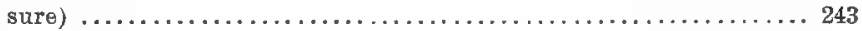

$142 a$ Buttress formed on the lower side of a branch................ 248

143 Terminal part of a growing branch showing the three regions of growth 249

144 Bud of Brussels Sprouts cut lengthwise................... 250

145 Portion of tree trunk near a burl ......................... 262

146 Diagram showing effect of weight applied to end of a heam ....... 265

147 Diagram of a girder................................. 266

148 Diagram showing the girder-like arrangement of strengthening tissues

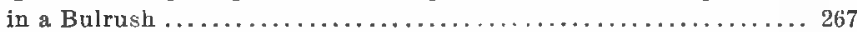

149 Cross-section of a portion of a Cahbage leuf $\ldots \ldots \ldots \ldots \ldots \ldots \ldots \ldots 7$

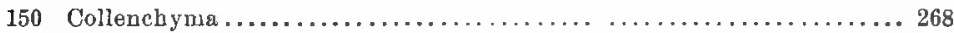

151 Clematis climbing on an evergreen...................... 271

152 Behavior of a strip of flower-stalk of Dandelion in water.......... 273

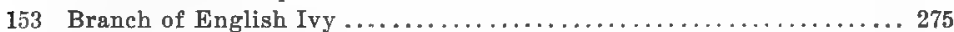

154 Method of investigating lenticels........................ 279

155 Metbod of investigating entrance of air into stem by way of stomata 280

156 Method of investigating entrance of air into stem hy way of stomata

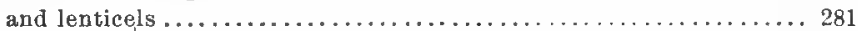

157 Willow twig suspended in a saturated atmosphere.............. 281

158 Apparatus for supplying air in a constant stream to an aquarium .... 283

159 Arrangement for supplying carbon dioxide to plants growing in water 284

160 Arrangement for growing water-plants in contact with a bubble of carbon dioxide or air ............................. 285

161 Cherry blossom cut open to show the parts of the flowr. $. \ldots \ldots \ldots . \ldots 288$

162 Ovary (seed-case) of Oat, with feathery style ................ 290

163 Branch of the style of Oat, with germinating pollen-grain ........ 290

164 Embryo sac of a Lily .................................... 291

165 Hanging drop arrangement for the cultiration of pollen-grains . . . . 293

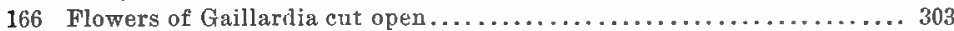

167 Flower of Iris, showing how the stigma removes pollen from the bee, etc. 304

168 Flowers of Partridge-berry cut open..................... 305

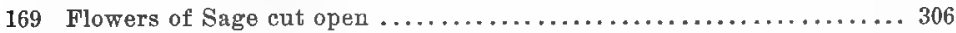

170 Fruit of Squirting Cucumber in the act of expelling the seeds ....... 321

171 Clematis fruit, which flies by means of the feathery style.......... 322

172 Linden fruit, which flies by means of a wing-like bract . . . . . . . . . 322

173 Hop fruit, which flies by wieans of a bract................... 323

174 Maple keys, which fly by means of a wing ................... 323

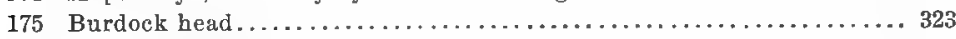

176 Fruit of Bur Clover . . . . . . . . . . . . . . . . . . . . . . 324

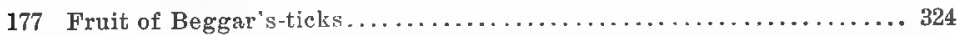

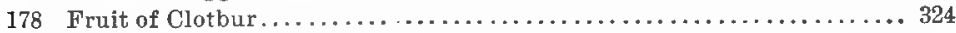

179 Potato which had been allowed to sprout and grow on a dry table.... 327 
FIG. PAGT

180 Potato showing the effect of light and dryness on growth ......... 328

181 Sprout of Prickly Pear grown in the dark .................... 329

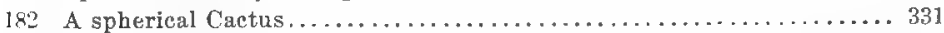

183 Branch of Cytisus . . . . . . . . . . . . . . . . . . . . . . . 332

184 Stems of Callitriche in cross-section...................... 333

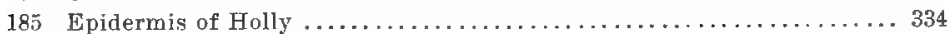

186 Waxy covering of Sugar Cane........................... 334

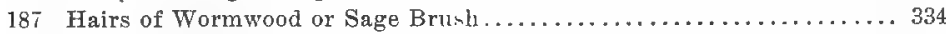

188 Hairs of Mullein . . . . . . . . . . . . . . . . . . . . . . . 335

189 Cross-section of stem of Water-polygoum grown in dry soil ....... 335

190 Cross-section of stem of Water-polygonum grown in water......... 335

191 Upper epidermis of Water-polygonum .................... 336

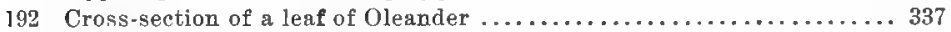

193 Arrowhead, showing effect of submersion on leaves .............. 337

194 Cross-section of the ribbon-shaped leaves of Arrowhead . . . . . . . . 338

195 Leaves of Water-buttercup (water-leaf and air-leaf) . . . . . . . . . . 339

196 Lower epidermis of Water-polygonum. . . . . . . . . . . . . . 340

197 Leaves of Dandelion, normal and in saturated atmosphere....... 342

198 Gorse, normal and in saturated atmosphere ................. 343

199 Leaves of Prickly Lettuce (sun- and shade-leaves) . . . . . . . . . . . . 344

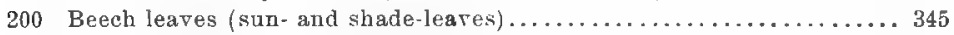

201 The effect of wind on the growth of a tree trunk ................ 348

202 Shows how branches are stuuted and killed on the windward side ... 349

203 The result of having branches mainly on one side (as in preceding

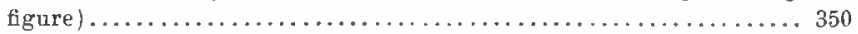

204 Branch of Iry Geranium . . . . . . . . . . . . . . . . . . . 354

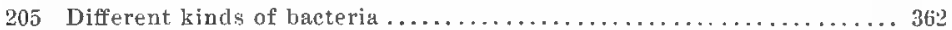

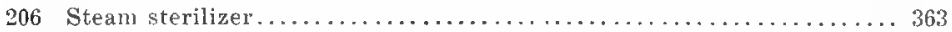

307 Tumbler containing a slice of boiled potato................ 365

208 A scraping from a potato culture....................... 36

209 Funnel with neck removed so as to tit into a tumbler . . . . . . . . . . 369

210 Flat bottle containing gelatin (for "plate culture ") ............ 370

211 Chart slowing the distribution of cholera cases in the Hamburg epi-

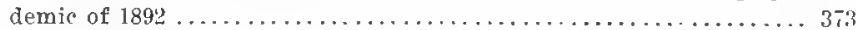

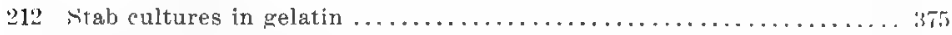

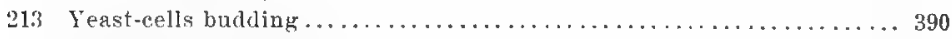

214 Block Mould of bread . . . . . . . . . . . . . . . . . . . . . . . 391

21.5 Same beginning to show upores at the rlues of the hreal .......... 392

216 More advanced stage of spore formation..................... 393

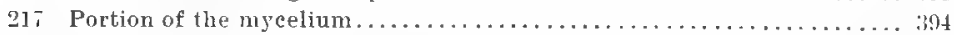

21x Black Mould of bread showing manner in which mycelium seuds ont root-like branches at hort intervals . . . . . . . . . . . . . . . 3!5

219 A single spore case of the Black Mould of hread . . . . . . . . . 395 
220 Formation of zygospores of the Black Mould of bread ............ 396

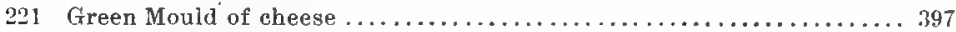

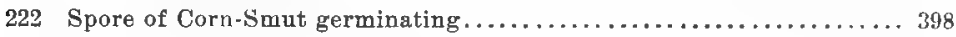

223 Spore of Corn-Smut producing conidia ......................... 399

22t Summer Spores, or uredospores of the Black Stem Rust of Wheat ... 402

225 Autumn spores, or teleutospores of the Black Stem Rust of Wheat... 402

226 Summer spores of the Black Stem Rust of Wheat, germinating on a

Wheat leaf and sending the germ tubes through the stomata...... 402

227 Autumn spores of the Black Stem Rust of Wheat producing conidia .. 403

228 Section of Barberry leaf showing Rust.................... 403

229 Cluster-cup of Black Stem Rust of Wheat .................. 404

230 Perithecium of the common Mildew of the Lilac ................ 407

231 Increased size due to hybridization (without selection) $\ldots \ldots \ldots \ldots \ldots 411$

232 Increased size due to selection (without crossing) ............... 411

233 Improved Beach Plum ................................. 413

234 Branch of Improved Beach Plum......................... 414

235 The Plumeot, a cross between the Plum and the Apricot ......... 415

236 The Stoneless Plum and its parents ...................... 416

237 Curre of variation ...................................... 418

238 Assymmetrical curve of variation ......................... 419

239 Double curve of variation .............................. 419

240 Shasta Daisy and its American parent....................... 423

241 Shasta Daisy, variations . ............................... 424

242 Shasta Daisy, double.................................. 425

243 Variation in leaves of hybrid Blackberries.................. 426

244 Variation in stems of hybrid Blackberries ................... 127

245 Tariation in leaves of hybrid Poppies ........................ 429

246 Plum blossom, with anthers and petals remored................ 4:1

247 Flowers of Lamarck's Evening Primrose..................... 444

248 Lamarck's and Dwarf Evening Primrose ................... 44,

249 Leaves of Lamarck's and Broad Evening Primrose.............. 446

250 Seedlings of Lamarck's, Pale and Broad Evening Primrose......... 447

251 Four-, fire- and seven-leaved Clorer...................... 448

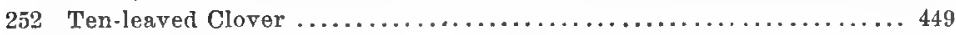

253 Atavistic Clover..................................... 449 



\title{
EXPERIMENTS WITH PLANTS
}

\author{
CHAPTER I
}

\section{THE AWAKENING OF THE SEED}

What is a seed? Study as types of seeds the Horsebean (or other large bean), the Castor-bean and Corn.

The Horse-BEAN.-Examine some dry and some soaked Horse-beans. Notice the shape and appearance (color, markings, surface, etc.) of the seed. The large black scar (hilum) at the end of the seed (Fig. 1) is the place of attachment to the pod.

Remove the cover, notice its

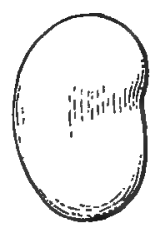

1. Horse-bean; the scir (hilum) at $(h)$. texture, thickness, etc.; is the cover everywhere

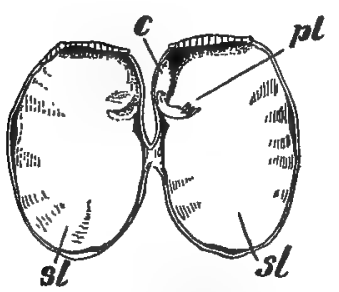

2. Horse-bean opened, showing the two seed-leaves $(s l)$, the caulicle (c) and the plu. mule $(p l)$. closely applied to the germ? Within the cover are two thickened halves, the seed-leaves (Fig. 2, sl) attached to a short rod-like body, the caulicle $(c)$, at one end of which is a cluster of very small leaves, called the plumule $(p l)$, which may be easily studied with a hand-lens, or 
even with the naked eye: these develop into foliage leaves. The seed-leaves, caulicle and plumule together', make up the germ or embryo plant. The seed of the Horse-bean, therefore, consists of an embryo plant provided with a cover.

The CAstor-BEAN. ${ }^{1}$-The seed somewhat resembles a beetle in shape and color. Its scar (hilum) is covered
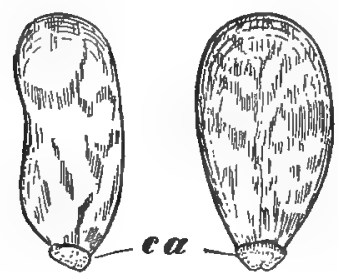

3. Castor-bean: at (ca) the car. unele. a spongy body which absorbs water during ger. mination; the scar (hilum) is concealed by it.

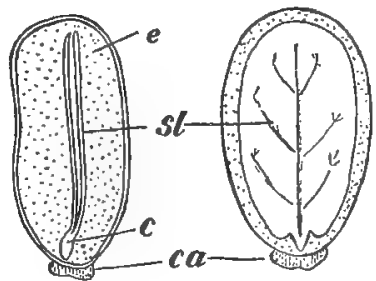

4. Castor-bean opened, showing endosperm $(e)$, cauliclo $(c)$. seed-leaves $(s l)$ and caruncle (ca).

by a spongy body (the caruncle, Fig. 3, ca). The cover has a very different texture from that of the Horsebean cover and fits loosely. The seed-leaves (Fig. 4) are thin and delicate in appearance, with prominent veins; the caulicle and plumule are much smaller than in the Horse-bean. Outside the seed-leaves is a white oily substance which surrounds the germ but is not attached to it: it is called endosperm (Fig. 4,e).

The Cors.-Both dry and soaked grains should be used. In the Corn (Fig. 5) the seed-case adheres to the seed and forms the outer layer of the seed-cover,

1 This is poisonous and should not le eaten. 
which is thin, transparent and fits snugly. If we cut through the grain, as shown in Fig. 6, we see

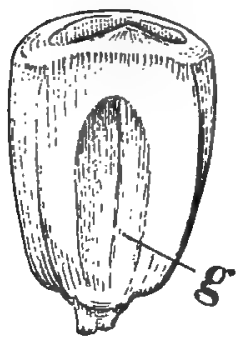

5. Corv. tho germ is located at $(g)$. the germ, consisting of a single seedleaf (7) with caulicle, plumule and a large mass of endosperm, which in Sugar Corn is clear and sugary, while in ordinary Corn it is hard and yellow on the

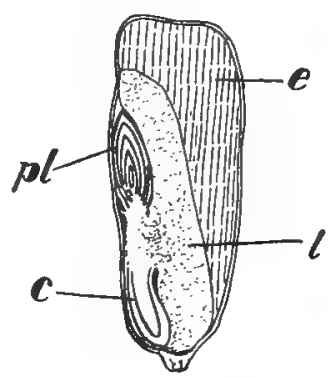

6. Corn cut lengthwise, showing caulicle (c), plu. mule $(p l)$, seed - leaf $(l)$ and endosperm $(e)$. outside, but floury toward the center.

In some plants the seed is covered only by the seedcoat (the skin of the bean is such a seed-coat), while in others it is covered by the seed-coat plus a part of the seed-case (the seedcase corresponds to the pod of the bean); the seed-case may be consolidated with the seed-coat, as in the, Corn, or be separate from it, as in the Sunflower (Figs. 7 and 8), Peanut (Figs. 9 and 10), Walnut (Fig. 24), Peach, etc. When the seedcase, or any part of it, remains attached to the seed the whole
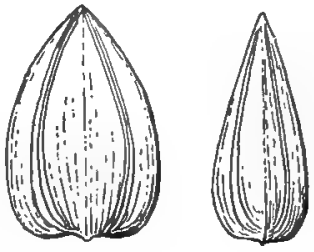

7. Sunflower seed.

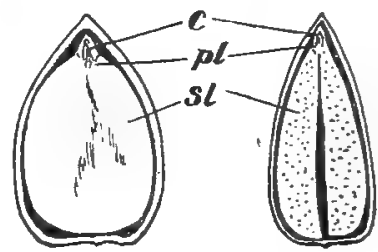

8. Sunflower seed opened, showing eaulicle (c), plumule $(p l)$ and seed-leaves $(s l)$. 
is called a fruit, but for convenience we may speak of it as a seed; its covering we may call a seed-cover,

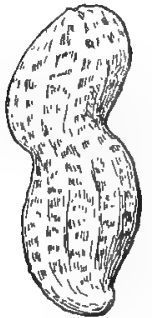
whether it be a simple seed-coat or something more.

Obtain all the seeds you can which are large enough for study (including those of common fruits, flowers, cereals, ete.), compare them carefully with the types we have just studied: discover the germ in each one 0. Peanut. and study it with especial care.

As the result of this comparison, we may conclude that a seed is an embryo plant provided with a cover, and in some cases with endosperm: before germination it is in a sleeping or dormant condition.

What is needed to awaken the seed? Many persons will say that water and warmth are necessary. Place some seeds in moist sawdust in a place warm enough to ensure germi-

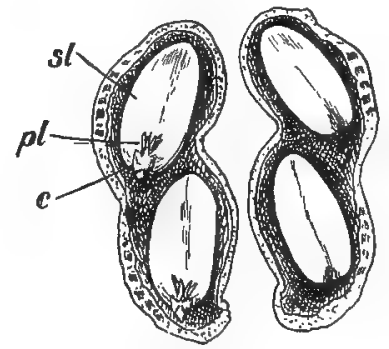

10. Peanut opened. showing canlicle $(c)$, plumule $(p l)$ and seed. leaf (sl). nation. The sawdust should be merely moist (not so wet that water can be squeezed out of it by the hand), and may be placed in boxes, pots or cans, which must have holes provided in the bottom for drainage: plant the seeds about an inch deep.

Place some seeds of the same kind on ice, as shown 
in Fig. 11. Ol,tain a box measuring about eighteen unches each way, place it in a larger box, and fill the space betwcen the boxes with dry sawdust; place the ice in the inner box and surround it with dry sawdust; enclose the soaked seeds in a piece of mosquito netting (to prevent losing them) and place them on the ice; cover them with moist sawdust (the melting ice will keep it continually moist). Fifteen pounds of ice will last several days under these conditions.

Place other seeds of the same sort under water: it suffices to simply put the seeds in a bottle, which is then submerged in water and tightly corked while under water, taking care to exclude all air-bubbles. Taseline may be smeared over the cork to make it air-tight (Fig. 12). Air may Je expelled from the water by boiling it for several minutes just before using, but

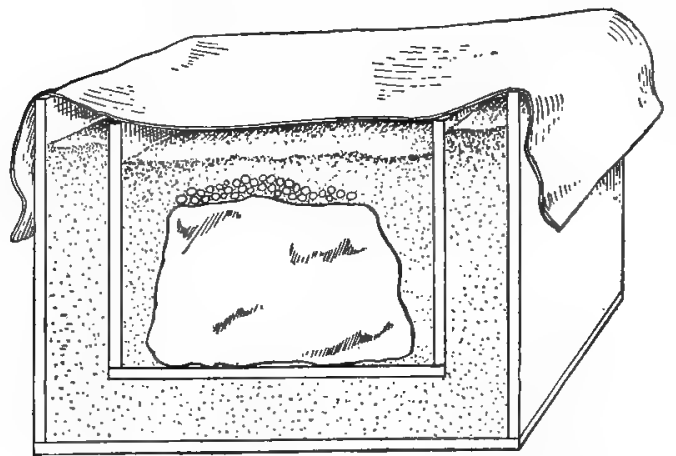

11. Arrangement for keeping seeds on ice; the spare between the boxes is fllled with sawdust, which also surrounds the ice.

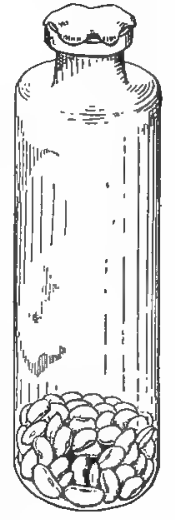

12. A bottle enntaining seeds. flled with water and corked sirtight, to test the power of seeds to germinate witl. out air. 
this is in most cases unnecessary. It is advisable to wire the cork firmly in place, since a certain amount of gas is given off by the seeds, which may force it out of the bottle.

For this, as well as for subsequent experiments on seeds, it is well to select kinds which germinate quickly, such as Horse-bean, Lima Bean (or other kinds of beans), Sunflower, Pea, Lupine, Radish, Squash, Wheat and Corn.

It will appear from this experiment that the seed needs a sufficient amount of water, air and warmth, in order to grow. Every need of the plaut presents a problem for the plant to solve. Some plants supply their needs in what seems to be the best possible way, while others adopt methods which appear much less efficient. We may say that the plant solves its problern well or ill, though in so speaking we do not mean to imply that the plant thinks or consciously adapts means to ends, since we are convinced that this cannot be the case. The problems which plants are called upon to solve are very numerous, and the penalty of solving them poorly is to clie, or be crowded out by more successful competitors. In studying the plant, we should try first of all to discover its needs and then try to think out for onrselves in each case the best solution of the problem involved.

Let us consider first the problem of water. How much water does the embryo plant require, and lıw 
is it obtained? Do seeds in their ordinary dry condition contain water? We may answer this question by placing some seeds in one end of a glass tube (a testtube is most convenient, but any glass tube a few inches long will answer; a tin cup covered with a piece of glass answers every purpose) and heating the end where the seeds are placed (Fig. 13). If moisture is present it will be driven off and condense in drops toward the cooler end, which should be left open. ${ }^{1}$ Explain the popping of Pop-corn.

The amount of moisture in the seed greatly affects its preservation (see page 45 ).

How does the seed absorb water? Place in water a lot of seeds of the same kind, as nearly alike as possible in size, shape and color, keeping other similar seeds dry for comparison. An interest-

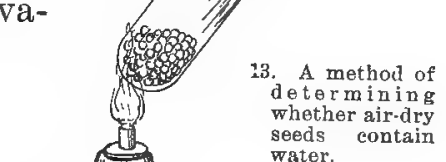
ing series for study is the Pea, Lima Bean, Castorbean, Filbert (or some other nut), Radish, Flax or Quince. Observe constantly for half an hour, and after

I If no moisture can be detected by this method, weigh out three or four ounces of seeds, heat them for some time in an oven or wherever they will not be scorched, and reweigh. Any loss of weight is due to moisture driven off by the heat. By heating on is water-bath (Fig. 54) until they cease losing weight, the exact pereentage of moisture may be ascertained by dividing the loss in weight by the original woight. 
that at frequent intervals. Notice whether soaking affects the size, color or texture. Does the cover wrinlile:
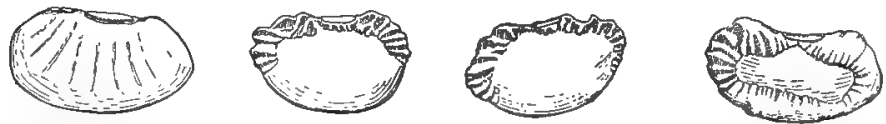

14. A Bean placed in water, showing suecessive stages in the process of wrinkling: the wrinkling indicates where the water enters and how it spreads inside the cover.

if so, where does the wrinkling commence, and in what direction does it progress? (See Fig. 14.) Does this indicate where water first unters the seed? What causes

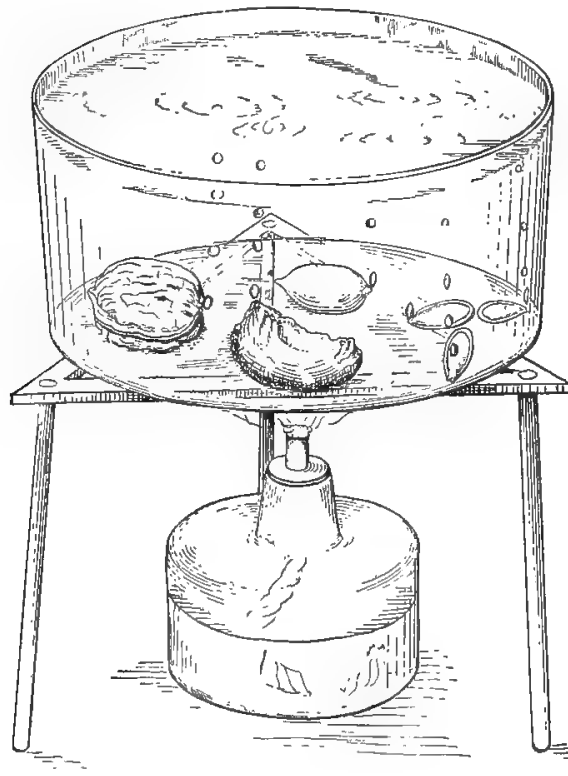

15. A method of determining whether openings exist in the seed-covers. the wrinkles? Why do they disappear after a time? Do the covers appear to hinder the water from being absorbed by the germ? Consider the apparently water-proof covers of the Castorbean, Buckeye, etc. Would it not be an obvious advantage to have openings in the cover through which the water might enter more rapidly? Are there such openings in the seed-covers? 
Place the seeds in water and heat (Fig. 15); stir the water to remove the bubbles that form on the seeds; keep the seeds submerged; if necessary, hold them under water by a piece of glass or wire netting or by placing them in a wire spring (see Fig. 16). Do you find openings: how many and where located? Test as many seeds as you can in this way. (The Squash, Walnut, Pecan and Brazil-nut give striking results; the Castor-bean is apt to be somewhat puzzling; the Filbert seems to have a good many openings; do they pass through the

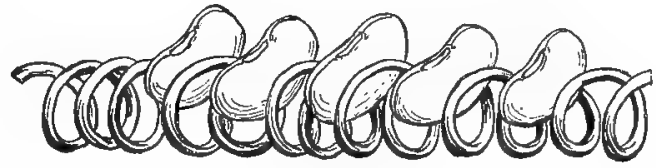

16. An arrangement for holding seeds while under water. shell into the cavity?) Many seed-covers become cracked in the course of time; distinguish between such cracks, which may occur anywhere, and openings which occur constantly in the same place. ${ }^{1}$

If any of the seeds do not yield bubbles when placed in warm water it does not necessarily mean that there is no opening; it may simply denote a lack of air in the seed. Such seeds may be further tested by soaking thoroughly, wiping the surface dry and squeezing to see where water is pressed out. Or, in the case of nuts, etc., any part of the shell where an

1 Where the cover consists of an outer and an inner part (i. e., seed-cnat proper plus the seed-case), as in the Walnut. Pcan and Filbert, the outer portion is of prineipal interest but the inner one may also be tested after the outer is removed. The shell of the Brazil-nut is a true seed-coat. 
opening is suspected to exist may be sealed to the end of a tube, which should then be placed under water and blown into forcibly (see page 31 ). We may also place the seeds in an air-pump and exhaust (see page 187).

Does most of the water enter through these openings? One way to find out is to stop up the opening, then submerge the seed and note how much the ah,sorption of water is thereby hindered (as compared with untreated seeds which are submerged at the same time). A good substance for closing the opening is rubbel cement (the kinds used for repairing bicycle tires are good and easily obtainable), or melted rubber applied hot (prepared by melting good black rubber in a spoon); if the latter is used, place whiting or flour on the surface of the rubber (after it is applied to the seed) to prevent it from sticking to other objects. Try to cover the opening only: it is difficult, however, to avoid covering at the same time the adjacent portions of the seed. Thus, in the case of the Horse-lwan, the scar is apt to get covered. Since this is apparently more porous than the rest of the cover, it may be that it admits water readily; hence in covering it we are perhaps introducing an error. This may be offset if we cover an equal area (including the scar) in the control seeds (i. e., those which do not have the openings covered) without interfering with the opening. 
Weigh both sets of seeds (i. e., the control and the others; there should be at least twenty in each set), treat them with rubber or ceinent, and weigh again.

Before proceeding with the experiment, test the seeds to see if the openings are stopped. Place some untreated seeds in water (the control seeds must not be used for this), and heat until bubbles begin to issue from the openings of all of them; then place the treated seeds in the warm water; if no bubbles issue from them we may consider it fairly certain that they are satisfactorily closed; the heat must not be too great or too prolonged, as it may in that case soften the rubber so that the expanding air inside may force an opening. Should any of the sealed seeds yield bubbles, it is better to throw all the sealed seeds away and prepare a fresh lot, until you succeed in getting them all air-tight.

Submerge all the seeds in cold water (the wire spring shown in Fig. 16 is useful for keeping them under water; the seeds may be placed in it and weighed, together with the spring, thus making it unnecessary to handle them separately). Remove the seeds at frequent intervals, dry them on the surface and weigh both sets, to see which is absorbing water more rapidly. Any seeds with cracks in the cover's must, of course, he rejected. At the end of the experiment, place the seeds again in warm water, to 
discover if any cracks have been formed which might admit water and so vitiate the results.

It is interesting to calculate the percentage of water absorbed and make a comparison after various periods of immersion.

The following will serve to illustrate the method:-

\begin{tabular}{|c|c|c|c|c|c|}
\hline & \multirow{2}{*}{$\begin{array}{l}\text { Weight be- } \\
\text { fore treat- } \\
\text { nent with } \\
\text { rubber. }\end{array}$} & \multirow{2}{*}{$\begin{array}{l}\text { Weight after } \\
\text { treatment } \\
\text { with rubber. }\end{array}$} & \multicolumn{3}{|c|}{$\begin{array}{c}\text { Submerged in wate } \\
15 \text { minutes. }\end{array}$} \\
\hline & & & Wt. & Gain. & $\begin{array}{l}\text { Per } \\
\text { cent } \\
\text { gain. }\end{array}$ \\
\hline $\begin{array}{l}\text { Twenty-five Scarlet Runner } \\
\text { Beans sealed. } \\
\text { Twenty-five Scarlet Runner }\end{array}$ & 31.0 grams & 32.0 grams & 32.34 & 0.34 & 1.1 \\
\hline Beans unsealed & $20 . \overline{5}$ grams & 30.8 grams & 31.62 & 0.82 & 2.8 \\
\hline
\end{tabular}

\begin{tabular}{|c|c|c|c|c|c|c|c|c|c|c|c|}
\hline \multicolumn{3}{|c|}{$\begin{array}{c}\text { Submerged in water } \\
35 \text { minutes. }\end{array}$} & \multicolumn{3}{|c|}{$\begin{array}{l}\text { Submerged in water } \\
60 \text { miutes. }\end{array}$} & \multicolumn{3}{|c|}{$\begin{array}{c}\text { Submerged in water } \\
90 \text { minutes. }\end{array}$} & \multicolumn{3}{|c|}{$\begin{array}{l}\text { Submerged in water } \\
15 \text { houls. }\end{array}$} \\
\hline Wt. & Gain. & $\begin{array}{c}\text { Por } \\
\text { cent } \\
\text { gain. }\end{array}$ & Wt. & Gain. & $\begin{array}{c}\text { Per } \\
\text { cent } \\
\text { gain. }\end{array}$ & Wt. & Gain. & \begin{tabular}{|c|} 
Per \\
cent \\
gain.
\end{tabular} & $W \mathrm{t}$. & Gain. & $\begin{array}{l}\text { Per } \\
\text { cent } \\
\text { gain. }\end{array}$ \\
\hline 33.30 & 1.30 & 4.3 & 34.45 & 2.45 & 7.9 & 35.69 & 3.69 & 11.9 & 56.21 & 24.21 & 78.1 \\
\hline 32.8 & 2.0 & 6.8 & 35.2 & 4.4 & 15. & 39.68 & 8.88 & 30.1 & 72.71 & 41.91 & 142.1 \\
\hline
\end{tabular}

After soaking fifteen minutes, the weight of the sealed lot was 32.31 grams; subtract from this the weight before soaking (:y), which gives the gain (0.34 grams); divide this by the original weight before treating with rubber (31 grams) to get the gin in per cent. In this case an area on the unsealed seeds was covered with rubber so as to equal the amount covered on the sealed seeds. 
The experiment may be repeated in a different form by placing the seeds in moist sawdust instead of in water. Care must be taken that none of the rubber is removed in manipulating the seeds.

This experiment requires a balance. If you have none at hand you should make one for yourself. The

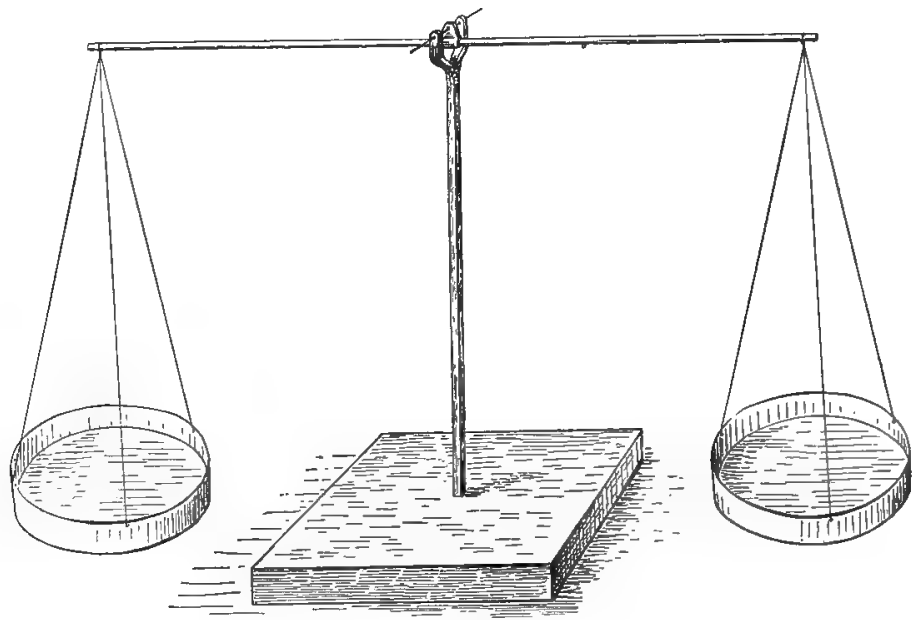

17. A home-made balance constructed of umbrella wire; it can be made sensitive to a tenth of a gram.

arms of the balance should be of equal length. Why? Try the effect of both equal and unequal arms. The pans should be attached at equal distances from the pivot. A very good balance is easily and quickly made of umbrella-wire, as shown in Fig. 17. The long rib is used for the arm of the balance, the short rib for the support. The rivet is taken out and a fine 
needle substituted for it; the varnish is burned off or scraped away. The upright piece is firmly wedged in a hole bored in a small block of wood (see Fig. 17).

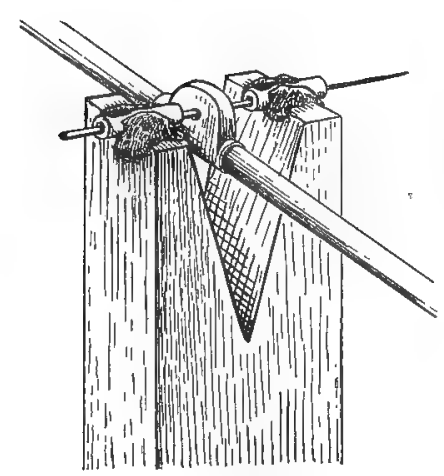

18. A modification of the balance.

The pans are made of tin covers, attached with silk thread. Their weights may he equalized by trimming the edges or by attaching a little sealing-wax to them; when balanced they should hang about an inch and a half above the table. Another kind of support, made by fixing two short glass tubes to a strip of wood (by means of sealing-wax) is shown in Fig. 18.

When the balance is set up, test it carefully; first get the pans to balance; then put weights in both pans until they balance; then exchange the weights; if the balance is properly made they should still balance; failure to do so shows that the pans are not of equal weight, or are not attached at equal distances from the pivot. An inaccuracy in the balance will not vitiate your results for comparative purposes if you always put the weights in the same pan. Thy?

If you cannot obtain weights, make some of lead (to correspond with a druggist's; the metric system is much more convenient than the ordinary apothecaries' weight). 
It would appear that considerable water enters through the opening, the amount being different in different kinds of seeds. The question may be raised, Does all the water enter in this way? If, in the experiment just concluded, the openings were securely stopped, it would seem that we must, in many cases at least, answer negatively. However, all doubt on this point may be removed by partially submerging the seeds without allowing the opening to come in contact with the water. A very convenient way is to place the seeds in sand which is kept saturated with water (see Fig. 23): for keeping the sand saturated, the device shown in Fig. 27 may be used. Or we may cut in a cork notches large enough to receive the seeds; after wedging them firmly in place, put the cork in water (Fig. 19). If water now enter's the seed it must be through the cover itself, since the opening is not in contact with the water. Large, flat corks are best; if necessary they may be obtained

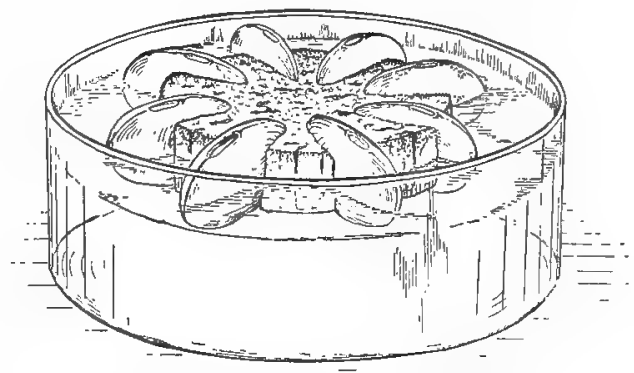

19. A method of keeping seeds half-submergel. in order to discover how the water enters. at drug-stores. (Cork soles or the cork strips used by entomologists are good.) Flat pieces of wood will serve in place of cork. This experiment may be 
carried on by weighing in the same way as in the previous one, and will afford interesting results for comparison.

What seed-covers admit water most readily? We may make a satisfactory test by splitting the covers of dry seeds in halves, removing the germ and allow-

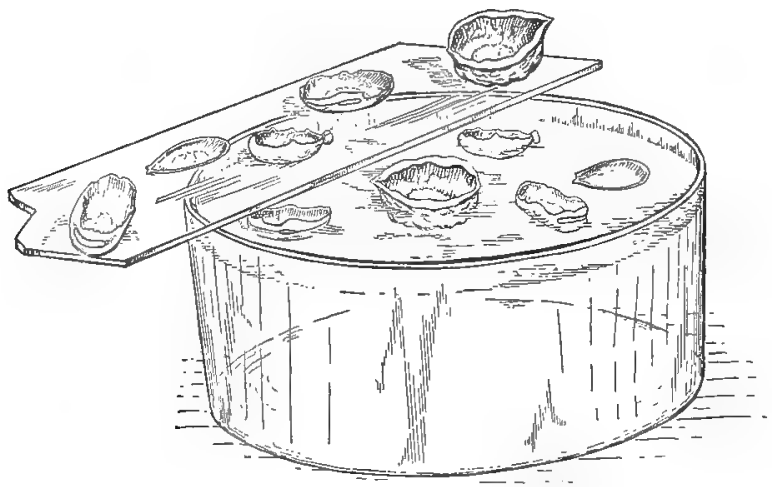

20. Seed-cover floating on water, each containing a few sugar erystals, which, by dissolving. indicate the rapidity of osmosis; controls on the glass strip.

ing the dry covers to float like boats on the surface of the water (see Fig. 20). Into each put a few crystals of sugar, the dissolving of which will indicate how rapidly water is absorbed through the cover. On a dry piece of glass, near the surface of the rater but not in contact with it, place other boats containing sugar crystals, to see whether the sugar can absorb enough moisture from the ail (or from the corer) to dissolve. In making the boats, we must take care 
that there are no openings or cracks through which water can enter; be careful that no water enters the boat at the rim. To imitate natural conditions more closely, place some boats on the surface of moist soil, pressing them down firmly. Test as many kinds of seed as possible.

Does the germ (or endosperm) possess the power to draw water through the cover as the sugar does? Repeat the experiment, substituting the ordinary seed-content (either a part or the whole) for the sugar: be sure that it is in close contact with the cover. Weigh it at the beginning of the experiment, and repeat the weighing at frequent intervals to discover how much water it has absorbed. Notice also whether it softens or appears moist.

The sugar, when placed in the boats as described above, seems to have the power to draw the water through the seed-cover; but if sugar were dissolved in the water on which the boats are floating, would it not exert a counter-attraction, and tend to prevent the water from being drawn ${ }^{1}$ up through the seedcover" Prepare some boats (all from the same kind of seed-cover); place sugar in them and float some on pure water, other's on a thick syrup made of sugar and water. Many other substances besides sugar have a strong attraction for water: the germ contains

1 The sugar is spoken of as drawing or attracting the water in a popular sense only. 
substances of this sort (salts, starch, sugar, etc.), and we suppose that the seed owes to them its power to absorb water. Now we have just found, in the experiment with sugar in the boats, that water is absorbed more rapidly than syrup. Is it so in the case of the seed? Place weighed lots of seed of the same kind in water, in syrup and in a very strong solution of common salt (dissolve as much salt as you can in the water). After a day or so remove the seeds, dry them on the surface and weigh. Can you make the solution strong enough to prevent all absorption? Rinse the seeds in water and plant them in moist sawdust, to see whether the sugar or salt have injured them in any way.

Do you think that the seeds will germinate in seawater? If this cannot be obtained it can be made artificially by dissolving about $3 \frac{1}{2}$ per cent of seasalt (obtainable at grocers' and druggists') or common salt in water $\left(4 \frac{1}{2}\right.$ drams of salt to a pint or $3 \frac{1}{2}$ grams to $100 \mathrm{cc}$. of water). The seeds may be placed in the apparatus shown in Fig. 95, but cotton soaked in the sea-water is to be substituted for the wire netting. Are the seeds of plants which inhabit the seashore able to germinate in sea-water? How is jt with alkali soils in this respect?

In the boat experiments just described, we are struck with the fact that water appears to $\operatorname{com} \theta$ through the cover only where the sugar or germ is in 
contact with it. Is this really the case, or does the water come through elsewhere, but so slowly that it evaporates as rapidly as it reaches the inner surface of the cover? Repeat the experiment as follows: Prepare the boats as before, and seal them to strips of glass by means of sealing-wax, as shown in Fig. 21. Smear the rim of the boat with hot sealing-wax, in-

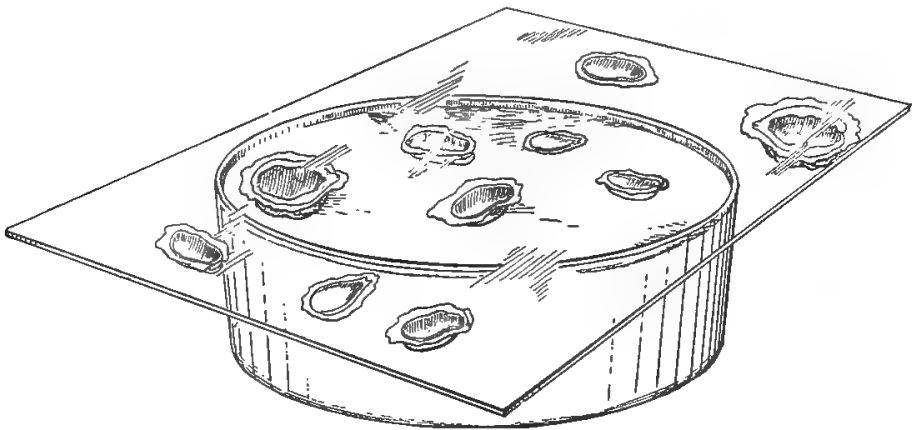

21. Jlodification of the experiment shown in Fig. 20.

vert it on the glass and run a hot piece of wire around the rim until a tight joint is secured. Place the glass (boats down) on a tumbler, and carefully pour in water until it touches the boats; do not let it touch the glass strip. If water enters the boats, moisture will collect in drops. Let some of the boats so treated stand near by but not in contact with water, as a control experiment.

If, as appears to be the case, the water does not come through the seed-cover except where the germ (or endosperm) is in contact with the cover (and 
draws it through), it would seem advisable to have as much contact as possible. Some seeds hare the cover closely applied to the germ so as to be in contact everywhere; others (Peanut, Filbert, ete.), where the seed-contents are loose inside the cover, have a small amount of contact; investigate this point in as many seeds as you can. In some seeds the cover separates in places from the germ when the seed is placed in water, so that the amount of contact is diminished; subsequently the cover becomes closely stretched over the germ; in what seeds does this happen?

It would seem that the portion of the germ which is in immediate contact with the opening must receive water more quickly and in larger quantities than other" parts more remote. Do you usually find the caulicle

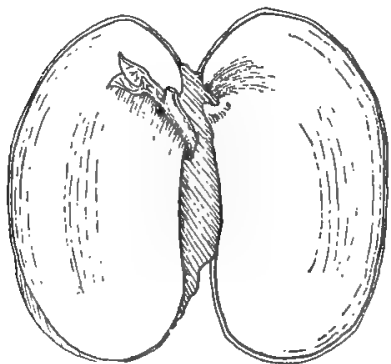

22. Searlet Runner Bean opened, showing the pocket into which the caulicle fits. near the opening? 1 Does the caulicle usually swell and grow more quickly than other portions of the seed? Do you consider its position advantageous? Notice the pocket around the canlicle in the Beans (Fig. 22), Pea, Buckeye (Fig. 46), ete. Do you think this might help to draw up water (by capillarity) and retain it, so keeping the caulicle moist?

1 Examine particularly the Peach, Plum, Cherry, Walnut, Pecan, etc. 
Not only is it important that the germ should be in contact with the cover, but also that the cover should be in close contact with the soil. Hence the

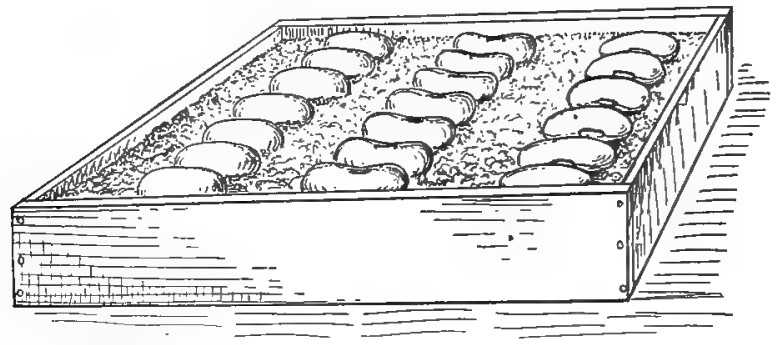

23. Seeds half-submerged in wet sand, to determine how the water enters.

necessity of rolling the soil to pack it firmly about the seeds as practiced by farmers, and "firming" the soil about the seerls as practiced by gardeners, i. e., by covering the seeds and then treading on them or by pressing down the soil with a board.

Since the opening is so important, it may be that its position with reference to the soil may be important when the seed lies on the surface. On the surface of the soil in some pots (or boxes) place some seeds, one-third with the opening up, one-third with the opening down, one-third flat on the soil (see Fig. 23). Press all seeds firmly into the soil, so that each one is just half-buried. Which germinate first? Corn gives very striking results (Fig. $23 a$ ). Does the natural position of the seed on the soil usually bring the opening in contact with the earth? Do you see any 
advantage in having the seed flattened? In a flattened seed, what is the best position for the opening? Where is the opening usually found in a flattened seed ?

What course does the water take after entering the seed? Perhaps the best way to trace the path of the water is by dissolving some coloring matter in it. Eosin (obtainable as Eosin Pink, one of the Diamond

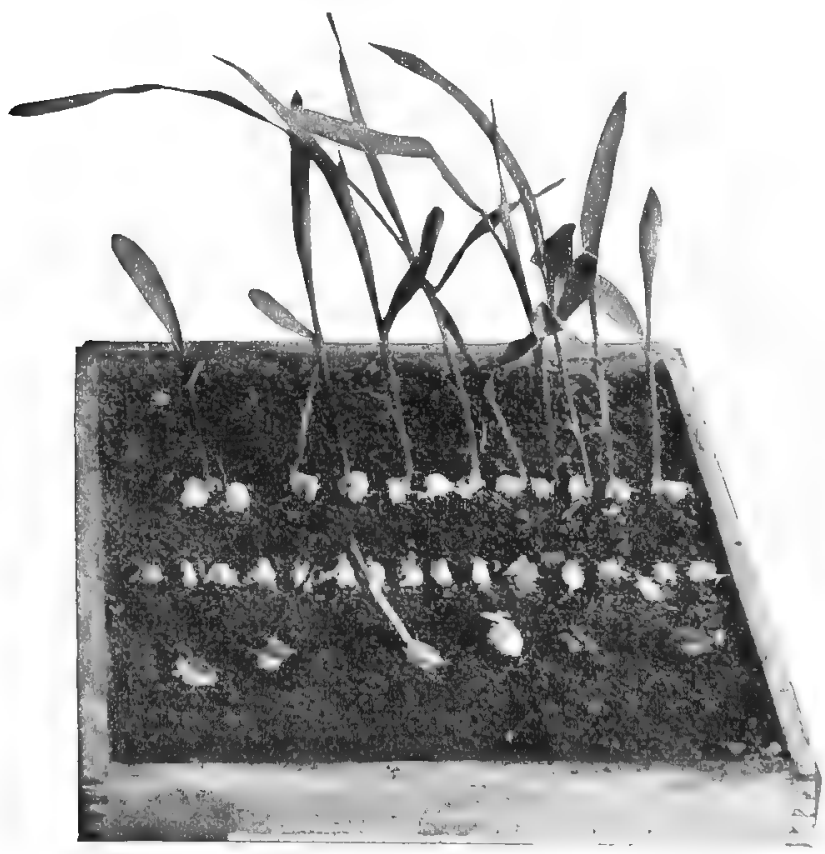

23a. Three rows of Corn planted at the same time, erch grain being hall-buried in the moist soil: those in the first row were plnced flat on the surface: those in the second row with the pointed end upward; those in the last ruw with the pointed end downward. 
Dyes, at (l'ug-stores) or ordinary red ink answers admilably. Dissolve enough in water to make it bright red, and then submerge the seeds in the solution; it is well to use a good many seeds and to remove some every few minutes and take off the cover's to see how far the water has penetrated. ${ }^{1}$ Do you find that the water penetrates first at the opening? In what direction does it spread inside the seed? What external indications do you see of this in the Bean (Fig. 14)? Trace it with especial care in the Walnut and Pecan. Although in these nuts the contact between the germ and the cover is small, yet this is offset by an absorb-

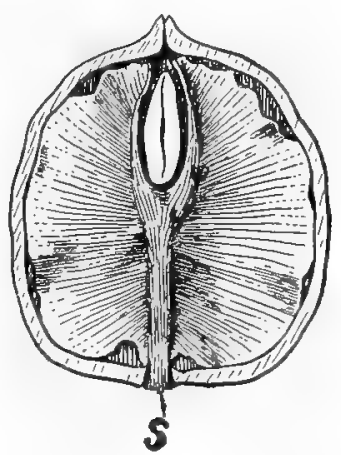

24. Walsut divided in half, showing the wick-like, central strand $(8)$ by which the water travels through the seed to the caulicle and the broad absorbent plates by means of which it spreads. ent, wick-like, central strand which takes up water directly from the opening and from which water spreads out into the broad partitions which are in contact with the folds and surfaces of the germ; the caulicle lies at the end of the fibrous, wick-like strand (Fig. '24).

We shall probably find that the coloring matter will not penetrate into the germ, although the water does; the method is only trustworthy as showing the

1 The seed should be washed and wiped with a cloth to remove the dye. Eosin stains may be removed from hands and colorless fabric by Javelle water (obtainable at druggists') or by bleaching powder (obtainable at grocers'). 
path of the water to and around the germ and endosperm, but not into it.

In most of the thick covers (Filbert, Walnut, Pecan, Peach, etc.) we shall find that the water pursues special paths in the tissue of the cover. These represent the paths which the sap took while the fruit was still attached to the plant. It will prove interesting to obtain young fruits of various kinds and place the cut surface of the stem in eosin solution, to trace the path taken by the sap.

It may prove interesting to raise the question, Is not the seed-cover (in spite of the opening) a serious hindrance in absorbing water? We may answer this by removing the covers from some seeds and placing them in water (together with the untreated seeds for comparison). Select ten lots of seeds (twelve in each lot) free from cracks, etc. Remove the covers from one lot and then weigh each lot separately. Submerge them all in water, keeping the different lots separate. After half an hour remove one of the untreated lots; take off the covers and weigh. Let the corers stand until "air-dry," and then weigh them. Deduct this weight from the original weight of this particular lot; this will give us approximately the original weight of the seer-rontents (i.e., the seed minus its covers). We now know aplroximately how much the seed-contents weighed at the start, also how much they have gained. We may compare 
this with the gain of the seeds which were deprived of their covers at the start. After another half an hour, remove another lot and weigh; repeat this each half-hour. Any seeds may be used; it would seem desirable to test some which have thin covers (Bean, etc.) and some which have thick covers (Filbert, Peach, etc.).

If you can obtain seeds of the Moonflower, Mexican Morning-glory or Lupine, the weighing will be unnecessary; the results will be sufficiently striking to the eye to leave no room for doubt.

Nurserymen recognize that the covers of many seeds (e. g., Peach pits, etc.) are a hindrance to germination, and before planting them usually crack the cover: other seeds have the covering cut by a knife or file, while still others are mixed with sand and rubbed or pounded. Acacia seeds are boiled for five or ten minutes, which aids the penetration of water through the hard coat and makes a difference of months in the germination, while some kinds are placed in boiling water and allowed to cool slowly. ${ }^{1}$

How much water is necessary for germination? We may get an approximate answer to this question by taking several pots of the same size, filling them with dry sand and placing in each twelve seeds (the same sort in each pot). Water the pots regularly, giving to No. 1 a very small quantity of water each time,

1 The heat may have an important stimulating effect. 
to No. 2 twice as much as to No. 1, to No. 3 twice as much as to No. 2, and so on.

Another method is to use fruit-jars (one-quart or tro-quart), placing the seeds on the bottom of the jar and covering them with half an inch of sand. Add

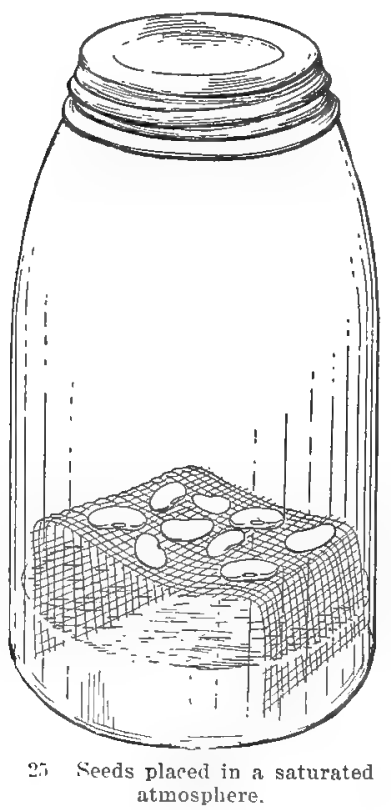
different quantities of water to the different jars, and screw on the tops tightly.

Whichever method be used, it is interesting to determine the amount of water in the seed at the stage when the caulicle begins to protrude. This may be ascertained by weighing the seed and then drying it (on a water-bath; see Fig. 5t) until it ceases to lose weight; dividing the loss in reight by the weight of the undried seed will give the peremtage. The determination is especially interesting in the cilse of the seeds which germinate with the minimum amount of moisture.

It often happens that a serd has little or no water at its disposal excent the moisture of the air. Unless it can absorb this in sufficient quantities, it camnot germinate. 


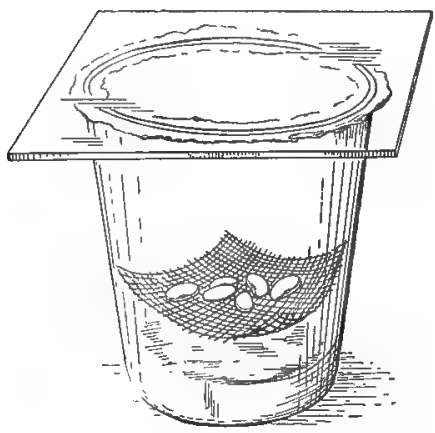

26. Another method of keeping seeds in a saturated atmosphere.

The question mar lor raised, Can seeds absorb enough water from moist air alone to enable them to germinate? This may be answered by placing some seeds in a saturated atmosphere for a time. Place the seeds in a fruit-jar, supported on a piece of wire netting, as shown in Fig. 25. Place a little water in the bottom of the jar and screw the cover on tight. Drops of condensed moisture are not apt to fall on the seeds when a fruit-jar is used, but should this happen start the experiment over again, protecting the seeds ly a small inverted cone of wire netting or a small glass fumnel. The apparatus shown in Fig. 26 may also be used: vaseline is used to make an

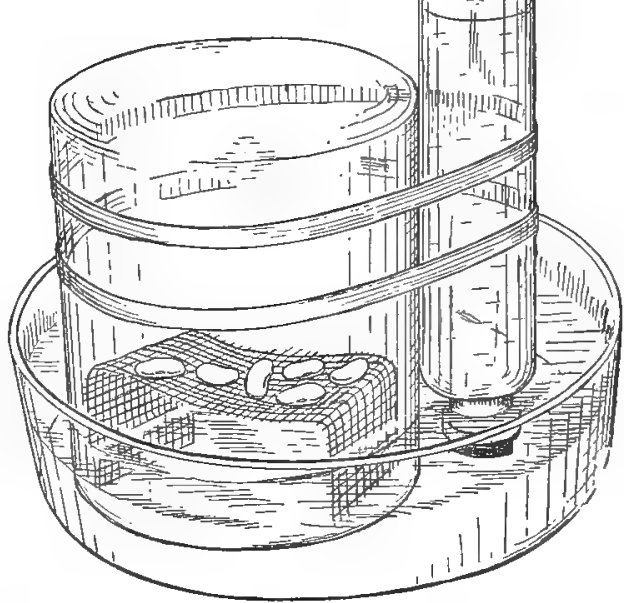

27. Hethod of maintaining a saturated atmosphere and a constant water-level. 
air-tight joint with the glass cover. The apparatus shown in Fig. 27 is very convenient for this purpose: the inverted bottle has a cork in the sides of which two grooves are cut, so that as soon as the water sinks below the mouth of the bottle air enters through the grooves and water runs out until the level rises and closes the grooves: the water-level thus remains almost constant.

As the experiment is to last for some time, it is advisable to take precautions against the growth of mould. Place the seeds in a tumbler and set them in a jar or pail in the bottom of which is a little formalin: cover the pail so as to confine the formalin vapor, and let it stand five or six hours.

Control seeds (treated in the same way) should be planterl in moist earth or sawdust.

The experiment should be continued two or three months if necessary. The percentage of moisture in the seeds may be determined at the beginning and again at the end of the experiment, to see how much moisture they have absorbed and also the minimum amount which will enable the seed to germinate.

The power to absorb water from moist air may be of great practical importance in storing seeds, etc., since if kept in a damp place they may easily germinate or decay.

Of especial interest, in considering the absorption of water, are the mucilaginous covers of Flax, Quine's, 
Radish, Squash, etc. Such covers can absorb a large amount of water even in a passing shower and hold it after the surrounding earth is again dry. Many seeds have spongy covers which act in much the same way, as, for example, the Walnut, Hickory, Almond (in which cases the spongy cover is usually removed before the nuts come to market), Nasturtiums, etc. The Walnut (Fig. 24), Hickory and Pecan have a central, wick-like strand of absorptive tissue which conveys the water directly to the germ, over the surface of which it is spread out in a thin layer by means of thin plates of absorptive tissue. In the grasses and grain-plants the seeds are surrounded by parts of the flower (the "chaff"), which assist greatly in soaking up and retaining moisture, while the pulp of soft fruits and berries serves the same purpose. In the Castor-bean (Fig. 3) the large, spongy outgrowth at one end (caruncle) serves the same purpose, as can be shown by planting Castor-beans deprived of the caruncle alongside of unmutilated ones; its position is such that the water passes from it directly through the opening to the radicle, and it will be noticed that the germ is attached to the cover only at this one point.

We have now found out something about how the seed gets water, and we can see clearly that, while the neerl is the same in all cases, the means adopted by different plants to supply this need are various; in other words, the same problem is solved in a variety 
of ruys. Perhaps we cannot say in all cases which solution is the best: certainly, in absorbing water the thinnest and most permeable cover is the best, but whether such a cover would in all cases furnish sufficient protection to the seed before germination we cannot tell without a special study of that question.

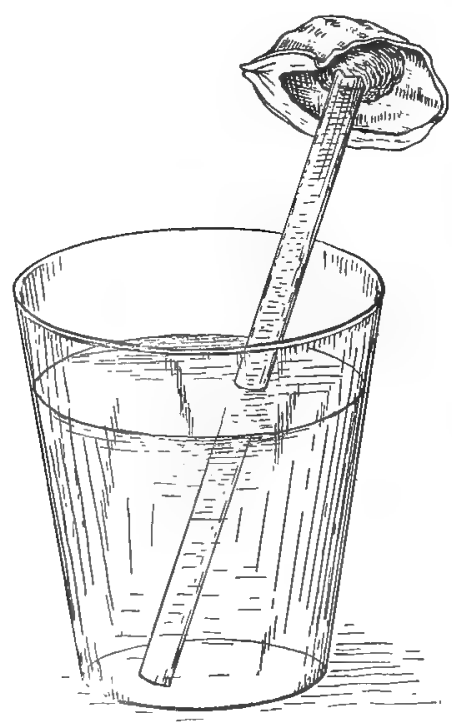

28. Method of testing the permeability of the seed-cover to air.

We know that, besides water, air is needed. How does the germ get air? Does air pass readily through the sect-cover? We may find out by sealing the cover (air-tight) to one end of a glass tube, filling the tulve with water and inverting it, as shown in Fig. 28, in a glass of water, taking care not to admit any air into the tube; the water should be boiled just before using, in order to expel the air. To seal the tube to the cover, smear the end of the tube liberally with hot sealing-wax; remove the superfluous wax from the interior of the tube, press the end of the tube firmly against the cover (which must be free from cracks or openings), and run a hot wire around it until a tight joint is secured; allow the wax 
to harden, then test the joint by placing the sealed end of the tube under water and blowing into it forcilly. The weight of the water-column tends to draw air through the cover. If any air enters it will appear as a bubble at the top of the tube; should this happen, empty the tube and test the joint as before by blowing forcibly. If no leak is detected, refill the tube and invert it as before. Test different sorts of seeds, especially those whose covers seem most porous and permeable to air. It should be remembered that in this case we are testing a seed-cover which is in constant contact with water; perhaps in a dry condition it would armit more air. This may be tested by filling the tube only partly full, so as to leave a large air-bubble at the top of the tube; mark its limit exactly on a piece of paper pasted on the outside of the tube; the entrance of air can then be detected by the increase in the size of the bubble. We may, if we wish, avoid any contact of water with the cover, by sealing on a cover, warming the tube well and placing the unsealed end in water; as the air in the tube cools, water will be dramn in. Which of these three methods approximates closest to the condition of the cover during germination?

Does air enter the seed through the openings? You may test this matter by closing the openings of seeds which have been previously thoroughly soaked (in order to ensure a sufficient supply of water for 
germination) and placing them in an atmosphere saturated with water (to prevent them from losing any water), together with untreated seeds as control. The openings may be closed and tested as described on page 10.

The seeds may be placed on wire netting, in a fruitjar containing water, as shown in Fig. "25 (the cover" must be tightly screwed on). At least a dozen seeds should be treated and the same number used as a control. The precautions against mould mentioned on page 28 should be observed. Set the jar in a place warm enough to promote germination. If the seed depends largely upon the opening for the admission of air, we shall expect to find the germination of the treated seeds noticeably delayed.

How much air is necessary for germination? We may get an approximate idea by taking six bottles of the same size and filling them to various heights with moist sand, as shown in Fig. 29 (the first, one-sixth full; the second, two-sixths, etc.). To exclude air from the sand, the bottle may be first filled with water and the dry sand slowly poured into it to the desired height; the superfluous water may then ho poured off. The seeds (well soaked) may then be put in (the same number in cach bottle), the cork may then be pusherl down below the rim and sealed air-tight with vassline or sealing-wax. A closer approximation to the correct amount could easily be made if the experi- 
ment were to be repeated and the bottles filled more nearly to the right degree at the start. We may vary the experiment by dispensing with the sand and simply filling up the bottles to various heights with soaked seeds.

The fact that so much air is necessary seems to indicate that some part of the air is changed (or

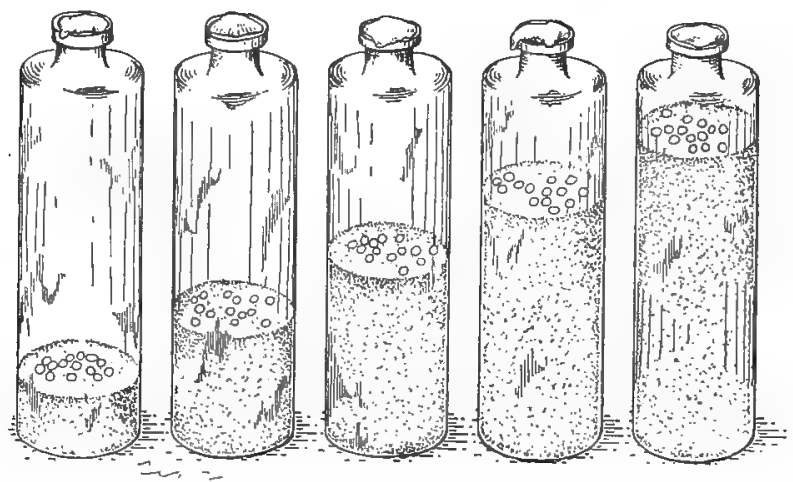

29. Seeds on wet sand with different amounts of air at their disposal.

"used up") by the seeds. Let us see if this is so. After two or three days, cautiously remove the cork from one of the bottles (containing about five-sixths air) and immediately lower a lighted match into it; or, better still, take a tall bottle or jar, place a layer (an inch or so deep) of seeds in the bottom, stopper tightly, allow it to stand a day or so and test with lighted match. If the match goes out, it indicates that the oxygen of the air has united with some other 
substance so that it no longer supports combustion. We may now pour a little lime-water into the jar,

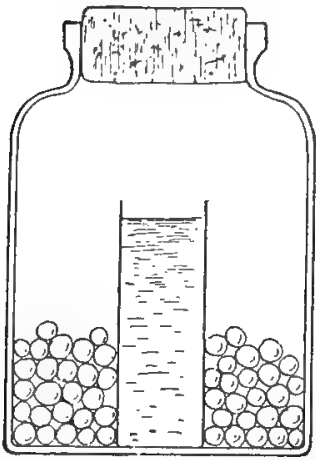

30. Apparatus for determin. ing whether germinating seeds produce carbon dioxjde, the vial is filled with lime-water. (Seen in seetion.) replace the stopper and shake vigorously. (Lime-water is prepared by placing a little unslaked lime in a metal dish or pail, filling the pail with water and allowing it to stand for a day; the water should then be filtered through filter-paper or through a cotton plug in the neck of a funnel.) If the lime-water turns milky, it indicates that the oxygen has united with the carbon of the plant to form carbon dioxide, a gas familiar to us as sodawater gas. Arrange an experiment, as shown in Fig. 30 , by placing a rial of clear lime-water surlounded by soaked seeds in a jar and stoppering loosely. As a control, use a similar arrangement without the seeds. We may make use of the fact that carbon dioxide is readily absorbed by lye to perform a further experiment. Arrange two bottles (pint or half-pint), as shown in Fig. 31, by fitting them with
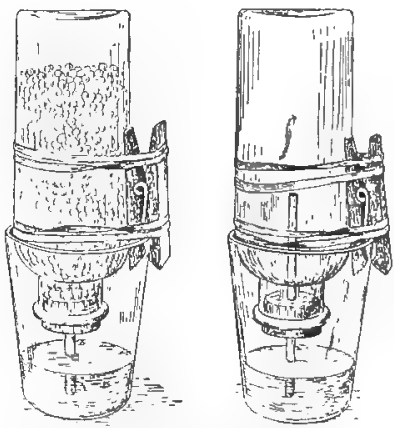

31. Method of measuring the amount of carbon dioxide produced by germinating seeds, the tumblers contain Jye control at the right). 
rubber stoppers or cork stoppers which have been soaked in melted paraffin (obtainable at grocers'; we may also obtain it in the form of paraffin candles). Pierce the stoppers with closely fitting glass tubes long enough to reach nearly to the bottom of the bottle. Place seeds in one bottle to the depth of an inch; leave the other bottle empty. Support both in an inverted position (by means of clothes-pins and rubber bands or wire, as shown in the figure), allowing the tubes to dip into a strong solution of lye. As the carbon dioxide is formed it will be absorbed by the lye, which will rise in the tube and thus indicate the amount produced.

When carbon unites with oxygen we say that it burns. Whether we burn wood, coal, oil or alcohol, the principal combustible substance is the carbon, which, by uniting with the oxygen, produces carbon dioxide and sets free heat. The heat of our bodies is due to the same process of burning and the carbon dioxide is given off in the breath, as is easily shown by placing one end of a tube under lime-water and blowing into it. The carbon of the body burns, but it does so very slowly. In the seed the process is still slower. The slight degree of heat set free can be measured by carefully comparing two thermometers (by placing them side by side in water at various temperatures and comparing their readings) and then arranging them as shown in Fig. 32. One tumbler is filled with 
soaked seeds, the other with moist cotton (to make the conditions equal so far as evaporation is concerned), and a piece of cardboard is laid over the top. The thermometers are inserted to equal depths and readings are taken every fifteen minutes. A difference of more than a degree is not to be expected in most cases and it is often less than this. The tumblers must not be placed in the sunlight.

How do seeds get air under ground? Does the soii contain air? Fill a bottle just half-way to the neck with the soil to be tested; place a thin layer of wet

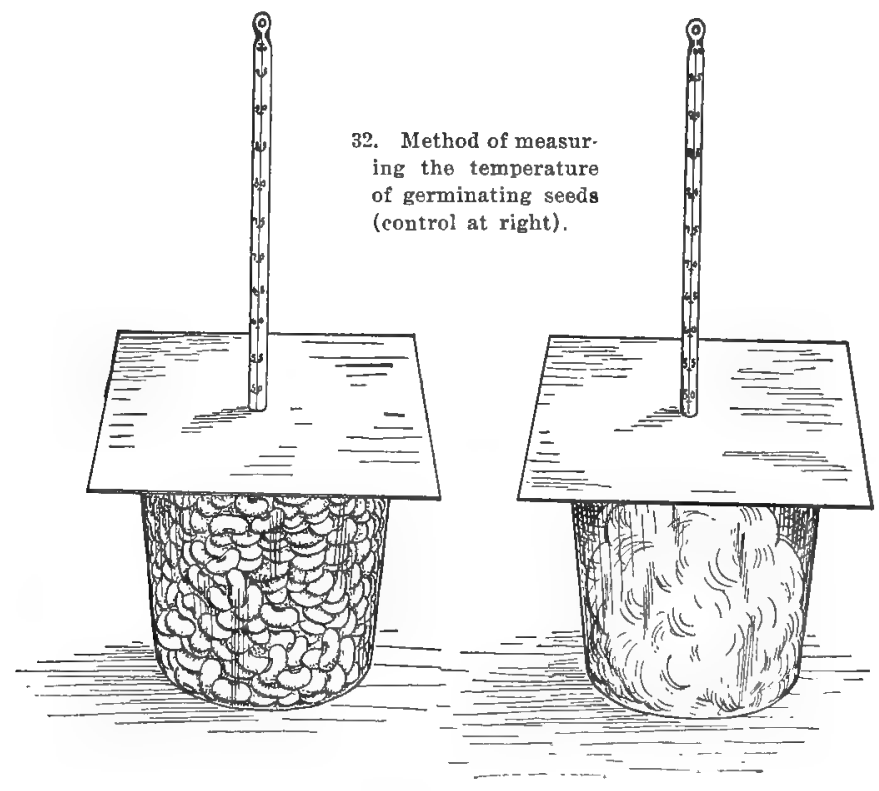


soil on top of it and tamp it down well with the blunt end of a lead-pencil; fill the bottle to the neck with water so that the spaces occupied with water and soil are about equal (the tamped-down layer is to prevent the water from penetrating the soil before we are ready). Insert a cork pierced with a wire (as shown in Fig. 33) and force the wire down so as to puncture the tamped layer (move it from side to side if necessary until the air begins to bubble up). When the air has all risen, we can tell approximately how much was contained in the soil.

When the method is understood, we may dispense with the cork and tamped-down layer and proceed as follows: Take two bottles of the same inside diameter;

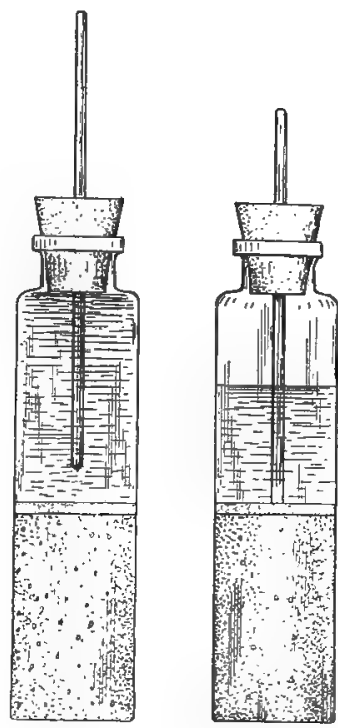

33. Method of determining whether air exists in the soil.

fill both to the same height (half-full or less), one with water, the other with the soil to be tested; pour the soil slowly into the bottle containing water. If the soil contains no air it should cause the level of the water to rise to just twice the height at which it stood originally; the amount by which it fails to do this measures the amount of air in the soil. The result depends somewhat on how tightly the soil was 
packed in the bottle at first. The natural condition of the soil could be more closely simulated by forcing a tin eylinder (a tin can with the bottom removed would do) into the soil (using a rotary motion), measuring the cylinder of soil so obtained and pouring it slowly and carefully into an equal bulk of water.

The deeper the seed lies in the soil, the less will be the circulation of air about it. A constant renewal of air is necessary, as we have already learned. The question naturally comes up, How does the depth at which the seed is buried affect germination? One way of finding out is by means of a box, with one side of glass, in which seeds may be planted at different depths, as shown in Fig. 34. A convenient way of making such a box is to prepare the sides (as shown in the figure) and then make saw cuts in them to receive the glass, which is then easily removed whenever necessary. A wooden strip for the bottom and another for the side (to give rigidity) complete the box. Both sides may be of glass, or one of glass and the other of wood. A box an inch wide at the top, with sides a foot square, is of very convenient size. The joints may be made air-tight by means of putty. In planting the seeds, the box should be tilted and a row of seeds placed directly on the glass; earth should then be pressed down on them; another row of seeds should then be planted, and so on until the 
top is reached. The box should then be filled with earth and the last row of seeds planted on the top.

The soil should be kept moderately moist and at a temperature favorable to germination. The seeds are now under approximately the same conditions as exist in the soil; as we go deeper we find more water, less air (and less circulation of air) and less warmth (in our apparatus the lower layers of soil are apt to be warmer than is naturally the case). Our experiment indicates that there is a certain depth where the three needs of the germinating seed are best provided for.

Various mechanical devices are in use for planting seeds at uniform depths in the soil (e. g., corn-plant-

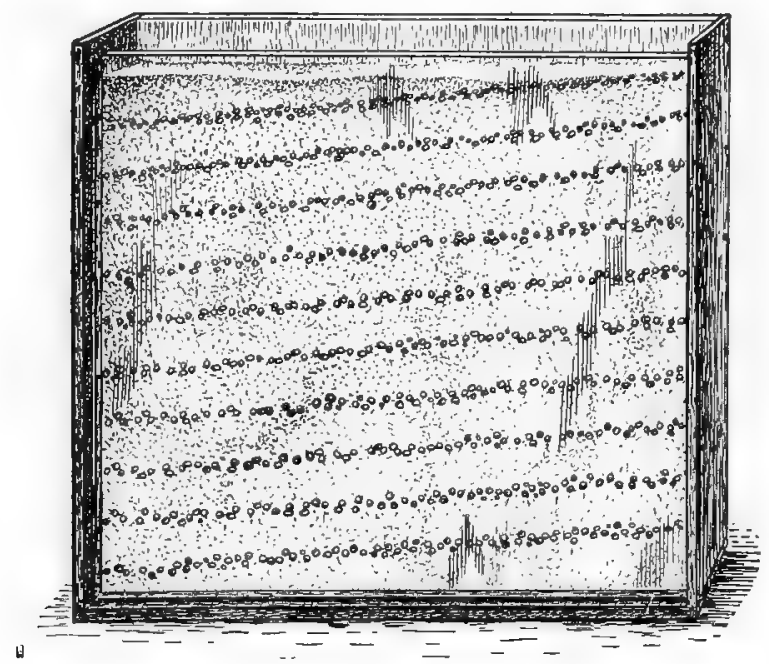

34. Apparatus for determining how deep seeds should be planted. 
ers, etc.). In sowing seed in the garden, the simplest and most effective way is to press a board edgewise into the soil to the right

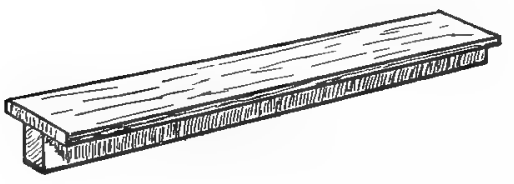

35. A planting stick, to secure uniform depth in planting seeds. depth, place the seeds in the depression, fill it with earth and pack it firmly by pressing the board down upon it. A board such as is shown in Fig. 35 may be used to secure a uniform depth.

The circulation of air in the soil will depend on the way in which it is packed in the box, on the condition of the surface (whether a crust forms or not), on the kind of soil used and on the amount of moisture in the soil. It will be found worth while to vary the conditions by filling one box with sand, another with clay and another with a mixture of equal parts of sand and old loam, which makes a very excellent soil for seeds. Water the boxes equally throughout the experiment. Gardeners always recognize the necessity for "good drainage" (i. e., proper circulation of air in the soil), and secure it in a variety of ways. The seeds are usually sown in shallow boxes, porous earthen dishes, or in ordinary pots, in which case a layer of pebbles or pieces of broken pots is placed in the bottom. The surface of the soil is protected from baking (which forms a crust) by a cover of sawdust or litter, or by being shaded; the shade is also of value in 
protecting the seeds from drying. A screen made of lath or brush, as shown in Fig. 36, affords an excellent means of shading a seed-bed; a screen of muslin cloth is very commonly used.

The quality of the soil should be carefully attended to. It should be of such consistency that it will pack firmly around the seeds but will not bake into a hard crust: a mixture of sand and good garden loam in equal quantities usually makes a good soil for this purpose. In some cases moss or cocoanut fiber is used instead of soil.

Very small seeds are sown on the surface of the soil, which has been sifted and then carefully smoothed. They must then be protected against drying up by a glass frame placed over them, or sometimes by a board laid over them: after they have germinated,

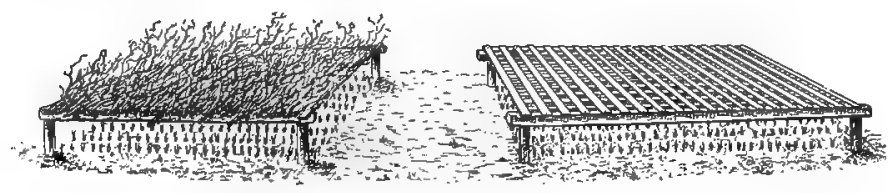

36. Screens for seed-beds; a brush screen on the left, a lath screen on the right.

the board is replaced by a piece of glass raised an inch or so above the soil.

In some cases such seeds are covered with fine moss. In sowing grass seeds for lawns, it is very desirable to cover the seeds with stable manure or straw. Such a covering not only keeps the seeds from 
drying up but prevents them from being washed away in watering. In watering small seeds where no such covering is used, a cloth may be laid over them or water may be applied to the soil from below (by set-

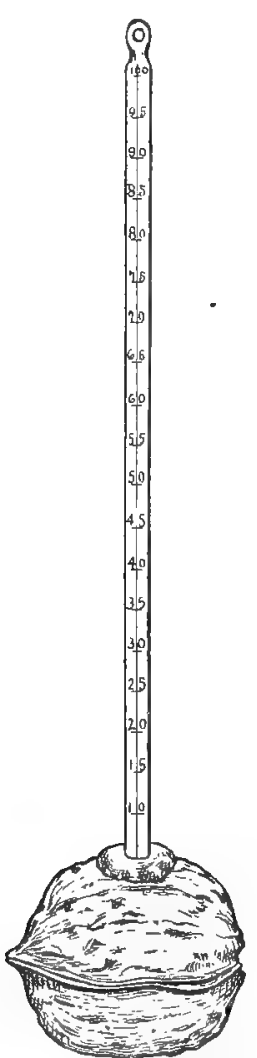

37. Method of testing the permeability of the seed-cover to heat. ting the box or pot in water for a short time).

Is it possible to prevent germination by keeping the soil too wet (i. e., by excluding air by water)? Would a reservoir of air in the seed be useful in very wet soil? Peanuts and Castor-beans are said to rot in wet soil if their coats be removed, but not otherwise; do you see why this may be true? Try planting them (with the coats both off and on) in pots of earth which are allowed to stand in pans of water.

How does the seed absorb warmth? Is the seed-cover a hindrance in this respect also? Seal the bulb of a thermometer into a seed-cover, as shown in Fig. 37 (first removing the contents of the seed). Place this, together with a naked thermometer, which has first been carefully compared with it, on the surface of the soil in sunlight (thus imitating the condition of a seed so placed); take readings every ten or fifteen minutes. 
Place the bulbs of both thermometers equally deep (from half an inch to an inch and a half) under the surface of the soil (thus imitating the condition of a buried seed), and take readings as before (the soil should be placed in the sunlight).

Place both thermometers at the same distance from a sheet of hot metal (or a stove or steam radiator), and take readings.

Heat both until they stand at the same temperature $\left(100^{\circ}\right.$ to $\left.150^{\circ} \mathrm{F}.\right)$, and then place them in a cool place, to see which loses heat more rapidly.

Test several kinds of seeds in this way.

Does wetting the seed-cover make any difference?

What kinds of soil absorb warmth (from the sun) most rapidly? What kinds retain it longest? Does the amount of moisture in the soil affect this? Devise an experiment to answer this question.

We have learned something about the awakening of the seed, but there are still many questions of interest. How soon can the seed awaken? Try immature seeds to see if they will germinate, especially seods of Tomato, Wheat and Barley. (Rain at harvest-time often causes grain to sprout in the ear. Seeds from half-grown green Tomatoes are used by some gardeners for special purposes. Plants from such seeds give earlier and larger crops of fruit.) Some seeds seem to require a period of rest before awakening. How long is this period in the Lima. 
Beal, Castor-bean, Sunflower, etc? The fruit of the Cockle-bur contains two seeds; it is said that one of these will germinate the first year if given the right couditions, but that the other will not germinate before the second year.

How long will seeds live if not awakened? The numerous accounts of seeds, three thousand years or more, taken from mummies and made to germinate are untrustworthy; but there is fairly good evidence that seeds which have been deeply buried for many years can germinate under the proper conditions. It has been found that seeds which have apparently lost the power of germinating can sometimes have their vitality restored by soaking in certain ferments.

A rapid method of testing seeds which is often employed is to place them in water; those which sink are declared good, while those which float are rejected. Test some seeds in this way, and plant both those which float and those which sink (the same number of each) and record what percentage of each germinates. (This test may work fairly well for some kinds of seeds, but prove of no value in other cases.) Seedsmen find it necessary to test the germinating powers of their seeds by accurate methods. For this purpose, the seeds are placed in shallow trays on moist cloth, paper, porous earthenware or plaster of Paris and kept at a constant temperature at the degree which is ascertained by experi- 
ment to be the best for the particular kind of seed which is being tested.

What is the best method of keeping seeds? Find out what you can about this from gardeners and nurserymen. What special precautions are taken in the case of oily seeds? Do you see any reason why they should not keep as well as starchy ones?

The amount of water in the seed affects its keeping qualities. If seeds are stored without being sufficiently dried, they are very liable to decay. Ordinarily they are dried in the sun. The pulp of soft fruits may be removed by washing; this process is hastened by adding a little lye to the water and allowing them to stand for an hour or so before washing. In more difficult cases the fruits are crushed and allowed to ferment before washing. If the seeds are to be stored, they should then be carefully dried.

Seeds are usually sent to or from tropical countries sealed up air-tight in tin boxes, to protect them from the moist, hot air, which causes them to sprout or to decay. It very often happens that the seeds contain so much moisture that they decay inside the box: consequently, both the seeds and the packing materials should be dried with great care before shipping.

Ordinarily seeds may be transported without any special precautions. A large part of the flower seeds used in this country come from Germany each year 
by mail without any other protection than a paper bag enclosed in a cloth bag or wrappirg.

In general, a cool dry place is best for keeping reeds. Some kinds of seeds should not be thoroughly dried. Hard, bony seeds, such as nuts, seeds of forest trees, etc., are most successfully preserved by burying them in earth. A layer of sand is placed on the bottom of a box, then a layer of seeds, another of sand, and so on. The boxes are then buried (one or two feet deep) for the winter, or they are placed in a shed and covered a foot deep with straw. This method closely imitates natural conditions. Freezing is supposed to be beneficial, though not absolutely necessary; it probably helps to crack the nuts and so assists germination.

What seeds germinate most quickly when favorable conditions come? What plants come up first from seed out-of-doors when the season for germination comes? Is quick germination an advantage? Why? In making a lawn, what usually comes up first, - the grass or the weeds? Does this help to explain the success of the weeds in the struggle for light and for space above ground and below?

Quick germination may possibly be a disadvantage if the first rains are succeeded by long periods of dry weather so that the seed which has sprouted dries out again. Will the seed die if allowed to dry up after it has sprouted? Allow some seeds to sprout until 
their caulicles are half an inch long: then allow them to become thoroughly dry, and again place them in a moist place. If they sprout let them dry again, and repeat this as long as they continue to live. Wheat and Peas and Rye may be especially recommended for this experiment: very favorable are also Oats, Buckwheat, Corn, Radish and Onion.

Does light affect germination? Place two lots of seeds on the surface of the soil in different pots: cover one pot with a glass cover, the other with an opaque cover which extends to the table so as to exclude the light completely (a pasteboard cover is good for this purpose). Place the first pot in diffused light, the second where the seeds will be at nearly the same temperature as in the other pot. Thermometers should be introduced into the pots so that the temperatures may be ascertained.

Some seeds (e. g., some kinds of Larkspurs, Poppies, etc.) are said to germinate imperfectly or not at all in the light.

Will the seed germinate more rapidly if deprived of its covers? Plant several kinds of seeds, having previously removed the covers from half the seeds of each lot. Plant some in very moist earth, others in earth that is comparatively dry, and take care to maintain this relation during the experiment. Which germinate first? In very wet earth it often happens that seeds deprived of their covers rot or mould, while 
whole seeds do not. The rotting is perhaps due to lack of air, and the seed-cover may prevent this by keeping a certain amount of air around the seed. The cover likewise protects the germ from mould. But, under favorable conditions, and probably in the great majority of instances, the seed-cover is a hindrance to germination.

Inasmuch as our experiments indicate that in very many instances the seed-cover is a hindrance to germination, it would seem to be important for the plant to get rid of it as soon as possible. This is the next problem to consider.

What covers seem hardest to burst open? How much force does the seed exert in bursting the covers? We may get an approximate idea of this by placing the seed in a pair of pliers, as shown in Fig. 38; one of the two handles of the pliers is firmly wedged in a hole bored in a block of wood, while the other is attached by means of a wire nail, which is bent as shown in the figure and passed through the hole at the end of the rod attached to the spring in an ordinary balance. 'The balance is to be wired at the other' end to a bolt which passes through a hole in a small vertical piece of wood which is firmly screwed to the block. On the end of the bolt is a nut, by turning which the position of the balance may be adjusted. If a seed is placed between the shorter arms of the pliers and water is poured into the tumbler until the 
seed is about half submerged, it will soon begin to swell and force the free arm to move, thus stretching the spring and causing the indicator of the balance to move also. If a small piece of glass be smeared with vaseline and placed in front of the indicator, it will move forward with it and record the highest pressure reacherl. We may now set the balance at any desired pressure by lengthening or shortening one

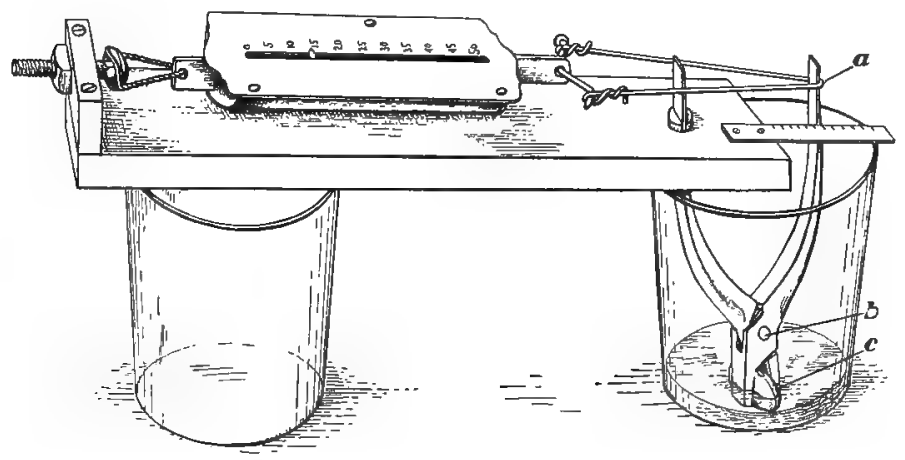

38. Arrangement for testing the swelling power of a single seed.

of the wire loops, or by turning the nut, or by both methods, and leave it for forty-eight hours. If at the end of that time an increase of pressure has been registered, we may replace the seed by a similar one of about the same size, taking care to set the balance at the outset at a somewhat smaller pressure than the highest recorded in the experiment just finished.

The experiment should be watched and the pressure recorded from time to time. It must be remembered 
that while the force with which the seed swells may be great, the bulk of swelling may be small; hence, if set at zero it may raise the pressure only to 4 , while if it had been set at 6 it would have raised it to 10 .

If it were convenient to watch the apparatus constantly, we might get still better results by varying the pressure so as to just prevent the seed from swelling. For this purpose a short section of ruler should be attached to the block near the movable arm and any motion of the arm at once counterbalanced by turning the nut until the arm returns to the place at which it stood at the beginning.

Owing to the fact that the pliers act as a double lever, the pressure must be calculated as follows: Divide the distance $a b$, from the wire to the rivet, by the distance $c b$, from the (center of) the seed to the rivet, and multiply by the registered pressure. In order to get the pressure per square inch, we must divide the calculated pressure by the area of the seed which is in contact with one arm (if the contact areas of the two arms differ, an average must be taken).

We shall probably find that individual seeds of the same kind vary somewhat in the amount of pressure they exert; for this reason it is better to test a considerable number at once and get an average result. We may do this by means of the apparatus shown in Fig. 39. It consists of a half-pint acateware cup fitting into another slightly larger one in 
which the seeds are placed and which has been pierced with a few holes to admit water: if the bottom of the outer cup is not flat, a disk of wood should be fitted beneath it so that the pressure will not spring it. In the smaller cup is placed a block, on which rests a small iron support. For a lever we use an iron rod one inch thick and three feet long, secured at the end

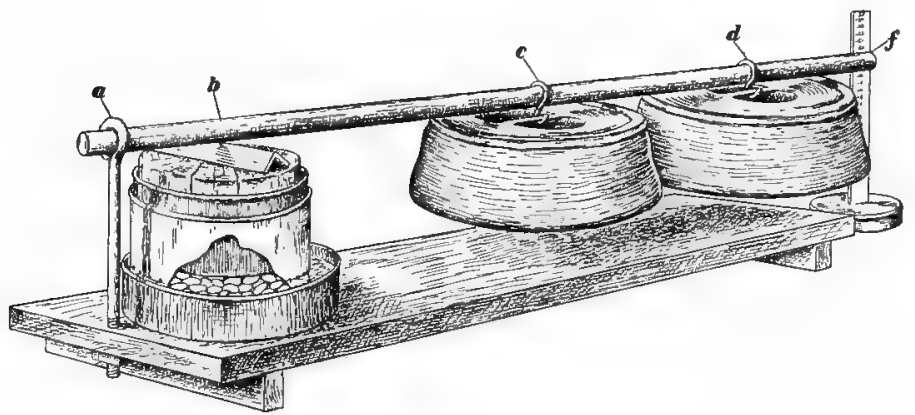

39. Arrangement for testing the swelling power of a mass of seeds (a portion of the outer cup is represented as cut away in order to show the seeds).

by an eye-bolt, as shown in the figure. For weights we may use ordinary fifteen-pound iron hitchingblocks, suspended from the lever by hooks. An upright ruler near the end of the lever serves to indicate its position. The whole apparatus rests upon a suitable board about three feet long.

We commence the experiment by filling the larger cup about half-full of dry beans (Pink Beans give excellent results) and arranging the apparatus as shown in the figure (the height of the lever may be 
adjusted by means of the nut at the bottom of the eye-bolt). Arrange the weights as desired, and pour water into the pan in which the cups stand. Observe from time to time; if the lever rises, move the weights away from the cups until it sinks to the level it occupied at the beginning. If, on the contrary, it falls, watch it, for it will probably sink for a time and then begin to rise, in which case add more weight. If after forty-eight hour's no additional rise is apparent, we may consider the experiment at an end and may then proceed to calculate the pressure exerted. This we must do for each weight separately. Thus, for the first weight divide the distance $a c$ by $a b$ and multiply by the weight; for the second, divide $a d$ by $a b$ and multiply by the weight. Add these products together, and then add the pressure exerted by the bar itself, which may be calculated as follows:

$$
\text { Pressure }=\frac{(\mathrm{a} f) \times(\text { weight of bar })}{(\mathrm{a} b) \times 2 .}
$$

Thus, if the length of the bar $(a f)$ is thirty-six inches, the distance $a b$ two inches and the weight of the bar eight pounds, the equation is

$$
\text { Pressure }=\frac{36 \times 8}{2 \times 2}=72 \text { pounds. }
$$

The results obtained by the above methods are only rough approximations. It should be remembered that while, theoretically, one layer of seeds can exert as 
much pressure as several layers, nevertheless we get a higher pressure recorded when several layers are used, for the reason that much of the force which is expended in squeezing the seeds together and changing their shapes is not recorded, but this error grows less the more seeds we use. Nevertheless, the result must always be too small, for this reason.

That seeds exert considerable force in swelling may be simply illustrated by means of a fruit-crusher, as shown in Fig. 40. To calculate the pressure, divide $a c$ by $a b$, and multiply by the pressure registered on the spring balance. Only a fraction of the pressure can be measured in this apparatus. A still simpler method is to fill a bottle

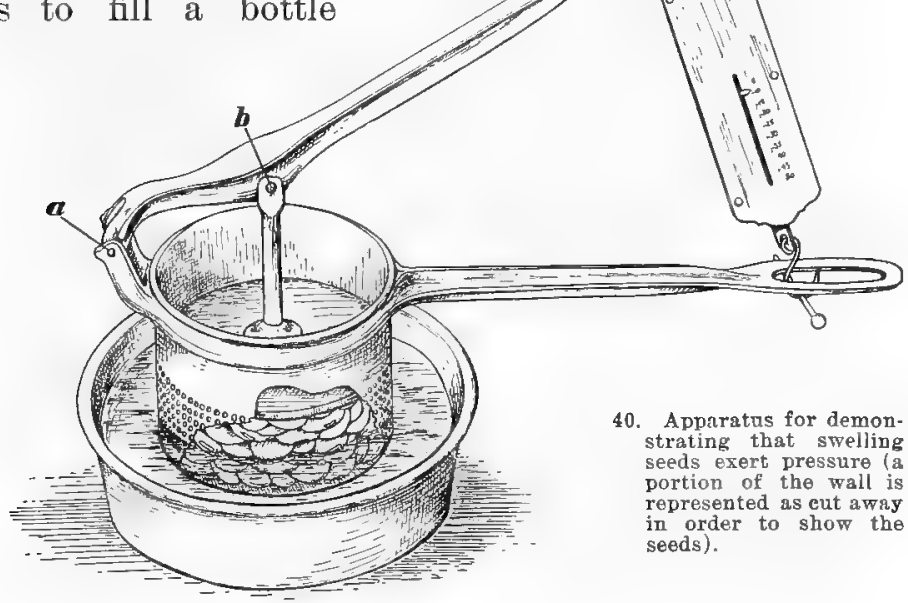




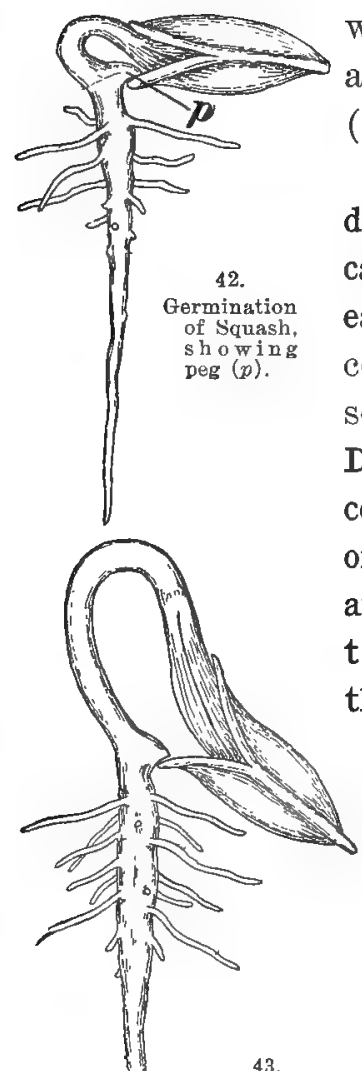

with dry seeds, put some elastic bands about it and place it under water (Fig. 41).

Do you find any devices to render escape from the cover easy? What seedcovers become softer on soaking? Do you find any covers which split or break more easily at certain spots, thus permitting the plant to escape more readily? Examine carefully seeds of the Squash, Walnut, Pecan, Almond, and stones of

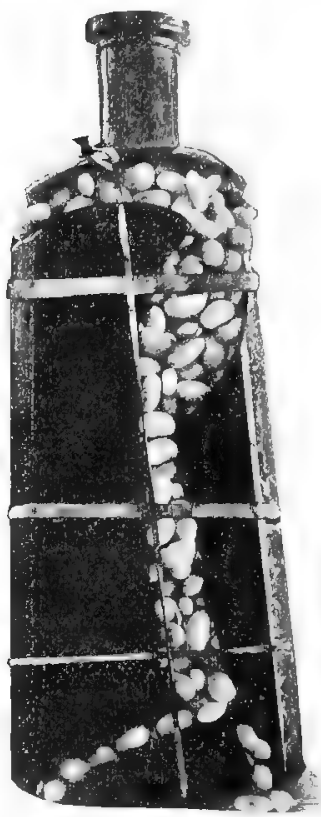

41. The result of placing seeds in a bottle under water.

Peach and Plum. The Squash gerLater stage of
germination germination the seed: leaves ate escaping from the seed-cover. select it for study. Place several soaked seeds flat on the surface of moist earth, cover with a piece of glass, and observe them every day. Notice the "peg" (Figs. 42 and 43) 
which develops at just the right time and place to do its peculiar work of helping the plant to get rid of its seed-covers. Could the squash get out of its covers without the aid of the "peg"? Cut off the "peg" or slip the cover up above it, and see what happens. What would happen if the seed were placed vertically instead of horizontally? Try it and see. The seeds should be

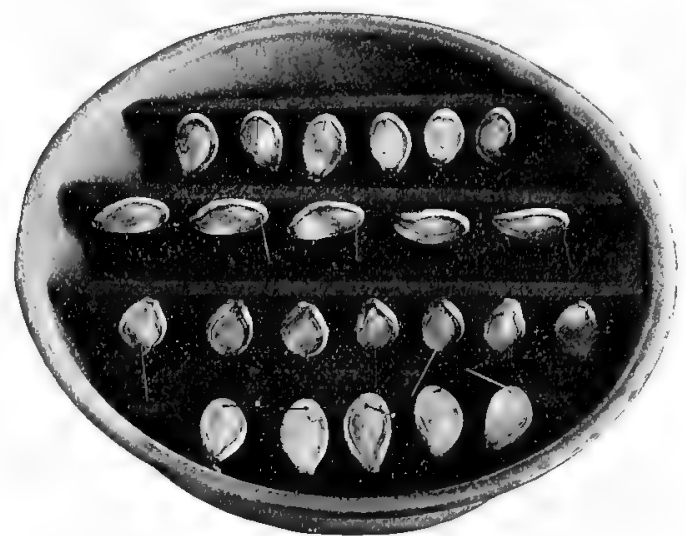

44. Squash seeds arranged for germination experiment.

firmly pinned (at the large end) to vertical strips of wood (as shown in Fig. 44), which are nailed to a wooden block and placed in a pan. A little water should be poured into the pan and a glass cover placed on it to prevent the moisture from escaping. The seeds should be well soaked before being put in position. Some may be placed with the pointed end up, others with the pointed end down, and still others with 
the long axis horizontal but standing on edge or lying flat as shown in the figure. Remove the covers from some of the seeds before planting; does the "peg" form just the same?

What seed has the hardest cover? You will probably agree that it is the Cocoanut. How does the plant get out of it? Where do you find the germ? It is very small (about a third of an inch long) and lies under the softest of the three "eyes." Notice how thin and soft the substance of this "eye" is, and you can readily see that it offers the plant an easy way of escape. Originally there was a germ under each eye, but in the struggle for space and nourishment two of these germs have perished, leaving the survivor with a great abundance of food (occasionally two of the germs survive). Almost any wholesale fruit-dealer can procure for you Cocoanuts which have germinated during the sea voyage. These are usually thrown away as worthless when the cargo is unloaded. Or you can germinate them for yourself by keeping them in a hotbed or in a box corered with glass in the summer-time. Plenty of moisture and warmth are needed for success. They should be buried in earth or sawdust and kept where they will get as much heat as possible. Fig. 45 shows the appearance of a germinating Cocoanut, with the outer husk still in position. This husk is fibrous and has a tough outer shell, through which the roots seem to 


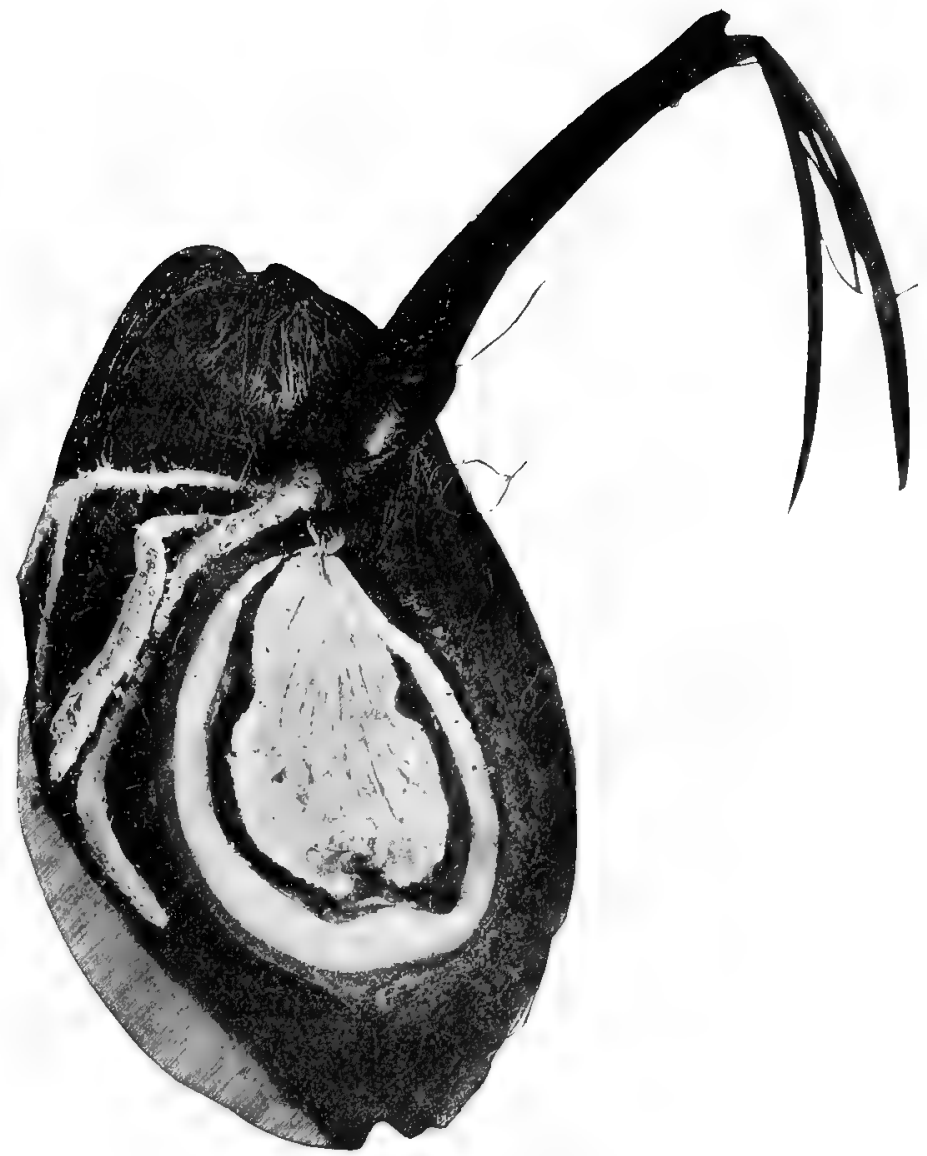

45. Germinating Cocoanut eut lengthwise, showing the outer fibrous husk, the roots making their way through it, the young palm leaves, the meat enclosed by the hard shell and the huge absorbent sucker which, by its growth, fils the eavity and absorbs both the milk and the meat. At the point of eonstriction between the sucker and the stem is the "eye" through which the germ escapes from the hard shell. 
penetrate with some difficulty: in many cases they seem unable to break through it, but turn aside on reaching it and grow down through the fibrous mass inside. Careful inspection of the "eye" where the plant has

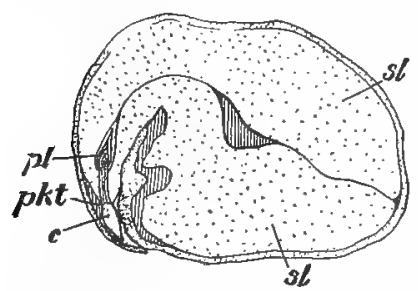

46. Buckeye cut open, showing the seed-leaves $(s l)$, the phrmule $(p l)$. the eauliele $(c)$ and the poeket ( $p k t)$ into which the cauliele fits.

grown out through the thick inner shell will show how thin the shell is at this point and how very slight is the obstacle to be overeome by the plant in order to break through. The enormous sucker developed by the plant for the purpose of absorbing the food in the Cocoanut soon fills the whole cavity and consumes not only the milk but the flesh as well. This absorbing organ is soft and spongy and traversed by straight fibers (plainly shown in the figure), which convey the nutriment directly to the growing plant. Preparations like that shown in the photograph are obtained by sawing the nut through the middle (beginning at the larger end) to a point about two inches from the "eye," and then prying the halves apart. The break then occurs exactly through the "eye."

Do you find that each kind of seed has a definite spot where the first rupture of the cover occurs? Is this due to the location of the caulicle, to the local weakness of the cover (e. g., to the presence of the opening), or to some other cause? When the opening 
in the cover is not near the caulicle (as in the Walnut, Peach, etc.), where does the rupture occur?

What part of the plant is the first to burst through the opening? What advantage in this: Is it the caulicle only which grows, or do other parts enlarge and help to push it out? What part grows most rapidly at first in the Buckeye? (See Figs. 46 to 49.) In the Walnut? In the Onion? What other seeds

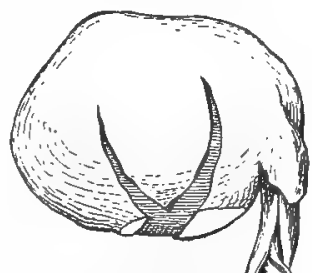

47. Buckeje. The plumule emerging from between the elongated stalks of the seod-leaves. are like them in this respect? Do the seed-leaves grow at all in such seeds as the Scarlet Runner? What has broken the covers

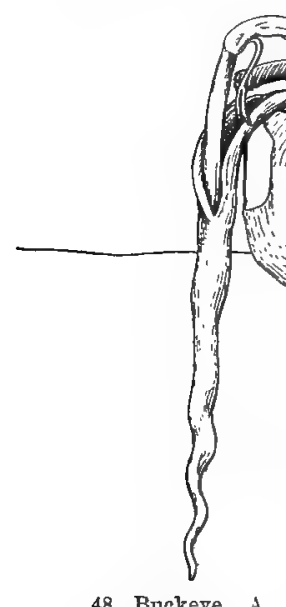

48. Buckeye. A later stage. transversely, as shown in Fig. 50?

Does the caulicle invariably push straight out through the cover? Why does it not turn aside on meeting the cover, like the roots of the Cocoanut in Fig. 45? Study the germination of Corn: what is the direction of least resistance for the caulicle? Examine the Buckeye, and notice the pocket into which the caulicle fits (Fig. 46, pkt); does this direct its growth? Do you find anything similar 
in the Bean, Pea or other seeds? (See Fig. 20.)

The surprising amount of force developed by swelling seeds is obviously connected with the absorption of water, by means of which they increase in size. It is very easy to construct an apparatus in which the absorption of water will generate pressure just as it does in the seed. For this purpose we take a piece of glass tubing about one-sixteenth of an inch in diameter (inside), or a little larger; smooth one end by heating in a flame until it

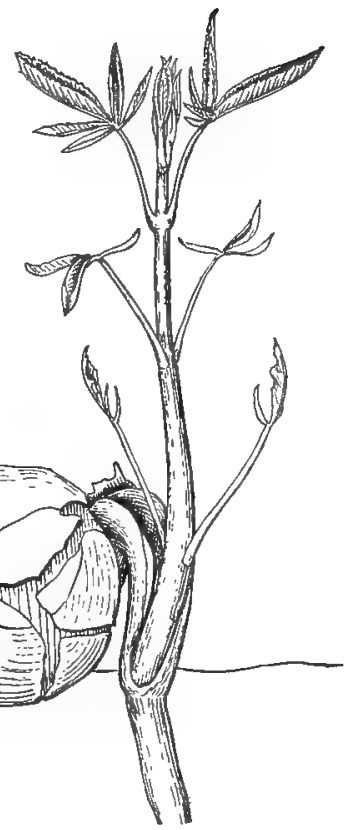

49. Buckeye. A still later stage. fuses slightly, and when it has cooled stretch over it a piece of ox-bladder or heavy parchment paper (ob-

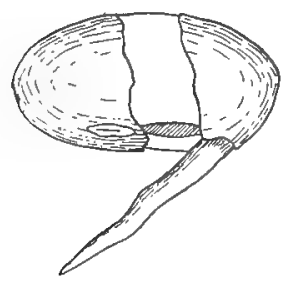

50. Scarlet Runner Bean germinating; the cover split across. tainable of druggists). Hold the piece of bladder stretched like a drum-head across the mouth of the tube, and let an assistant wind it tightly elear to the tube's mouth with ordinary cotton twine; tie it with a square knot and let it soak for several hours, during which 
the twine will shorten and make a tight joint. It is well to prepare several tubes, since some are sure to work better than others.

Place in each tube a strong syrup (a solution of sugar in water), stand them in a tumbler of water, mark the height of the liquid in each tube, and leave them over night. In the morning it will be found that the sugar has absorbed water through the membrane and that the liquid has risen in the tube. Choose the one which shows the greatest rise, for future experiments.

To demonstrate that the absorption of water can produce pressure, it suffices to fill the tube completely full of syrup, invert in a tumbler of syrup and tie on a piece of sheet rubber (such as toy balloons are made of), holding the end under the syrup all the time so as to exclude air. The rubber should be tied on in the same way as the bladder. The tube may now be rinsed in water and then placed in water as before (see Fig. 51). In a day or so the rubber will become tightly stretched, showing that pressure has been generated.

In order to estimate how much pressure is produced, we may proceed as follows: Remove the rubber and fill the tube to within

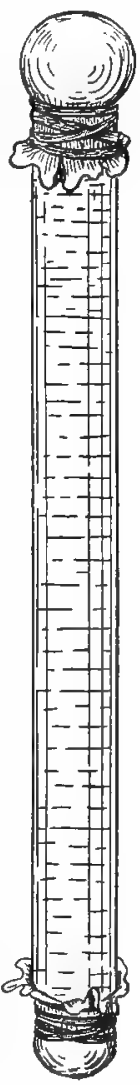

51. Apparatus for demonstrating that osmosis exerts pres. sure. 
an inch and a half of the top with fresh syrup. Fit a small rubber cork to the tube and push it down

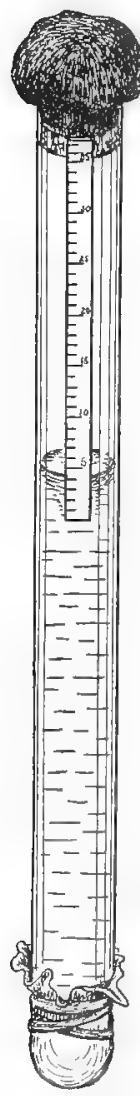

52. Apparatus for meisuring the pressure due to osmosis. about half an inch into the tube; insert a needle at one side of the cork, so as to allow the compressed air to escape and restore the normal pressure. Withdraw the needle and carefully dry out the inside of the tube abov' the cork. Melt some sealing-wax in a spoon, and pour it slowly into the tube until it runs over. With a hot knife smear it over the outside as far down as the cork, so as to close the tube air-tight (see Fig. 52). Obtain or prepare a strip of paper ruled in fine divisions (millimeters or twenty-fourths of an inch, if possible), and gum it to the upper part of the tube for the purpose of measuring the length of the air-column in the tube. Place the tube in water, note the length of the air-column, and observe it frequently during the experiment. The amount of pressure produced in the tube can be easily calculated from the amount of compression which the air undergoes. The formula for the calculation is:

Length of air-column at start $=$ Pressure at finish.

Length of air-oolumn at finish Pressure at start.

Thus, if the column measure one inch at 
the start and one-half inch at the finish the equation will be

$$
\frac{1}{1 / 2}=\frac{\text { Pressure at finish. }}{15 \text { pounds per square ineh. }}
$$

whence thirty pounds per square inch equals pressure at finish

The results are approximate only and will vary according to the character of the membrane, the strength of the syrup, etc., and cannot be regarded as indicating what the same solution would do with a different kind of membrane (such as is to be found in the plant, for example), but the pressure is clearly demonstrated and one method of measuring it illustrated.

In our apparatus the sugar attracts ${ }^{1}$ the water with considerable force so as to generate the pressure we have observed; we believe the pressure manifested by swelling seeds to be generated in much the same way, by substances within the seed (sugar, proteids, etc.) which attract water with considerable force. We have already learned that if we add water-attracting substances, such as sugar or salt, to the water in which the seeds are submerged, these substances exert a counter-attraction which hinders or prevents the absorption of rater by substances within the seed. We may even withdraw water from the seed by placing it in a sufficiently strong solution of salt or sugar.

i This expression is used only for the purpose of describing the fact in popular language. 
Carefully weigh and measure a dry seed, place it in water for twenty-four hours, and then measure it again. Now place it in a very strong solution of salt or sugar until it returns to its original weight, and remeasure. Does it return to its original volume? After the seed has grown for a time it is not possible to shrink it back (by means of strong solutions or by drying) to its original volume, even if we succeed in bringing it back to its original weight. The growth has become fixed, or "set." The seed is composed of very small chambers or cells (as may be easily seen by examining the broken surface of a Horse-bean seed-leaf with a hand-lens), each of which, like our apparatus, contains substances which absorb water and so generate pressure by which the walls of the chamber are distended (just as was the rubber fastened to the end of the tube in our apparatus). The rubber returns to its original size as soon as the pressure ceases. The stretched walls of the cells behave in the same way at first, but after a time they are strengthened and reinforced by the deposit of more material; when this has occurred the pressure may be removed and, while they will collapse to a certain extent, they will not shrink back to their original size. The growth may then be said to be "set." We may ascertain when this occurs by the method described above.

The explanation which has been given of the 
growth of the seed applies to the growth of all parts of the plant at all stages of development. We may cut off an inch from the tip of the root or stem and, after measuring and weighing it, place it in water, where it will continue to grow: we may then deter-

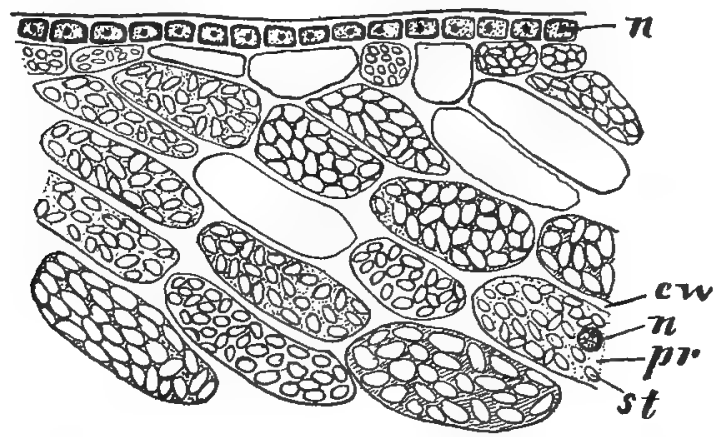

53. Section of a bit of the seed-leaf of the Horse-bean, showing cells filled with starch-grains (st), the protoplasm ( $p r$ ) lying between them, the nuelei $(n)$ and the cell-walls (cw).

mine when the growth has "set" by the method which we have just used for the seed.

To get a better idea of the appearance of the cells, we may proceed as follows: Holding a well-soaked seed-leaf of the Horse-bean in the left hand, cut thin sections with a sharp razor held in the right; cut slowly with a drawing cut, place the sections in water and select the thinnest ones, even though they be very small pieces. Place them on a glass slide in a drop of water, cover with a cover-glass and examine under the mieroscrope. Fig. 53 shows the appear- 
ance of the cells under the microscope. Each cell has a cell-wall ( $c w$ ) composed of cellulose, a firm substance almost identical in nature with ordinary paper or cotton or linen cloth. Within this firm cellwall is the living substance or protoplasm $(p r)$, soft and jelly-like in consistency, which can be made clearly visible if we place the sections in weak eosin solution. It takes up the eosin rapidly and becomes deep red in color, leaving unstained the cell-wall and the starch-grains (st), which are the white glistening bodies embedded in the protoplasm. If we place some sections in iodine (see page 164) the starch-grains become bluish black and the protoplasm yellow. If we place other sections in safranin solution until they are deeply stained and then rinse in alcohol until they fade to a deep pink, we shall find in each cell a small, deeply stained body called the nucleus $(n)$; this can be more easily seen in the outermost row of cells (where there are no starch-grains to obscure it), and still more easily in sections of the caulicle. Every living cell contains protoplasm and a nucleus, and is usually surrounded by a cell-wall.

The living substance (protoplasm) of the cells is the source of all their activities. It may be killed in a variety of ways; e.g., by heat, poisons, ete. It then behaves very differently to what it does when alive. We may kill some seeds to see how this affects their power of growth. The most convenient way to 
kill the seeds in a dry condition is by heating them. To avoid scorching them, we may put them on a water-bath consisting of two tin-cups, as shown in Fig. 54. Water is placed in the lower cup, the seeds are placed in the upper one and covered, and the apparatus placed on a stove.

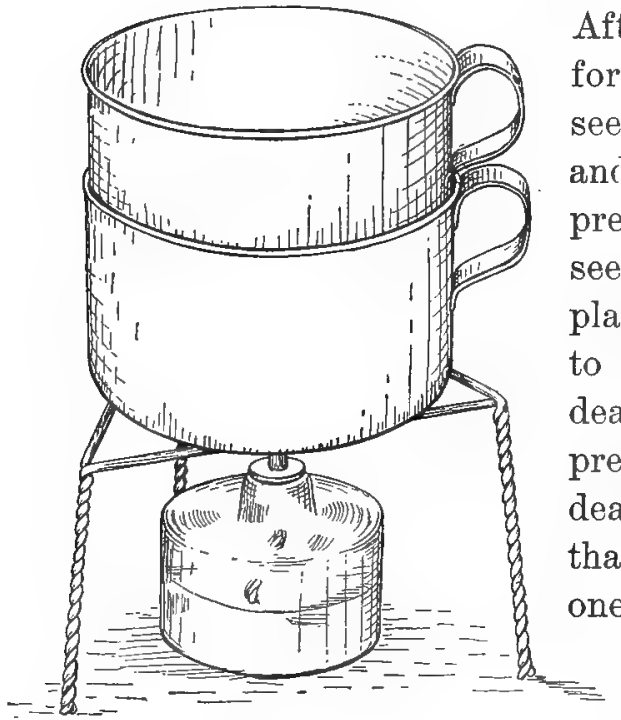

54. Water-bath. After the water has boiled for about an hour, the seeds should be removed and tested by the methods previously used for live seeds (some should be placed in moist sawdust to see if they are really dead). How does the pressure generated by dead seeds compare with that produced by living ones? To what extent do they "grow"? Does the growth become "set"?

We may, as the result of these experiments, distinguish two stages of growth, a temporary and a permanent. The temporary stage lasts until the cell-wall has been sufficiently reinforced by new material to prevent it from collapsing when water is withdrawn. Cut off an inch from the tip of a root and of a 
stem, kill it with boiling water, place in water and observe whether there is any growth, i. e., increase of weight or length, and whether such growth "sets."

Inasmuch as wood and many other substances derived from plants (and animals) possess the property of swelling up in water, even when dead, it may be interesting to compare them with seeds in this respect. Test the swelling power of dead, dry wood in the same apparatus which you have used for seeds.

How much water does the wood absorh? Wood has the power of taking moisture from the air to such an extent that it has been used to foretell changes in the weather by means of thin strips, which warp in opposite directions as the air grows moister or drier.

A very important practical question is, whether wood swells equally in all directions. Draw two lines ten inches long on a piece of dry plank,-one with the grain, the other at right angles to it. Keep the piece of wood under water for two or three weeks, and then remeasure. Find out something about the behavior of different kinds of wood in shrinking, warping, etc., and the practical bearings of these facts.

These experiments will serve to give clear ideas about certain physical aspects of growth which are of very general application. 


\section{CHAPTER II}

\section{GETTING ESTABLISHED}

Do seeds germinate better on the surface of the ground, or when buried in the soil? Experiment with several kinds of seeds both in the laboratory and outof-doors. The amount of moisture in the soil has a great deal to do with the matter and should be taken account of in arranging the experiments. What seeds, if any, do you find out-of-doors germinating successfully on the surface of the soil?

How do seeds get buried in the soil? Find out all you can about the agencies which help to bury seeds, including wind, rain and running water, which cover the seeds with earth and mud; cracks and fissures in the earth into which the seeds fall; burrowing animals and insects, such as gophers, ground-squirrels, woodchucks, earthworms and ants, which bury seeds accidentally while burrowing, or carry them to underground storehouses; blue jays (and perhaps other birds), which are known to store seeds by burying them in the ground; and various animals which trample the seeds into soft earth or mud.

How deeply are seeds buried by these agencies? From 
a field long fallow, from the margin of a stream and from the edge of a wood take successive layers of earth (each an inch in depth) from the surface down to six or seven inches deep. Let these be placed in separate boxes and watered, in order to find out how

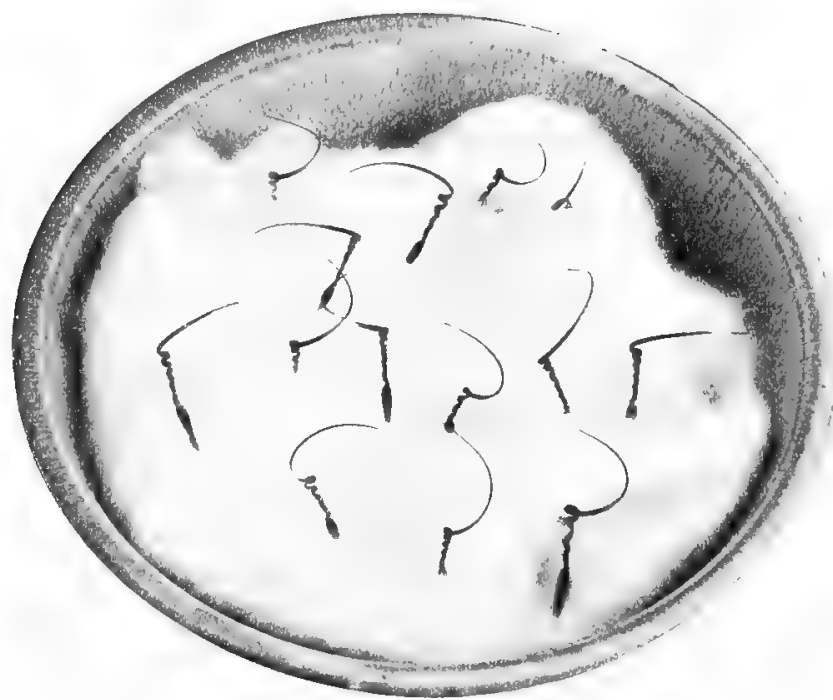

55. Filaree seeds burrowing into cotton.

many seeds capable of germination are contained in each layer.

Some seeds are carefully buried by the parentplants; the Peanut is one of these; by all means, watch this process if possible. As the flower-stalks lengthen they bend downward and bury the Peanuts beneath the ground. 
Some seeds bury themselves. The Filaree, Foxtail and Wild Oats have seeds of this kind. If you can

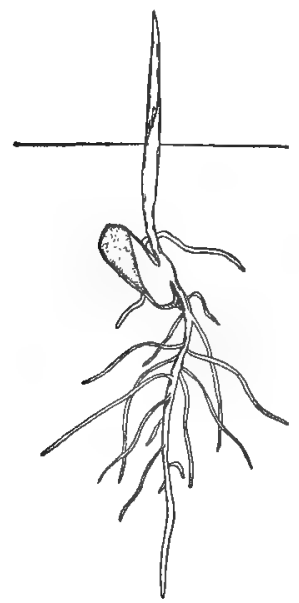

56. Corn making its way above ground. obtain these, place them on the surface of moist soil (a rough, uneven surface is best), and water them occasionally. How do the "clocks" assist in burying the Filaree? In order to see them work to best advantage, they should be placed (seed end down) on moist cotton (see Fig. 55). The seeds of the garden Geranium (or Pelargonium) act in the same way, but to a very slight degree as compared with the Filaree.

Buried seeds, which escape from their coverings only to find themselves imprisoned under ground, have before them the problem of getting their stems up into the air and light; which plants seem to achieve this most easily? Notice the Corn (Fig. 56 ), which seems to pierce the soil with ease by means of its sharp bodkin of firmly rolled leaves; the Scarlet Runner (Fig. 57) seems clumsy by comparison, ramming its crooked stem forcibly through the soil and

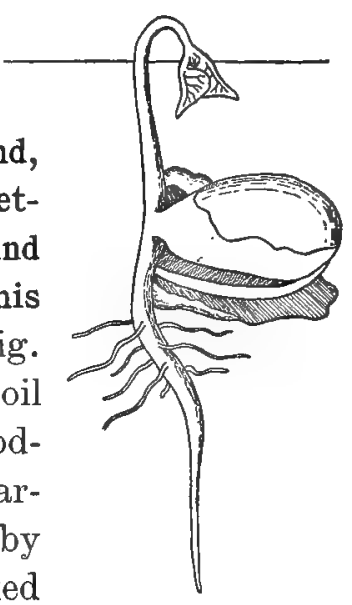

57. Bean getting sbove ground. 
often lifting up a good-sized lump of earth on emerging; the Castor-bean doubles and twists (Fig. 58), like an athlete straining every muscle; why does it have so much trouble? Does the growth of the seed-leaves while still underground account for it? Suppose we remove all hindrances from the Castor-bean; will the stem still form the characteristic "loop"? Allow some to germinate on the surface of the soil, or, better, in a

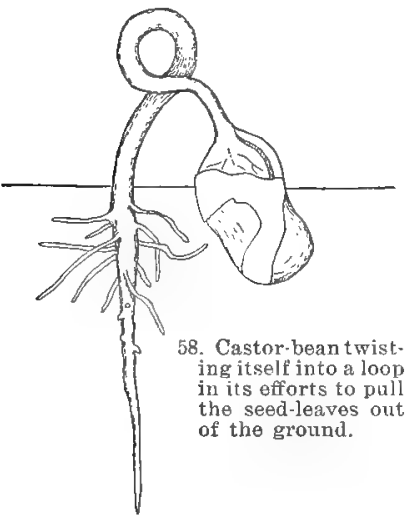

flower-saucer which has been boiled (since Castor-beans are very apt to mould). Cover this with a piece of glass which has been boiled in water or rinsed in two per cent formalin. Remove the coats from a part of the seeds, so that they may be freed from all hindrances which might cause the formation of the "loop." Place some with the caulicle downward, others with the caulicle upward. Try the same experiment with other seeds which form a "loop." What part of the plant forms the "loop" in the Onion? What plants do not form a "loop"? (Notice especially Corn and Grasses.)

How much opposition can the stem overcome in forcing its way upward? TVe may test this by means of the apparatus shown in Fig. 59. Find two bottles 
(about one inch in diameter), one of which fits inside the other; cut off the smaller one as shown in the figure and make a spiral spring of the same diameter. (The spring is easily made by winding a piece of brass wire, about No. 18, closely and evenly around a spool.) In a piece of board (which should be about an inch thick) bore a hole large enough to snugly fit the larger bottle. Support this by two blocks (as shown in the figure), so that it may hold the bottle in a vertical position. Allow the plant to grow up into the smaller bottle and press upward against the spring: put a little cotton in the bottle as a cushion for the plant to press against. A suitable weight (about two pounds) must be placed on the apparatus; sufficient earth should be removed at the bottom of the bottle to allow access of air. Each day mark on the outside of the larger bottle the height to which the inner bottle has been raised (a strip of paper gummed to the outer bottle will serve for this). When

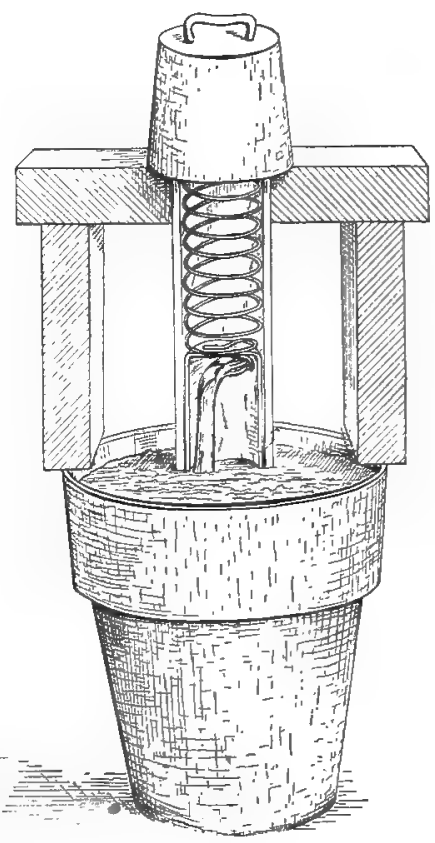

59. Apparatus for measuring the force of the upward growth of the plaut. 
the plant can compress the spring no further, remove it, invert the bottles, substitute for the inner bottle a larger one of the same diameter, and pour shot into it

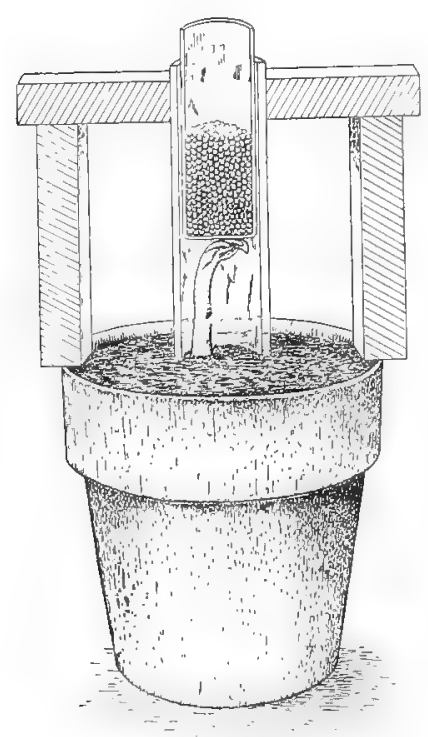

60. Modification of the apparatus shown in Fig. 59. until the spring is compressed to the same point as it was by the plant. The weight of this bottle with the contained shot, plus the weight of the inner bottle and cotton (since the plant raised these in addition to compressing the spring), will give the pressure exerted by the plant: if we divide this by the area of the cross-section of the stem just back of the crook we shall obtain the number of pounds pressure to the square inch. Thus, in one case the plant exerted a pressure of one pound. The diameter of the stem just back of the crook was one-eighth inch. The equation is

$$
\frac{1 \text { pound }}{\pi \mathrm{R}^{2}}=\frac{1}{3.1416 \times\left(\frac{1}{16}\right)^{2}} 81.5 \text { pounds per square inch. }
$$

It is interesting to note, in this connection, that the pressure of steam in the boilers of ordinary sta- 
tionary engines does not usually exceed eighty pounds per square inch.

If a spring is not at hand we may use in place of it a bottle filled with shot, as shown in Fig. 60 .

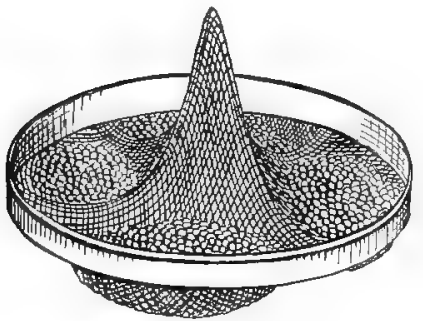

61. An arrangement for weighting an upward-growing stem.

A simple method of testing the force of the upward growth of the stem is by presparing a strainer, as shown in Fig. 61, by thrusting the finger upward through the bottom. The plant is allowed to grow up into the cone thus formed and receives both air and light; shot may be poured into the strainer until the plant can no longer lift the weight. As it is somewhat difficult to balance the load, we may use for this purpose the apparatus shown in Fig. 62. Three stout wire nails, about five inches long, are driven through holes previously bored in a board so as to be as nearly vertical as possible. They are

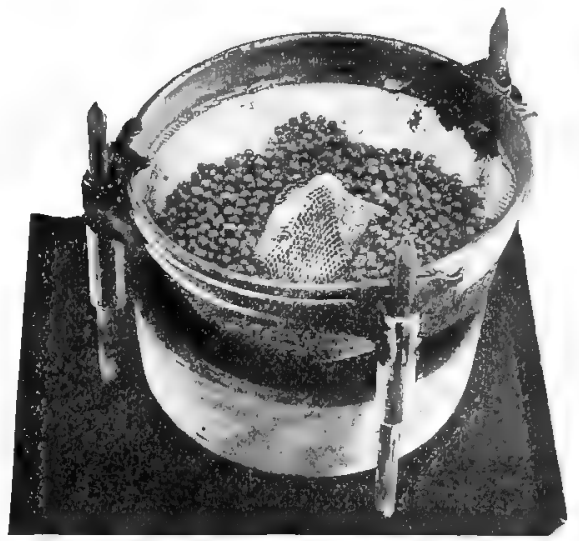

62. Modification of the arrangement shown in Fig. 61. 
so placed that the strainer slips down easily between them. Pieces of glass tubing about an inch long are attached by sealing-wax to the sides of the strainer in the manner shown in the figure. (This is most easily done by attaching lumps of wax to the tubes, placing them on the nails and then heating the strainer at the proper points. On placing it in position the wax will adhere to it.) They should be large enough to slip easily over the upright guides. A hole large enough to receive a small flower-pot is now bored in the board and two upright side-pieces nailed on so as to prevent the pot from resting its weight on the table. The strainer should slide on the guides with a minimum amount of friction.

It must be remembered that if we prevent the stem from bending (e. g., by enclosing it in plaster of Paris), it will probably exert a much greater pressure. Ine amount which is registered by any of these methods is only a very rough approxinution and is, as a rule, much smaller than what the plant can exert.

We must not be too hasty in thinking the limit of "reight has been reached; for, after waiting a reek or so, the plant will sometimes begin to lift a load which seemed at first too heavy for it.

Plants sometimes come up through soil which is extremely hard. It is interesting to watch the behavior of the plants in a very hird, resistant soil. Observe all the cases you can. Plant some Beans 
about four inches deep and pack clayey soil firmly upon them. How long before they appear above ground? Do they come up through the cracks (especially at the sides), or not? Sometimes they lift up the whole mass of earth as a solid cake and thrust it out of the pot. After witnessing a feat of this sort

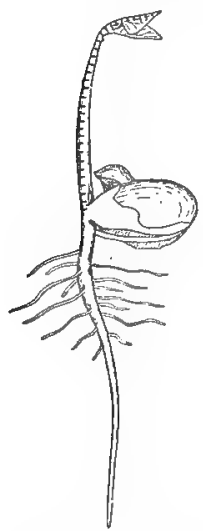

63. Bean with the stem marked, in order to determine the region of greatest growth. we are more ready to believe the tales about mushrooms which lift flagstones and the like.

In what part of the stem is the force developed which makes these feats possible? Bend a piece of wire (about three inches long) into $\mathrm{a}$, and connect the ends by a fine thread (a single strand taken from a silk thread) so that the latter will be stretched taut; moisten this with India ink; hold a cardboard scale (or ruler) against the stem and mark the stem at intervals of exactly one-eighth of an inch by touching it with the inked thread; stems devoid of hairs are most easily marked (Fig. 63). The growth of the stem will cause the ink marks to separate, and the degree of separation will indicate the place of most rapid growth. Where is the region of most rapid growth? How long does the growth continue most rapid in this particular region? How long does this region continue to lengthen? How much of the stem is growing at a given instant? 
Stems and other parts of plants may be quickly and evenly marked by means of the apparatus shown in Fig. 64. It consists of a small spool (such as is used for silk twist) with threads at regular intervals; it revolves on a small wire handle. The spool is first notched at regular distances in the following manner: Two knife-blades are fastened together (by clamps or strong spring clothes-pins) with a strip of wood (about one-twenty-fourth of an inch thick) between them. The double knife is then pressed against the two flanges of the spool, so as to make simultaneously two cuts in each. One blade is then inserted in a cut

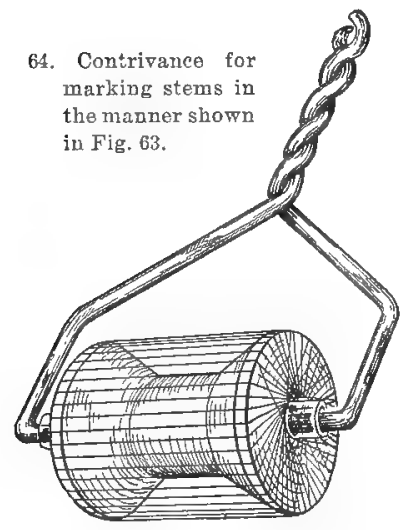
and the knife again pressed down so as to make a fresh cut. By proceeding in this way, all the cuts will be the same distance apart. A small piece of glass tubing is secured (by means of sealing-wax) in the center of the spool, and the thread is firmly wound upon it in a manner shown in the figure. A piece of wire, inserted in the glass tubing and then bent and twisted as shown in the figure, serves as a handle. The thread may be inked by rolling the spool over a pad (made by wrapping any absorbent cloth around a stick) saturated with India ink. 
By means of this apparatus any part of the plant, even if bent or crooked, may be instantly marked

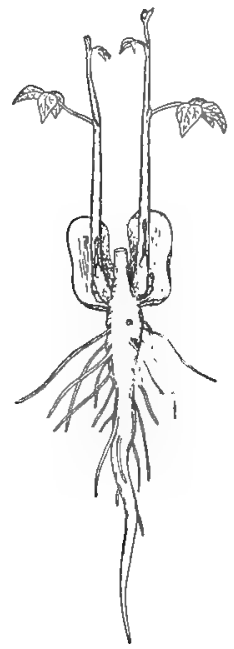

65. Scarlet Runner Bean with top (terminal bud) removed. and with much greater accuracy than if done in the usual way. In place of a spool we may use two small notched wheels (obtainable of watchmakers) soldered together on a small piece of wire.

What protects the delicate tip of the stem as it is driven forcibly through the soil? Compare the devices by which the Corn (Fig. 56) and Scarlet Runner (Fig. 57) protect the tip. What happens if the tip is injured? Remove it and see (compare Fig. 65). Do new branches arise? When? Where? In what direction do they grow? Is this the direction which branches normally take? What advantage in this direction of growth?

What happens if a stem meets an obstacle which it cannot push aside? Plant some seeds two or three inches deep against the

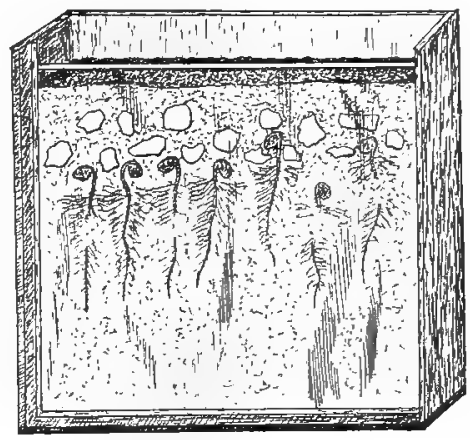

66. Radish seedlings gropring upward along the glass side of a box toward obstacles placed in their path. 
glass sides of a box, such as is shown in Fig. 66. As the stems begin to grow up along the glass, fasten small blocks of wood to the glass (by means of sealingwax) directly in their paths. Let some of the blocks have several holes (about one-fourth of an inch in diameter) bored in them, to see whether the plant will find these and grow up through them. Do you see how . plants find the crevices in concrete and brick sidewalks and come up through them?

Does the position of the caulicle make any difference in the time it takes the plant to get above ground?

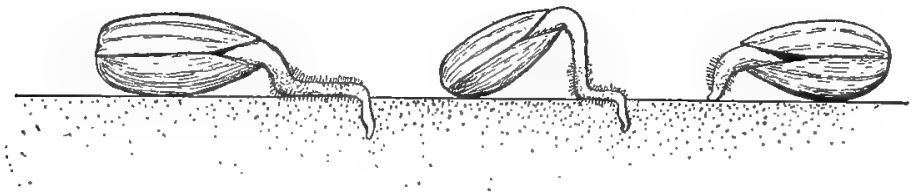

67. Sunflower seedlings penetrating the soil.

Plant (about an inch deep) an equal number of seeds of the same kind (at least ninety in all), some with the caulicle up, some with the caulicle down, some with the caulicle at one side. Keep them all under the same conditions (as regards depth, moisture, warmth, etc.), preferably all in the same box. Which appear first above ground?

Let us see what happens to the seed which lies on the surface of the soil. Its first problem is to get its root down into the ground. Have you ever noticed what difficulty some seeds have in doing this? 
Place on the surface of quite moist soil seeds of Mustard, Morning-glory, Wheat, Squash, Sunflower, Onion, Lima Bean and Horse-beam. Notice how the roots of the lighter seeds, in trying to penetrate the soil, raise the seeds up and even turn them over, and how the root-hairs and rootlets anchor these light

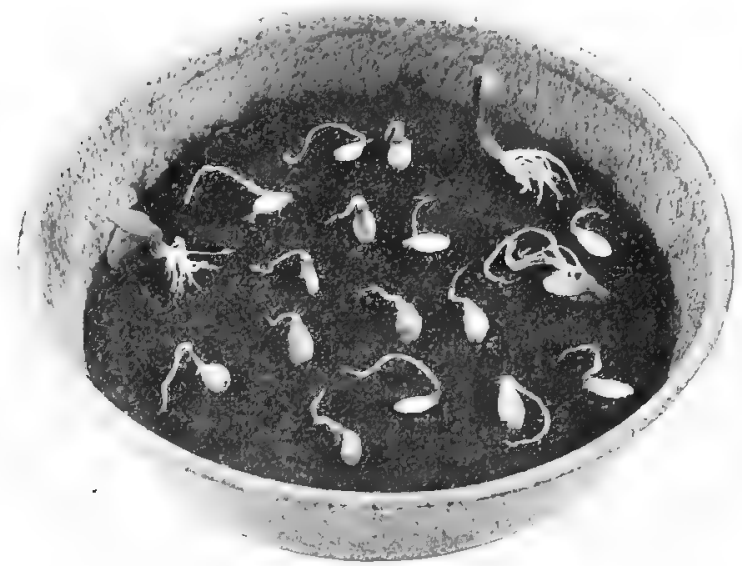

68. Squash seedlings endeavoring to penetrate the soil.

seeds to the soil so that the roots finally penetrate it (Fig. 67). This is more noticeable when the soil is hard or firmly packed down. Fig. 68 shows the various somersaults performed by Squash seeds which were all originally placed flat on the surface of the soil.

How much force can the root exert in boring its way into the soil? The contrivance shown in Fig. 69 may be used to answer this question. It consists 
of a student-lamp chimney (size No. 1) containing several corks (small enough to slide easily in the chimney) fastened together end to end by means of sealingwax. In the enlarged base of the chimney a large cork or wooden disk is fitted, through which passes a clothes-pin of the sort indicated in the figure. Through the wire coil in the clothes-pin passes a wire nail, which is firmly held in place by two wire loops, which are securely fastened to the narrow neck of the chimney; another wire is passed around the chimney just below the nail, to hold the wire loops in position. A stopper is inserted in the end of the chimney and water poured in. A Horse-bean with a caulicle about a quarter of an inch long is inserted in the clothes-pin, which is then firmly wedged into the cork (a small wooden wedge may be used if necessary), and placed in such a position that the tip of the caulicle rests in a small excavation in the center of the topmost cork. If the pressure of the cork float is so great as to break or injure the root, stick a pin into the topmost cork in such a way as to temporarily remove the pressure from the

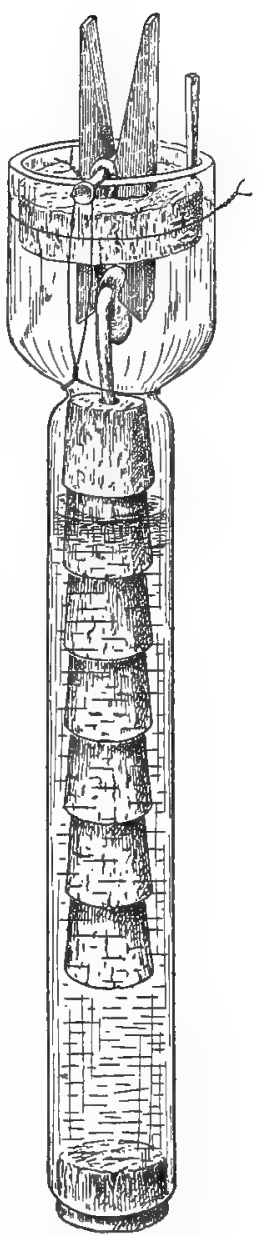

69. Apparatus for determining how much foree the root exerts in growing downward. The root depresses the cork float. 
caulicle; the caulicle will soon grow down and press against the cork. The amount of pressure may be regulated by the amount of water placed in the chimney. The wire nail is now passed through the two wire loops and the coil of wire in the clothes-pin. The clothespin is now firmly held at two points, and may be wedged if necessary. The seed should be surrounded by moist cotton, and grooves should be cut in the edge of the cork to admit air.

On a strip of paper gummed to the outside of the chimney marks should be made from time to time to indicate the position of the float. When the plant can depress it no further, the force exerted should be measured by removing the clothes-pin, etc., and depressing the float (by means of a bottle filled with shot) to the lowest mark recorded on the gummed slip. The pressure per square inch may then be calculated, as in the case of the stem, by finding the diameter of the root just back of the tip.

Another simple apparatus may be arranged to test the pressure of the root, as shown in Fig. 70. It consists of a tube flled with earth, into which the root is allowed to grow, and a larger tube into which this fits; the larger tube contains a wire spring, which is compressed by the growth of the root. The larger tube may be one-fourth of an inch in diameter: the smaller tube should slide easily inside it; its edges should be smoothed in a flame. It is well to break 
off the pointed end a little so as to allow a small opening for drainage; to prevent the root from growing through this opening, close it with a piece of gravel. The spring should be of such a stiffness that an ounce will compress it about an inch. Such a spring is

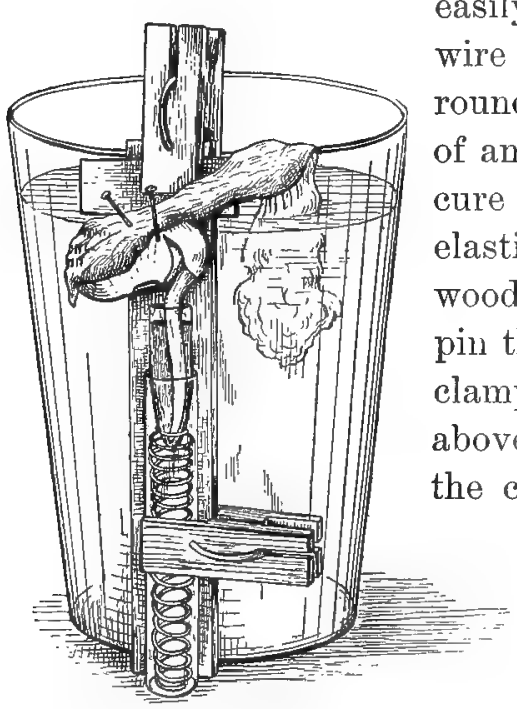

70. Apparatus for determining the force of growth of a root by means of a spring. easily made by winding a brass wire closely and evenly on a round stick (about one-eighth of an inch in diameter). Secure the tubes with wire (or elastic bands) to a strip of wood, as shown in the figure; pin the seed to this strip and clamp a small piece of wood above for it to press against; the clothes-pin which secures the piece of wood also serves to secure the whole apparatus to a tumbler filled with water. Arrange a strip of cotton, as shown in the figure, to keep the seed moist; take care, however, that the soil in which the root grows is not kept too moist, since in that case it will probably rot. As the root grows it forces the tube downward, compressing the spring; when it comes to a standstill, remove the root (but not the earth) from the inner tube and place 
upon the latter a funnel closed at the bottom with a stopper; into this pour shot until the spring is compressed to the same point as it was at the end of the experiment. The weight of the funnel with the contained shot gives the pressure exerted by the root.

By preventing the root from bending, as suggested on page 76, we could obtain much larger pressures. Such a condition of things would occur naturally only in a very firm soil.

Another way to roughly test the power of the root to penetrate the soil is to use a box with a bottom of wire netting (the meshes being about five-eighths of an inch square). On the netting place cloths of various thicknesses, tin-foil, slices of potato, or anything else that the class may suggest. Fill the box with earth and plant the seeds; it may be easily observed if the roots are able to penetrate any of these objects; for this purpose hang the box at a convenient height.

What part of the root develops the energy necessary for such strong growth? Remove some roots which are growing in moist air (as shown in Fig. 78). Mark them in the same way as you have already marked the stem (Fig. 71). Remove only one root at a time, mark

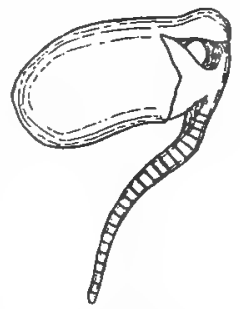

71. Root marked in order to determine the region of great. est growth. it and place it as quickly as possible in water, where it will continue to grow. Strong roots, such as those 
of the Horse-bean, Lima Bean, Buckeye, or the roots of an Onion bulb are best for this experiment. In what region is the most rapid growth? How long does it continue in this particular place? To what region does it then move?

When the root forces its way into the soil so energetically, what protects the delicate tip from injury? Notice the protective cap which covers the end of the root. Roots of Wandering Jew grown in water (Fig. 85), caulicles of Sunflower, Squash, ete., show this cap well. Can you find it in other plants? Use a lens if necessary. Why is the tip the most tender and delicate part of the root? Why can it not be strengthened by tough woody fiber? Would such fiber prevent growth? Would it be an advantage to locate the growing region elsewhere than at the tip? What would happen to the side roots and root-hairs (which are firmly fastened in the soil) if the growing region were above, instead of below, them?

What happens if the tip is injured? Remove the tips from tap-roots growing in water; do new roots appear? Where do they arise? In what direction do they grow? What advantage in this peculiar direction of growth? 


\section{CHAPTER III}

\section{THE WORK OF ROOTS}

What is the function of the root? Find six healthy plants of about the same height. By an oblique cut sever the main roots of three of these about half an inch below ground, disturbing the earth as little as possible. It will be necessary to support the plants by tying them to a stick thrust into the soil (Fig. 72 ). This calls attention to one important function of the root, namely, to anchor the plant in the soil ${ }^{1}$. What sort of root is best adapted to anchor the plant firmly, a straight, deep root or a shallow, spreading one? What plants are hardest to pull up? Explain why this is so. What kinds of trees are most easily uprooted; why?

Examine the injured plants every day and note any abnormal symptoms. Notice

1 The roots of Carrot, Bulbous Buttercup and many other plants (especially such as grow in crevices of rocks, or such as hug the ground) contract when full grown and pull the plant down some distanse into the soil. The tips of many Blackberry vines, which take root in contact with the soil, are soon drawn beneath the surface by the contraction of the roots. Make observations on this point. What advantage in this action of the root?

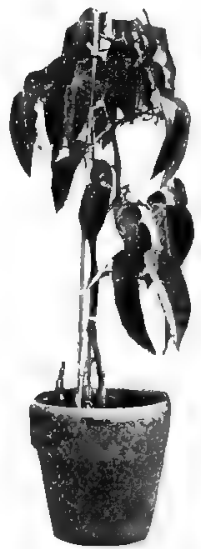

72. Plant attached to support ready to have the root cut off. 
any changes in the color, shape or position of leaves and other parts. What do you think these indicate? Allow some uninjured plants to go unwatered for a time; do they show the same symptoms? What does this indicate as to the work of the root?

In what direction should the main root grow, to do its work most effectively? Does the main root always grow straight down? Pin soaked seeds on corks in various positions (see Fig. 73), and allow the corks to float on water; pin the seeds in such a position that they will remain partly submerged; cover the dish with a piece of glass. Put some soaked seeds in various positions on the surface of moist soil and cover with an inverted tumbler, or place them in a pot half full of soil and lay a piece of glass on the top,

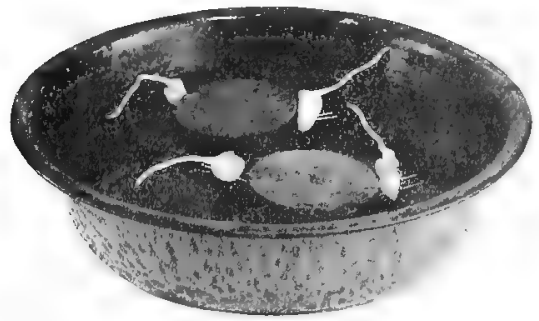

73. Seeds pinned to corks which aro flouting on water. to keep the air moist. If the roots bend downtarl, change the position of the seeds so that they point upwar't or lie horizontally. Do they hegin to grow downwark agiain?

Why does the main root persist in doing this, no matter in what position it is placed? The iclea has been advanced that the tip of the root, being not very rigid, drools downward of its own weight and that 
this starts the growth in the right direction. This idea may be tested by a very simple experiment. In a small saucer, place some mercury; fasten two or three clothes-pins to the side of the dish (Fig. 74); to these pin germinating seeds (Peas are especially good) with perfectly straight caulicles about half an inch long; let the caulicles, especially at the tip, rest on the surface of the mercury. Pour in

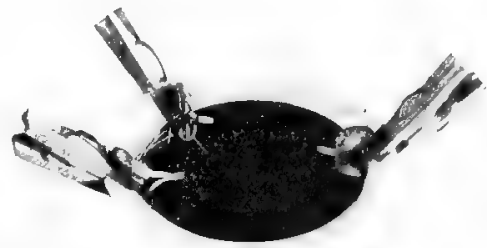

74. Seeds arranged with their caulicles resting on mercury, whieh is covered with a little water.

enough water to partially submerge the seed. If, now, the root-tip bends downward into the mercury, overcoming its resistance, the idea that it droops of its own weight cannot be correct. If the mercury is not clean it may kill the root, since mercury salts are poisonous; it is well, therefore, to first clean the mercury with a little cotton wool, and afterwards with running water. In place of mercury we may use gelatine (one part of gelatine dissolved in five of water), in which case no water is to be placed in the dish, but it should be covered with a piece of glass to prevent the roots from drying up.

What starts the root in the right direction? Is it light, moisture, air, warmth, food or gravity? We may test the first five simultaneously by a very simple experiment. Fill a box (having a bottom of wire 
netting) to one-half its depth with damp sawdust; on this lay the seeds, well soaked, and add enough sawdust (equally damp with the first) to fill the box even with the top. On top of this put several layers of well-soaked cloth or blotting paper, and keep this wet during the experiment; let the edges press closely against the box. Hang the box up so that the under side may be easily observed. Air, light and warmth now come mostly from below instead of mostly from above, while moisture, ordinarily more abundant below the seed, is now about equally abundant above and below, and the same is true of any food the moisture contains. Since the sawdust is alike in depth above and below, it cannot influence the roots to grow in one direction more than in another.

If, now, the roots grow downward (and the stems upward) it must be in obedience to some influence other than these.

Perhaps this is gravity: How can we test this suggestion? What would happen if we should make the force of gravity of no effect by placing the serels on a revolving wheel? If the wheel turns always at the same rate, each side of the root will in its turn be underneath for a short time, but no side more than another. So when all sides are equally affected by the downward pull of gravity, will it influence the root to grow in any one direction more than in another? We may use the apparatus shown in Fig. 75 to answer 
this question. The essential parts are an ordinary clock and a small tub (of wood or, better, of wood fiber), with two holes to admit a stiff wire or knittingneedle. The wire should be bent at one end and wired to the minute-hand of the clock. In order to prevent the minute-hand from slipping, it may be necessary to fasten it to its axle with a little solder or

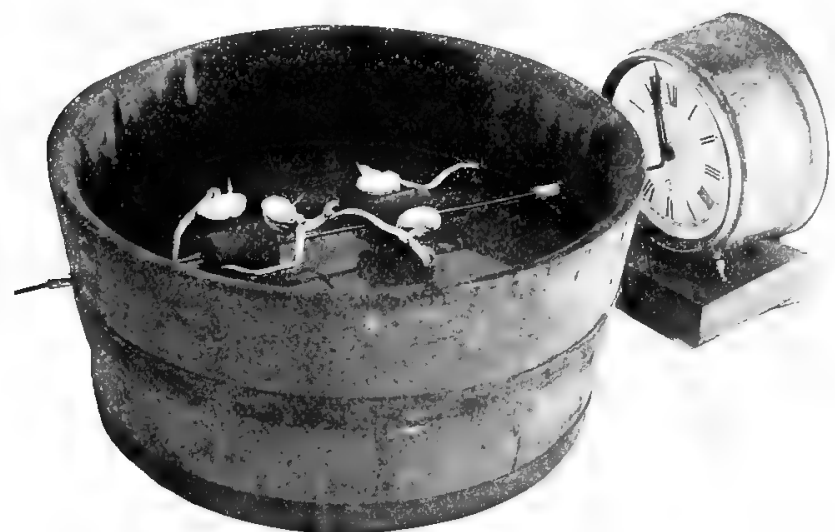

7.) Arrangement for causing germinating seeds to rerolve slowly.

sealing-wax. Short bits of glass tubing are inserted in the holes in the tub, to act as bearings. The germinating seeds are to be pinned to corks impaled on the wire; the roots should point in various different directions; pour sufficient water into the tub so that the seeds dip in it each time they revolve; cover the tub with a piece of glass, place over this a piece of cardboard or cloth to exclude light, and set the 
clock going. The roots grow well under these conditions; do they continue to grow in different directions, or do all assume the same direction? ${ }^{2}$.Does this (in connection with the previous experiments) indicate that it is gravity which causes all roots, under ordinary circumstances, to assume the same direction? How do the stems behave? It seems at first rather puzzling to conclude that gravity, which causes roots to grow downward, also causes stems to grow upward; but there seems to be no escape from such a conclusion.

We may now go a step further and substitute another force for that of gravity. This we may do by making the wheel revolve more rapidly. If a piece of wire is bent around the spoke of a wheel, so as to form a loose ring, and one spins the wheel, the ring will be hurled to the rim by a force commonly called centrifugal force. If the wheel be turned rapidly enough, the centrifugal force will be much greater than the force of gravity. Will a seel revolving rapilly on such a wheel direct its roots in accordance with the centrifugal force? To test this, we may construct a water-wheel as shown in Fig. 76. Cut out of thin sheet zinc a circular piece six inches in diameter. Have this cut to allow the insertion of corks, as shown

1 It may happen that the root will grow on perfectly straight in the direction given to it when fastened to the cork, or it may bend as the result of injury, influence of moisture, light, ete. If such bendings do not occur in the control experiment (which should be made) it indicates that the directive foree which prevents such bendings, and causes all the roots to grow in the same direction in the control experiment, has been nullified by the revolving wherel. 
in the figure. Let the flaps made by cutting remain in place. Fix round, flat corks in the cut places, aud bend the flaps so as to support the corks as firmly as possible. For the axle use a knitting needle, impaling two rubber stoppers upon it, one on each side of the zinc disk, to hold the latter in place. They should press firmly against the disk, to insure its turning with the axle. The two upright wooden supports fastened to a block of wood are

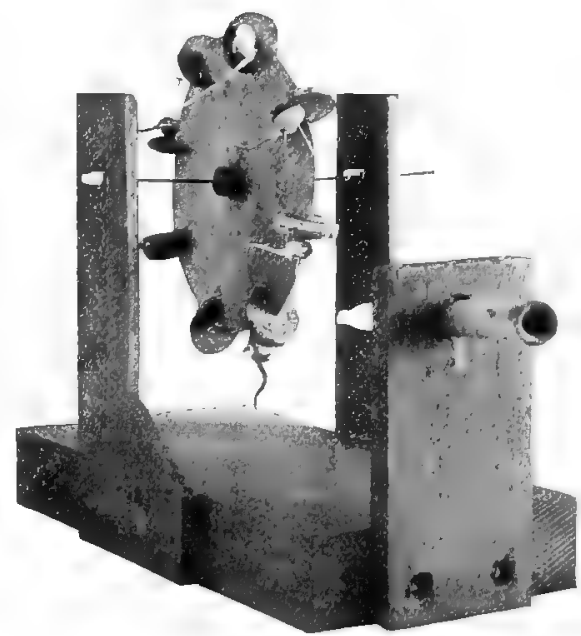

76. Water-wheel for the purpose of making germinating seeds revolve rapidly. pierced by holes just large enough to admit the small glass tubes in which the axle rests. Each of these is closed at the end, to keep the axle from slipping too far. We place the apparatus in a sink, and attach a rubber tube to a faucet. At the end of this tube is a piece of glass tubing drawn to a point. The manner in which this is supported is shown in the figure. It should be wedged firmly in place by wooden wedges, and be so directed that the stream will strike the wheel just at its rim. The stream must be powerful 
enough to make the wheel revolve rapidly (two or three times a second). A piece of cloth must be put over and around it, like a tent, to confine the flying drops. Germinating seeds (preferably Peas) should be pinued to the corks on the sides not struck by the stream of water. In the course of a day or so, provided the wheel is turning rapidly enough, we shall expect to see the roots all bending away from the center of the wheel and growing straight out in the direction of the radius, while, on the other hand, the stems grow straight in, pointing toward the center of the wheel.

Let us see what will happen if we place the apparatus on its side so that the wheel revolves horizontally. If the plants have become inconveniently large we may replace them by fresh ones with caulicles about an inch long. 'Two forces now act on the plants, -the centrifugal force and that of gravity. The roots take up an intermediate position, growing away from the center of the wheel as before, but also obliquely downward; the stems grow in the opposite direction.

These experiments lead us to think that when root and stem issue from the seed, gravity determines the direction in which they grow: we can therefore understand how the seed, whether above ground or below, unerringly sends its stem and root in the right direction. We can readily see that this is an important matter for the plant, for the quicker it gets its stem 
above ground into the light and air and its root down into the soil the better will be its chances of living through this period of its life, which is more critical and more beset with dangers than any other. We can also see that in this connection gravity is the best guide the plant could have, since it is more constant and uniform than any other - the only one, in fact, that is absolutely constant.

What happens if the root in its downward course meets with a dry region? When seeds are grown in damp sawdust, in a box provided with a bottom of wire netting, as described on page 90 , how do the roots behave as they grow down through the netting into the dry air? Often we see them turn upward, as in Fig. 77. Is this because they try to avoid air, light, etc., or are they attracted by something in the sawdust? We may test this by arranging the experiment as fol-

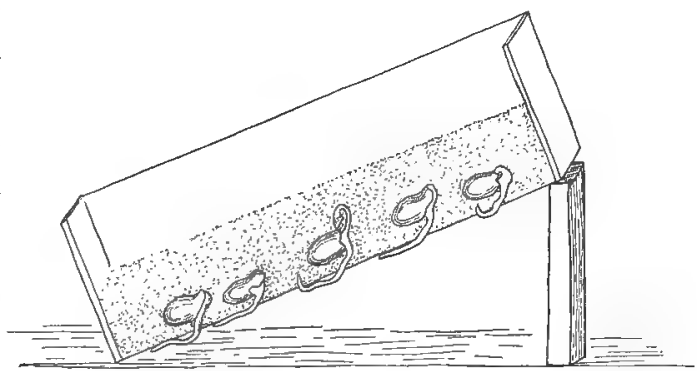

77. Arrangement for testing the effect of moisture on the direction of growth of roots.

lows: Fill a tumbler one-third full of water and tie a piece of cheese-cloth over the top; on this put damp sawdust, and in the sawdust place several soaked seeds; invert another tumbler over the whole, as shown in 
Fig. 78. Do the roots, on emerging from the sawdust, turn back to it? The air now contains much more moisture than before, but in other respects there is no essential change. It would seem that in the first instance they turned back because the air was so dry, or, in other words, were attracted by the water in the sawdust.

As a matter of fact, we know that tree roots find (and fill up more or less completely) cisterus and drains which are three humdred feet or more distant from the tree; in many towns there exist ordinances prohibiting the maintenance of certain trees within a hundred feet of a sewer.

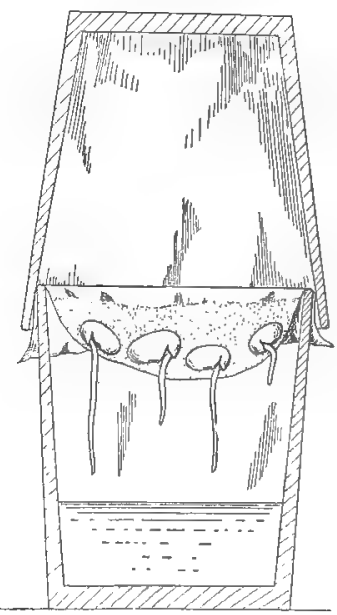

78. Arrangement to test the behavior of roots in moist air. (Sectional view).

In the above experiments the roots are not under perfixtly natural conditions; we may approach these

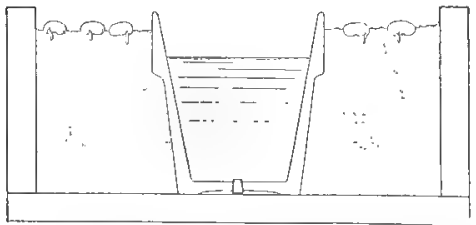

79. Arrangement for ascertaining whether roots grow in the direction of moisture: the flower-pot is filled with water, which slowly diffuses through its walls into the soil. (Sectional view.) more nearly by the arrangement shown in Fig. 79. In the middle of a box of earth place a flower-pot, the hole of which has been tightly closed ly a rublere or cork stopper or by seal- 
ing-wax. Let the earth be reasonably moist when the seeds (well soaked) are placed in it, but do not water it further except by pouring water into the flower-pot, from which it will diffuse through the soil. After a few days examine the roots, to see what direction they have taken. What is the greatest distance from the flower-pot at which the direction of growth of the roots is affected? By using a shallow box (about one and one-half inches deep), with a glass bottom, and placing the earth directly on the glass, we can watch the growth of the roots without disturbing them; but, since the glass affords no drainage, very little water may be used, else the soil will become so saturated with moisture as to spoil the experiment. The result will depend partly on the amount of water present and partly on whether the roots are growing in sand, clay or sawdust.

What direction should the side roots take to explore the soil most

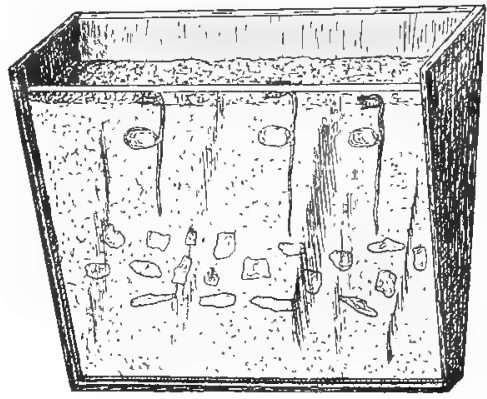

80. Apparatus for observing the behavior of roots as they encounter obstacles. effectively for moisture? In a box with a sloping: glass side (see Fig. 80), filled with moist soil, place several seeds with caulicles (about an inch long) pointing straight downwards. Mark on the 
glass $^{1}$ the direction which seems to you most advantageous for the main roots and side roots and the

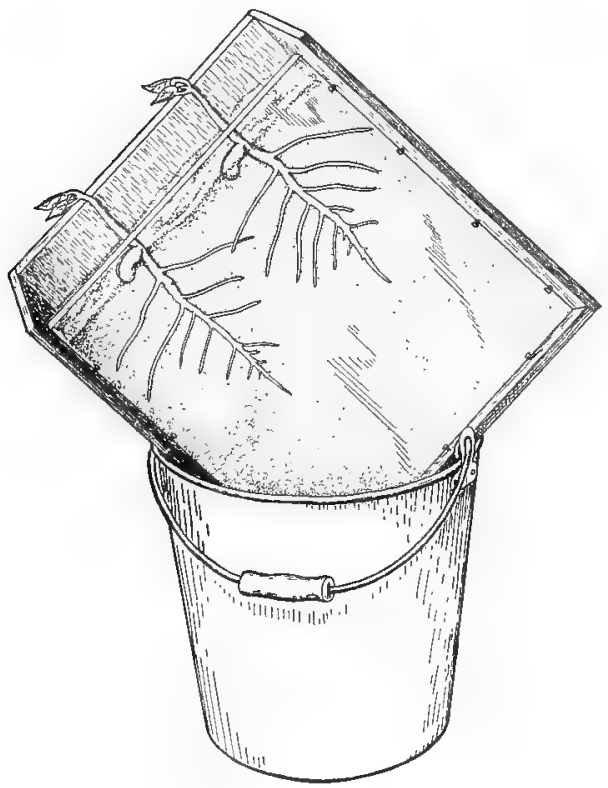

81. Apparatus designed to test the behavior of side roots under the influence of gravity. rootlets which spring from the latter; begin the marking directly over one (or more) of the roots. Exclude light completely by covering the glass with cardboard or cloth.

What direction do the side roots have when they burst out of the main root? Do they afterward change this direction? If so, when? Do you think they solve the problem of direction in the best way?

Are they guided in the direction they take by light, heat, moisture, food or gravity? Light has been carefully excluded. If it were heat, moisture or food that guided them, we should expect to find adjacent side

1 A mixture of glue and whiting put on with a brush is excellent for marking; white paint will do, but drios more șlowly; yellow pencils for marking gInss are good. 
roots turning in the same direction, instead of which they radiate in all directions from the main root; and not only so, but roots from neighboring plants cross each other growing in opposite directions. Is it, then, gravity? We may test this very simply. When the side roots have grown some distance, tip up the box, as in Fig. 81. Carefully mark on the glass the position of each side root; mark with especial care the position of the tips. Leave the box undisturbed. and make daily observations. Do the side roots change their direction? Do the rootlets which spring from them change theirs?

As we watch the roots growing along inside the glass, we may occasionally see them encounter small sticks or stones or other obstacles; what do they do then? Obstacles may be provided in abundance by fastening small pebbles or blocks of wood to the glass with sealing-wax before putting the soil in the box (Fig. 80 ), or to the sides of a glass funnel (as in Fig. 82). Do

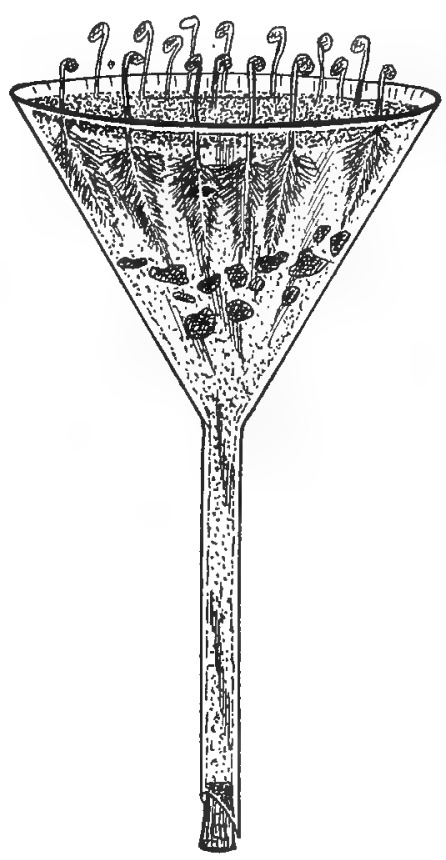

82. Modification of the apparatus shown in Fig. 80. 
the roots diverge from their course more than is absolutely necessary to avoid the obstacles? Do they resume their original course as soon as they have passed the obstacles?

Study, as far as is practicable, the rootlets which spring from the side roots in the same way in which

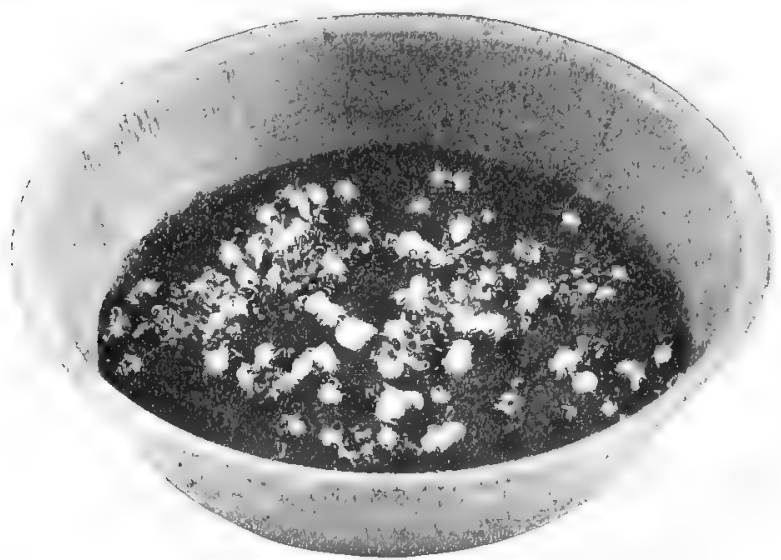

83. Radish seedlings grown on moist snnd, showing root-hairs.

you have studied the main root and the side roots.

From the main root, the side roots and the rootlets, spring root-hairs; these can be seen in great profusion if we sow Radish seeds on moist earth in a pan (Figs. 83 and 84), and cover it with a piece of glass to retain the moisture. Sometimes the roots become covered with mould, which may at first he mistaken for root-hairs. The best way to obviate this is to obtain clean seed; if this is not possible, rinse the dry seeds 


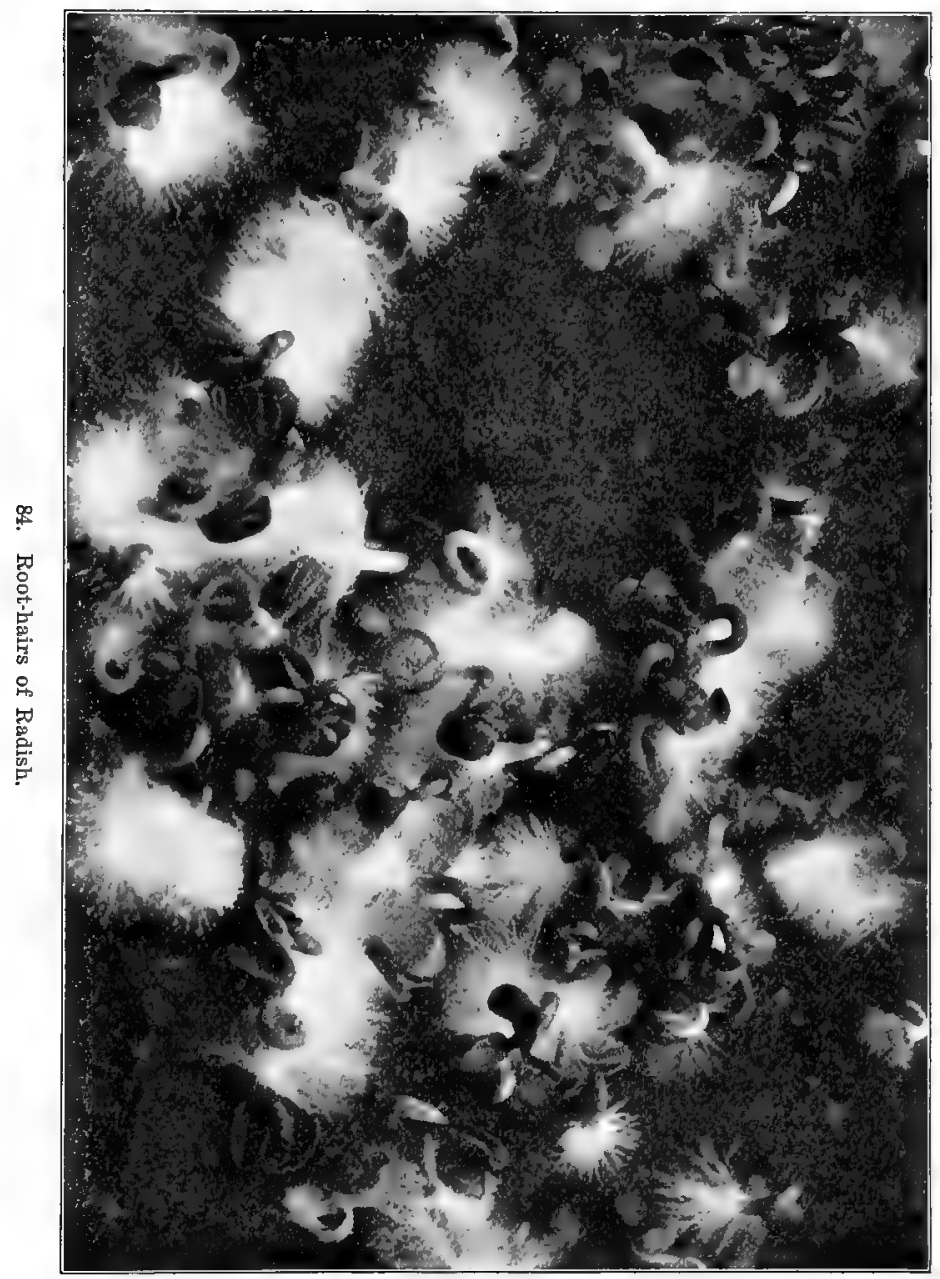


a few moments in five per cent formalin and then rinse in clean water; heat the moist earth in the pan (which should be covered during the operation) so

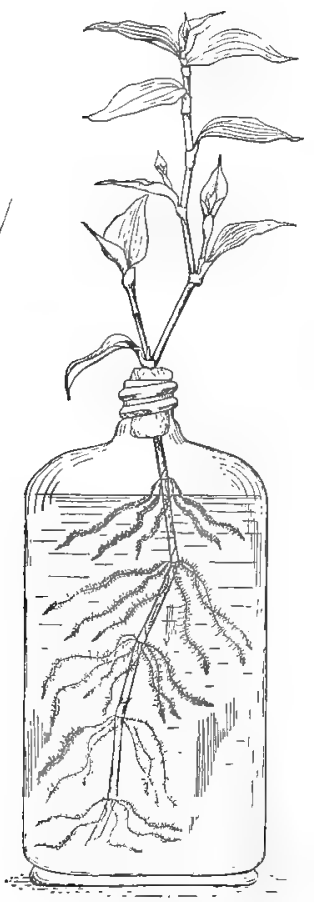

85. Cutting of Wandering Jew in water, showing root-hairs which increase the absorbing surface from fifty to seventy - five times; in order to get an equal surface without roothairs each of these roots would have to be from one to six inches in diameter. that it steams for ten or fifteen minutes; allow it to cool and then place the seeds upon it. While the roothairs are growing, the glass cover should not be disturbed.

Does the amount of moisture affect the luxuriance of growth of the roothairs? Use a series of pans, with the soil varying from wet to fairly dry. The seeds should be well soaked when placed in the pans; the moisture in each pan can be regulated by lifting the glass cover so as to permit greater or less circulation of air.

\section{What is the use of the root-hairs?} The absorptive surface of the root is increased many fold by the roothairs. The long, feathery root-hairs which develop on the roots of cuttings of the Wandering Jew placed in water (Fig. 85) increase the root surface from fifty to seventy-five times; to get so much surface without the device of root-hairs each 
root would have to be from fifty to seventy-five times thicker, i. e., from an inch up to five or six inches in diameter.

How do the roots (and especially root-hairs) manage the absorption of water from the soil? Do they find themselves surrounded by water? Tie over the bottom of a lamp-chimney (a student-lamp chimney, size No. 1 is rery good) a piece of cheese-cloth; fill the chimney with soil that is moist enough to allow good plantgrowth, and place it in a pan. Pour water into the pan and noive its rise in the soil. Are the spaces between the soil-particles filled with air or with water at the beginning of the experiment? Take some more moist soil, and spread it out on a thin layer on a piece of paper. Notice the glistening appearance of each particle; as the soil dries this disappears and the particles become dull in appearance; why? If fine gravel is used, the whole process is very easily seen. It appears, then, that in moist soil the water is in the form of thin films around each particle and the spaces between these particles are filled with air; only in wet soil are these spaces more or less filled with water.

In order to understand how the root absorbs water from the soil, we must understand what the soil is. Let us, therefore, take up the question, of what is the soil composed? I Take a handful of earth, rub it up

${ }^{2}$ See King: "The Soil." 
well in water to form a paste. Place it in a fruit-jar, fill the jar with water, fasten the cover on, shake the jar well for some time, and then allow it to stand until the soil settles to the bottom. Examine the soil after it has settled. The coarse material on the bottom is sand, above this is finer material consisting mostly of clay, the finest particles of which remain in suspension in the water, making it turbid. On the top of the water floats a little vegetable matter which in its decomposed state is called humus. These three constituents of the soil have very different properties, which should be clearly understood, since the entire fertility of the land dopends on a proper admixture of these constituents. A more complete separation may be effected by first skimming off the vegetable matter, then shaking up the soil again in water and pouring the turbid water through a cloth. Continue the process until the clay is all removed: the sand will remain in the bottom of the jar. A still better separation may be effected by siphoning water from a pail through a piece of rubber tubing into a tumbler (with vertical sides) which contains earth (this should be constantly stirred with a pencil during the passage of the current); the current may be regulated by compressing the rubber tubing; the overflow from the tumbler should be caught in a second tumbler, of larger size, plared beneath the first. Beginning with a weak current, the finest particles will be carried over into the second 
tumbler. When this has been accomplished and the water runs clear, remove the second tumbler, substitute another, and increase the strength of the current. By continuing in this way the soil may be separated into numerous portions, in each of which the size of the particles will be confined within certain limits. The time which the particles require for settling in these various portions is of importance. Make notes on this point.

SAND.-Sand is made up of larger particles than clay, as may easily be seen in the experiments just described: the diameter of the particles ranges from .00004 inch to .001 inch and larger. Sandy soils are usually called "light" because they are more easy to work, although a cubic foot of dry sand weighs one hundred and five to one hundred and ten pounds, while a cubic foot of dry clay weighs only seventy to eighty pounds. Test this statement. They are more open, more porous, warmer and drier than clay soils. Pure sand contains practically no plant-food; it comes from quartz rocks; the purest sand consists of practically nothing but particles of quartz which have a very characteristic appearance under the microscope. In order to examine sand microscopically, breathe on a slide, place a little sand on it and then turn it up edgewise so that all the sand falls off, with the exception of a few scattered grains which adhere to it. Examine in the ordinary way with the aid of the mirror, giving a bright background, and also 
without the mirror, giving a dark background: use the low power of the microscope.

Clay.-Clay is mostly made up of particles less than .00004 inch in diameter; the particles have a tendency to cling together and become cemented with sand-particles so as to form aggregate particles, or soil-crumbs, which may be of much larger size than the particles of sand. A clay soil, therefore, varies greatly in character, depending upon the degree of aggregation of its particles and its content of sand. In drying, clay tends to form a hard, compact mass which plant-roots cannot penetrate. When it becomes wet it is apt to assume a greasy, sticky texture, ${ }^{1}$ impervious to water and impenetrable to plant-roots. In this state it may be further compacted by chemical agents, by kneading or by pressure, to form hardpan, which is really soil reverting to rock. Hardpan may also be formed of compacted gravel. Clay lands are usually said to be heavy, stiff and cold: the first two terms refer to the fact that they are difficult to work, the last to the fact that they contain more water than sandy soils. Clay is usually the part of the soil richest in plant-food: it results from the decomposition of rocks containing feldspar. Examine some dry powdered clay under the microscope: do you find aggregate particles? are the particles of different colors? Find out what you can about them.

1 How do the properties of burnt clay differ from those of unburnt clay? Why? Why does burning clay land improve it? How is the operation carried out? 
The experienced eye easily distinguishes between the particles of hornblende (which are black), those of mica (which are brownish) and those of quartz and feldspar, which are both of light color but differ in form.

Humus.-Examine a little leaf-mold: can you make out its nature? Place some of it under the microscope: place some on a red-hot shovel for some minutes: what change takes place? Perform the same experiment with some dark colored soil: does it change color? The simplest way to remove all the humus from a soil is to burn it thoroughly; we then find that the dark color of the soil is due entirely to the humus. The fact that humus burns so readily recalls the origin of peat and coal, which are formed from humus: find out what you can about this. Humus gives to the soil a loose, open texture such as we see in leaf-mold; it makes the land "mellow" and gives it "heart"; it retains an extraordinary amount of water (up to nearly twice its own weight) and is rich in plant-food. It often accumulates in forests to considerable depths. In ordinary soils humus is present to the depth of three or four feet (i. e., the depths to which the roots ordinarily penetrate), and this part of the soil has a looser texture and darker color than the underlying subsoil, which is devoid of humus.

By a proper admixture of humus, sand and clay we can obtain a soil of any desired consistency or texture and of any grade of fertility. The gardener does this 
extensively, the farmer to a lesser degree. The gardener has various mixtures for various purposes: for plants requiring much water he makes a clay loam (loam is a soil containing about equal parts of sand and clay mixed with humus: a clay loam contains more clay than sand, a sandy loam more sand than clay). For plants which require but little water, such as Cacti, he makes a sandy loam: for Ferns he uses a soil composed very largely of humus. For young plants he makes an open, porous soil, which he replaces by a heavier soil as they grow older. In this way he succeeds in raising from a small pot of soil as large a plant as the farmer ordinarily produces by the use of a thousand times as much earth. The farmer is much more restricted in this respect, but he mixes humus with the soil by plowing in straw, stable manure or green plants: he also adds ashes, clay or sand to the soil when necessary.

What kind of soil is best for euttings? Why? Which eróps need a light soil; which a heary soil? Classify the soils of your region according to the following scheme:

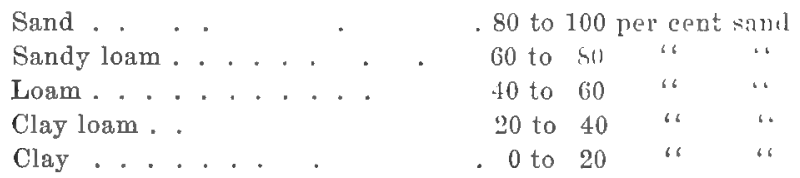

The red or yellow color of soils is due to tỉn iron in them: the black color to humus. Point any differ- 
erences you can in the crops borne by the different kinds of soils in your region. Examine the different soils with the microscope (as described ahove): find out all you can about their composition and method of formation.

How is soil formed? Wherever there are rocks, soil is being formed. Most rocks tend to break up until they are completely changed to soil. Among the agencies which bring this about may be mentioned:

(1) The mechanical action of moving water, ice and wind; (2) changes of temperature; (3) the chemical action of air and water; (4) the action of plants and animals. Find out what you can alout these agencies. ${ }^{1}$

Study the weathering of rocks in your vicinity, also of building materials (including stone, brick, cement and mortar); which kind of building material weathers most rapidly? Why? On hillsides and mountains the soil can be seen in the act of originating from the rock which lies beneath it; such soil is said to be formed in place. In valleys, on the other hand, we find soil which has been transported from the hills or mountains by ice (drift soils) or water (alluvial soils). Moving water always carries some soil with it, and later on deposits it as the current slows down. This can be seen in any stream or in the little rivulets which are formed

1Consult Bailey: "Principles of Agriculture," Chapter I; Johnson: "How Crops Feed," Chapter II; Gaye: "The Great World's Farm," Chapters I to VII; King: "The Snil," Chapter I; any good text-book of Physical Geography; Durwin: "The Formation of Vegetable Mould Through the Action of Worms" 
everywhere during rains. To study it more carefully, we may construct a trough about twelve feet long, a foot wide at the bottom, with sides six inches high. This is best made in three sections, each four feet long, fastened together end to end by strong hinges, so that they may be inclined at different angles. The lowest section should be level, the next inclined at an angle of fifteen or twenty degrees, the next at an angle of twenty-five to thirty-five degrees. Line the trough throughout its entire length with a piece of oilcloth twelve feet long and two feet wide: at the lower end gather up the oileloth and tie it firmly to a piece of hose, which will serve to carry off the waste water. Leave the lowest section empty; fill the next section with sand; fill the highest section with clay (placed in the trough in a dry, powdered condition) or a mixture of clay and sand (the clay should be pulverized and nixed with the sand while dry). Attach a piece of rubber tubing to the faucet and allow a small stream of water to trickle down the entire length of the trough. The clay (or mixture) in the upper part of the trough will behave in the same way as rock (only the action will be much more rapid), and will show clearly how rock is sculptured by running water; how masses of it become detached and fall off, and how as these are carried down stream they lose their sharp edges (this occurs especially where the clay overlaps . the sand). If different layers of clay (or mixture) are 
colored by earth colors (obtainable at a paint store) and placed over one another and then compressed or moulded so as to form folds like those of rock (synclines and anticlines), and placed in the upper section, we shall be able to see clearly how the water wears its way down through different layers of rock (the layers may be made of different hardness by mixing in more or less sand so as to imitate harder and softer rock layers). In the second section we shall see landslides, ${ }^{1}$ terraces, meanders, oxbows, bubbling springs (where an obstacle occurs), and all the other features of stream action. In the third section we shall see alluvial fans and cones, deltas, beaches, the deposit of coarse materials near shore, and of finer materials further out and all the features of lake and ocean formations. Now that we have learned something of the nature of the soil, let us investigate further the manner in which it retains the soil-water.

What becomes of the rain water which falls on the soil? Fill a box about eighteen inches square and four inches deep with sand. On the surface of this place a layer of wet clay; smooth it carefully so as to leave no cracks and bring it down over the outside edges of the box so as to completely cover the sand. Place a quart of water in an ordinary garden sprinkler and slowly sprinkle it on the surface of the clay. Collect

In regard to all these features, consult any of the standard elementary text-books of Physical Geography. 
the water by means of a piece of oilcloth about three feet square placed beneath the box. How rapidly does the water run off? How much remains behind? Place a layer of moist cotton batting, about an inch thick (sawdust or sphagnum moss such as florists use may be employed) on the surface of the clay, and repeat the experiment. Remove the clay from the sand and rereat the experiment, with and without the cotton. In this experiment the cotton represents a covering of vegetation on the soil: such a covering retains the water in precisely the same way as the cotton. Compare as well as you can by observation the amounts of rain which run off from the surfaces of the following:

Clay soil without covering.

Sandy soil without covering.

Soil with a covering of turf.

Soil with a covering of tall weeds or other plants.

Soil with a covering of shrubs or trees.

It is believed that the floods of our great rivers, such as the Mississippi, could be wholly averted by preserving the forests at the headwaters. Find out the annual damage of these floods. This represents the interest on the sum which could be profitably invested in preserving these forests. What does this sum amount to? If you live in a region where damage by flood occurs, make a similar estimate for your own region. When it is not feasible to reforest these areas, the natural growth of shrubs and undergrowth should be 
encouraged by preventing fires, keeping out sheep, etc. ${ }^{1}$ Such a cover not only prevents floods, but it prevents the washing away of the soil on hillsides and slopes: the damage to good farm land from this source may assume enormons proportions and it is exceedingly difficult ever to remedy it or restore the land so ruined.

The water which rums off without penetrating the soil is called the runoff: that which soaks into the soil is known as the percolating vater.

For convenience we sometimes divide the soil-water into three kinds: (1) free water, which flows under the influence of gravity and percolates down through the soil ; (2) capillary uater, which is held in the capillary spaces or pores of the soil and is not influenced by gravity but moves upward or in any direction where the soil is becoming drier ; (3) hygroscopic water, which is so firmly held as a film around each particle that it does not move about like the capillary water but can be removed only by heating to the boiling point of water', when it passes off as steam : the driest of "air-dry" soils contains considerable hygroscopic water.

In what kind of soil is percolation most rapid; in what kind of soil is water retained longest after a rain? Fill two chimneys as described above -one with clay, the other with sand; put them in separate pans. Pour an equal quantity of water into each chimney, taking care that none runs over; through which does the water run more ranilly? Why? Which kind of soil

I Consult Roth, "First Book of Forestry," pp. 202-209: also Toumey, "Relation of Forests to Stream Flow," Year-Book of the U. S. Dept. of Agriculture for 1903 . 
has the larger particles; the larger spaces; does this explain the matter? An inch of rain is said to pene-

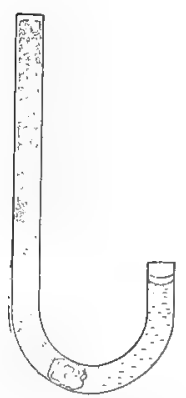

86. Apparatus for measuring the rate of evaporation from a saturated soil.

trate four inches in clayey soil and six to eight inches in sandy soil. What do you think of this statement? Does air in the soil hinder percolation?

What becomes of the rain-water which percolates down through the soil; is any of it drawn back up again as the surface dries? Prepare a bent tube as shown in Fig. 86, one arm being about eighteen inches long and the other about four inches. Push a little wet cotton nearly to the bottom of the longer arm; fill this with clay; fill the longer arm of a similar tube with sand. Attach a funnel, as shown in Fig. 87, and pour water upon the soil in each tube until the shorter arm of the tube is partly filled; when it stops rising, remove the funnel and pour a few drops of oil on the surface of the water in the shorter arm of the tube, to prevent evaporation. Mark accurately on a strip of paper gummed to the tube the height of the water-column (it should be about the same in both tubes). If the water falls in the

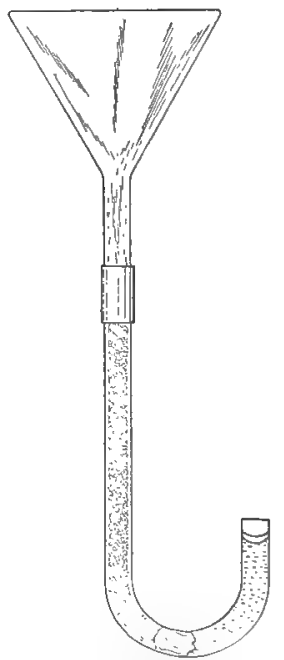

87. Method of supplying water to the apparatus shown in Fig. 86. 
shorter arm, it shows that some of the water which has run down through the soil is being drawn up again. In which tube does this take place more rapidly? Is it hastened by putting the tulues in the sun? Explain. It often happens that a bed of gravel lies from three to six feet below the surface of the soil; how does this affect the upward movement of water in the soil ? Place a little gravel in the tube and note the effect.

To retain the moisture in the soil, the farmer resorts to cultivation and mulching, i. e., placing on the surface of the soil something (straw, dead leaves, stable manure, etc.) to prevent evaporation.
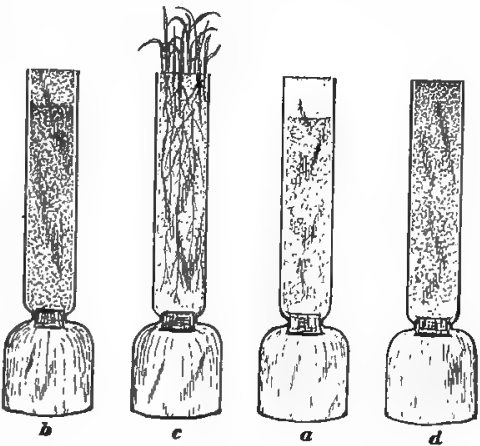

88. Four lamp-chimneys filled with soil for the purpose of studying the rate of evaporation from the surface: (a) surface envered with a mulch of sawdust; $(b)$ surface tilled; (c)surface planted; (d) control.

Take four student-lamp chimneys (Fig. 88), cork them securely at the bottom and fill them with good moist soil (which should be previously well mixed so as to be uniform throughout). On the top of the soil in one, place a layer of dry sawdust four inches deep (a); in another place a similar layer of sifted dry soil not packed down $(b)$; in another plant Wheat $(c)$, and leave the last as a control $(d)$. Weigh each of them, and repeat the weighing at intervals 
of a week. Which loses the most water; the least? Explain.

The result of cultivating the soil is to keep a layer of loose, dry soil on top, which acts like the sawdust in preventing evaporation, by reason of the fact that its large capillary spaces cannot take the water from the smaller spaces of the underlying soil. This is further illustrated by the fact that a dry brick will take water from a moist sponge, but a dry sponge will not take up water from a moist brick: it may be said

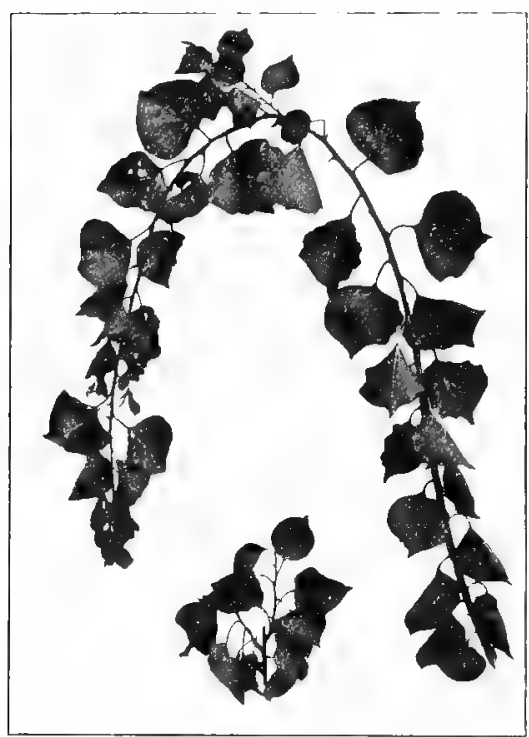

88a. New growth on Apricot trees growing side by side. Above, the cultivated; below, the uncultivated. that the surface crust energetically draws the water away from the underlying soil, just as a brick will suck a sponge dry. It is often noticed that where the soil has been well tilled every wagon-track ol' footprint remains moist after the soil around has become dry, and weeds spring up noticeably in such places owing to the fact that the compressed soil maintains 
capillary connection with the moist earth below. How a surface layer of loose, dry soil conserves moisture is well seen in Fig. 88a, which shows the new growth, during one summer, of two trees side by side under the same conditions, except that in one case the ground was cultivated while in the other it was not.

The loose, dry layer of earth, known as the surface mulch, must be maintained by cultivating the surface as often as it becomes baked into a crust. The surface mulch not only prevents evaporation but it admits air (which is excluded by the crust). It prevents the soil from cooling off quickly at night and keeps it from freezing deeply in winter (snow acts as a mulch). It also prevents rain from running off the surface. In view of these facts, the advice "Water" your garden with the rake" becomes important: i.e., as soon as the water has sunk into the ground go over it with a rake and break up the surface crust so as to form a mulch.

(What connection is there between evaporation from the soil and the formation of dew? Invert a small tumbler on the surface of moist soil and leave it over night. Are you able to find any dew on the glass the next morning? Why is dew ordinarily formed only at night and more copiously in absence of wind or clouds?)

Is all of the rain-water which soaks down through the soil drawn back up again? How are springs formed? How deep must we go before we find wet 
soil, i. e., soil in which the spaces are filled with water instead of air? This level is called the watertable; does the height of water in a well indicate this point reliably? From how great a depth is the water drawn up by the soil? Get a glass tube about six feet long, or make one by joining together short lengths by means of rubber tubing. Fill this with clay (dried and pulverized), and place the lower end in water; it may be several weeks before the water stops rising. Clay lifts further than sand, because the spaces between the particles are smaller, but it cannot apparently lift more than six feet." This means that practically all water which sinks five or six feet below the roots of a plant is permanently lost to that plant. Moist soil draws up water more rapidly than dry, but can lift it no higher.

Find out what you can about the height of the water-table in your vicinity at various seasons of the year; does it follow exactly the elevations and depressions of the surface of the land? How many feet does it rise and fall yearly? What is the ideal depth for the water-table? Does the rise of the water-table in spring help to thaw out the ground?

From these experiments it appears that in soil which is moist and in good condition for growing plants (but not wet) the water exists in the form of

The finest silt may lift water as high as ten feet: this necessari]y occupies a vely long time. 
drops which are held in the angles between adjacent soil-particles (see Fig. 89, which represents a fairly dry soil); it also forms a very thin film on the surface of each particle. The remaining space is filled with air.

The water causes the soil-particles to adhere to each other, just as two glass plates do when wet. or the hairs of a brush dipped in water.

We may picture the relations of the root-hairs to the soil-particles by the aid of Fig. 90, in which the soil-particles $(s p)$ are represented as surrounded by water, as

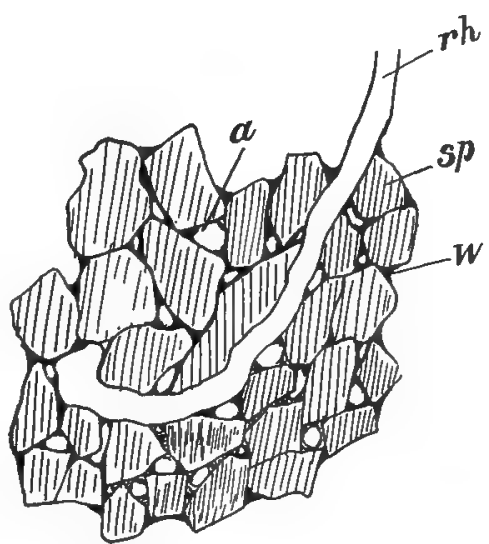

89. Diagram of a frirly dry soil, showing the relations of a root-hair $(r h)$ to the surrounding soil-particles ( $s p)$. The water $(w)$ is held in the form of small drops (menisci) between the angles of adjacent particles; the water also forms a very thin film on the surface of each particle, as well as on the surface of the root-hair. The remaining space is oceupied by air $(a)$.

shown by the contour lines; this represents a wet soil containing the maximum amount of water in which plants can grow. Here and there air-bubbles (a) occur which furnish the root with oxygen. The root-hairs absorb water whenever they come into contact with it; this causes more water to flow from neighboring particles not actually in contact with the root-hair. In this way each root-hair drains a considerable extent of territory. The absorbed water 


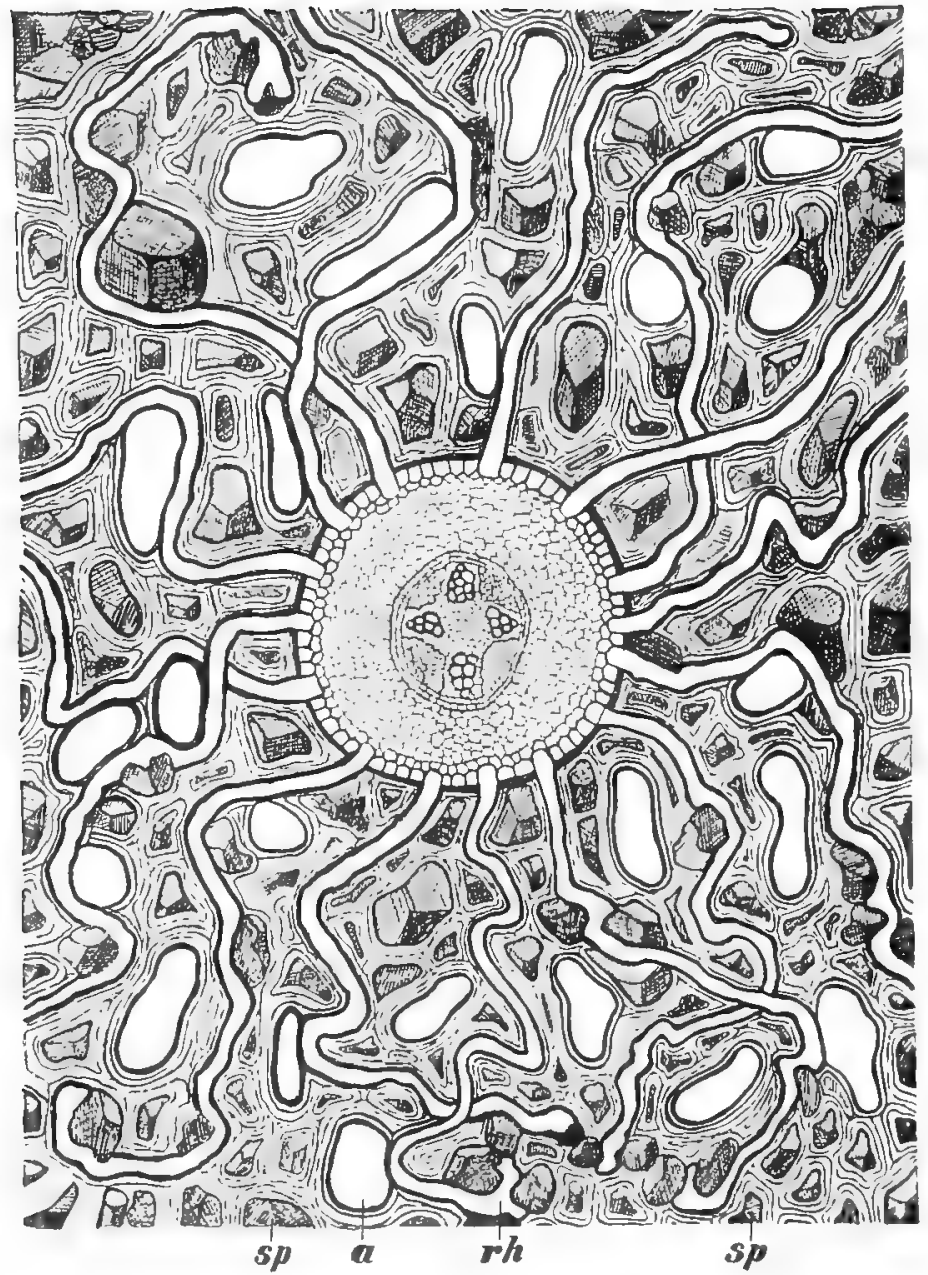

90. Cross-section of a root, as it grows in the soil, showing the relations of the root-liairs $(r h)$ to the soil-partioles $(s p)$ and the air-spaces $(\alpha)$ : this soil is represented as containing the maximum amount of water compatible with good plant-gowth. Whenever a root-hair absorbs water, more tlows toward it from the surrounding region; a single root-hair is thus ensbled to drain a considerable ares. The water absorbed by the root-hairs passes through the loose outer rind or cortex of the root to the wood-cells (shown as four groups of thick-walled cells in the center of the root); alternating with the four groups of wood-cells, are four croups of thin-walled bast, while in the center is pith. 
passes through the root-hair and the soft outer part (rind or cortex) of the root to the woody strands in the center (shown in the figure as four groups of thick-walled cells), and by means of these up into the stem. (The four groups of thin-walled tissues alternating with the wood are the bast: in the center, surrounded by the wood and bast, is the pith.)

Do the root-hairs attach themselves closely to the particles? Place some well-soaked seeds (Radish seed is especially good) on the surface of fine, moist gravel in a pan; over this lay a piece of glass to retain moisture. In two or three days the roots will be covered by a thick felt of glistening, white root-hairs. As they come into contact with the particles of gravel they become firmly attached to them. When this has happened, lift the seeds; are the attached particles lifted with them; how large a pebble can be lifted in this way; when the pieces are too large to be lifted does the root-hair loosen its hold or does it break, leaving a portion attached to the particle? What conclusion do you draw as to the closeness and firmness of the attachment?

In dry soil the water exists in the form of innumerable little reservoirs, which must be tapped by the root-hairs. To remove the water some force must be used, for the water adheres quite firmly to the soilparticles. Not only must the reservoir be tapped but the water must be drawn forcibly from it. How does 


\section{the root-hair pull the water away from the particles?}

It would seem that there must be substances in the root-hair which attract water, just as the sugar draws the water through a Walnut-shell or bladder (pages 16 and 61). In some roots we can taste sugar (Carrot, Parsnip, Beets, etc.); by applying chemical tests we find in all roots sugar or other substances capable of attracting water. It appears, then, that the root-hair, which is a long, closed sack (as you may easily see with a good hand-lens or with the low power of a compound microscope), contains substances which attract water. We can easily make an artificial root-hair ${ }^{1}$ of any sort of membrane which will allow water to pass through but retain the sugar inside; such are ox- or" pig-bladder or parchment paper; perhaps the most convenient is the membrane which lines an egg-shell; empty the contents of the egg through a small hole at one end; place the shell in a tumbler and cover with weak acid or vinegar; place another tumbler inside the first, to keep the egg submerged. When the shell is dissolved away, fasten the membrane to a glass tube (about one-fourth of an inch in diameter), as shown in Fig. 91; three or four turns of tightly wound string (or, better, of elastic band) fasten it satisfactorily. ${ }^{2}$

1 Artificial root-hairs may be made by hollowing out Carrots, using an entire egg, etc., but it seems better to eliminate all living parts from the apparatus, that the purely physical features may be emphasized.

2 It is well to prepare several tubes and then choose the one which gives the best results on trial. 
Place it under water, and blow gently into the tube to make sure there are no leaks. Pour into the tube enough strong syrup (sugar and water) to fill it to a point a little above the membrane. Submerge the membrane in water, and mark the height at which the syrup stands. If, now, this artificial root-hair absorlss water, we can detect it by the rise of fluid in the tube. How rapidly does it rise? How far will it rise? As we have already learned (pages 61 to 63 ), the absorption of water generates pressure inside the (closed) artificial root-hair. In the real root-hair pressure is generated in the same way.

What happens if we now extract water from the artificial root-hair by submerging it in a strongel syrup than that which is inside of it? Pour sugar into the tumbler and stir it until a very strong syrup is formed; what happens to the liquid in the

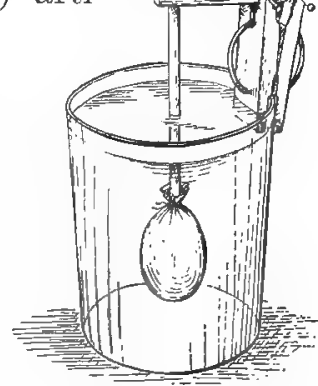

91. Artificial root-hair, made of the membrane which lines an egg-shell. tube? Try the same experiment with the root-hairs; have some seedlings with good root-hairs growing in water; add sugar to the water until a strong syrup is formed. The stiffness of the root-hairs is due apparently (like the stiffness of an inflated balloon or bicycle tire) to the pressure inside; this pressure is 
due to the absorption of water; when we draw this water out the root-hairs collapse.

Just as in the case of the seed (see page 18), the presence of water-attracting substances (e.g., salts, etc.) in the soil-water hinders absorption by the root; this is the case in salt marshes, alkali, soils, peat bogs, ete.

In order that the roots may be able to explore the soil freely and absorb water from it, it must be in the proper physical condition or, to use a more common term, it should be mellow, i.e., of a loose, friable texture. The physical condition of the soil is known as tilth.

How may the soil be kept in good tilth? This involves two things: (1) keeping the soil-crumbs of the proper size, (2) keeping up the circulation of air in the soil.

1. The size of the soil-crumbs is of the greatest importance. If they are too large, the surface exposed to the action of the roots is relatively small. Suppose that by tillage we break them up so that they are only one-tenth of their original diameter, we thereby increase the surface available to the roots ten times and multiply the possibilities of plant-growth accordingly. Soil composed of too large erumbs not only allows the rain-water to leach through too rapidly, but is unable to lift it up again to any great extent from the watertable. 
If, on the other hand, the crumbs are too small, the soil becomes impervious to water and wholly unfit for plant-growth: this is the case with the finest clays or puddled clay soils. As already explained, the surface mulch of larger-sized crumbs produced by cultivation conserves the moisture of the soil by preventing surface evaporation.

2. The air in the soil is kept in slow but constant circulation by the fluctuations of barometric pressure by which it is alternately forced into the soil and sucked out again: this phenomenon is sometimes so pronounced that the air, escaping from the lower strata of soil and rushing up through wells, produces a loud noise, causing them to be known as "whistling wells." But, despite this, it is necessary to stir the soil frequently in order to admit air if we wish to get the best results from crops. The great importance of air as an agent which promotes chemical changes in the soil is now becoming better understood: this point will be discussed later.

The necessity for a supply of air may be strikingly shown by placing a potted plant in a pail of water so that the water-level stands a little above the top of the pot. Note the appearance of the plant from day to day. Alfalfa fields, if flooded for two or three days in summer time, turn yellow and the plants die. Note the effects of flooding on meadows or trees whenever an opportunity occurs, A crust on the surface of the soil 
excludes air. Paved streets and sidewalks often cause injury to trees by preventing access of air; for this reason it is better to leave an open space about them and aërate the soil by frequent cultivation. We frequently see Willows and other trees on the banks of streams living with their roots completely submerged in water or in saturated soil; this seems at first glance to be in contradiction to what we have just learned about

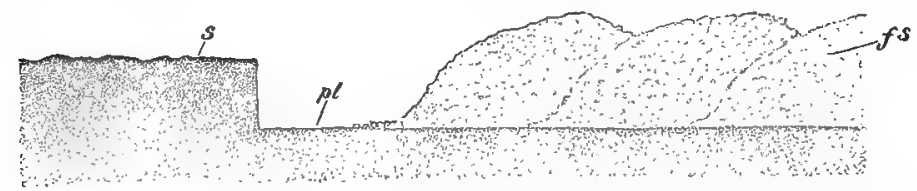

92. Diagram to illustrate the effect of ideal plowing. The compactness of the soil is indicated by the density of the shading. Before plowing, there is a compact surface erust (a), below which the soil grows less compact as we go deoper; after plowing, this compact mass is broken up into a loose, friable mass of soil-erumbs, or floccules, with a consequent increase in the bulk of the furrow-slice $(f s)$; compacted plow sole at (pl). (After Hilgard.)

the necessity for a supply of air for the roots. In this case, however, the roots are in running water and are able to make use of the small but continually renewed supply of air which it contains. Where the soil is saturated with water, without free circulation, the air-supply is quickly exhausted. Not only are the roots unable to breathe but chemical processes injurious to the plant are set up in the soil.

Plowing and surface tillage are the principal means used to secure good tilth. The result of ideal plowing is shown in Fig. 92, in which the density or compactness of the soil is indicated by the density of the 
shading (the dots are not intended to represent individual soil-particles or aggregations). At $(s)$ is the surface-crust, which may become very hard by the baking of the sun and the beating of rain upon it, as well as by the deposit of salts which are left behind as the water evaporates. In soils where such salts are very abundant (alkali soils) they form a whitish deposit on the surface. This action of salts may be very clearly illustrated by placing a little strong eosin solution or a little table salt in the bottom of a tumbler and then filling the tumbler with wet sand and allowing it to stand in the sun for a few days.

As re go deeper the soil becomes less compact (as indicated in the figure) until a certain depth is reached, when it begins to grow more compact as the subsoil is approached.

The plow removes a slice of soil and inverts it; in ideal plowing the inverted portion (called the furrow slice, $f s$ ) is left in a loose, friable condition. On examining it, we find it broken up into small rounded masses (soilcrumbs, or floccules), as shown in Fig. 93. Each

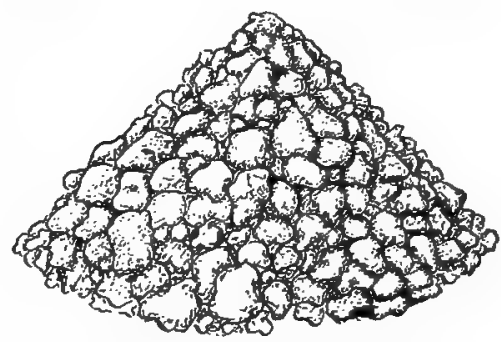

93. Part of furrow slice (of Fig. 92) magnified to show floccules, or soil-crumbs. one of these masses is made up of a number of small soil-particles, as shown in Fig. 94, which repre- 
sents a single soil-crumb greatly magnified. The particles are held together by the water $(w)$, just as are two plates of glass or the hairs of a brush when

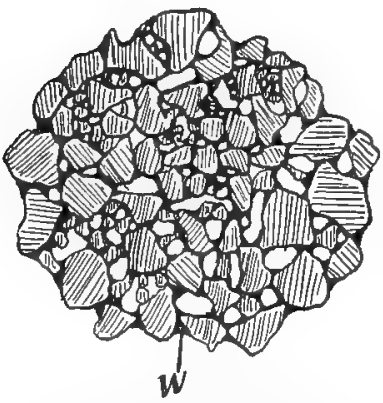

94. A single soil - crumb magnified to show the soil-partieles of which it is composed; the partieles are held together by the water $(w)$, just as are the hairs of a brush when wetted. The white spaces between the particles represent air.

wetted. If the brush be dry or submerged in water the hairs tend to fall apart; the same is true of the soil-particles.

At the same time that the soil is broken up it is mixed with air. It will be noticed that the surface of the plowed land is much higher than that of the unplowed: there has been a noticeable increase of bulk due to the spaces between the soilcrumbs formed by tillage. These spaces are filled with air, so that the increase in bulk represents the amount of air which has been mixed into the soil in the plowing.

Surface tillage is accomplished by the harrowing which follows plowing, and also by placing the plants in rows several inches apart and running a cultivator between them. This serves the triple purpose of destroying weeds, breaking up and aërating the soil, and maintaining a surface mulch.

It is important not to till the soil when it is too wet, since in that case the tendeney is to break up the soil-crumbs into their constituent soil-particles, which 
results in the formation of a pasty mass impervious to water, as can be easily seen by kneading a little wet clay. Such a soil is called a puddled soil, and its properties are illustrated in the making of reservoirs, the bottoms of which are sometimes lined with wet clay, which is then kneaded by driving sheep into the enclosure: the result is a layer which is water-tight. To a certain extent, puddling of the soil is caused by the beating action of rain, as well as by baking in the sun and the deposition of salts by evaporation. (Mulches prevent this action; so also does a covering of plants, which explains why the soil of meadows, natural pastures, woodlands, etc., remains in good tilth.)

It is interesting to note that puddling may also be caused by tilling the soil when it is too dry, the effect being to reduce it to a fine powder, which forms a pasty mass on becoming wet.

Puddled soil is improved by mixing manure, burnt clay, straw, coal ashes or sand with it. Try an experiment to test this. The addition of lime is also beneficial, since it tends to form floccules (see page 152).

The texture of the soil is more important than its richness, and it is almost useless to apply manures to soil which is in poor tilth: tillage is of more importance than manuring. ${ }^{1}$

${ }^{1}$ See King : "The Soil," and "Irrigation and Drainage": Bailey: "Principles of Agriculture," Chaps. II, III and IV. See articles in the Year-Book of the U. S. Dept. of Agriculture, for 1894 by Whitney, Galloway and Woods; for 1895 by Whitney; for 1900 by Briggs ; for 1903 by King. 
How much water should the soil contain to give the best results in growing plants? Take five tumblers, fill them with soil: add to the first $15 \mathrm{cc}$. of water each day: to the second, half as much; to the third, half as much as to the second, etc. Plant the same number of Wheat-grains (or other seed) in each. After two or three weeks a great difference will be noticed: those which receive too much water will not grow, on account of lack of air ; those which receive too little will suffer from drought. Somewhere between will be the happy medium where the plants grow best. What per cent of water does this soil contain? We may ascertain by weighing a sample of the soil and then drying it in an oven and weighing again. For practical purposes we may turn the question around and ask, How much air should the soil contain? A simple method of answering this is to insert a small tube to the bottom of the soil, connect it with a funnel and then pour in water (from a receptacle containing a measured quantity of water) until the water stands level with the surface of the soil. Since the water displaces the air in the soil we may consider that the volume of water poured into the soil represents approximately the amount of water it contained: this may be easily compared with the rolume of the soil.

In watering gardens and potted plants, and in irrigation on a larger scale, it is important to know how much water to apply. The greatest ignorance prevails in this respect. One irrigator will use ten times as 
much water as another on the same land and for the same crop; house-plants are more often killed by injudicious watering than by any other cause. The greatest harm is done by over-irrigation, which not only drowns the roots but ruins the soil-tilth. Whenever it is possible, irrigation should be done by means of underground pipes or drains: these deliver both water and air to the roots precisely where they are needed, and, if a good surface mulch be maintained, there is almost no loss by evaporation. This method is especially adapted to greenhouses and intensive horticulture generally. It is stated that by this system, as practiced in the open, only a twentieth part of the ordinary amount of water needs to be given and the tilth of the soil is kept in the best condition, while the sulface of the land is left free for tillage.

The amount of water which the soil should contain to give the best results will vary somewhat, according to circumstances (some plants require much more than others). In general the soil should not contain more than 60 per cent of its water-holding capacity, i. e., at least two-fifths of the spaces should be occupied by air. The water-holding capacity of a soil may be determined by saturating it with water, draining off the surplus, weighing a portion of it and then drying it on a water-bath to constant weight. The loss in weight divided by the dry weight gives the percentage of water (i. e., water-holding capacity of the soil). 
Compare the water-holding capacity of sand, clay and humus (leaf-mold).

Air reaches the roots of potted plants not only from above but also through the sides of the pot. How permeable the latter is to air may be tested by cementing a piece of it to a glass tube and proceeding as in the experiment shown in Fig. 28, or by simply placing a piece in an air-pump (see page 187) and exhausting. The outside of a pot should be washed occasionally to keep it clean and porous, so that air may enter it freely.

To retain in good condition the soil in which potted plants are grown, they should not be watered too often, but, when water is given, it should be applied copiously (preferably by submerging the entire pot in a pail of water). A good rule is to water about once a week in this way and to delay watering in any case until the pot sounds hollow on being tapped. The frequent application of a little water merely wets the top layer of soil, leaving the bottom dry. On the other hand, too much water deprives the roots of air and causes them to decay. Devise an experiment to determine in the case of some house plants how much water should be given.

How may the soil moisture be regulated? We may answer this question by reviewing what has alleady been said. (1) Moisture may be decreased hy underground drains or by plowing land without subsequently 
making a surface mulch, in which case it soon liries out; (2) moisture may be increased by a surface muleh which hinders the rain-water from running off and largely prevents loss by subsequent evaporation; by keeping the soil in good tilth; by the addition of humus; by artificial application of water.

Other things being equal, the yield of a crop is directly proportional to the amount of water it receives within the limits mentioned above. ${ }^{1}$

How thoroughly do roots explore the soil for moisture? This may be investigated by carefully removing the earth in successive layers, or, better still, digging a trench around the plant and lifting out a large ball of earth, which should be carefully washed away by means of a hose. The roots of Corn, Barley, etc., examined in this way show a dense mat extending downward three or four feet. In a root-system of this kind we find practically every cubic inch of the soil explored by one or more (sometimes by very many) roots: a conservative estimate of the extent of the root-system of four well-developed Corn plants gave an aggregate length of over a mile of roots, not counting root-hairs. The estimate was made by calculating the number of cubic inches of soil (the roots occupied a cube of earth a little less than three and one-half

1See Bailey, "Principles of Agriculture"; King, "The Soil" and "Irrigation and Drainage"; also articles in the Year-Book of the U.S. Dept. of Agriculture for 1895 by Taft; for 1898 by Briggs; for 1900 by Johnson and Stannard; for 1902 by Beals. 
feet on a side), which were thoroughly explored by the roots, and assuming each cubic inch of earth to contain only one linear inch of root. The entire root-system of a Squash vine was found by actual measurement to be over fifteen miles in length (not counting roothairs), and of this length the major part must have been produced at the rate of 1,000 feet per day.

The spread of the root is, in general, about the same as the spread of the branches. Thus the "feeding roots" (the fine, branching roots which do most of the absorbing) of a tree are largely located beneath the tips of the branches where the drip of the rain and dew falls directly upon them; and the same is true to a great extent of shrubs and herbaceous plants. With these general facts in mind, it will be of interest to investigate a few special cases, especially of trees or crops common in your region. It will also be of interest to examine the behavior of the roots of potted plants.

As a rule, the roots of ordinary crops do not penetrate the soil to a depth of more than three or four feet, but in dry regions they may penetrate ten or twelve feet (or more) into the soil in the search for moisture; in consequence of this they are enabled to withstand long periods of drought. Alfalfa grown in dry soil may penetrate more than twice as deep as this. Some erops, Grasses, etc., are known as "surface feeders." Such are often grown in orchards, etc., 
since they do not interfere with the deeper roots of the trees. (Monocotyledons are mostly shallow-rooted, because the roots spread out near the top.) Other's, for the opposite reason, are known as "deep feeders." It is of the greatest importance to take these facts into account in hoeing and cultivating the soil: the deeper the roots the deeper should be the plowing and subsequent cultivation. It is of importance to know that by proper irrigation it is possible to control the growth of the roots so as to cause them to grow deep or near the surface: the more the soil is saturated with water the nearer the surface will the roots stay, on account of their need of air. Where there is a long dry season the water-table sinks steadily: if the crop is planted early enough the roots follow the water-table down and so maintain themselves, but if planted two or three days too late they are unable to do so and the plants perish. What crops stand drought best? Are they deep-rooted plants?

CARe of Roots. - When roots become sickly, water sparingly; place the plant in a cool, shady place, sprinkle the leaves from time to time and, if necessary, prune off some of the leaves and branches. Under these circumstances the plant will need little water (for reasons, see page 212) and the roots will have an opportunity to recover.

In repotting plants, invert the pot and tap smartly until the ball of earth is loosened. On removing the pot, 
a perfect felt of roots will usually be found next the pot. These should be removed, since they are sure to be injured in any case and their subsequent decay may affect the rest of the root. Remove the outer part of the ball of earth (which has become compact and sour), hold the plant with the left hand at the proper height in the new pot, and with the right hand pack the fresh earth about the roots. The pot may then be immersed in water until bubbles cease to rise.

Trees which are intended for transplanting should have the roots confined to a small space by transplanting and root-pruning once a year. Trees with spreading roots may be treated as follows: Some time before the tree is to be transplanted a trench is dug about it and filled with good earth. From their cut-off ends the roots will send out new rootlets into this earth. When this is accomplished the tree, with its ball of earth, may be pulled over and then raised by a suitable tackle, and transported. (In addition to these precautions, it is important in transplanting trees to see that the points of the compass remain in the same relation to the tree in its new position, i. e., that the north side shall remain the north side after transplanting; for reasons, see page 220.)

The water contained in the soil dissolves out from it mineral substances (such as the salt, which is constantly carried to the sea, and the lime, which is deposited in boilers, tea-kettles, etc.). Are these mineral 
matters absorbed by the plant? We may easily answer this question by burning the plant, since whatever remains after thorough burning represents mineral matters which have been absorbed by the plant. We first dry the plant thoroughly in the sun or in an oren; we then break it into small pieces, place them on a small iron shovel and heat it red-hot. Continue the heating until the ash becomes white, or nearly so, on cooling.

If we weigh the plant before and after drying, and also the ash left after burning, we shall know approximately how much water, how much cellulose (see page 66) or woody fiber (the combustible part), and how much mineral matter it contains.

Is the absorbed mineral matter of use to the plant? In order to deprive the plant of its supply of mineral matter, we must furnish it with distilled water instead of ordinary water. We may obtain distilled water by means

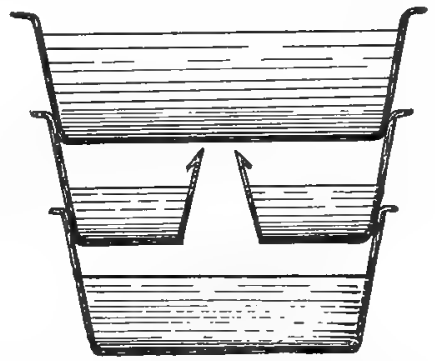

95. A still for making distilled water: it consists of two pans and a caketin (all of graniteware or tinware). of the apparatus shown in Fig. 95. It consists of two pans and a cake-tin, the central cone of which has been shortened to the proper length by making vertical cuts with a pair of stout shears and then bending back the flaps as shown in the figure. Water is 
placed in the lower and upper pans and the whole apparatus set on a stove. When the water in the lower pan boils the steam rises until it strikes the under surface of the upper pan, which is kept cool by the water in it. The steam condenses in drops and collects in the cake-tin.

It is desirable to use graniteware utensils for this apparatus, but tinware is equally good so long as it is kept bright and free from rust. Distilled water may be made in this apparatus at the rate of over a quart an hour. The cost of the whole apparatus need not exceed half a dollar.

The purity of distilled water (like that of rainwater) depends on the fact that when water evaporates it leaves behind any substances which may be dissolved in it. (We may use, if necessary, freshly collected rain-water in place of distilled water.)

Wheat may be recommended for this experiment. Place the seeds in boxes of sawdust; water one with distilled water; the other with pond-, river- or tapwater (giving the same amounts to each). We may also grow the plants directly in water. For this purpose slips (about eight inches long) of the Wandering Jew or Inch Plant (Tradescantia) may be recommended. The slips are placed in fruit-jars containing about two quarts of water, and placed where they will receive about the same amount of light as is needed by ordinary house-plants. We may carry the 
experiment further and add to the tap-water various mineral substances, to stimulate the growth of the plant. Saltpeter and bone superphosphate (one ounce of each dissolved in three quarts of water) may be used in this way. Experiments carried out in this way have shown that the mineral matters indispensable to the plant consist of four bases and four acids.

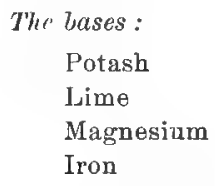

The acids :

Nitric

Phosphoric

Sulphurie

Carbonic (from the air)

If we dissolve in distilled water all the above substances (except carbonic acid), plants may be grown in it until they flower and fruit and produce perfect seeds; but if we omit any of the elements involved (except carbonic acid), the plant soon stops growing and fails to flower or fruit. (Carbonic acid is necessary to the plant but is absorbed from the air, as we shall see later.) Fig.96 shows the result of such an experiment made with the Wandering Jew or Inch Plant.

All these substances must exist in the soil in order that the plant may thrive, and they must not only exist there but be soluble in the soil-water. The carbonic acid of the soil is of great service to the plant, since it dissolves many substances which would otherwise remain undissolved. If, for instance, we add to lime-water (which has been filtered clear) a little soda- 
water (i. e., water highly charged with carbonic acid; it is bottled under pressure and sold as "plain soda"), we shall get a milky precipitate or sediment of carbonate of lime (due to the union of lime and carbonic

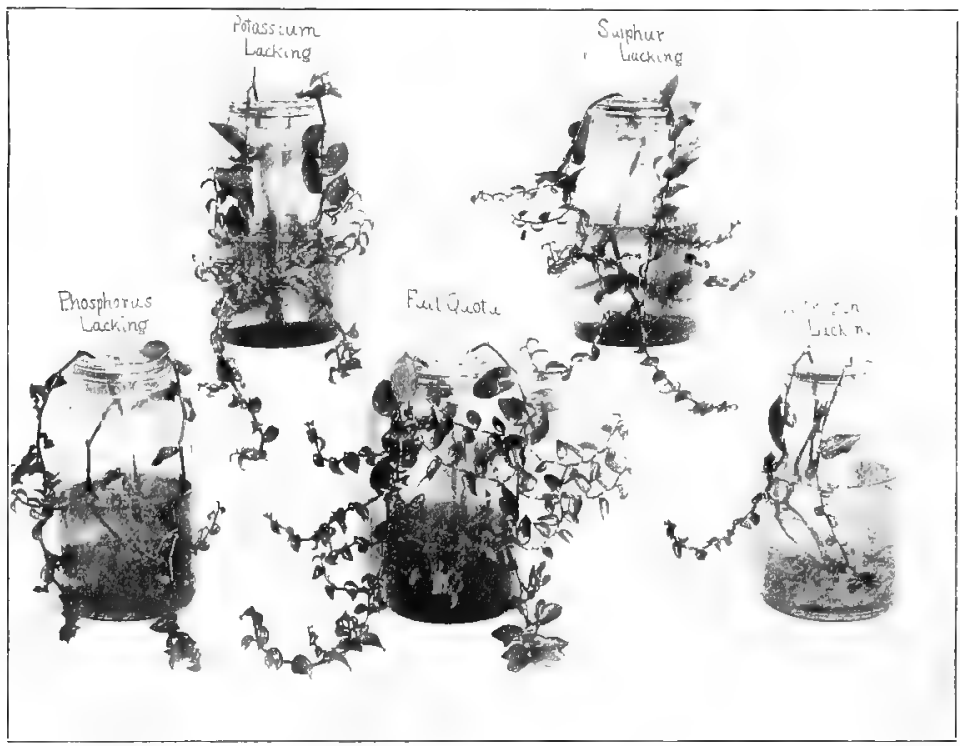

96. The result of a (five weeks) water culture of Wandering Jew: the one marked "full quota" had all the indispensable food-substances dissolved in the water; each of the others lacked one element.

acid). On adding more soda-water, the milky appearance vanishes and the water becomes clear, owing to the fact that the carbonate of lime has been dissolved by the excess of carbonic acid. If we now heat this clear water, the excess of carbonic acid will be driven off (as shown by the constant and rapid 
rising of bubbles), and the milkiness will reappear as the carbonate of lime separates out in solid particles.

This experiment may also be performed by stirring up fine marble dust or whiting (both of which consist of carbonate of lime) in a little water, pouring off a little of the milky fluid into two separate tumblers and adding to one a considerable quantity of tap-water, to the other the same quantity of soda-water. Cover each tumbler with a piece of glass and set them aside, to see in which the carbonate of lime will dissolve first.

Since carbonate of lime is the principal constituent of marble and limestone, we can readily understand how these rocks are dissolved by water containing carbonic acid and also why they are deposited on vessels in which such water is boiled. The carbonic acid in soil-water comes mostly from the decay of animal and plant remains. It dissolves not only limestone, etc., but practically all other minerals which the plant uses as food.

We have already learned (page 34) that seeds give off carbonic acid; if the root also has this property it must be of very great advantage to it in dissolving the plant-food immediately around it. Does the root give off carbonic acid? We may test this by growing roots in lime-water. Fill two similar bottles with lime-water (filtered through filter paper or cotton wool), and cut in the cork of each a notch large enough to receive the stem of a seedling plant two or three inches long (Peas, Beans, ete., grown in sawdust answer excel- 
lently). Place the seedling in the bottle so as to submerge the roots, and tuck a little cotton around the stem of the plant where it passes through the cork. Arrange the second bottle in the same way, but put no plant in it; simply fill the notch in the cork with cotton. If, now, the roots give off carbonic acid we shall expect to find the lime-water in which they are submerged turning milky after a time, while that in the control bottle remains clear (or shows a slight degree of milkiness due to the carbonic acid of the air).

In order to get a better idea of the giving off of acid by the root, we should grow some roots in gelatine to which litmus has been added. This rery interesting experiment may be performed in a variety of ways. Some of the so-called "sparkling gelatines" used for cooking are preferable. Dissolve one part of gelatine in about five parts of water. This is most conveniently done by letting it soak in cold water orer night and then putting it on a water-bath (see Figs. 54 and 206). When the gelatine is dissolved, add enough litmus dissolved in water ${ }^{1}$ to give the gelatine a strong (reddish purple) color. Now add lime-water cautiously until the color changes to blue. The gelatine should now be filtered, as described on page 369, and should then be quite clear. Pour some of it into white saucers to the depth of a quarter of an inch; when it has "set," take some Peas (or other seeds, with straight

1 Obtainable at druggists". 
caulicles, about an inch long, and thrust the caulicles horizontally into the gelatine so that they are covered by it; arrange several seeds in a saucer in this manner, and then cover it with a piece of glass. If carbonic (or other acid) is being given off by the root, we shall be able to detect it by the change in color (from blue to reddish) of the gelatine around it. The result will be most apparent if the color of the gelatine is as pronounced as possible without being strong enough to make it opaque.

A still better method is to stopper the neck of a small glass funnel at the lower end with a small cork, and then pour in the gelatine until the neck is completely filled. A Pea with a straight caulicle may then be placed in the funnel with the caulicle directed downward into the neck and submerged in the gelatine. The funnel should then be covered with a piece of glass, to retain moisture (Fig. 97), and may be conveniently supported in the manner shown in the figure.

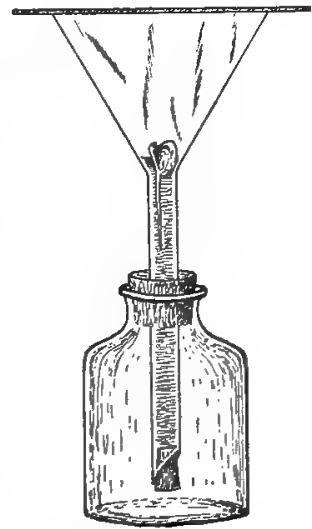

97. Apparatus to determins whether the root exeretes acid; the root is growing in gelatine which has been colored blue by the addition of litmus.

A simpler method is to use ordinary blue litmus paper, folded as for filtering and placed in a funnel, which is then filled with earth ${ }^{1}$ in which seeds are

t The action of the soil on litmus paper must be tested, since sour soils will redden it. 
planted, as shown in Fig. 82. Water it until the roots have grown down along the litmus paper; then cease watering. In the course of a day or so the result should be plainly visible. This method, while simpler, is much less beautiful than the preceding.

Another way for testing the roots for excretion of acids is to obtain a piece of polished marble, on which is placed a layer of moist sand about an inch deep, in which seeds are placed. As their roots come in contact with the marble they should, if they excrete enough acid and the time is sufficient (two to six weeks), produce a slight etching of the polished surface; if such etching occurs it may be made more striking to the eye by rubbing powdered graphite (obtained by scraping the lead of a pencil) on the marble. It is often more convenient to use a seedling with a stout root (Bean, Scarlet Runner or Pea), which is laid directly on the polished marble, covered with wet filter paper which dips into a dish of water and is pressed down by laying a piece of glass over it. In place of marble we may use a mixture of equal parts of plaster of Paris (previously well heated) and whiting (or fine marble dust) rubbed up together in water and then poured out on a piece of glass and allowed to harden: if this be carefully removed from the glass the surface will have sufficient poiish for the purpose.

Roots are able to decompose even the hardest rocks, 
such as lava and basalt, though of course much more slowly than soft rocks, such as limestone, etc.

Clay (which consists of alumina combined with silica and water) is of great service to the plant in "fixing" plant-foods. We may illustrate this by filling a lamp-chimney with clay or good garden soil (so firmly packed that the liquid takes an hour or so to run through) then pour in ammonia water at the top; the water will be deprived of the ammonia in passing through the soil and will come out at the bottom without any odor of ammonia. The ammonia has been "fixed" (principally by the compounds of alumina) in the soil so that it cannot be readily washed out by rain, etc. The same thing happens with dung liquor, phosphoric acid (fixed by lime and magnesia and, to a slight extent, by iron in the soil) or potash (for the last two, tost with litmus paper).

The carbonic acid of the soil and the alumina and silica of the clay act, not as foods of the plant, but as servants which store food; the clay (and likewise humus) "fixes" soluble food which would otherwise be washed out of the soil by the rain, the acids in the soil (carbonic acid, humus acids, etc.) render this "fixed" food soluble and available to the plant. The air which circulates in the soil is of immense importance in promoting chemical processes which prepare and set free plant-food of all kinds and especially nitrogen compounds (see pages 148 and 383). Where the air sup- 
ply is deficient, the soil becomes sour by the accumulation of carbon dioxide and humous acids and the roots are killed; at the same time poisonous substances are formed which, if air were present, would be converted into plant-food. Subsoils, when exposed to air, usually change color, an indication of chemical action.

The soil is not only a sponge, from which the plant may obtain water, but also a storehouse of plant-food, and a laboratory in which plant-food is prepared and dissolved for the use of the plant.

The amount of food in the soil depends partly on the kind of rock from which it is derived, partly on its "fixing" power, and partly on the kind and quantity of plants which grow upon it. In all these respects clay is superior to sand ${ }^{1}$; the rocks from which it comes are richer in food than the quartz from which sand is formed: it has greater "fixing" power than sand ${ }^{1}$ and produces a greater growth of plants whose decay enriches it still further: decay proceeds more slowly in clay than in sandy soils (since it is colder and wetter), and the products of decomposition are more fully fixed by it. For these reasons (and also because they contain more water) clay soils are richer in plant-food than sandy ${ }^{1}$ soils. The best soil is a mixture of sand, clay and humus, which gives abundant food and good tilth.

1 The so-called "sand" of arid regions is as rich or richer than clay, since it comes from rocks rich in plant-food and is not leached by frequent rains. 
Even the best soil becomes exhausted of certain elements in time if crops are continuously removed from it. The deficient food elements must then be replaced by fertilizers. The chief substances which it is necessary to replace in this way are nitrogen, phosphoric acid, lime and potash. It is important to understand how best to supply these elements, since this knowledge often makes all the difference between successful and unsuccessful farming.

How may nitrogen be supplied to the soil? Manure piles smell strongly of ammonia gas (which contains over 80 per cent nitrogen), and manure is the most available source of nitrogen as fertilizer. In fresh manure the nitrogen is mostly insoluble, but on standing it decomposes (by the action of bacteria, see page 383 ) into soluble substances containing nitrogen and into ammonia gas and nitrogen gas. These gases will mostly escape into the air and be lost unless we mix soil with the manure so as to form compost: the soil absorbs the ammonia gas to a marked extent and it is then changed to soluble compounds of nitrogen. ${ }^{1}$ Air

1 The absorption of ammonia gas by soil may be shown by filling a testtube with mercury, closing with the finger and inverting in a dish of mercury so that it contains no air: now introduce ammonia gas by heating ammonia water in a flask, through the cork of which passes a tube to conduct the gas into the test-tube (heat at first long enough to drive out air); when the testtube is full of gas, introdure a lump of dry clay from below: it will absorb the gas and the mercury will rise. In a control experiment use sand. Cottonseed oil may be used in place of mercury by wedging a Iump of clay in the top of an ordinary tube, dipping the tube into a vessel of oil and then corking it at the top with a rubber cork in such a manner that the oil fills the tube nearly to the clay. Raise the tube and introduce the gas as before. In each case use a control tube containing no soil. Decomposing humus also absorbs a good deal of ammonia gas. 
hastens decomposition, and if it is admitted too freely into the compost heap the gases will form more rapidly than they can be absorbed: if, on the other hand, air is excluded, decomposition almost stops. Hence decomposition may be regulated by regulating the moisture and compactness of the heap. Since manure contains all the mineral constituents needed by the plant, it is by far the best fertilizer for general purposes.

Another source of nitrogen is decomposing plants, such as leaf-mold, peat, etc. This is known as humus. It contains less soluble nitrogen than manure and decomposes more slowly. The humus in decomposing forms ammonia and sets free acids which promote the formation of soluble plant-food: these acids often change the color of the soil where it is in immediate contact with dead roots, etc. Humus may be applied to the soil by plowing in straw, stubble, weeds or special crops grown for the purpose.

Rapidly acting nitrogenous manures are urine, guano (manure of sea-birds), saltpeter and Chili saltpeter, all of which contain large amounts of nitrogen in soluble form. They are especially valuable as "forcing" manures and to tide a crop over a critical period.

Experiments have shown that not more than onehalf to one-third of the nitrogen applied as manure is recovered in the crop: the waste is due partly to the 
escape of ammonia and nitrogen gas and partly to the rain, which washes the soluble nitrogen compounds out of the soil.

Some plants have the power of taking nitrogen

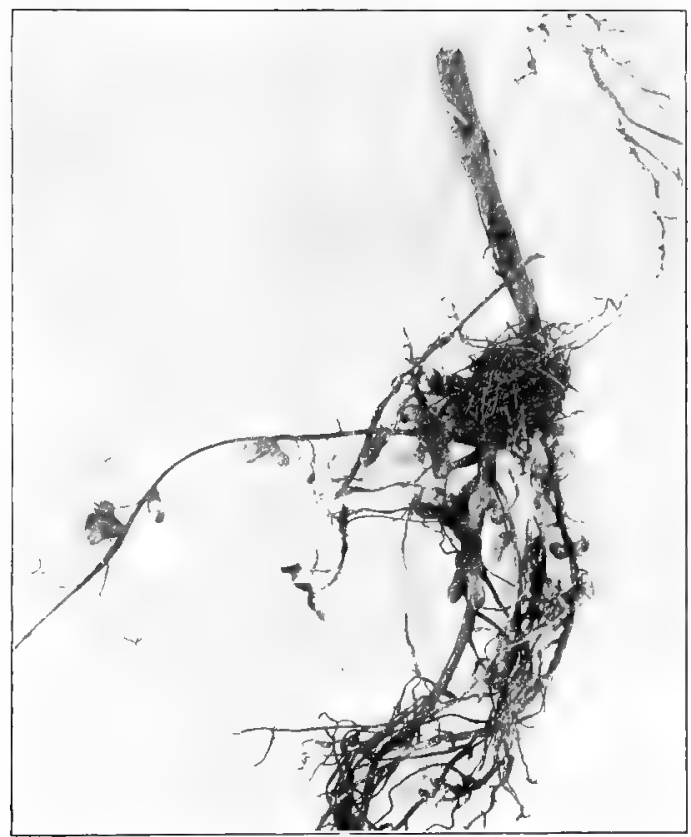

98. Tubercles on roots of Clover.

from the air by means of the bacteria or minute plants which inhabit tubercles on the roots. Such plants are Clover (Fig. 98), Lupines, Beans and other members of the Pea family. A crop of Clover or Lupines plowed under and allowed to decay furnishes nitrogen 
to the soil: such crops are called green manures (see page 384).

Certain other bacteria living free in the soil take nitrogen from the air and render it available to plants, while still others act on the humus and set free nitrogen in soluble form (see pages 383 and 384 ).

Most forest trees have their roots covered with fungi (small colorless plants), which absorb and decompose the humus in which such trees grow and render it available to the roots.

How may phosphorus be supplied to the soil? Phosphorus as fertilizer is chiefly obtained from bones. If we soak a bone in muriatic acid it retains its form but becomes like gristle, because the mineral constituents are dissolved out: if, on the other hand, we burn it, it also retains its form but becomes brittle because the gristly substance has been burned away, leaving the earthy constituents, which consist of phosphorie acid and lime. The burned bone may now be pulverized and spread on the land as fertilizer, where it is so very slowly dissolved by the carbonic, humous and other acids in the soil-water as to be scarcely at all avaitable for absorption by the roots. By treating bone with sulphuric acid, we obtain what are known as superphosphates, which dissolve readily in water: when placed in the soil the superphosphates are changed hack into the ordinary "insoluble" phosphates, but they are divided into very fine particles 
and distributed just where the roots can get at them instead of $b$ ing in coarse particles on the surface, as is the case with ground bone, burnt bone, etc. Consequently the superphosphates give far better results than ordinary ground bone.

Bone meal is usually ground bone, steamed to render it more soluble. It contains both the earthy and the gristly constituents (the latter contain nitrogeu), but on account of its greasiness decomposes slowly and dissolves very little. Bone-black is burnt bone; it contains practically no nitrogen. Certain rocks rich in phosphoric acid are also used as fertilizers.

How may lime be supplied to the soil? Aside from the bones, we have as sources of lime, marl, marble, shells, land-plaster ${ }^{1}$ (also called plaster of Paris, gypsum and sulphate of lime), limy soils, etc. Lime acts much more quickly if burnt, since it then dissolves in water, while if air-slaked it is more slowly dissolved by the acids in the soil-water. The amount of lime in the soil can be judged by the condition of the wellor spring-water. If this contains much lime it is "hard" and deposits a scale (composed principally of lime) on the insides of tea-kettles, boilers, etc. It may be softened for cooking purposes by boiling, or for washing purposes by adding soda (or other alkali).

1A story is told of Benj. Franklin, that he strewed ggpsum on a Clover field in such a way that the words "This has been plastered" appeared conspicuously, owing to the more luxuriant growth where the gypsum was applied. 
It may also be softened by adding more lime (about one pint of lime-water to ten pints of hard water). Waters which readily redden litmus contain much lime.

In addition to being itself a food, lime sets free potash in soluble condition from the insoluble compounds in which it is held, and increases the power of the soil to "fix" potash and phosphoric acid; lime greatly hastens the decomposition of humus and manure, sweetens the sour soil by combining with acids and destroys many injurious insects and fungi. It improves the texture of the soil by flocculating clay. This may easily be shown by rubbing up clay in water and adding a little of this turbid water to lime-water (use distilled or rain-water as a control). We may also mix burnt lime with clay and observe the effect on the mass when it hardens.

How may potash be supplied to the soil? Wood ashes contain large quantities of potash and constitute the best potash fertilizers. "Muriate" of potash (potassium chloride) and sulphate of potash are also used. Gypsum and lime set free soluble potash in the soil from insoluble compounds, as does also common salt. Crops may be, therefore, supplied with potash by applying lime or gypsum to the soil, where the soil contains sufficient insoluble potash.

Fertilizers which dissolve quickly when applied to the soil are much superior to those which decompose slowly (unless the cost is too great), since they give 
immediate results: the use of such fertilizers (e.g., guano and superphosphates) has revolutionized agriculture and made high farming and intensive farming possible. For example, we now use from 100 to 200 pounds of superphosphates per acre where a hundred years ago 1,000 to 2,000 pounds of bone were used; i. e., for the same cost it is now possible to fertilize six to eight times as much land.

When the soil is deficient in one constituent only, a small amount of fertilizer containing this constituent will give results out of all proportion to its cost. ${ }^{1}$ Hence it is important to know what elements of plantfood are lacking in the soil before attempting to enrich it. Chemical tests are useful, but in most cases the question is practically settled by applying fertilizers and noting the result. For the soil of our particular region we may arrange an experiment as follows: Lay out beds wherever convenient, or bring in the soil and place it in pots. On each bed or in each flower-pot place a single fertilizer or combination. We may use whatever is obtainable. A good series is

General fertilizers:

(a) Well-rotted stable manure
Special fertilizers:

(b) Chili saltpeter

(c) Superphosphates

(d) Wood ashes

(e) Quicklime

1See Bailey: "Principles of Agriculture," Chapters V and VI; King: "The Soil," Chapter III; Roberts: "Fertility of the Land"; also articles in the YearBook of the U. S. Dept. of Agriculture, for 1894 by Wiley and Webber; for 1895 by Snyder; for 1896 by Wiley; for 1898 by Means; for 1899 by Wiley; for 1901 by Woods; for 1902 by Holmes, Woods and McKenney. 
Lay out six beds a yard square; ${ }^{1}$ in each bed place it different fertilizer, working it well into the soil with a spade. The amount to be used may be determined by finding the amount used per acre in practice and dividing this by 4,840 (the number of square yards per acre). The following will give an approximate idea of these amounts:

Lbs. per acre.

(a) Stable manure ...5,000 to $8,000 \ldots 1$ to $1 \frac{1}{2}$

(b) Chili saltpeter ... 200 to 300, . $\frac{1}{24}$ to $\frac{1}{18}$

(c) Superphosphate.... 200 to $300 \ldots \frac{1}{24}$ to $\frac{1}{16}$

(d) Wood ashes ... 1,500 to $2,500 \quad 1 / 3$ to $1 / 2$

(e) Quicklime . . 8,000 to 20,000 . .11/2 to 4

The wood ashes used should be unleached ashes from cordwood (i. e., ordinary wood-stove ashes), in which case they contain about one pound of potashes in twelve of ashes: the rest consists chiefly of lime. If we wish to add potash without lime we may use commercial potashes, saleratus or pearl-ash at the rate of one thirty-sixth to one twenty-fourth pound per square yard: this should be dissolved in two or three gallons of water and applied in liquid form.

Inasmuch as the amount needed varies greatly with the character of the soil, it would be desirable to make a parallel series of three beds for each kind of fertilizer, using on one only half the amount given above, on another the given amount, and on the third half as much again as the given amount. In case there seems

1 These should be separated from each other by an interval of several feet. to prevent the applied fertilizer from diffusing from one plot to another. 
to be an injurious effect due to too much fertilizer, try the effect of giving it in two or three applications a few weeks apart.

In each bed should be sown Wheat or some staple crop; the watering and other conditions should be alike for all the beds. 'The result is, of course, strictly valid only for the special soil and special kind of crop used, but if the soil be typical of the region and the crop a staple there the result will be of great value. Moreover, it will also have important general applications.

The following rapid method of soil-testing, used by Prof. R. H. Loughridge, of the California Experiment Station, enables one to make a test in half an hour which is sufficient for all practical purposes. ${ }^{2}$

Nitrogen and HuMUs. - To 1 part (by volume) of soil add 5 parts (by volume) of 10 per cent caustie potash; this is best done in a testtube. Heat to boiling point and then set aside for five to ten minutes. If the liquid is black and opaque, it indieates abundant humus and nitrogen: if the liquid allows light to pass through when held up at a window, the humus and nitrogen content is low; if the liquid is merely yellow, the content of these substances is very low. The test really tells us about the humus only, but, since in all except very arid regions the humus content is an accurate index of the nitrogen content, the test is of great value. Try this test on a soil rich in humus, snch as leaf-mold or soil from a grove or forest; also on some sandy soil containing little humus. The color of the soil is a good indicator of the amount of humus it contains; the blacker it is the more humus in it.

PhOSPHORUS. - First prepare a standard of comparison as follows: Take about a pint of sand (as pure as possible) and pour on it about three times its volume of dilute hydrochloric acid, made in the proportion of one part of acid to four of water. Allow this to stand for an

1The necessary reagents are obtainable at drug stores. 
hour or so, stirring it up from time to time. Next place it in the sink and allow water to run through it for some time, until water, after being thoroughly stirred up with it, no longer gives any acid reaction to litmus. Spread the sand out to dry and when fairly dry take 25 grams for the experiment, setting the rest aside for subsequent tests. The sand thus treated has all the soluble plant-food washed out. We will now proceed to add to it definite amounts of plant-food in order that we may see what results these amounts give in our tests. A good content of soluble phosphoric acid in the soil is one-tenth of ome per cent. We will therefore add this amount to the sand and $\operatorname{mak} \theta$ a test. To the 25 grams of sand add 5 ce. of $1 / 2$ per eent phosphoric acid (made by dissolving on $\theta$ gram of solid phosphoric acid in $200 \mathrm{ec}$. of water): this will give .025 gram in 25 grams of sand, or one-tenth of one per cent. Take two grams of the sand which has been moistened with the acid, burn it for five minutes on a red-hot shovel: ${ }^{2}$ place it in a test-tube and add 3 or 4 ce. of pure nitric acid; heat until it just begins to boil; add 2 or 3 ec. of water and filter. Allow 4 or $5 \mathrm{cc}$. of water to run through the sand into the filtered liquid, in order to wash out the acid, and add to the filtered liquid an equal volume of a solution of molybdate of ammonia. (This is made by adding 10 grams of ammonium molybdate to $25 \mathrm{cc}$. of distilled water; then add $15 \mathrm{ce}$. of strong ammonia (chemically pure) and 150 grams nitric acid (chemically pure): keep warm and if a yellow precipitate occurs pour off the clear liquid for use.) Warm until it feels rather hot to the hand, then put it aside to settle. Pour off the clear liquid at the top and transfer the rest to a small funnel, ${ }^{3}$ the neck of which is not more than one-twelfth of an inch in diameter inside and whieh is sealed tightly at the bottom with sealing-wax. On the outside of the neck paste a paper scale ruled in millimeters (or in tenths of an inch). L t

1 That is, soluble in the acids which are ordinarily used in making tests: the soil may contain a great deal more phosphoric acid in insoluble form, but this will not appear in the tests and, being insoluble, is not directly available to the plant.

${ }^{2}$ The burning is for the purpose of removing vegetable matter and humus, and should, with ordinary soil samples, be carried on until the soil is light gray in color.

${ }^{3}$ Still better are the tubes used with centrifugal apparatus. 
us suppose that the precipitate ${ }^{1}$ when it has all settled in the neek of the funnel forms a column one millimeter high. We know that this indicates a content of one-tenth of one per cent of phosphorus in the soil examined. If we now examine soil from the garden in the same way and find only one-half a millimeter of precipitate (using the same funnel), it indicates only one-twentieth of one per cent, which is poor. Such a soil will be benefited by the application of phosphoric acid in $\operatorname{som} \theta$ of the forms previously described.

Lims.- We usually know whether a soil contains much lime by the hardness of the water and the amount of scale it deposits on tea kettles and boilers. If a drop of strong hydrochloric acid produces effervescence (i. $\forall$. , an appearance of bubbles of gas) when placed on a sample of soil, it indicates the presence of an excess of lime. Take 25 grams of the sand which has been treated with dilnte hydrochloric acid as described above, and add to it a quarter of a gram of whiting or marble dust, which will give us a content of one per cent of carbonate of lime in the soil: this should be thoroughly and equally mixed throughout the entire mass of sand. Place 5 grams of this sand in a test-tube; add 4 or 5 ce. of bydrochloric acid (chemically pure); heat until it just begins to boil; add strong ammonia water (chemically pure) until the liquid smells of ammonia; filter while hot and add $5 \mathrm{cc}$. of a saturated solution of oxaIate of ammonia (made by filling a bottle about one-fourth full of oxalate of ammonia, then filling with water and allowing it to stand until saturated). Transfer to the funnel just deseribed and allow the precipitate $^{2}$ to settle. If the column of precipitate is two millimeters long we know that a sample of soil treated in the same way which gives a column of precipitate one millimeter long indicates only ong-half as much lime, or $1 / 2$ per cent, etc. In a sandy soil 1 to 2 per cent of lime is about right; in a clay soil three-tenths to five-tenths of one per cent is good; 10 to 15 per cent is an excess in any soil.

AlKali.- To 20 grams of the sand which has been treated with dilute hydrochloric acid add $4 \mathrm{cc}$. of a solution made by dissolving in $100 \mathrm{cc}$. of water 1 gram sodium carbonate ${ }^{3}$ (washing soda), 1 gram sodium chlo-

${ }_{1}^{1}$ The precipitate is molybdo-phosphate of ammonium.

2 The precipitate is oxalate of lime.

${ }^{3}$ Allowance has been made for water of crystallization. 
ride (common salt) and 3.3 grams sodium sulphatel (Glanber's salt). This gives a content in the soil of one-tenth of one per cent soda, twotenths of one per cent common salt and three-tenths of one per cent Glauber's salt: these are all excessive and hurtful amounts, and a soil which contains so much of either is not suitable for ordinary crops. Place filter paper in a funnel and put the soil in it; add $20 \mathrm{cc}$. of water and let it leach through into a test-tube; test with litmus paper. The rapidity with which the paper turns blue indicates the amount of black alkali or sodium carbonate: if it quickly turns deep blue it indicates an excessive amount (one-tenth of one per cent or more: if it turns blue very slowly it indicates a lesser amount). Dilute some of the filtered liquid with one, two and three volumes of water and test with litmus paper. Save some of the filtered liquid to be used as a standard of comparison on future occasions. Take a portion of the filtrate and test for common salt as follows: Add a few drops of nitric acid (chemically pure) and then a drop or two of a 1.7 per cent solution of nitrate of silver (this is made by adding 1.7 grams to $100 \mathrm{cc}$. of water); a curdy preeipitate ${ }^{2}$ shows an excessive amount of salt (two tenths of one per cent or more) and from this we may find, in testing soils, all amounts down to a trace which gives only a slight milkiness on the addition of nitrate of silver. Take another portion of the filtered liquid, and test for Glauber's salt, as follows: add a few drops of hydrochloric acid (chemically pure), heat and add a few drops of barium ehloride to the hot solution: transfer to the funnel described above and measure the amount of precipitate: ${ }^{3}$ this will of course indicate in the present case a content in the soil of three-tenths of one per cent, which is an excessive and injurious amount.

By these simple tests which, although only rough approximations, nevertheless serve admirably for practical purposes, we may, after our standards of comparison are once established, in a few moments learn whether a given soil is deficient in any of the important elements of plant-food and whether it contains injurious amounts of alkali.

${ }^{1}$ Allowance has been made for water of crystalization.

2 The precipitate is silver chloride.

${ }^{3}$ The precipitate is barium sulphate. 
AlKali Solls. - The tests for alkali are of importance in arid and semi-arid regions. Whenever the ranfall is small the salts are not leached out of the soil so fast as they are formed and they accumulate. As the rainwater evaporates they are left on the surface (see experiment on page 127), where they often form a whitish deposit which disappears during a rain but reappears as soon as the soil begins to dry out. These salts may be in the form of "black alkali," or sodium earbonato (so called because it combines with the humus to form a black mass); such "black alkali" spots are very conspicuous. This is the worst form of alkali, for it corrodes the plant just at the surface of the soil and kills it. By adding gypsum (sulphate of lime) the "black alkali" is changed to "white alkali," Glauber's salt (sodium sulphate) and carbonate of lime. Glauber's salt, together with common salt (sodium chloride), magnesium salts, etc., are called "white alkali": they are much less injurions than "black alkali." Quantities of alkali saits are often found at varying distances (down to several feet) below the surface of the soil, where they form compact masses known as alkali hardpan; its presence may be ascertained (like that of any hardpan) by sounding the soil with a sharp-pointed steel rod to the depth of four or five feet at least or by digging holes. When we begin to irrigate such land the alkali of the hardpan often rises and the alkali spots on the surface gradually become larger and larger. The experiment already deșcribed on page 127 shows clearly how this takes place; in this case the salt in the bottom of the tumbler represents the alkali hardpan. This rise does not take place if the irrigation is properly done; only excessive application of water brings it about. This suggests that we might reverse the operation by flooding the land with water and earrying it of by means of drains placed underground. This would correspond to placing the tumbler of sand used in the experiment under the faucet and allowing the water to run out of a crack in the bottom; it is very evident that the salt would soon disappear. Large areas of alkali lands have been reclaimed in this way, which furnishes the only practical method of reclamation. To wash out the salts completely would be a disadvantage, since they consist, to a considerable extent, of substances needed by the plant. The water of moderately alkaline lakes can be used for reclaiming alkali soils, if enough 
be used to wash down through the soil and out through the drains. But, if only a little be used, it remains in the soil and finally evaporates at the surface, thus adding its dissolved salts to the alkali already present in the soil. In addition to the injurious effects mentioned above, the alkali salts (especially the black alkali) destroy the tilth and keep the soil in a permanently puddled condition; this is noticeable at the surface, where a thick, hard crust forms on alkali lands.

Each kind of crop needs a somewhat different food from any other kind. A cereal crop takes from the soil only one-half as much nitrogen and about onefourth as much potash as root crops. Clover will grow where Wheat cannot and will leave the land fit for Wheat again. This is partly on account of its deep' roots, which take food from a considerable depth and raise it to the surface, partly on account of its power" of taking nitrogen from the air and partly because the roots and stubble, etc., improve the tilth of the land.

In practice, crops with similar needs are not raised in succession on the same land: deep-rooted crops alternate with shallow-rooted, etc.: white crops (cereals) are usually alternated with green crops (Clover, etc.). This alternation is known as the rotation of crops. Find out as much as you can about the rotation of crops in actual practice. ${ }^{2}$

From what has just been said, it is evident that

1 See Hilgard: "Origin, Value and Reclamation of Alkali Lands;" FearBook of the Dept. of Agriculture, 1895. Also the following bulletins of the California Experiment Station: Bulletin No. 133, R. Loughridge, "Tolerance of Alkali by Various Cultures"; Bulletin 128, Hilgard, "Nature, Value and Utilization of Alkali Lands."

${ }^{2}$ Rotation of crops also tends to destroy weeds, fungi, insect pests, etc. 
each plant selects from the soil certain elements which it absorbs and uses for its growth, to the partial or total exclusion of others. Thus, when we grow plants in a solution of Chili saltpeter (sodium nitrate) the plant takes up all the nitrogen and only a trace of the sodium, leaving the rest in solution. From ammonium sulphate the plant takes the ammonia, leaving most of the sulphuric acid.

This selective action depends on the fact that more nitrogen is used or combined within the plant than sodium. This action of the plant may be imitated artificially by closing the end of a tube or lamp-chimney with a piece of bladder, as doscribed on page 60, placing within it water and a few pieces of zinc and setting it in a glass containing a solution of copper sulphate (blue stone) in water. The copper sulphate diffuses through the membrane and the copper is deposited on the metal and so removed from the solution, while the sulphuric acid is left behind: another substance, e.g., eosin in solution, will not be taken up by the zinc but will be taken up by the membrane, which becomes strongly colored: another substance, e. g., common salt, will not be taken up by either glass, membrane or metal, but will remain in solution in its original strength.

Inasmuch as the root is the most tender and succulent part of the plant, it is liable to attacks by insects and animals. Some roots, such as Monkshood, Yellow 
Jasmine, etc., are protected against such attacks by poisonous substances; others by a bitter taste, such as Chicory, Dandelion and Rhubarb. Immense damage has resulted from Phylloxera, an insect which attacks the roots of grape-vines in Europe. For some reason the roots of native American grapes are not attacked by the insect, and the European varieties are therefore grafted upon them. It is not known how the roots of American vines protect themselves, but the great importance of such protection is very evident. 


\section{CHAP'TER IV}

\section{THE WORK OF LEAVES}

We have become familiar with the seetl-leares, or first leaves of the plant. We have learned something about their general appearance and structure; the question may now be raiser, of what use are the seedleaves? Remove the seed-leaves from a number of plants (Fig. 99) about an inch high (growing in pots or boxes of earth), and mark them by loops of colored twine; mark a number of uninjured plants of the same size with white twine, to serve as controls. Vary the experiment by removing the seed-leaves from the soaked seeds before they are planted; from some remove one, from others both seed-leaves. Place them on the surface of moist earth in a pan, and cover with a glass. Does the removal of the seed-leaves check the growth of the plant?

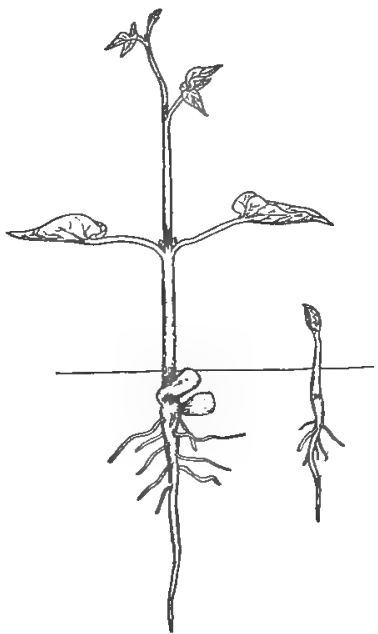

99. Two Searlet Runner Beans of the same age, from one of which the seed-leaves were removed shortly after germination. 
Why? We notice that the longer the seed-leaves remain on the plant the more they shrivel and lose substance. It looks as though the plant were absorbing the substance of the seed-leaf to obtain food for its growth.

Do the seed-leaves contain food substances? The principal food substances needed for the growth of plants and animals are (a) starches and sugars, (b) fats and oils, and $(c)$ proteids (substances like white of egg). Let us test the seed-leaves to see whether they contain these substances.

Test for starch by means of iodine solution, made by dissolving potassium iodide ${ }^{1}$ in water (about one part to seventy-five of water), and adding iodine crystals ${ }^{1}$ until the solution becomes dark brown in color. Apply the solution to a freshly cut or broken surface of the seed-leaf (if the seed-leaf is dry it will take the solution some time to soak in). A dark blue or blackish coloration indicates the presence of starch.

Sugar, if present in sufficient quantity, may be detected by taste (be careful not to taste poisonous seeds, e.g., Castor-beans) ; if none is detected by this means, use Fehling's solution, which can be made up by a druggist. ${ }^{2}$ The seed-leaf to be tester is cut up into thin slices and boiled for a moment or two in the

1 Obtainable at drug stores.

2 This can be made up by any druggist. Dissolve 34.65 grams of purified copper sulphate in $200 \mathrm{cc}$. of water to make Solution I. Dissolve 173 grams of sodium potassium tartrate (Rochelle salt) in 480 cc. of 10 per cent sodium 
solution; a red precipitate, or sediment, indicates the presence of grape-sugar; the precipitate may not appear until the boiled solution has been allowed to stand for a time. (Cane-sugar may be tested for, if desired, by the methods described in works on chemistry; it is found in seeds to such a small extent that it may be neglected.)

Fats and oils, whenever abundant, will ooze out if a pin is stuck into the dry seed-leaf; a better" method consists in powdering the substance of the dry seed-leaf (scraping with a knife usually suffices for this) and placing it on a piece of paper on a clean plate in a warm oven (not hot enough to scorch the paper); the oil, if present, will make a spot on the paper. Very small quantities of oil may be detected by grinding up the seeds and extracting with benzine (or gasolene, ether, chloroform, etc.); on standing, the benzine will evaporate, leaving the oil. Care must be taken in using benzine (or the other substances mentioned) not to bring it near a flame or stove, as the vapor is highly inflammable.

Proteids may be tested for by nitric acid, a drop of which should be placed on the seed-leaf; it may be followed by a drop of ammonia to intensify the color. A yellow color indicates the presence of proteid sub-

hydrate (soda lye) in water to make Solution II. To make up the reagent, add to a giren quantity of Solution $I$ two and one-half times its volume of Solution II, and one and one-half times its volume of water. Make up the reagent fresh whenever needed. 
stance; if the seed-leaf is dry, time must be allowed for the acid to soak into it. Apply the test to a little hard-boiled white of egg.

Another very excellent test is made by placing on the seed-leaf a drop of a saturated solution of canesugar in water; upon this place a drop or two of strong sulphuric acid (chemically pure); a bright red color indicates the presence of proteids.

Which of the three classes of substances seems to be most abundant in the seeds familiar to you? Make a table showing the results of your tests, and indicate by the terms "abundant," "little" or "none," the relative quantity found.

In order that the food materials may reach the places where they are needed, they must travel from cell to cell, passing through the cell-walls. To do this they must be made soluble. The process of making the food soluble is, in a general way, similar in animals and plants: in animals it is called digestion; the process in animals is better understood than in plants and we may profitably study it in both. In the human body it begins in the mouth, the saliva of which contains a chemical compound called diastase, belonging to the class of bodies known as ferments. In order to observe the action of the diastase, boil a little starch in water to form a paste, and place a little of the cooled paste on the tip of the tongue. After a short time it tastes sweet, indicating that some of the starch has been 
changed to sugar by the diastase (ptyalin) of the saliva. Mix a little starch paste with saliva, warm it to body temperature (by placing it in a tube and holding the latter in the hand). Allow it to stand at this temperature for a few minutes; then add Fehling's solution and boil. Do you get any indication of grapesugar? Test the starch paste and the saliva separately, before mixing, as a control.

Starch is changed to grape-sugar by uniting with water: such union of substances with water is called hydrolysis, and the ferments which bring it about are called hydrolyzing ferments. It can be brought about by boiling starch in water for a long time, or, in a much shorter time, by the addition of acid to the water. Make a very thin starch paste in water, add hydrochloric acid (a few drops of acid to 100 ce. of water; the more acid used the quicker the reaction). At intervals of about five minutes stir the mixture and take out two samples ${ }^{1}$; test one of these (after cooling) by adding a few drops of iodine solution; test the other by adding two or three times its own volume of Fehling's solution and boiling. At first we get a blue coloration with iodine; after boiling for a time, a brownish color is obtained; still later we find a yellowish coloration.

The brown and yellowish colorations are due to the

If a strongly acid solution is used, the samples should be treated before testing by adding lye until they turn red filter paper blue. 
fact that the starch is changed to dextriu, a substance familiar to us in the crust of bread, where it is formed by the action of the heat on the moist starch of the flour. The characteristic color and taste of the crust are due to the dextrin, also its stickiness when moistened with water (dextrin is used commercially as mucilage). After the acid solution has boiled for a sufficient time the dextrin is all changed to grapesugar, as will appear upon testing.

In seeds which contain starch we may expect to find ferments which have the power of hydrolyzing starch and converting it into soluble form; i. e., into sugar. The most favorable seed for examination is Barley, but any Grain will serve the purpose excellently. Grind some of the dry grain in a mortar with water, filter, and to the filtered liquid add twice its volume of Fehling's solution and boil. Allow it to stand, and note the amount of precipitate. Do the same with some Barley which has so far germinated that the caulicle is about a quarter of an inch long. What difference in the amount of precipitate? Has the amount of grape-sugar increased? Grind up some more dry grain in water, filter, and add to the filtered liquid a little starch. After twenty-four hours, test for grape-sugar with Fehling's solution.

The first step in the process of brewing is to allow Barley to germinate until the starch is mostly changed to sugar; the grain is then killed by heat and a watery 
extract (called malt) is made; yeast is then added, by the action of which the sugar is changed to alcohol.

It is generally found that seeds which contain starch contain also diastase, and that during germination the starch is more or less completely changed to sugar and transported to the places where it is needed. The cells through which it wanders usually contain starch, owing to the fact that the sugar is frequently changed back to starch again, probably as often as it reaches a certain concentration in the cell. For this reason it is comparatively easy to trace the path from the seedleaves to the growing parts of the plant by cutting the plant into halves lengthwise and applying iodine solution to the cut surfaces. Trace the path of the starch in this way in the seedlings you have at your disposal.

The power of changing starch into sugar, which, in human digestion, is begun in the mouth, is completed in the small intestine, into which the food passes after leaving the stomach. The pancreas (or sweetbread) pours into the small intestine the pancreatic juice, containing different sorts of ferments, which act, one on starch, another on fats and others on the proteids.

In order to study the behavior of fats, take a little fat or oil in liquid form (melted butter, cotton-seed oil, olive oil or cocoanut oil) and mix it with water; shake it up in a bottle until the mixture becomes milky in appearance. Allow it to stand and notice the sepa- 
ration which soon occurs. Add a little alkali to the mixture and shake again. Does it separate as before? This is called an emulsion. Examine a drop of it under the microscope. Notice the very small drops of fat which float freely in the liquid. Compare the appearance of milk under the microscope. The pancreatic juice is alkaline and has the power of emulsifying fats.

It also has a further action, which may be illustrated by melting a little cocoanut oil ${ }^{1}$ (preferably on a water-bath) and gradually adding a strong solution of caustic soda, stirring it in the meanwhile. Very soon a solid substance forms, whereupon the addition of soda may be stopped. On dissolving this solid substance in water, we recognize from the feeling, taste, odor and general behavior that it is soap. Through the action of the alkali the oil has been changed into soap and glycerine. A similar reaction takes place in the presence of the pancreatic juice: this reaction is due to a ferment called lipase (steapsin), which attacks fats in the small intestine and breaks them up into glycerine and soap, ${ }^{2}$ both of which are soluble in water, so that they readily pass through the cell-walls.

Lipase is found in oil-containing seeds, especially in the Castor-bean. If a few of the Castor-beans (just sprouting) be crushed and arded to fresh

1 Obtainable at drug-stores.

2 Lipase also has the power of causing these substances to unite so as to form fats; its action is therefore said to be reversible. 
cottonseed oil (which gives little or to acid reaction to litmus on being shaken up with a little alcohol and water) and allowed to stand a few hours, the oil will give an acid reaction, due to the fact that the lipase of the Castor-bean has split the oil into glycerime and fatty acids, which latter react with the litmus in the presence of alcohol and water.

Proteids are acted upon in the animal hody by both the gastric juice of the stomach and the pancreatic juice of the small intestine. The first contains a ferment, pepsin, which acts only in acid solutions, the second a ferment, trypsin, which acts only in neutral or alkaline solutions.

Obtain a pig's stomach: dissect off some of the inner lining, cut it up into small pieces with scissors and pound it in a mortar with water and a little glycerine. Filter the fluid, ${ }^{1}$ and add to it pure strong hydrochloric acid in the proportion of $1 \mathrm{cc}$. of acid to $150 \mathrm{cc}$. of liquid. In this place a little fibrin ${ }^{2}$ or

1 Pepsin (obtainable at drug-stores) may be dissolved in water in the proportion of one-half gram to $50 \mathrm{cc}$. of water to make artificial gastric juice. It is unuch better, however, to obtain a stomach for the experiment.

2 Fibrin may be obtained in dry condition (at drug-stores), in which case it shonld be softened by soaking in water, or better, in water containing about 1 cc. of hydrochloric acid in every $100 \mathrm{cc}$. Fibrin may be prepared from blood (obtainable of butchers) by whipping it with a bundle of sticks or wires : the stringy, elastic substance which collects on them is the fibrin : this is a proteid substance (apply the test for proteids); wash it in water, what is its color? To the fibrin is due the clotting of blood when wounds are made: it is very quickly coagulated by sugar, hence the value of treating euts, etc., by sprinkling them at once with sugar: other substances, e. g., iron chloride, have a similar action. If a little blood be allowed to stand in an open bottle the fibrin, together with the red corpuscles, collects into a clot, learing a straw-colored liquid which occupies about half the space : this is the serum : it is the serum which fills a blister. Find out what you can regarding the composition of blood. See any good text-book of physiology. 
some coagulated white of egg, and put in a warm place. Keep as near the body temperature as possible. Place a little fibrin or white of egg in water, also some in acidulated water ( $1 \mathrm{cc}$. of hydrochloric acid in $150 \mathrm{cc}$. of water) as controls. Place another portion of coagulated white of egg in pancreatic extract and keep in the same place.

It should be noted that both the gastric and pancreatic juices contain ferments which coagulate the proteid of milk (casein): this is subsequently rendered soluble.

By the action of pepsin and trypsin the proteids are changed into soluble substances which can readily be absorbed by the cells. It is only natural to look for pepsin and trypsin in seeds. In germinating Corn, Barley and other seeds pepsin occurs, while in others (Pea, Rye, Oat) it has not been found: it is natural to suppose that in such cases other ferments take its place. In certain plants which capture and digest insects (Sundew, Nepenthes or Pitcher Plant) occurs a ferment which resembles pepsin.

One may easily ascertain the presence of a digestive ferment in the juice of the Pineapple by expressing the juice, filtering and placing a little fibrin in it (this, if purchased dry, should be previously softened in water). Place a little fibrin in water as a control. The ferment of Pineapple works best in alkaline or neutral solution and hence resembles trypsin rather than pepsin. 
Food is used in two ways: (1) as a source of material for growth, (2) as a source of energy for doing work and keeping the living machine in motion. The energy is obtained from the food by burning it (just as in an engine: see page 35 ). The burning or oxidation is accomplished by means of ferments of various kinds which abound in both the plant and the animal organism.

The amount of energy furnished by a food is called the fuel value, and may be ascertained by measuring the heat produced by burning it directly or by feeding it to an animal and measuring the amount of heat given off by the body during a given time. The latter method does not give as high results as the former, since the body resembles other machines in not getting the full theoretical amount of energy out of its fuel (it is, however, a far more perfect machine in this respect than most machines devised by man): moreover, not all the energy of the fuel is set free at once as heat, since a certain part is used in doing mechanical work, chemical work, etc. The fuel value of proteids and carbohydrates is in general about the same, while that of fats is about two and one-half times as great.

Since the energy is obtained from the food by burn-

1 See Peabody, "Physiology and Anatomy," Chaps. II and IV. Also the following bulletins of the U. S. Department of Agriculture. "Foods: Nutrition and Cost," "Meats: Composition and Cooking," "Milk as a Food," "Sugar as a Food," "Fish as a Food," "Food and the Principles of Nutrition." Also articles in the Year-Book of the U. S. Dept. of Agriculture for 1894, by Atwater (see also p. 547 ff.); for 1902, by Milner; for 1903, by Snyder and Woods. 
ing or oxidation, and since the carbon is the principal substance burned, producing as the final result carbon dioxide, we may measure the carbon dioxide given off by an organism and calculate the amount of carbon burned and consequently the amount of energy used. Thus it has been found by experiment that burning one gram of carbon sets free about eight large Calories ${ }^{1}$ and produces about two liters of carbon dioxide. Whenever we find that an organism has given off two liters (or about two quarts) of carbon dioxide, we know that it has set free from the carbon of its food materials about eight large Calories. ${ }^{2}$ This energy can be used by the organism in the form of heat, chemical work, mechanical work, etc. If the whole eight large Calories were used in mechanical work they would suffice to raise $(8 \times 426=) 3,408$ kilograms (= about 7,500 pounds) one meter (= about 39 inches or, roughly, 1 yard).

We may look at the matter in another way. When an organism has produced its own weight of carbon dioxide it has set free from the carbon in its food enough energy to raise itself about 600 miles. A man

1 A large Calorie is the amount of heat needed to raise the temperature of one kilogram (about a quart) of water from $0^{\circ}$ to $1^{\circ}$ centigrade. This is roughly the amount needed to raise the temperature of one pound (or one pint) of water through $4^{\circ}$ Fahrenheit.

2 While the amount of energy yielded by burning aram of carbon differs somewhat, depending on whether the carbon at the start is in the form of char. coal, starch, fat or proteid, the difference is not large enough to affect the calculation here given. 
exhales in twenty-four hours carbon dioxide amounting to about 1.2 per cent of his own weight, while some bacteria give off in the same length of time twice their own weight of carbon dioxide. It should be remembered that foods contain other combustible substances besides carbon (e. g., hydrogen), and that the above figures leave out of account the energy liberated by burning these substances. They do not, therefore, indicate the total amount of energy set free, but only the principal part.

By the mothod illustrated in Fig. 31, we can measure approximately the volume of carbon dioxide given off, and from this calculate the amount of energy set free from the carbon of the food in a given time. We may also find the weight of the carbon dioxide (one liter of carbon dioxide weighs about two grams), and so calculate how far the energy set free would raise the organism if applied as mechanical energy. Make these calculations in the experiment described on page 34 (Fig. 31). The experiment may be modified by setting the bottle containing the seeds upright and bending the tube which passes through the stopper so as to make its free end dip into a vessel containing lye.

The giving off of carbon dioxide is accompanied by the absorption of oxygen: this process is called respiration: it occurs in every living cell, since every such cell has need of energy to perform its work. 
In plants each cell probably absorbs its oxygen directly from the air, which penetrates all parts of the plant: in insects a somewhat similar method is found, in that branching tubes convey the air to all the viscera; while in animals the air is conveyed to the lungs, absorbed by the moist membranes of the lung tissue, whereupon the oxygen combines with the red coloring matter (hæmoglobin) of the blood, changing it from dark to bright red. The hæmoglobin is carried to all parts of the body (principally in the arteries), where it gives up its oxygen to the various tissues and is thereby changed back to dark red and returns to the lungs (principally through the veins) for a fresh supply.

While both plants and animals need all three kinds of food, i. e., proteids, fats and carbohydrates (sugars and starch), they requile them in different proportions. In dietetics proteids are spoken of as fleshor muscle-formers, while starch, sugars and fats are said to furnish fuel. This is not by any means true absolutely, but it is probably so in the main. The animal needs much more nitrogen-containing food (proteid) than the plant: the animal excretes large quantities of nitrogen (in the urine and feces), while the plant excretes none. It is interesting, in this connection, to compare the composition of the food container in seeds with that contained in eggs. While the white of a hen's egg, for example, is almost pure 
proteid, the yolk is largely fat and oil. The egg (minus the shell) contains about 14 per cent of proteid and 13 of fat; this is a higher percentage of proteid than most seeds possess, lut Peas, Beans, etc., contain as much as 24 per cent of proteid: in oily seeds, fat may be present to the amount of 60 per cent.

Of especial interest is the composition of Grains; as an example of these we may take Wheat. Moisten some ordinary Wheat flour with water and place it in a muslin bag. Allow a stream of water to run slowly through the bag while the dough is kneaded with the fingers. Collect the milky fluid which runs through the cloth: this contains the starch, which gradually settles to the bottom. When the starch is all removed there remains behind a mass which, from its glutinous consistency, is called gluten: this is the proteid of the Wheat (apply the proteid tests to it). It forms about 10 per cent of the flour, while the starch forms about 75 per cent.

Take some grains of Wheat which have been sufficiently softened in water (a few minutes suffices in hot water) to cut easily, and with a razor cut thin slices across the grain. Place some of these in a drop of water on a glass slide, cover with a cover-glass, and examine with the low power of the microscope. Remove the cover-glass and add a drop of iodine solution. Notice the blue-black color of the internal part 
of the gram and the intense brown or yellowish brown of the peripheral layer. Place another section on a slide, remove all superfluous moisture with blotting paper, and place upon it a drop of a saturated solution of cane-sugar in water. Then add a small drop of chemically pure sulphuric acid (by means of a pipette or medicine-dropper). Add a second drop of acid if necessary; use no cover-glass; be careful that no acid is spilled upon the microscope. Notice the bright red color of the peripheral layer; this indicates the presence of proteid. The outer peripheral layer is much richer in proteid than the rest of the grain: owing to its dark color it is considered undesirable for flour and is separated from the rest of the grain in milling, forming the bran, so that ordinary Wheat flour cousists of the internal part of the grain only. As the bran forms about one-fifth of the grain, this is a wasteful process. Whole Wheat flour contains the bran as well as the inner portion and is not only more nutritious but more easily digester and more healthful in other respects. Find out what you can about the process of milling and the use of flour in bread, etc. ${ }^{1}$

Note the great difference between the seed-leaves of the Horse-bean (Fig. 2) and the Castor-bean (Fig. 4). Can you explain this difference of structure on the

1 See Johnson, "Chemistry of Common Life," Chap. V; Williams, "Chemistry of Cookery," Chap. XII ; Williams and Fisher, "Theory and Practice of Cookery." Also an article by Suyder and Woods in the Year-Book of the U. S. Dept. of Agriculture, for 1903. 
ground of difference in function? The Horse-bean seedleaves are very thick and gorged with food; those of the Castor-bean are extremely thin and contain practically no food: on the contrary, the nutriment (endosperm) is packed around them and it is their task to absorb it. For this purpose they are closely and firmly attached to it and are provided with veins which help to convey the nutriment directly to the germ. As soon as germination begins they enlarge, and so increase their absorptive surface, and they continue to absorb the nutriment long after they have come above ground. When the food has entirely disappeared the husk falls away, leaving the seedleaves free.

The Corn has a seed-leaf (Fig. 6, l) which is both a storehouse and an absorbing organ; it is the small white, shield-shaped portion of the germ which is closely applied to the starchy endosperm (the endosperm is shaded in the figure). If Sugar Corn can be obtained, a drop of iodine will show that the endosperm contains little or no starch, while the seed-leaf is gorged with it. Remove the endosperm from germinating plants of Corn and Castor-bean, and compare their subsequent growth with that of uninjured control plants.

What other familiar seeds have endosperm and absorbent seed-leaves? Notice the curious seed-leaf of the Cocoanut (Fig. 45), which consists of a soft, 


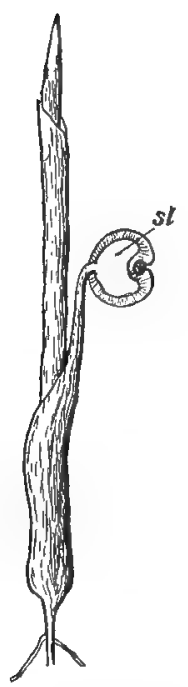

100. Germi. nating Date, showing the large absorhent seed-leaf $(s i)$.

spongy mass, traversed by fibrous veins which convey the food. At first it is very small, but grows rapidly during germination and soon fills the whole cavity. It absorbs the milk and then the meat of the Cocoanut (both of these together make up the endosperm, which is partly solid and partly liquid). Study also the germination of the Date (Fig. 100), which resembles that of the Cocoanut in the formation of a large absorbing organ.

Between the seed-leaves and the next leaves produced by the plant, i. e., the foliage-leaves, there is a great contrast in appearance. Some of the differences between the two, in the Horse-bean, are as follows:

Seed-leaves:

Small

Thick

Pale yellow

Underground

Gradually grow smaller

Fall off after a time

Obseurely veined

No stalk

No stipules (appendages at base of stalk)

Brittle; not fibrous

Opposite
Foliage-leaves :

Large

Thin

Bright green

Above ground

Gradually grow larger

Remain on a long tim $\theta$

Conspicuously veined

Stalked

Stipules present

Tough and fibrous

Alternate 
Can you explain these differences of structure as due to differences in function? What is the function of the foliage-leaves? Remove the foliage-leaves (a) from some young plants which have not yet exhausted the supply of food in their seed-leaves; $(b)$ from. some older plants in which this supply is exhausted and from which the seed-leaves have fallen away; in each case have control plants for comparison. Does the removal of the leaves check the growth? In which of the two cases $(a)$ or $(b)$ is this most apparent? Does the result indicate that the foliage-leaves, like the seed-leaves, nourish the plant?

Do the foliage-leaves, like the seed-leaves, contain food? Remove some foliage-leaves from a healthy, vigorous plant, preferably one which grows out of doors, with a good exposure to sunlight (a Nasturtium is excellent for this purpose). Remove some of the leaves at sundown. Boil them in water as soon as removed and place them in alcohol; let them remain in it until the green coloring matter is extracted. When this is accomplished (twelve to twenty-four hours is ususually sufficient), rinse in water, and place them in watery iodine solution. Do you find starch present? (The other tests mentioned on pages 164 and 165 may also be made; the sugar test should be made on sap expressed from the fresh leaves; the test for oils and fats on leaves dried without being placed in alcohol.) 
Does this starch come from the supply stored up in the seed-leaves, or is it manufactured in the foliage-leaf?

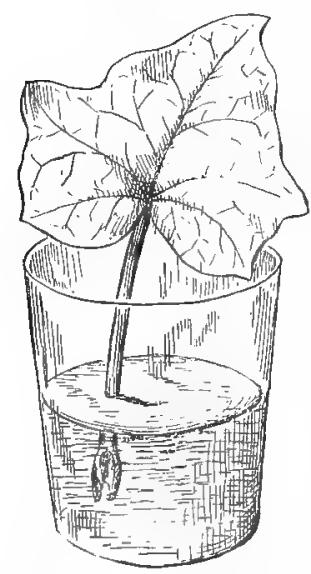

101. T,eaf of English Iry deprived of stareh and plitced in water, to seo if it ean mike stareh when separated from the plant.

Keep a plant in darkness ${ }^{1}$ until the leaves no longer give a starclı test, then cut off several leaves and place them in tumblers of water; place one-half the number in sunlight and the other half in darkness; take care that the stalk (but not the blade) of the leaf dips under the water (Fig. 101). In two or three days test the leaves which have been in the light. Do you find any starch? This sturch must have been made by the leaves after they were removed from the plant. Now test those which have been in darkness. Is the difference due to the ahsence of light? We may put this to a final test in a very simple way. Pin corks to the oplosite sides of a leaf, as shown in Fig. 102, so as to completely exclude light from the covered portion; over another leaf put tin-foil so as to cover both sides, having first cut ont letters or figures from the tin-foil on the upper surface.

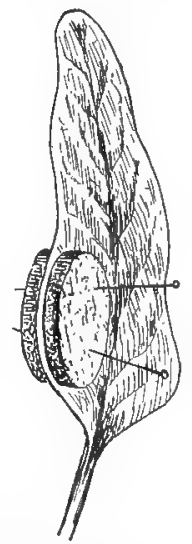

102. A r r n gement for ex. cluding light from a part of the lenf.

I The plant máy be covered with a box or a cone made of pasteboard. 
The cork or tin-foil must not be applied so closely as to prevent the free circulation of air between it and the leaf. The leaves must not be removel from the plant and should be placed where they may obtain abundant sunlight; Nasturtium leaves may be recommended for this experiment. In two or three days test for starch.

Now of what use is the starch in the foliageleaves? Is it absorbed by the plant, like the starch in the seed-leaves? If so, ought we not to find less starch in the leaves in the morning than at sundown (since the starch which is taken away from the leaf during the night cannot be replaced until it is again exposed to light)? Remove some leaves from a plant near sundown and place them in alcohol; early the next morning remove some more leaves from the same plant and test both sets of leaves for starch. We may also make the experiment by cutting out a sample from a leaf at sundown, to be compared with a sample taker from the same leaf the next morning. Has the starch disappeared? Would it have done so har the leaves not been left on the plant? Repeat the experiment, but cut the leaves off and leave them over night in a tumbler of water (the stalks must dip well under the water).

It is now time to see whether we can answer the question, Why are the foliage-leaves and seed-leaves (of the Horse-bean) so different? You can see that it is of advantage to the plant to have the foliage-leaves re- 
main as long as possible on the plant. You can also see why they should have as large a surface as they can, since the more light they catch the more starch they can make. You can see, too, why the seed-leaves

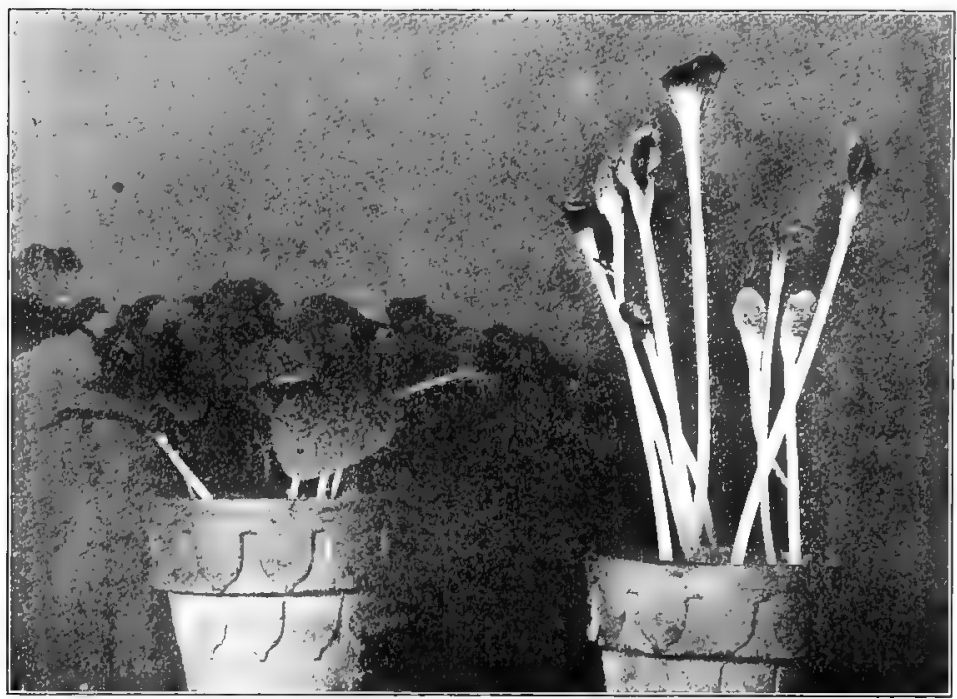

103. Two lots of Squash seedlings of the same age. Those on the left were grown in the light, those on the right in the dark.

need to be thick and bulky, so as to store up a great real of starch. The reasons for the other differences in structure will become apparent as we go on. Perhaps you do not see why the foliage-lures are green and the seed-leaves pale yellow. You will understand this if you put a few seeds into a pot containing soil or sawdust and keep it entirely in the dark until the plants 
are several inches high. The plants grow very tall and slender and the leaves are small and yellow, resembling the seed-leaves in color (Fig. 103). Put the plants in the light for a day or so. Test them for starch. Leave them in the light until they turn green. Then test again for starch. Does the result indicate that the green substance is necessary for making starch ? 1 It is this substance, called leaf-green, or chlorophyll, which is extracted by the alcohol when you test the leaves for starch. Usually it is not formed in darkness. Do you now see why the seed-leaves are not green? Remove some of the earth so as to expose them to the light. Do they turn green?

The seed-leaves and foliage-leaves are different because they have different tasks to perform, and their structure must be adapted to the special kind of work they have to do. We may sum this up by saying, function determines structure.

A good illustration of this is seen in the history of the Castor-bean seed-leaves. At first they are absorbing organs, pure and simple, and their structure is admirably adapted to the work they have in hand. Later, when they come to do the work of foliage-leaves, they grow much larger, thicker, tougher and more fibrous. They spread out above ground in a position to catch the light (Fig. 104), and their internal structure

1 Find out whether leaves variegated with white spots make starch in the colorless portions. 
becomes greatly modified so as to be like that of foliage-leaves. At the same time they acquire a green

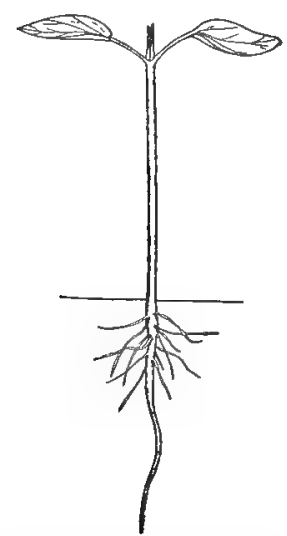

104. A seedling of Castorbean, showing how the seed-leaves assume the form and function of foliage-leaves.

color and begin to manufacture starch.

This principle is so general that we are justified in looking for similar structures wherever similar functions occur.

Of what is starch made? We may get some indication of this by decomposing starch by means of heat in the apparatus shown in Fig. 105. If a test-tube is not obtainable, use any piece of glass tubing (the thinner it is the less liable it is to crack) sealed at one end. Place the starch in it and heat slowly. When the starch begins to turn brown, water will collect on the sides of the tube; this also takes place if we dry the starch to constant weight, at the temperature at which water boils, before beginning the experiment. The water must, therefore, result from the decomposition of the starch. If we conduct the

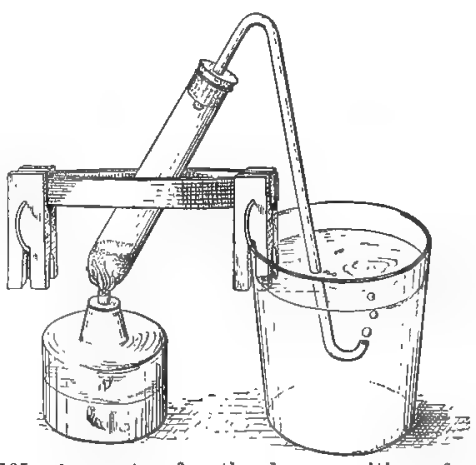

105. A pparatus for the decomposition of starch; the gases pass into a tumbler of lime-water. 
gases over into lime-water, as shown in the figure, it will soon become milky. The starch, therefore, appears to break up into water and carbon dioxide. What other substances may be formed we cannot determine with the means at our disposal, but these may be neglected, since chemical analysis shows that starch may be considered to result from the union of these two substances.

The question now arises, Is there any evidence that the plant makes starch by putting carbon dioxide and water together? We know from previous experiments that there is carbon dioxide in the air, since lime-water exposed to air soon forms a precipitate on the surface. We also know that the leaf is well supplied with water. Is it well supplied with air? The best way to answer this question is to place the leaf in an air-pump, which we may construct as shown in Fig. 106. A disk of rubber (leather or rawhide may be used) is fitted to the inside of a student-lamp chimney (the larger size, No. 1, is preferable), and pushed down to the neck of the chimney. The

106.

Air - pump made from a lamp-china. ney, umbrella wire and rabber stopper. 
chimney is now inverted, the enlarged base is then carefully warmed and melted sealing-wax poured in to the depth of an inch or more. A slightly larger disk of rubber is now prepared by fitting a rubber stopper

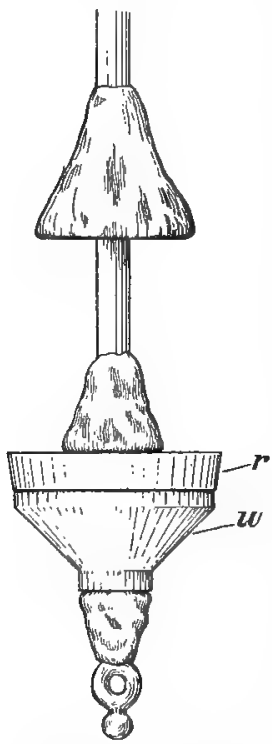

107. Details of piston of air-pump.

into the small end of the chimney and eutting a slice from it just above the chimney's edge (leather may be used if rubber is not available). This rubber disk $(r)$ is to be impaled on an umbrella wire, as shown in Fig. 107 (the larger of its surfaces is to be uppermost), and firmly supported on one side by a wooden disk $(w)$. The end of a spool is excellent for this purpose; it should be trimmed down to such dimensions that it will slip easily into the chimney. Below the wooden disk we place a little sealing-wax to keep it from slipping off; above the rubber disk we also place sealing-wax, as shown in the figure. All the joints must be made air-tight with sealing-wax; this is facilitated by filling the core of the spool with sealing-wax, sharpening the end of the wire, heating it and forcing it through the center of the rubber disk, and then through the core of the spool. We must not be discouraged by a few failures in constructing the apparatus, since, after a little practice, we shall be able 
to make one successfully in a few minutes. When these arrangements are complete, apply vaseline to the edges of the rubber disk and mouth of the chimney. (this precaution is important). Pour some water into the chimney and force the piston slowly down until the water stands half an inch or so above the piston; the rubber bends back as it is forced down, allowing the ail to escape; when the piston is drawn upward the wooden disk prevents it from bending and so keeps the air from entering. Pull the piston back nearly to the top of the chimney and secure it by means of a clothes-pin, as shown in the figure; a lump of sealing-wax fastened to the wire above the clothespin prevents it from slipping back. Any leaks in the piston may now be detected by inverting the chimney; they may be stopped with sealing-wax if they occur in the joints; if the leak occurs around the edge of the rubber disk a larger one must be substituted. On the other hand, the trouble may result from having too large a rubber disk, in which case it will not lie flat and a smaller one must be substituted. In withdrawing the piston from the chimney, it is advisable to draw it out slowly, with a twisting motion.

A somewhat more convenient form of piston may be made by a mechanic, after the plan shown in Fig. 108. It consists of a brass rod (about one-fourth of an inch thick), with a thread at the end carrying two nuts (Fig. 109, n, n), a small washer $(w)$, and a brass 
disk (d) which supports the rubber disk $(r)$. It has the advantage of allowing a quick change of the rubber. Through a small hole about four inches above

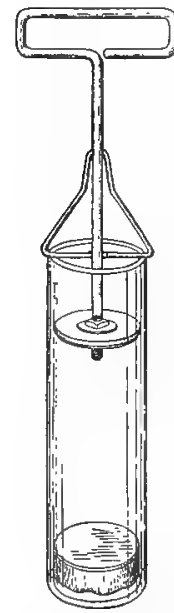

108. Air - pump with auto. matic arrangement to prevent the piston from slipping back.

the rubber passes a stout piece of piano wire (or any steel wire suitable for springs), which is bent as shown in the figure and has its ends passed through another hole about an inch above the rubber. When the piston is drawn up, the wire springs out

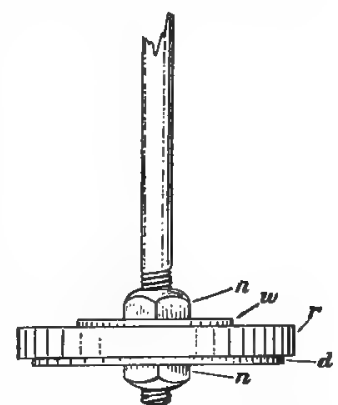

109. Details of piston of the air - pump shown in Fig. 108: $(r)$ rubber disk, $(d)$ metal disk, $(w)$ washer, (n) nut. and prevents it from slipping back.

When the apparatus is ready, place a leaf in the chimney and cover it with water. Force the piston down slowly until the water stands half an inch or so above it, and then pull it up and secure it in place. Does air issue from the leaf? If so, at what points? Notice especially whether more air issues from the upper or from the lower surface. Allow it to remain until all the air is drawn out, making another stroke with the piston if necessary. Notice the appearance of the leaf when injected with water. Explain its close resemblance to a leaf which has been boiled.

If we prevent air from entering the leaf, how will it 
affect starch formation? Keep a plant in the dark until the leaves no longer give a good starch test. Remove the plant to the light and treat several of its leaves by covering both sides of a portion of the leaf with vaseline. Remove some of the untreated leaves from the plant, and place them in tumblers of water so that the stalk of the leaf and about half of the blade dip under water. Place all of the leaves where they will get abundant sunlight. In two or three lays, test all the leaves for starch (removing them from the plant at sundown). Do you find starch in the portions from which air has been excluded?

Does the leaf decompose carbon dioxide? Invert a large bottle or fruit-jar in water, as shown in Fig. 110, and introduce a lighted candle set in a cork. After a short time the candle goes out, indicating that some of the oxygen of the air has heen converted by burning into water and carhon dioxide. Withdraw
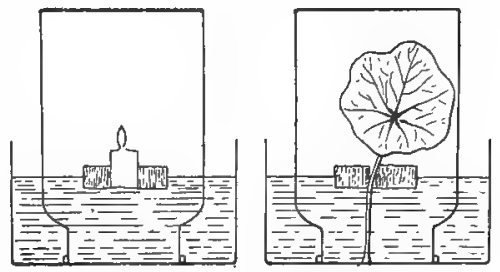

110. Arrangement for investigating the power of a leaf to "restore" air which has been "vitiated" by a burning candle. (Sectional view.)

the candle by means of a string attached to it and introduce a leaf, the stalk of which passes through a hole in the center of a cork, as shown in the figure: do this without lifting the bottle above the surface of the water. The experiment should be commenced in the 
morning and continued until near sundown (the leaf should receive sunshine in the meanwhile: prolong the experiment two days if necessary). We then lift

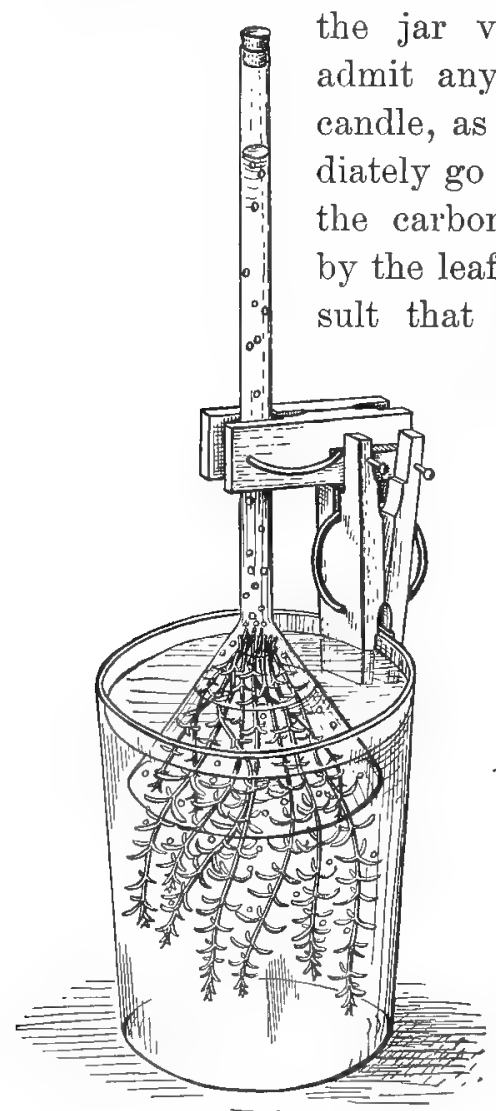

111. Arrangement for collecting the gas given off by a water-plant in sunlight. further combustion is possible. As a control use a bottle with no leaf in it.

Chemical analysis shows that if carbon dioxide and water unite to form starch, oxygen must be given off, just as we have found in this experiment. Another way of testing this matter is shown in Fig. 111. A plant which naturally grows submerged in water is put into water in a glass jar and placed in sunlight. The gas evolved is collected in the funnel, which is first filled with water by submerging it and corking it 
under water. When sufficient gas has collected, the cork is removed from the neck and a glowing splinter is quickly thrust into the neck. If it glows more brightly or bursts into flame, it indicates that the gas in the funnel is richer in oxygen than ordinary air, and, consequently, that the plant is giving off oxygen.

These results, taken in connection with the fact that the formation of starch is prevented by depriving the leaf of air, make it highly probable that the leaf makes starch by causing carbon dioxide and water to unite, accompanied by the giving off of oxygen. It would lend greater certainty, however, if we could deprive the leaf of carbon dioxide without at the same time depriving it of the other constituents of air. We may do this by means

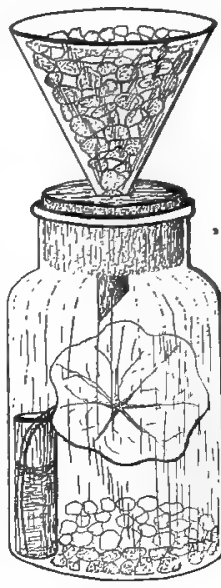

112. Apparatus for growing a leaf in air deprived of car. bon dioxide: lumps of lye are placed in the funnel and on the bottom of the bottle. of the apparatus shown in Fig. 112. A bottle or fruit-jar is fitted with a stopper of cork or wood, through which passes a funnel filled with lumps of lye which will absorb the carbon dioxide from the air as it enters the bottle. On the bottom of the bottle we place some lumps of lye and a small bottle of water in which is a leaf of Nasturtium (or some other leaf which normally gives a good starch test) which has 
been deprived of starch in the way previously described. Place the stopper in position and close all joints airtight with vaseline. Prepare a control in which the lye is replaced by some indifferent substance, such as pebbles or broken glass. After a day or so of exposure to sunlight, test both leaves for starch. Has the leaf which is deprived of carbon dioxide (but not of the other constituents of the air) been able to make starch?

The leaves, by their power of giving off oxygen, "restore" foul air and make it fit for animals to breathe; this is especially noticeable in aquaria where, if a proper balance be struck between animal and vegetable life, the air contained in the water ajoes not need to be renewed. Ordinary air contains about fourhuudredths of one per cent carbon dioxide. It is calculated that a square meter of ordinary leaf surface decomposes every hour in sunlight as much carbon dioxide as is contained in 1,000 liters of air. To offset this, carbon dioxide is continually poured into the air by combustion of all kinds as well as by the respiration of plants and animals. We have learned (pages 34 and 142) that roots and germinating seeds give off carbon dioxide just like animals. Leaves give off oxygen only in the sunlight. Do they give off carbon dioxide at other times, just as roots do? We may easily investigate this by partly filling a bottle or jar with water, putting in as many leaves (with their stalks dipping in 
water) as it will conveniently hold, and then inserting a small vial partly filled with clear lime-water. Set the bottle away for a day or two in darkness. Prepare a control bottle in which no leaves are placed. Both bottles should be sealed air-tight. In which is more carbon dioxide produced, as shown by the lime-water test? As the result of this experiment we may say that in the dark a green plant behaves in regard to respiration like a colorless plant or an animal.

There is a popular belief that plants are unhealthful in sick-rooms at night because they vitiate the air. As a matter of fact, it would take a very large number of plants to do as much harm in this respect as a single candle.

Since the leaves have work to perform during the day, as well as during the night, we should expect to find the process of combustion going on then also, since it is this which furnishes energy to do work; yet we have found that carbon dioxide is used up and oxygen produced by the leaves in daylight. Careful determination of the relative amounts of the gases has shown that both processes take place simultaneously; the sunlight furnishes energy for the work of starchmaking which results in the production of oxygen; the combustion which results in the production of carbon dioxide furnishes energy for work of other kinds.

Since the energy which is absorbed in the making of starch is all given out again when the starch is 
burned, it may be considered to be equal to the heat of combustion (or "fuel value" of starch) which is about 4.5 large Calories for every gram of dry starch. If we estimate that a square meter of leaf surface produces one gram of dry starch erery hour in sunlight, it must in so doing absorb the energy of the sunlight to the extent of about 4.5 large Calories. But this amounts to only about one-half of one per cent of the total energy which falls upon it during that time in the form of sunshine. It should be noted that it is principally the red rays which bring about the chemical changes here considered, just as in the eye they, more than others, bring about the chemical changes which result in the sensation of sight, and for that reason appear much brighter to the eye than the blue rays. The latter, as is well known, are the ones which bring about the chemical changes in a photographic plate.

What is the nature of the openings through which the air passes? With a sharp knife, make a shallow cut and tear off a small piece of the delicate, semi-transparent epidermis from the lower surface of the leaf, ${ }^{1}$ place it on a glass slide in a drop of water and cover with a thin cover-glass. Examine first with the low (one-half inch or two-third inch objective) and then with the high power (one-sixth inch or one-eighth inch objective) under a compound microscope. The epi-

1 The best leaves for this purpose are those of a Lily (or any plant of the Lily family, e. g., Hyacinth, Narcissus, etc.), Iris, a Grass (especially the Oat), Wandering Jew, Anemont, ete. 
dermis is then seen to be made up of a series of cells, all lying in one plane, with their edges closely joined except at certain points where openings exist (Figs. 113 and 114, s). Each opening (called a stoma, plural stomata) is surrounded by crescent-shaped cells called the guard-cells $(g)$. The openings are filled with air, giving them a dark appearance. Compare the number of openings on the upper and the lower surfaces. Does it correspond with what you have already learned by means of the air-purp?

Now let us examine the interior of the leaf. ${ }^{1}$ For this purpose roll a leaf tightly, hold the roll firmly between the thumb and forefinger of the left hand, and with a sharp razor, moistened in water, cut the thinnest possible slices across the leaf; the slices should be so thin as to appear almost or quite colorless. Transfer some of these with a wet camel's-hair brush to a drop of water on a slide, cover and examine as before. The epidermis of the upper surface (Fig. 113, e) appears as a nearly. colorless row of cells. The function of the epidermis is to protect the leaf from drying up, as well as against the attacks of parasites, insect enemies, etc. For this reason its outer wall (cuticle, Fig. 114, c) is thickened and made water-proof (or almost so). Below the epidermis appear long,

1 The leaf of the common Yellow Mustard is chosen here because it is easy to obtain and easily prepared, while showing the parts of the leaf with great distinctness: leaves of Beet, Beech, ete., are excellent: any thin, tender leaf may be used. 


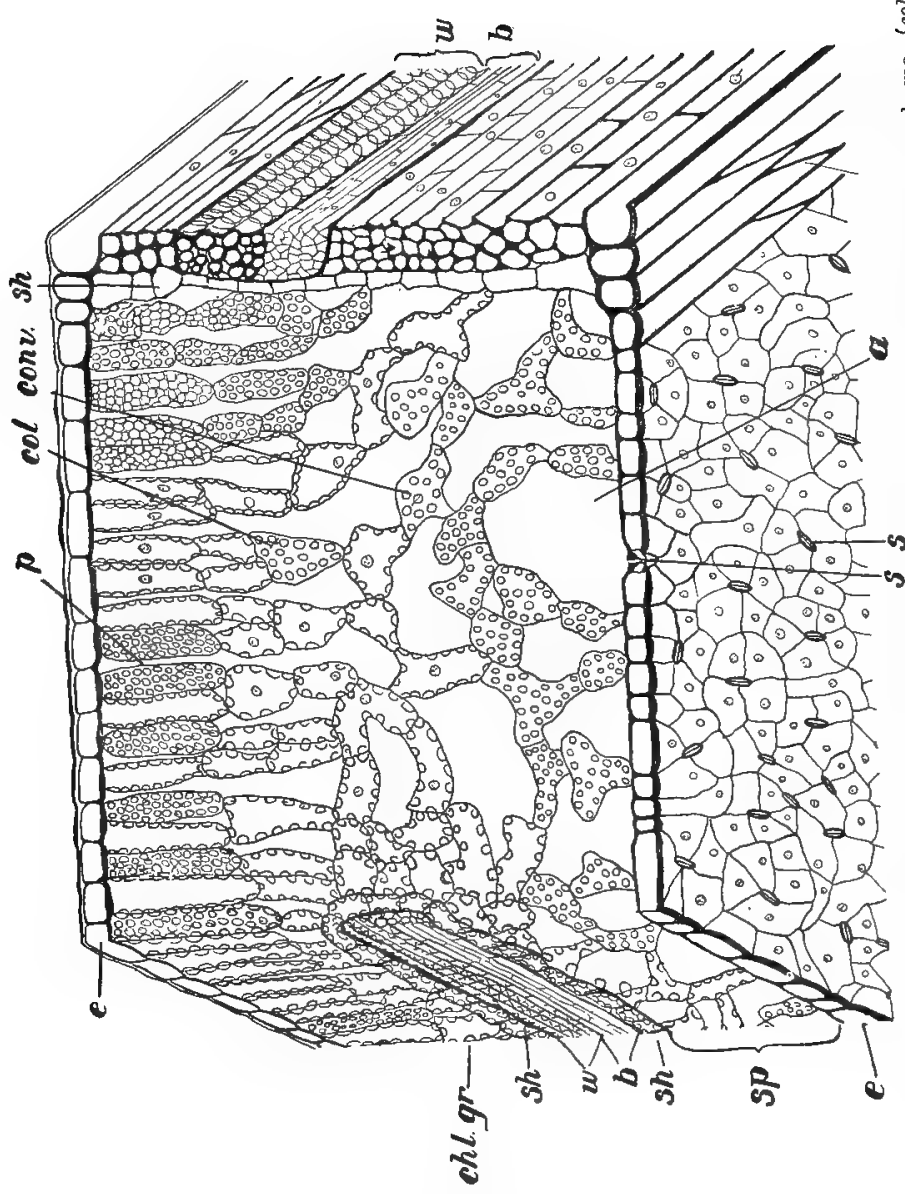

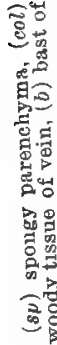

$\stackrel{n}{*}$

घ

뭉

क

웅

可

동 of of 요렬 进 를 히응 - 80 룰영 동 $2 \Phi$. 7 on 5 . 50 D 응 들

न है

हों

릉

$80+$

붕

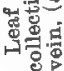
둘 


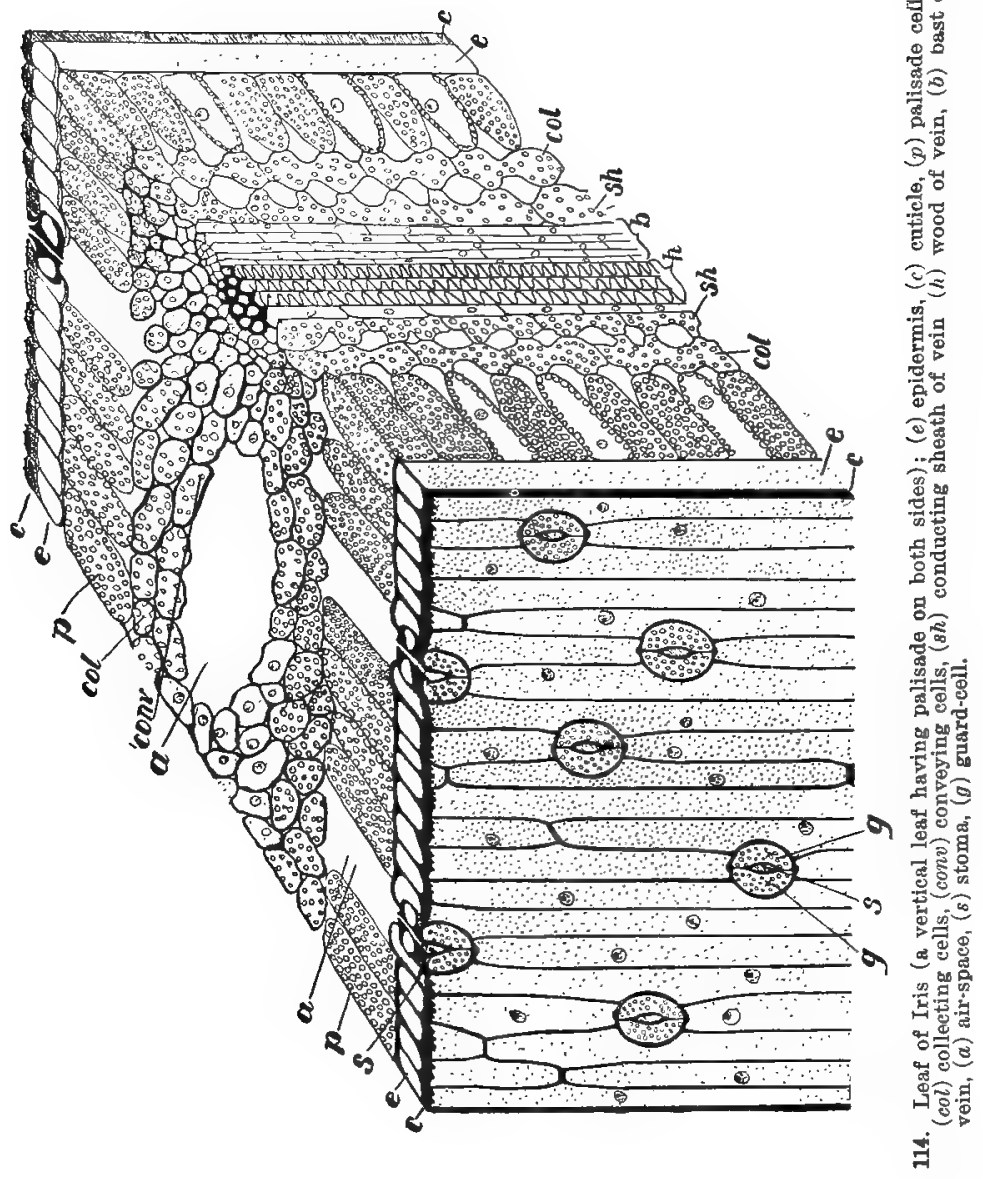


cylindrical cells, like a lot of tubes standing on end, closely packed together. These cells ( $p$, called the palisade cells from their resemblance to a palisade) contain a good deal of leaf-green, or chlorophyll, in the form of drops or granules (these are called chlorophyll granules, chl. gr.) thickly scattered upon the inner surfaces of the walls of the cells. Below these is the spongy tissue $(s p)$, composed of loosely joined cells, with large air-spaces between them. Under the microscope the air-bubbles in these spaces have a dark appearance. Finally comes the lower epidermis, resembling the upper, but provided with abundant stomata, one of which is shown cut across at $(s)$. Notice the opening with the two guard-cells, seen in section, and, just above the opening, a large air-chamber $(a)$ which communicates with the air-spaces of the spongy tissue. The air, therefore, may penetrate through the stomata to the interior of the leaf, where a great absorptive surface (many times greater than the external surface of the leaf) is spread out. As the cells of the leaf are full of liquid, this surface is constantly moist, and therefore in the best condition for absorbing carbon dioxide, just as the moist surfaces of the lung-cells are in condition to absorb oxygen. If these surfaces should become dry they would lose their power of absorbing gases almost entirely.

The leaf is, therefore, an absorbing organ, as well as the root: the one absorbs air-food (carbon dioxide), 
the other soil-food (water and the substances dissolved in it). These two kinds of rau, or crude food meet in the leaf, and there unite to form elaborated food, i. e., sugars, starch, fats, oils, proteids, ete.

The leaf absorbs not only food, but energy, i. e., sunlight, which is needed to manufacture elaborated food. The absorption of light is the work of the green coloring matter, the chlorophyll, and especially of the palisade cells, which are on the upper side of the leaf, directly exposed to the light. If we examine a section of a leaf which exposes both sides equally to the light (such as Iris, Gladiolus, etc.), we find palisade cells on both surfaces (Fig. 114). In many leaves there is but a single row of palisade cells, while in others we find a double row (Fig. 113), which results in the more complete absorption of light. The ability of leaves to absorb light is easily tested by making a tube (about an inch in diameter and twelve inches long) of cartboard, directing it toward the light, placing a leaf over the end and looking through it. Find out how many thicknesses of leaf are necessary to absorb the light completely.

Within the tiny chlorophyll granules, the chlorophyll is scattered in the form of very minute drops (Fig. 115), which arrangement enormously increases the absorptive surface of the chlorophyll, and consequently its

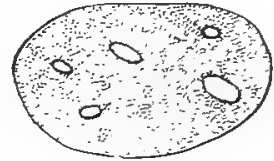

115. A single chlorophyll grain containing rery young starch-grains: it is dotted to indicate the fact that the chlorophyll is distrihuted in the form of very minute drops. 
efficiency. In order to do its work of starch-making, the chlorophyll must absorb rapidly large quantities of carbon dioxide, as well as large amounts of energy. The union of carbon dioxide and water under the influence of the absorbed energy (sunlight) produces grape-sugar, which is stored up in the form of starch, or else diffuses out into the cells and thence to the veins. The transfer to the veins is greatly assisted by. the funnel-shaped collecting cells (col.) and the conveying cells (conv. Figs. 113 and 114).

If we examine (with the high power of the microscope) a section of a leaf which has been removed

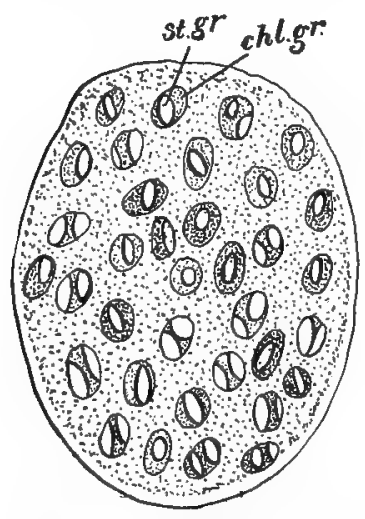

116. A single cell of a leaf with ehlorophyll girains (chl.gr), containing starch-grains (st. gr.) from the plant toward the close of the day, we find the chlorophyll granules full of small white glistening bodies which turn dark when we place the section in iodine solution (Fig. 116). These are the small grains of starch, which have been formed by the union of carbon dioxide and water under the influence of sunlight. During the night they are again changed to sugar, which travels along the veins down into the stem and root. This movement of sugar takes place during the day also, but the sugar is then manufactured faster than it can be 
carried away, and it is consequently stored up as starch.

Every one has noticed that leaves removed from the plant quickly dry up unless placed in water. It would seem that they must lose water rapidly by evaporation. Is this normally the case when they are growing on the plant? Obtain two watch-crystals of about the same size (pieces of mica or glass may be used if the watch crystals are not obtainable), and fasten them to opposite sides of a leaf by a piece of wire bent to form a clip, as shown in Fig. 117. Seal the joints

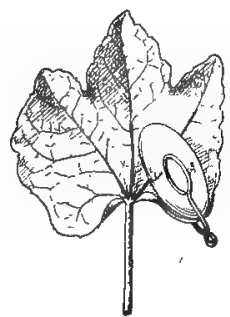

117. Arrangement for determining whether a leaf gives off water vapor. between the leaf and the glass air-tight with vaseline (the leaf should not be removed from the plant and care should be taken not to injure it in any way). If the leaf gives off water-vapor, it will condense in the form of drops inside the watch-crystal, especially when cooled. Examine the leaf from time to time and remove to a cool place if necessary. Do you find that the leaf gives off water? 1 From which side is more given off? Is this the side on which the greater num-

I A more quick and accurate method is to cover the leaf with paper impregnated with cobalt chloride (4 to 5 per cent dissolved in water); this is dried over a lamp until it appears intensely blue. It is then placed on the leaf and covered with miea or glass held in place by a clip, as shown in Fig. 117. If water-vapor is escaping from the leaf the paper quickly assumes a reddish tint. 
ber of stomata occur (as shown by the air-pump or by microscopical examination)?

Does the water escape through the openings only? Select a plant in which there are very few stomata, or none, on the upper surface of the leaf (many species of Begonia, Holly, Willow, Poplar, Lilac, Tulip Tree, Mahonia, Oleander, Scarlet Runner, etc.). After making sure, by testing with the air-pump or by examination with the microscope, that the stomata are absent from the upper surface, remove several leaves from the plant and treat one lot by covering both the stalk and the lower surface of the leaf with vaseline or graftingwax; treat another lot by covering the stalk and the upper surface of the leaf; treat a third lot by covering the stalk and both surfaces of the leaf. Attach to each leaf a stout piece of thread (of about the same weight in each case), and weigh (taking care not to rub off any of the vaseline in the process). Suspend the leaves by the attached pieces of thread, and reweigh from time to time. Does it appear that much more water has escaped from the under surface than from the upper? Has there been any loss from the leaves which were entirely covered? If so, it indicates the amount of experimental error due to the incomplete sealing with vaseline, and this should be diminished as much as possible by. any suitable means. (It must be remembered that unless care is taken some of the vaseline may rub off, or in a sunny place some may 
melt and run off if it is too thickly smeared on ; for this reason grafting-wax is better.)

In examining the epidermis of leaves under the microscope, we find the stomata sometimes open and sometimes closed, as in Fig. 113. Since, as we have already found, all, or nearly all the water passes out through the stomata, we may judge whether they are open or closed by the amount of water the leaf gives off. This may be measured by the methods just described or by means of the apparatus shown in Fig. 119. A leaf is removed from the plant and suipped into a cork borer (just large enough to receive it), which has been previously forced through a rubber stopper, as shown in Fig. 118. On withdrawing the cork

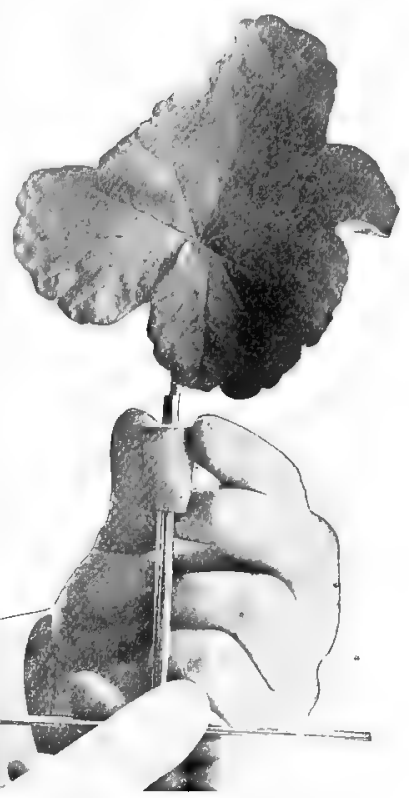

118. Method of inserting a leaf-stalk air-tight in a rubber stopper. borer, the leaf will be found firmly fixed in the rubber stopper. In this way a leaf or a stem may be quickly fixed air-tight in such a stopper without injury. A piece of small glass tubing, about fourteen inches long (the smaller the bore the better), bent as shown 
in Fig. 119, is now forced through an opening in the stopper and the stopper is slowly forced into the neck of the bottle, which is filled to the brim with water. Enough water will usually run into the tube during this operation to fill it completely; should this not happen, fill the tube with water before forcing the stopper into the bottle and keep the water from running out

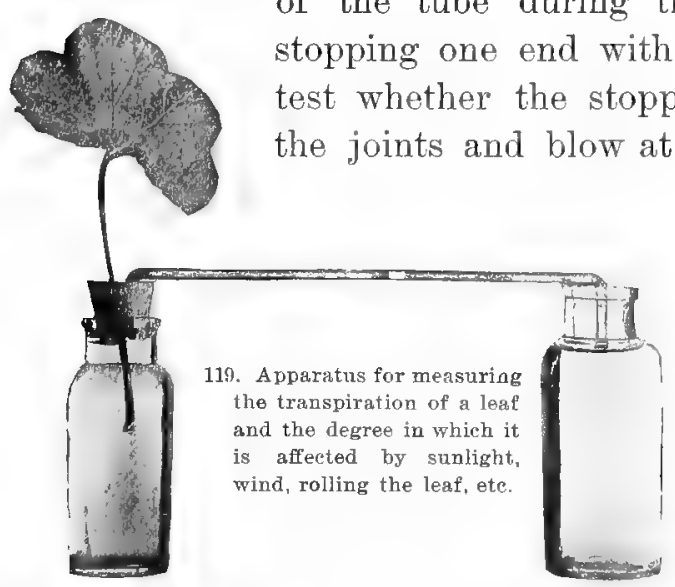
of the tube during the insertion by stopping one end with the finger. To test whether the stopper is tight, dry the joints and blow at the free end of the tube to see whether water can be forced out. If the joints are tight, set the apparatus in a cool, shady place, and let it stand until a little of the water has been absorbed by the leaf and a small bubble of air (one-fourth to one-half an inch long) has been drawn into the end of the tube. When this has occurred, dip the end of the tube into water, as shown in the figure, attach a ruler to the glass tube and, by means of a watch, time the progress of the bubble along the tube (which should rest in a horizontal position). When the bub- 
ble has passed into the bottle, admit another by raising the end of the tube above the water for a short time. When the rate of water absorption and evaporation (usually called transpiration) becomes fairly constant, transfer the apparatus to the sunlight and take observations (make the experiment also with a leafy branch).

If an increase in the rate of transpiration occurs in the sunlight, it may be attributed either to the opening of the stomata or to the increase in transpiration (through the already open, or partly open, stomata) due to rise in temperature. In most cases both causes coöperate to increase the amount of transpiration. We can see why it is of advantage to the plant to have the stomata open in sunlight, since it is then that starch-making goes on, and if the openings of the leaf were closed the absorption of carbon dioxide would be impossible. We can also see why the more rapid evaporation of water which occurs when the stomata are open may be an advantage, since it leaves behind in the leaf mineral substances (just as boiling water in a tea-kettle leaves behind a crust of lime and other mineral substances which are dissolved in the water) which, as we have already learned, are of value to the plant.

The stomata usually close when the supply of water begins to run low, and we can readily see why this is advantageous, since otherwise the leaf would soon wilt, and may even do so in spite of the closing 
of the stomata, as we may observe on very hot days, and especially in hot dry winds. Place the apparatus

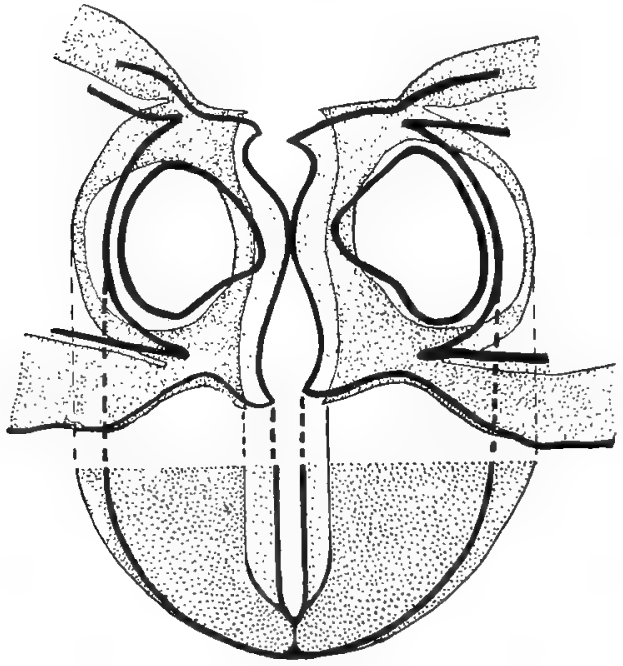

120. Diagram showing in section and surface view the form and position of the guard-cells when closed (heavy lines) and open (light lines). out of doors in the wind (the hotter and drier the wind the better), and observe the effect on the rate of evaporation.

On the other hand, the stomata open as soon as favorable conditions for starch-making (i. e., the requisite supply of water, sunlight and warmith) return.

The plant has in the stomata and guard-cells an automatic apparatus of great efficiency, yet wonderfully simple, on whose proper working its very life depends. If we examine a stoma carefully, we see the two sausage-shaped guard-cells filled with green chlorophyll granules, while the surrounding epidermal cells have none. It is on this that their opening and closing depends. Under conditions favorable for starch-making, the guard-cells produce sugar, which 
draws water from the neighboring cells and causes the guard-cells to expand and open the stomata. When, on the other hand, unfavorable conditions come, the sugar-making ceases, and if the water supply begins to run low the guard-cells collapse and close the stomata.

The manner in which the opening and closing is effected may be explained by reference to Fig. 120, which shows a stoma of Iris in both the closed and the open position. The guard-cell (as seen in crosssection, Fig. 121) has a thick wall on the side toward the stoma and a thin wall on the opposite side. According to mechanical laws, when such a structure expands from internal pressure (due to the absorption of water) the thinnest or weakest side must bulge outward, causing the cell to curve (as shown by the light lines in Fig. 120). When the guard-cells expand,

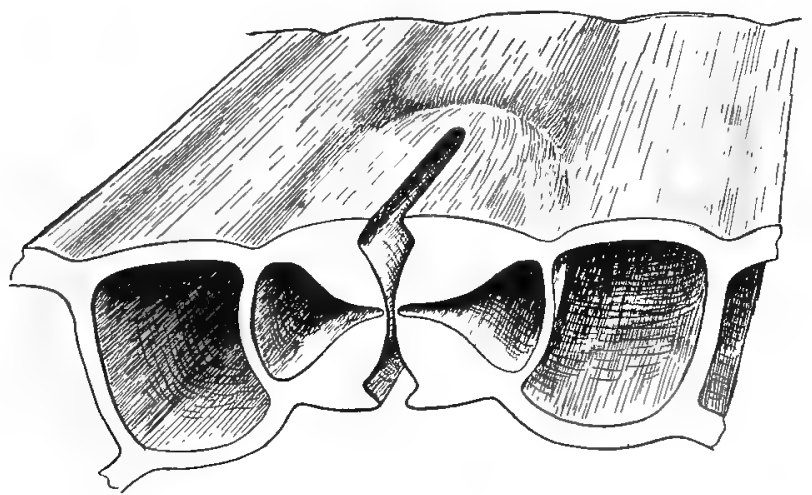

121. Diagram of a stoma of Iris (seen in section) showing guard-cells and neighboring cells of epidermis. 
7 therefore, they curve away from each other, leaving the stoma open; when they collapse again, it closes. Various modifications of this mode of action occur. The general relations of the guard-cells and surrounding cells may be seen in Fig. 121.

If we tear off a strip of epidermis from a leaf of a Lily or Amaryllis and mount it on a slide in water, we shall (if the plant is well supplied with water and exposed to sunlight) probably find the stomata open : if now, we lift the cover-glass and introduce a drop or two of sugar or salt solution, the water will be withdrawn from the guard-cells and they will at once collapse and close the stomata.

The principle by which the stomata open and close may be illustrated by means of the model shown in Fig. 122. A piece of quarter-inch, thin-walled, black rubber tubing, which is not.so old as to have lost its elasticity, is reinforced throughout its entire length, with the exception of half an inch in the middle, by a strip of elastic band (about one-eighth inch wide) firmly attached with rubber cement. It is then bent in the middle, as shown in the figure, so as to bring the reinforced walls facing 
each other, and is secured at the bend by a clothes-pin. The free ends are connected to the arms of a glass U-tube which have been bent near together. The end of the U-tube is connected by a stout piece of rubber tubing with a bicycle pump. The connections are all tightly tied with twine or elastic bands, and air is pumped in. As the pressure increases, the outer, thinner walls of the rubber guard-cells bulge outward, causing them to curve and leave the stoma or space between them open; when the pressure is released they collapse and close it. The degree of opening or closing is great or small according to the elasticity of the rubber, the rigidity of the reinforced wall, etc.

If a $\mathrm{U}$-tube is not at hand, use in place of it two short glass tubes inserted in a rubber stopper (enlarged a little at the end to prevent them from slipping out), as shown in Fig. 123; the cork is inserted in a piece of glass tubing, at the other end of which is a similar cork pierced with a glass tube which is connected with the pump. A wire may be passed over both stoppers to hold them firmly in place.

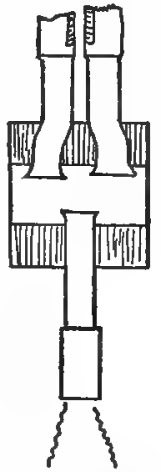

123. Modifieation of part of the appara. tus shown in Fig. 122.

The danger of drying up is the most serious with which the plant has to contend, and nothing affects the health of a plant so quickly as lack of water.

Plants suffering from dryness show very character- 
istic symptoms i.e., wilting, drooping and yellowing of the leaves, followed in time by the fall of the leaves, beginning usually with the oldest. In regard to the cause of the falling of leaves in autumn, see page 332 . It is interesting to note that when the leaves fall away they leave a smooth scar; this is due to the formation of a layer of loose cells just at the base of the stalk (as may be easily seen in a section under the microscope). If leaves of the Kentucky Coffee Tree, Tree of Heaven (Ailanthus), Walnut or Ash are wrapped in a moist cloth and placed in the dark, this layer forms very rapidly (in the Coffee Tree within forty-eight hours), with the result that the leaflets fall off, leaving a clean scar. Is such a scar formed in most monocotyledonous plants, such as Corn, Grasses, Lily, etc.?

Plants which are suffering from drought should be watered, set in a cool, moist place and sprinkled with water. If the plant has suffered severely it may be necessary to remove some of the older leaves. Cutflowers which have wilted may be placed in water and covered with a wet towel, when they will quickly revive.

Leaves have various devices to protect themselves against the wilting due to heat and dryness. (What leaves remain fresh longest when removed from the plant for purposes of decoration? Why?) Some of these are obvious, and we may test them by means of the apparatus shown in Fig. 119. Roll the 
leaf or fold it two or three times, after the fashion of a fan, and secure it by a rubber band. How does this affect the rate of transpiration? Do you find devices of this kind among plants? Many Grasses (e.g., Corn) roll up their leaves in the heat of the day or fold the stomatic surfaces together so as to diminish transpiration. Young leaves are far more easily injured by drying agencies than old; they are nearly always rolled or folded (as they issue from the bud) in a manner that greatly reduces evaporation, and it will be noted that if one surface is more exposed than another it is the stomatic surface which is protected. Make observations on this point: study especially the Tulip Tree, Canna, fruit trees, Maple, Ferns, etc. (see Gray's Lessons, under vernation or æstivation). Many leaves are permanently rolled (Heath plants, etc.).

Again, we may cover the leaf in our apparatus with cotton wool, pressed down tightly against the leaf by means of wire netting laid over it and held in place by clothes-pins. We may cover both sides of the leaf or the stomatic surface only, and may note the rate of evaporation in both sunlight and shade. Do you find coverings analogous to this on leaves? Study the leaves of the Dusty Miller, Horehound, Sage, Wormwood, Mullein, Cinquefoil, etc. Many leaves have a hairy covering during their youthful, sensitive period, but lose it as they grow older (Horse-chestnut, Beech, Service-berry, White Poplar, Pear, etc.). 
We have already learned how a coat of vaseline stops evaporation from the leaf. Do you find leaves coated with water-proof substances, such as resins, gums, varnishes, wax, etc.? Notice especially the varnishes, gums, etc., on buds, which prevent them from drying up. Remove the scales, which are covered with varnish, and note the result. Many leaves have a coat of varnish during their youthful period but dispense with it as they grow older and less sensitive, and the epidermis thickens (Cherry, Poplar, Birch, Alder, Peach, etc.).

Take two leaves of the same size which are thickly coated with wax (the young horizontal leaves of Eucalyptus are especially good); remove the wax fron one by rubbing with a soft cloth; seal the cut surfaces with vaseline, place a leaf in each pan of the balance, and balance them by adding weights to the proper pan. Observe from time to time which is losing water more rapidly, as indicated by the rising of the pan.

It will be noticed that leaves (Iris, Bamboo, Dusty Miller, Oxalis, Silver-leaved Poplar, Blackberry, etc.) which have a covering of hairs, wax, etc., have a glistening silvery appearance under water; this is due to a layer of air which is held tenaciously. On dipping such leaves in water we find that the stomatic surface is so protected that it does not become wet; this is an advantage, since, if water penetrated into the stomata, it would completely prevent the passage of air and the 
absorption of carbon dioxide. One of the great dangers to plants in the neighborhood of factories, etc., is the choking of the stomata with soot and dust. Wherever there is much fine dust, plants suffer in this respect unless frequently washed by rain. ${ }^{1}$ Houseplants are much benefitted by an occasional washing of the leaves with water.

We can readily understand that it is an advantage to have the stomata placed on the under side of the leaf, since they are then better protected against dust, rain, direct exposure to the sun, etc., and this is the position in which they principally occur.

Other devices for reducing evaporation that may be studier are the sinking of the stomata in pits (Oleander) or channels (Cytisus, Broom, etc.), the reduction in the number of the stomata (universal in plants growing in dry situations), the reduction of leaf surface (in succulents, such as Hen-and-chickens, Liveforever, Ice Plant, etc.), dispensing with the leaves during a portion of the year (some Switch Plants), or complete and permanent loss of leaves (Cacti). Obtain any leaves you can of these kinds, and test the amount of evaporation which goes on in them. For this purpose

1 Plants are sometimes injured when sprayed with oily liquids (to destroy insect pests), by the clogging of the stomata with oil. The result is that the leaves turn yellow and begin to drop off soon after the spraying occurs.

The fumigation of plants with poisonous gases (to destroy insects) must be earried on at night when the stomata are closed. Otherwise the plant is killed. 
remove the leaf, weigh, seal the cut surface with raseline or grafting wax and reweigh; expose the various leaves simultaneously to the same conditions for the same length of time (five or six hours in sunshine), and weigh again; divide the loss in weight (i. e., the difference between the results of the second and third weighings) by the original weight (results of the first weighing) to get the percentage of loss. Compare the percentages for the different leaves (e. g., a leaf of Squash with that of Hen-and-chickens).

Plants which have adapted themselves to dry situations have, as we have seen, a surprising ability to retain water. In all of the thick-leaved, fleshy plants, the so-called succulents, sufficient water is stored up in reservoirs (consisting of spongy colorless tissue) in the interior of the leaf to last from one season of rain to another, often for a period of months. Such is the case with the Hen-and-chickens, Live-forever, Ice Plant, etc. In many of these, gummy, mucilaginous substances or hygroscopic salts are present which hold the water tenaciously. Try the experiment of exposing on a piece of glass drops of pure water, together with drops of fluid expressed from such leaves or drops of a strong solution of salt, sugar or gum arabic. Which is the first to completely evaporate?

Along with modifications in structure go (hanges of position (e. g., from horizontal to vertical) which diminish evaporation. Notice the vertically placed leaves 
of Iris, Gladiolus, Eucalyptus, Acacia, etc. Observe the behavior of Grasses in this respect. Many young leaves remain vertical until their epidermis becomes thick enough to prevent evaporation, when they change to the horizontal position. Note as many cases of this as you can. Many adult leaves change their horizontal position to the vertical one in the middle of hot summer days, when the light and heat are too intense. Study the familiar plants about you and find as many cases of this sort as you can.

We have already learned (page 124) that plants may have their roots submerged in water and yet suffer from lack of it. This is because there are substances in the water which attract it away from the plant. Try the experiment of placing leaves (or whole plants) with their stalks dipping in strong salt solution. Plants in alkali lands and along the seashore, as well as in peat bogs, etr., suffer in this respect and consequently show the same devices to diminish evaporation as we find in plants of desert or semi-arid regions.

While it is an advantage to have the leaf placed vertically when the sun's rays pour' straight down, making the light and heat excessive, it will, under ordinary circumstances, be far better to have the leaf placed at right angles to the light, since in this position the leaf can absorb the maximum amount. The same leaves which in the excessive heat of midday 
place themselves vertically (i. e., parallel to the light) will be found in the morning and afternoon with their faces perpendicular to the light; in this way they fol-

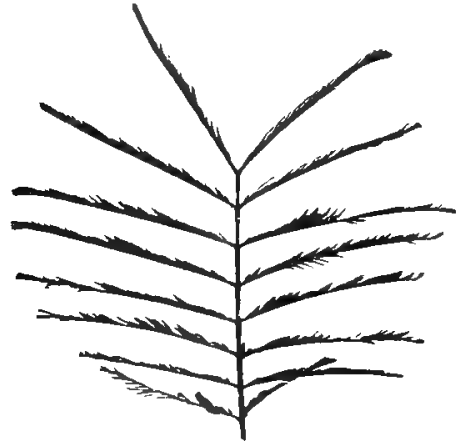
low the sun all day, facing eastward in the morning and westward in the afternoon (plants of the Pea family, some Mallows, etc.). What common plants do this? Study Clovers, Lupins, Melilotus, etc. Notice the cushion-like joints, or hinges, on which the leaves 124. Acacia leaf, night or sleep position. turn.

Study the "sleep-position" of leaves at night in Oxalis, Clover, Acacia (Figs. 124 and 125), also in seed-leaves of Sunflower, Squash, etc. This position may be of advantage in reducing evaporation or in diminishing the loss of heat, or both. It may in many cases be prođuced artificially by putting the plants in darkness for a time during the day (Oxalis, Acacia, Clover, etc).
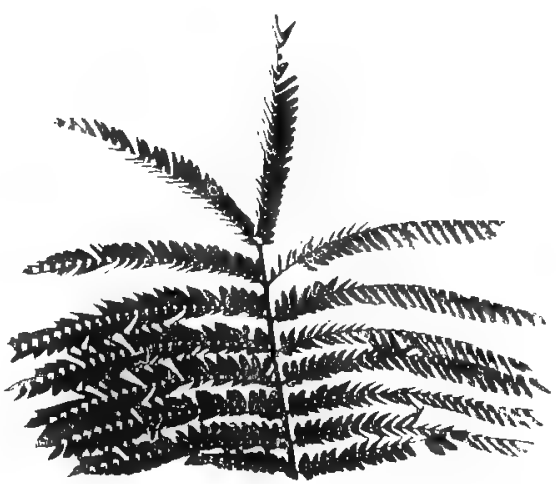

125. Acarcia leaf, day posttion. 
The ability to turn toward the light must be extremely useful. Do all leaves have this power? Experiment with as many plants as you can, placing them before a window, or shading

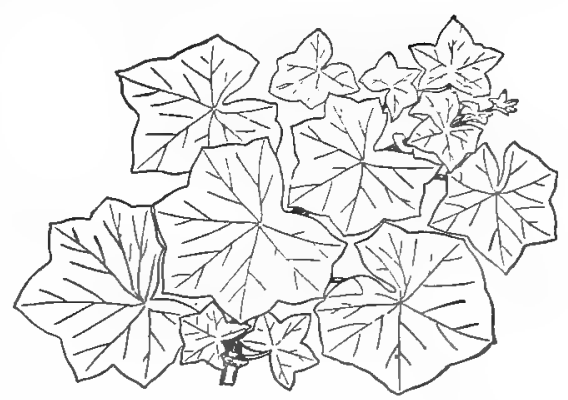

126. Leaf mosaic of Ivy Geranium. them on one side as they grow out-of-doors. Notice any cases where the plants grow near walls or are for any reason shaded on one side. Study especially climb-

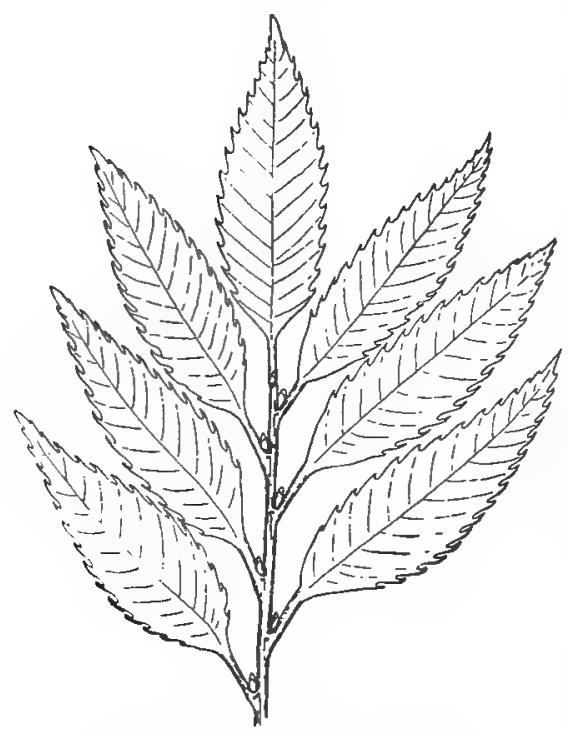

127. Leaf-mosaic of Chestnut. ing vines, like the English Ivy, Boston Ivy, etc. Do the leaves in these plants seem to avoid shading each other? How do you explain this? When leaves cover over the available space so as to catch all of the light without interfering with each other, their appearance suggests a mosaic (Figs. 126 and 127), and is called a leaf-mosaic. 


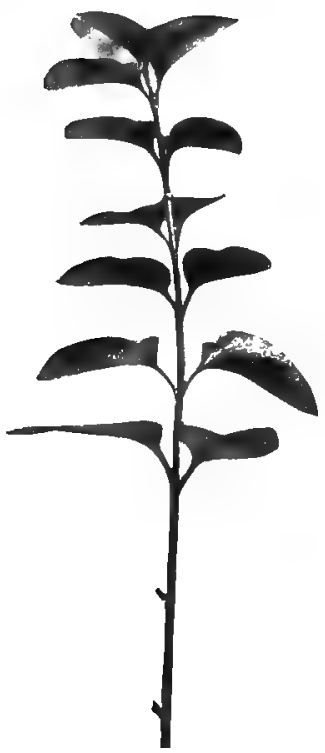

128. Upright branch of Periwinkle (Vinca).

What are the most perfect leafmosaics you can find?

Notice the difference between the arrangement of leaves on horizontal and vertical shoots of the same plants (see Figs. 128, 129 and 130). Which arrangement requires the greatest bending and twisting of the leaves out of their original position?

In what part of the leaf is the mechanism located by which these bending and twisting movements are accomplished? Study especially in this respect the leaves of the Scarlet Runner or other bean, and examine the cushionlike swelling at the base of the stalk of each leaf and leaflet.

Inasmuch as a tree forms its branches and leaves with reference to the light, prevailing winds, ete., it follows that when it is transplanted its orientation should not be changed, i. e., the same side should be toward the nortl both before and after planting.

Study both trees and shrubs (the smaller plants as well), to discover

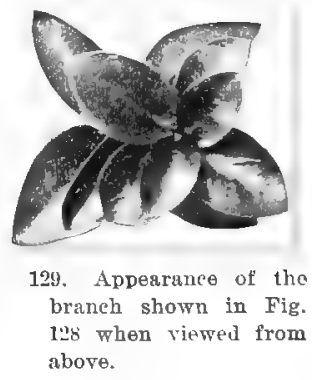


on which side their greatest development occurs and how this is affected by light.

The leaf, more than any other part of the plant, needs protection against animals, insects and parasites. Devices for this purpose are found in great variety. Make a practical study of the following forms of protection.

(a) Prickles, spines, thorns, hairs, etc. These protective weapons are borne hy both leaf and stem, and may be outgrowths from the surface (prickles of Rose and Thistle, stinging hairs of Nettle, which break off in

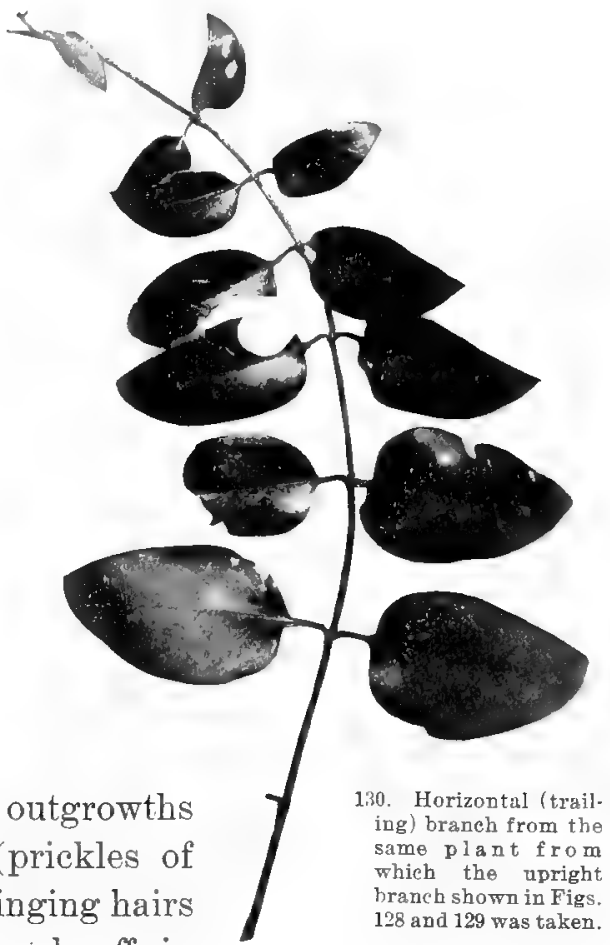
the wound and discharge an irritating poison into it, hairs of Mullein, which are irritating to the mouth, etc.), or the spiny tip of the leaf (Thistle, Spanish Bayonet, etc.), or the teeth of the edge of the leaf 
(Sedges, Grasses, Holly, Century Plant), or the stipules of the leaf modified into thorns (Locust), or the whole transformed leaf (Barberry), or a transformed branch (Hawthorn, Honey Locust).

(b) Bitter or poisonous substances. It would be very interesting to know how animals, both wild and domestic, learn to avoid poisonous plants. Many plants have a disagreeable or offensive odor which warns them away, as the Jimson Weed or Thorn Apple, and many others. Many have a disagreeable taste, e. g., Poppies.

But there are many others which to us have neither disagreeable taste nor odor, and yet are avoided by grazing animals of all kinds. In this respect their instincts are superior to ours. There are some poisonous plants, notably the "loco weeds," which are eaten by domestic animals and which produce dizziness, vertigo and insanity. It is stated on good authority that the loco habit may be taught by a single animal to a whole herd, and that an animal which has been apparently cured of the habit by treatment is never entirely trustworthy thereafter. ${ }^{1}$

In general, however, poisonous plants are avoided, and the same is true of many plants which are bitter or disagreeable without being poisonous (e.g., Worm-

1 The annual loss from poisonous plants on the western stock ranges is about $\$ 400,000$. See the article by Chestnut, in the Year Book of the U. S, Departmenl of Agriculture for 1900. 
wood, Ragweed, Boneset, etc.). There can, therefore, be no doubt of the efficiency of this kind of protection. (c) Woody, leathery texture, as in Rushes (or flinty, as in Horse-tails), is a means of protecting many plants, a fact which is familiar to all.

(d) Hugging the ground is a very successful device employed by plants, such as Knot-grass, Cinquefoil, Purslane ("Pusley"), Wild Strawberry, ete. 


\section{CHAPTER V}

\section{THE WORK OF STEMS}

THE work of the stem and the work of the leaf are closely connected. We have learned that the leaf needs a constant supply of water; this is absorbed by the root, but in order to reach the leaves it must be conveyed upward through the stem. Where does the water travel in the stem? Cut off a leafy branch (preferably of Squash, Sunflower or (Geranium), and place the cut end in water in which enough eosin has been dissolved to give it a bright red color. Place it where the conditions are favorable for evaporation, and

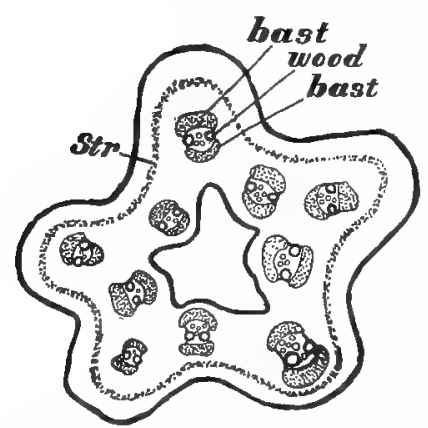

131. Diagram of cross-section of Squash stem: (str) strengthening fibers. in an hour or so cut off the stem two or three inches from the lower end; if the liquid has risen in the stem trace it upward by means of successive cuts. Make a diagram showing the portion of the stem in which the colored liquid rises. If a Squash stem be used, the appearance when cut across resembles 
Fig. 131 in the essential points. In each of the angies of the stem is a large, fibrous bundle or strand; alternating with these are tive bundles toward the center of the stem. The central portion of each bundle (the wood) is colored red by the fluid; on each side of the wood is a mass of softer tissue somewhat translucent (the soft bast), from the cut surfaces of which issue mucilaginous drops.

Allow the branch to stand in the solution until the leaves become colored red, and then cut the stems lengthwise and trace the course of the bundles up through it and out into the leaves. Hold the leaf up to the light and notice the branching of the bundles, or veins. Use a lens to follow the finer branches. Place a very young leaf, not over a quarter of an inch long, on a glass slide in a drop of alcohol to

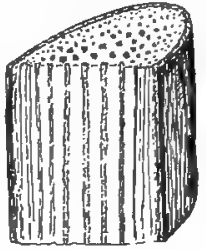

132. Corn stalk showing arrangement of fibrous bundles. which lye has been added, and allow it to bleach; rinse with water, mount on a slide in water, examine with the microscope and try to find the ends of the veins. Trace the bundles down into the root. Pull up some vigorous plants by the roots, cut off the ends of the roots, place the plants in eosin solution, and follow the path of the solution into the root and up into the stem. Make a diagram of the path of the solution in the root (see Fig. 90). Examine the Corn (Fig. 132), tracing the bundles up through the stem and out into the 
leaves. Bundles which group themselves into a circle in the stem and form a branching network in the leaves, as in the Squash, are characteristic of a great group of plants, the Dicotyledons (plants with two seed-leaves); a scattered arrangement of bundles in the stem, together with a parallel course in the leaves, as seen in the Corn, is characteristic of the great group of Monocotyledons (plants with one seed-leaf).

Place a small leafy branch of Oak, Hickory or some other hard wood in the solution, and follow the path of the liquid to the very extremity of the growing tip. At the very tip the wood is in separate bundles, as in the Squash, but as we follow it down toward the older part of the stem the separate bundles very soon coalesce to form a continuous ring of wood (and also of bast).

Take one of the Squash vines which has stood in the solution for some time, eut it square across, and from the cut surface take (with a sharp razor) sections (thin enough to be translucent but still fairly thick), and place them (without water or cover-glass) on a slide, and examine with the low power of the microscope. The fibrous bundles show the wood (i. e., the central portion of each bundle) colored red, with the uncolored bast lying on either side of it. Turning our attention to the wood, we see in it two large openings, the ducts (see Fig. 133). In tracing the colored fluid 


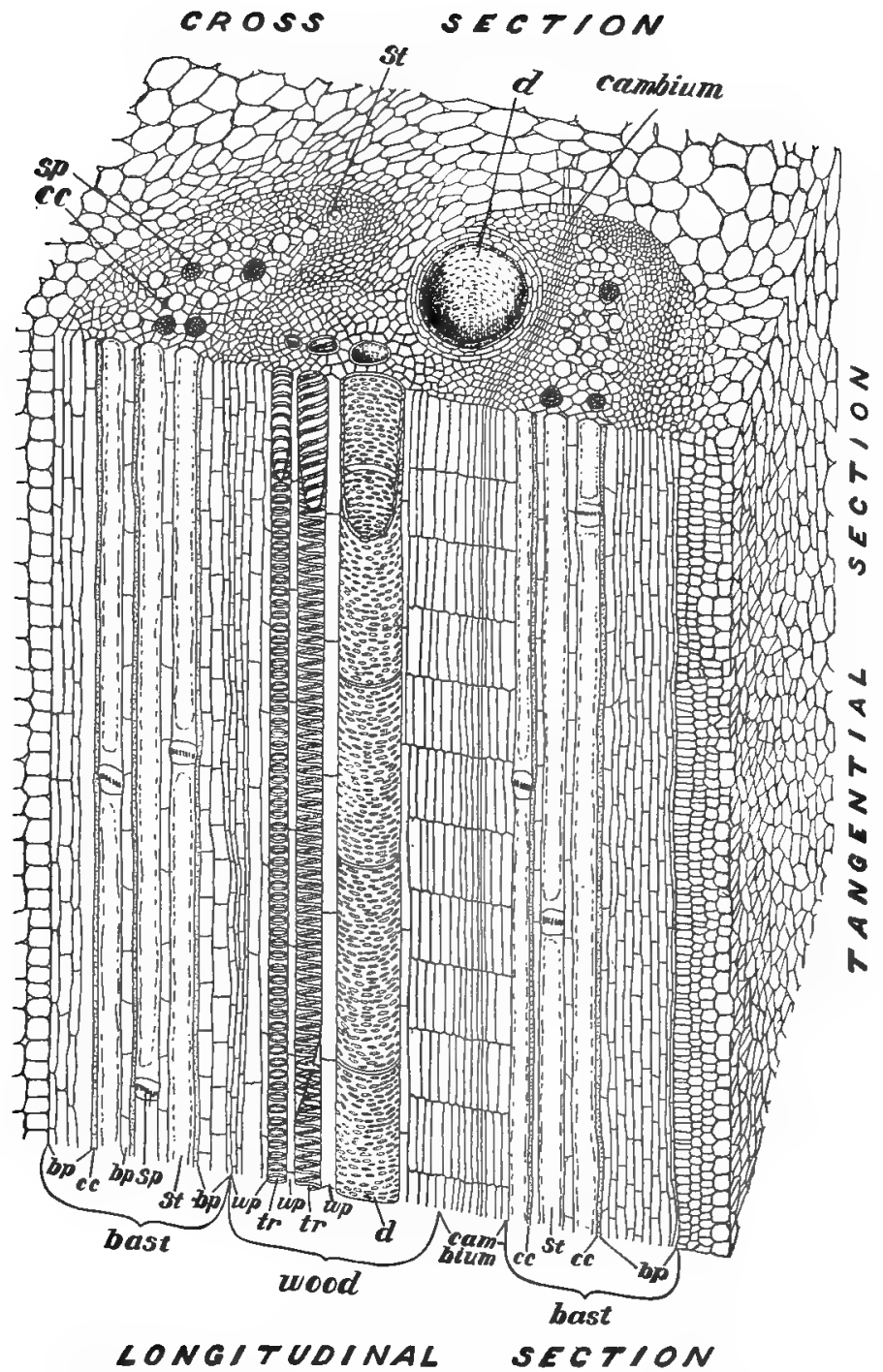

133. Stem of Squash: (d) duct, ( $(o p)$ wood parenchyma, (tr) tracheïd, (st) sieve-trbe, $(s p)$ sieve-plate, $(c c)$ eompanion cell, $(b p)$ bast parenchyma. 
up the stem, we notice that it travels much faster in these ducts than in the other parts of the wood. Between the ducts is a mass of smaller cells, which also become colored by the liquid after a time and which appear therefore to assist in conveying water.

Having made out these points, we may take from the cut surface of the stem, by means of a razor moistened in water, the thinnest possible slices (when thin enough they are almost colorless and will sink in water ; in this way they may be separated from the thicker ones). Transfer them (by means of a camel'shair brush dipped in water or the point of a knife) to a glass slide, and cover with a cover-glass. Examine first with the low and then with the high power of the compound microscope.

Let us now cut the stem lengthwise in such a way as to divide a bundle lengthwise into two halves in a plane passing through the center of the stem. From one of the cut surfaces take sections (thin enough to be translucent), place them (without water or coverglass) on a slide, and examine with the low power. We now see that the bundle consists of a mass of elongated tubes packed closely together, the central portion of which, the wood, is conspicuous by the red coloration due to the eosin; the ducts are very conspicuous by reason of their large size.

Let us now cut much thinner sections from a cut surface prepared in the same way, mount them in 
water under a cover-glass and examine with the high power. We see that both the ducts (d, Fig. 133) and some of the smaller cells of the wood are covered with regular markings, round or elliptical in shape; these are thin places in the walls called pits ( $p$, Fig. 138) through which water may pass readily from one cell to another. The smaller cells of the wood are of two kinds; short cells with blunt ends (called wood parenchyma, wp), and longer cells with pointed ends (called tracheids, $t r$ ) ; these latter have thin walls with spiral or annular (i.e., ring-shaped) thickenings. The spiral and annular thickenings of the cell-wall are exceedingly useful to prevent the cells from being crushed by the pressure of the surrounding cells and so rendered useless for the conveyance of water. As we follow the bundles up into the tip of the stem, we notice that the spiral and annular tracheids are the first elements of the wood to be formed, and that their structure allows them to stretch so as to keep pace with the growth in the length of the stem, since they are formed in the growing region of the stem near the tip. The thick-walled elements of the wood can stretch little or not at all, and they acquire their thick walls (and characteristic structure) in the region just below the growing portion of the stem where elongation has practically ceased (see page 249).

Can you explain why the water rises so much more rapidly in the ducts than in the other cells? Not only 
are they larger, but the water meets with no obstructions in passing through them, while in the smaller cells there are cross-walls at frequent intervals through which it must pass. Such cross-walls occur also in the ducts at an early stage of their development, but they are soon broken down and absorbed, and we find only remnants of them in the form of rings here and there on the walls of the ducts (as shown in Fig. 133).

On comparing a fibrous bundle of the Corn (Fig. 134) with that of the Squash, we find also two large ducts $(d, d)$, together with (usually) an annular tracheid $(a)$ and a spiral one $(s p)$, beside which is a large air-space, the effect of a tear in the tissues caused by rapid growth; the rest of the wood consists of wood parenchyma $(v p)$.

Let us now investigate the wood of an Oak (or other hardwood tree such as Hickory, Chestnut, Ash, Acacia, etc.) and of a Pine (or other softwood tree such as Spruce, Cypress, Juniper, etc.) by first tracing the path of the water (by means of eosin solution) and then examining sections under the mieroscope. Cutting sections of woody stems presents certain mechanical difficulties, but these are easily overcome if we choose young stems (not more than two or three years old) and trim the surface to be cut until it is not more than an eighth of an inch in diameter. 


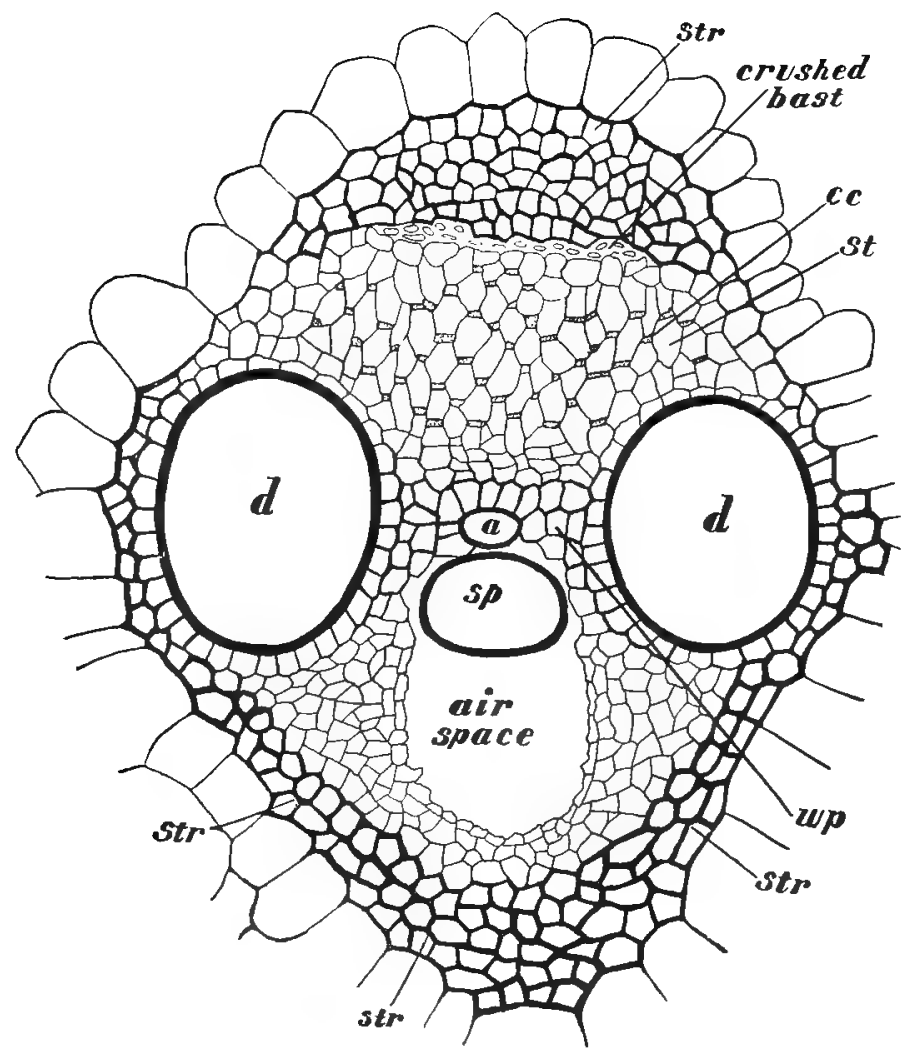

134. Cross-section of a bundle of Corn: (d) duct, (a) annular tracheïd (i. e., with ringshaped thickenings), ( $s p)$ spiral tracheïd (i. a. with spiral thickenings), ( $v p$ ) wood parenchyma, (st) sieve-tube, (cc) companion cell, (str) strengthening fibers. 


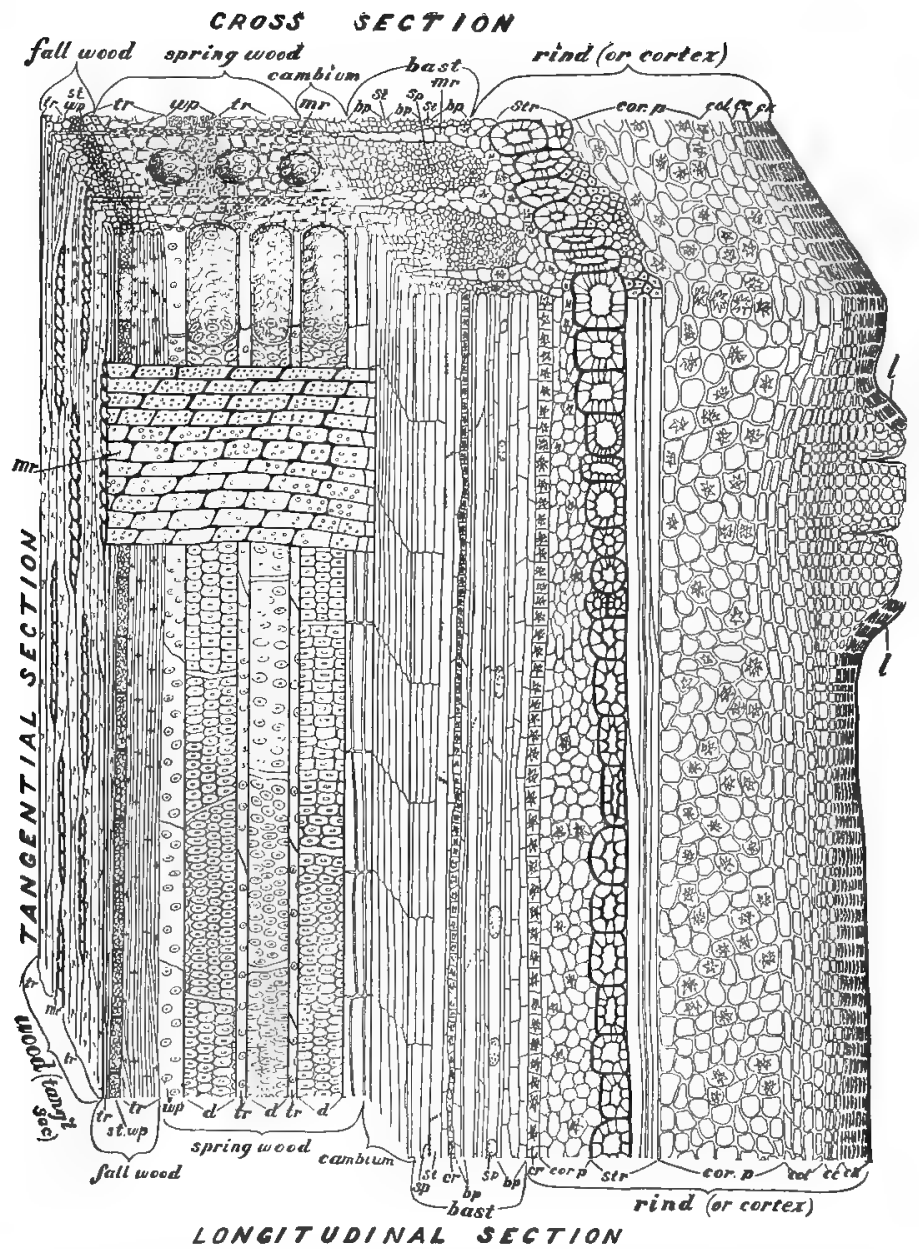

135. Oak branch: (ck) cork, (cc) corls cambium, (col) collenchyma, (cor. p) cortical parenehyma, (str) strengthening cells, $(c r)$ crystal-bearing cells, $(b p)$ bast parenchyma. (sp) sieve-plate, (st) sieve-tube, (d) duct, (tr) tracheïd, $(w p)$ wood parexehyma, $(s t, w p)$ wood parenchyma rontaining stareh, $(\mathrm{mr})$ medullary ray, (l) lenticel. 
In the wood of the Oak (Fig. 135) we find the same elements as in the Squash, namely, ducts $(d)$, wood parenchyma ( $w p)$, and long, pointed tracheïds $(t r)$, dovetailed together at the ends. Most of the tracheids in the Oak are pitted; tracheilds with spiral or ringshaped thickenings occur only in the innermost wood next to the pith. The wood parenchyma cells are usually distinguished by being filled with starch, so that by placing the section in iodine they stand out prominently; at the same time the medullary rays $(m r)$, or silver grain of the wood, stand out unmistakably by reason of their starch-content. Whether we look at the cross or the longitudinal section, the starch, by its dark coloration, forms a distinct pattern, which shows very clearly the course it travels from the outer green-celled tissue of the rind, inward through the narrow, ribbon-like medullary rays, and from them into the intersecting bands of wood parenchyma in which it travels freely up and down the stem. The form of the medullary rays $(m r)$ is easily understood from the figure. They consist of cells elongated in the direction of the radius of the stem, and run from the rind (or cortex) through the bast into the wood, many of them reaching clear to the pith, to which they convey large quantities of starch. In the longitudinal section the cells of medullary rays are shown in surface view (i. e., not cut open), consequently we see the pits which occur in their walls; it is principally 
through these pits (which are openings in the wall closed by very delicate membranes) that the starch

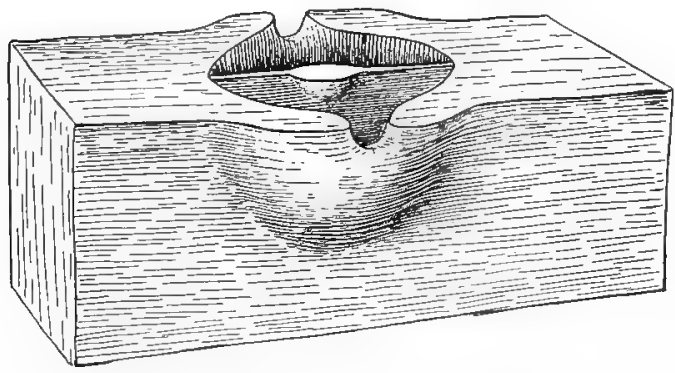

136. Bordered pit, eut in half (diagrammatic). passes in the form of dissolved grapesugar from cell to cell. These pits occur on all the cell-walls of the wood and are shown in the cross-section as dots in the cellwall (for details see Fig. 136, which is a diagrammatic representation of one of these bordered pits cut through the center; a similar section of a simple pit is shown in Fig. 137). These figures make it clear that the pits are nothing more than holes in the wall across which are stretched delicate membranes which allow water to pass through but prevent the passage of air-bubbles, starch grains, ete. On looking at a bordered pit, the narrowed entrance to the hole appears as a smaller circle within the larger one which corresponds to the diameter of the hole at its widest part. It is possible that

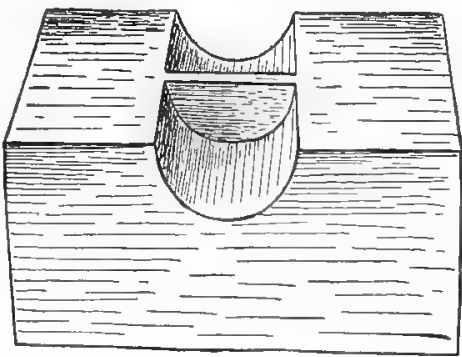

137. Simple pit, cut in half (diagrammatic). 
air-bubbles, which would hinder the rise of the water, are trapped in these pits and so rendered harmless. The tracheilds and wood parenchyma are also pitted so as to allow water and dissolved substances to pass readily from one to another. The great elongation of the tracheïds especially fits them for conducting materials lengthwise through the stem, while their dovetailed arrangement increases their surface-contact and so promotes the diffusion of liquid while at the same time it gives them great mechanical strength. Let us now investigate in the same manner the wood of the Pine (Fig. 138). Here we find only tracheïds. The only thing which resembles a duct is the resin duct $(r d)$, which does not convey water, but contains resin, scattered in irregular drops. The tracheïds are large and are provided with very large bordered pits. Make a careful comparison of the wood of the Oak and the Pine.

A very good way to study wood-cells is by isolating them. Place some rather thick longitudinal sections in a dish, add a few crystals of potassium chlorate, and pour in enough nitric acid to cover them. Set the mixture outside the window until fumes cease to come off, then wash the sections in water and tease out with needles, if necessary. The wood-cells will then have separated from each other and may be studied in their isolated condition; in this way we may learn the length of the tracheids; to ascertain the length of the ducts 


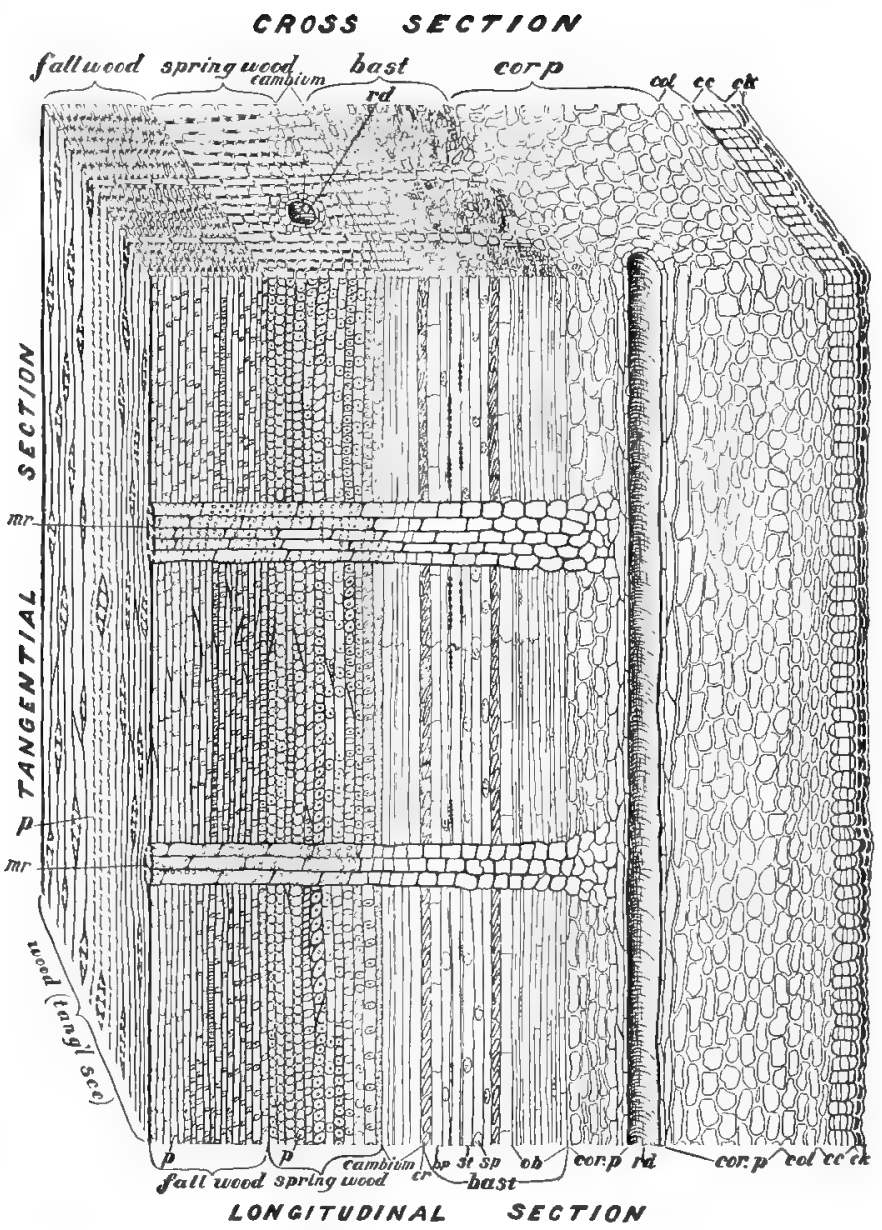

138. Pine branch: (ck) cork, (cc) cork eambium, (col) collenchyma, (cor. $p$ ) eor: tical parenchyma, $(r d)$ resin duct, $(o b)$ old bast, $(s p)$ sieve-plate, $(s t)$ sievotube, $(b p)$ bast parenchyma, $(p)$ pit, $(m r)$ medullary ray. 
we must employ another method. For this purpose we force one end of the stem through a hole in the center of a rubber stopper which fits into the airpump in the manner shown in Fig. 139. If we now place the free end of the stem in water and withdraw the piston, water will be drawn up into the ducts. We must place in the fluid some coloring matter which cannot pass through the cell-wall; for this purpose we may use India ink or cinnabar rubbed up fine in water and filtered through filter paper so as to take out all the coarser particles. We now exhaust for about half an hour, making as many strokes with the piston as necessary. If none of the coloring matter comes through, shorten the stem by cutting a piece off the end and proceed as before; repeat this until the stem is short enough to permit the coloring matter to pass through. ${ }^{1}$ If we now remove the stem anil cut it open, we can easily ascertain the length of the ducts, tracheids, etc., and

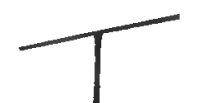
whether there is open communication between them.

We should suppose that water would travel faster in the open ducts than in the closed tracheilds; the

1 The liquid may also be forced into the stem by means of the apparatus shown in Fig. 141. 
Oak would seem to have an advantage in this respect over the Pine. In order to compare their efficiency, cut a live branch of each about twelve inches long and

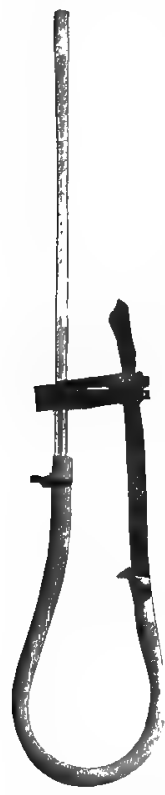

140. Arrange. ment for forcing water through a branch. as free from leaves or branches as possible. Remove the leaves and branches which are present, and comnect the base of the branch by means of two or three feet of heavy white rubber tubing to a glass tube three or four feet long (the tube may be formed of several pieces joined together by rubber tubing). Hold the tube upright with the branch hanging straight down, and fill it with water; compress the rubber tube several times to expel air. Place the branch upright and secure it by a clothespin in the position shown in Fig. 140 (which shows a slightly different arrangement from the one here described). Connect the upper end with a piece of glass tubing (about six inches long), in which place a little water. Place a little oil on the top of the water in each of the tubes. Make the joints water-tight by winding with elastic bands (or with wire); close with sealing-wax any wounds made by the removal of leaves, branches, etc. The diameters and lengths of the branches should be as nearly alike as possible. The height of the water-column in the long tubes (measured from the 
level of the water in the short tube) should be the same in both cases. Mark carefully the height of the water-column in all the tubes at the beginning of the experiment, and at the end of twenty-four hours compare the amount of water that has run through the two stems, as indicated by the rise of the watercolumns in the short tubes.

In order to gain some idea of the energy required to force the water needed for transpiration through the stem in each of these trees, we may first ascertain the normal rate of flow and then the amount of energy required to force water through the branch at the same rate. Cut vigorous leafy branches, one of Oak and one of Pine, three or four feet long, and place them in jars of water, on the surface of which we pour a little oil (cottonseed or olive) to prevent evaporation. Having done this, we weigh each jar with its contents and, after exposing it for twenty-four hours to conditions favorable to transpiration, weigh again.

We now take a section of a lamp-chimney or of glass tubing, at least an inch in diameter, fit it at each end with a stopper of rubber or paraffined cork, and insert air-tight in one of these corks a glass tube (one-eighth to one-fourth inch in diameter), about three feet long. Now heat the tube and bend it till it comes in contact with the large tube (as shown in Fig. 141), and secure it firmly in this position by wire. 


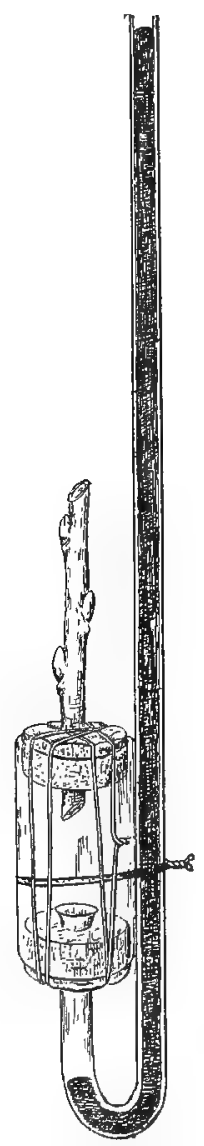

141. Modification of arrangement shown in Fig. 140.

Trim away from the Pine branch all its leaves and twigs (the wounds made in so doing should be covered with sealingwax), insert the base of the branch airtight in the cork, fill the large tube brimful of water and insert the cork with its branch so as to exclude air as much as possible. Pass a wire over both corks, as shown in the figure, and secure it firmly. Attach a glass tube five or six inches long to the top of the branch, and pour mercury into the long tube until there is sufficient pressure to make water flow through the branch at the same rate as it flowed when intact (as shown by the weighing). Perform the same experiment with the Oak branch. ${ }^{1}$

The same experiment may be performed by basing the comparison on the rapidity of rise of the sap as shown by eosin solution (instead of on the amount). In this case two similar branches from the same tree should be compared, one being placed intact in eosin solution, the other stripped and connected with the tube as before, so as to force the eosin solution through it.

1 It is possible to perform the experiment on short twigs by pouring water insteqd of mercury into the long tube, 
It is of course impossible to estimate from the results of the above experiment how much pressure is required to force water to the top of a Pine tree fifty or one hundred feet high, hut we know that it must be a much greater amount than is nreded to fore it through a short branch such as we have used. Te have at least found out that a powerful force is at work.

Is the water raised by a force acting from above (i. e., pulled up), or by a force acting from below (i. e., pushed up), or by both methods? As we have already learned, there is in the leafy branch a powerful force at work lifting the water, and this too when the branch is completely separated from the root. In this case the force must reside in the stem or in the leaves. Determine the amount and rapidity of sap-flow in a leafy branch, as compared with a similar branch deprived of its leaves (and with the wounds caused by their removal sealed with sealing-wax). Does the result indicate that the force resides principally in the leares?

It would appear probable from this and other experiments which have been made that the water is pulled up by a force acting from above. If this were the case it would create a partial vacuum in the ducts whenever the supply of water from the roots ran low. Do we find any evidence of such a state of things? Allow a vigorous plant (Squash, Sunflorer, etc.) to wilt slightly, thus showing that the supply of water from the root is running low. Now bring a part of the 
stem under eosin solution in a shallow pan, and cut the stem underneath the liquid by a quick, clean stroke of a sharp knife or scissors. After two or three minutes, remove the stem and determine how far the eosin has penetrated.

In what manner do the leaves exert this force? We have already learned (page 122) that the root-hairs draw up water by reason of the water-attracting substances which they contain. We determined the waterattracting power of the root-hairs by placing them in weak solution of salt or sugar and increasing the strength of the solution until it attracted water from them and they became flabby; we may do the same with the leaves, and we then find that it takes a much stronger solution to attract water from them than from the root-hairs. If, then, the leaves are so much richer in water-attracting substances ${ }^{1}$ than the root-hairs, the most probable explanation seems to be that they attract water from the root-hairs through the intervening cells and ducts, and so supply what they lose by evaporation. It is at present doubtful whether this explanation can account for the rise of sap for more than 150 to 200 feet. $^{2}$

1 The youngest leaves, which are richer in water-attracting substances than the old ones, are also the first to be colored when a short piece of stem is placed in eosin; this indicates that they attract water more powerfully than the older leaves.

2 Two factors which are little understood as yet must be reckoned with; the tensile strength of the water-column and the frictional resistance of the duets, tracheirds, etc. 
The fact that the run of sap commences in the spring before the leaves appear (as in the Sugar Maple, etc.) is apparently due to the formation at that time of large quantities of sugar and other waterattracting substances in the stem which draw up the water in large quantities.

It is a matter of common observation that at certain times of the year many plants bleed (i. e., exude water) when cut or trimmed. Test some vigorous, well-watered plants in regard to this point (especially Squash, Sunflower, Dahlia, Begonia, Corn, etc.) by cutting off the plant near the ground and connecting the stump to a glass tube by means of a section of rubber tubing (see Fig. 142). Pour a little water in the tube and support it in an upright position. Place a little oil on the water and mark the height at which it stands. In favorable cases the water will rise in the tube; this is due to what is known as root-pressure; some observed cases of rootpressure show that it could, in certain plants, under favorable circumstances, raise the water many feet; but at the time of year when transpiration is greatest little or no

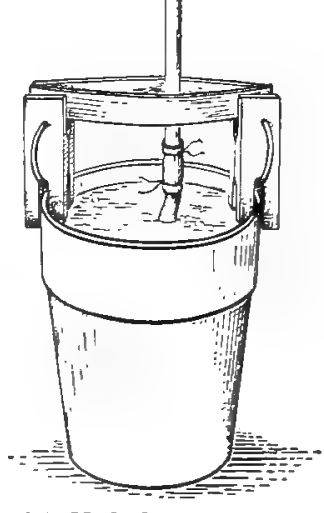

142. Method of measuring the amount of bleeding from a stamp (root pressure). 
root-pressure is, as a rule, observable. We may therefore leave it out of account in this connection.

The amount of water necessary to supply the leafy crown of a large tree must be very large, and we might naturally suppose that all the wood of the trunk is employed in conveying it. It is often noticed, however, that in old trees the heart-wood decays and leaves the trunk hollow without affecting the health of the tree. Moreover, on sawing off a tree or branch six or eight inches in diameter and placing the cut end in eosin solution, we find that the colored liquid does not rise in the inner portion of the wood but only in the outer. (In case this experiment is carried out, the tree may be removed from the solution and allowed to dry with its leaves on and will serve for years as demonstration material.) The cells of the interior portion of the wood are more or less stopped up with various substances, and appear more deeply colored than those of the outer portion; this inner portion is called the heart-wood, and the outer the sap-wood.

If water is prevented from traveling in the sap-wood, can it travel in the heart-wood instead? We may answer this question by cutting a ring-shaped groove all around the tree or branch deep enough to go through the sap-wood and prevent the water from traveling in it. The wilting of the leaves will indicate the extent to which the water current is interfered with. No one who has seen this experiment carried 
out can thoughtlessly destroy a tree by hacking it without realizing the injury he is inflicting.

In connection with the study of wood and its structure, take up as far as possible the practical aspects of the matter. What is meant by the seasoning of wood? What does this involre? How is it best accomplished? Why? Does the water escape principally through the sides or through the end of the $\log$ ? What occurs if the end is painted or rendered water-proof? Does the Trod crack less if allowed to season with the leaves on? What kinds of wood shrink most in drying? What kinds contain most water? ${ }^{1}$

That deterwines the usefulness of a wood? What kinds of woods are used for the various parts of wagons? Whए? Can you explain their peculiarities by a study of their cell structure? What woods growing in rour region are useful in any way? Why? What woods last longest when exposed to the weather? What is the best treatment to preserve woods??

Learn how to read the history of a branch $\mathrm{l} y$ the inspection of the scars on it. ${ }^{3}$ In some cases (e.g., Alder) this history can be read back many rears.

As the sap-mood grows older it changes into heart-

1 In regard to the absorption of water by wood, see page 68 .

2 See articles in the Year-Book of the C.S. Department of Agriculture for 1894 by Fernow; for 1896 by Roth: for 1903 bs von Schrenk. On the management of forests, etc., see Roth: "First Book of Forestry"; Pinchot: "Primer of Forestry": also articles in the Year-Book for 1895 by Fernow; for 1898 and 1899 by Pinchot.

3Set Bailey: "Lessons with Plants," p. $73 \mathrm{ff}$. 
wood, and new sap-wood must be formed to take its place. If we examine sections of the Oak (Fig. 135) or Pine (Fig. 138), we can see how the new wood is formed. At the outer edge of the wood is a tissue called the cambium, composed of very small, rapidly growing cells. We can see how these cells grow larger to form wood on one side and bast on the other (this is well shown in the Squash, Fig. 133). In the middle of the cambium layer the cells divide frequently into two, thus forming more cells, which ultimately develop into wood or bast. If we make sections of the extreme tip of the stem, where the bundles are still separate, we find that the cambium layer grows out from the bundles and unites to form a ring, which soon forms wood and soft bast in a complcte circle around the stem.

When we separate the bark of a tree from the wood, we find between the two a white, glistening, juicy layer; this is the cambium. If we carefully make an incision in the bark of a tree (preferably a young tree on which the bark is thin), and slip a thin piece of metal (a ten-cent piece hammered thin is very good for this purpose) between the cambium and the wood, it will be found in the course of a year to be covered with a thin veneer of wood as the result of the activity of the cambium. You may easily try this experiment for yourselves. Axe-heads, iron bolts, etc., have been taken from the heart of trees which were covered by 
many annual rings of wood. The annual ring of wood is the growth made by the cambium in one vear. The wood formed in autumn (or toward the end of the season of growth) is much denser and harder than that formed in the spring and composed of smaller cells (Figs. 135 and 138); the difference is apparent to the naked eye and the rings may be easily counted, thus fixing the age of the tree (see Fig. 145). If, on account of drought, destruction of the leaves by insects, or for any other reason, there are two seasons of growth in a year, there are two more or less sharply defined rings. The formation of denser wood in the fall is probably due partly to the unfavorable conditions of growth then prevailing and partly to the "binding" of the bark, which gets tighter as the expanding wood stretches it, so hindering the growth and making the cells smaller. Cut a section (about one-fourth of an inch thick) from a twig during the growing season. Slit the bark on one side and peel it off carefully. Now replace the ring of bark on the twig; can you make the ends meet? What does this show in regard to the stretched condition of the bark? Fruit-growers often slit the bark of trees in the spring with the point of a knife, in order to allow the wood to expand: washes of soap or lye are also used to soften the bark. Trees exposed to a prevailing wind grow thicker in the direction in which the wind blows; this is believed to be due to the stretching and loosening of the bark on 
opposite sides by the bending of the tree in the wind. The buttresses (Fig. 142a) below large branches are probably due to the sinking of the branch under the weight of foliage, thus loosening the bark below and allowing the wood to expand, while above the branches the reverse is the "ase. Experiments may be made to

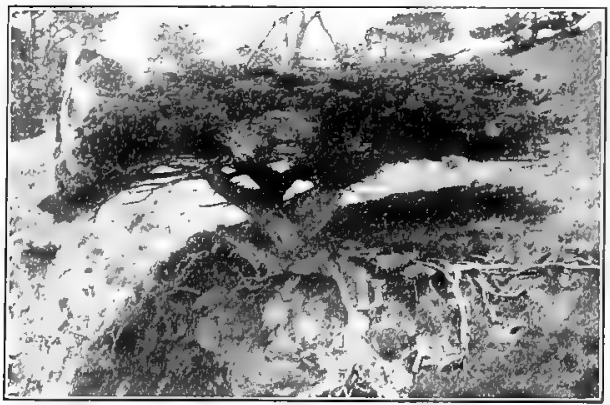

1.La. Buttress formed on the lower side of a branch where it joins the trunk.

test the effect of "binding" on the growth of the wood by wrapping a branch securely with wire during the growing season and investigating it at the close of the season. Try also the experiment of slitting the bark with a knife.

The growth of the cambium adls each year a layer to the bark, as well as to the wood, so that although the bark continually wears off on the outsile it grows thicker each year as the tree grows older. (The stems of Monocotyledons have no cambium and do not grow thicker from year to year.)

It is by means of the growth of the cambium that the scion and stock unite in srafting. Find out what you can about this. Make sections through the place 
of union and examine under the microscope. If possible, try some experiments in grafting. For directions see Hunn and Bailey: "The Practical Garden Book"; also consult some one who is skilled in the matter.

The cambium is not the only portion of the stem that grows, for, as we have already learned, the stem grows in length at the tip. We may divide the tip into three regions (Fig. 143): (a) the extreme end, occupied by a bud in which leaves are continually being formed; we may call this the formative region; (b) the elongating region, just back of the formative region (see page $7 \vec{T}$ ), and $(c)$ the maturing region (region of differentiation), in which the various tissues, having

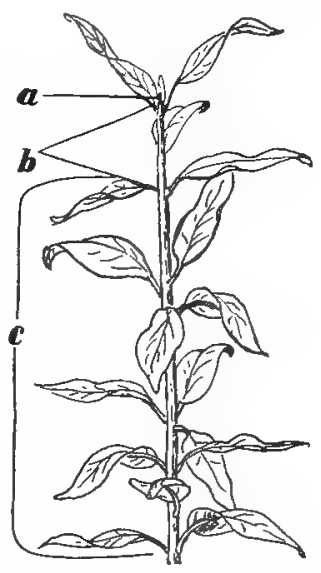

143. Terminal part of a growing branch: $(a)$ formative region, (b) elongating region, (c) maturing region( region of differentiation). ceased almost entirely to grow in size, assume their characteristic forms and structures. It will be noticed that the buds are formed in the axils of leaves (i. e., just above the junction of the leaf and stem) ; exceptions to this are the buds formed from callus (see page 263) and the buds formed on roots, e. g., the buds which grow up into sprouts or suckers from the roots of fruit trees, Poplars, Elms, ete.

A peculiar method of growth at the joints or nodes 
is found in the Wandering Jew, Grasses and some other plants. Examine some growing Grass or Grain: notice how tender and succulent the joints are; also how much sugar they contain, as shown by the taste. Cut off a stem half an inch above a joint. Three or four inches below the joint make another cut and place the piece in a moist atmosphere with the base in water or wet sand. The growth at the joint will soon manifest itself by contrast with the sheathing base of the leaf which surrounds it and which grows very little

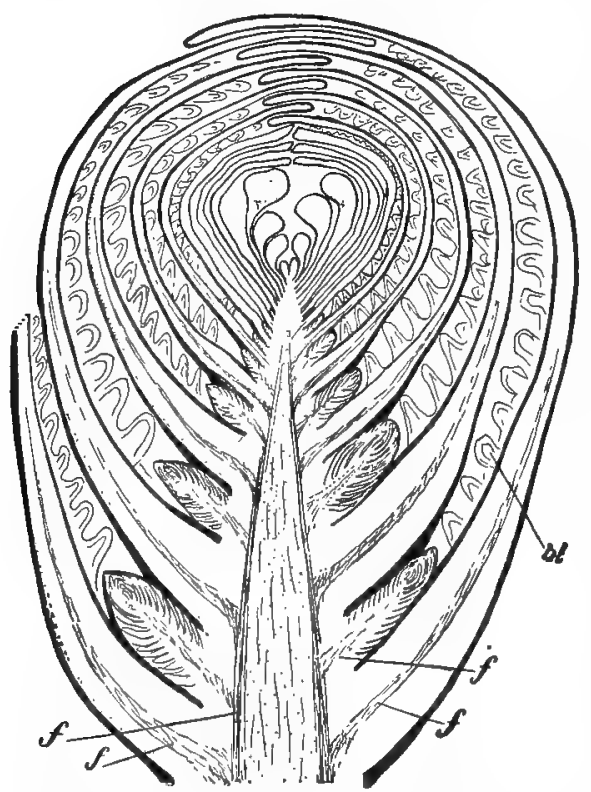

144. Bul of Brussels Sprouts eut lengthwise: $(f)$ fibrous bundles, (bl) the crumpled leaf-blade. or not at all.

In order to get a clear idea of what goes on in the formative region, let us study a large bud, such as a head of Cabbage or Brussels Sprouts (Fig. 144). The end of the stem is seen to be conical; at its extreme tip are small outgrowths (easily seen with a handlens); these are the youngest leaves. Next to these are slightly older ones, 
beginning to show a differentiation into blade and stalk. A little lower down the thin blade (bl) of the leaf is seen, crumpled in a wavy manner between the successive thickened veins. In the axil of each leaf is a tiny bud, a miniature of the larger one in which they are contained. Notice that the fibrous bundles $(f, f)$ extend almost to the tip of the stem and send off branches to each leaf and each bud. You can trace their course clearly by placing the cut end for a a time in eosin solution.

Notice how the overlapping of the older leaves protects the younger ones. Protection from drying is very necessary, for the younger leaves are exceedingly sensitive. Remove most of the outer leaves and note the effect on those which remain.

Remove the bud-scales from winter-buds, and note the effect. The water-proof varnishes of such bud-scales are an excellent protection against drying (the popular notion that bud-scales protect against cold is a fallacy); see also pages 213 and 214 .

The protection of the tip of the stem by the overlapping bud-scales and young leaves is due to the fact that these organs grow faster on the lower side than on the upper, thus causing them to curve inward. When the bud opens, the reverse process occurs, growth becoming more rapid on the upper side. In some leaves this condition persists, giving them a permanently curved appearance or causing them to flatten 
themselves out on the ground as in the Dandelion (experiment by placing a Dandelion upside down with its root wrapped in moist cotton). Study the unrolling of Fern leaves.

In this connection let us consider the general conditions of growth. Every one is familiar with the expression "growing weather," which clearly indicates that growth depends on certain conditions. We may experiment on three of these - namely, warmth, moisture and light. For this purpose obtain a lot of seedling plants (of the same kind) as similar as possible in respect to vigor and general condition. They must be grown in pots or boxes.

(a) Temperature.- Select three pots, and mark the stem of each plant with ink two inches from the tip. Cover each pot with an opaque cover (a pasteboard cylinder or box will answer), to exclude the light. Insert a thermometer, if possible, in each, so that it may be conveniently observed. Place one pot in the warmest spot about the building, another in the coolest, and the remaining one in a place of medium temperature. After forty-eight hours, measure the growth of each.

(b) Moisture. - Use two potted plants, provided with opaque covers to exclude light, keeping them all together in a spot where the temperature is most favorable to growth. Before commencing the experiment, allow one of them to suffer from lack of water, 
keeping the other well watered. Then place the covers on them and observe the growth as before.

(c) Light.-Repeat the experiment, giving both pots of plants plenty of water and warmth (the same amount to each), but keeping one covered with an opaque cover while the other is exposed to strong light. Do plants grow faster during the day or during the night?

The growth of the stem requires a great deal of food. Test the growing portion (especially the formative region) for food substances (for fat, use the alcanna test, page 259). Study especially the behavior of starch in buds (e. g., buds of Hawthorn, Maple, Linden, Lilac, etc.). In general the embryo leaves contain no starch in the fall, although there is plenty in the tissue just beneath them. In the spring it wanders into the young leaves and furnishes material for their growth. Buds furnish nutritious food to many kinds of animals. How are the food substances brought here from the leaves? See if you can trace their paths through the stem. This will probably be easier in the case of starch than in the case of the other substances. Starch cannot pass through the walls of the cells which compose the plant, but it is readily changed into sugar, which can pass from cell to cell and so reach the growing region; when it arrives there it may be changed into fats, oils, or even into proteid (by combining with nitrogen, sulphur and 
phosphorus); it is probable that in this process oxalic acid is formed, which unites with lime to form the numerous erystals of oxalate of lime which are seen in the neighborhood of the bud: they are easily observed with the low power of the microscope (see also Fig. $135, \mathrm{cr}$ ). The sugar may be changed temporarily into starch, not only in the growing region but in the cells through which it travels to get there; and for this reason it is easy, in most cases, to trace its path by the application of iodine solution to the cut surfaces of a stem divided lengthwise.

To trace the proteid substances may not be so easy unless we have a favorable plant, like the Squash or the Pumpkin. On cutting across the stem of a Pumpkin, the proteid substances at once ooze out at certain spots and coagulate. The stem may be laid for a time in alcohol (to coagulate the proteid and extract the chlorophyll), and the nitric acid test (also the sulphuric acid and sugar test described on page 166) may then be applied. In less favorable cases iodine may be applied; this turns proteids brown (not blue or black). (It may be necessary to use a hand-lens or a compound microscope.) Our examination of the Squash stem shows us that the proteids are contained principally in the bast. The bast lies on both sides of the wood and is composed, like the wood, of large and small cells. The large, wide cells, called sieve-tubes (st, Fig. 133), are, as we see in sections, really long 
tubes with openings in their end-walls through which the proteids may pass; the importance of these openings lies in the fact that most proteids cannot pass through the cell-wall and hence could not be transported to the growing regions were it not for the sievetubes. What causes the proteids to move in the sieve-tubes is not definitely known, but the pressure on the surrounding cells on the sieve-tubes, which causes the proteids to flow out when the stem is cut, must help to force proteids into the young and growing portions of the plant, and the bending of the plant in the wind probably assists this.

The smaller cells of the bast are of two kinds, those which are closely connected with the sieve-tubes and whose end-walls correspond with theirs, hence called the companion-cells (cc), and shorter cells, called the bast parenchyma $(b p)$. The function of these two kinds of cells is not known, but it is conjectured that they assist in some way in the transportation of the proteids.

The openings in the end-walls of the sieve-tubes may be easily studied in the cross-section ( $s p$, Fig. 133), where they are seen to be so numerous as to give the wall a sieve-like appearance, hence the name sieve-plate is applied to these walls. The bast may be traced, in connection with the wood, clear up into the leaf and also down into the root (see Fig. 90). Most plants are not so well provided with sieve-tubes as 
the Squash or Pumpkin. The usual arrangement is a single mass of bast lying outside the wood, instead of both outside and inside, as in the Squash.

If we examine a branch of a tree (see Figs. 13.5 and 138) we find the bast lying just outside the cambium. In the stems illustrated the sieve-plates occur on the side-walls as well as on the end-walls; this is quite common in trees; it permits a more rapid transfer of proteids from cell to cell. The outer part of the bast soon dies and then becomes crushed by the pressure of the surrounding cells; this is shown in Fig. $138(o b)$. As the branch grows older, thin layers of cork are formed here and there in the rind, cutting off small portions of it from the interior; these portions die and eventually fall away; the cork-formation finally encroaches on the bast. The result is bark, which has an inner portion consisting of living cells and an outer portion consisting of cells which have become dry and dead; these cells, even though dead, render valuable service to the plant, since they protect it against insects, fungi, gnawing animals, fire and many other foes. Notice how quickly the cambium and other tissues dry up and die whenerer the bark is removed. (Protection of the stem against animals is, in many cases, afforded by hairs and spines; see page '21.)

What happens if we ring the tree so as to prevent the proteids from passing downward in the soft bast? To 
answer this question we take a cutting, preferably of Willow, about five inches long (cut so that the lower cut surface comes just below a bud) and ring it just above the lowest bud by removing a ring of bark about a quarter of an inch wide, so as to lay bare the wood.

We now place the cuttings in a jar of water so that they stand upright, about half submerged (the ring or girdle should be under water). Under these conditions they put forth roots and shoots, whose relative development above and below the ring will indicate the relative supply of nourishment. The experiment must be continued for some weeks.

Inasmuch as in ringing we cut away the rind or cortex in which the starch and sugar chiefly travels, we may institute a control experiment to see how far this affects the result by ringing some cuttings in such a way as to cut the rind only but not the soft bast. At the end of the experiment, test for starch. Does it accumulate in the cortex above the cut?

Ringing is often practiced in grape culture. The branch is ringed some distance below the young cluster of grapes, and the food which would otherwise pass down through the soft bast is retained and used by the growing fruit, which grows to unusual size.

In testing trees for food substances, we find considerable starch in the wood, and on tracing it back find that it travels thither in the so-called silver 
grain of the wood, which runs from the center outward to the bark at right angles to the ordinary grain. On splitting an Oak stem squarely in two, this silver grain is very conspicuous and, on testing, is found to be filled with starch. In sections (Figs. 135 and $138, m r$ ) the silver grain is seen to consist of long, tubular cells like the wood-cells (ducts are absent) running in a radial direction, at right angles to the course of the wood-cells. The silver grain is called by botanists the medullary rays (medulla means pith); they serve as channels of communication between the wood-cells and the cells of the outer portion of the stem; they may convey food, water or gases.

Why is so much starch conveyed to the wood? Little or no growth is taking place in that portion of the wood to which most of the starch is conveyed; moreover, the amount of starch increases instead of diminishes during the growing season. Just after the leaves have fallen off the wood is very rich in starch, while the fallen leaves contain practically no food substances of any sort (test this matter). It would appear that the starch is conveyed from the leaves to the wood for the purpose of storing it up there. Not only in the wood but also in rind or cortex do we find starch stored up at this time of year. Later on, during the winter, we find that some of the starch has disappeared, but on testing we find an increase in the amount of sugar; we conclude, therefore, that a part 
of the starch has been converted into sugar; in the spring, with the approach of warmer weather, the starch reappears and remains until it is used up by the growth of the new leaves and branches. On account of the starch which they contain in winter, such trees as the Oak, Willow, Hazel, Lilac, etc., are called starch trees. On the other hand, many trees, such as the Linden, Birch, etc., contain no starch in midwinter; it has been transformed into fat, as is indicated on placing sections in alcanna tincture. ${ }^{1}$ Such trees are called fat trees; on the approach of warmer weather in spring the fat is changed back into starch. Does the temperature seem to control these changes? Bring in a branch of Linden in midwinter and test for starch; set it in a jar of water in a warm room, and after three or four weeks test again.

When the buds are preparing to unfold in the spring, the sap begins to run. We can observe this especially well in the Sugar Maple, Birch, etc., and here the taste of the sap shows that it contains a considerable quantity of sugar. In this case, then, the sugar travels upward in the wood; this sugar, as we can easily convince ourselves, comes from the transformation of the starch and serves to supply the young leaves and branches with material for their vigorous spring growth. Investigate other trees, test-

1 This is obtainable at drug-stores. It is made by placing alcallna root in alcohol until the coloring matter is extracted. It has the property of staining fats and oils red. 
ing with Fehling's solution (see page 164) if necessary, and determine their behavior in this respect.

The storage of food is extremely advantageous for the plant, not only for the period of rapid growth in the spring but also for the period of flower and fruit. We find various parts of the plant userl as storage reservoirs, according to the particular needs of the case. We may say that the problem of storage has been solved by the plant in a great variety of ways. Storage in leaves is seen in seed-leaves, in the scales of bulbs, and in the leaves of succulents (Live-forever, Century Plant, etc.). Storage in stems is seen in trees, in Cacti, in tubers of the Potato (examine the Potato and notice the buds, or "eyes," placed in regular fashion and the minute bundles which are more easily seen if the tuber is allowed to stand with the cut surface in eosin until the fluid rises in the bundles; these are indications of its stem nature), the corm of Crocus, the root-stock of Iris, ete. Storage in the root is seen in the Carrot, Turnip, ete.

In all of the storage organs the form is such as to give a great bulk with little exposed surface, and in very many cases they are sheltered undel ground, where they are protected from foes and transpiration is lessened. When above ground they are usually protected from foes by thorns, spines, hairs, etc., or by a bitter or disagreeable taste; to prevent transpiration they have much the same devices as leaves: 
bulbs, corms, etc., are usually protected by the dead leaves of the previous season which enwrap them.

The beautiful arrangements of leaves whereby they spread out over a great area so as to absorb sunshine without mutual interference would not be possible without a proper grouping of the branches on which they are borne. How do the stems aid the leaves in securing the best arrangement? What do you think is the most advantageous arrangement of the branches (and of the leaves upon them), in order that the greatest amount of sunshine may be absorbed with the greatest economy of material? Take into consideration the daily motion of the sun. Notice the difference between a tree growing in the woods and one growing in the open, where it receives light from all sides. As soon as we begin to study the forest-grown tree we notice that the lower part of the trunk appears free from limbs, not because none have appeared in that region but simply because they have perished from lack of light. This process is called self-pruning, and to it is due the value of the tree for lumber, since it results in straight timber free from knots. In the tree grown in the open self-pruning also occurs, though to a much smaller extent.

There is a continual struggle going on among the branches for light and space, which results in stunting and dwarfing the weaker ones or in killing them altogether. Many factors affect the result; the position 
of the branch, the supply of sap, of sunshine, of elaborated food from the stem, and from the leaf in whose axil the branch starts, etc. On pulling off the bark of a tree (e.g., of a Pine or of an Oak) we find under the bark, projecting from the wood, numerous little incipient branches which have never been al-

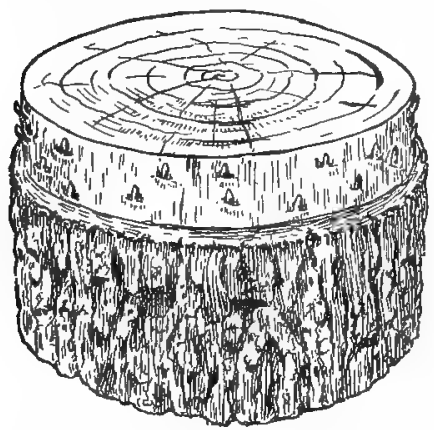

145. Portion of trunk near a burl, show. ing latent buds beneath the bark. lowed to develop (Fig. 145). By splitting open the stem, we may trace them inward toward the heart through several annular rings, thus determining their age. Their growth keeps pace with that of the stem, but they thicken scarcely at all; in some cases they branch, causing the appearance familiar to us in "bird's-eye maple." In almost any good-sized tree we may find such latent buds, as they are called, which for several years have patiently awaited their chance to develop. If now the tree be cut down, thus removing the fierce competition of the upper branches, they spring up at once into wonderfully vigorous growth.

In this connection study cuttings and make such experiments as are practicable. Do cuttings require a light sandy soil in which air circulates freely? It has been found that cutting a plant prodnces local ferer just as in an animal and an increased quantity of 
oxygen is consumed. The growth of the callus and of the new roots also requires a considerable amount of air.

If there are leaves on the cutting they should be removed partially or entirely, to diminish the loss of water, since there are no roots to keep up the supply. Shading the cuttings and keeping the air moist assist greatly in this respect. ${ }^{1}$

In many cases we find new branches springing directly from the cut surface of a limb or a stump. If we examine closely we find that these come, not from latent buds, but from buds newly formed, as it were for the emergency, by a tissue which grows out from the cambium. This tissue, called the callus, will in time, if left undisturbed, cover over the cut surface entirely. This is of the utmost advantage to the tree, since it prevents the entrance of water, fungi and other agents of decay. If, however, the cut surface is large, it should always be painted over, to preserve it until the comparatively slow growth of the callus covers it. (It may also be remarked that a branch should always be cut off close to the tree and not at a distance from it.) Pruning is the method by which man regulates the struggle among the branches for his own ends, and is a study by itself; to prune properly requires a careful study both of the individual plant and its surroundings. Pruning is a fasci-

1See Hunn and Bailey: "The Practical Garden Book," p. 84. 
nating study. Find out all you can about it and the principles underlying it. ${ }^{1}$

The form and arrangement of the branches determine the "habit" of a plant, by which we recognize it even at a distance; the object of this arrangement is to spread out the leaves in the best possible fashion for their work, with the least expenditure of material for construction. What plants do you think have the most advantageous habit? How many distinct kinds of hal,it can you distinguish?

What controls the habit of the plant? As we have already learned, the main stem grows upward in response to the influence of gravity. Do the branches, especially the horizontal ones, assume their positions in response to the influence of gravity? Notice whether the tip of a growing branch points in the same direction as the branch itself. If not, how is the change of direction effected? Fasten tips of horizontal branches in various positions, some pointing upward, some downward, and if possible exclude the light by conducting them into boxes which can be kept dark inside. This experiment is not conclusive, but indicates the probable force at work. The most careful experiments so far made seem to indicate that the principal influence is gravity.

\section{Does light also affect the direction of growth? Place}

1See Bailey: "The Pruning Book"; also articles in the Ytur-Book of the U. S. Department of Agriculture for $1895 \mathrm{ky}$ Woods; for $1896 \mathrm{by}$ Webber and Lodeman; for 1898 by Saunders; for 1902 by Powell. 
potted plants (especially seedlings of Grasses, Radish, etc.) in a box which admits light through an opening on one side ouly (or shade the plants as they grow, so as to accomplish the same result). The effect of different kinds of light may be shown by covering the opening with a flat flask or bottle filled in one case with a solution of potassium bichromate, in the other with ammoniacal copper sulphate (i. e., blue vitriol dissolved in water with the addition of ammonia to give a beautiful blue color). The first transmits red, orange, yellow and a part of the green rays; the second the rest of the green, together with blue, indigo and violet rays.

As the plant grows taller and develops a larger crown of foliage, the stem is exposed to greater and greater strains from the action of the wind. How to secure the necessary strength with the smallest outlay of material is a problem which we may now consider. If we fasten a small beam securely at

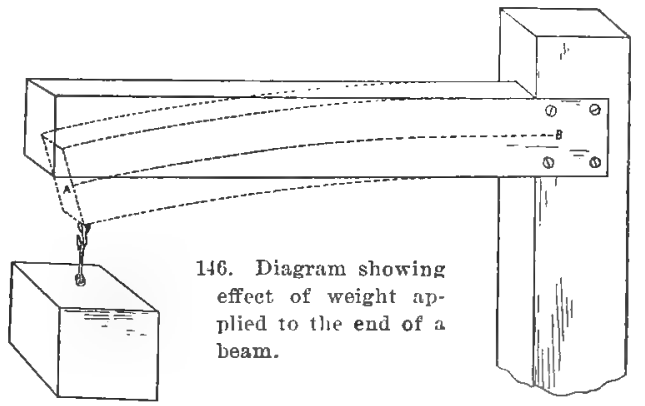
one end and attach a weight to the other, as shown in Fig. 146, the beam will tend to bend and take the position shown by the dotted lines; the upper surface 
lengthens and the lower shortens, while midway between them, along the line $\Lambda B$, there is no tendency either to lengthen or to shorten. We do not, therefore, need so much material along this line, and may transfer a large part of it to the upper and lower surfaces,

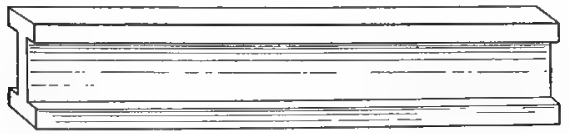

147. Diagram of a girder. where the greatest strain comes. By so doing we make a girder (Fig. 147) which contains the same amount of material as the bearn but will bear a much greater load. On the same principle, a hollow cylinder will bear a greater load than a solid one containing the same amount of material. Do you find the principle of the girder and hollow cylinder employed in the construction of the stem? On examining the crosssection of an herbaceous stem under the microscope, we find the thick-walled cells partly in the wood and partly in the strengthening fibers (Fig. 131, str) which may surround the bundle, as in the Corn ${ }^{1}$ (Fig. 134, str), or may lie external to it. In all cases the strands of strengthening fibers are connected with each other or with the strands of wool by intervening tissue so that they act as the flanges of girder's (see Fig. 148), or else they form hollow cylinders (as in Fig. 131). It

1 It will be noticed in the figure that, at the sides of the bast and thereabouts, the strengthening fibers form only a very narrow layer, so as not to prevent the passage of materials from the bast and wood to the pith at this point. 
will be noticed that the thick-walled cells are placed at or near the periphery, where the greatest strain comes, while the center is hollow or occupied by pith.

Cut off the head of a stalk of Wheat, weigh the stalk, and find a wire (of steel, iron, copper, brass, or, better still, one of each) of the same length as the stalk and as nearly the same weight as possible; attach the head of Wheat to it with a small bit of sealing-wax

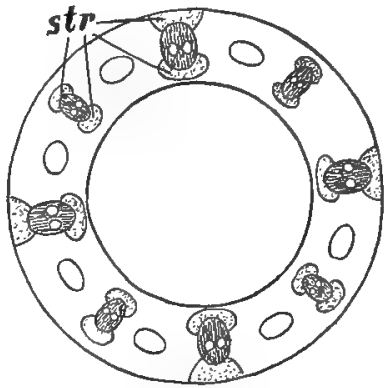

148. Diagram showing the girderlike arrangement of strength. ening tissues $(s t r)$ in a Bulrush (Scirpus). and compare its rigidity in an upright position with that of the Wheat-stalk.

In the blade of the leaf we find that each vein is a girder, or a system of girders, and usually projects from the under side of the leaf (see Fig. 149), which is the best theoretical construction.

In the root we find the woody cells, not at the

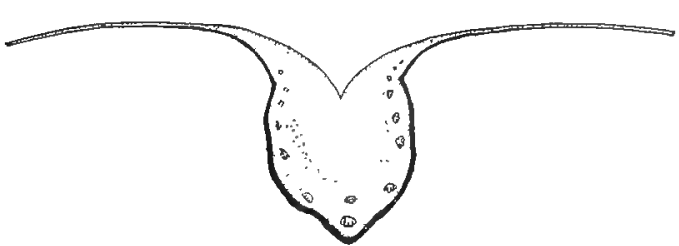
periphery, but at the center (Fig.90). This may seem at first glance a

149. Cross-section of a Cabbage leaf through the midrib. poor construction. When we remember, however, that the strain which comes upon the root is a pulling strain, we see 
that the construction is the best possible; it is, as you can easily see by experimenting with a strand composed of several strings (not twisted together), the construction that will stand the greatest pull. The bracing roots (above ground) of the Corn, which have to resist both thrust and pull, have strengthening tissue both at the center and at the periphery.

In the case of actively growing parts of plants we have a different problem, since thick, woody cells, like those of the wood and strengthening fibers, would not be permissible; we must have cells that are highly elastic, so as to be easily stretched, thus permitting

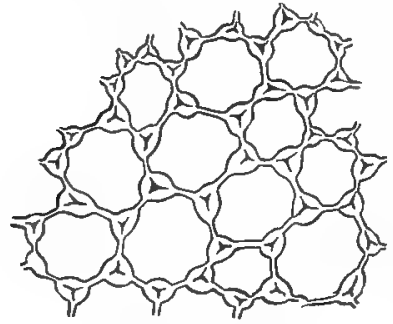

150. Collenehyma. the growth of the stem and yet rigid enough to give stiffness. The strengthening tissues of this part of the stem (called the collenchyma, Fig.' 150) have these properties; they are composed of cells thickened at the corners only; they are able to grow by absorbing nutriment through the thin places in their walls, and so keep pace with the growth of the stem. The rigidity of the growing parts is helped by the fact that the pith and internal tissues are compressed by the outer ones, which grow more slowly, and so set up strains (just as a spiral spring is more rigid if placed in a cloth bag which is too small for it). Cut from the tip of a growing Elder stem (or stem of 
Grape Vine, Corn, Sunflower, Corn-stalk or any pithy stem) a piece at least a foot long, carefully remove a thin slice from the outer part of the stem and place it in water; trim away everything from the pith, take a slice from it and place it in water beside the other. Both slices must be the full length of the piece of stem. Keep both slices under water, and examine at the end of twenty-four hours. Which has grown the more? A further illustration of this inequality of growth may be had by splitting a Dandelion stalk (see Fig. 1.52) lengthwise into four pieces and placing in water (other pithy or succulent stems or stalks may be treated in the same way).

The rigidity of the tip of the stem is also largely due to the fact that the cells are filled with water under pressure (just as in the ease of the root-hair, see page 123), which renders them rigid. Cut off the tip of an herbaceous stem two or three inches in length, place it in a strong solution of salt or sugar for an hour or so. Explain the result. Place a wilted stem in the apparatus shown in Fig. 140 or 141, and force water into it under pressure.

As a result of all these devices, the herbaceous stem is a model of strength, lightness and elasticity, serving its purpose perfectly; and we may say that this problem has been exceedingly well solved. In the case of tree trunks, the mere accumulation of woody material provides the necessary strength; while 
in water-plants there is no problem of this sort, since the water supports them, and consequently we find them almost destitute of woody fiber.

What plants get their leaves up into the sunlight with the greatest rapidity and the least outlay of material? Consider the twining and climbing plants in this connection (see Fig. 151). The problem of climbing is one that has been solved by various plants in a great number of different ways, so that it would hardly seem possible to suggest other solutions than those actually found in nature.

Beginning with the simplest cases, we have what we may call weaving plants, which weave themselves in and out among the branches of other plants and cling by means of their branches and straight or slightly curved leaf-stalks or by means of hooks, spines, etc. As examples of this class of climbers, study the climbing Roses, Blackberry, Raspberry, Jasmine, etc. How does the plant behave when it first starts up from the ground? Where does it begin to branch? How does it reach or find the support? How does it cling to it? Does it always prevent its leares from being shaded by the plant which supports it? Do you think that its stem seeks the light?

More special and elaborate adaptations for climbing are found in tendril-bearing plants. The leaf-stalk in many cases acts as a tendril, as in the Nasturtium, Clematis and the Potato vine; in other cases the leaf- 


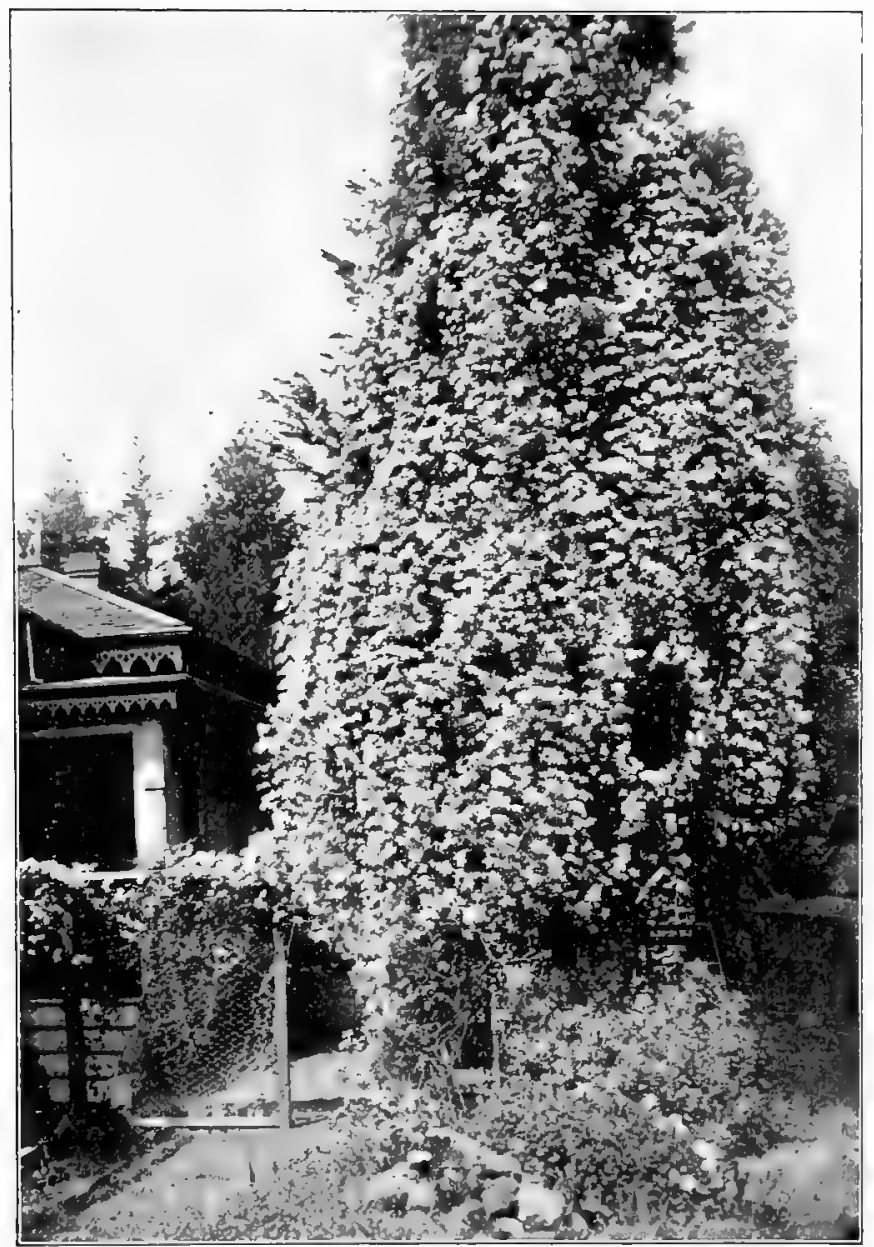

151. Clematis on an evergreen (in California) showing the advantage of a climbing habit. 
blade, either in whole or in part, becomes transformed into a tendril, as in the Pea family; in still other cases it is a branch which becomes a tendril (as shown by its position and development, or by the fact that it may occasionally bear leaves), as in the Squash, Pumpkin, Grape-vine and Passion Flower. The last'mentioned plants have tendrils which are especially suitable for study. Find out all you ean about the development of the tendrils and their behavior. Does the tendril always grow out straight at first? How large must it be before it becomes sensitive to contact? Does the tendril tend to swing around in a circle, as if seeking a support? How long does it take to make a complete circle? Does this depend somewhat on the temperature? Does this movement seem to be performed by the tendril or by the stem on which it is borne? How soon does the tendril coil after finding a support? Sticks of wood about the thickness of a lead-pencil fastened to upright pieces by a single nail so that they may be set at any angle are very convenient for experiments of this kind. The upright piece (a lath or portion of one) should be sharpened so as to be easily set in the ground. Is the tendril everywhere equally sensitive? Can the tendril coil equally well regardless of the angle at which the support is set? How does it behave when the support is too large for it to coil around? Do rain-drops falling on the tendril cause it to coil? 
A part of the shoot may be brought indoors and placed with the cut end in water, while a stream of water from the faucet is directed on it. Do you see any advantage in this behavior of tendrils? Does the part of the tendril between the stem and the support coil; if so, in what direction? Do you see any advantage in this coiling? Do the tendrils which find support grow stronger and more woody than those which do not? What is the advantage of this?

Why does the tendril coil? The best answer we can give to this question at present is that contact with a solid body arrests the growth of the contact side and promotes that of the opposite side. Why this is so we do not know. If we imitate the coiling of a tendril by cutting out a strip three or four inches

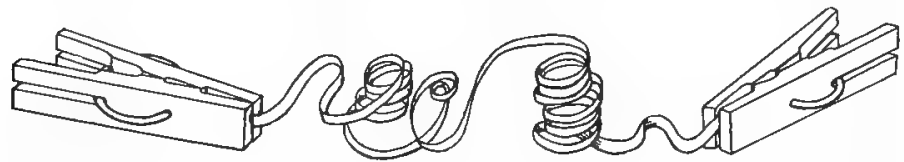

152. Behavior of a strip of flower-stalk of Dandelion, fastened at both ends and immersed in water (to show the reversal of eoiling which oceurs in tendrils).

long from a Dandelion stalk (Fig. 152) and fastening the two ends by clothes - pins, we find on putting it in water that it shows the same reversal of the coils which is shown by a tendril which has fastened itself to a support; it would seem that the reversal of the direction of the coiling is due to purely mechanical reasons, since the same result can be gotten with a twisted string. 
Study also the tendrils of the Virginia Creeper or of the Boston Ivy (sometimes called Japanese Ivy). Why do they grow toward the wall? Bend back the tip of the vine so that the tendrils are directed away from the wall, and fasten it in this position. How do the tendrils (especially the newly formed ones) behave? Is this due to the light? Conduct some of the growing tips into boxes fastened on or near the wall, so that you can control the direction of the light as you please or exclude it altogether (if the plants are growing on a brick or stone wall the boxes may be simply wired to nails driven into the mortar between the bricks or stones). How do the tips of the tendrils behave on touching the wall? If the little cushions by which the tendril attaches itself be injured or removed, can the tendril replace them? How long does it take a branch of the tendril to attach itself firmly? How much weight does it take to tear it loose when it has firmly attached itself? Attach a small box to it and pour shot into it until the tendril breaks loose from the support.

In what direction do the main stem and the branches of these plants grow? Is this direction due to gravity? Bend back and fasten some of the tips (of both main stems and branches) in a horizontal position and also pointing downward. Is the growth of the stem affected by light? Experiment on the stems by changing the direction of the light and by 
excluding it altogether. Can you now explain why the tips of the stems press themselves to the wall?

How do the main stem and branches behave when they reach the top of a wall? How do they behave when unable to attach themselves?

The English Ivy climbs in the same manner as the Boston Ivy, but attaches itself by roots (Fig. 153) instead of by tendrils. Study its behavior carefully.

The most interesting adaptations for climbing are found in the twining plants. The Morning-glory, Bindweed, Hop, Scarlet Runner, Pole Bean (or String Bean), Lima Bean or Sweet Potato may be studied as examples of this class of plants. How does the stem grow at first? When does the tip begin to droop? Does it appear to swing around in a circle as if seeking a support? As you look down on the stem from above, does the tip move like the hands of a watch (clockwise) or in the opposite direction (counterclockwise)? How large is the circle de-

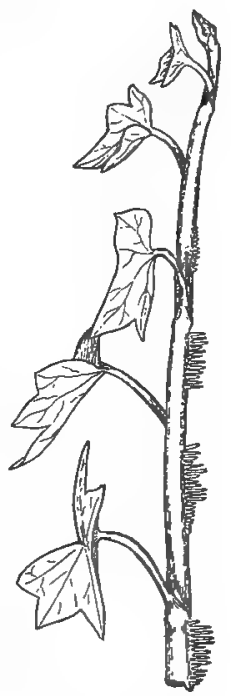

153. Branch of English Ivy. scribed by the tip? How long does it require to make a revolution? (Does the temperature affect the rate of the revolution?) How does the stem behave when it meets a support? What is the size of the largest and the smallest support it can twine about? Is it more advan- 
tageous for it to twine up large stems or small ones (remember that it must, in order to thrive, get its leaves above those of the plant on which it twines)? Does it twine best on a vertical or on an inclined support? Can you see any advantage in this? Place the support on which it is twining in a horizontal position; how does the plant behave? Does this make it appear as though gravity were a cause of the twining? Reverse a vertical support on which the plant has made several turns, so that the tip of the plant points downward; how does the plant behave? (For this experiment potted plants, with upright sticks set in the soil as supports, are very convenient, since it is only necessary to incline the pot or turn it upside down.) Does light affect the twining? Keep the plants in darkness, and observe the result.

Are the turns of the stem equally steep at the tip and at the base? Does this arrangement help to hold the plant in place by causing it to hug the support? Can the plant twine as well on a smooth support (e. g., a glass rod) as on a rough one (a branch or twig)? How does the plant behave when it reaches the top of the support?

What causes the plant to twine? The best answer we can give at present to this question is that the twining is due to the influence of gravity, which stimulates one side to grow more rapidly than the other. When the tip points north it is the west side which is 
stimulated in clockwise climbers, the east side in counter-clockwise climbers. Why gravity should stimulate the east side rather than the west (or vice versa) we do not know, any more than why it should stimulate the lower more than the upper side in so many cases.

Many plants have underground stems (e. g., Iris, Ferns, etc.). Such stems are advantageous in many ways; the plant may die down in the fall and come up again from these stems in the spring (in such cases food is stored in them [Potato, etc.] which enables the plant to get a good start in the spring); they enable the plant to spread and take slow but sure possession of a great area (e. g., Horse-tail, Mints, Grasses, etc.); they are indispensable to the plant in sand-dunes and similar places, since they bind the soil together and keep it from blowing away. ${ }^{1}$ It is interesting to note that these underground stems, whose work is similar to that of the roots, closely resemble roots in their general appearance and are commonly mistaken for them. This affords another illustration of the fact that function determines form and structure. If we force underground stems to grow up into the light and air, they begin to function like ordinary stems and assume, in a measure, the ordinary appearance and structure of stems.

1 Plants which have this habit are of great importance for binding the soil of dikes, levees, banks of canals, etc. 
The intimate connection between the work of the stem and that of the leaf, which we have had occasion to note frequently in this chapter, is further emphasized by the fact that in most cases the stem (in the younger portions at least) contains chlorophyll and shares in the work of starch-making.

Does the stem use up oxygen and produce carbon dioxide, as germinating seeds, roots and leaves do? Repeat the experiment described on page 194, using pieces of stems instead of leaves.

How does the stem obtain the necessary supply of air for these processes? Do you find stomata in the epidermis?

Strip off a piece of the epidermis and examine it for stomata (as described on page 196). Examine also a thin section in water, and observe the bubbles of air between the cells (under the microscope they have a very characteristic dark appearance). Examine an older part of the stem (where the color is no longer green) in the same way. Attach a bicycle pump to the stem by a short section of thick, white rubber tubing (which should be secured at the joints by elastic bands or wire), close the free end of the stem with sealing-wax, place the stem under water and pump air into it (Fig. 154). The openings, which are visible to the naked eye and which (in the Birch, Cherry, etc.) may become an inch or more long, are known as lenticels. A section through one 
of them (Fig. 135, $l$ ) shows that it consists of a mass of loose cells which by their growth have ruptured the epidermis. This process always begins under one of the stomata, and a greatly enlarged opening is formed by tearing. The figure also shows that a layer of cork has been formed under the epidermis; it is this which gives the brown color to the stem. The cork is a necessary protection to the stem, for, as it grows older, the epidermis falls off. When the stem gets still older the bark is formed; this consists of a

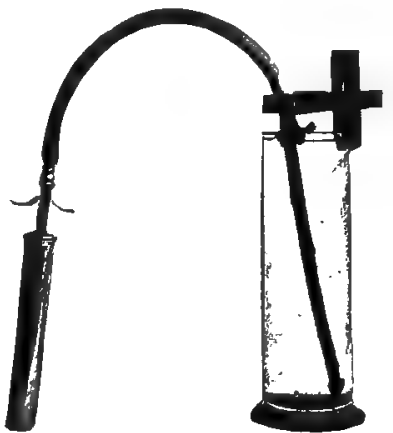

154. Method of investigating lenticels (air is pumped into the sub. merged stem by means of the bicycle pump). mixture of cork, strengthening cells and the dead cells of the bast. The growth of the stem causes the bark to split and fissure, thus allowing air to enter.

The lenticels are very clearly shown by sealing both ends of a short piece of stem with sealing-wax, placing it under water in the air-pump and exhausting. In some cases merely placing the stem in hot water suffices.

In order to see how readily air may travel down from the leaf into the stem, we may fix a leaf airtight in a rubber stopper (as described on page 205), and fix this in a tube to which we fit a piston (constructed as deseribed on page 188); pour in a little 


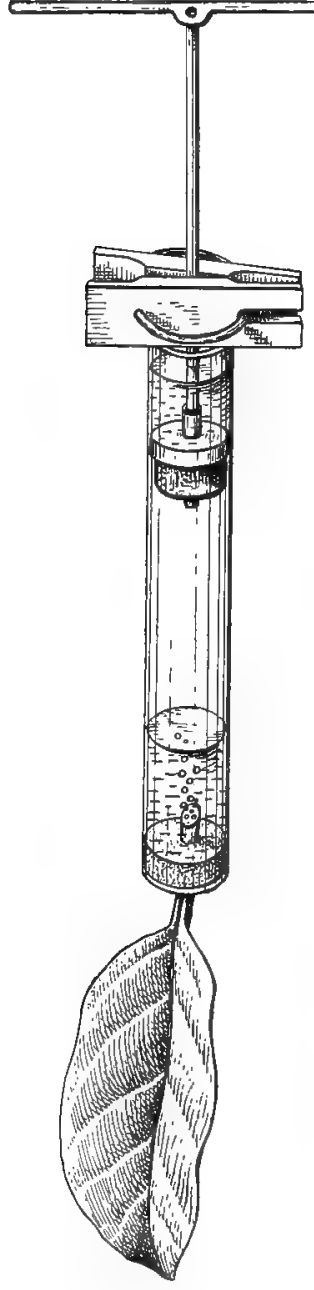

155. Method of investigating the entrance of air into the stemby way of the stomata.

water and exhaust the air (Fig. 155). Leaves of Geranium, Magnolia, Laurel, etc., may be recommended for this experiment.

Having tried this experiment, perform the following: Fix a leaf or leafy branch air-tight in a cork and insert the latter into a bottle brimful of water so as to exclude air as much as possible (it will be necessary to insert the point of a knife beside the cork to let the water escape). Hang up the bottle in the sunlight (Fig. 156). The transpiration of the leaves will withdraw water from the bottle, causing a partial vacuum, with the result that air will be drawn in through the leaves and rise in bubbles from the cut end of the stem. The experiment shows clearly that the air and the water travel in different channels in the stem, so that they do not interfere with one another.

In order to test how far the air penetrates and where it travels 
in the stem, fix a short piece of stem air-tight in a cork and fit this in a lamp-chimney (as shown in Fig. 139). Pour in water, and exhaust. Or force air through the stem by an arrangement similar to that shown in Fig. 141 , in which case we may observe with a hand-lens just where the air issues.

It sometimes happens that in coating trees with tar to protect them from insects and fungi, they suffer severely from too liberal an application, which deprives the stem of air.

To determine the effect of ex-

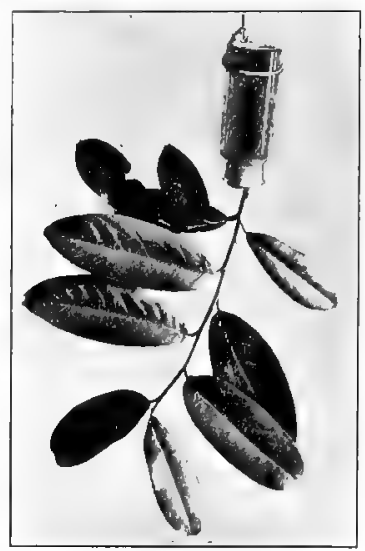

156. Method of investigating the entrance of aix into the stem by way of the stomata and lenticels.

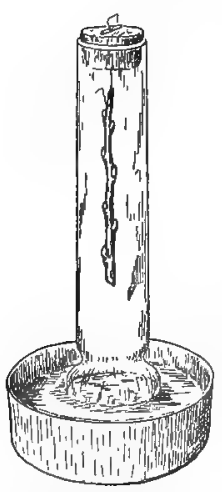

157. Willow twig suspended in $a$ saturated atmosphere.

cluding air from the stem, we may take Willow cuttings and suspend them in moist air (see Fig. 157), by attaching them to a cork fitted into a lampchimney which stands in water. As the experiment is to last for several weeks, the constant level apparatus described on page 27 (Fig. 27) may be used. Let some of the cuttings be completely smeared over with vaseline, so as to entirely exclude air. Place all the cuttings under favorable conditions of growth. 
When the untreated cuttings have put forth vigorous shoots, those with vaseline on them will probably show little or no development of shoots. Now carefully wipe off the vaseline with a rag, and then rub the stems well with dry sand and place them again in the chimney or set them in water, to see if they will grow.

Cuttings and seeds sent long distances, especially to or from the tropics, are frequently ruined by starting to grow prematurely in transit. Of the three factors which promote growth, namely, moisture, warmth and air-supply, the attempt is constantly made to control the first two, which is in most cases difficult or impossible, while the control of the air-supply, although easily accomplished, has been neglected. Sealing up the plants in air-tight tins or packages has been tried, but this is far less effective than sealing each cutting by means of wax, paraffin or similar substances. This seems to promise a favorable field for experiment.

How do the submerged portions of water-plants get air? When they have leaves which project above the water or float on its surface, they may receive a supply of air through them. Examine some plants of this sort (e. g., Pond Lilies, Arrowheud, etc.), and notice what enormous air-passages exist in them. Do these passages extend up into the leaves? Examine also swamp plants which have their roots in water or 
mud. In the case of plants which live entirely submerged it would seem that they must get their air from the water. Does water contain air? We have already gained some evidence on this point in our previous experiments. Place some tap- or springwater in the air-pump, and exhaust. Are air-bubbles formed? Boil some of the water for half an hour, allow it to cool, place it in the air-pump, and exhaust. Are bubbles formed to the same extent as before? Careful tests have shown that water may dissolve a large amount of air. It is this dissolved air in the water on which totally submerged plants depend for their supply.

In order to grow water-plants successfully in aquaria, it is frequently necessary to furnish them with a constant supply of air. This may be done by means of the apparatus shown in Fig. 158. It consists of a long, vertical glass tube about one-eighth inch in diameter, widened a little at the top. When a drop of water falls into this from the siphon it will, if it strikes in the center, fill the tube and then fall down, carry-

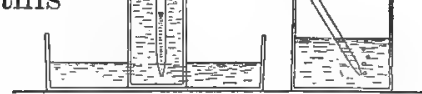

158. Apparatus for supplying air in a constant stream to an aquarium. ing the air before it (i. e., it acts like a piston). On arriving at the T-tube connection, the air passes over 
into the aquarium, while the water falls straight down into a receptacle below. The water outlet tube must dip a little deeper under water than the air outlet tube; otherwise the air, following the path of least resistance, will escape by the same outlet as the water. In order to keep the latter submerged to a constant depth, use a small jar as shown in the figure: the shallower the depth the greater the amount of air which will pass over, since enough drops must accumulate in the tube to overcome the pressure of the water at the outlet where it escapes. The drops should be made as large as possible and should strike the tube nearly in the center; if the bore of the tube is too large the drop will not fill the cross-section and consequently will not act as a piston. In order to regulate the rate

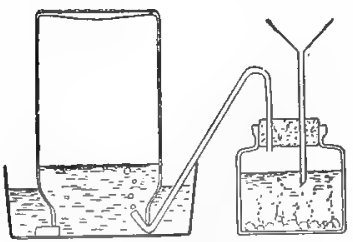

159. Arrangement for supplying "iuprou dioxide to plants growing in water. of flow of the siphon, it may be drawn out to a fine point (as shown in the figure), which can be broken off to the requisite degree and covered with cotton (held in place by an elastic band) to filter the water.

A very successful way of growing algæ and other water-plants is shown in Fig. 159. A jar or bottle is filled with water and inverted over water: carbon dioxide is conducted into it from a bottle containing fragments of marble (or marble dust or whiting), into which we slowly pour weak sulphuric acid by means of 
a funnel passing through the cork: a tube passing through the cork serves to conduct the carbon dioxide into the jar. A few moments must be allowed for the carbon dioxide to drive the air out of the bottle and tube; the tube should then be introduced into the jar" and the evolution of gas continued until the jar is nearly filled with gas.

Another method is to grow the algæ in small tubs (of wood fiber) filled with water, keeping a huge bubble of carbon dioxide or air just below them, as shown

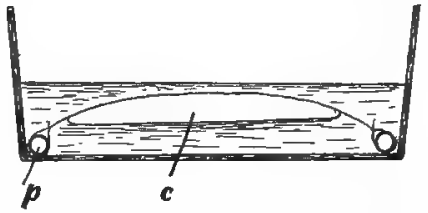

160. Arrangement for growing waterplants in contact with a bubble of earbon dioxide or air. in Fig. 160. This bubble is kept in place by means of a net (made of cheese-cloth or mosquito netting) attached to a circular hoop of small flexible lead-pipe $(p)$, which rests on the bottom of the tub. The bubble may consist of air, or air blown from the lungs, or of carbon dioxide generated in the apparatus shown in Fig. 159.

The common method of placing aquatic animals and insects and aquaria in order to supply carbon dioxide is excluded for our purpose, for the reason that they feed on the algæ. We may, however, place a welldeveloped cutting of Willow or Wandering Jew (Fig. 84) in the jar; the carbon dioxide excreted from its roots will be a great stimulus to the algæ. 


\section{CHAP'IER VI}

\section{THE WORK OF FLOWERS}

IN preparation for flowering, the plant stores up a supply of food. How long does this take; what kind of food is stored, and where? Compare the behavior, in this respect, of plants which live for a year only (annuals), plants which live two years (biennials) and plants which live on from year to year (perennials). Which method of preparation for flowering seems to you in general most effective? Find out what you can about the behavior of Cacti and the Century Plant. Study especially the different kinds of bulbous plants. Cut open the bulb of a Hyacinth, and notice the food stored for next spring's growth, and the flowers already formed and prepared to open at the earliest opportunity.

The formation of flower-buds during the previous season would seem to be an advantage. Does this occur in most plants? Open, and examine with a hand-lens the large winter-buds of the Horse-Chestnut, Buckeye, Hickory, Maple, Poplar, ete. Can you find any traces of flowers? In some cases the flower-buds may be recognized by their position; for example, 
some Plums have a flower-bud on each side of the leaf-bud. As the new leaves come out in the spring, we find the three buds already formed in the axil of each leaf, and the flowers which are soon formed inside the flower-buds must wait a full year before opening. In the first stages of their formation the flowers may be too small to be seen (except with the microscope) ; we must not, therefore, be hasty in concluding that they are not yet present in any given case. Fruit-growers have thought it desirable to know the exact time when the flowers were formed in the bud, in order that they might try to control this process by irrigating and applying special fertilizers at the proper time. Learn what you can about these points.

Examine some flower-buds which are just opening. Do you find an abundance of food in them and in the stems on which they are borne? What kind of food predominates? Is there a rapid consumption of food by the developing flowers? Repeat the experiment described on page 34 , using flower-buds instead of seeds. (Buds of Composite flowers, e.g., Sunflower, Dandelion, Daisy, etc., are especially good.) What does the result signify? Can you detect any setting free of heat in the developing buds (see page 36) ?

of what use is the calyx, or green covering, of the flower-bud? We may endeavor to answer this question by removing the calyx from the bud at as early a 
stage as possible in its development. The Passion Flower, Bindweed, Cobæa and other flowers where the calyx is large and inflated are especially well adapted to such experiments, but any large flower, such as the Poppy, Rose, etc., may be chosen. Remove the calyx while the loud is still quite small, taking care not to injure the petals or other parts of the flower. It seems natural to suppose that the calyx protects the flower-bud against drying in the same way that the bud-scales protect the leaf-bud. What does the experiment show in regard to this? Since petals are more easily injured than leaves by rain, frost, etc., even when the calyx is not removed, we should keep sharp watch to see whether the flowers deprived of calyx suffer more than the controls in these respects.

Do you find that flowers which have been deprived of the calyx are able to develop normally? Does the

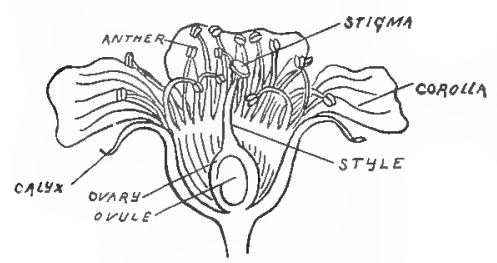

161. Cherry blossom cut open, to show the parts of the flower, result depend on how early the calyx is removed?

Let us now look at the interior of the flower. If we cut open flowers of the Cherry, as shown in Fig. 161 , we find the seed-cases (or ovaries), containing the tiny seeds (or ovules). Surrounding the ovary are the anthers, or pollen-cases, mounted on short stalks, and containing a yellow dust, the pollen. 
When the pollen is fully formerl, the anthers open and allow it to escape. Of what use is the pollen? 'T" answer this question, we may drmive the flower of pollen. For this purpose, choose flowers which are large enough to permit of the necessary manipulation; select unopened buds; cartully open them at the tip, and remove the anthers with a forceps, taking care not to injure the other parts of the flower. The flower is nuw rleprived of all its pollen; but more pollen may be easily brought from neighboring flower's by the wind or by the bees (and other inserts), which ronstantly fly from flower to flower. To inerent this, we may protect the flowers by covering them with small paper bags tied tightly on the stalk, so as to completely enclose the flower. Do flowers so treated form fruit? Tr must, in every case, have controls which set fruit, in order that we may know whether the experimental conditions are responsible for the lack of it.

If the pollen is neressuly for fruit-making wh may next ask, How does it operate? We "dn see this most rearly if wa examine the flower of some Gras or Grain. (Timothy is lest for this purprose.) Examining a flower whose anthers liare witlered, w ser what appears to be a tiny brush projecting from the flower. On remoring the outer roverings of the flower with needles, we s+s the ovary (semd-case) with two brush-like styles or stigmas: on examinilug with a hand-lens we sep that they are covered with pollen- 
grains. Fig. 162 shows the appearance of these in the Oat.

Placed in a drop of water on a slide, covered with a cover-glass and examined under the high

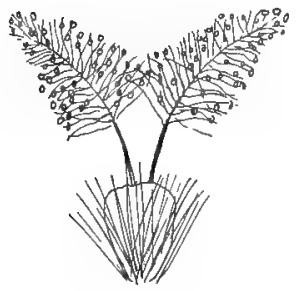

162. Ovary (seed-case) of Oat with feathery style. power of the microscope, many of the pollen-grains are seen to be sending out long tubes (Fig. 163) which grow down along the brush-like style toward the ovary. What happens after that can be seen only in good sections, but may be described in a few words. Inside the ovary lies (as you may see with a hand-lens) a tiny seed or ovule (Fig. 161). Within this is a mass of tissue, in the central cavity (embryo sac, Fig. 164) of which lies the egg. In the center of the egg is a nucleus. The pollen-tube approaches to within a short distance of the egg and opens at the end; a nucleus issues from it which unites with the nucleus of the egg, so that the two form a single nucleus. The egg then begins to develop and eventually forms a tiny plant, with caulicle and leaves, such as we find in the ripened seed.

Unless the union of the nuclei takes

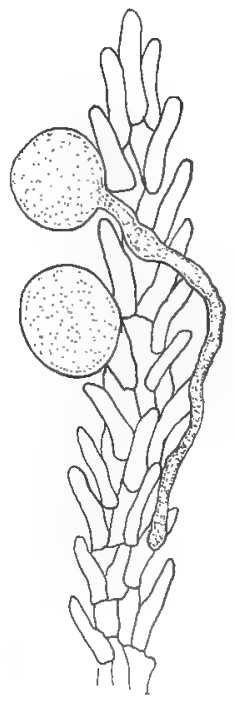

163. A branch of the style of Oat, showing a pollen-grain pusling out a long tube (poll:"n-tnlie), which grows down toward the ovary (seed-case). 
place, the egg does not ordinarily derelop; hence we see why pollen is necessary in order to set seed. If we examine various flowers with a handlens, we find the pollen deposited in a particular spot, which is provided with brushes, hairs or sticky substances in order to retain it. This spot is called the stigma (see Fig. 161). What happens if we remove the stigma? Remove the stigma before the bud is open, being careful not to injure the other parts of the flower. Do not protect the flowers from insects, but rather assist pollination by placing pollen on the flower. Do you find that flow-

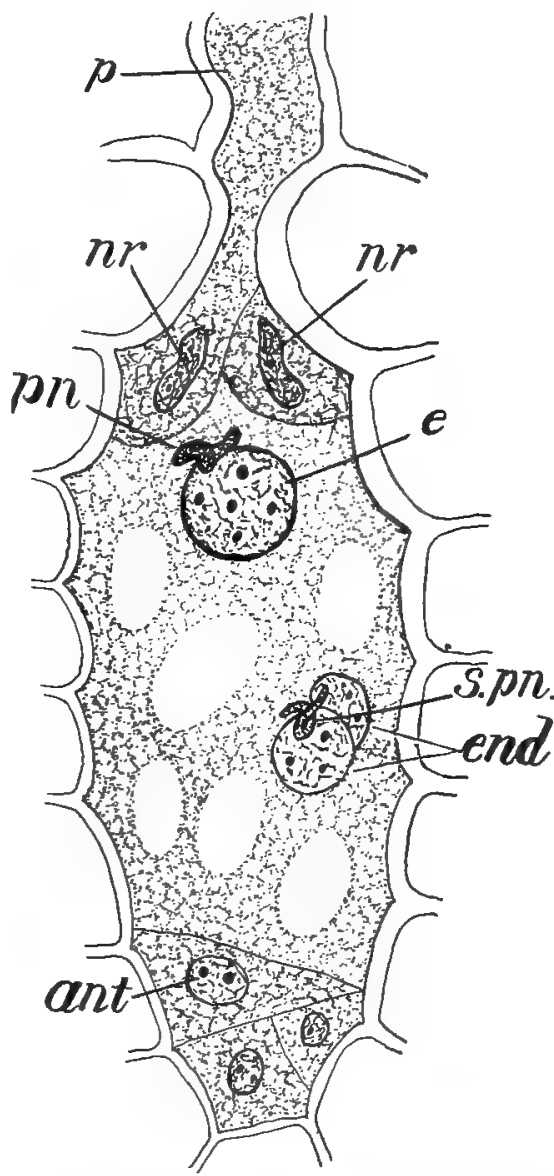

164. Embryo sac of a Lily, showing the uninn of the nucleus from the pollen-tube $(p n)$ with the egg (e): the second pollen-tube nucleus (spn) unites with two endosperm pro-nuelei (end), which multiply and form the endosperm: (ant) antipodal cells, $(n r)$ nurse nuclei which help nurish the egg, etc., $(p)$ polleu-tube. 
ers so treated are ahle to set seed? We must, of course, have unmutilated flowers (if possible on the same plant) for comparison, and it is important that we choose a plant whose flowers set seed freely.

The effectiveness of the stigma in retaining pollen may be tested by dusting the flower with flour or any white powder and afterward endeavoring to blow it away. In the Monkey-flower the stigma has two lips which come together and holl the pollen firmly when it has been deposited. Touching the open lips with the point of a peneil will cause them to close at once. The silk of the Corn is practically a long stigma covered with projections to retain the pollen, which is carried by the wind: Wheat and Grasses generally have such stigmas, but they are much shorter and lesis conspicuous than in the Corn.

It is the work of the stigma not only to capture and retain the pollen, but also to provide favorable conditions for its germination and to nourish it during the growth of the pollen-tube. The sticky substance on the stigma contains sugar (as you ean rasily ascertain by tasting or applying a chemicnl test), which serves the germinating pollen-main for food. If we places pollen-grains in a "lrop" of sugar solution of the right strength, we shall be able to observe their germination, which may, in some cases, take placo in a few minutes (Willow, Sweret Pea). It is alvisalile to make up cane sllear solutions of :3.) per cent, 10 per cent and 5 per 
cent, and test pollen-grains of various species in each. The following may serve as a guide: 3 lmr cent, Tulip, Narcissus, Onion; 1; per cent, Sweet Pea, Nasturtium (Indian Cress).

A very convenient method is to take a glass or metal ring, or one cut out of wax (about one-half inch in diameter), and cernent it to a glass-slide with vaseline: on this lay a cover-glass from the center of

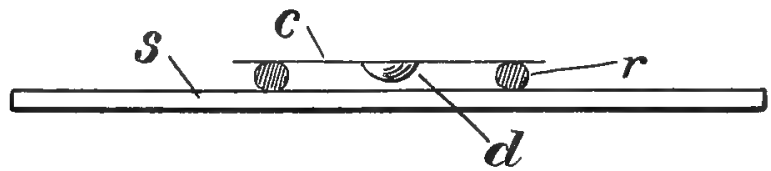

165. Hanging dron arrangement for the cultivation of pollen-grains: $(s)$ slide, (c) rover-glass, $(r)$ ring, ( $d$ ) hanging drop. (Sectional view.)

which hangs a drop of sugar solution containing the pollen (Fig. 165); seal this air-tight by means of vaseline.

In each case, make control experiments by placing some of the pollen in rain-wuter (tap-water or springwater may be used). In which medium does it grow best? Vary the experiment by cutting off the tip of the stigma and placing it at one edge of the drop. Do the pollen-grains show any tendency to grow toward it?' If so, it may help us to explain why the pollen-tubes grow down to the ovary. Presumably, in such cases, the stigma gives off substances which attract the pollen-

1 The fact that the pollen-tubes have at tendency to grow away from the air at the edge of the drop should be taken into account. Make some experiments on this point, ly leaving the chamber open to the air and also by sealing it air - tight with raseline. 
tubes; and we suppose that the tubes are attracted to the ovules in the same way.

The fact that pollen-grains germinate or burst when placed in water shows the importance of protecting them from rain and dew, since they are not, when germinating, in suitable condition for transportation (any more than germinating seeds would be). ${ }^{1}$ Notice how quickly they dry up and perish if exposed to dry air while in this condition.

Do you find devices to protect the pollen from rain? Examine as many kinds of flowers as you can after a shower, or sprinkle them with a watering-pot and note the result. Here we find so many different ways of solving the same problem that it is an interesting matter to study. The flowers may be protected by the leaves (Jewelweed, Linden), by the sepals (Acanthus), by the closed petals (Pea family, Snapdragon), by an arching roof (Violet, Monkshood), by contracting the tube of the corolla above the stamens (Phlox, Primrose) or by the stigma (Iris). ${ }^{2}$

Many flowers grow in a horizontal position or hang downward, which effectually prevents the entrance of rain. Others, which grow upright, assume a droop-

1 The pollen, like the seed, varies greatly in the length of time it retains its vitality. Ordinarily it will keep for at least a week in a cool, dry place, without deterioration. The Arabs, who gather the pollen of the Date Palm for artificial pollination, appear to keep it for one or even two years without nuch loss of ritality. See an article by Fwingle on the Date Palm in the rear Book of the U. S. Ierpt. of Agriculture for 1900 .

2 See Kerner and Oliver, "Natural History of Plants," Vol, II, p. 104. 
ing position on the approach of rain (Wood Anemone, Scabious, Herb Robert, Potato, ete.); others accomplish the same result by closing the flower tightly, and are useful as weather indicators (Poor Man's Weatherglass, Water-lily, Dandelion, etc.). Such flowers are regularly closed during the night, and thus the pollen is protected from the dew. Many other flowers seem to have no means of protection, but it will be found in many cases on examination that the anthers themselves close to protect the pollen (Plantain, Grape, Castor-bean, etc.), or a layer of hairs or a waxy covering prevents the pollen from becoming wet.

It should be noted that most of these devices protect the nectar, or honey, equally with the pollen.

Flowers, as a rule, open and close quite regularly at certain times of day: the great Swedish botanist, Linnæus, constructed a floral clock in which the hours were told by the opening and closing of the flowers. This naturally raises the question, Is the opening and closing of the flower due to the action of light? Select some flowers which open and close quickly, such as Oxalis, Dandelion, ${ }^{1}$ etc., and try the effect of covering them with a box in the middle of the day or of keeping them under a dark box for two or three days, during which time they should be examined at intervals; try to keep the temperature as nearly like that

1 Some flowers never open a second time and consequently cannot be used for the experiment. 
of the controls as possible; on exprosing them again to the light, what happens?

Temperature, as well as light, plays a part in the nrocess. The Crocus or the Tulip can be made to open or close at any time of lay by changing the temlerature. The experiment should be commenced in the morning before the flower has opened, and the temperature should not go above $15^{\circ} \mathrm{C}$. On placing it where the temperature is $21^{\circ}$ to $25^{\circ}(\mathrm{C}$. it begins to open: if it be returned to the original temperature it will soon begin to close. In this way it is possible to make it open, close and open again all within an hour. ${ }^{1}$

The flowers of some alpine plants have been obsurverl to open and "lose several times luring the course of an hour as they were illuminated or dark(2)ert hy passing clouds.

The amount of moisture in the air also has something to do with the matter. A flower of the Poor Man's Weather-glass kept in a satmated atmosphere refuses to open even when given the normal amount of illumination. Make experiments on this point. The flowers may float on a cork in a glass jalr which is (n) verel with a piece of glass cemented on air-tight with vaseline. (The jar should be large enough so that the flower will not suffer for lack of oxvgen :

1 Simply submerging the flower in water which is almot $10^{\circ}$ ('. Warmer than the atir, will in most cases cause it to open rapidly. 
a few green leaves placed in it will be of great assistance in this respect.)

The opening of the flower seems to be caused by more rapid growth of the inner side of the petal; the closing by more rapid growth of the outer side of the petal: how far the latter process would go if the other petals did not hinder it, may be easily seen by cutting them away.

It appears, then, that the petals protect the pollen from rain and dew; we have already found that the calyx prevents the inner parts of the flower from drying up during their development, and it seems probable that the petals serve the same function also. It would be easy to determine this point by a few experiments. But, so far as protective purposes go, the most striking thing about the petals, i. e., their color, would seem to be useless. We may therefore ask, of what use is the color of the flower? It is quite safe to say that every one has been told that insects are attracted to flowers by their colors. The petals, with their bright and showy colors, have been compared to sign-boards, which advertise to the bees the presence of the honey and pollen of which they are in search. The insects, in their visits, carry pollen from flower to flower, and so enable the flower to set fruit.

It is true that there exist a great number of devices for making the flower conspicuous, chief of which are striking color and the grouping of flowers in masses, 
so that the color is visible from a distance (Elder, Parsley family, etc.). The head of a Dandelion or Sunflower is such a group, being made up of numerous small flowers, and in the Sunflower there is an interesting division of labor, in that the onter flowers are for show only (producing no seed), while the inner are incouspicuous but devote themselves entirely to seed-bearing. It should be noted, morever, that the contrast in color between the black center and the yellow rim makes the flower much more conspicuous than either color alone. Make an experiment on this point by covering the center with the yellow petals and then going off some distance to note the effect. Look out for cases of color contrast, e.g., contrast between the flowers and the background of leaves, between the stamens and the petals, between the old and fading flowers and the young ones, etc.

Notice flowers which are growing beside a wall or other screen which euts off the light. Do they turn toward the light? Does this aid in making them conspicuous? Perform some experiments to test their sensitiveness to the light. Study the behavior of Dandelion, Sunflower and Wild Mustard flowers, with reference to "following the sum."

It is said that not only are insects attracted by the colors of flowers, but that they are partial to certain colors. Bees are said to prefer line and violet, to care little for yellow, and to avoid scarlet. In my 
garden it happened that Parsnip and Chickory grew side by side, the blue flowers of the one mingling with the yellow flowers of the other. In this case I have watched with interest the striking difference in the behavior of bees and flies. The bees were abundant on the blue flowers, but in several hours of watching not a single bee was seen to alight on a yellow flower, although they would often spring over one to get at the next blue flower. On the other hand, the yellow flowers fairly swarmed with flies of different species, while not a single one appeared on the blue flowers.

We must take into account, in this connection, a peculiarity which the bee has of visiting, as a rule, but one kind of a flower at a time. I have often performed the experiment of placing a branch of the blue-flowered Thyme (of which the bees are very fond) in a bed of Yellow Lupine, in which they were busily at work. They avoided the Thyme uniformly, going over it or around it to get at the Yellow Lupine flowers. But, on placing a cluster of Lupine flowers in a bed of Thyme blossoms, they paid no attention to it.

Flower's which display no conspicuous sign-boards are, nevertheless, visited eagerly by bees or other insects (e. g., Grape, Virginia Creeper, Mignonette English Ivy, etc.). It appears quite certain that it is the odor which attracts them in these cases. Night- 
blooming flowers are proverbially sweet-scented, and doubtless depend principally on the odor to attract the moths which visit them, although the color may be of some assistance also (such flowers are usually white or light in color). The question therefore arises, Does not color, after all, play a subordinate part in attracting insects? especially as it has been shown, by experiment, that bees and wasps cannot cieariy distinguish objects more than two feet away (butterflies and moths see but a few feet); while they can scent honey for long distances. In the case of flowers which produce nectar (or honey), therefore, color would seem to be not so important.

A very interesting series of experiments can readily be made by any one who has sufficient leisure to watch the visits of the insects for a time. Choosing a plant which is freely visited, note the number of insect visits in an hour: remove the petals from a part of the flowers, and cover the remainder with screens made of green leaves (a single large leaf may be folded so as to form a sort of cap for the flower). Endeavor, by noting the number of insect visits in an hour, to determine whether the loss or concealment of the color has an appreciable effect.

The flowers of many plants are not visited by insects (e. g., Grains and Grasses, Oaks, Hazels, Poplars, ete.; Pines and other Conifers, Palms, Hops, Nettles, etc.); in these cases, the pollen is transported by the 
wind. A good example of such a plant is the Corn: the anthers (i. e., the "tassel") produce abundant pollen, which is carried by the wind to the "silk"; the strands of "silk" are long stigmas, with projections to catch the pollen; the pollen-tube must grow down the whole length of the "silk." Wind-pollinated plants produce great quantities of pollen, since wind-pollination is a very wasteful process. The pollen from Pine forests often forms a yellow coating on lakes or on the ocean two hundred miles away, and has been mistaken hy peasants for showers of sulphur. The pollen-grains of the Pine are provided with hollow vesicles, which buoy them up in the air very much on the principle of a box kite: these may be easily seen under the microscope.

In order to determine to what extent flowers are dependent on insects (or wind) for pollination, it is only necessary to enclose them, before the bud is open, in paper bags (see page 289). If this be done, no fertilization or setting of seed can take place unless some of the pollen of the same flower arrives on the stigma. This is said to be self-pollination, as opposed to cross-pollination, which means bringing the pollen from a different flower.

Darwin made a series of experiments to determine whether cross- or self-pollination is more advantageous. He found that, in the case of the Morningglory, cross-pollination gave plants which in height 
exceeded those from self-pollination as 100 to 76 . He carried this out to the tenth generation, when the proportion was 100 to 54 . The average was about 100 to 77, or about 30 per cent gain. There was also a corresponding gain in fertility. In this case the crosspollination was with plants growing near together; on bringing pollen from plants growing in another garden, it was found that the plants obtained exceeded the cross-pollinated plants previously obtained as 100 to 78 in height, as 100 to 57 in number of seed-pods, and as 100 to $51 \mathrm{in}$ the weight of seed-pods: that is, they were nearly 30 per cent more vigorous and, as compared with self-pollinated, over 44 per cent more vigorous. Similar results were obtained with Cabbage, Buckwheat, Beets, Corn and Canary Grass.

It appears, therefore, that cross-pollination is more advantageous to the plant than self-pollination, and there are numerous devices in flowers which promote cross-pollination and prevent self-pollination. An effective means of preventing self-pollination is to have the anthers and ovaries borne in separate flowers; both kinds of flowers being on the same plant, as in the Squash, Walnut, Pine, Corn, Castor-bean, ete. (termed monœcious), or the staminate (pollen-bearing) flowers on one plant and the pistillate (ovary - bearing) on another, as in the Hop, Poplar, Willow, ete. (termed dioecious). Study as many cases of this kind as you can. 
Where both anthers and seed-case are borne in the same flower, self-pollination is often prevented by having them active at different times; thus the stigma is pollinated and withers long before the anthers of the same flower are open in Deutzia, Elm and Plantain (this method is especially common in the Rose, Honeysuckle, Nightshade and Mustard families), while, on the other hand, the anthers mature first in a great variety of flowers (especially common in Pea, Mallow, Pink, Mint and Composite families). This can be clearly seen in Fig. $166(A)$, which represents one of the small flowers from the center of a head of the garden Gaillardia. The flower is tubular and is represented as cut open so as

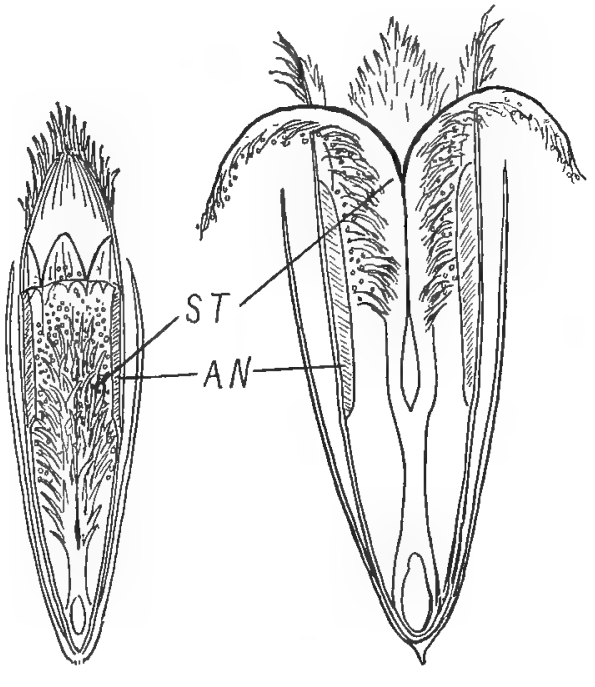
A B

166. Gaillardia flower cut open, $a$, bud, showing the pollen falling on the style $(s t) ; b$, open flower. showing the style-branches bent back ready to receive pollen from another flower.

to show the anthers (an), which are united together to form a small tube into which the pollen falls and so comes directly on the stigma (st) : nevertheless, self- 
pollination does not take place, for the reason that the stigma is not yet mature. In the process of development it is slowly pushed up, thus gradually expelling the pollen from the tube so that it can be carried away by bees. When this is accomplished it opens up, as in Fig. $166(B)$, exposing the smooth surface, which is the receptive part: the pollen which is now deposited

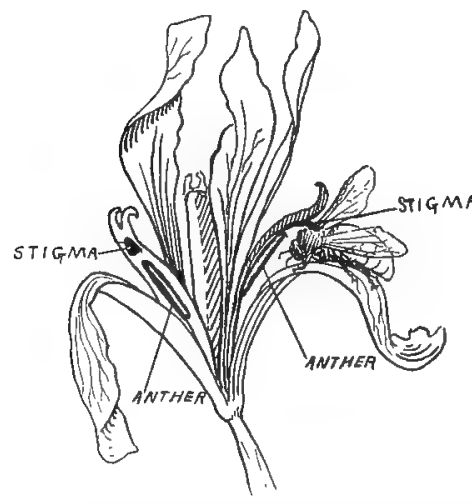

167. Tris flower, showing how the stigma first removes the pollen from the bee, iufter which the anther deposits a fresh supply, which is carried to another flower. on it comes from another flower. Good examples of this arrangement will be found in the Daisy, Aster, Cosmos, Sunflower, Coreopsis, Zinnia, etc.

Another method is by placing the anther's and stigma in different positions. This is illustrated by the Iris (Fig. 167). As the bee enters the flower the stima surapes off some of the pollen with which its back is covered: as it goes deeper into the flower its back receives a fresh supply from the anther: as it backs out of the flower this pollen is not deposited on the stigma (owing to the manner of its attachment to the style), but is carried on to the next flower.

The behavior of the Partridge-berry (also caller? 
Twinberry, Checkerberry, Deerberry and Squaw-vine) illustrates another method. Fig. 168 represents two flowers cut open. In one of these the anthers are placed high up in the tube, while the stigmas are below: in the other the reverse is true. The bee, in thrusting its long tongue into $A$, receives the pollen on the lower portion of the tongue and, going to $B$, deposits it on the stigmas: in going from $B$
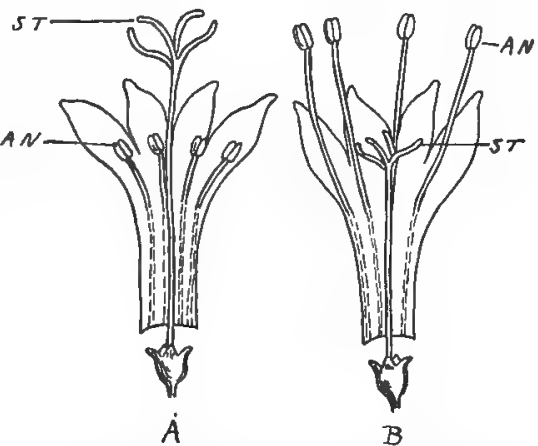

168. Partridge-berry flower cut open: the bee's tongue receives pollen upon its lower portion in $a$, from the anthers (an), and deposits it on the corresponding stigma $(s t)$ in $b_{1}$ and vice versa. to $A$, it would receive the pollen on the upper portion of its tongue and deposit it on the stigmas in the corresponding position. On going from $A$ to another flower of the same kind, the pollen from $A$ would not reach the stigma, and, even if it should, experiments indicate that it would not take effect: it is effective only when deposited on a stigma of corresponding position. A similar arrangement is found in the cultivated Primrose and in the Houstonia (also called Quaker Ladies and Quaker Bonnets).

The.Sage has a neat device for the purpose of loading the bee with pollen and preventing self-pollination. Fig. 169 (A) represents the flower-tube cut open, 
showing the anther (an) with a bee entering and about to strike his head against the lower part of the anther-
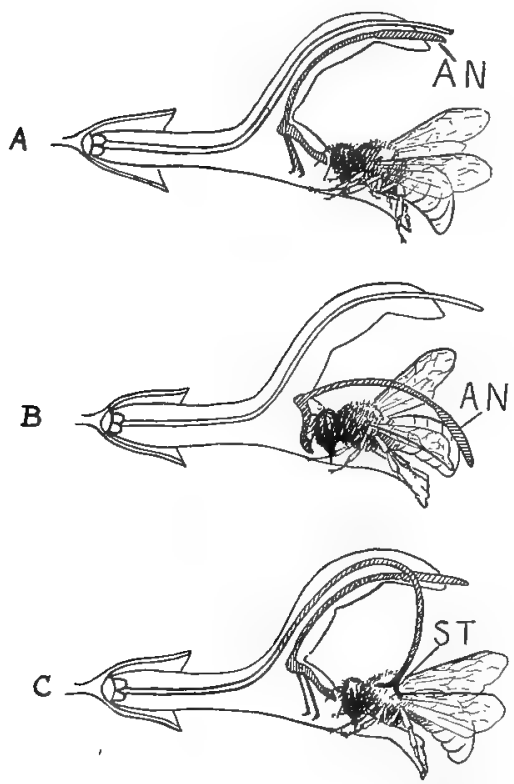

169. Sage flowers cut open: $a$, a bee entering the flower; $b$, an anther (an) striking the bee; $c$, the stigma (st) of an older Hower removing pollen from the bee.

stalk. The stalk of the anther turns on a hinge or pivot, so that, when the lower part is struck, down flops the anther and discharges pollen all over the bee (Fig. $169, B)$. In the meantime the stigma $(s t)$ is up out of the way, but when the pollen is all discharged it grows down and takes the position shown in Fig. 169, $C$. When a bee enters such a flower the pollen is transferred directly to the stigma.

There are numerous other devices for loading the insect with pollen, including the pumping mechanism of the Pea flower, the irritable stamens of Barberry, Prickly Pear, etc., which spring when touched at the base, thereby scattering pollen on the insect, and also the curious arrangements found in Orchids. An arcount of these, together with other matters concerning pollination, will 
be found in Kerner and Oliver"s "Natural History of Plants," Vol. II. See also Müller, "Fertilization of Flowers"; Weed, "Ten New England Blossoms"; Newell, "Outlines of Lessons in Botany"; Gibson, "Sharp Eyes" and other books; Lubbock, "British Wild Flowers"; Darwin, "The Various Contrivances by which Orchids are Fertilized by Insects."

The peculiar shapes of flowers are usually adaptations to the visits of insects, either for the purpose of securing cross-pollination or covering the insects with pollen, or affording platforms on which they may alight, such as the lower lip of the Sage (Fig. 169). See also Iris (Fig. 167) and examine the Pea, etc. It is an interesting experiment to watch how the bee alights on the flower; and, when this is ascertained, carefully out away the platform or other support, and notice the subsequent behavior of the bees.

In such flowers as the Pea and Sage, it is quite evident that the position of the flower is of importance. If it should accidentally be turned upside down and were unable to right itself, the platform would be out of place and the devices for loading the insect with pollen would not operate; the same is true of a great many other flowers. Moreover, we notice that in many cases the old and the young flowers assume different positions, as in the Clover, Poppy, Strawberry, Laburnum, Geranium, Honeysuckle, etc.; the general effect of this is to get the young flowers which are not yet 
ready for pollination, and the old flowers which have been pollinated, out of the way of the insects which visit the flowers. What determines the position of the flower and fruit? If the plants are growing in pots, ${ }^{1}$ invert them; place some in the dark and others in the light, and observe the effect on the flowers. If the flowers are in a long cluster, keep the main stalk from bending by attaching a small weight to the end, and then observe the behavior of the individual flowers. Try the effect of placing the plant in a horizontal position. What parts bend? Do the flowers resume their original position? Is the result due to light, or gravity, or to both? Are the movements performed by the stalks alone if the flowers are removed?

In the Snapdragon, Pea, etc., notice that when the bee alights on the lower lip, the flower, which, up to that time is closed, opens as the result of its weight. A smaller insect would not be able to get into the flower, since its weight would not suffice to bend the lower lip. This is an advantage, since it keeps out small insects, and especially creeping insects, which would not distribute the pollen advantageously. Another device for keeping out creeping insects is a band of woolly or sticky hairs below the flower, which serves the same purpose as the tar applied to the trunks of trees. In other cases a mass of roolly

1 If the plants are not in pots, the flowering branches may be carefully bent downward or cut off and placed in water, and then inverted, 
hairs in the tube of the flower constitutes an effective defence.

In many plants (especially among Pears, Plums and Grapes) pollen from the same flower or even from another individual of the same species is without effect: pollen from another variety must be employed in order to set the fruit. This is usually accomplished by planting a few trees of the proper variety in the orchard, so that the bees may carry the pollen. This condition is known as self-sterility, and is frequently brought about by hybridization or even by cultivation. Climate may also assist in bringing it about; it is noticed that some varieties which are self-sterile in the North are not so in the South.

The effect of pollination and fertilization is not confined to the seed, but extends to the seed-case and often to surrounding parts. Thus, the pulpy part of the Strawberry consists of the swollen end of the stalk, which is stimulated to grow as the result of the fertilization of the seeds. In the Apple the fleshy part is partly the wall of the ovary and partly the calyx : the fruit has five compartments, and, if the seeds in only one or two of these are fertilized, the fleshy growth around these compartments is stimulated more than elsewhere, producing a one-sided fruit. Just how the development of the seed influences that of surrounding parts is not known, but it seems to be due to chemical changes which take place in the developing embryo. 
In the Fig the end of the stalk develops as a hollow, fleshy structure, which is lined with numerous flowers closely crowled together (like the flowers in a Sunflower head). These produce the seeds ${ }^{1}$ which we see in the Fig as it comes on the market. In some varieties the Fig develops without fertilization, while in others it drops off without developing unless the seeds are fertilized. This peculiarity of Figs has led to a great amount of confusion which has only recently been cleared up. ${ }^{2}$

Aristotle described the practice known as caprification as it is still practiced today. It consists of taking figs from the Wild Fig (or "caprifig") and hanging them in the branches of the cultivated Fig tree of the orchards. Ever since the time of Aristotle, scientific men have disputed whether this process were useful or not. Recently it has been shown that in the case of the best Figs of commerce, i. e., the Smyrna Figs, the process is absolutely necessary, while in the case of some others it is not. The key to the puzzle lies in the fact that the most valuable varieties of Figs are like the Hop plant in having the pollen-bearing flowers on one plant and the seed-bearing flowers on another. The "wild Fig," or "caprifig," is the pollen-bearing plant, and when its figs are hung in the branches of

1 Each one of these "seeds" is really " fruit, since it is contained in a separate seed-case.

2See the article by Swingle on "Smyrna Fig Culture in the United States," in the Year-Book of the Department of Agriculture for 1900. 
the orchard Fig (which is the seed-bearing plant) tiny wasps, all covered with pollen, ereep out of the caprifigs and enter the edible figs, and so pollinate the flowers, which consequently are enabled to set seed. It is the seed which gives to the Smyrna Figs the peculiar nutty flavor which makes them so valuable for the market.

The Smyrna Figs do not develop fruit without fertilization: they contain true seeds. The Mission Fig of California and other varieties which develop fruit without fertilization have no true seeds, but only hollow shells containing no embryos.

For a long time there has been a belief that the pollen can not only stimulate the growth of the seed-case and surrounding parts but also influence their color, form, etc. (this phenomenon is known as Xenia). A white Corn pollinated with a dark Corn produces in the course of the same summer an ear with white and dark kernels mingled, giving the ear a very curious appearance. Examination shows that in this case it is not the seed-case whose color is affected but the seed itself; it is the endosperm of the seed which is colored, and this arises from a nucleus which, like the egg nucleus, fuses with a nucleus from the pollen-tube (Fig. 164), and so can receive the qualities of the pol. linate parent. Many different kinds of evidence go to show that the nucleus is the bearer of hereditary qualities, and that where two nuclei fuse the resulting nucleus bears the qualities of both. 


\section{CHAPTER VII}

\section{THE WORK OF FRUITS}

THe first work of the fruit ${ }^{1}$ is to convey nourishment to the young seeds (ovules) and protect them during their development. How great is the importance of the food supply to the seeds is shown by the fact that there is never enough to develop all of them, so that a fierce struggle ensues among them to determine which shall develop at the expense of the others. You can see evidences of this struggle in almost any young fruit you open. Almost from the first, certain seeds take the lead and grow larger than the others, and these are usually the ones which in the end absorb all the nourishment from the others so that the latter shrivel up and finally disappear. The struggle among the individual fruits on the plant is just as vigorous; many must perish in order that a few may mature. It is often necessary to thin out the fruit in an orchard several times in a season, so that the ground under the trees is each time covered with fruit.?

1 The word fruit as here used means any ripe (or ripening) ovary or seed. case, with its contents and any other parts pertaining to it.

2 In thinning, the grower proceeds on the assumption that the amount of fruit (by weight) is much the same, whether thinning is practiced or not; but by thinning he gets this in the forn of fewer and larger fruits. Thinning must be done with good judgment. 
It is clear that to mature the seeds properly there must be a good food supply and some means of conveying it directly to the developing seeds as fast as needed. We have already noticed that a large amount of food is stored up in preparation for flowering. This is especially noticeable in such plants as the Carrot, Turnip, Parsnip, etc. Find out, by means of the tests mentioned on pages 164-166, the kind of food stored in these roots. Make the tests also on any bulbs which are available (especially Onion, Hyacinth, Lily, etc.): in these the food is stored in the leaves. Examine also some underground stems which are used for storage (such as the rhizome of Iris, Solomon's Seal, tuber of Potato, etc.), and make tests to see what kinds of food they contain. How does the stored food reach the seeds? Endeavor to trace the starch from the rhizome, bulb or other storehouse up into the seeds. The other foods may be traced also, though not quite so easily as the starch. In what tissues of the stem and fruit do they travel? Examine several trees which have starchy seeds, such as the Oak, Buckeye, etc. Where is the starch stored; in what tissue does it travel to the seed?

How completely the stored food may be used up is seen in the case of Grains. During the season of growth the plant is engaged in storing up starch and other foods, with the result that the stalks are very nutritious and eagerly eaten by animals. When the 
seed begins to ripen the plant stops growing and the stored food moves toward the seeds, where it becomes concentrated, leaving the stalks empty of nutriment so that they cannot be used as food for cattle. The withdrawal of food from the stalk goes on after the stalk is cut, consequently the best time for cutting grain is just before it is fully ripe; it can then be transported without loss of seeds by shaking, and will absorb nutriment from the stalk and ripen as well as if left uncut (this does not apply when the grain is "headed," i. e., when the head is removed from the stalk by a special machine known as a "header"). For a forage crop, like hay, cut after the seeds are formed. but before they are ripe.

A great number of plants (annuals, biennials, also the Century Plant, etc.) resemble the Grains in giving up all their store of food to the seeds, and dying after the seed is ripe. Is the food transformed on reaching the fruit? The seeds of the Rape contain, while developing, much starch, which can be traced from the leaves directly to them; but, when mature, this is all changed into proteids and fats. Examine any available plants which have oily seeds or fruits, to see if the same is true of them.

In fruits and seeds which contain large quantities of sugar, is there any indication that starch accumulates and is subsequently transformed into sugar?

Along with the production of sugar there is, in many 
f'uits (e. g., Currant, Raspberry, etc.), a marked production of acid. It is these fruits which are principally used in the preparation of jams, jellies, etc. The "jelling" depends on the presence of gelatinous substances (pectin compounds and allied substances) which are present in the ripe fruit and are increased in quantity by boiling the fruit; in this process, the acid contained in the fruit acts on various substances and transforms them into other substances which readily "jell"; in the young fruit, these bodies, as well as the acids, are lacking to such an extent that such fruits can not be used for jelly-making. On the other hand, they disappear from over-ripe fruit to such an extent that it, too, is unfit for this purpose.

Along with these changes which occur during the process of ripening, go changes in the sugar-content. The young fruit is either tasteless and insipid or else acrid and sour; as it approaches ripeness, it gets sweeter, and the sugar may accumulate to such an extent as to almost completely mask the taste of the acid (which is, however, still present in undiminished amount). The sweetness (and the characteristic flavor) of the fruit is increased by dryness and warmth: mountain-grown fruit is, for this reason, sweeter; overirrigated fruit is insipid. Sweetness may also be increased in some cases by appropriate fertilizers, and, even, in the case of oranges, by spraying the fruit with chemicals. 
The color of the fruit also undergoes changes in ripening; in this, light plays a great part. Try the experiment of covering a green apple (which is well exposed to light) with tin-foil (held in place by elastic bands), in which a circle or letter has been cut (in France there is a practice of attaching photographs to the fruit in this manner).

The changes which occur in the ripening fruit, whereby some substances disappear and others take their places (or result from their transformation), go on after the fruit is detached from the plant, as is evident from the familiar practice of placing pears in drawers to ripen. In order to control these processes and preserve the fruit properly, special methods have been developed. Thus it is found that pears which ripen fully on the tree are much more gritty than those gathered earlier and placed (not more than three or four deep) in trays, and kept in a cool, rather dry room, with little circulation of air. It is very important, in picking all kinds of stalked fruits, to leave the stalk attached to them, since its removal leaves a wound, which readily softens and decays. It is important to keep the fruit in a cool place, and to avoid exposing it to the sun; otherwise the ripening and subsequent decay will proceed rapidly. The ideal method is to put the fruit in cold storage.

Watm, as well as food, is needed by fruits. Many fruits when ripe contain from 90 to 96 per cent water. 
How does this reach them? A squash or a pumpkin is a favorable object for study: it may take up as much as a pound and a half of water in twenty-four hours. Cut a young growing squash from the vine and place the cut end in eosin solution, and allow it to stand for several days. Trace the eosin up through the bundles to the seeds. Do you find a bundle reaching to each seed? Does the bundle grow larger as the seed develops" Does the fruit lose water by transpiration? Test this matter in the fashion already described for leaves. Do you find any stomata in the epidermis of the fruit (examine microscopically and also test in the air-pump). Grapes are of especial interest in this connection: examine also apples, pears, etc. Admirable means of protection against transpiration are found in the thick, woody walls of nuts, drupes (Peach, Eucalyptus, ete.).

Does the fruit need a supply of air? Repeat the experiment shown in Fig. 31, using immature fruits instead of seeds. Try the effect of smearing over young fruits completely with vaseline: does it retard their development? Do they contain much air in their tissues? Place some of the tissue (preferably a piece of watermelon flesh) under water in the airpump, and exhaust.

How does the air travel through the stalk, etc., to the fruit? Investigate by the methods previously descrịbed. 
In order to increase the production of fruit, various methods are employed. The best method is to increase the vigor of the tree by good tilth and occasional application of fertilizers. In applying fertilizer's, it is to be noted that nitrogen tends to produce vegetative growth at the expense of fruit, while phosphoric acid tends rather to produce fruit (this effect of phosphoric acid has been demonstrated in some cases but not generally): potash is probably the most necessary fertilizer for orchards.

If the growth is so vigorous that the tree produces wood at the expense of fruit, this tendency may be checked by seeding down for a time, decreasing the amount of tillage and using mineral rather than nitrogenous fertilizers.

A local check is often applied, in the case of a branch which does not bear, by ringing or girdling. This varies in degree from simply running a knife around the branch near its base to removing a strip of bark from one to several inches wide (see p. 257), or simply by cutting a notch.

Partially cutting off the water supply by bending, twisting, breaking or notching the branch often causes it to bear. In bending the branch, it is turned downward and fastened in that position. This method is used most frequently for Grapes and fruit trees trained against walls. Twisting acts like bending but more energetically; the branch is twisted half-way round; 
splits are made, 'which consequently become filled with parenchyma, and a swelling forms at the twisted place. The branch is subsequently bent to form a loop. In layering Quinces, branches are twisted whenever roots are to be formed. In some localities the stems of nearly ripe grapes are twisted, thus diminishing the water supply and making the grapes sweeter. Breaking the branch over the blade of a knife acts like twisting. Pruning the roots or simply laying them partially bare is sometimes resorted to with excellent results. In this connection it is interesting to note that a drought (or a frost) often starts the trees of an entire region to fruiting at the same time. It has been observed that the attacks of borers, by checking the growth, often cause trees to bear: for the same reason, driving nails into Plum and Peach trees sometimes causes them to bear.

It is, of course, well known that the exposure of the land has much to do with fruitfulness. For this reason vineyards are placed on hillsides with a southern exposure, and vines and fruit trees are frequently trained against walls with like exposure. Protection from wind is also important, since the wind dries young fruits and causes them to fall and also lowers the temperature: for this reason windbreaks are indispensable in many orchards.

To summarize, then, we may say that in order to produce abundant fruit we must provide for an early 
and generous development of foliage; as the fruiting season approaches, decrease of water and increase of light and heat are desirable: succulent fruits require more water than others.

Protection of the seeds from animals and insects is accomplished in various ways. Look out for examples of the following:

(1) Spines, etc. (Chestnut, Thorn-apple or Jimson-weed).

(b) Hard coverings (Pines, Eucalyptus, nuts, Peach, etc.).

(c) Bitter or acrid taste while young, disappearing with ripeness (orchard fruits, berries, etc.).

(d) Suspension on slender stalks protects from mice, ete. (Pea).

(e) Concealment under ground (Peanut, some Evening Primroses).

The outer covering of a fruit also acts as a protection against parasitic fungi and against too rapid drying.

When the fruit is ripe its work is not yet done, for the seeds must be scattered as much as possible in order that they may propagate far and wirle: this dissemination is, in most cases, the work of the fruit.

Gather a quantity of nearly ripe pods of the Linpine, and place them on the floor of an unused room where they may dry moprly. As they lwame dry, peculiar cracking sounds are heard and the seeds are 
thrown to a distance of several feet. Try to discover by what mechanism this is accomplished; notice the twisting of the pod which accompanies the expulsion of the seeds; how is this twisting brought about? Many other members of the Pea family have this peculiarity. Interesting to study in this connection are the fruits of the Touch-me-not, Violet, 00 Wood-sorrel (Oxalis), Witch-hazel and many 0 others. The Squirting Cucumber (Fig. 170) throws its seeds twenty feet or more by means of a curious contrivance. The end of the stalk is enlarged to form a sort of stopper. The fruit is filled with a mucilaginous substance in which the seeds are imbedded. When this has absorbed considerable water, sufficient pressure is generated so that a touch causes the stopper to be ejected, and the seeds are sent flying.

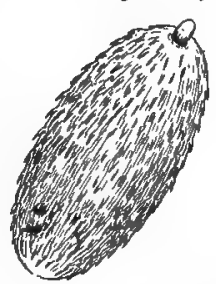

170. Fruit of Squirting $\mathrm{Cu}^{*}$ cumber in the aet of expelling the seeds: the fruit absorbs water until sufficient pressure is generated to eject the enlarged stopper-like end of the stalk and the seeds with it.

While these wonderful contrivances serve excellently to distribute the seeds for a short distance, they are but poor and ineffective compared to those which make use of the wind as a carrier. Thistledown flies to great distances; the fruits of Maples, Elms, Pines, Birches, etc., travel far and wide by the aid of the wind. On windy days, when the snow is covered with a smooth crust, such fruits go skim- 
ming over its surface at a high rate of speed, and every footprint is soon carpeted with them. On the We plains the Russian Thistle and other "tumbleweeds" are blown over the level surface of the ground, scattering their seeds at every step (in this case the whole plant assists in the dissemination).

The problem of flying is solved in various ways: sometimes the calyx is modified into a parachute (Dandelion, Thistle, etc.); sometimes the style (Clematis, Fig. 171) is used for this purpose; a bract may serve as a wing (Linden, Fig. 172, and Hop, Fig. 173), or the wall of the ovary may grow out into a flattened wing-like appendage 171. Clemwhich flies by means of $\operatorname{th} \theta$ t'eathery style. (Maple, Fig. 174), while in other cases it is the seed-coat which grows out in this way (Pines). Find out what you can about this. A very simple way of testing the effectiveness of these flying devices is to drop the seeds from a height down a stair well or wherever the air is still, and time them in their fall to the earth. Are the flying attach-

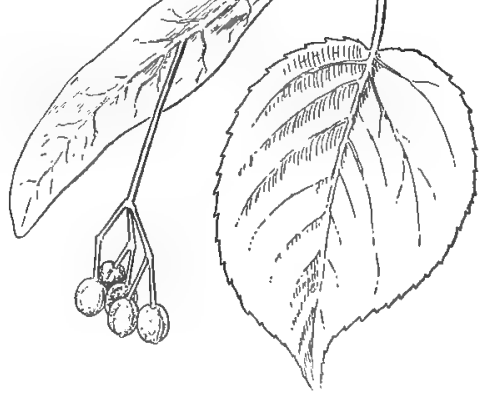

172. Linden fruit, which flies by means of a wing.like bract. 
ments of seeds, especially the parachutes, impaired by rain and dew? Test them by placing them in water"; are they readily wetted? Iou have probably noticed that fruiting Dandelion heads opell only in dry, sunny weather, when the seeds can fly to best advantage; at the approach of rain they close up tight, so that the tiny parachutes are kept perfectly dry. Study also the Willow Herb (Epilobium) and the Pines in this connection. In many cases you will find that while the
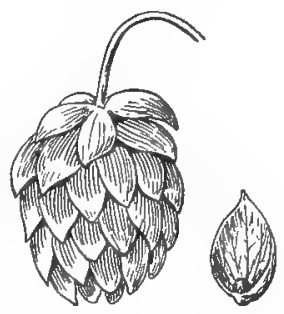

173. Hop fruit, which flies by means of at bract.

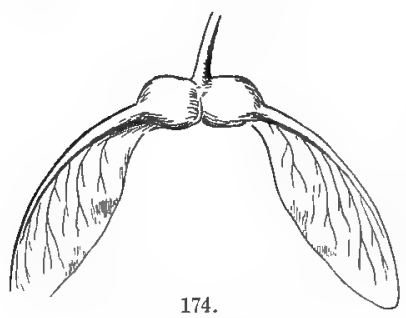

Maple keys, which fly by means of a wing which grows out from the wall of the seed-case (ovary).

seeds are not protected from rain, and may become drenched, yet they do not beconie detached from the parent plant until perfectly dried out and in condition for flying.

The burs, "stickers," and other troublesome fruits which attach themselves to clothing, show how easily plants distribute themselves by means of animals. Usually the organs of attachment are not borne on the seed itself, but on the ovary-wall, on bracts or on the stem or flower-stalk. On examining such fruits (Figs. 175 to 178) with a hand-

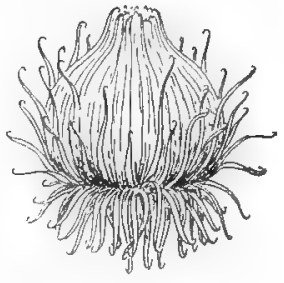

175. Burdock head. 
lens, we see that they are covered with spines, prickles, hooks, claws or barlos of the most various description,

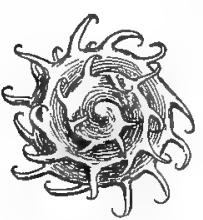

176. Frait of Bur Clover.

so that we may say that plants have tried almost every possible device in solving this particular problem. Many fruits are sticky, and will cling even to the smoothest surfaces, while some, like the Tarweeds, are both sticky and armed with hooks, so that they cling equally well to rough and smooth objects.

A simple way to test the efficiency of these devices is to toss them against a blanket hanging vertically, and notice which eling most readily to its surface. Examine the coats of animals to see what plants are most successful in attaching their seeds or fruit: .

Many seeds are carried about by birds (and other animals) in the mud which sticks

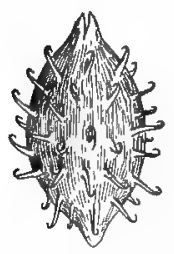

178. Fruit of Clotbur.

to them. This is especially the case with such birds as frequent

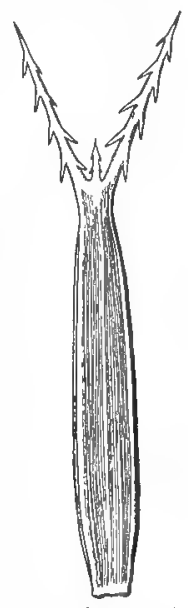

177. Fruit of Beggar's-ticks. swampy and muddy places. Birds distribute seeds principally, however, by eating the berries and other fleshy fruits, and afterwards voiding the seeds uninjured. Such fruits are usually sour, acrid or otherwist disagreeable to the taste during their de velopment; but, when ripe, become swret and fine-flarored: at the same time they assume a characteristic and usually conspic- 
uous coloration, whereby the fact of their ripeness is alvertised to the birds which feed upon them. The lright tints and sweet taste of the fruits thus serve a similar purpose to the honey and gay colors of the flowers. Experiments have been made to test the germinating power of seeds which have passed through the digestive tract of birds, with the result that the seeds germinated readily. Cherry, Apple and Juniper trees are frequently planted by birds in this way, especially along roadside fences, etc., which are frequented by them.

What seeds, especially of plants growing by brooks, streams and lakes, are able to float? Place such seeds in water, and see how long it takes them to sink. Examine any accessible water-course for evidences of distribution of seeds by water.

The Coroanut (Fig. 45), seems especially designed for floating, inasmuch as its outer filorous husk forms a veritable life-preserver; it has been known to float hundreds of miles on the surface of the ocean. On reaching a strand, it readily germinates; in this way coral and volcanic islands in the South Seas are populated with Cocoanut Palms. ${ }^{1}$

1 On seed distribution see Kerner and Oliver; Natural History of Plants, Vol. II; Beal: Seed Dispersal. 


\section{CHAPTER VIII}

\section{HOW PLANTS ARE INFLUENCED BY THEIR SURROUNDINGS}

WE have already learned that the needs of the plant correspond closely to our own physical needs: they consist, namely, of food, water, light, air and warmth. Depriving a plant of any one of these kills it: on the other hand, an excess of any of these is usually as bad as an insufficiency. In situations where all these needs are properly supplied, plants grow to perfection; but such situations are limited in extent, and, in the fierce competition to which plants are subject, many are foreer to grow in unfavorable situations or not at all. How they make the best of these situations and adapt themselves to them is an interesting study, which is best approached by experimental methods ${ }^{1}$.

WATER.-Let us knewn with the influence of water on the plant. An excellent plant to illustrate this is the Potato. A potato contains sufficient water to sprout by itself, even when kept rather dry: if a potato which has just starter to sprout is placed where it is not exposed to direct sunlight, it will continue to grow

I See an article by Webher in the Year Book of the I'. s. Dept. of Agriculture for 1895 . 
lying on a dry tałle-top, and will finally assume the appearance ${ }^{1}$ shown in Fig. 179. On comparing it with a potato grown under normal conditions, we see that its growth has been excredingly slow (the normal Potato of the same age is a hundred or more times as large), its branches are thick and clumsy in appearance, with closely erowded nodes; ${ }^{\prime}$ it

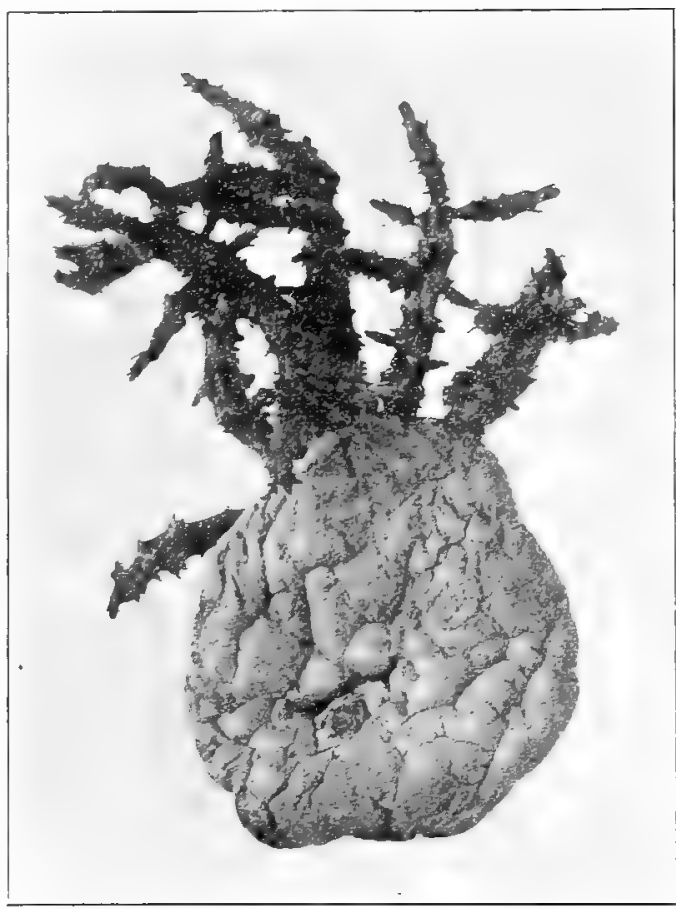

179. Potato which has been allowed to sprout and grow on a dry table-top before a north window, showing Cactus-like habit.

A somewhat similar but less pronounced effect is produced by the action of strong light, even when abundant moisture is present: in general, the effects of light and dryness are elosely similar. Fig. 180 shows the striking contrast between potato sprouts which receive little water and abundant light, as compared with those which receive abundant water but no light. In the latter the nodes are further apart and the stem more elongated and much weaker than in a normal plant, while the leaves are small and the whole plant of a pale color.

2 The nodes are the places where leaves and buds appear on the stem. 
bears no leaves, but their work is performed by the grem riud of the stem and branches. As compared with the normal plant, the loss of water in per cent of

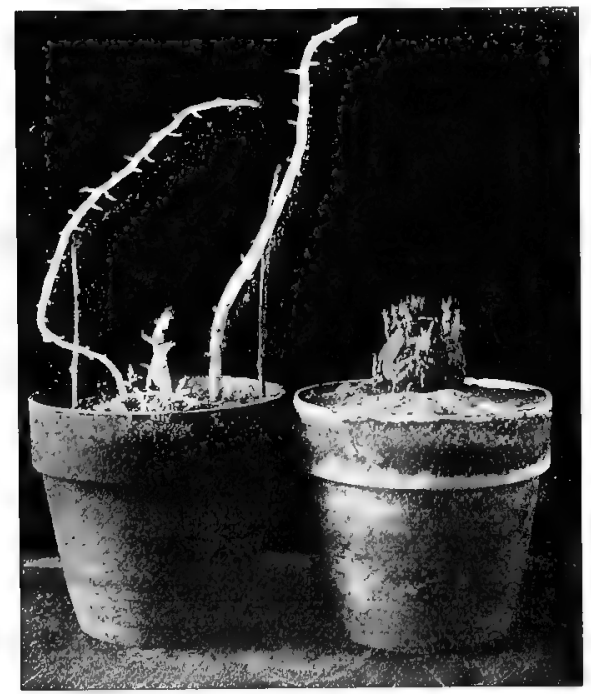

180. The potato at the left grew in a moist place in darkness: the one at the right grew in a dry place in strong light: both grow for the same length of time.

its own weight is very small. Just how much it amounts to we may determine by weighing at intervals. For purposes of comparison we may cut off a branch of the normal Potato, trim off the lower end until the branch weighs about thw same as the other, and then place it with the cut end in water, over which we pour a little cotton-seed or olive-oil. We now determine loss of weight in the usual way and compare (tests should be made under the same conditions for both).

If we take sections of the stem we find that, as compared with a normal plant, the cuticle is thicker, the cells are much smaller, and are very densely filled with starch, i. e., the stem is used as a place for storage of food. 
All these features are very characteristic of desert plants; in fact, the whole aprearance and behavior of this plant reminds one of a Cactus.

On the other hand, we may, by growing a Cactus in the dark, with abundant moisture, cause the spines to grow out into succulent, leaf-like organs. Fig. 181 shows a sprout which has grown from a Prickly Pear under these conditions. It will be noticed that the sprout appears cylindrical, and that in its whole appearance it is more like an ordinary plant than is the Potato plant shown in Fig. 179. This sprout was obtained by taking a joint of Prickly Pear which was preparing to sprout, placing it in a pot of sand, and setting this inside a closed box to exclude the light.

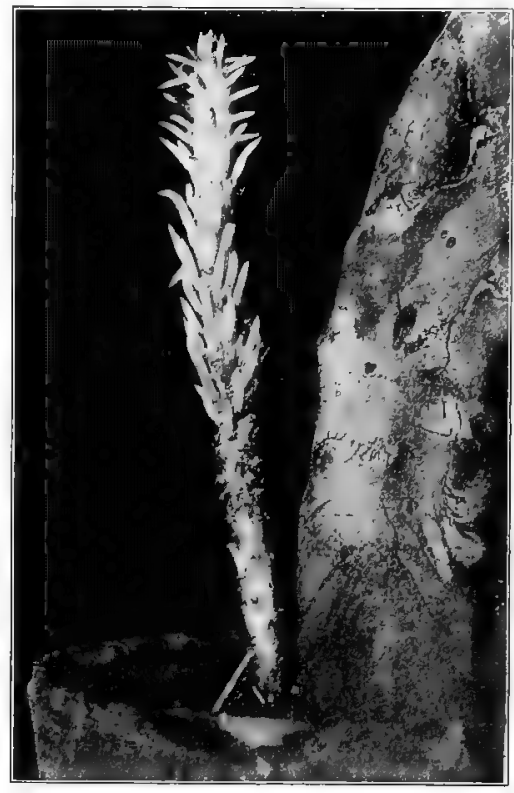

181. Sprout of Prickly Pear grown in the dark, showing leaf-like organs.

It was watered frequently, and in the course of about two months produced the sprout shown in the figure. We believe that the ancestors of the Cactus had 
leaves like ordinary plants and that their thickened, leafless stems have been brought about by the dry conditions under which they have lived, not directly as in the Potato, but by a long-continued process of change. We suppose that when the ancestors of the Cactus first came to live under drier conditions than they were accustomed to, some few of them were somewhat better adapted to stand drought and so lived on and propagated themselves under the new conditions, while their fellows perished. Among the offspring of these plants the same thing happened; those best fitted to the new conditions maintained themselves, while the others perished. In each succeeding generation the fittest ${ }^{1}$ survived and crowded out the less fit in the struggle for existence, the result being that in the course of time the plant became better and better fitted to its surroundings. In this way we suppose the various forms of Cacti to have developed to their present condition, this process of development being known as evolution. It will be seen from the illustration that evolution works by destroying the unfit ${ }^{2}$ (thus giving the fit a better chance to develop), and results in bringing the plant into better and better harmony with its surroundings, or environment. The process of destroying the unfit and preserving the fit is called

1 Whether the fittest originated gradually or suddenly (by mutation) is discussed in Chapter $\mathrm{X}$.

2 This, it should be said, is not the sole method by which evolution works, but the only one of immediate importance in this connection. 
"natural selection," and finds a close parallel in artificial selection as rracticed by man in adapting plants to his needs. All our farm and garden plants have been brought to their present condition largely by artificial selection.

We beliere that all the various kinds of plants and animals have reached their present condition by erolution and that evolution is still going on, though at a comparatively slow rate.

An examination of plants which live in dry situations slows that they have the following rharac'teristics.?

(1) Reduced surface, obtained l,y suppression if leaves (complete

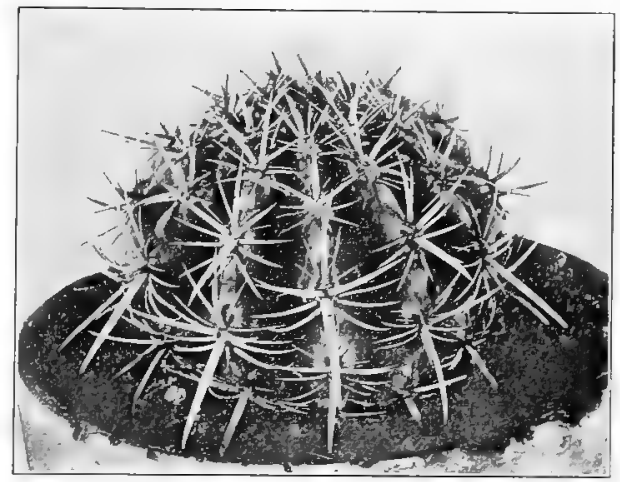

14. A spherical Cactus; a form which presents the miniraum surface for evaporation with a maximum bulk for storage.

or nearly so). This is accompanied by thickening of stems in the Cacti (Fig. 182), some of which assume a spherical form, which gives a minimum surface. The Switch Plants, such as the Gorse (Fig. 198, a), Cytisus (Fig. 183), ete., assume the form of green, rod-like switches.

1 See Chapter $X$.

2 For experiment on this subject, see pages 215-218. 
The discarding of leaves in winter by deciduous trees and shrubs is an adaptation to the drought from which the plant suffers in winter, since the roots are

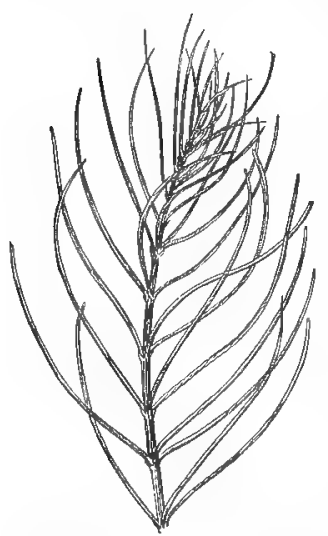

183. Branch of Cytisus (a switch plant), showing the green switch-like branches which perform the work of leaves. then unable to absorb sufficient water to supply the leaves. We may test this by the following experiment: Take two vigorous plants growing in pots; place ont on ice (by means of the arrangement shown in Fig. 11); keep the other near it at normal temperature; give both the usual quantity of water. Which plant wilts first? On continuing the experiment for a few days, it will be found that the plant on ice sheds its leaves (Begonia may be recommended for this experiment).

The fall of the leaf is precerled by the withdrawal of all nutriment from it and the formation of a layer of loose cells at the base of the stalk; this layer finally breaks apart, leaving a clear, smooth scar (see page 212). The disorganization of the chlorophyll gives rise to the gorgeous colors of autumnal foliage and, while not caused by frost, is hastened by it.

Trees which retain their leaves in winter have various devices to restrict evaporation. Study in this 
respect Pines, Spruces, Holly, etc. The branches are protected against evaporation by cork and bark; the buds, by gums, varnishes, wax, hairs, etc. (see page 214).

(2) Reduced surface obtained by having smaller leaves (Moor plants, Heaths, etc).

(3) Reduced air content obtained by diminishing

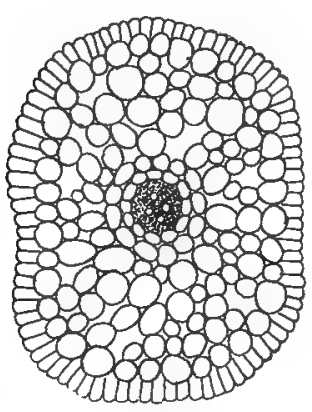

$a$

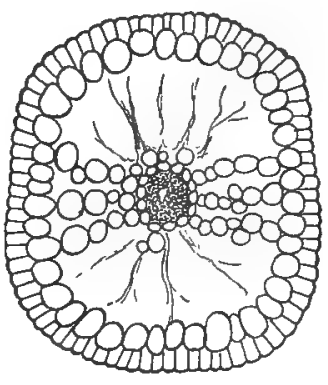

$b$

184. Stems of Callitriche in cross-section: (a) land form, (b) water form. Showing the larger air spaces in the latter.

the sizo of the interior air-spaces (Callitriche, Fig. $181)$.

(4) Reduced evaporation obtained by means of thickened epidermis, as seen in Cacti, Century Plant, Holly (Fig. 185), Oleander (Fig. 192), and most plants of dry situations.

(5) Reduced evaporation obtained by means of coverings of wax (Sugar-cane, Fig. 186, Eucalyptus, Iris, Spruce), or hairs (Dusty Miller, Wormwood or 
Sage Brush [Fig. 187], Mullein [Fig. 188], Fivefinger, Immortelle, coverings of many winter-buds), or

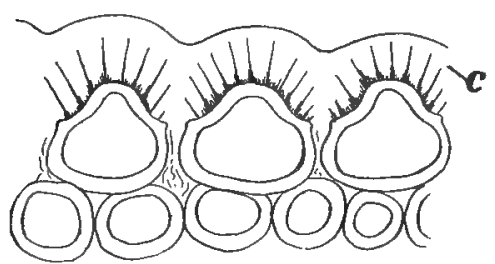

185. Epidermis of Holly, with thick cuticle (c).

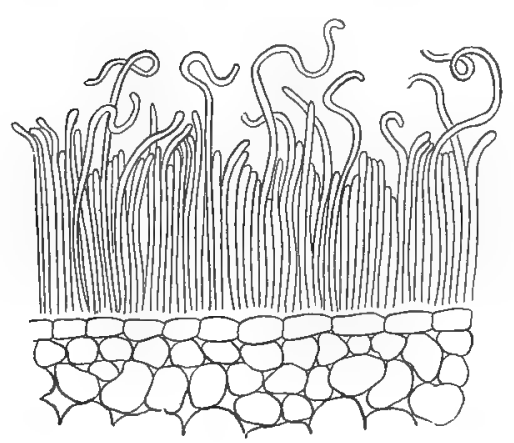

186. Waxy covering of Sugar Cane (in the form of rod-like autgrowths).

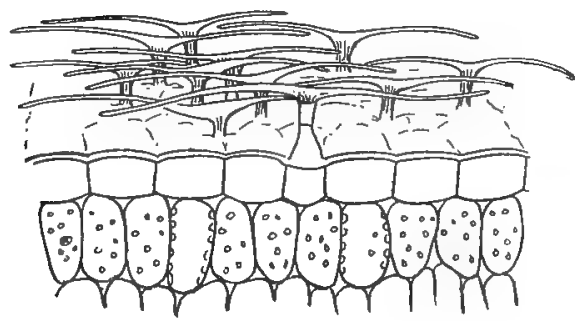

187. Hairs of Wormwood or Sage-brush. varnish and resin (coverings of most winter-buds and many leaves when young; Cistus, Pines. etc.).

(6) Reduced evaporation obtained by rolling the leaves (Corn, ${ }^{1}$ many Grasses) or keeping them in a vertical position (Eucalyptus, Iris).

(7) Storage of water (and food) in thickened leaves (Live-for-ever, Century Plant, Hen-and-chickens), or in thickened stems (Cacti, Fig. 182, ete.). The stored food and water are tempting to many animals, hence the Cacti are protected by sharp spines. The Century Plant is proterterl hy the sharp points of its leaves:

1 Șee page 213. 
it goes on storing up food for several years, when it blooms and uses up the nutriment stored in the leaves, then dies. Hence the naine, Century Plant, due to the popular belief that it blooms but once in a century.

(8) More a b u n d ant woody fiber (see Figs. 189' and 190).

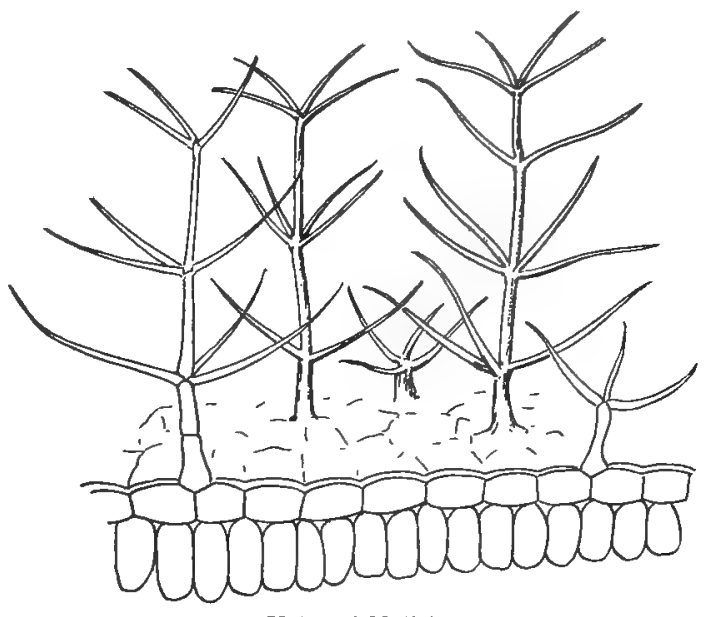

188. Hairs of Mullein.

(9) Longer palisade cells in the leaf (Fig. 194).

(10) Reduction in number of stomata (Fig. 191) and sinking of the stomata in wells and depressions

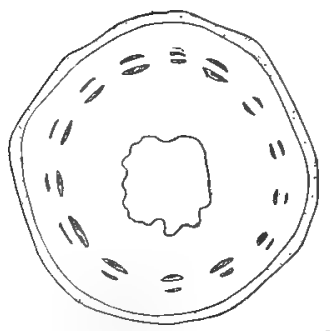

19. Cross-section of stem of Water-polygonum grown in ary soil; the fibrous bundles and strengthening tissue are shaded.
(Oleander, Fig. 192).

All plants growing in dry situationsshow some of these characteristics, and many of them can be produced in

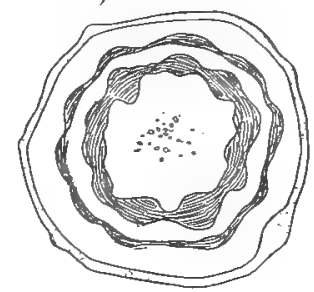

190. Cross-section of stem of Water-polygonum grown in water: the fibrous bundles and strengthening tissue are shaded. 
336

any plant by growing it with a reduced amount of moisture. Make such experiments as you can on this point.

Study every case you can ${ }^{1}$ and, if possible, make experiments, by growing the plants in pots (or plots) and regulating the amount of water given them.
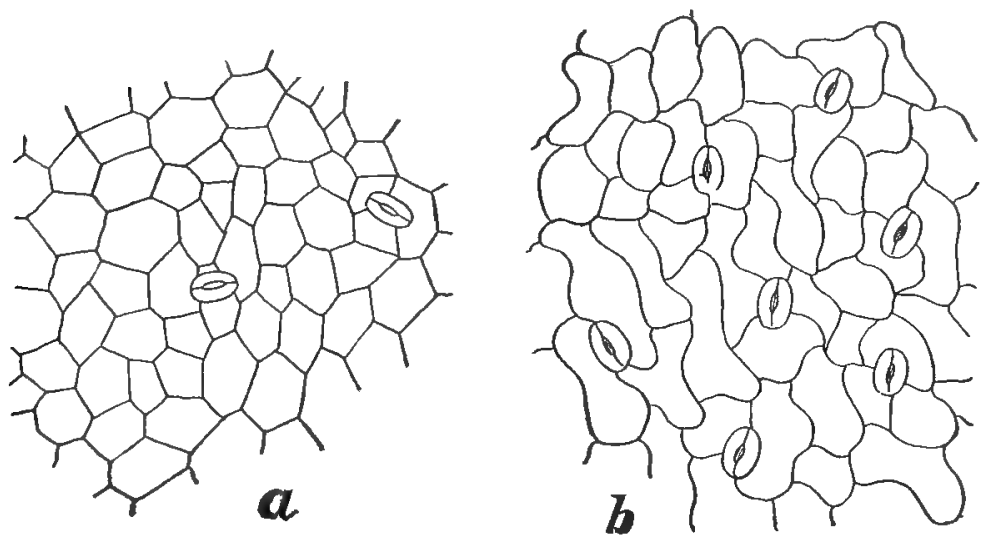

191 Upper epidermis of Water-polygonum: (a) from a leaf of a plant eultivated las.... dry conditions, $(b)$ from the first leaf produced by such a plant after being pliced in water, showing a larger number of stomata.

It may seem surprising to find that many plants which grow in damp places show the features described above: such are plants growing in alkali soils, on the seashore, in swamps and damp moors. The explanation is that in these places there are substances in the water which hinder its absorption by the roots (see page 124).

1 Plants subject to the drying action of strong winds show these featuress excellently. 


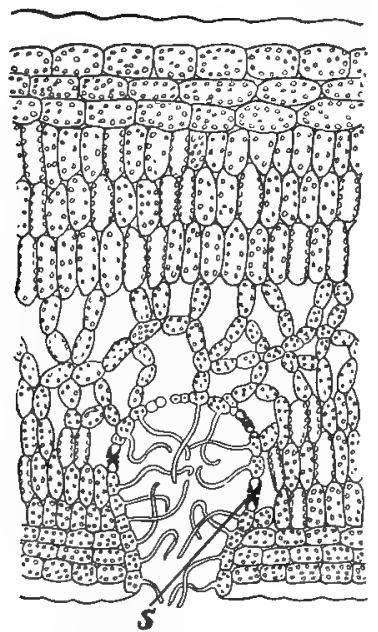

192. Cross-section of a leaf of Oleander, showing the stomata $(s)$ sunken in depressions, which are filled with hairs.
Very different in appearance are the plants which inhabit streams and lakes, such as the Water-lily, Spatterdock, Arrowhead, ete., which are typical water-plants, with broad thin leaves, devoid of hairy coverings and provided with enormous air-spaces, especially in the leaf-stalk. These great airspaces are necessary to convey air dlown to the loots and other submerged parts of the plant. The submerged leaves (and other

submerged parts) of waterplants obtain air from the water (see pages 193 and 283 for experiments); the leaves are usually split up into fine divisions by which a greater surface is secured. Fig. 193 shows the behavior of the Arrowhead, which produces ribbon-like leares under water and the characteristic Arrowhead leaves above water. The figure also shows a heart-

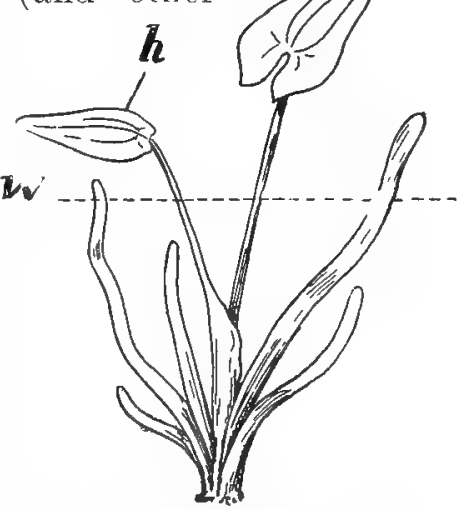

193. Arrowhead, producing ribbon-like leaves below the surface $(w)$ of the water and an inrowhead leaf above the surface; the heart-shaped leaf ( $h$ ) forms a transition between the two forms. 
shaped leaf, a transition form between the two. Fig. 194 shows at (b) a section of a submerged portion of a ribbon-like leaf, while at $(a)$ is a section of a por-
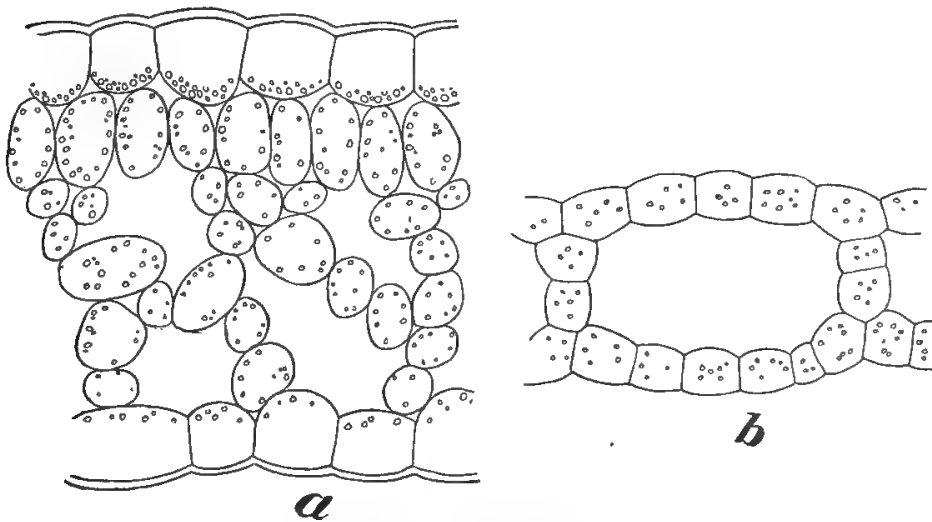

194. Cross-section of the ribbon-shaped leaves of Arrowheud, (a) from a part of a leaf above the water, $(b)$ from a part of a leaf below the surface, showing thinness, lack of cuticle and larger air-spaces.

tion of a ribbon-like leaf which projected into the air. Fig. 195 (a) shows a sulumerged leaf (water-leaf) of the Water Buttercup, while beside it $(b)$ is another leaf which grew abore the water (air-leaf). 'The Water Buttercup presents a trausition from a land-plant to a water-plant. If the water sinks, so that the submerged leaves are exposed to the air, they dry up and perish, while the air-leaves live on and the plant continues to flourish.

We have good reason to believ's that the rraterplants (with the exreption of certain groups of flow- 
erless plants) were originally land-plants which were forced by competition to take to the streams and lakes. Some of them still possess the power to live on land if the water falls away, while others can live only in water and quickly perish when left without it (Hornwort, Water-lily, Pondweed, etc.). The water-plants in general show exactly opposite features to those already enumerated as characteristic of desert-plants. They have a large exposed surface, thin cuticle, no waxes, varnishes, resins or hairs on the surface, a minimum amount of woody fiber, very large air-spaces and poorly developed palisade.
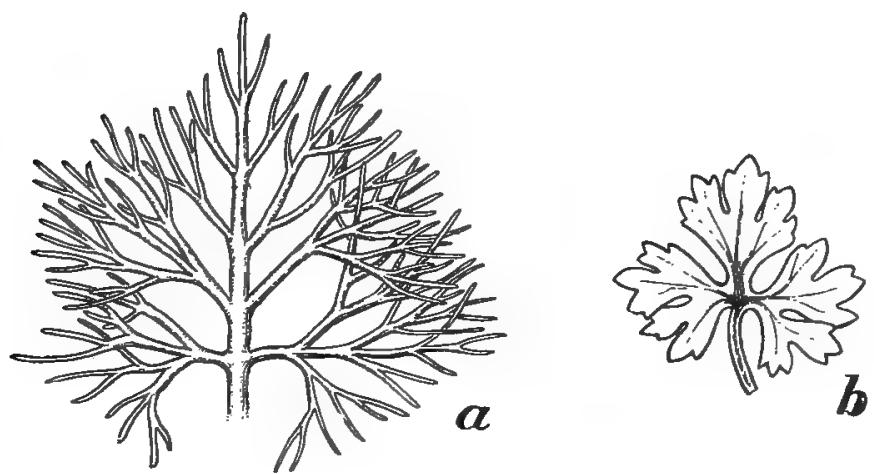

195. Leaves of the Water-buttereup: (a) water-leaf, (b) air-leaf.

Stomata occur, as a rule, only on surfaces which are directly exposed to air (Fig. 196).

Water-plants have usually a very poorly developed root-system : many of them have no roots at all, but float about on the water, sinking to the bottom on the 
approach of cold weather and rising to the surface again in the spring. Such plants, as a rule, have the custom of breaking up into pieces, each of which floats away and becomes a separate plant.

A very interesting experiment may be made by growing the Water-hyacinth in soil instead of in water and observing the modifications it undergoes. We may also use the Water-polygonum for this experiment.
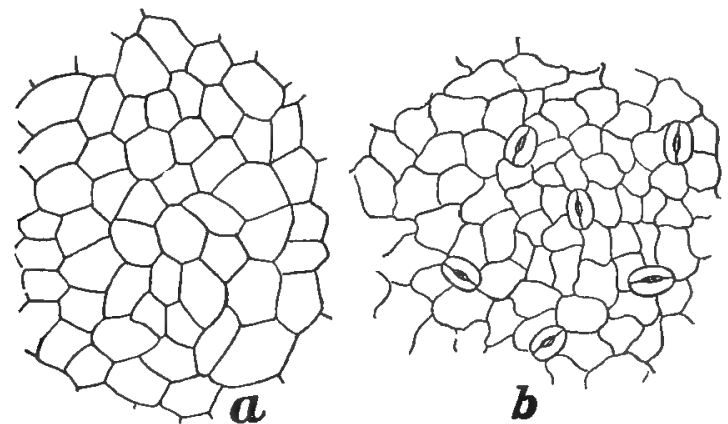

196. Lower epidermis of Water-polygonum; (a) from a submerged leaf, showing lack of stometa, ( $U$ ) from an air-leaf produced by a plant growing in water.

Water affects the size of every part of the plant noticeably, as may be seen by comparing plants grown in dry, sandy soil with the same species grown with abundant water (e. g., the weeds which come up in a garden as compared with those which grow in dry spots).

The large wood-cells produced in the spring (spring wood), as contrasted with the fall wood, are another illustration of this (see page 247). A scion grafted on 
a stock which supplies it overabundantly with water forms a mass of large-celled wood-parenchyma in place of ordinary wood.

It is often very noticeable that the leaves which are formed during a dry period are small and stunted, while those subsequently formed on the same branch during a rainy period may be four or five times as large.

The roots of many plants branch in a peculiar, compact fashion when they grow in water (for example, the roots of trees when they enter a cistern or drainpipe), hence the popular name, "water-roots."

Very interesting results are obtained when we grow ordinary land-plants in a saturated atmosphere, in the manner shown in Fig. 157. Select a bulb (or corm, tuber, etc.) which has begun to sprout: cut out a piece (two or three inches long) bearing a sprout at one end, place it in a dish, and cover it with a lamp-chimney. Pour in some water, and cork the chimney, covering the cork with sealing-wax or vaseline. The air within the chimney will soon become saturated with moisture, and its influence on the growth of the plant can be readily observed. The tissue at the base, which is in contact with the water, will eventually decay; but this will not interfere with the growth of the sprout. The results of growing Dandelion leaves and Gorse in this way are shown in Figs. 197 and 198.

Water seems to have a direct influence on the pro- 
duction of flowers and fruit. Land-plants growing in unusually moist situations run to stem and leaf, and produce flowers and fruit sparingly: on the contrary, when growing in unusually dry places, the same plants produce relatively more abundant flowers and fruit than usual. Such waterplants as are descended from land-plants are, as a rule, unable to flower or fruit under water (Water Plantain, Arrowhead, Hippuris, etc.). Gardeners induce plants to flower abundantly by digging a trench around the base of the trunk, and therely cutting off numerous active roots: another method is to simply lay the roots bare. Cacti which are allowed to become somewhat dry and shrunken bear more freely.

Bending and breaking the branches of fruit trees, which results in partially cutting off the water supply, is practiced for the purpose of causing trees to fruit. It also tends to make the fruit sweeter and of highe? flavor. Fruit grown in the mountains (where it is dryer and the light stronger) is usually superior in these resperts. Overirrigation has a tendency to produce watery fruit which is neither very sweet nor highly flavored. ${ }^{2}$

By knowing just when and how much to

I See pages 318 and 319.

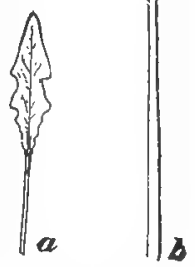

197. Leaves of Dundelion drawn on the same seale: $(a)$ normal, (b) grown in a satm rated atmosphere. 
irrigate, we may hope to control very largely both the 'flantity and quality of the crop. At present there is so much confusion in this regard that we may find one farmel using several times as much water as his neighbor for the same kind of crop grown under the same
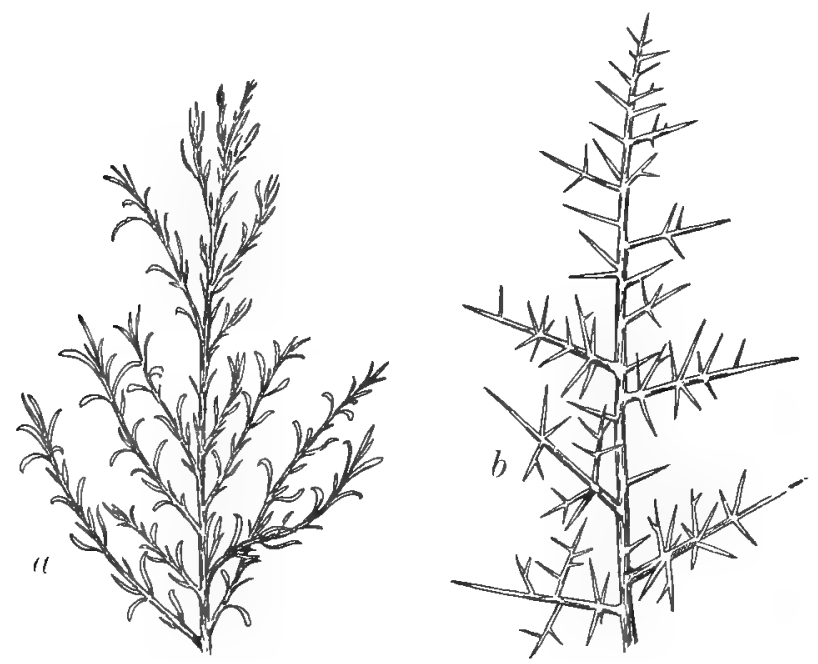

198. Gorse: (a) leafy form, the result of growing in a saturated atmosphere, (b) normal (leafless) form, the branches transformed to spines.

gene'al conditions. In general, crops cannot be grown to advantage when the soil contains more than 50 to 60 per cent of the total amount it is capable of holdir.g. The study of irrigation is bound to be of increasing importance, since it is becoming evident that it will pay to irrigate, even in regions where the rainfall is now ordinarily regarded as amply sufficient for crops (see pages 130 and 131). 
Light.-The effect of light on the plant is ordinarily much the same as that of dryness. In fact, some of the effects of strong light are due to the increased transpiration which it produces. In the case of the desertplants, etc., the effects of the two are difficult to distinguish. There are, however, many effects of light which are independent and are manifested equally

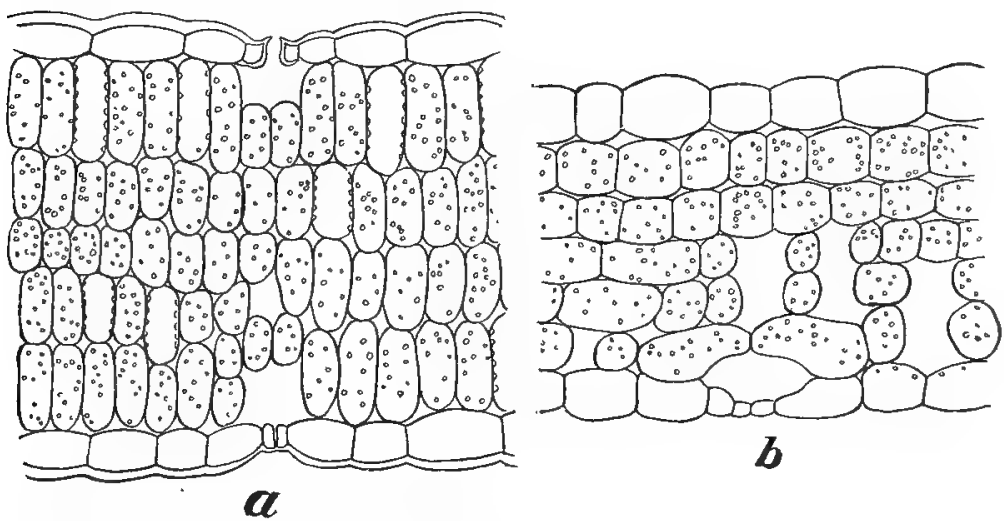

199. Leaves of Priekly Lettuce seen in oross-section: $(a)$ sun leaf, $(b)$ shade leaf. well when the plant is grown in a saturated atmosphere.

Some plants (sun-plants) prefer the direct sunshine, while others grow only in the shade (shadeplants). The latter (e. g., many Ferns, ete.) have leaves of paler color, relatively large and thin, and not well adapted to withstand direct sunlight: if exposed to it they soon die. Similar differences may be found in leaves growing on the same plant when, 
as often happens, some of them are directly exposed to the sun while other's are continuously shaded. Figs. 12s and 130 show two branches from the same plant: the one shown in Fig. 128 was well iliuminated, while the one shown in Fig. 130 was shaded: there is a corresponding difference ii the size of the leaves. Fig. 199 shows the appearance of sections of sun- and shadeleaves of the Prickly Lettuce and Fig.

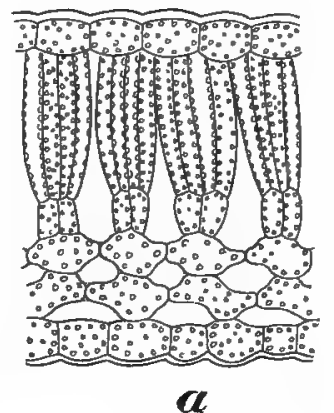

200. Beech leaves seen in cross-section: (a) sun leaf, (b) shade leat.
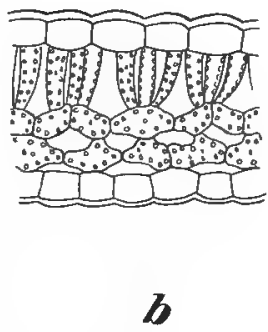

200 of sun- and shade-leaves of the Beech. Especially noticeable in the "sun-leaf" are the longer palisade cells, the smaller air-spaces, the greater thickness of the leaf, and thicker cuticle or outer wall of the epidermal cells; the number of stomata is also smaller. These effects are due partly to the light itself and partly to the dryness (or excessive evaporation) caused by the light, heat and wind.

Leaves arrange themselves with reference to the direction of the light, and many follow the sun during the day (see page 217). Some plants, inhabitants of dry countries, place their leaves in a rertical position, thus avoiding the full effect of the light (see page 
217). The leaves of the compass plants are vertical and directed north and south. Many leaves temporarily assume a vertical position in very strong sunlight (see page "217), and it is noticeable that young leaves, which are more sensitive to the light than the older ones, usually assume this position. (Plants can be grow by electric light; and this has proved profitable in foreing certain greenhouse crops in winter.)

The trunks of trees may suffer from "sunseald," due to injury of the bark by the intense light and heat of the sun, or to the alternate thawing and freezing of the bark on the southwest side in late winter. The trouble may be obviated ly shading the trunk with a screen of wire, boards, cornstalks, etc. Pruning often lets in too much light on the trunk, which suffers in consequence. (this is especially noticealle in the Weeping Willow).

Very interesting results are obtained by growing plants in darkness. To do this out-of-doors, it is only necessary to cover the plant with a section of stovepipe, a wooden box or a barrel. Within doors the plant may be placed in a dark closet or box. Such plants (Figs. 103 and 180) have very long, slender stems (the nodes are far apart); they are pale in color, have little woody fiber, ${ }^{1}$ and are consequently

1 This fact is taken advantage of in bleaching Asparagus, Celery and Rhubarb for market. The Celery is either "hilled up" or covered with gunny sacks, or the light is excluded by means of boards: the leaf-stalks are thus bleached and rendered tender and succulent. The "laying," or lodging of Wheat is due to the shading of the lower portion of the stalk, whicli results in an insuffirient produrtion of woody fihere. 
weak. The leaves ${ }^{1}$ (in most plants) remain small and pale in color. Hairs and even prickles tend to disappear in darkness.

It is well known that intense light causes a greater intensity of coloring of fruits, flowers and other colored parts of plants: this is especially noticeable in mountain regions. Compare the colors of flowers in shady woods with those in the sunlight of open meadows.

Light also affects the abundance of flower's and fruit. Many plants bloom little or not at all in poor light, while in strong light they do so abundantly. This is noticeable in house-plants cultivated at a north or northeast window, as compared with thos grown at a south window. The effect is due partly to the fact that with better light the leares produce more food for the nourishment of the flowers and fruit, partly to the direct action of the light (and temperature) on the organs themselves. If possible, make experiments on this point. Som plants can be kept for years in healthy vegetative condition at an intensity of illumination which is too low to permit them to blossom. Observe plants that are partially shaded (as by a house or hedge), and note especially whether more blossoms are formed (blossoms formed on one side may, by twisting, appear on the other) on the side which is shaded or on the side which is exposed to the light.

In many Monocotyledons the leaves continue to grow in darkness. The scale-leaves of subterranean stems often develop into green forage-leaves if exposed to light (e. g., Hawkweeds). 
In making these observations, it will probably be noticed that many flowers grow toward the light and place themselves so as to receive it as directly as possible. This has a useful purpose in making them much more conspicuous to insects. See page 298.

WIND.-Every one is more or less familiar with the

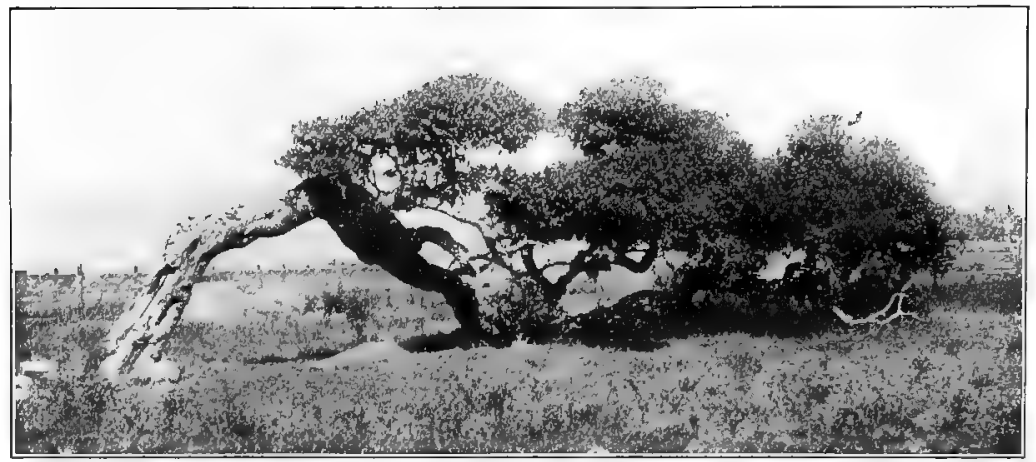

201. The effect of wind on the growth of a tree trunk.

effects of wind on plants. Near the seacoast, or on mountains, or wherever trees are exposed daily to strong wind, they show by their bent forms and curious shapes its potent influence (Fig. 201). The dying of the branches on the windward side (Fig. 202) is due to the drying effect of the wind, which may increase transpiration as much as twentyfold (see page 208). Even moist winds may have a drying effect. It is interesting to observe how the one-sided development of leaves and branches affects the stem. This is 
well shown in Fig. 203. It may be observed in vines, etc., which climb on walls.

The effect of wind in drying up the blossoms of fruit trees, etc., is well known. For this reason, and also because the winds lower the temperature and do considerable damage to trees laden with ice and snow, the use of windbreaks is often indispensable.

Food.-We have already learned (pages 137 to 162 ) that the kind of mineral food the plant ${ }^{1}$ receives affects its growth and general appearance. Thus,

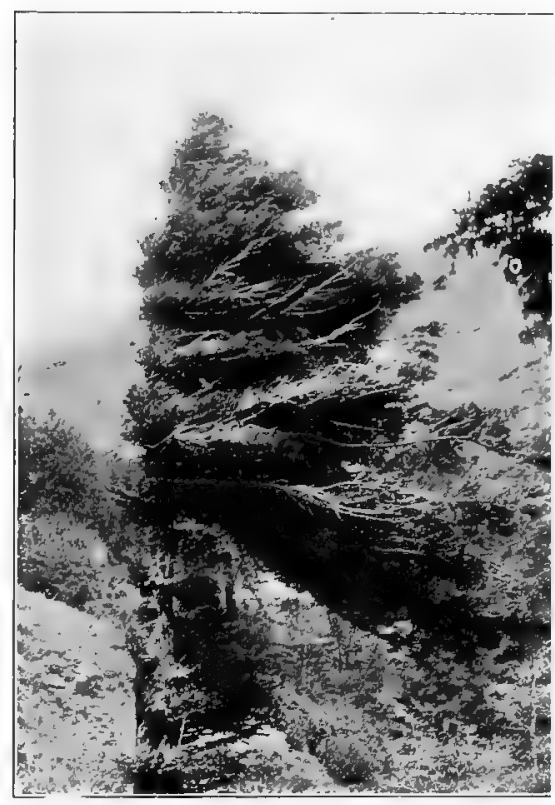

202. The effect of wind; branches stunted and killed on the windward side. abundance of nitrogen ${ }^{2}$ causes a particularly strong,

1 See articles by Riley and by Woods in the Year Book of the U. S. Department of Agriculture for 1901.

2 It is an interesting fact that abundant manuring with nitrogen, combined with abundant watering, very commonly produces "green flowers," i. e., flowers in which petals, stamens and even ovules are transformed into green leaf - like bodles. This happens frequently in garden Asters and other Compositæ. In some cases this greening of the flopers is caused by the attacks of plant-lice 
rank vegetative growth and imparts a deep green to the leaves, while phosphorus especially promotes the production of flowers and fruit. It is a well-known fact

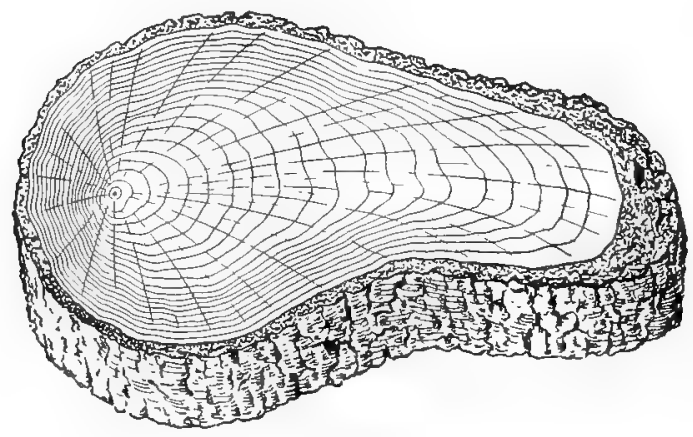

203. How one-sided development of brinches affeets the trunk. (See Fig. 202).

that starving a plant makes it flower and fruit much earlier. Depriving it of water has the $\mathrm{s}$ a $\mathrm{m}$ e effect (see page 318 ). An excess of a particular substance in the soil may render it unfit for some plants, while others flourish in it. Thus, Asparagus will stand so much salt that the weeds in an Asparagus bed may be killed by sprinkling on salt, while the Asparagus itself is not injured.

Soil too alkaline for ordinary crops will raise sugar Beets and Alfalfa, while land too alkaline for these crops will grow Salt Bush, which makes good fodder.

Peat Moss or Siphagnum is killed by a small amount of lime, while other Mosses flourish on limestone rocks and in water containing large quantities of dissolved lime. The presence or absence of lime usmally has a marked effect on the flora. Some plants are known as lime loving, other's as the rever'se. 
Some plants are found only in sour humus (either in wet humus, as Peat Mosses, sundrw, etc., or in dry humus, as Heath plants), while others are found only in "mild" humus (Log's Mercury, ('ow Wheat, etc.): some, indeed, are found only in a particular kind of humus, e. g., that of Conifers (Rattlesnake Plantain). Observe all you can in regard to the occurrence of plants in different kinds of soils. To a certain extent each kind of soil is characterized by certain plants. This has been noticed by prospectors, who have found that certain plants are found only wher's certain metals (e. g., zinc) abound.

A fuller understanding of the kind of soil preferred by different plants ${ }^{1}$ will not only enable us to better suit our crops to our land, but be of great assistance in determining the availability of hitherto uncultivated land for various crops.

Not only the chemical, but more especially the physical character of the soil and of the subsoil (whether hard-pan or porous), is of importance in this connection. Find out what kind of land is considered most suitable for the various crols with which you are familiar. Try also to eultivate the ability to judge of the character of the land by the wild plants which grow on it. Such plants are indicators not only of the chemical and physical character of the soil, but also of the temperature and other important factors of climate.

I The Trnited States Department of Agriculture is now making soil surveys in various states, to determine what crops are beat adapted to various soils. 
HEAT. - At the beginning of the chapter it was remarked that to give the plant too much of any of the things it requires is as bad as to give it too little. This is, perhaps, more strikingly seen in the case of heat than in other cases. We all know that too much heat quickly kills both animals and plants. On the other hand, if they have too little, they stop growing, and may die.

In general, the less water the plant contains, the more resistant it is to cold. This is well shown by the behavior of greenhouse plants; excessive watering makes them over-sensitive to heat and cold (and light as well; such plants are liable to "sunscald"). Plants which have just been transplanted are said to be less sensitive to frost, since they contain less water. Frost does not injure buds in winter when they are comparatively dry, but in spring, when they are full of sap, it kills them. Frost, during the period when sap is running, causes the bark to adhere to the wood, and it does not again become separable until the return of milder weather. In such cases, the health of the tree may not always be affected; but the crop of fruit fails.

Dry seeds which contain very little water (about 10 to $15 \mathrm{per}$ cent) stand extremes of temperature which would kill them if full of water. Seeds have heen kept at the temperature of liquid hydrogen (minus $2: 55^{\circ}('$, or minus $396^{\circ} \mathrm{F}$.) for some time, and 'alrefully thatred nut again, when they grew quite normally. 
The way in which a frozen plant is thawel out makes a great difference. Allow some potatoes to freeze (the may be easily frozen in a water-tight (an, sul)merged in a mixture of pounded ice and salt, or set in an ordinary ice-cream freezer). Place some of the frozen potatoes in water chilled by ice (but free from salt), and let them stand until the water reaches room temperature. Place others at once in a warm place, so that they will thaw quickly.

Frozen leaves (and other plant-tissues) have a peculiar transparent appearance on thawing; the same thing oceurs when they are boiled in water or injected with water in an air-pump (see page 190); in all these cases it results from the air-spraces becoming filled with water. It is supposed that when a plant is allowed to thaw rapidly this water evaporates and that the plant suffers injury, which might be avoided by slow thawing, which would permit the cells to again absorb the water which escapes from them into the air spaces during the freezing.

The action of frost on the trunk may result in long splits in the trunk or in the killing of the ends of the branches, which soon turn black. The best treatment is to remove the injured portions hy pruning and to direct the energies of the tree to making new wood (prevent it from bearing fruit for a season) to replace that which is killed.

Protection from frost is secured by covering the 
plants with a mulch, or, in the case of trees and shrubs, by bending them down (the roots must be eut in such a way as to permit this) on the approach of winter and covering them with straw or brush ${ }^{1}$.

Spraying or sprinkling with water at nightfall is a very effective means of protection; this depends on the fact that moisture in the air prevents the radiation of heat and consequent cooling of the trees and soil ; it acts, so to speak, as a trap for the heat. Filling the air with dense smoke

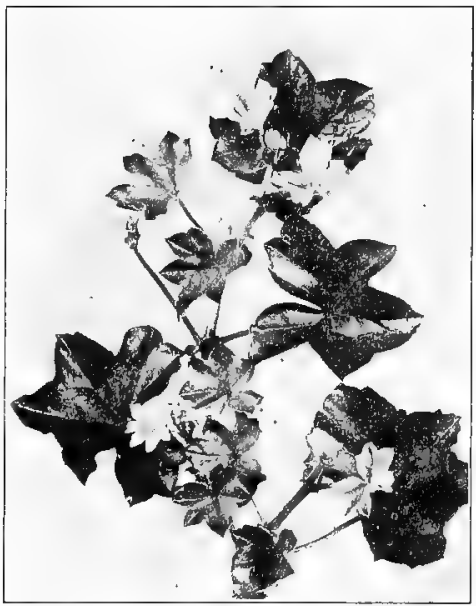

204. Branch of Iry Geranium after a few days of cold weather; the young leaves have developed without being able to turn green.

from bonfires of tar, resin or similar substances answers the same purpose.

The pale appearance of young leaves during cold weather, which is very noticeable in Winter Wheat, etc. (see Fig. 204 of the Ivy Geranium), is due to the fact that for the formation of chlorophyll a higher temperature is required than for growth. The leaves consequently develop but cannot turn green.

It is noticeable that some kinds of plants stand far

1 See an article by Galloway in the Year Book of the U. S. Department of Agriculture for 1895 ; 
more cold than others (just as some kinds stand more water, light or alkali than others). Individual plants vary considerably in this respect: after a frost which kills most plants of a particular species it is often possible to find one or two individuals which have survived, not because of a more sheltered position but by reason of their greater hardiness. By preserving the seed of such plants and selecting seed from the hardiest plants year after year, hardy varreties may be obtained.

Of equal importance with hardiness in securing varieties for cold regions is the ability to ripen quickly (earliness). This may also be obtained by selection, as has happened in the case of Wheat in the United States; as a result the Wheat belt has moved steadily northward, especially in the last fifteen years. We have a record of one case in which a winter Wheat was in three years converted into a summer Wheat in this manner: conversely, in three years a summer Wheat . was converted into a winter Wheat. The same thing is even more strikingly true of Corn, which on the plains of Santa Fé in South America requires six months to ripen, while in the Rainy Lake district of Lake Superior it ripens in two months and a half. This great change has all been accomplished by man.

It has been found repeatedly in experiments that cuttings (of the same kind of plant) taken from a northern region and placed side by side with those of 
a southern region develop from fifteen to twenty days earlier than those which are accustomed to the warmer region. Early varieties of flowers, etc., ar'e constantly imported from northern points. Temperature, more than anything else, determines what kinls of plants grow in a given region ${ }^{1}$. The tropies, the temperate and the arctic zones have each their characteristic vegetation. Plants which flourish in the tropics may be cultivated in the temperate zone (e.g., Date Palm, Rubher Plant, ete.), but remain stunted and refuse to bear fruit. The study of the various zones to be found in a country is very important in determining what part is best adapted for various crops. ${ }^{2}$

Wherever there are high mountains there are opportunities to study these zones to great adrantage, since as we ascend the mountain we pass through successive zones. It will then be seen how much depends on exposure; i. e., the southern face of the mountain being so much warmer than the northern, the zones will run higher, etc. The same may be seen in even a small hill or elevation. For this reason

1 An interesting illustration of this is seen in the forests of the United Situtes and Canada. As we go northward from Florida we find, considering anly good and well-watered soils, that the hardwood forest gratually diminishes, both in the number of trees and the number of kinds represented, until we come to the great pineries of the northern ['nited States aml c'mada. Sill further north these are suceeded by Birch, Willow and Alder: these gradually diminish northward until we rowh the tropless wastes.

"The "Crup Zones" of th" United States are now being d"tumined hy the United States Biological Surrey. 
the "lay of the land" is vely important for plants. It often happens that one sile of a valley yirlds good crops, while the opposite side is valueless for cultivation.

It is interesting to notice that during the day the hillside (especially the southern and southwesterly exposure) is warmer than the valley (except when a cold wind blows); the same is true at night, for the cold air, being heavier, sinks down into the valleys, so that they often have frost at night when the hillsides above are exempt from it.

Plants which grow in high altitudes have stunted stems with limbs densely branched or hugging the ground in the form of rosettes. These features have been produced experimentally to a certain extent by growing ordinary plants under favorable conditions by day and keeping them in an ice-house during the night. This imitates natural conditions, since the plants in question are comparatively warm during the day when the sun is shining, but cool off very rapidly after sunset and remain cold during the night. Normally the greatest growth takes place at night, hence chilling them at this time explains, in part at least, their stunted growth.

Alpine plants have very commonly larger and brighter colored flowers, which are also richer in honey, so that the mountains are particularly good for bee-keepers. The foliage of these plants shows many 
of the same devices for preventing evaporation which we have seen in desert plants : the strong light, rarefied air and the constant winds tend to promote evaporation, while the coldness of the ground hinders absorption.

Owing to the short time which such plants have for flowering and fruiting, they perform these opera. tions very rapidly, often in half the time needed by similar species in the lowlands.

The plants of northern latitudes resemble alpine plants in most respects, and especially in the lastmentioned feature, i. e., early-flowering and fruiting. Gardeners take advantage of this to get early varieties by importing seed from northern regions. Sometimes seed is sent to such regions to be grown until the desired earliness has been obtained.

Of the plants familiar to you, which are most sensitive to cold? which are least sensitive? Do you find differences in individual branches of the same tree in this respect?

In view of the facts which we have just discussed, we may realize vividly that the life of every plant is a continual and delicate adjustment to its surroundings. Some plants possess the power of aljustment to a greater degree than others; but all must exereise it constantly in order to survive; and this is a fundamental characteristic of all living organisms.

We may illustrate this further by considering a tree. 
It is a very exact index of its surroundings, so that a skilful woodsman knows at once, on looking at it, the conditions under which it has grown. The influence of light, water, prevailing winds, have all left their marks on it. Its position, with reference to the compass, can be told by examining it. For this reason, in transplanting a tree, we should be careful to set it so that the same side faces the north after, as before its removal.

These facts serve to show that the form of the plant is largely determined by its surroundings. It may also be greatly changed by diseases, especially the attacks of fungi, to which are due the remarkable growths known as "witches" brooms," etc., as well as by insects, which not only cause the formation of all sorts of curious galls, but even in some cases produce the greening of flowers, in which the petals, anthers, ete., are transformed into green, leaf-like bodies.

Moreover, the development of each part of the plant is influenced by that of every other, as is demonstrated every day by the experience of making cuttings and of pruning (see pages 79, 86, 257 and 263). If the tip of the main axis of a Pine be removed, the branches just below it begin to straighten up to take its place; one finally does so and the rest then fall back to their original positions; the one which becomes upright changes its structure and becomes like the tip of the main trunk whose place it takes, e. g., it becomes alike on all sides (and the internal structure changes 
accordingly) instead of having an upper and a lower side (with a corresponding difference in internal structure). The Potato furnishes another illustration; if the young tubers be cut off as they are forming, the tuberforming material accumulates in the parts above ground and produces tubers in the branches; these are green and bear leares. Try both these experirnents, if possible.

This influence of one part on another is called correlation. Numerous other illustrations might be given; it will suffice to mention the effect which the fertilization of the ovaly has on surrounding parts (see page 309). Experiments on this point may easily be made by removing the anthers in the bud and preventing pollination by paper bags.

It is hoped that the facts set forth in this chapter will lead to experiments when practicable, and to constant observation of the experiments which are everywhere spontaneously occurring in garden and field. 


\section{('HAPTER IX}

\section{PLANTS WHICH CAUSE DECAY, FERMENTATION AND DISEASE}

What is the cause of decay? Formerly it was supposed to be due to some property residing in the organism itself; our present knowledge is that it is due to plants called bacteria. Although too minute to be seen except with the microscope, they can nevertheless be studied with the simplest apparatus.

To begin with, we may get an abundant growth of bacteria by putting a little hay in water and allowing it to stand a few days, when the bacteria will form a gelatinous film on the surface. On mounting a drop of this in water on a slide and examining it under the microscope, the bacteria appear as very small, glistening bodies approaching in shape some of the forms shown in Fig. 20.5; very probably some of thess will be in motion. This motion may be merely mechanical, i. e., a dancing motion such as any small particles (e. g., India ink or vermilion) show in a liquid, or it may be due to the activity of the bacteria, which move by means of whip-like protoplasmic projections (cilia). Pour off some of the liquid in which the bacteria are 
362

EXPERIMENTS WITH PLANTS

growing, strain it through a cloth, and fill five vials or bottles almost half full of it. Insert in the mouth of each vial (or bottle) a firm cotton plug made by
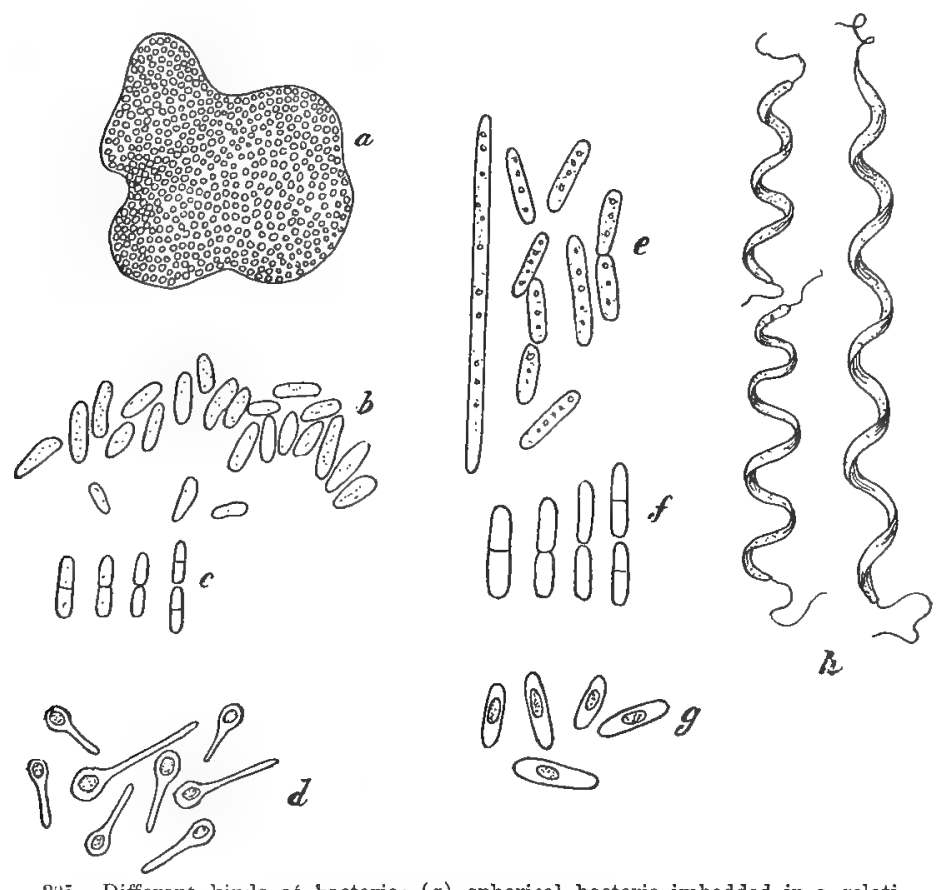

205. Different kinds of bacteria: $(a)$ spherical bacteria imbedded in a gelatinous film which floats on the surface of the liquid, $(b)$ rod-like forms, $(c)$ back. ceria multiplying by division into two, (d) bacteria of lock-jaw (tetanus), with a spore at one end, (e) elongated rods, $(f)$ rod-lik
like forms with a spore in each, $(h)$ spiral forms.

rolling the cotton into a firm roll just large enough to fit the vial. Place one of the bottles ( 1 ) in a warm place in the light, another $(b)$ in a warm place in the dark, another $(c)$ in a cool place (preferably on ice) 
in the dark. Into the fourth bottle $(d)$ put a drop of formalin, and place alongside of $(b)$. The fifth bottle $(e)$ we will subject to the heat of steam. This is most conveniently done by placing the bottles in a pan and inverting another pan over it as a cover, or by means of the apparatus shown in Fig. 206. It consists of a pail (six to eight inches in diameter) and two pans, all preferably of graniteware (tin may be used). One pan serves as a cover, while the other, which is pierced with holes, serves as a support. A little water is put into the pail, and it is then set on a stove or over a burner. The rials or other dishes are placed on the support, the corer is fitted on and

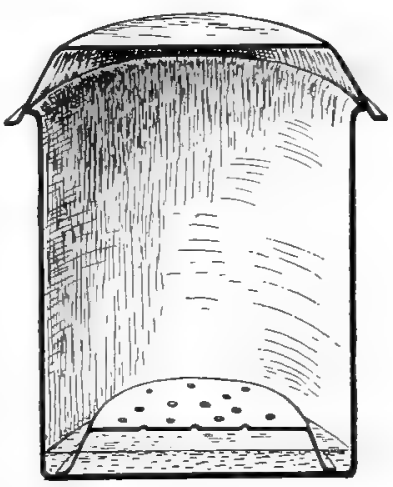

206. Steam sterilizer, consisting of a rail, a pan for cover and a smaller pan pierced with holes as a support (all should be of tin or agateware). (Sectional view.) the water is allowed to boil. When it has boiled for half an hour we remove the vials. This process is knomn as sterilizing (the apparatus is called a steam sterilizer). We place the sterilized vials in a warm place in the dark, and renew the sterilizing each day until they have been sterilized three days in succession.

Examine all of the rials every day. In which does the most rapid growth of bacteria occur, as shown by the cloudiness of the liquid and the formation of a surface film? 
Bacteria in general grow best at from $80^{\circ}$ to $95^{\circ} \mathrm{F}$. Below $40^{\circ} \mathrm{F}$. and above $110^{\circ} \mathrm{F}$. they make practically no growth. The temperature of ice fails to kill many kinds; even that of liquid air (minus $310^{\circ} \mathrm{F}$.) does not kill all kinds.

Bright light kills many kinds, while others are not much affected by it.

Formalin is a good example of a disinfectant which kills the bacteria. (Disinfectants which kill the germs are called germiciles, those which thoroughly check their growth or stop it are called antiseptics.) One part in 5,000 or 10,000 of water is said to be efficacious against many bacteria; articles may be disinfected by leaving them for a few hours in a closed box exposed to formalin vapor, or sulphur may be burned in any closed space with good results. Other chemical disinfectants are chloride of lime, corrosive sublimate, carbolic acid, potassium permanganate, strong mineral acids, tetc. ${ }^{1}$

The effect of sterilization is due to the fact that bacteria in their ordinary or vegetative condition are killed by the heat of steam. Some of the bacteria found in

1 The following will serve to indicate approximately the strength to be used: Carbolic acid 3 per cent or one tablespoonful of the ordinary solution to a pint of water; lysol I to 2 per cent; copper sulphate 1 to 2 per cent; chloride of lime 3 per cent; potassium permanganate 1 to 2 per cent (useful as deodorizer also); corrosive sublimate one-tenth of 1 per cent; hytrogen peroxide nearly full strength; listerine full strength. Wounds should be well Wished with disinfectant solution by means of a pipette and then covered with iodoform. 
hay infusions produce resistant bodies known as spores (compare Fig. 205, $g$ ) which are not killed by this temperature. On standing a few hours the spores germinate and pass into the vegetative condition, when they may be killed by steam heat. Hence the value of sterilizing for three successive days. Ordinarily, however, one sterilization of half an hour answers every purpose.

It was formerly supposed that the growth which occurs in infusions, etc., was due to spontaneous generation, i. e., to the origin of living organisms from lifeless matter. This view received confirmation from the fact that an infusion may be boiled and growth nevertheless occur. With the discovery of resistant spores and of the fact that after several sterilizations no growth occurs, the doctrine of spontaneous generation was overthrown.

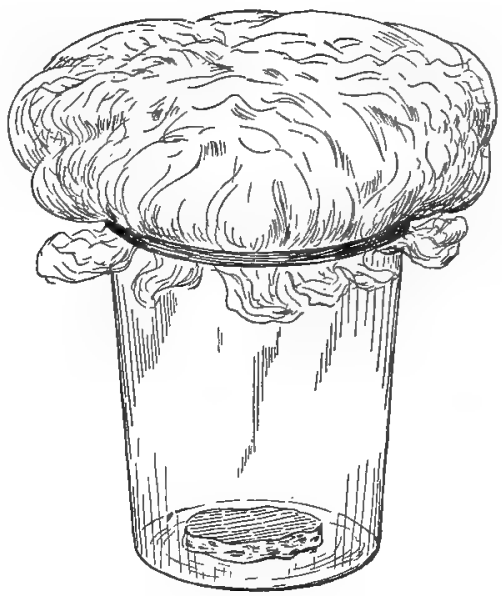

207. Tumbler containing a slice of boiled potato, closed by a cotton plug held in place by an elastic band.

Let us now take three tumblers, place a slice of boiled potato in each, cover with cotton held in place by an elastic band as shown in Fig. 207 (or use 
small tumblers and insert a cotton plug as in Fig. 212) and sterilize them all for half an hour. After they have cooled down again, remove the cotton from one (a), expose to the air for a minute and replace the cotton: to another (b), transfer a minute quantity of bacteria from the liquid by means of a needle. ${ }^{1}$ For this purpose we pass the needle back and forth several times through the flame, and when cool dip it into the liquid. We now lift the cotton at the edge and draw the needle once across the surface of the potato and at once replace the cotton. Leave the third tumbler $(c)$ intact, as a control.

Put all the tumblers away in a warm place in the dark and observe them daily. The bacteria in (a) come from the air; many disease-producing bacteria (e.g., those of tuberculosis) are wafted about in the air; for this reason consumptives should take special precautions to avoid infecting the air. Do the spots of decay appear in (b) anywhere except along the needle track: do any appear in (c)? Does the potato beneath the spots alter in color, consistency, ete.? Scrape a bit of the potato from one of these spots, mount the scraping in a drop of water, and examine under the microscope. The large, glistening bodies are starch grains, while the bacteria appear as minute bodies floating

1 This is prepared by heating the end of a glass rod in a flame until it fuses and then forcing into it s piece of fine steel (or platinum, if obtainable) wire about two inches long. 
about in the liquid (Fig. 208). Add a drop of iodine solution, and observe.

We may get a good idea of the relative size of the bacteria by comparing them with the starch-grains, which latter are too small to be distinctly visible to the naked eye but are easily seen with a hand-lens.

Do you find that the spots on the potato differ in color, consistency, shape and general appearance? If so, they are, in all probability, due to different kinds of bacteria. In order to separate the various kinds, we may proceed as

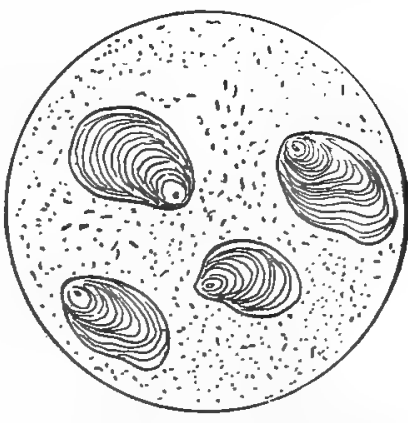

208. A seraping from a potato culture, showing starch-grains and bacteria. A good way to get an idea of the size of hacteria is by comparing them with some well-known object. such as a starch-grain.

follows: Fill a vial half full of distilled water, and sterilize for half an hour. Then pass the needle through the flame two or three times; when cool touch it to the spot from which a culture is desired, and stir it about in the vial. Remove the needle, sterilize in the flame, and then dip it in the vial again and touch it to a previously sterilized slice of potato (arranged as before in a tumbler), at various points a little distance apart, and at once replace the cotton. ${ }^{1}$ If the amount of water used is sufficient, the bacteria will be so scattered that

1 During this operation the tumbler sbould be beld nearly borizontal, to keep bacteria from falling upon the potato from the air. 
each minute drop of the liquid will contain not more than one of them, so that whenever we touch the potato we shall deposit not more than one; hence each spot will be the result of the growth of a single bacterium: this is a pure colony: if we infect a sterilized potato (or other medium) from such a colony, so as to get only one kind of bacterium in the culture, we obtain a pure culture.

It is interesting to consider, in connection with this mode of propagation, that, as long as an individual keeps on dividing, there can be no such thing as death from old age, since the parent is completely absorbed into the offspring.

Bacteria are distinguished not so much by their form and general appearance under the microscope as by their behavior when grown on various substances, such as potato, gelatine, beef-broth, etc. They are classified largely according to the size, shape, consistency, color, ete., of the spots or colonies which they produce.

One very interesting form, which may be easily recognized, appears frequently on potato and breadcultures: it is bright red in color, and is of especial interest as causing the "bloody-bread" of the middle ages, which was beliered to bleal miraculously.

The bacteriological examination of watel is so important and at the same time so simple that we may well turn our attention to it. For this purpose we may prepare some nutrient gelatin as follows: Make some 
beef-broth by heating a pound of chopped beef for half an hour (at about $65^{\circ} \mathrm{C}$.) in a pint of water. Strain it through a cloth, and add two ounces of gelatin (the "sparkling gelatin" used in cooking is preferable), and let it soak over night. In the morning, heat in the sterilizer until dissolved, then add one-tenth ounce salt (best accomplished by adding one ounce salt to 100 c.c. of water, and taking 10 c.c. of this) and one-fifth ounce peptone (obtainable at drug-stores; it may be omitted if necessary), add a tablespoonful of molasses and finish by adding dilute lye or lime-water until the gelatin is slightly alkaline to litmus. Remove the neck from a funnel so that it will fit into a tumbler (Fig. 209), and filter the gelaiin through filter paper or cotton, keeping the whole hot in the sterilizer during the process. If the gelatin does not appear clear,

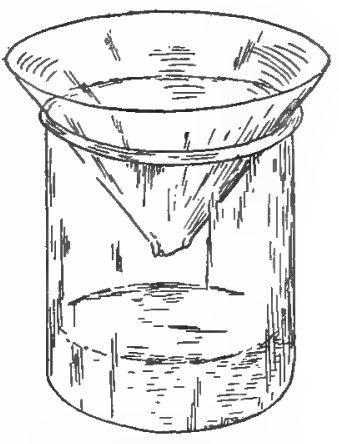

209. Funnel with neek removed so as to fit into a tumbler: the whole is plared in the steri. lizer, in case gelatin is to be filtered hot. filter again, first beating in a little white of egg. It may then be placed in a bottle and, the neck being plugged with cotton, sterilized. If necessary, repeat this for three successive days, when it will keep indefinitely. (Each time the bottle is opened it must be sterilized again.) Now obtain sereral flat-sided bottles of the same size, and put into each sufficient gelatin to cover the side when the bottle is flat on the 
table (Fig. 210). The same amount should be placed in each bottle; this is easily managed with a sterilized pipette or medicine-dropper. Wipe the mouth and neck

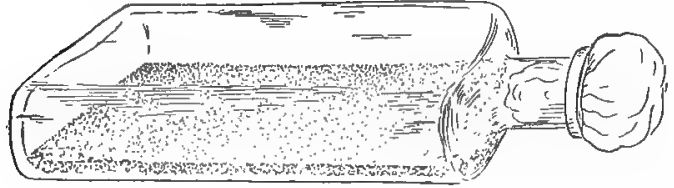

210. Flat bottle containing gelatin: used for "plate cultures." of each bottle, and plug with cotton; then sterilize and set aside for a day or two. If no bacterial growth appears, wr may procert. Warm the bottle just enough to liquefy the gelatin, remove the plug, and introduce (by means of a sterilized pipette or medicine-dropper) the same quantity of water (several drops) into each bottle (a separate sterilizerl lipette must be used for each). Replace the plug, mix the contents by turning the bottle from side to sicle (do not allow gelatin to get on the plug) and plan the bottle on its side in a dark place. Such cultures are called plate cultures, and they serve excellently to tell how many bacteria the water contains, since wr may count the colonies which come from a given yuantity of water (in this case we assume that each colony comes from a single bacterium).

It is well, in making this experiment, to compare some water from the drinking supply, some from a stagnant pond or pool and some from a larnyarl. In the latter raste we shall probally find bubloles of wils forming in the gelatiu. This is an indication of the 
colon bacillus which is characteristic of animal excrement, and when found in water shows sewage contamination; such water should not be drunk without being boiled, and a sample should be taken to the health officer for examination.

One fact which cannot help striking us in observing these cultures is the rapidity with which the bacteria grow. A single bacterium produces in forty-eight hours: a spot or colony containing thousauds on thousands. If we ohserve the bacteria in a hanging drop (see Fig. $165)$ under the microscope we can see the manner in which they multiply: it consists in simply dividing into two as shown in Fig. 205 (c). It has been observed that this division into two may ocrur as often as once every half-hour; if this rate could be maintained for twentyfour hours and none should die, we should have at the end of that time more than two hundred and eighty trillions of descendants from a single germ. It may be readily realized that even at a much less rapid rate of increase a few typhoid germs might soon infect a whole water supply.

In the bacteriological examination of water, it is customary to count the bacteria by the method just described, and also to examine for the colon bacillus and for disease-producing bacteria, such as those of typhoid, cholera, etc. These are identified by their appearance in the cultures and under the microscope. It is important to know that typhoid may be con- 
tracted by eating raw oysters, which are frequently grown in water contaminated by sewage.

Fig. 211 shows the distribution of cholera cases in the Hamburg epidemic of 1892. It will be noticed that, in the words of Professor Koch, "cholera went right up to the boundary of Altona and there stopped. In one street, which for a long way forms the boundary, there was cholera on the Hamburg side, whereas the Altona side was free from it." This is equally true when the boundary runs diagonally through a block. The explanation lay in the fact that while both cities used the same water supply (which received raw sewage from several towns), Altona filtered the water carefully, while Hamburg did not.

The filtration of water is a very simple process. It is passed through several feet of sand (sometimes mixed with charcoal) and a film soon forms on the surface of the sand which catches the bacteria. Such a film may be artificially produced, if necessary, by adding chemicals ( $\bullet . g$. alum) to the water without injuring it for drinking purposes. Every town or city water supply should be filtered; the cost is slight and the benefits very great. The small filters sold for household use are for the most part highly injurious and serve only as breeding places for bacteria, owing to the fact that they cannot be properly cleaned.

Let us now examine some milk. Fill three vials half full of nutrient gelatin, plug, sterilize, and set 


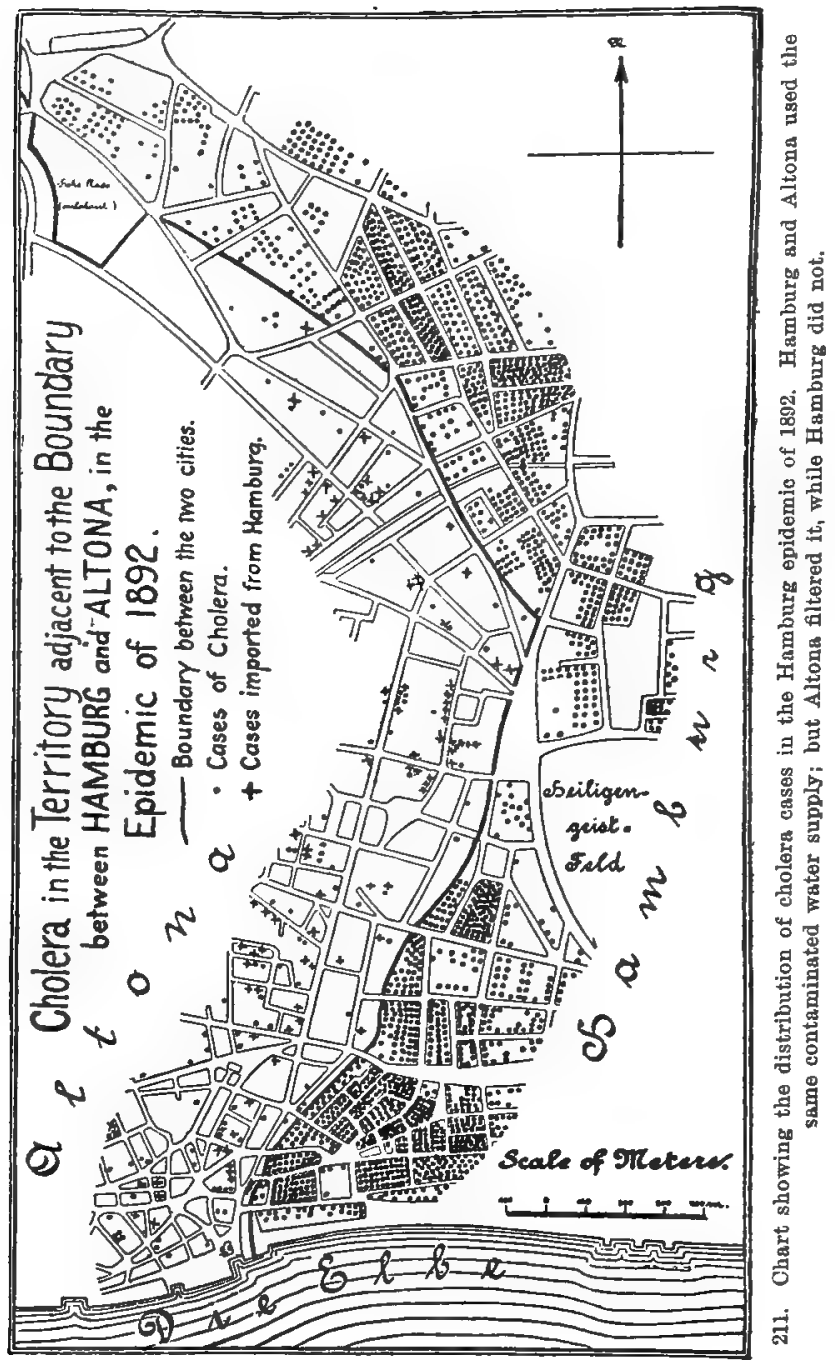


aside for two or three days, and if 110 growth appears, proceed to make a bacteriological examination of milk. For this purpose obtain some milk freshly drawn; some milk which has stood for from twelve to twentyfour hours, and some sour milk. Make so-called "stab cultures" by dipping the point of the sterilized needle into the milk, and then plunging it straight down through the center of the gelatin to the bottom; the needle must be sterilized in the flame after each stab. The plugs should be replaced at once, and the vials set aside. In which do you see the first signs of growth; in which is the growth most abundant; what do you conclude as to the relative number of bacteria in the three kinds of milk?

Stab cultures are especially interesting because some of the bacteria are placed deep in the gelatin where they are deprived of air, while others are left on the surface. Some kinds of bacteria die if deprived of air; other kinds die if exposed to the air, while there are still other kinds whirh can live under either condition. In a stab culture we have an opportunity to judge which of these classes of bacteria we have. Thus, a culture which grows like Fig. 212 (a), indicates the first class; if like Fig. $212(b)$, the second class; if like Fig. $212(c)$, the third class (or a mixture of the first two).

In order to determine whether bacteria use up oxygen and produce carbon dioxide, we may take an infusion 
which is filled with bacteria, place it in a wilte-monther bottle, and place in it a vial containing rlear water, and stopper the larger bottle as shown in Fig. 30. As a control, use a similar arrangement with pure water in place of the infusion. A still better arrangement is
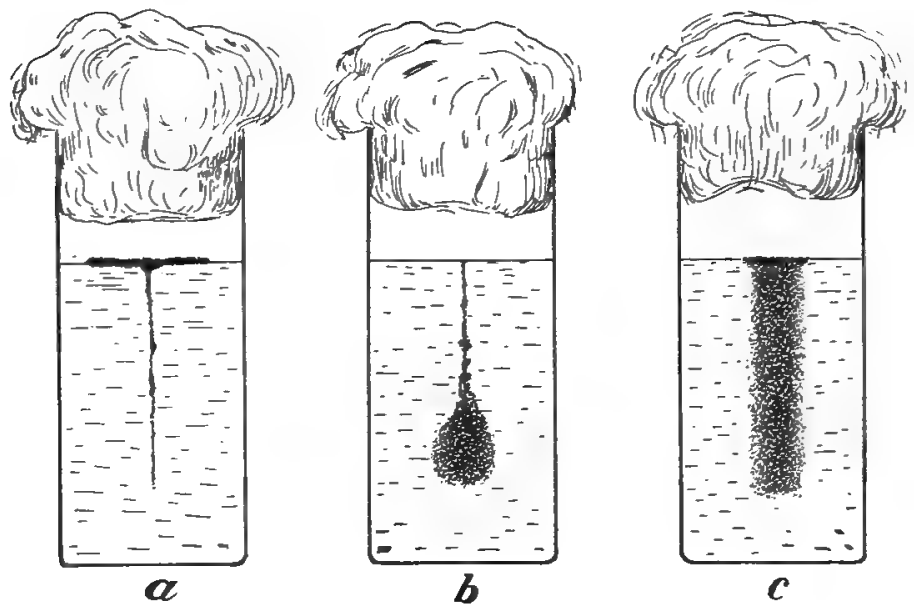

212. Stab cultures in gelatin: $(a)$ air-loving bacteria, $(b)$ bacteria not able to grow in the presence of aix, (c) bneteria which grow equally well with or without air.

to repeat the experiment described on page 34, Fig. 31 , using the infusion in place of the seeds.

We may now place some milk in vials or bottles, close the mouths with cotton, and sterilize for ten minutes on three successive days. Open one bottle three days after the last sterilization, another a week later, and another two weeks later. Do you detect any 
sign of souring? It appears that the souring of milk is due to bacteria.

Our stab cultures have shown us that while there are comparatively few bacteria in perfectly fresh milk, they increase very rapidly, so that after standing a few hours the milk is full of them. Some of these bacteria cause the souring of milk, others impart disagreeable flavors and odors (if the milk is allowed to stand long enough); some seem to have no effect on the milk, while still others produce the agreeable flavor of butter and cheese. These latter may be procured in pure cultures by dairymen, and added to their butter or cheese to produce the desired flavor.

In milk may oceur bacteria which produce typhoid, diphtheria, scarlet fever, cholera, tuberculosis (disputed), and intestinal troubles (cholera infantum). The infection may come from the cow, from the people who handle the milk, or from water. In Stamford, Connecticut, there occurred in 1895, 386 cases of typhoid, of which 97 per cent were on the route of one milkman who rinsed his cans in cold water from a polluted well. Milk-cans and utensils should be carefully sterilized, and scrupulous cleanliness both of the animals and the persons who handle the milk is highly desirable.

In order to keep milk from souring, it may be boilerl, by which process the bacteria are mostly killed; but since many persons find the flavor of boiled milk 
disagreeable, it is preferable to pasteurize ${ }^{1}$ it, i. e., to place the bottle of milk in water which is heated to $155^{\circ}$ F. for twenty ininutes, and then cooled. In practice it is usually more conrenient to heat the water to $155^{\circ} \mathrm{F}$. and then sut it aside to cool slowly. Treat several bottles of milk in this way (they should be stoppered with cotton, or well corked). How long does it keep sweet (a bottle once opened must he discarded); do you detect any unpleasant flavor due to the heating?

Pasteurizing is a legitimate process, but the use of formalin and other preservatives by milkmen is to be strongly condemned; milk so treated is especially harmful to infants. A rough test for formalin which is sometimes used is as follows: Pour ordinary commerrial (impure) sulphuric acid slomly into a glass of milk, letting it run down the sirle of the glass. If a purple color appears at the junction of the milk and acid it indicates the presence of formalin, and the milk should be taken to the health officer for a test. Put a little formalin in some pure milk and make the test: how great a dilution will give the test?

We notice that the sulphuric acid curdles the milk: this is due to the fact that the milk contains a proteid called casein, which (like the white of an egg) is coagulated by acids (cheese is made from the casein of the milk). The curdling of milk is caused hy an

1 See an article in the Year-Book of the U. S. Dept. of Agriculture for 1894 by Schweinitz; for 1895 by Moore. 
acir (lactic acid) produced by bacteria which change the sugar of the milk into lactic acid (test some sour milk with litmus). After a time this process ceases, long before the milk-sugar is all used up, because the acid checks the activity of the bacteria. If we now add enough lime-water to neutralize the acid, they will begin to grow and form more acid, as you will see on testing with litmus paper a few hours later. Make this test. It is a general rule that both animals and plants are poisoned by their own excretions.

When bacteria live in the bodies of animals or plants, ${ }^{1}$ they are dangerous or harmless according as their excretions are poisonous or not to the organism in which they live. It is well known that the human body contains many bacteria which are perfectly harmless, because their excretions are not poisonous to it. On the other hand, the poisonous excretions (known as toxins) of other sorts may produce death in a few hours (as in lockjaw, ete.). It is not necessary that the bacteria should enter the body at all; if their toxins are introduced into the body the same effect is produced as if the bacteria themselves were present. Bacterial diseases would invariably cause leath wherever they obtained a foothold were it not for the fact that the body, when the toxins make their appearance in it, produces antitoxins, e. g., sub-

tVery few baeteria are known which can live when injected into a live plant; in most cases they die in a few hours. 
stances which neutralize the effect of the toxins by combining with them just as the lime-water combines with the lactic acid produced by the bacteria in milk. The antitoxins may remain in the blood for a long time after the disease disappears, thus making it difficult or impossible for the disease to reappear. This condition is known as immunity, and is familiar to us in the cases where one attack protects against another for a long period, sometimes for a lifetime (smallpox, typhoid, scarlet fever, etc.).

The principle of vaccination depends on the fact that in the case of smallpox, for example, germs taken from a cow with "cowpox" (a similar disease) may be introduced into the human system and produce an exceedingly mild form of the disease, with the result that the body produces enough antitoxins to give it immunity from the disease for a long period.

In some cases it has been found possible to obtain the antitoxins from the blood of an immune animal and, by injecting them into another animal (or the human system), confer immunity upon it.

In addition to antitoxins, there are antibacterial substances (produced in much the same way as the antitoxins') which act, not by neutralizing the effect of the toxin, but by destroying or checking the bacteria.

By the application of vaccination, antitoxins, etc., we may hope ultimately to conquer such diseases as 
typhoid, lockjaw, tuberculosis, diphtheria, pneumonia, cholera, yellow fever, etc.

Bacteria which live in living plants or animals are known as parasitic, while those which live in decaying substances are called saprophytic. There are some kinds which live in both ways; such are capaile of multiplying outside the living body, like typhoid bacilli, and may cause infectious diseases; these may be carried by the air, by streams, etc., and widely distributed. Railway trains are also agents of distribution. Flies are especially dangerous, since they carry disease from the filth in which they breed directly into the house. Try the experiment of letting a fly crawl over sterilized gelatin and observe the colonies of bacteria which spring up in its footprints. Bacteria which cannot live outside the body can cause contagious diseases only (i. e. diseases communicated only by direct contact with the diseased person). In some cases such bacteria (or other disease-producing organisms) can be transferred by mosquitoes (malaria, yellow fever) or by fleas (bubonic plague). ${ }^{1}$

We have now had our attention called to several kinds of bacteria, $(a)$ those which produce decay and putrefaction, e. g., those which flourish in infusions and which attack and destroy the potato or gelatin; (b) those which cause fermentation, e. g.,

1 See an article by Howard in the Year-Book of the U. S. Department of Agriculture for 1901 . 
those which change milk-sugar into lactic acid and so cause the souring of milk, and (c) those which produce disease. It must not be supposed that these three groups can be sharply separated, for all bacteria cause fermentation and decay in a certain sense. Still, the above division may be used for convenience; let us proceed to examine the first two classes a little more in detail.

Decay is necessary in order that life may exist; hence the bacteria of decay do an indispensable work in decomposing the dead bodies of animals and plants into such substances as may again be taken up by plants as food and so eventually made available to animals.

Hardly is an animal dead before the bacteria commence the work of decomposition. The proteids, fats, sugars, etc., are rapidly split up into simpler compounds, with the result that finally they are nearly all converted into ammonia, carbon dioxide, water and hydrogen sulphide (a gas familiar as the source of the characteristic odor of rotten eggs). In the decay of plants the same thing occurs, with the addition that certain special bacteria decompose the cellulose and woody fiber into carbon dioxide and water with some evolution of hydrogen and marsh gas.

The action of these bacteria is further illustrated in the decomposition of manure and sewage. Two methods of purifying sewage by bacterial action are in extensive use, 
In the first, the sewage is left for six to twelve hours in a shallow open basin (contact bed), the bottom of which is covered with furnace clinkers or coke (these substances help to purify the liquid): it is then conducted into a similar bed for six to twelve hours, at the end of which it is so purified that it may be allowed to flowsinto a neighboring stream.

In the second, a closed underground chamber (septic tank) with a vent-pipe for gases is employed: the sewage is allowed to flow slowly through it in a constant stream; on emerging from this it is greatly purified.

This helps us to understand the self-purification of rivers and streams. For example, the sewage of Chicago is now emptied into the Illinois river, which, after flowing some three hundred miles, empties into the Mississippi a few miles above the point from which St. Louis takes its water supply. This at first seems to be an alarming condition of things, but on examination it has been found that this water has no more bacteria than neighboring rivers which are not recipients of sewage. The purification probably depends largely on the fact that the bacteria use up the food supply (i. e., the sewage matter) very rapidly and then perish, and, further, on the fact that they slowly sink to the bottom, are devoured by other organisms, and are killed by sunlight and iëration.

In order to study the effect of aëration, take an 
infusion which has a thick film of hacteria over it and pass a current of air into it by means of the apparatus shown in Fig. 158. Observe the rapidity with which the water becomes clear.

From these illustrations we may gain some idea of the useful work done by the bacteria, which have been appropriately called the scavengers of the world.

The decomposition of manure is effected ly bactria, the most important product from a practical standpoint being ammonia gas. The ammonia gas is in turn acted on hy a special class of bacteria, the nitrifying bacteria. Of these there are two kinds, the nitrous bacteria, which convert ammonia gas into nitrous acid (and nitrites); and the nitric bacteria, which are so sensitive to ammouia gas that they cannot begin to work till it has all disappeared, but which have the power of converting nitrous acid (and nitrites) into nitric acid (and nitrates), in which form it can be used by green plants. In order to carry on their work the nitrifying bacteria must have plenty of air. Hence it would seem to be useful to allow a circulation of air in the manure-heap: it is found, however, that there are denitrifying bacteria which convert nitric acid into free nitrogen, which escapes into the air ; it is better, therefore, to keep the heap closer to the air until the denitrifying bacteria have criserl their growth, after which air may be admitted to stimmlate the work of the nitrifying bacteria (see 
page 147); these bacteria, it should be said, are not confined to the manure-heap but are found almost everywhere in soil which contains organic matter. ${ }^{1}$

Occurring in soil and water, along with the bacteria just mentioned, are found the nitrogen-fixing bacteria, which have the power of fixing the free nitrogen of the air and converting it into compounds which eventually become available to the plant. Our knowledge of these bacteria is as yet scanty, but several of them have been isolated and studied, and one of them is offered for sale as an almost pure culture under the name of "alinit" (its practical value is still in dispute and probably depends a good deal on local conditions). Since these bacteria need abundance of air, good tillage is important in promoting their activity.

Another kind of bacteria which also possess the power of fixing free nitrogen and making it available to the plant inhabits the root-tubercles of certain plants (principally members of the Pea family), which are thus able to draw supplies of nitrogen directly from the air. On this account they are of inestimable value as green manures (see page 149).

It is found that if these plants are cultivated in sterilized soil no tubercles appear; furthermore, such plants begin to suffer after a time from nitrogen hunger; if now they are watered with soil infusions

1 See an articlt in the Year-Book of the U. S. Department of Agriculture for 1895 by Wiley; for 1902 by Moore, 
containing the tubercle-forming bacteria, they soon form tubercles and recover, while the control-plants which are without bacteria do not recover. It is furthermore found that if the roots of such controlplants are pricked with a needle covered with the hacteria, the tubercles develop at the points pricked.

It has been found that certain kinds of Beans fail to grow well in certain localities until the soil there is infected with the proper hacteria $b y$ bringing soil from another locality where the Beans in question flourish. A practically pure culture of one species of tubercle hacteria is sold under the name "Nitragin." Its use has been very satisfactory in some cases, but not in others, which may depend on the fact that it is adapter to certain kinds of leguminous plants, but not to others, and perhaps also on the character of the soil, ete.

In order to preserve foods, the bacteria of decay must be kept in check. This may be accomplished by:

(a) Drying.-Bacteria camnot grow in dry substances. Their growth ceases, as a rule, when the water-content falls below 25 per cent. Seeds are not subject to decay as long as they are dry. Hay and dried fruits are further illustrations. Dried meat is commonly smoked as well as dried; the smoke has both a drying and a germicidal action.

(b) Preservatives. - The most important of these is common salt, which is so extensively used in the 
preservation of butter, fish, salt pork, corned beef, etc. Inasmuch as salt does not kill the bacteria (but only checks their growth), such flesh may contain diseaseproducing bacteria, and be unsafe for eating.

Sugar is an important preservative. In some dried fruits, e. g., raisins, there is enough water to permit the bacteria to grow were it not for the sugar which checks them; the same is true of condensed milk.

In addition to harmless preservatives such as salt, sugar and vinegar, there are a number of injurious or poisonous substances used, such as formalin, salicylic acid and boracic acid. The public should insist that pure food laws be made and enforced, to prevent the use of such preservatives.

(c) Heat. - The important, practical application of this is canning, in which the bacteria are destroyed by heat, and the cans hermetically sealed. Tomatoes and corn are difficult to can properly on account of the presence of resistant spores which are not killed by the heating, and which cause fermentation inside the can; the cans become swollen with gas so that the head bulges out; such cans should always be rejected.

(d) Cold. - The use of refrigerators by families, and the construction of great cold-storage plants in cities, illustrates the importance of this agent of preservation. It should be remembered that cold does not kill many kinds of bacteria, and that ire may be a source of infection. For this reason it is always better to cool 
water by putting ice around the ressel containing it rather than in it.

In the case of eggs, bacteria often gain entrance before they are laid; if this is not the case they can bo preserved hy keeping the bacteria out. For this puryose the pores of the shell are filled by dipping them into water-glass (vaseline and other substances have been userl; they are also packerl in brine, etr.).

Prominent amoug the bacteria of fermentation alr, in addition to the lactic-acid bacteria of milk, the vinegar-making bacteria. In order to study these har:teria it is only necessary to take a little "mother" (which is a cratinous mass containing the bacteria) from vinegar and place it in a little hard cider or a weak solution of alcohol (containing not more than 6 or $\tau$ per cent alrohol) neutralize with lime-water, add enough liquid litmus to give a good blue color aud allow it to stand in a warm place (light should be excluded). If the liquid be poured over a mass of excelsior or shavings, the vinegar is fromed with great rapidity, as shown by the color of the litmus. The reason is that in this case the bacteria are abundartly supplied with air, which is essential to their activity. This experiment may be conveniently carried out in a coverent wooden pail or tub fillerl with excelsior (or sharings).

In recent rears the use of silage has become rery extensive. Silage is made by filling a pit or other

1 Ordinary litmus paper may be used in place of liquid litmus. 
air-tight compartment with Com (or some other plant) chopped into small pieces. It is packed into a solid mass; frequently pressure is used to solidify it. The top is covered (so as to prevent the access of air). A rapid rise in temperature oceurs (sometimes going as high as $150^{\circ} \mathrm{F}$.) ; after a few days the mass cools, but the evolution of heat continues to a lesser degree for several weeks. At the end of this time it is found to be somewhat acid, with a fint aromatic flavor which causes it to be eagerly eaten by cattle. Silage can be made just as well in small pails or tuks as in larger quantities, and the phenomena here descrilued can lee observed (only the rise in temperature will be very small) in the school-room.

The whole process looks like fermentation, and was until recently supposed to lot due to bacteria; the latest studies indicate that bacteria have little or nothing to do with it, especially in the early stages, where the rise in temperature seems to be due to the activity of the wounded plant-cells. In this respect there is a close agreement between animal- and vegetable-cells in the rise of temperature (or fever) which follows a wound.

The fermentation of tobacco, long supposed to he due to bacteria, has lately been referred to the selfactivities of the cells of the leaf: this sul,ject is still somentwat in lispute.

The "sweating" of hay is in all probability a similar 
process to that of tobacco-reuring, luut how far it is produces ly bacteria is not known.

Another class of plants, very different from the bacteria, whirh ause finnentation are the Yeasts. linb up a ruarter of a yeast-cake in water to make a biste; ard this to a pint of water in which a tablespoonful of honty or sugar has been dissolved. Fill three good-sized bottles half full of the (well-stirred) liquid, and stopper them ly simply allowing the cork to rest in the neck of the bottle without forcing it down into it.

Put one in a warm plare in the lark, one in a corrl place (preferally on ice) in the dark, and one in a warn place wonosed to bright light. Ohserve every few hours, noting the turbidity of the liquid, growth of the Yeast, evolution of gas bublurs, change in taste, ete.

Repeat the experimints shown in Figs. 30 and 31, using Yeast instead of seris. The experiment of lowering a lighted match into a bottle in which Teasts are growing may also be trierl: if it goes out it indicates the presence of carbon dioxide.

Examine under the microscope a little of the yeastrake rubber up in rater: notice the appearance of the Yeast-cells: add a little iodine, and observe. How is the yeast-cake prepared?

Take some of the sediment from the bottom of the yeasi culture and examine under the microscope. Notice the appearance of the Yeast-cell (Fig. 213) 
with its cell-wall, ${ }^{1}$ and protoplasm filled with shining drops or granules. The mode of multiplication call also be easily made out: it is by budding, $i$. e., an nutgrowth from the rell becomes cut off, and forms a

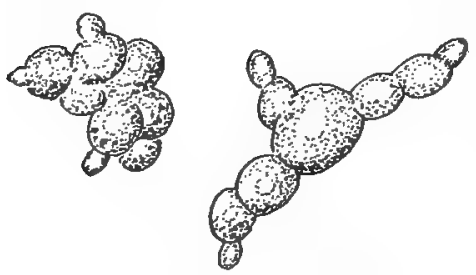

21:3. Yeast-cells budding. new cell. The cells so produced often hang together. in chains (Fig. 213).

The bubhles of gas which rise in the liquid are practically pure carbon dioxide. At the same time that evolution of gas goes on, aloohol is formed, and the sulua disappears (as can lie shown by tasting the liquid). Chemical analysis shows that the sugar is hrokm up by the action of the Yeast into aleohol and carkon dioxide. The presener of alcohol can be shown by alutiously heating the liquid in a cup until enough vapor forms so that it may be ignited by a match: we may also distil off the alcohol hy means of the apparatus shown in Fig. 9.).

This process is very general in nature. Nearly all fruits have Yeasts on their surfaces which cause fermentation when the fruit bewius to decay, converting the sugar present into alcohol and carbon dioxide. Test some ripe grapes by crushing them, corering them with water and allowing them to stand for a time; when fermentation ocrur's examine for reasts.

1 If there is any difficulty in seeing the cell-wall, shrink the colls by the use of a little glycerine or strong salt solution. 
In the manufacture of beer, etc., the sugar is obtained by allowing the grain to germinate until a large part of its starch has become sugar (see page 169), then killing it $\mathrm{w}$ heat and extracting the sugar by means of water; the Teast is then added. In addition

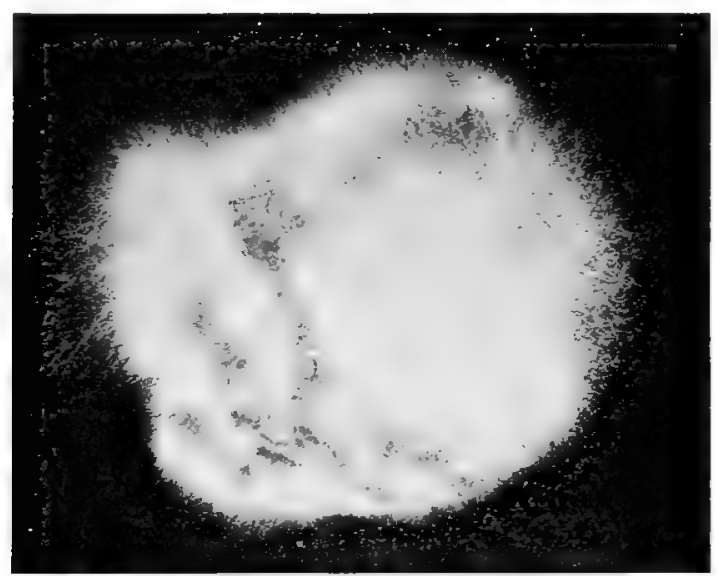

2lf. Blitck Mould of bread (Rhizopns), showing mycelium.

to the useful Yedsts, there are others which impart a disagreeable taste or odor to the product; and these must be carefully excluded. The use of pure cultures of Yeasts is now becoming general: they are obtained by the same methods as pure cultures of bacteria.

Another class of plants which resemble the bacteria in causing decay are the Moulds. A very common one which occurs eгer!where on decaying fruit, vegetables, bread, ete., is the Black Mould of bread (known as Mucor stolonifer, or Rhizopus nigricans). 
Obtain a little of this Mould and scatter it over a slice of bread which is kept moist in a granite-ware pan sovered with a plate of glass (Figs. 214, 216). The first thing to appear is an abundant growth of white, threadlike, interlacing filaments, the vegetative part of the plant (called mycelium). This is shown in Fig. 217.

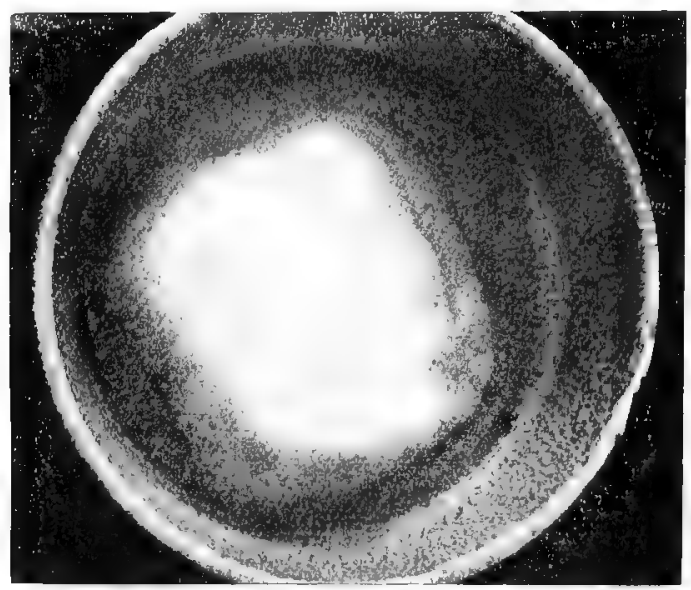

215. Same beginning to show spores at the edges of the breat.

Presently this begins to darken around the edges of the slice (Figs. "215, 216). When we examine into the cause of this, we find numerous little black bodies raised on slender stalks above the surface of the bread (Fig. 217). If we now remove a portion of the weft with some of these bodies attached, and place it in a drop of alcohol on a slide, and place a cover-glass on it, and add a drop of water at one migre, we may 
examine it under the microscope and make out it: structure (Fig. "21s).

The now see that slender threads growing orer the surface of the bread send out root-like branches at frequent intervals, and that from these points stalks

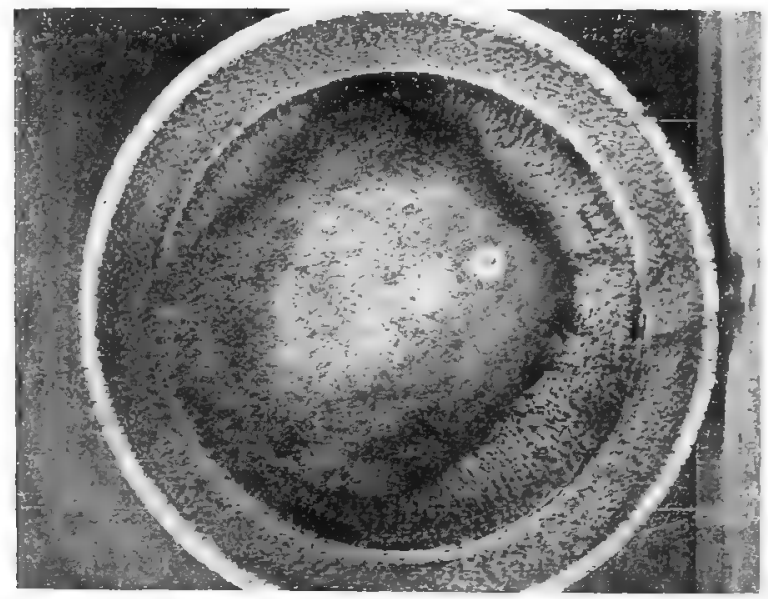

216. More advanced stage of spore formation.

arise, bearing at their fulk round bodirs (about as big as the head of a rery small pin) which are at first white, and later turn dark. On examining with the high power of the microscope, we see that each of these bodies (Fig. 219) has a chamber (rrescent-shaped in section) full of small round spores, which become dark as they ripen (crushing by pressing on the cover-glass with a pencil-eraser helps to bring out these points).

Try to find the youngest stages you can of these 


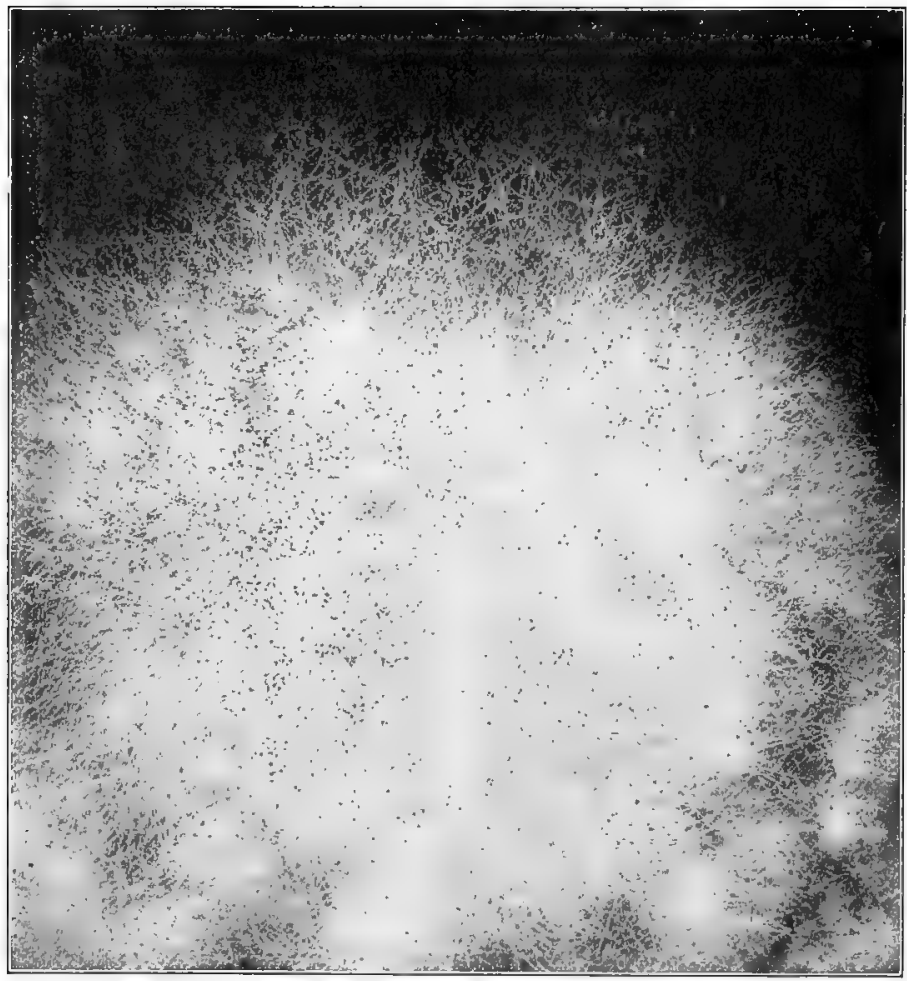

217. Portion of the mycelium, showing the immature spore-etses (white) and mature ones (black).

spore-cases. Why do they appear first at the edges of the slice (has the amount of moisture anything to do with it)? Does the Mould grow better in the light or in the dark? What effect has temperature on its growth? Does it produce carbon dioxide? (Grow some in a closed jar with a bottle of lime-water.) 
Sow some spores in a hanging drop, as shown in Fig. 16.5, and observe their germination. They grow well in the sweetenerd juice of stewed apricots, in water in which hay has been boiled, or in sireetened water. Spread a thin layer of nutrient gelatin (see page 369 ; ordinary gelatin sweetened will do, or even a little
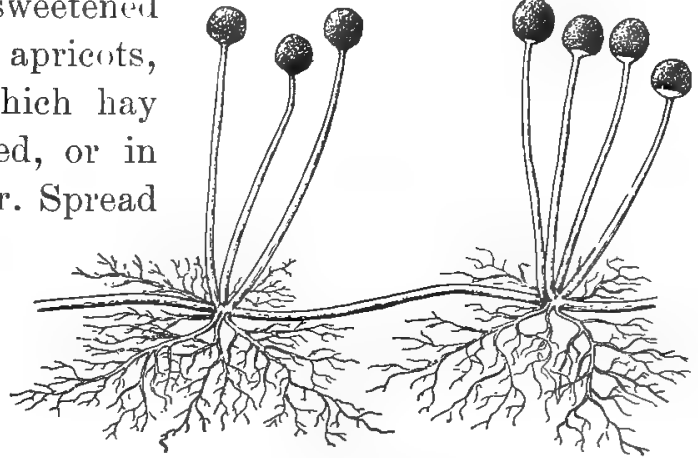

218. Black Mould of bread, showing the manner in which the mycelium sends out root-like branches at short intervals: from these places spring long stalks bearing spore-cases.

clear apple or other fruit jelly) on a slide, sow the spores in it, and keep the slides in a moist atmosphere

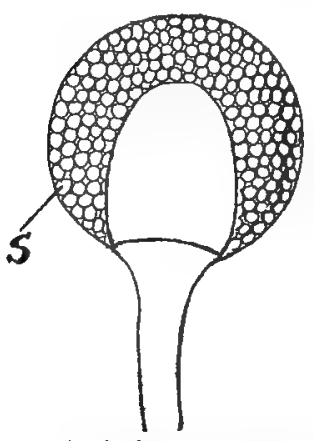

219. A single spore-case of the Black Mlould of bread, showing the $\mathrm{chamber}$ (erescent-shaped in seetion) in which the spores $(s)$ are contained. (for this purpose they may simply be laid on top of the bread culture in the pan or placed in a special pan on a support to keep them from contact with the water in the bottom of the pan). We may remove the slides from time to time and observe the development of the Mould; since they are injured hy exposure to dry air it is better to have a number of slides, one of which may be removed each day. 
'The spor's of' the Mould are (like the spores of the bacteria) resistant cells which are not injured by exposure to dry air and are, in fact, carried about by the wind so as to suatter the Mould everywhere. When ripe the sportanse bursts, so as to set the spores fiee.

In addition to thess spores (called asexual spores) there often orm larmer ones (called sexual spores,
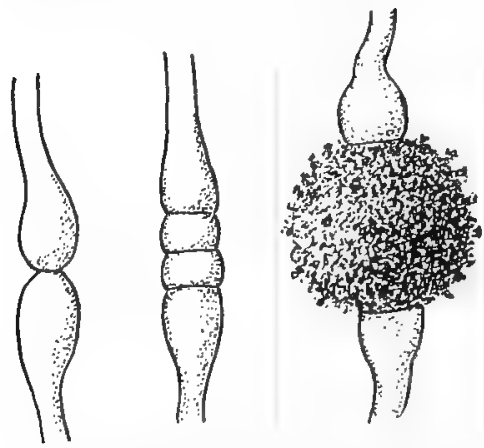

220. Formation of zygnspores of the Black Iould of brits: at the lett two branches tnuching. to the right stiuges in the fizsion, the litst being the fully tormed zygospore.

ol zygospores, because the result from the union of two branches), which are folmed, as shown in Fig. '2ul, by two branches coming together and fusing so as to form a large, thick-wallerl spore of a deep blark color. These spores are lar'or, mole lesistant, contain more nutriment and sive lise on germination to a mole vigorous growth than the ordinary asexual syores.

Anothel very common Momld is the Green Mould (Prnioillium) of rhrsese, hrard, jellies, ete. In this Nomkl the sropes are in long rhains at the end of the stalk (Fig. 2.21), and are not molosed in a spolp-case, as in the Black Momld.

What effrect ro these Monlels have on the substances 
on which they grow? C'an foods be protect d against them in the same way as against bacteria? ${ }^{1}$

An inmense amount of damage, amounting in the? United stater alone to a great many millions of dollars earch year, is done to crops by the Smuts, Rusti and Milders. For this and other leasons it is worth while to derrete some study to these planti, in order that we may more cloarly understand their mode of life and the best remodies against then.

The "ommon Corn-smut begins to appear in the leares when the plant is three or four feet high, forming small white spots raised abore the surface of the leaf and somewhat

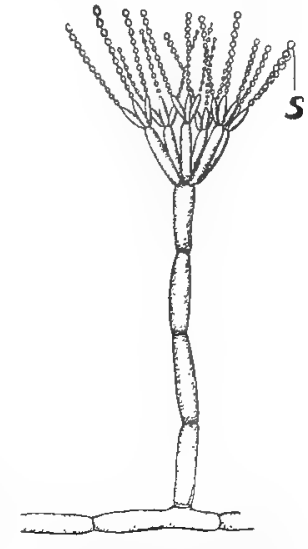

2:1. Green Mould of checur. etc.. showing the manner in which the spmen (s) are borne. wrinkled (frequently surrounded by a reddish discoloration of the leaf). Later on they turn black (or disappear altogether). The Smut appear's on the stalk, inside the sheathing base of the leaf, near the joint or node. It also appears in the form of pustules scattered through the male flowers or tassel; it also appears on the ears, corering them partially or completely, forming white masses with a peculiar soft, silvery luster; later these burst and

1 A rery good method of sealing jellies is to pour melted paraffin on top : the heat kills the Moulds and bacteria while the paraffin seals the tumbler bernetically. 
discharge a perfect cloud of black spores. If we investigate these masses before they have grown to the size of a pea we find a mass of mycelium, similar, in a general way, to that of the Bread Mould; later on this mycelium forms spores by breaking up into its constituent cells, which separate from each other, each cell becoming a spore. The spores are scattered by the wind and germinate in the soil or wherever they can find moisture and suitable food. Germination may take place at once or may occur the following season. In order to see the germination of the spores, we may

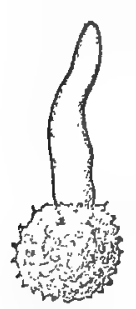

222. Spore of Corn. smut germinating. cultivate them in a hanging drop of sterilized slung liquor, sterilized plum juice (made by stewing prunes in water and just neutralizing the acid by adding ammonia water), Pasteur's solution ${ }^{1}$ with sugar or in modified Cohn's solution. ${ }^{2}$

The spore first puts out a germ-tube (Fig. 202); when this has become several cells, long elongated spores make their appearance (Fig. 223, r); these are called conidia. They derelop much more abundantly in contact with air (i.e., on the surface of the liquid). It is the conidia which infect

1 This can be made up by a druggist as follows: Monobasic-potassium ohosphate, 20 parts; tribasic calcium phosphate, 2 parts; magnesium sulphate, 2 parts; ammonium tartrate, 100 parts; cane-sugar, 1,500 parts; water, 8.576 parts.

2 This may be made up by a druggist as follows: Distilled water, 42.38j grams ; cane-sugar, 7 grams; ammonium tartrate, .250 grams; potassium phosphate, .125 grams; magnesium sulphate, .125 grams; calcium phosphate, .125 grams. 
the Corn plant. Borne by the wind, they settle upon the plant and penetrate it wherever the tissues are sufficiently teuder, i. e., at the terminal buds and at the base of the leaves, inside the sheath. Anything which tends to make the Corn tender and succulent (e. g., rich land and abundant water) favors infection; moisture in the air also helps to preserve the vitality of the conidia, which are injured or killed outright by drying up. The conidia germinate by sending out a germ-tube, which penetrates into the tissues of the Corn

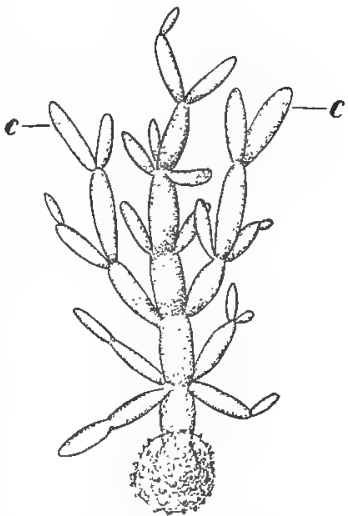

223. Spore of Corn-smut producing conidia (c). plant, where the mycelium rapidly spreads to all parts. (When food is not abundant they frequently unite in pairs before sending out the germ-tube.)

The best method of infecting the Corn is as follows: Grow the spores in one of the above solutions (preferably plum juice or Pasteur's solution with sugar), until examination shows the formation of abundant conidia. With a medicine-dropper place a few drops of the liquid $(a)$ on some Corn seedlings (with leaves about half an inch long) grown between folds of moist cloth or blotting-paper; leave them for at least twentyfour hours more in the blotting-paper, then transplant several of them to pots of sterilized soil (leaving the 
others still in the blotting-paper). Have a number of uninfected plants as a control. If growing Corn is available, (b) place a few drops in a young ear by gently opening the eud of the ear and forcing the pipette down into the center. Results from $(a)$ should be apparent in about two weeks. If no result is obtained, repeat the experiment.

The yearly loss from ('or'n-smut in the United States alone is estimated at over $\$ 2,000,000$. The best remedy is to go through the fields once or twice during the growing season and again when the Corn is ripening, collecting all the smutted portions each time and burning them. Formerly the seed was treated with bluestone, but this is of no valur, because the infection occurs after germination.

The Smuts of Grain (i. e., the Black Smuts of Wheat, Oats, Barley and Rye and the Stinking Smut of Wheat) do not spread from plant to plant, like the Corn-smut; infection takes place only when the spores come in contact with the sext; for this reasou the attacks of these Smuts may be prevented by treating the seeds with a germicide. For this purpose bluestone (copper sulphate or blue vitriol) is used at the rate of a pound (or more) to a gallon: the seeds are dipped into this long enough to get thoroughly wetted (wheat for a few minutes, oats and barley, on ac-

1 See an article by Swingle in the Yuar-Book of the Lnited states Departnent of Agrieulture for 1894; for 1896 by cirrleton. 
count of their hulls, from eighteen to forty hours), and then dried (this is hastened by dusting them with plaster or slaked lime) before sowing. Very favorable results have been obtained with oats by dipping for ten minutes in formalin (one pint of formalin in thirtysix gallons of water). Other precautions, in addition to the use of germicides, are to grow some other crop besides Grain until the spores in the soil are dead (two or three years); to keep cattle and manure off the land where there is any danger of carrying the spores, and to disinfect the barn, bin, thresher, etc. The loss in the C'nited States from Oat-smut alone is estimated at over $\$ 18,000,000$.

If these smuts occur in your vicinity, it will be very easy to watch the germination of the spores in hanging drop cultures, and also to make experiments to determine the relative value of germicides and whether they impair the germination of the seed. If clean seed is obtainable, infections may be made.

The Black Stem Rust of Grain has a very different appearance and mode of life from the Smuts of Grain. Instead of being confined to the flowers, it appears on the whole plant, principally on the stalks and leaves, where it forms elongated black ("black rust") or red ("red rust") pustules. The red pustules contain onecelled spores (called summer spores or uredorspores), as is shown in Fig. 224; the black pustules contain two-celled spores (called autumn spores or teleuto- 
spores), as shown in Fig. 225. These two forms of spores are developed from the same mycelium, the one

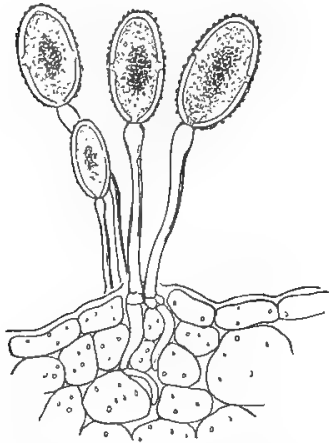

224. Summer spores, or uredospores (red rust stage), of the Black Stem Rust of Wheat.

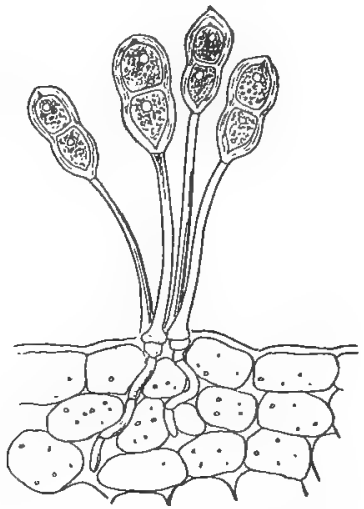

225. Autumn spores, or teleutospores (black rust stage), of the Black Stem Rust of Wheat.

(uredospores) earlier, the other (teleutospores), later in the season. The uredospores germinate during the snmmer; they send out germ-tubes which enter the stomata of the leaf (Fig. 226). The teleutospores rest

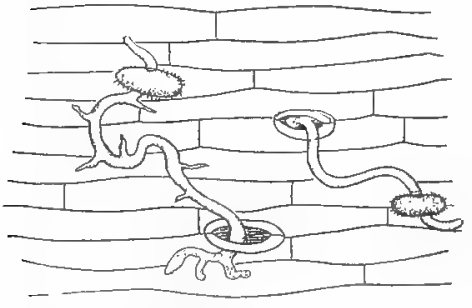

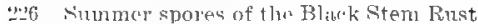

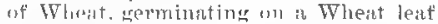
and somling tles gern tulses through the stomat th. during the winter; in the spring they germinate, produeing conidia (Fig. $27, c)$, which are borme hy the wind to the leares of the Barberry plant; here they greminate, penetrating the leat hy mealls of a germ-tube and forming 
a mycelium which spreads rapidly through the liaf alul finally forms spores known as cluster-cur, nmen $101^{\circ}$ rcidiospores). These spores, as their name implies, are arranged in clusters in cuplike cavities of the leaf (Fig. '2.) are produced by their growth. On examining thin sections of the leaf carefully, wr sue that the cluster-cup spores ar' in lown chains bornt on short stalks (Fig. 229). On the upper surface of the leaf occur smaller cavities filled with smaller slender spore-bearing stalks; their function is not understood. We see, then, that th Black Stem Rust of the Wheat occurs in three different forms, at different times of the year-the uredospores in the summer, the teleutospores in the autumn, and the elus-

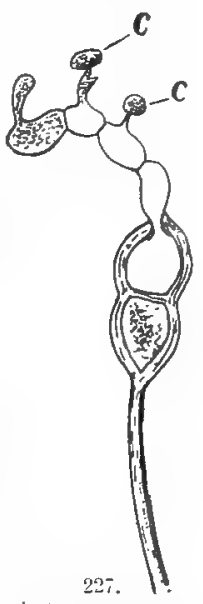

Autumn spores of the Black Stem Rust of Wheat purduring conidia(c). ter-cup spores on Barberry in suring. Formerly, when

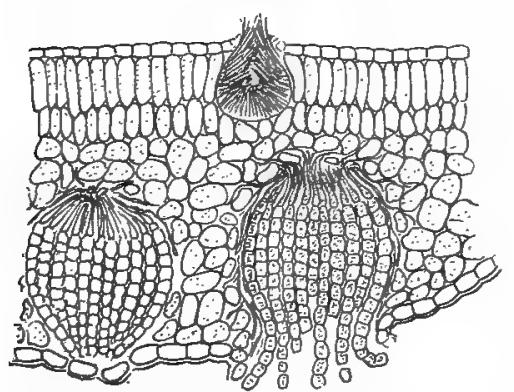

228. Section of Barberry leaff, showing the cluster-cup stage of Black Stem Rust of Wheat. it was not known that thess were all forms of the same fungus, they were described as separate genera. The discurery that the Barberry had something to do with the Rust on Wheat was first marle ly practical farmer's, who observed that 
Wheat was more affected with Rust when it stood on the leeward side of a Barberry bush; it was accordingly decreed by the Massachusetts Barberry Law of 1755 that the Barberry bushes should be destroyed.

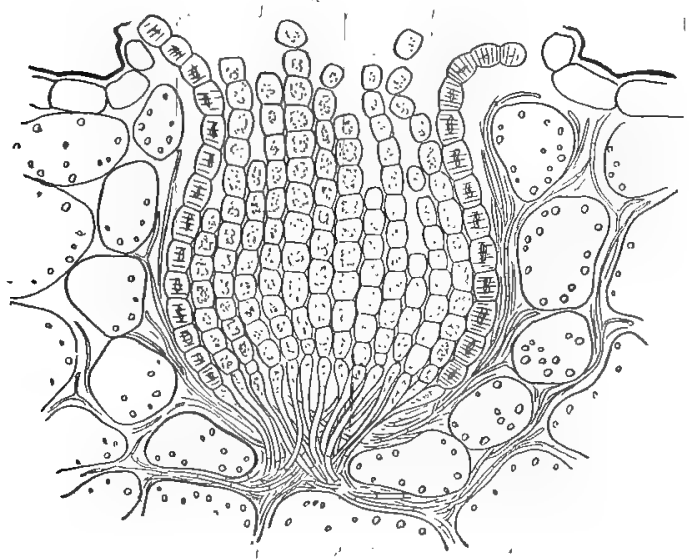

229. Cluster-eup (acidium) of Black stem Rust of Whest.

The matter was afterward taken up by botanists, who traced the connection carefully and came to the conclusion that the cluster-cup was a necessary stage in the lifehistory of the fungus. A difficulty arose in the fact that the Rust prospers even when there are no Barberry bushes, and it is now known that, in some cases at least (e.g., in Australia), the uredospores can live through the winter and infect the Wheat again in the spring. It is supposed, however, that the teleutospores cannot infect Wheat, but only Barberry.

The uredospores of the Black Stem Rust of the Wheat readily infect Barley, and rice versa; but it seems highly probahle that they cannot infect Oats (nor vice versa). The Black Stem Rust of Oats seems 
to be a distinct form, though it in every respect closely resembles that of the Wheat, and passes its clustercup stage on the Barberry. The samr is probably true of the Black Stem Rust of the Rye: it does not appear to affect any other Grain.

The Orange Leaf Rust of the Wheat is very similar in appearance to the Black Stem Rust; its cluster-cup stage is passed on Anchusa and Echium; the uredo lives over the winter in the United States. The Orange Leaf Rust of the Rye appears to be distinct from that of Wheat: its uredo lives over the winter in the southern states.

The Crown Rust of Oats is found only on Oats. It resembles the Orange Leaf Rust of Wheat. Its clustercup stages are passed on Rhamnus.

The method of observing the germination of the cluster-cup spores or the uredospores is simply to place perfectly fresh spores in a hanging drop of water. The teleutospores are to be treater? in the same manner, only they must be preserved during the winter, for they will germinate only in the spring. These germination experiments may not always succeed, but they are worth trying.

In order to make infections with uredospores, it is only necessary to grow some Wheat in pots during the summer; and when the leaves are three or four inches long, bring in a fresh leat of Wheat which is well covered with uredospores, and tie two of the growing Wheat 
leaves together, with the infected leaf between them, in such a way that there will be a close contact all along the leaf: this will ensure the uredo-spores reaching the growing leaves, and will prevent them from drying up. The moister the air is kept, the better; it may be well, therefore, to cover the plants with a paper bag (or, better still, witl a leell-jar if available).

The common Hollyhock Rust (found everywhere on Hollyhocks, the Round-leaved Nallow and other Mallows) is an example of a Rust which passes through its entire life-history on one kind of plant, thus contrasting with the Rusts of Grain: it produces teleudospores only; they germinate readily in water and may be used for infection experiments (either by putting a drop of water containing the spores between two leaves tied together or by using the infercted leaf in the manner described above).

The yearly loss from Grain Rusts in the I'nited States is rstimaterl at considerably more than $\$ 18$,1100,000 .

As an example of a Milkew we may sturly the "ommon Mildew of the Lilac. The nyelinm appears on thr. surface of the leaf as a whitish covering (scrape off a little of this, mount it in a drop of weak alcohol and "xamine under the microseope). After a time black specks, visible to the naker eye, appear here and thre wh the nyrelium. Remore some of them and examine under the microscope: they have the appearance 
shown in Fig. 2:30. The long, branching appendages of the rounded black bodies are rery characteristic. Press on the cover-glass with a rubber pencil-eraser. until some of the black bodies are "rmsherl; we may' then see the spore-sacs, containing four or more spores.

Mildews are very common on looth wild and cultivated plants and do a large amount of damage. They do not penetrate to any great extent into the leaf but a bsorb nutri- 230. Peritlerium of the common Mildew of the Lilnc; spore. ment by means saes (asei) issuing from an opening produce $\perp$ by crushing. of short sucking organs which penetrate into the epidermal cells.

Most of the loss from plant diseases is preventable by simple measures; among these are the following: ${ }^{1}$

(1) Spraying with chemicals (Bordeaux mixtur, sulphur, etc.) which do not injure the plant.

(2) Destruction of diseased plants or portions of them by burning; this of course destroys the spores.

1 Consult Ward: "Disease in Plants"; Lodeman: "The Spraying of Plants"; Ward: "Timber and some of its Diseases"; Massee: "Tert-book of Plant Diseases"; also articles in th» Year-Book of the $U$. S Department of Agriculture for 1895 by Waite and by Galloway and Woods; for 1896 by de Schweinitz and by Howard; for 1899 by Galloway; for 1900 by ron Schrenk. 
Weeds, volunteer Grain, etc., along roadsides and in fence corners may harbor the disease, and hence should be kept down as much as possible.

(3) Rotation of crops in the case of diseases which can live in the soil; this allows them to die out in the interval between crops. Plants with such diseases should be burned rather than plowed under.

(4) Disinfection of serel, seed bins, thresher, etc.

(5) Careful attention to wounds, cuts made in pruning, etc. These should be repeatedly painted with tar to prevent the entrance of disease.

Among the books which may be consulted on the subject of the chapter are: Conn: "Story of Germ Life," "Agricultural Bacteriology;" Newnau: "Bacteria." 


\section{('HAPTER $X^{1}$}

\section{MAKING NEW KINDS OF PLANTS 2}

IT was not long ago that the finest Tomatoes were so small, tasteless and full of seeds as to be utterly unfit to eat; at that time they were called "Loveapples" and were grown merely as curiosities. The splendid varieties of the present have all been made in a generation.

All our cultivated fruits have been similarly improved. How this is done is well illustrated in the work of Mr. Luther Burbank on Plums. He began by carefully studying the various kinds of Plums obtainable from this and other countries, with a view to finding out their individual peculiarities and possibilities of improvement. Then he crossed American, Japanese and European kinds together, and from the lesulting mixture selecterl the best for further experiments, destroying the rest. The results have been

${ }^{1}$ Indispensable for reading in connection with this chapter is "Plant Breeding," by L. H. Bailey. Both the second edition (1902) and the third edition (1904) should be at hand, since the former contains an interesting. chapter omitted from the last edition.

2 Of the illustrations in this chapter I am indebted to Mr. Luther Burbank for Figs. 231 to 236 and 240 to 245 , and to Professor Hugo de Vries for Figs. 247 to 252. 
extraordinary: they may be briefly summed up as follows:

1. Every possible variety of coloring of skin and flesh has been obtained, from a pure golden yellow to deepest blood-red. Mottled and rarisuated forms have alpurarl in abundance.

2. The shapes vary as much as the colors. The "Apple Plum" has the size, shape and appearance of an apple: other's are like an inrerted pear, while all the intermediate shapes are remenented.

3. The new flavors and aromas defy classification. While the Bartlett Plum tastes exactly like the Bartlett Pear, others suggest a banana, and all degrees of sweetness and acidity are found. Some have the aroma of pineapples, others of apples, and of certain kinds but a few are nteded to fill a whole room with fragrance.

4. The sizes have been increased up to three inches long and two and one-half in diameter. That the hybrid may sometimes exored either of the parents in size is well shown in Fig. 231. The parents are an American Plum (I'rmms Americana) shown on the right, and a Japanese Plum (I'rums triflora), shown on the left. Among the hybrisls which appeared in the first generation of this cross, before any selection harl taken place, was the one shown in the "enter" of the figure. The Giant Prune, over two and onehalf inches long, is another very interesting illustration 
of this point; it is a cross between the French Prune (shown in Fig. 2:36) and the Pond Plum (a European Plum about one and three-quarter inches in length),
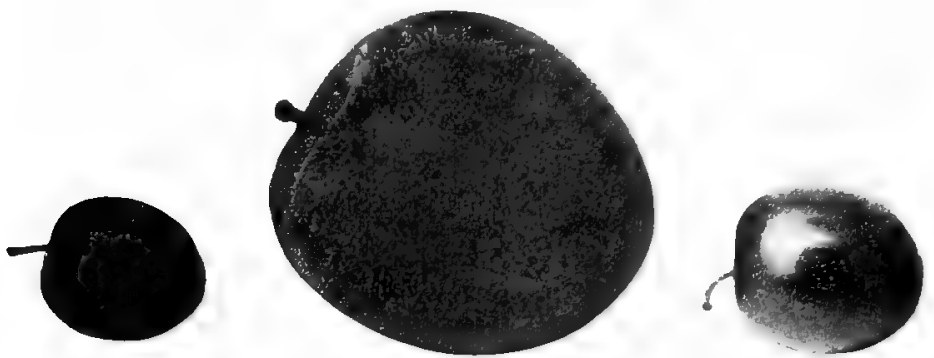

231. Iucratsel size in l'lums due to hybridization 'willout selection'. Japanese parent on the left, American on the right, hybrid in the center. Two-thirds natural size.

and was brought to its present huge sim. h. contimued selection: it therefor" owes its size to crossing plus selection. Another offspring of the French Prune, called the Sugar Prune (Fig. "s:3), is not only much larger but ripess a month earlier and is even sweeter than the parent, running as high as about "2t per cent sugar, or prartically one-fourth of the total weight of the fresh fruit. This was obtained simply hy sulection, no rossing having been done. Thesin thres. instances illustrate very well the different ways of securing increased size.

5. By producing varieties which ripen a month

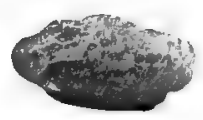

2.; In Increased size in Plums due entirely " selection (without errscing). Freneh Prune (dried) on the left: Sugar Prume (dried) on the right. Two-thurds natural size. 
before the earliest of the old varieties, and, on the other hand, varieties which last until December, the Plum season has been greatly prolonged. The importance of early and late varieties is very great, since they enter the market without competition in their particular line.

6. Some varieties have been produced which seem to be unaffected by frost. Even though the petals and young leaves are frozen and killed, the stamens and pistils go on performing their functions and the trees bear a full crop of fruit. Other varieties have been obtained which are enormously productive even where the old varieties fail. Many of these begin to bear abundantly the third year from the seed when grafted upon trees of ordinary size; others have been bred to stand shipping for long distance. Some kinds have been secured which remain on the tree from six to nine weeks in hot weather without deterioration, thus possessing a great advantage over many of the older varieties which must be picked as soon as ripe.

Some of these new Plums are accommodated to climates and conditions where the Plum has hitherto proved a failure. A notable instance of this is the Improved Beach Plum (Fig. 233), obtained by crossing the Beach Plum (Prunus maritima) with an American Plum (Prunus Americana). The Beach Plum is a wild species growing along the coast as a low, spreading shrub, not more than three or four feet high, with a 
very dull-colored, small, bitter fruit (see Fig. 29:3), utterly worthless except for preserving. It has the advantage of growing in all situations, thriving in dry sand or in the soggy soil of swamps, indifferent to cold and frost and wonderfully prolific.

By crossing and selection, the good qualities of both parents have been retained and the bad ones
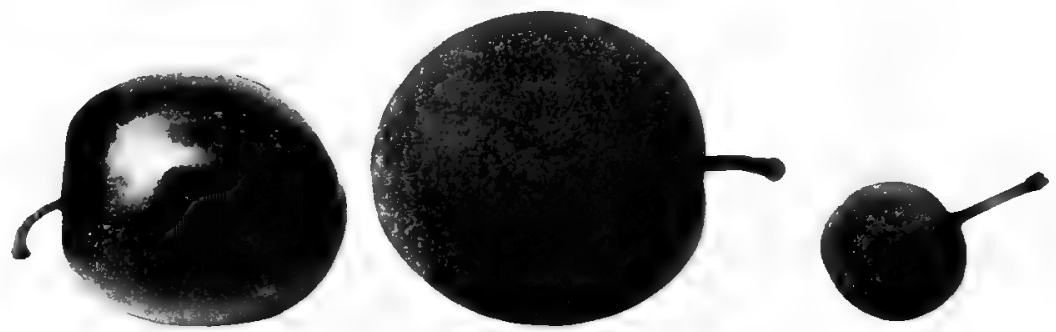

233. Inproved Beach Plum in the center. The parents are: Beach Plum on tha right, an American Plum on the left. Natural size.

eliminated. The Improved Beach Plum, as it is called, bears so abundantly that the fruit almost conceals the wood, as may be readily seen from the photograph (Fig. 234), which represents a branch three and a half feet long. The fruit is shown full size in Fig. 233. It is of a deep purple color, with white dots, with deep yellow flesh and a stone not larger than a cherry-pit. It is a delicious plum of unusually fine flavor, without a trace of the bitter taste of the Beach Plum. It is indifferent to frost, and grows and bears under the most trying conditions of soil and climate, and will 


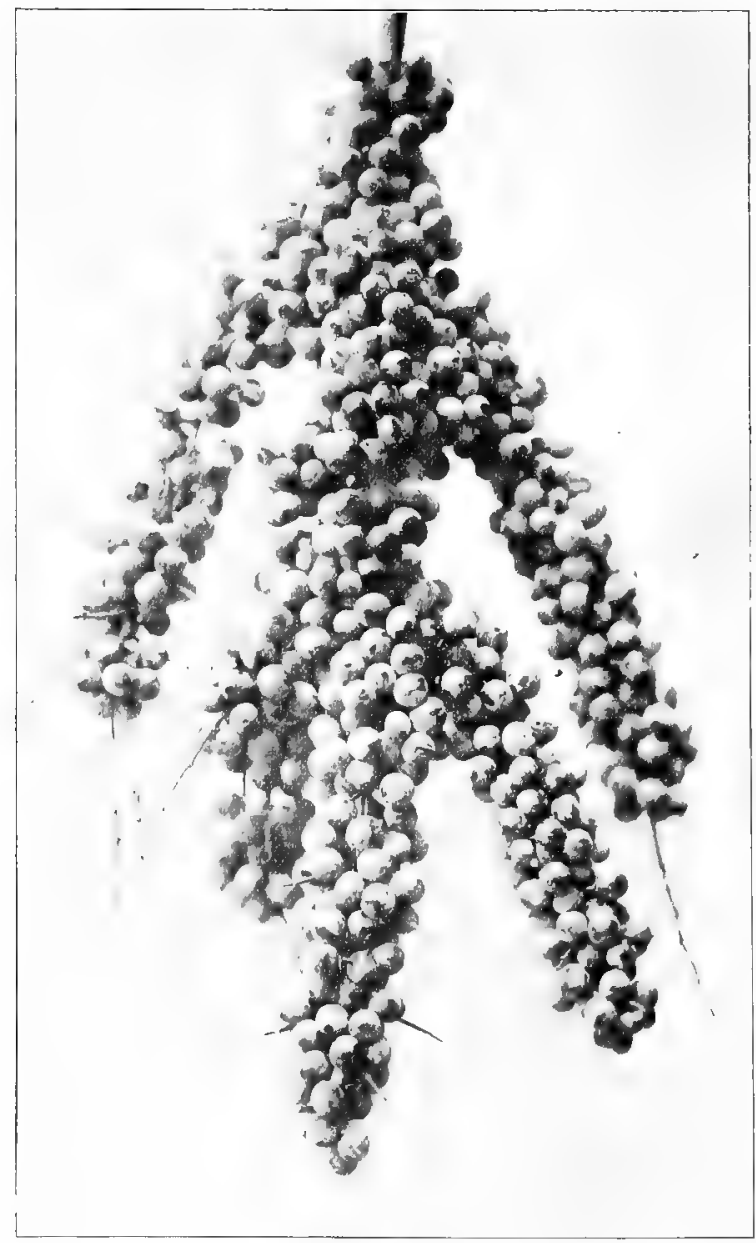

234. A branch of the Improved Beach Plum. (The fruit is shown natural size, in Fig. 233.) Less than one-eighth natural size. 
produce abundantly where Plum culture has hitherto been impossible.

An interesting clejarture has been made by crossing Plums with othel fruits. I cross between the Plum and an evergreen Cherry has been made which promises most striking results. A still more remarkable cross is between the Plum and the Apricot, which $\mathrm{Mr}$. Burbank succeded in making, after making many trials, and which he has called the Plumeot (Fig. .'3). This resembles an apricot but is more highly colored, with very fine silky down: the pit somurtimes resembles that of a plum, sometimes that of an apricot: the leaf is intermediate between the learrs of the parents. The flavors are unique and

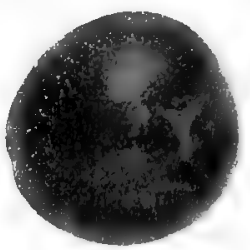

235. The Plumeot, a cross between the Plum and the Aprient. One- half' natural size. varied and, taken all together, it is a most remarkable and delicious fruit.

Not content with these achievements, he conceived the idea of producing a Stoneless Plum and Prune. Beginning with a small, unproductive variety, with fruit no larger than a cherry, but with a stone which only partially covered the kernel, he crossed it carefully with the French Prune and selected the progeny until a variety of new Plums were obtained, all of good size, good flavors and fine appearance, and all restitute of stones. In the center is no stone, but in it: place a cavity within which lies a more 
or less well-developed seed. Some of the seedir are normal in size and shape, others more or less deformed and abortive, while in a certain percentage seed and stone are both absent. Fin. 236 shows,
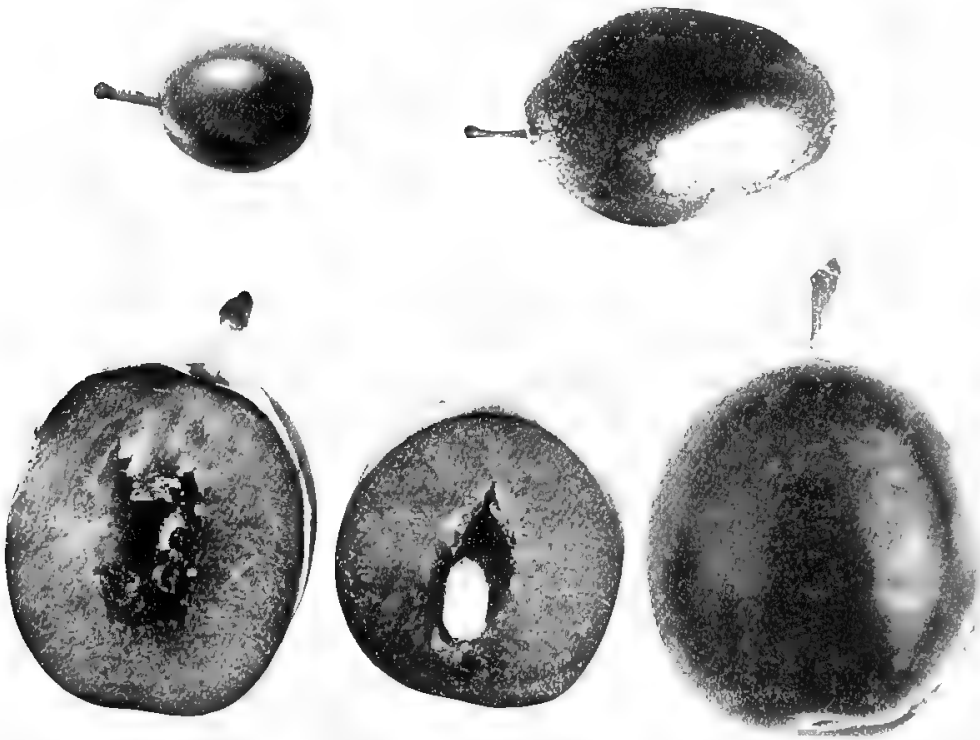

236. The Stoneless Plum, lower row; and parents, upper row. At the right in the lower row the Stoneless Plum, external appearance; in the midcle the fruit ent open showing a normal seed with a cavity where the stone would ordinarily be; at the left, another frnit eontaining neither stone nor seed, the latter being represented by a shriveled remuant. In the upper row the parents: at the right the French Prune; at the left the Prunier sans Nintau. All natural size.

in the middle of the lower row, one of these prunes cut across; in this a well-developed seer is present: on the left is shown another in which nothing remains of the seerl save an alortive remmint. While Mr. Burbank believes it perfectly possible to breed out 
the seed altogether, he does not consider it desirable to do so, for the reason that the seed adds flavor to the cooked prune.

These astonishing results represent but a portion - indeed a minor portion - of the achievements of one man during a few years of work, and they afford an excellent illustration of the possibilities of plantbreeding. The method by which they have been hrought about is simplicity itself: variation and selection are the two processes which produce all these results. We may now examine them more in retail.

It is a familiar fact that every plant shows some variation (since no two plants, or leaves even, are alike), and it has been discovered that variation obeys certain laws. It not only confines itself within certain limits, but there is a certain average form or type around which the variations group themselves. This may be made clear by means of a diagram. If we count the number of rays in a large quantity of daisies (the Common Ox-eye Daisy), we may find that it varies, let us say, from five to thirty-seren. If we sort them into piles, putting into the first pile all those with five petals, into the second all those with six, and so on, we shall find that the pile containing those with twenty-one petals is the largest. If, now, we string the daisies in each pile on an upright wire, so as to form rertical columns of them, we shall get ${ }^{1}$ The rays are the white outer parts, usually called "petals." 
the series represented by the upright lines in Fig. 237. The highest pile is the one containing those with twenty-one rays, and the size of the piles decreases in both directions from this: those which contain daisies with five and thirty-seven rays are the smallest and represent the two extremes. When we draw a line over the tops of the piles, we get a curve of

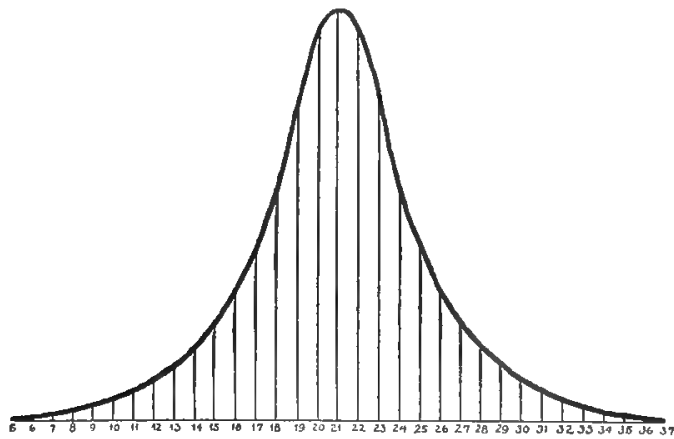

237. Curve of variation; the result of sorting daisies into piles according to the number of rays they possess.

very characteristic form. It has been found that, no matter what feature of an organism we study in this way, we get practically the same sort of curve (the only apparent exception being partial curves and double curves). This curve, therefore, becomes of great interest, especially as it is fomm that it can be expressed by a mathematical formula and that the variation obeys certain mathematical laws. The mathematical, or statistical, stuly of rariation has now become an important branch of biology. 
It may be remarked that a curve like that shown in Fig. 238 would indicate that the species was evolving

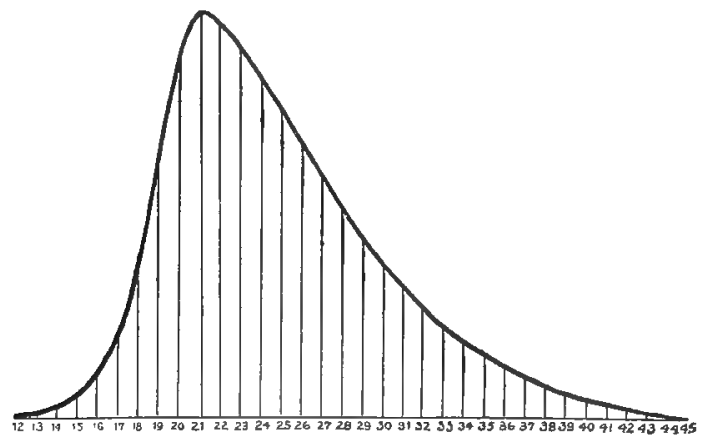

238. Asymmetrical eurve of variation.

in the direction of a larger number of rays, since it shows more individuals above than below the type in respect to the number of rays. A curve like that in

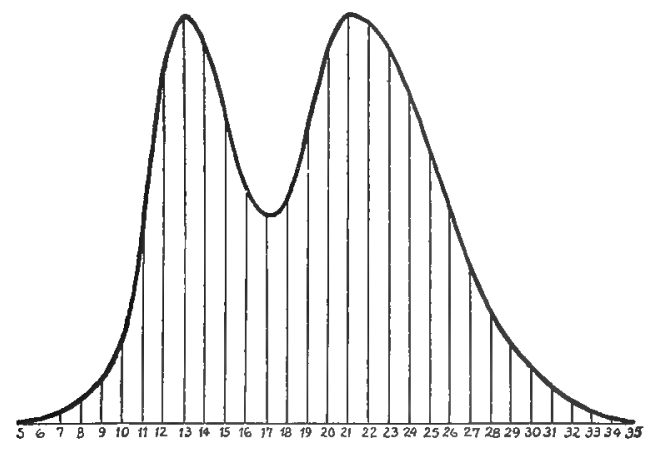

239. Double eurve of variation.

Fig. 239 would indicate a splitting up of the species into a form with thirteen and a form with twenty-one rays. 
The variations just discussed are the ordinary kind and may be called fuctuating variations (because they fluctuate around a mean, or average type) to distinguish them from sudden variations or sports (e.g., reversions and monstrosities), which are sudden and apparently lawless deviations from the type and only occur occasionally; fluctuating variations, on the other hand, occur everywhere and in all plants. A Peach tree occasionally protuces a branch which bears only nectarines; this is called a sport. If the lranch be cut off and used as a cutting it will produce a Nertarine tree. Oceasionally a branch of this may produce peaches: this return to the original condition is termed atavism, "reversion, and is also apt to oceur in plants which are not known to have originated as sports. When a sudden variation originates, as in this instance, from a single hud on a plant, it is called a "bud-variation." The various Moss Roses, many kinds of Chrysanthemums, many variegated plants, etc., ${ }^{1}$ have originated in this way. The word sport is usually applied to bud-variations, but is not necessarily limited to them. It may be used for any kind of sudden variation. The term monstrosity is commonly used to designate a sudden variation which has the appearance of an abnormality or deformity; as, for example, when a stem becomos flattener and

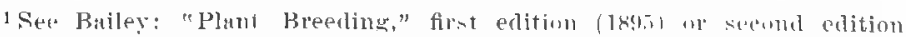
(1902), Lecture IV. (This lecture does not appear in the third edition, 1904.) 
fun-like as in the rimksonut, or when the edgus of the leaf unite and "allos it to assume the form of a pitcher, as happens not infrequently in various plants.

Sudden rariations may or may not come true to swerd. The greatest importanes is attributed to them by Professor de Tries, as will be seen later.

Whoever wishes to improve plauts must be on the alert to seize upon variations, whether they be of the ordinary fluctuating kind or sudden variations. Ordinarily only favoralile ones will be preserved, but when these do not occur the plant-breeder may continue to propagate the most variable individuals, hoping that in time favorahle variations will occur.

By varying thr conditions of culture ${ }^{1}$ and climate (rescribed in (halpter. TIII), it is possible for the breeder to produce variations in the desired direction, or, as he says, "break thr type." Some plants resprond rely readily to that treatment; others do not. In grmeral, however, this is a tedious process and of rery small ralue as compared with crossing.

By crossing, the breserler can create almost endless variations and at the same time direct them in the desired channels. ('rosing means the fertilization of a plant with pollen from a different variety or species. The result of the cross is ralled a hrorid.?

1 Sce an article by $T$ ebber in the Year-Book of the Trited States Department of Agriculture for 1896.

2See Bailey: "Plant Breeding." See footnote on page 420. Also an article hy Swingle and Webber in the Year-Book of the Irnited States Department wl Agriculture for 1897 . 
The hylırid may resemble both parents and possess intermediate character's. This is the more usual condition, and may show itself is a mixing of the charicters, as when a red flower crossed with a yellow one gives a spotted flower with red and yellow spots standing side by side; or it may result in a blending of characters, giring in this case a uniformly orange-colored flower; or, finally, we may have the characters both mixed and blended, giving orangecolored petals with red and yellow spots.

The hybrid frequently resembles one parent much more than the other, sometimes showing the character's of one parent only.

It rery frequently happens that the hyrbid is of grater size and rigor than either of the prarents. A good illustration of this is seen in Fig. "231. Another mase in point is the Shasta Daisy (Fig. 240), which also shows how the qualities of diverse parents may he skilfully combinerl. It is the result of a closs betwen the rommon Field Daisy of the eastern Uniterl States (chosen for its fres-flowering babit), a Furopean Daisy (rhosen for its vigor and rize), and a Jalumese Daisy ("hosen for the furuliar dazzling white luster of its petals). The hybrid proverl larger than it: parents and, by selertion, flowers have leetn obtained which under good "ultivation reach a diameter" of six inches (ser Fig. "240, which shows the thasta and the American parent; the English and Japiluese 


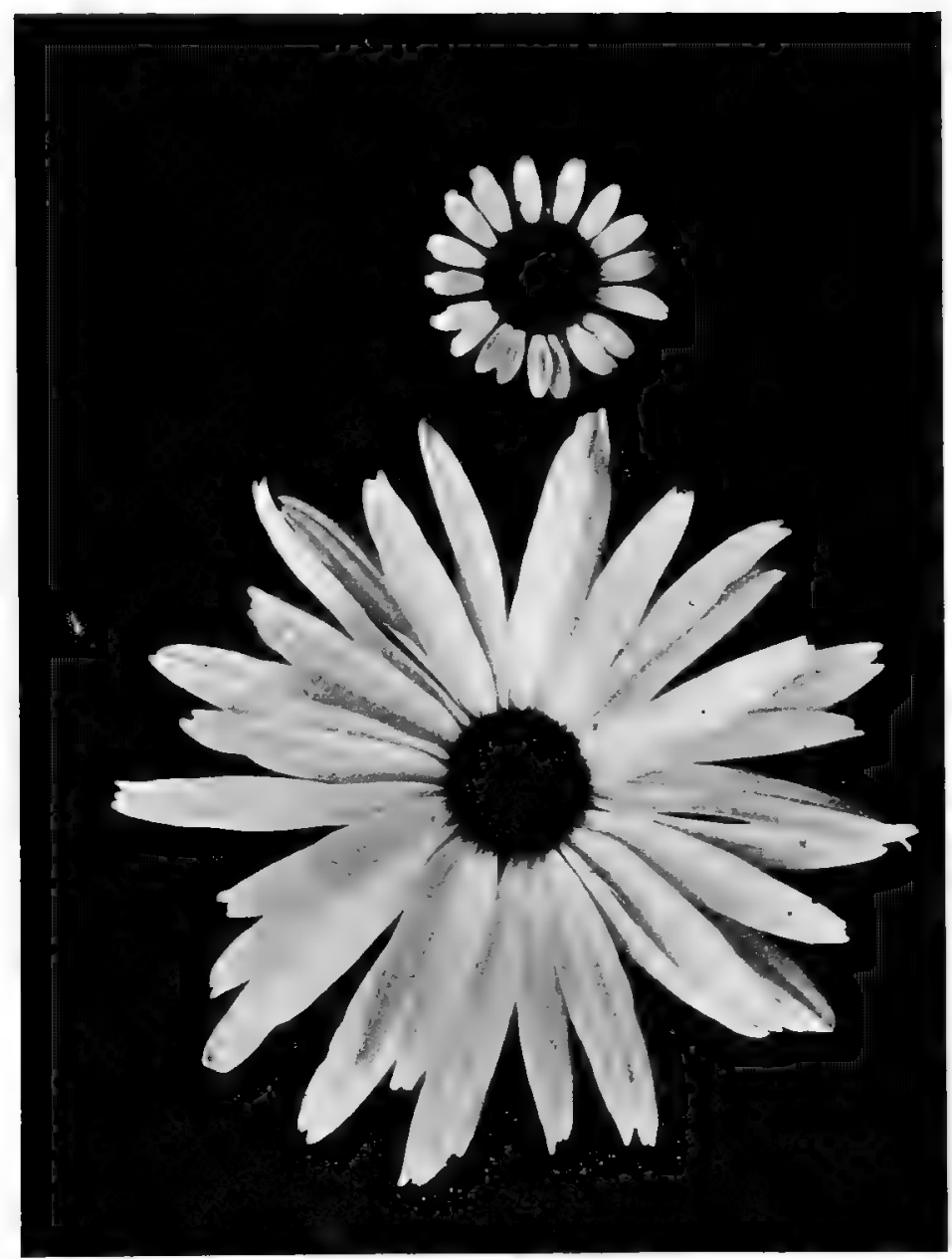

240. The Shasta Daisy and one of its parents, the American Field Daisy. About one-half natural size. 


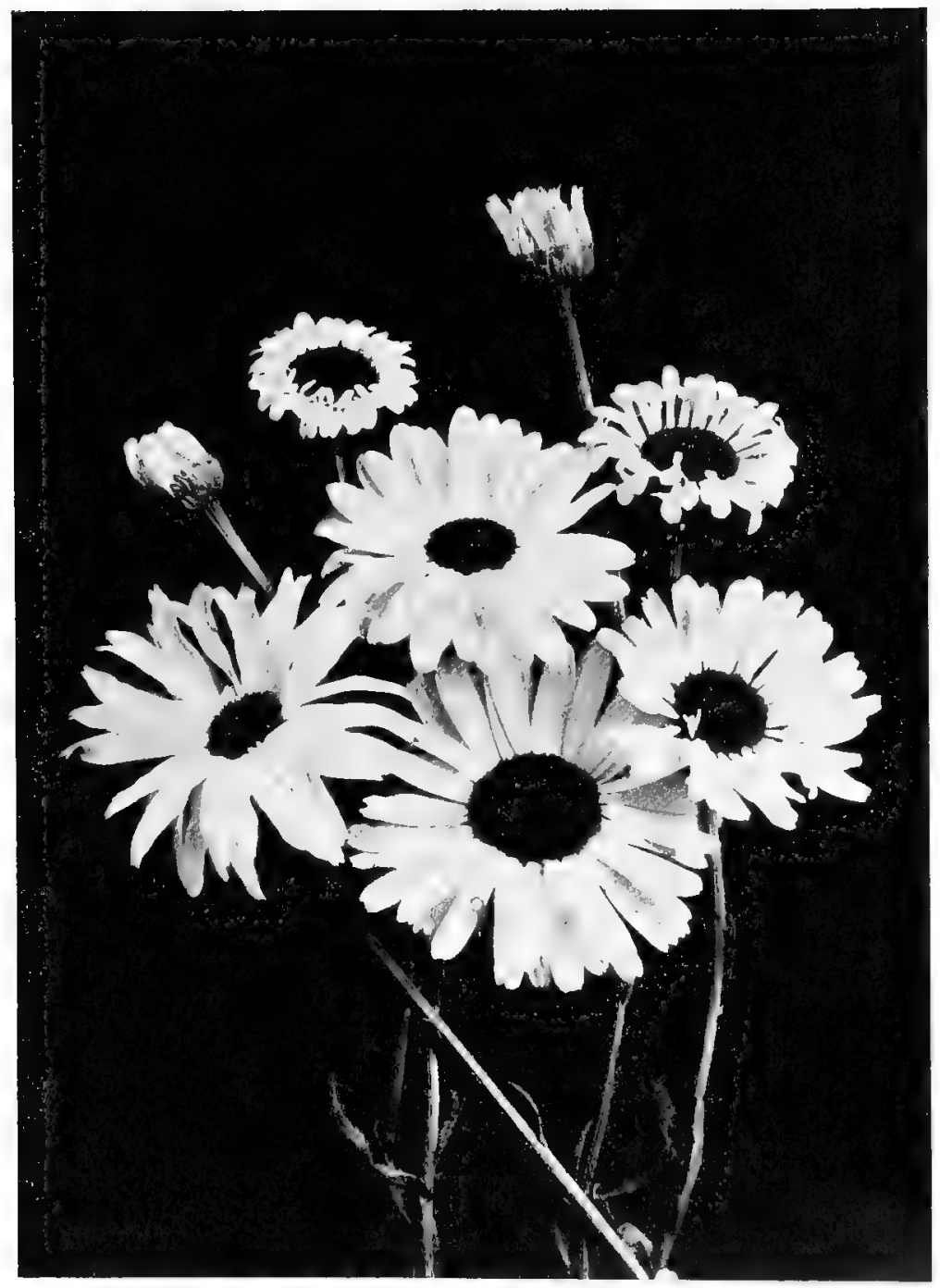

241. Shasta Daisies, showing variation due to crossing. 
parnits are about the size of the American). Not only st), but the good (pualities of the parents have all been retained and the bad ones eliminated. The hybrid is very hardy, blnoms abundantly and continus to blossom throughout the stasion (in California nearly all the year). The great white flowers stand up, each on a separate stalk, two to three feet long, making splendid cut-flowers, and remain fresh for two weeks after cutting. The petals have the peculiar whiteness and luster of the Japanese parent. Moreorer, the plants are perennial and bear more and more abundantly each season.

Not content with mere increase in size and productiveness, the originator, Mr. Burbank, endeavored to obtain new forms of rays (or petals). Among the hybrids which appeared we] such forms as arrs illustrated in Fir. 24 . By selection of these a number of different kinds of exceeding beauty and interest have been siterured, comparable

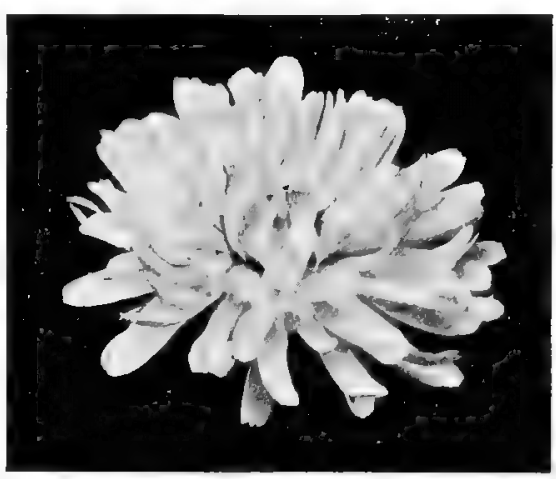

242. Double Shastia Dais. to the forms of Chrysanthemums. By continued selection the double form shown in Fig. 242 was obtained. 


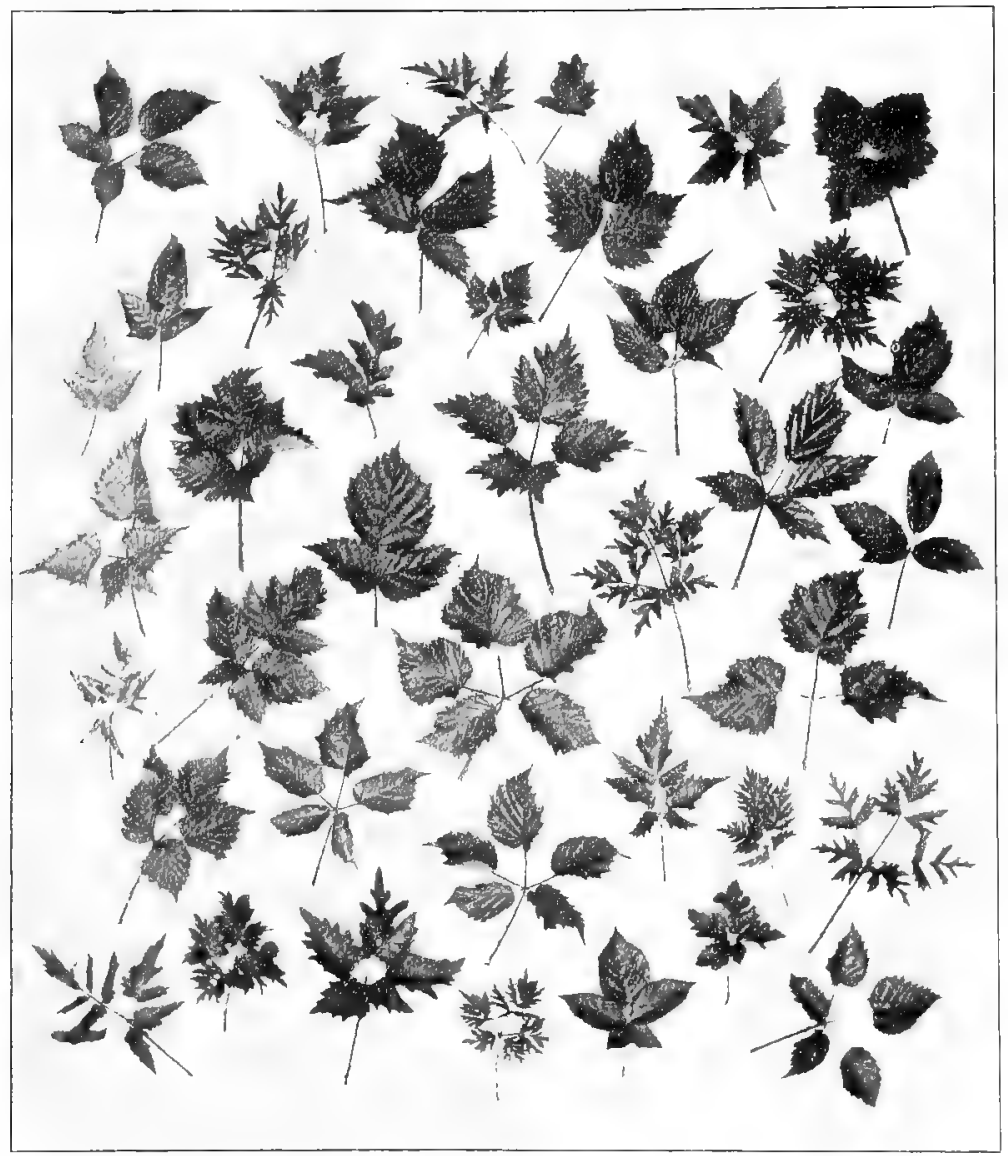

313. Variation in leaves of hybrid Blackberries, all from the seed of one plant. 
All these are propagated by cuttings, so that there is no trouble over fixation (see p. 433): Thus in the short space of a few years a disagreeable weed has been transformed into a splendid ornament of the garden!

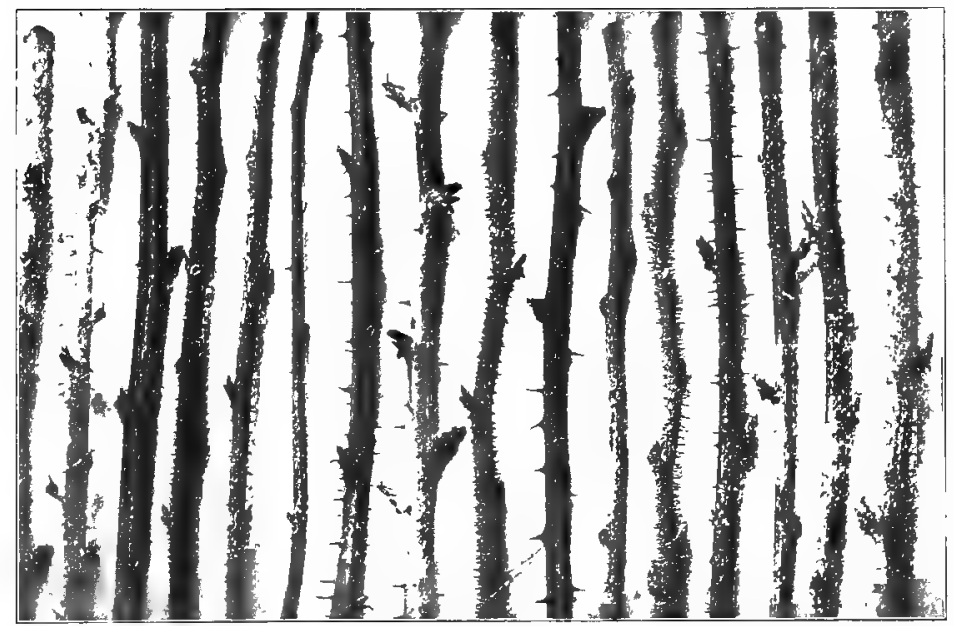

244. Variation in stems of hybrill Blickbarries, atl from the soed of one plant.

One of the most striking traits of hybrids is their tendency to vary widely. Figures 243 and 244 , showing the variation in leaves and stems of Blackberry hybrids all raised from the seed of a single plant, will repay careful study (the colors of the stems are as variable as the forms); what points of difference can you distinguish in these specimens? The parent forms are not shown in this case, but in Fig. 245, illustrating the leaves of hybrids between the Oriental 
anl the Opium Ponyy (the two common garden sorts), owe can trace clearly the influence of the parents and see how their characters combine to produce a great diversity of forms. These leaves I took from plants growing together in the same bed in Mr. Burbank's garden.

Study the hybrids which are to be found in our gardens, especially the Pansies, Cannas, etc., and see whether they are varialle. These, it should be remembered, have their variability reduced as much as possible by "fixing" before they are put on the market.

Mr. Burbank's experience with Beans illustrates how the tendeney to vary causes practical difficulties. On crossing the Cranberry Bean (which has red pods and white beans) with the Horticultural Pole Bean (which has red pods striped with white and red-and. white beans), a single seen was obtained: this was planted, and produced a plant having pods of mixer character but with all the beans black. When these were planted, an astonishing variety of plants appeared: some were Pole Beans rumning up twenty feet, others were Bush Beans; some sprear out on the ground but a few inches in hright; those latter in some cases produced pods taller than themselves. The variety of porks was bewildering, while the leans themselves reperesenter in size, shaje, rolor and markings almost every known sort. Professor Bailey 
records a similar experience with Squashes ${ }^{1}$ in which the seeds of one plant gave one hundred and ten kinds distinct enough to be named and recognized. Such hybrids perresent extremely variable types in which it is practically impossible to fix anything.

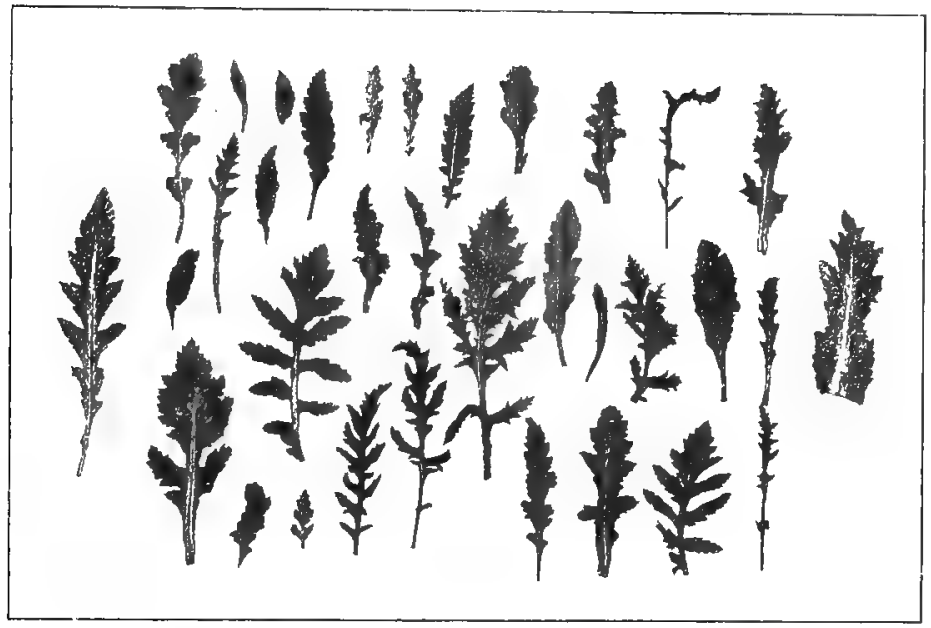

245. Hybrid Poppy leaves. At the left, a leaf of the Oriental Poppy; at the right, a leaf of the Opium Poppy; in the center a group of leaves of the hybrids.

To successfully combine the qualities of different plants by crossing requires a rare degree of skill and judgment. It might seem, perhaps, as though it would be a comparatively simple matter to make all possible Plum crosses, for example, and select the best. But in luration it is found that the number of

I Bailey: "Plant Breeding;" third edition, 1904, p. 78. 
possible combinations is so great, and the results so bewilderingly varied, that short-cut methods must be used. In other words, the plant-breeder must be able to judge beforehand what the result of crossing certain plants will be, in order not to waste time on profitless rxperiments. It is just here that the opportunity comes for the highest skill, baserl not only on empirical knowledge but on a profound insight into the laws of beredity and variation and a sound philosophy of nature. Moreover, there must be a clear-cut ideal present in the mind of the worker, toward which he persistently strives and from which he refuses to diverge even for the most promising side issues. He wields forces which at best are but partly understood; they manifest themselves in bewildering variety: to hold persistently to a definite ideal is the surest path to success.

There is no mystery in the method by which these crosses are made. Mr. Burbank's methods of pollinating Plums will serve to illustrate the matter. The flowers which are to furnish the pollen are carefully gathered a day or so beforehand, the pollen sifted out and kept in a cool place. The tree to which the pollen is to be applied is deprived of most of its blossoms, in order that the remainder may be sure to develop and that there may not be too many to look after properly. The blossoms which minain on the tree are prepared by cutting away the petals 
with the attached anthers, as shown in Fig. 246. By comparing with Fig. 161, one can see just what part of the flower is removed. The pistils and stigmas are left exposed and uninjured. This is done before the buds are open. Mr. Burbank finds that the time when the hum of the bees is first heard in the trees is the

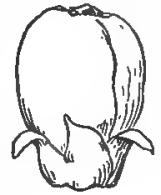
best for pollination, as the stigma then seems to be in a receptive condition. The pollen is applied by simply dipping the finger into it and touching it to the stigmas. The tree is then left to itself: the bees do not visit the flowers: the petals are not present to attract them, and there is no foothold for them should they come. So there is little danger that any other pollen will be brought. (Where it is important to know the exact parentage, the flowers may be covered with bags, as described on page

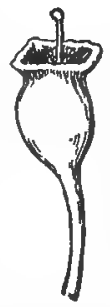

246. Plum blossoms showing the manner in which the petals, together with the attached sta. mens, are cut away preparatory to pollination. 289: for practical purposes this seems to be, as a rule, unnecessary.)

The application of pollen may or may not result in the setting of fruit. If the parents are of very dissimilar species, fruit will not set at all: or it may do so occasionally, say once in a thousand times. Sometimes fruit appears to set, but on ripening it is found to contain no seeds: again, seeds are produced which look well but are incapable of germina- 
tion. Or the seeds may germinate, but the young plants prove so weak that they cannot be raised. Even in favorable cases not all the flowers yield seed, but if only a few good seeds are olstained it is sufficient for a start. ${ }^{1}$

All the seeds from the tree are carefully saved and sown: as soon as they come up, the judgment of the breeder comes into play. From the foliage he is alske to judge beforehand what the fruit will be, and so save needless time and trouble by preserving only the most promising. In order to make these fruit quickly, they are cut off near the ground when only a few inches high and grafted upon other trees, where they often proceed to flower the third year from the seed. When the blossoms appear, another important question must be decided. Shall they be pollinated with the pollen of a sister hybrid, or of one of the two parents, or of another variety? Here, again, comes the opportunity for the greatest skill and judgment, amounting in its highest manifestations to positive genius, and yielding in the brief slace of a few year's results which a lesser skill conld not compass in a lifetime. A snccessful plant-breeder judges plant character as a great organizer judges human character, partly by evident signs, partly by an intuitive feeling for tho more subtle differences

1 The more difionlt the pross bhe grmiter should be the mumber of plants used. Thus, Mr. Burbank has surereded by using large mumbers in crossing the Tohsteco and the Petmia, I rely difficult cross indeet. 
which can hardly be defined in words and which way be completely hidden from the ordinary observer.

When the fruit appears it is carefully examined, compared and tested: the seeds of the best are preserved and the rest are destroyed: out of a thousand or more, only one or two may survive the rigid tests which are applied. The seeds of these are sown and the best again selected. This is continued indefinitely until a desirable variety is secured, or until it becomes evident that no good results are to be expected: in that case the plants are all destroyed, and the work of years ends in nothing.

It is very evident, therefore, that hybridization, with all its marvelous results, is but the beginning of plant-breeding. All that it does is to furnish variations. To seize upon these, even though they be slight, and divert them into the proper channels, to intensify the good and suppress the undesirable qualities, until the ideal is reached, is the task of selection. ${ }^{1}$

When plants can be propagated by cuttings, grafts, bulbs or other vegetative parts ${ }^{2}$ the ideal once achieved is easily maintained, for plants so propagated "come true," or, in other words, maintain the characters of the parent plant, with little variation. Far otherwise, however, with plants which are propagated by

1 See articles in the Year-Book of the Inited States Department of Agriculture for 1898, 'y Webber; for 1901, by Hays; for 190, by Webber.

2. (.., leaves, corms, rootstocks, roots, tubers, etc. 
seed; for, after selection has achieved the ideal, it has still the task of "fixing" it so that it will come true to seerl.

In order to achieve our ideal, we have had to set in motion the tendency to variation, or, as we say, we have" "broken the type.", When the ideal is achieved, this same tendeney which we have set in motion will Testroy our ideal unless selection is able to suppress the tendency and so "fix the type," or", in other words, bring the plant again to a state of equililırium. This we can do to a great extent, but not so fully that continued selection is unnecessary. And it often happens that, after: an ideal is achieved, years elapse before it is sufficiently fixed to put it on the market.

The great possibilities of selection are well illustrated in the case of corn-breeding as carried on by Professors Hopkins and Shamel at the Illinois Experiment Station. ${ }^{3}$ At the same time, these experiments illustrate the great value of a thorough acruaintance with the plant and its possibilities, comlined with a knowledge of the desirability of the various possible lines of improvement as shown ly the demands of the market. Suppose you were to undertake the production of an improved variety of

1 See "rom Culture and Breeding," Thirteenth Report Kansas Board of Agrieulture, XVIII, $78 . \overrightarrow{3}-817$. Also Bulletin No, 82, Illinois Agricultura] Fxperiment Station, 525-539. Also articles hy Profexsor Shamel in the r'ssmopolitan for May. 1903; hy W. \& Harwood in World's Work for September, 1903, and by C. P. Hartley in Year-Book of the United States Defartment of Agriculture for 1902 . 
Corn. You would have before you the possibility of improving along any one of the following lines:

1. Increased yield.-In the ordinary corn-field one well-developed ear to a hill means a yield of about fifty-five bushels to the acre; two ears means orer one hundred bushels, three ears over one hundred and fifty bushels. Now in Illinois, where a great corn-breeding movement is in progress, it was found that there are, on the average, more than two stalks to the hill, each capalle of hearing a well-developed ear; yet the average yield is less than thirty bushels to the acre. The trouble is partly due to barren stalks, partly to poorly developed ears. Consequently an effort was made to improve the Corn in these respects. Now, it was found that a barren stalk produces more pollen than a productive one, since none of its strength goes to producing an ear: consequently it fertilizes a larger number of plants than the pollen from a productive stalk: the result is that the tendency to barrenness is consequently on the increase. Obviously one thing to do was to go through the fields looking for barren stalks, and eutting off their tassels before the pollen was shed. In this way the percentage of barren stalks was noticeably decreased.

Another thing to be done was to select seed from the best ears. To do this properly requires skill and experience. Not only the size and shape of the ear but the manner in which it is filled out, especially at 
the end; the weight and color of the grain and of the cob; the number, size und shape of the kernels, and many other points must be considered.

It is not sufficient to select the best ears: we must know which of the selected ears can transmit its good qualities in the highest degree; in other words, we must determine what is known as the hereditary percentage ${ }^{1}$ (i. e., the percentage of offspring which inherit the desirable characters). For this purpose the kermels from each ear are sown by themselves in a separate row, so that the offspring of the different ears can be realily compared.

The poor, or barren stalks, and the suckers are removed before the tassel appears. Since the pollen is carried by the "wind for about a mile, it is an obvious advantage to have the field well separated from other fielks likely to contaminate it. In the fall the seed for next year's crop is selected from the rows which, all things considered, give the best results.

The results of this work may be illustrated by the experience of a farmer in southern Illinois who was induced to plant three hundrel acres with improved Corn seed. These three hundred acres yielded thirty bushels per acre more than the fields planted with unimproved seed, or, in other words, gave about

1 The hereditary percontage is one of the most important matters in selection and is only too commonly lost sight of by breeders. 
double crops. Now, as thr cost of labor, rtr., remains the same, whether improved or minnurover sered is planted, the gain is all clralr profit. An increase of only ten bushels per are in the yield of corn woukl mean an increase in our national wealth of over four hundred and eighty million dollars a year.

2. Quality.-A bushel of enru, weighing fifty-six pounds, contains approximately:

36 pounds diy starch, worth $1 \frac{1}{2}$ cents per pound.

7 pounds gluten, worth 1 cent per pound.

5 pounds brin or hull, worth $1 / 2$ eent per pound.

$4 \frac{1}{2}$ pounds germ, 40 per cent of which is oil, worth 5 cents per pound. $3 \frac{1}{2}$ pounds water and soluble matter, worth 0 cents per pound.

Which one of these constituents shall we increase to improve the quality of the corn? We might endeavor to increase the percentage of oil, ${ }^{1}$ since this is the most valuable component. We must, however, first consider whether any one will pay a correspondingly higher price for corn containing more oil. As a matter of fact, a company which buys about fifty million bushels of corn per year offered to pay a higher price for corn containing a higher percentage of oil: an increase in oil of one pound per bushel would increase the price of corn five cents per bushel. The Illinois Experiment Station surreeded in increasing the amount of oil from 4.7 per cent to

1 The oil is valuable as a component of "artificial mbber" used for electrical purposes, and is of especial importance in view of the decrease of the world's supply of rubber. The oil is also used for lubricating purposes, for adulterating olive-oil, as well as in the manufacture of soaps, paints, etc. 
numly $\rightarrow$ rom cent in six reals. The wethod at first involved a rigid chemical analysis of the ears and selection of the best. Afterward it was found that for practical purposes the chemical analysis could be dispenserl with: since the germ contains most of the oil, it is only necessary to select the kernels with the largest germs. On the other hand, Corn with a lower oil-content is wanted as a feed for hogs, since it produces harder, firmer bacon. So the Station proceeded by selection to decrease the amount of oil to less than " per cent. It would, therefore, depend on market conditions whether we should try to increase or decrease the ainount of oil in the corn.

In the same way we should breed to increase the amount of protein if the corn is to be used for food, but to decrease it if the corn is to be used for starch. The Station workers were able to increase the protein from 10.92 per cent to 16 per cent in about six years, and to decrease it to 6.66 per cent in the same l'mentl of time. Here, again, it is found practicable for ordinary purposes to dispense with chemical analysis and select thos kernels which have the white, starchy part around the germ best or least developed, according to which is desired: this is possible becanse the protein is almost all contained in the germ and in the horny outer part of the kernel, while the star'h is practically all in the white portion which lies between them. 
3. Size, shape, color, etc.-Some of the points already mentioned might appropriately ronw" m1 this head also: in addition, we may mention that the Station has increased the length of shank nearly two fert in five year's' selection, and has been able to shorten or lengthen the ear, to increase or derrease the width of the ear and to raise or lower the purition of the ears on the stalks. Further changes in the appearance of the Corn plant could be made almost indefinitely if they seemed desirahle.

The color of the kernel is of some importance; some markets demanil golden yellow meal and others white: furthermore, manufacturers of white meal prefer white to red cobs, since llebris from the latter is apt to color the meal. Hard kernels from which the germ readily separates are desired by hominy-makers.

Large ears (one to a plant) are desirable when the corn is to be shucked by hand and shelled or sold for milling. Smaller ears (tro or more to a stalk) are desirable where machinery is to be used and the pars fed to cattle.

4. Earliness, etc.-To obtain early rarieties is, in general, a very difficult matter. Two things must be secured; first, hardiness, i. e., resistance to frost, sudden changes, ete.; second, the alility to ripen fruit in a shorter season. This is a difficult combination to obtain: nevertheless, the Corn-beit has moved rapidly northward in the last fifteen years. 
The original home of the Corn was in ('entral America, and it has mover all the way to Laks Superior, with the cousequent gain in hardiness and ability to ripen quickly, as the result of selection by man.

5. Adaptation to peculiar regions or conditions.There are thousands on thousands of acres of land where Corn cannot now be grown, simply because the soil contains too much alkali. Yet the same soil will grow Sugar Beets excellently. Why should it not be possible to breed a race of Corn tolerant of alkali? A race of Corn resistant to drought would also prove of great value.

6. Resistance to disease, etc.-An immenst amount of damage is annually done by Corn smut (see page 400). Yet in the most badly infested fields some sound ears will the found. By careful selection of these a resistant variety might he ohtained.

Any one who should attempt the improvement of Corn on the old hit-aml-miss principle might possibly stumble on good results, but the chances would he largely against him. To he sure of sureess, he must, after taking into account such considerations as thome mentioned above, deride which particular line of improvement is most feasible and most profitable, and, after formulating a definite ileal, work persistently toward it. The greater his skill and the more accurate his judgment the sooner will he aleenmplish his aim; in this work it is impossible to set any limits 
to the results which are obtainable in the hands of a master. ${ }^{1}$

From the standpoint of economirs, plant- and animal-hreeding is of the lighest importan'r, since it adds, in a superlative ingres, to the pelmanent wealth and increiserl material happiness of a nation. The work of our successful plant-and animal-breeders cannot be too highly estimater, and it is a pity that it so seldom results in much pecuniary gain to themselres. (rorernment work in this line has been totally inconmensurate with the importance of the subject. The Lnited States Gorernment, however, has made a beginning by astahlishing a laboratory for plantbreeding.?

The whole doctrine of plant-breeding is intimately comnected with the qurstim of the origin of species. Darwin, seeking an explanation of this question, took his cue from the experience of plant-and animalbreenters, and conceived that species mas originate

1 Even in unskilled hands good results may often be obtained. For the remarkable achievements of Canadian school-children, see an article wy George Iles, "Teaching Farmers' Children on the Ground," in the World's Wrork for May, 1903.

2 On the general subject of plant-breeding, see articles in the Vear-Book of the Tnited States Departneent of Agriculture for In:49. by Tebtif and Bessey; for 1901, by Hay (also those already referred to). Also the bibliography in Baileg"s "Plant Breerling." also articles in Norilwtrs for July, 1904, by Harwood; in the C'wmopotitan for July. 1901, ls G Gardner; in Country Life in Amrira for July, 1903. by Bailey; in the World's Work for 19n? (Fol. II, p. 1209), by Bailes, and in the sumet Magazine for Deeemher, 1901, February and April, 1902, by Wiekion. 
in nature, just as forms originate in the garden, by the selection of ordinary fluctuating variation alone. In other words, an ordinary fluctuating variation may be so intensified by selection as to form a distinct. mark of difference between the improved and the original form: when all the intermediate forms have perished, we have two species instead of one. Darwin ${ }^{1}$ believed that species originated in this way both in the garden and in nature (where the struggle for existence selects the fittest and destroys the rest), and that the species so formed remain distinct. Professor de Vries has recently called this view in question on the basis of some very remarkable experiments. ${ }^{2}$

Selection cannot make new speries, he derlares,

1 Darwin likewise believed that species could origimate by sudden rarjation, but was inclined to lay less emphasis on this modt of origin.

2 In these experiments (which bave lasted over twenty years) Professor de Vries has comlined in brilliant fashion the special points of superiority of various methods. The plant-breeder has the advantage of being able to grow and judge large numbers of individuals in a limited space: of this he has made use. The animal-breeder in the most important cuses keeps in a book a pedigree-record of ench individutl animal, its characters and those of its offspring. Professor de Vries lins also done this in all the most important cases, giving a number to eavh bed, other numbers to each row in the bed, and also to each plant in every row. Thus, each plant receives a number, and a record is kent both of it and its offspring. In many cases the seeds of each separate plant wre sown in separate beds, in order that the hereditary percentage might lu clearly determined. Most careful precautions bave been taken to prerent crossing, by enclosing the flowers in parchment paper bags. Finally, he has made extensive use of the statistical methods described above (p. 417) and thus diseovered many important principles which would not otherwise bave come to light. 
either in the garlen or in vature; all selection can do is to temporarily intensify the selected character and increase the frequency of its occurrence: when selection ceases the percentage of frequency soon falls to the original figure and all becomes as it was before. Moreover, new species are not formed gradually, as the selection theory dernands, but they originate suddenly, fully formed and constant from the start, without any intermediates between them and their parent-species. As there are no intermediate forms, it is useless to search for such "missing links," for they never existed. This mode of origin of species, which he calls mutation, he has observed yeal after year in his garden at the University of Amsterdam. It occurs in one of the Evening Primroses (Enothera Lamarckiana, or Lamarck's Evening Primrose, Figs. 247 to 250 ), which each year produces several new species. These remain constant and perfectly distinct, and never produce intermediates between themselves and their parent-species. They originate without any of the means ordinarily considered necessary: no extended lapse of time is demanded; no fluctuating variation, crossing or struggle for existence appear to enter directly into the matter.

It is not to be supposed that this process can be observed in the majority of plants. The opponents of Darwin have already contended, on the ground of careful experimental evidence, that species, instead of 


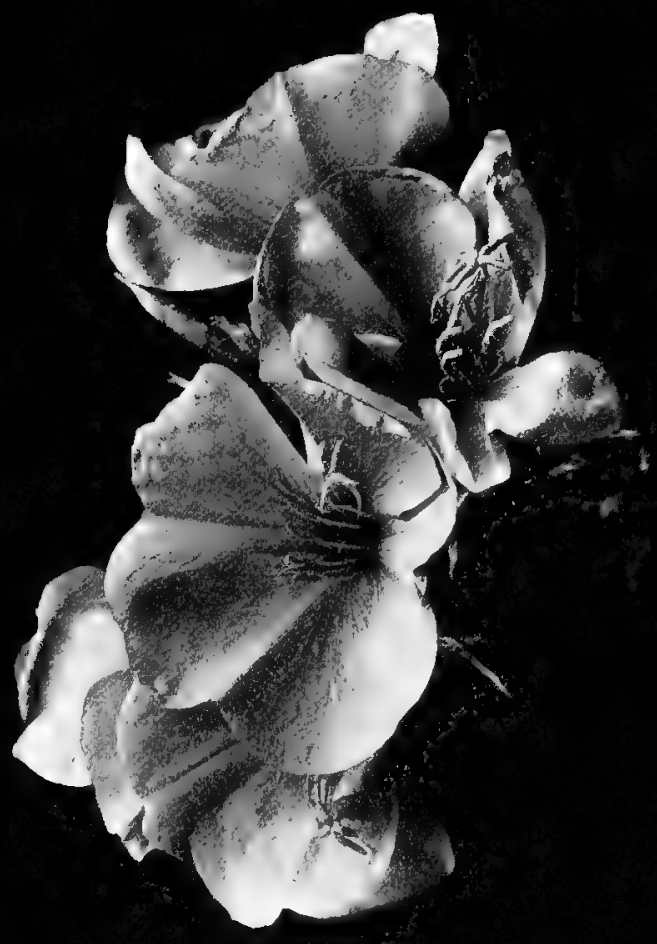

O 
being in a state of continual slow change, are constant. Professor de Vries, as the result of his own experiments, believes that species are constant except at certain mutation periods which may occur only at long intervals. perhaps of some hundreds of years.

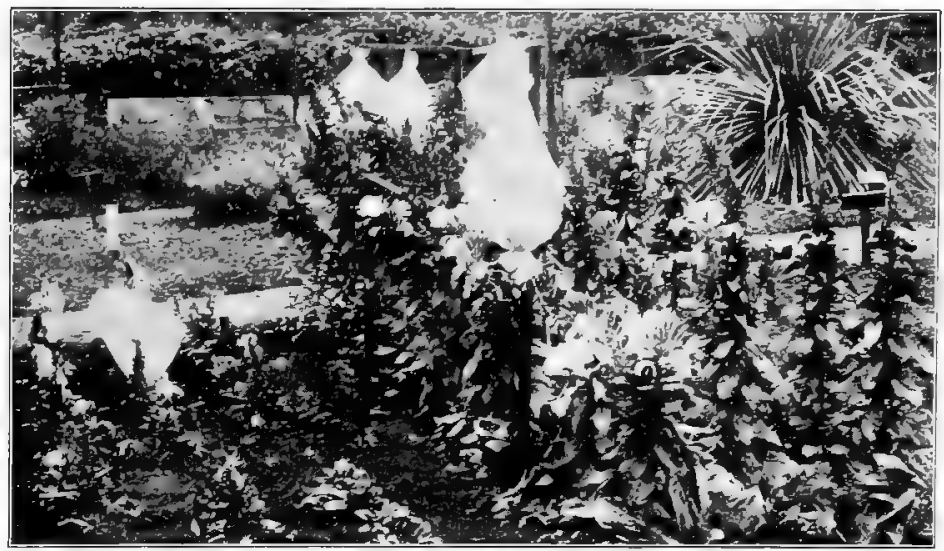

248. Lamarek's Evening Primrose at the right, and one of the new species which has arisen from it (Dwarf Evening Primrose) at the left. The bags are for the purpose of excluding insects from the flowers which are being artificially pollinated. Botanic Garden of the University of California.

The differences between the new species and the parent form may be great or small: it does not matter which they are, if only they are fixed and constant. Fig. 248 shows a striking difference in appearance between the parent-species and one of the new ones. This difference cannot be overcome by culture; the tallest Dwarf Evening Primrose is always much smaller than the shortest Lamarck's Evening Primrose. 
In Fig. 249 is shown a leaf of Lamarck's Evening Primrose and also one of a new species which sprang from it, namely, the Broad Evening Primrose (Eno-
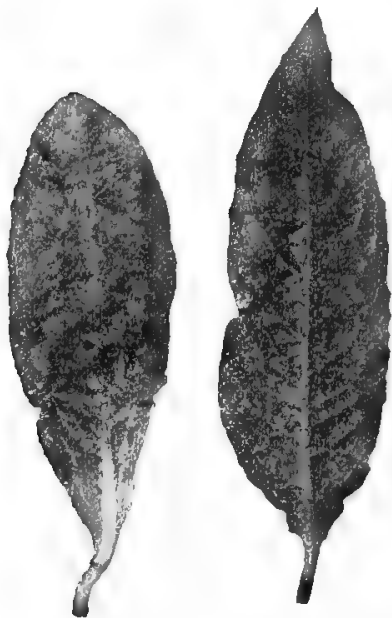

249. Leaf of Lamarck's Evening Primrose on the right, and of Broad Evening Primrose on the left.

thera lata). The latter leaf is not only somewhat shorter and broader, but is blunt instearl of pointed at the tip. This was the first species to originate in Professor deVries' cultures. The seed of the Lamarck's Evening Primrose which he had gathered in an abandoned field and sown in his garden produced, the first season, among a large number of ordinary plants, three which were distinctly different from the rest though closely similar to each other. They had broader, less pointed leaves, swollen buds and small fruits: the stems were noticeably small, weak and brittle: at the tips of the branches the young leaves and buds were collected in crowded rosettes so that the plants were at first called "roundheads." Most curious of all, these plants were entirely unable to produce good pollen. Such was the origin of the Broad Erening Primmost; and each subsequent year, as the seed of the Lamarck's Evening Primrose 
has been sown, the origin of the Broad Evening Primrose from it has been observed. It is possible to identify this and other new wrecits in the seedling stage. Fig. 250 shows the difference in the appearance of the seedlings of Enothera Lamarcliana and Enothere lata: while the strikingly small and pale

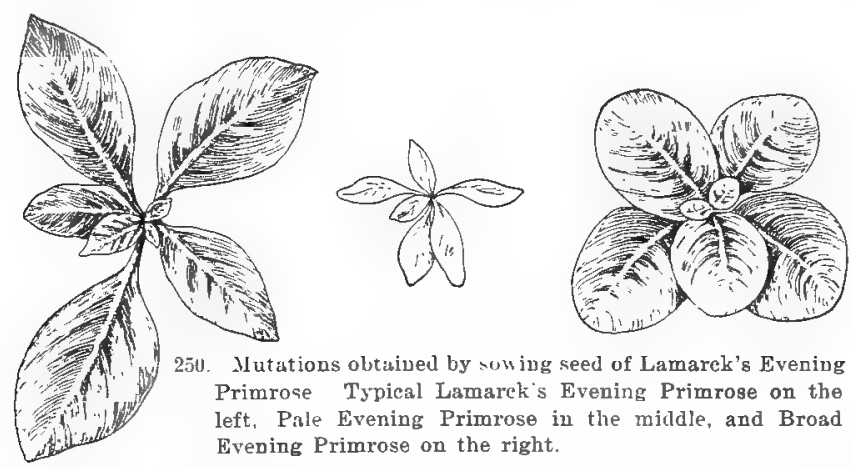

leaves of Enothera albida, another of the new specier, contrasts with both the other two species. Most of the other new species (of which there are several) can be identified in the seedling stage; $s$ that they can be early transplanterl and isolatel from each other. This greatly facilitates the handling of the specimns, and makes it possible to deal with much larger numbers than would otherwise be the case.

Professor de Tries' ideas may be well illustrated by means of his experiments on the Red Clover. Every one knows that four- and fire-leaved Clovers are found occasionally. Beginning with a plant which 
bore (in addition to the normal leaves) one four-leaf and one five-leaf, he sowed its seed and found that

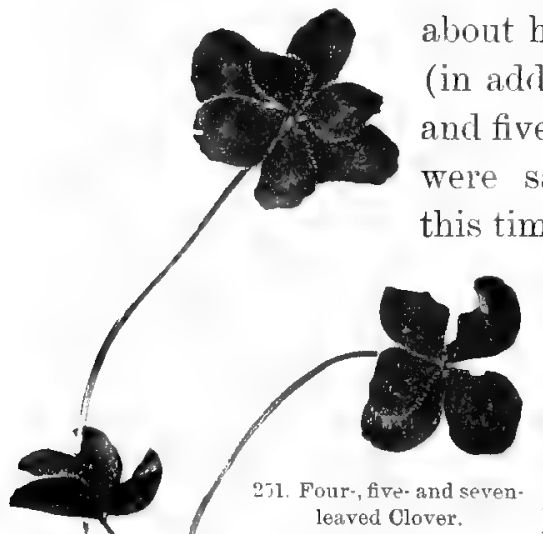
about half the resulting plants bore (in addition to normal leaves) fourand five-leaves. The best four plants were saved and their sexpl sown: this time 80 per cent of the offspring had the four- and five-leaves and a few six- and sevenleaves made their appearance. This process of selection was continued until practically all the offspring were of the new type (i. e., three- to sevenleaved, Fig. 251), or, in other words, the seed came true. One might suppose that it would now be possible to go on and make plants with eight and nine leaves. The attempt, however, proved fruitless. The limit of selection was reached with seven, and it was impossible to go beyond it. On the ground of many similar experiences, he comes to tha conclusion that all plants have a limit which is quickly reached by selection, and here its power muls. The improved race is not a species: it has no constaney, and when left to itself quickly roturns to the original tỵe.

${ }^{1}$ He helieves that it is wren possible 10 10ll befomband bow mach a plant can be improved by selection and where the limit will be. 
There is a well-known freak or monstrosity oceulring in many species of plants in which the leaf splits lengthwise more or less completely. 'This occuroccasionally awong the Red Clover plants just described, and gives rise to leaves with higher numbers (four to fourteen). For example, a fiveleaf may, ly splitting, become a ten-leaf, such as is shown in Fig. 2.5:. Professor de Vries believes that this is to be classed as a mon-

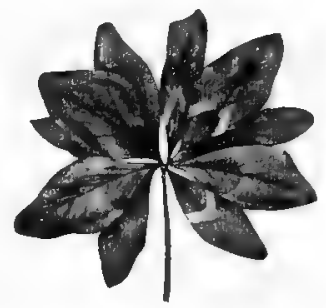

252. Ten-leaved Clorer. strosity and is quite different from the four-, fire-, six-, and seven-leaves just described, which are due to fluctuating variation and obey mathematical laws. It occurs rarely, appears and disappears suddenly, bears no constant relation to the whole number of leaves, and is to be classed as a sudden variation.

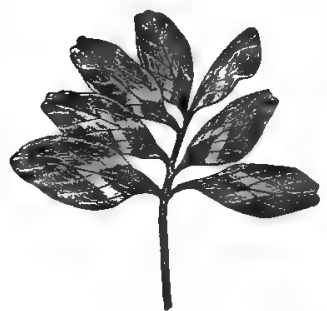

253. Atavistic Clover leaf.

Occasionally a Clover leaf is met with of the form shown in Fig. 253. It might at first sight be classified as one of the abnormalities just described. When we consider, however, that the arrangement of the leaflet in two rows, one each side of the stalk, is the same as that possessed by the allies of the Clover and the arrangement which the ancestors of Clover itself probably had a long time ago, it seems prob- 
able that it is a latent character, which has long lain dormant, but is now brought out by some unknown cause. This phenomenon is called atavism and the plant is called an atavist (see p. 420). If the seeds of such a plant are sown, probably few atavists or none at all will appear in the progeny. It is to be classed as a sudden variation.

If, now, we should find a plant all of whose leaves showed an increased number, say nine, and all of whose descendants showed the same number coming perfectly true to seed, and kept this up without any need of selection, this would constitute a mutation. ${ }^{1}$ Such a plant has not been found, but Professor de Tries hopes it may occur, and is continuing his propagation of the Red Clover with this end in view.

The example of Clover makes clear Professor de Vries' ideas as to the kinds of variation. We have, first, ordinary fluctuating variation (dus partly or wholly to differences in nutrition caused by external conditions): second, sudden variations, e.g., monstrosity, atavism, ete. (due to causes wholly unknomn); if these should come true to seed they rould he called mutations, otherwise not. A mutation is a sudden variation which comes true to seed, and he believes

1 This would constitute an extreme case. The mutation might, and probably would show fluctuating variation in the leaf numbers, so that not erery leaf would be a nine-leaf hut the type would he (for explanation of type see page 420 ), and this type would remain absolutely constant without selection. 
that this alone can give rise to a new species. Furthermore, he includes in mutation the effects of crossing: he believes that new speries can arise from hybridization and that there an wrll-established instances of this.

Professur de Vries does not reny the great value of selection for cultivater plants: he merely insists that the effect of selertion is only temprorary and soon ceases when selection stops. Each year the seedsman must carefully go through his beds and "rogue," i. e., remove the rogues or plants which do not come true to saed or which in any way fall short of the standard: only so can he keep the sued at all purr and true to type. And this is the best proof that he has not succrerled by selertion in making a true species. Where he does get a constant form, Professor de Vries believes it is due to the selection of mutations which the seedsman does not distinguish from fluctuating variations. He believes that our garden varieties have mostly originated in this way, since be finds that most of those with which he has experimented are constant. The reason why they are not regarded as such is that they are usually grown side by side with the parent forms (or other nearly allied forms), so that crossing takes place and hybrid seerls are produced: these, when sown, give rariable forms after the manner of hybrids, and much confusion results. His experience is that if a pure (i. e., not crossed) white variety of a 
normally colored flower be pollinated from its own flowers it will produce white flower's only and provt constant. Such varieties, lie cousiders, are really species.

Every one who has opportunity should be on the lookout for suddeu variations, both in garden and field. Should one be found it should be kept under observation, protected from crossing by paper bags (as described on p. 289), and hand-pollinated. The seed shoull be saved and sown, in ordel to see whether it jroves constant.

Professor de Vries offer in satistactory reply to the opponents of evolution, who contend, first, that species are constant and, second, that if evolution were going on we should be able to see the process. He says that species are constant except at mutation periods: moreover, evolution is going on and he has seen it, not once merely, but year after year in his garden: he has furnished seel to other botanic gardeus in various parts of the world, and the same phenomena have been observed. The seed sown at the University of California producen about 8 per cent of mutations, which I have had the privilege of personally observing'. Further, his theory makes it umecessary to seek for a continuous series of "missing links," since it assumes that they never existed in such a series. His discoveries demonstrate conclusively that evolution can he studied experimentally in a manner hitherto unsus- 
pected. and furthermore raise the important question whether we can control erolution and so produce speries at will. sinwe experiments already made in this direction are rers encouraging and open up a promising field of leseallh. ${ }^{1}$

In rearl to thr. Wurk of Profentre de Vries, consult: de Vries, "On the

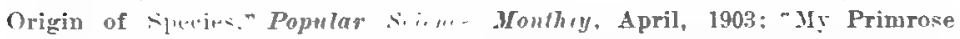

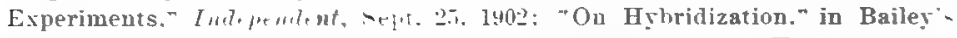
"Plant-Breedins" third edition, 1904, p. 15!?. Al-n Hobrech, "Hugo de VrieTheory of Mutations," Pupular science Monthly, Juls. 1904: MacDougal: "Profescur de Tries" Experiments on the Orsil of Sirecir." Independent, sin. 25. 140: Lrle. "Plant-Making in a Duteh Garden," Everybody"s Mugazine for June, 1902; MacDougal: "Yutation in Plants," American Saturalist for 1903 . 
, 


\section{INDEX}

\section{Asterisk (*) denotes illustrations}

Al,normality, 420,421, 449.*

Absorption, due to osmosis, $17,60,63,64$, $67,1: 2-124$.

of ammonia by soil, 145,14 .

- carbon dioxide, 191,*192,*194; 195, 200 20 ?.

- endosperm, 57,* 179, 180.*

- light by leaf, 196, 201.

- nitrogen by plants, 147, 149, 383, 384.

- - soil, 145, 147-150, 383, 384.

- organie substance from soll, 150.

- oxygen, $33,34,{ }^{*} 35,175,194,195,200$, 2x- $717,388,390$.

- phosphoras $1, y$ soil, 145.

- potash by soil, 1t5.

- salts by plant, 136, 137, 161.

- stored food, 5 - * $^{*} 164,179,180,{ }^{*} 183$, $260,28 \%, 313$.

- water by root, $88,102,103,119,{ }^{*} 120 *-$ $123 . *$

- - - - affected by temperature, 332 .

- - seeds, $6,{ }^{*} ; * 8^{*} 9^{*}-15^{*}$ 16-19, $20, * 21, * 23 * 23, * 26, * 27$, *

- - soil, 111-114.

$-\rightarrow$ wood, 68.

- - affected by dissolved substances, $18,124,217,336$.

- - foree required for, 121-123,* 124.

A':aria, protection of, against drying, 217 . seeds of, boiling to hasten germination, 25.

sleep position of leaf of, 21\%*

rood of, 2:30.

Acanthus, protection of pollen by, 294 .

Acid, exreted bs roots, $141-143, * 14,145$. in fruit $a, 315$.

- soil, 141, 143,145, 146.
Acid, acetic, manufucture of, 387. boracic, as preservative, 380 . earbonic, as plant-food, 139.

- as solvent of plant-food, 139-145.

- given off by root, 141, 14: 143,* 144 .

- sonrce of, in suil, $1+1$.

- See, also, Carbon Dioxide. carbolic, as disinfectant, 364 .

fatts, 171 .

hydrochloric, 155, 157.

lactie, 3-3-379.

nitric, as plant-food, 139,110 .*

- for irrlating wood cells, 235.

- test for proteids, 165.

oxalic, a by-product in proteid formation. 254.

phosphoric, as plant-food, 139,140 .

salicylie, as preservative, 386.

sulphurie, as plant-food, 139, 140.

- in manufacture of superphosphates, 150.

- as test for formalin, 37.

- - - - proteids, 166, 178.

Acer. Lee Maple.

Acouitum. Set Monkshood.

Adaptation, 326-361.

Ecidiospores, 403.*

Aerotropism, 89, 98, 135, 293.

Esculus. See Buckege and Horse Chest nut.

Evtivation, protection against drying by. 213.

Agave. See Century Plant.

Ailanthus, leaf sear of, 212 .

Air affects direction of growth of pollentube, 29.3 .

affects direction of growth of root, 89, 98,135 . 
Lir, apparatus for supplying to aquaria, I Alcohol, coagulates proteid, 254. $283, * 285, *$

in fruit, 317.

- leaf, 187-191, 198,* 199,*200.

- seed, $8,{ }^{*} 32,83,{ }^{*} 34,{ }^{*} 35$.

- how absorbed, $30, * 31,32$.

- stem, how absorbed, 258, 278, 279,* $280, * 281, * 282$.

- soil, 36, 37,*38, 39,*40,103, 119,* 120,* 124, 105, 125, 130, 132 .

- - amomnt best suited to plants, 130.

- promotes beneficial chemicial changes, 125, 126, 145, 146.

- water, 283.

kept from roots by flooding. 125.

$-\ldots-$ sidewalks, 126.

- - - soil crust, 125.

- - stem by coutings of tar, 281.

kills bacteria, 382 .

method of exeluding, 5.*

- saturating with water vapor, $20, *$ s.. *

livek of, effect on plant, 281,*282.

leted $\|_{t+1}$ by fruit, 317 .

- - leaf, 191,* 192,* 193,*194, 195.

- - plitnts, 326.

- - roots, $125,126$.

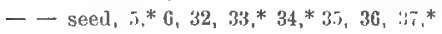
$38,39,40$.

- for stareh formation, 191.

nitrogen of, used by plant, 149, 38.3-38.

- taken from, by bacteria, 383-38\%.

plant-food in, 139, 191,* 192,* 193,* 194 , 195.

"restorel" by leaves, 191,* 192, 194, 195. trapped by pits of wood-cells, 235 .

"vitiated" by combustion, 191,* 192, 194.

- - animals and plants, 194, 195.

-. See Respiration.

water vapor of, absorbed by seed, $20, * 27 . *$ - - - - - sood, bs.

Siex, also, Carbon Dioxide, Oxygen, and Nitrogen.

Air-pump, 187,* 188,* 189, 190, 353 .

Air-spilces, effect of light on, $34 \%$

larger in water plants, 339.

Alhumin. See Proteid.

Aleanna, as test for fats and oils, 259.

Alcohol and lye for bleaching, 225. dissolves ehlorophyll, 181, 2it. produced by yeast.169, 390 . use of, as mounting medium, 392.

Alder, in northern latitudes, 356 . leaf-scars of, 245 . protection of, against drying, 214.

Alfalfa, killed by flooding, 125 . roots of, penetrate deeply, 134.

Ninit, 384 .

Alisma. See Water Plantain.

Alkali, black, 159.

for softening water, 151 . renders absorption diffieult, 336. ialts of, form erust, 127, 159. tolerated by some erops, 350 . white, 159.

Alkali soils, 127, 157-160. - reclamation of, 159, 160.

- salts found in, 159.

- tests for, 157, 158.

Alium. See Onion.

Alluvial fans, 111.

Almond, cover of, retains water, 29. escape of, from seed-rover, 54.

Alnus. See Alder.

Alpine plants. See Plants, Alpine.

Althæa. See Hollyhock.

Altonil, cholera epidemic of, $372,373 . *$

Alumina, as constituent of clas, 14.. fixes plant-food, $14.5,147$.

Amaryllis, stoma of, 210 .

Amelinehier. See Serviee Berry.

A merican Grapes, protection of roots of, 162 . Plum. See Plum, American.

Ammonia, as reagent, 156. fixed by clay, 145, 147. produced by bacteria, $147,149,383$. test for proteids, 165.

Ammonium molybdate, 150 . oxalate, 15. sulphate, action of plant on, 161.

timpelopsis. See Ivy, Boston.

Amsterdam, University of, 443.

Anagallis, See Poor-man's Weather-Glass.

Ananassa. See Pineapple.

Anchusi, Rust of, 405.

Anemone, protection of pollen by, 295, stomatic of, 190. 
Animals, aid in soil formation, 109.

avoid poisonous nlants, 222.

bury seeds, 69 .

combustion in, 35 .

decay of, 381 .

digestion in, 166-Ji2.

distribute seeds, 323-32:-

food needed by, 164, 176 .

give off carbon dioxide,

how supplied with oxygen, 176 .

protection agrinst. She I'rotertion.

respiration of, $3 \overline{5}$.

Annual rings, 247 .

Annuals, seed formation of, 314 .

Annular traeheïds, 227.* 224. 230, 231.*

Anthers, 288.*

opening of, 289 .

transformed into leat-like holles, 33.

withering of, 289.

Antibacterial substances. 379.

Anticlines, 111.

Autipodal cells, 291.*

Antirrhinum. See Snapdingon.

Antiseptics, 304 .

Antitoxins, 378,379 .

Aats bury seeds, 6!?

Apium. See r'elery.

Apple, effert of fertilization of, :319.

ppidermis of fruit of, 317 .

seed of distributed hy birds, 32.-.

stomata of fruit of, 317 .

Apple Plum. See Plum, Apple.

A pricot crossed with Plum, $415 . *$

Aquaria, balanced, 191.

method of supplying air to, $283^{*}$,

- - - cartion dioxide to, 284, * 285.*

Arabs preserve Date pollen, 294.

Arachis. See Peanut.

A rid regions, richness of soil of, 140.

Aristotle on the Fig, 310 .

A rrowhead, $337, * 338, * 342$.

air passages of, "28".

Artemisia. See Wormwood.

Arteries, 170.

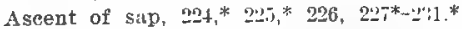
$232 *-236, * 237 * 23,240 *-243,2.2$.

Asexual reproduction lyy spores, $362,{ }^{*} ; 6.3$. 393. 394, $3955^{*} 396, * 397, * 398, *$ 399, *

401, $402, * 403{ }^{*} 404 .^{*}$
Ihectial reproduction by vegetative parts, 433.

1sh, leaf-sear of, 212 .

wood of, 230.

Ash of plants, 137.

Ashes as fertilizer, 152, 153, 154 .

benefit puddled soils, 129 .

Asparagus, bleaching of, :345.

tolerates salt, 350 .

Aster, cross-pollination of, 304.

green flowers of, 349 .

Ativism, 420, 449.*

Atriplex. See Salt Bush.

Attrchment of plant to soil, $x_{-}$.

- root-hairs to soil-particles, $119{ }^{*}$ $120 * 121$.

Attraction of salts, etc., for water, $8,12 t$, 217,336 .

Atwater on foods, 173.

Australia, Rusts in, 404.

Autumnal coloration, 332.

Avena. See Oat.

Bacteria, 301-389.

air-hating, $374,375$.

air-loving. 374, 375.

behaviour of in cultures, 368 .

cannot live in plants, 378 .

classification of, 368 .

eultivation of, $361-365, * 366,368-370$, $374-375 . *$

denitrifying, 383 .

disinfectants for. 364 .

effect of :iir on, 382,383 .

- - hest on, 363,364 .

- - light on, $364,382$.

forms of, 361,362 * $^{*}$

immcrtality of, 368 .

nitrifying, 383-384.

of air, 3606,367 .

- "bloody bread," 368.

- cholera, 371, 372, 373,*376.

- of decry, 381-387.

- liphtheria, 376.

- haty, 361-365.

- lockjaw, 362 , 378.

- milk, 372-378, 381.

- root tubercles, 384,385 .

- scirlet fever, $37 \%$ 
Bacteria of tuberculosis, 376 .

- typhoid, 371, 376.

- vinegar, 387.

- water, 368.

parasitic, 380 .

prepare nitrogen for the plant, 149,* $150,383$.

propagation of, $362, * 371$.

pure cultures of, $367-368$.

respiration of, 374

suprophytic, 380.

spores of, $362, * 365$.

Bagley, acknowledgement to, $\lambda$.

Bailey on agriculture, 109, 129, 133, 153.

- gardening, 249, 263.

- plant-breeding, 409, 420, 421, 428, $441,453$.

- pruning, 264.

- study of branches, 245.

Balance, method of making, 13.* 14.*

Bamboo, protection of stomata by, "214.

Barberry, protection of, against animals, 222.

Rust of, $402,403,{ }^{*} 404$. $^{*}$

Bark, 262,*279.

binds stem, 248 .

formation of, 256.

function of, 256,333 .

protects against drying, 333 .

slitting of, to prevent binding, 248 .

softened to prevent binding, 248.

stretching of, 247.

Barley, pepsin in, 172.

roots of, explore soil thoroughly, 133.

Rust of, 404.

seeds of, germinate while immature, 43,

Swut of, 400-401.

Bartlett Plum. See Plum, Bartlett.

Barium hydrate, 158.

Bast, 120,* 198,* 199,* 294,* 225, 226, 227,* $231, * 232, * 233,236, * 254-257$.

Bast-ring, 226, 246.

Beach Plum. See Plum, Beach.

Beals on soil, 133.

Beam, effect of strains on, 265.

Isean, $77, * 141,144$.

food in, 177 .

gut+ing :blove ground of, $71 * 76,77$.

putl of water in the seed of, $8,23$.
Bean, poeket of seed of, 20*

root tubercles of, 149 .

Bean. See also Horse-bean.

Bean, Cranberry, hybrids of, 428.

Bean, Horticultural Pole, hybrids of, 428.

Bean, Lima, absorption of water by, 7 .

- germination of, 81, 85.

- resting period of, 43 .

- twining of, 275.

Bean, Pink, germination of, 51.

Bean, Pole, twining of, 275.

Bean, string, twining of, 275.

Bean hybrids, 428.

Beech, hairy covering of young leaf of, 213. - sun- and shade-leaves of, 345 * $^{*}$

Beer, manufacture of, 169, 391.

Bees, partial to certain colors, 298, 299.

- power of scent of, 300 .

- visit but one kind of flower at a time, 299.

- visual powers of, 300 .

Beet, sugar in, 122.

self- vs. eross-pollination of, 302 .

Beet, Sugar, tolerates alkali, 350, 440.

Beggar's-ticks, dispersal of seed of, $324^{*}$ *

Begonia, 332.

root pressure of, 243.

transpiration of, 204.

Bending stem to increase fruit production. 318.

Benzine, test for fats and oils, 165 .

Berberis. See Barberry.

Bertholetia. See Brazil Nut.

Berries, pulp of, retains water, 29.

Bessey, on plant-breeding, 441 .

Beta. See Beet.

Betula. See Birch.

Bichromate of potassium. See Potassium bichromate.

Biennials, flowering of, 286.

seed formation of, 314 .

Bindweed, calyx of, 288 .

twining of, 275.

Birch, contains fat in winter, 2.0.

dispersal of seods of, inc1.

in northern latitudes, 356 .

protection of, agninst drying, 214.

lenticels of, 278 .

run of sap of, in spring, 259. 
Birds bury seods, 69.

distribate seeds, $: 24,325$.

Bird's-eye. II aple, 262.

Bitter taste as protection against animils, $222,223$.

Blackberry, climbing of, 270.

contraction of root of, $k i$.

proteetion of stomata by, 214 .

rooting at tip of, 87 .

Blackberry hybrids, 406 , 43 , *

Bleaching powder, 23.

Bleeding of plants, - 213 .*

Blood, coagulation of, $1 \overline{1} 1$.

composition of, 171 .

in relation to oxygen, 176 .

Blue, preferred by bees, $998,299$.

Iilue rass cut out by potassium bichromate, $26 . \%$

Blne jays bury seeds, 69.

Bluestone. See Copper Sulphate.

Blue Vitriol. See Copper Sulphate.

Boilers, pressure in, it.

Boiler-scale, 151.

Bone as fertilizer, 150, 151, 153.

phosphorus from, 150 .

Bone-black as fertilizer, 151.

Bone-meal as fertilizer, 151 .

Bone-superphosphate, $139,150,153,154$.

Boneset, protection of, against animals, 12:5.

Boracic acid. See Acid, Boracie.

Bordeaux mixture, 407.

Bordered pits, 227,*232,*234.*

Borers, may promote fruit production, 319 .

Buston Iry. See Iry, Japanese.

Bran, 17.

Branch. See Stem.

Brassica. See Brussels Spronts, Cabbage, Hustard and Rape.

Brazil nut, micropyle of, $8_{2}^{*} 9$.

Bread, 1is.

"rust of, contains dextrin, 168.

Mould. See Mould.

Breaking stem to increase fruit production, $31 \%, 319$.

Briggs, on soil, 129, 133.

Brine, as preservative, 386, 387 .

Brootn, protection of, against drying, 215.

Brownian motion, 361.

Brussels Sprouts, bud of, 250,*251.
Buckeye, flower-buds of, 286.

fruit of, how supplied with food, 313.

germination of, $58, * 59, * 60, * 85$.

pocket of seed of. $20,58 .{ }^{*}$

preparation for flowering of, 286 .

seed-corer of, 8 .

seed of, structure of, $58,{ }^{*}, 79,{ }^{*} 60$.

See. also, Horse-chestnut.

Buckwheat, germination, 47. self- vs, cross-pollination, 302 .

Buds, erystals in, 254.

flowers of, 286-2n8.

food in, 253.

formed on roots, 249 .

latent, 262.*

opening of, 25 .

protection of, against dryness, 213, 214, 251, 334 .

structure of, $250, * 251$.

Bud̀-scale, 288.

function of, 214, 251.

Bud variation. See Variation.

Bulbs, propagation by, $43 \%$.

storage of food in, 260, 261, 286.

Bulrush, strengthening fibers of, 267.*

Bundles. See Fibrous Bundles.

Bur Clover. See Clover, Bur.

Burbank, acknowledgement to, $x, 409$. work of, $409-411, * 412,413_{1}^{*} 414^{*} 415_{1} *$ $416, * 417,42-3,42, * 424, * 425, * 44_{1}^{*}$ $4:-* 428,429 *-432$.

Burdock, dispersal of seeds, 323.*

Burs, 323.*

Butter, emulsification of, 169, 170.

preservation of, 386 .

Buttercup, contraction of root of, 87 .

water, 338,339 ,*

Butterflies, visual powers of, 300 .

Cabbage, self- vs. cross-pollination of, 302. strengthening fibers of leaf of, 267 .

Cactus, effect of water and darkness on, $329 * 32^{*} 0$. 331 . $^{*}$

fruit of, production of, increased by dry ness, 342.

habit of, $329,330,331 . *$

protection of, against animals, 334 .

--- dryness, 215 , 333.

storage of food in, 286. 
Cactus, storage of water in, 334.

soil needed by, 108.

California, University of , $445, * 45$ '.

Callitriche, air-spaces, 333,*

Callus, 249, 263.

Calorie defined, 174.

Calyx, 288**

work of, 287, 288.

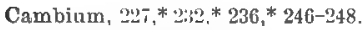

Cambium-ring, 246.

Canada, forests of, 356 .

Canal banks protected by plants, 277 .

Cane, Sugar, protection of, against drying, $333,334 . *$

Cane-sugar, 16.5.

Canna, protection of, against drying, 21:3.

Canna hybrids, 428.

Canning, 386.

Capillary action of soil, 116 .

Caprification of Fig, 310, 311 .

Carbohydrates. See Starch and Sugar.

Carbon, energy from, 173.

Carbon dioxide, thsorption of, by chlorophyll, 202.

- - - leaf, 200.

- apparatus for supplying to aquarit, $28,3, * 284, * 285$, *

- as constituent of starch, 180 .

- as measure of energy set free, 174 ,

- is plant-food, 139.

- decomposed by leaf, 191,* 192,*193,* $194,195$.

- generation of, $284 . *$

- in air, 187, 194.

- measurement of, 34,*175.

- produced by leaves, 194, 195.

- - Moulds, 394.

- - root, $14 \mathrm{t}, 142,143,{ }^{*} 144$.

- - seeds, 6, 33, : : $4, * 35$.

- - Yeast, 390.

- rôle of, in respiration, 175 .

- supply of, affects stureh formation, 193.*

- unites with water to form stareh, $1 \times 7$ 193, 202.

See, also,Acid, Carbonic, and Respiration. Carbonate of lime. See Lime "itrturiall. Carbonic acid. See Acid, Cirlınir.

Carex. See Sedge.
Carrot, contraction of root, 87

for artificial root-hair, 12:.

storage of food in, 260,313 .

sugar in, 122.

Carunele, 2.

function of, 29.

Carya. See Hickory, Pecan.

Casein, 172, 377.

Castanea. See r'hestnut.

Castor-bean, 1, 2.*

alssorption of water by, 7 ,

ibir reservoir of seed of, $4:$.

cross-pollination of, 302 .

caruncle of, retains water, 29 .

endosperm of, function of, 170.

getting above ground of, 72 .*

lipise in, 170, 171.

micropyle of, 9 .

protection of pollen by, 295.

resting period of seed of, 44 .

seed-cover of, 8.

seed of, strueture of, 29 .

seed leaf of, function of, $17 k, 179,185$, 186 .*

self- vs. cross-pollination of, : 102.

Caulicle, $1, * 2, * 3, * 4, *$

direction of growth of, 59 .

pocket around, 20,*58.*

Colery, bleaching of, 346 .

Cell, antipodal, 291.*

bast $, 120, * 198, * 199, * 2 \cdot 4, * 225, \cdots 26,207, *$ $231, * 232, * 233,236$, 254 23,

cambium, $227, * 231, * 2 ;: 2, * 2 ; 6, * 246-248$.

chlorophyll granules in, 1:t, * 199,* 200 , $201, * 202$.

collenchyma, 268.*

crystals in, 232,* 2hit.

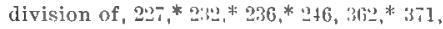
$390 . *$

egg-, $290,291, *$

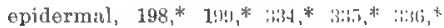
$337, * 35, *$ i3 0 , * $444, * 345 * *$

guard- 198,* 199,* 200, 20\%,* 20!1,* 210,* $211, * 336, * 337, * 310, * 344, * 34.7$

hair-, 324,*335,*337,*

in relation to growth, 64, $0.5, *$ titi-1is.

isolation of, 235 .

muclens of $65, * 66,290,291, * 311$.

osmosis in, 64, 123, 124, 208, 209. 
Cell parenchyma, of leat, 198* 199*-202, :337,* *138,*344,*345.*

- - seed, $65 . * 66$.

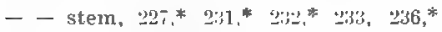

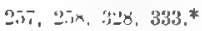

- root, 1:0* 121.

pits in wall of , 227,* 224, 23\%, 235, 234,* 235.

protoplasm of ${ }_{*}\left(6,5,{ }^{*} 66,290,291\right.$. $^{*}$

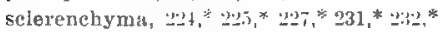
$236, * 266,26 \pi^{*} 268$.

starch in. See Starch.

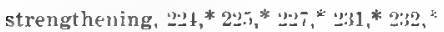
$236 * 266,267 * 268$.

struicture of, t5., *66.

water in, 64, 123, 124, 208, '209.

wood-, 120,* 121, 198, 199,* 204:-2, * * $228-231,232 *-234,235,236-2,3,233 \%-$ $240, * 341$.

Cell-wall, 64, 65, * 166

Cellular structure. Tee Histology.

Cellulose, $65, * 66$.

decomposition of, 381 .

Centrifugal force, effect of, on direction of growth of stem and root, $92,93 * 94$.

Century Plant, protection of, agatinut animala, 220. 334.

- protection of, against drying by epidermis, 333 .

- seed formation of, 314 .

- storage of food in, 260,286 .

- storage of water $1 \mathrm{n}, 334,345$.

Ceratophyllum. See Hornwort.

Cereals in crop rotation, 160.

Chareoal, :32.

('he kerberry. See Partridge-berry.

Cheere, $3 \pi$.

Chemical action due to light. $18: *{ }^{*} 184,{ }^{*} 18 \mathrm{j}$, $195,196,201,316,364,382$.

- in the plant, $366-17,182-196,253,2.4$. -4. 259, 314-316.

- soil, 125, 139-153.

- - soil-formation, 109.

-. See, also, Respiration.

Chemotropism, 29:3, 394

Cherry, evergreen, 415.

flavor of, $2 x \%$ *

lenticels of, 278

protection of, against dryiug, 2:14.
Cherry, seeds of, distributed by lirds, 32.5.

Chestzut, on poisonous plants, 222.

Chestnut, leaf mosaic of, 219*

protection of fruit of, 320 .

wood of, 230.

Chic'go, sewage of, $36 \%$.

Chickory, flowers of, attract bees, 299.

protection of root of, 162 .

Chili saltpeter. Ste Sodium nitrate.

Chloride of lime. See Lime chloride.

Chloroform in testing for fats and oils, 165.

Chlorophyll absorbs carbon dioxide, $20^{\circ}$. cannot form in cold weather, 354 .

- - - darkuess, 18j.

decomposition of, causes atumnal colors, 332.

effect of light on. $184,{ }^{*} 185$.

function of, 185, 201.

in stem, 278 .

Chlorophyll-granuler, 198, 199,*200,201, 202.*

Cholera, $3 \bar{\imath} 1-373, * 3 \bar{\imath} 6,380$.

Chrysanthemum, sports of, $4 \div 0$.

Cichorium. Tiee Chickory.

Cinnabar, injection of wood with, 237.

Cinquefoil, hairy covering of leat. 213, 334 . protection of, against drying, 334 . protection of, against animals, 213.

Cistus, protection from drying, 334 .

Clay, burning of, 106 . burned, wenefits puddled soils, 129. composition of, 106,107 .

fixes ammonia, 145, $11 \bar{i}$.

- dung liquor, 14 .

- plant-foods, 145.

floceulated by lime, 192

is impervious to water, 1:5.

lifts water higher than sand does, 118.

microscopical examination of, 106.

percolittion in, 113.

plant-food in, 106.

properties of, 106.

richer in plant-food than sand is, 146.

size of particles of, 106.

water-holding capreity of, 132 .

Clay loam, 108.

Clematis, elimbing of, 270,271 ,

dispersal of seeds of, 32..* 
C'limbing plants, 270, 271,*272, 273,* 974, $275 . *$

Clock, floral, 295.

('lotbur, dispersal of seeds of, 324.*

Clover, benefited by lime, 151.*

in crop rotation, 160 .

leaves of, follow sun, 218.

position of flowers of, 307.

root tubercle of, $149 . *$

sleep position of, 218.

Clover, Bur, dispersal of seed of, $324, *$

Red. variation in, 448,*419*-450.*

Cobrea, calyx of, 288.

Cobalt chloride, as index of transpira. tion, 203.

Cockle-bur, resting period of seed of, 44.

Cocownut, distribution of, by water, 325. endosperm of, function of, $57,179,180$. germination of, $56,57, * 58$.

structure of fruit of, $56,57, * 58$.

Cocoanut oil. See Oil, cocoanut.

Cocos. See Cocoanut.

Cohn's solution, formult for, 398 .

Cold. See Heat.

Collenchyma, 2lis *

Colon bacillus, 371.

Color of autumn leaves, 332 .

- flowers, $997-300$.

- fruits, 316, 325

- fruits and flowers affected by light, 347 .

- night-blooming flowers, 300.

preferzed by insects, 298, 299.

Color-eontrast in flowers, $297,298$.

combustion, 35 .

as source of energy, 17is.

brought about by ferments, 173.

Companion cells, 227,*231,*232,*25.

Compass plants, 346 .

Composite family, cross-pollination of, $30 \% *$

- green flowers of, $3+9$.

Composition of soil, 103-109.

- starch, 186,*187.

Compost, 147, 148.

Conditions of growth, 252, 253.

Conduction. See Stem, path of air, etc., in. Conidilu, 399, 402, 408 .
Conifers, humus of, preferred by some plants, 851 .

pollen of, earried by wind, 300 .

See, also, Pine.

C'onn, on bacteria, 408.

Contagious diseases, 380 .

Contact-bed for sewage, 342 .

Contraction of root, 87 .

- wood, 68.

Convolvulus, Sis Bindweed,

Copper sulphate, 161 .

as a disinfectant, 364, 400, 401.

Coreopsis, cross-pollination of, 304.

Cork, 2.32,* 236, 256 , 979.

protects against drying, 333 .

Cork-cambium, 232,* 236.*

('nrms, propagation by, 43'3.

storage of food in, 260,261 .

("orn, hran of, 437.

breeding of, $355,4: 34-141$

canning of, 386 .

eross-pollination of. $30^{2}$.

endosperm of, $3, * 17,3$

fat in, 437.

fibrous bundles of, 22.5, 226,* 230, 2:31.*

food in, $3, * 4 i \pi$.

germ of, $3,{ }^{*} 43 \pi$.

germination of, $21,22, *+7,71, * i 2$.

getting above ground of, $71 .^{*}$

in silo, 388.

leaf-scar of, 212

oil of, 437 .

original home of, 440 .

pepsin in, 172 .

pollen of, carried by wind, 301, 436 .

protection of, against drying, 213, $3: 4$.

- - tip of stem, $71, * 79$.

proteid in, $4: 7$.

roots of, explore soil thoroughly, $1: \%$.

- - strength of, 268.

- - structure of, 368 .

root pressure of, 243.

seed-leaf of, $3, * 179$.

self- vs. cross-pollination, 302.

silk of, 202, 301.

Smut of. See sinut of Corn.

starch in, 3, 437 .

tem of, struw ture of, $23, * * 230,831$.* $^{*}$

- - rigidity of, 269 . 
Corn, stigma of, $9(1) \cdot 301$.

strengthening filuers of, $2: 1, * 266$. structure of grain of, 2, 3.*

wandering of, 440 .

water in, 437.

Xenia in, 311.

Corn, Sugar, endosperm of, 3.

- seed-leaf of, 17!.

(“)rina, 288.*

Correlation, $79 * 359.360$.

Corrmise sublimate as disinfectant, 364 .

Cortex. See Rind.

Corylus. See Filbert, Hazel.

Cosmos, cross-pollination. 304.

Cottonseed oil. Ste ril, Crittonseed.

Cotyledons. See Seedleaves.

Cover. See Seed cover.

Cow Wheat loves mild humus, 351 .

Cowpox, 379 .

Cracks, seeds buried in, 69 .

Cratsegus. See Hawthorn.

(rocus, opening and closing of flower of, affected by heat, 296. storage of food in, 260.

Crops, dependence on water supply, 133.

green, in rrop rotation, 160.

rotation of, 160,161 .

white, in crop rotation, 160.

Eronsprillination, 301, 302, 303, $304, * 305, *$ 306 .*

Crossing, process of, $430,431, * 4, \cdots$.

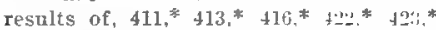
421.* $425,426 * 42 \div * 428,429$, 434 .

speeies originate from, 451.

utility of, 421 .

Crude food. See Food, t'rude.

Crist. See Soil crust.

Cucumber, Squirting, dispersal of seed of. :12*

Cucurbiti. See Pumpkin and Squash.

Crystals, $230,{ }^{2} 54$.

Cultivation conserves soil moisture, $115, *$ $116,{ }^{*} 11 \%, 195,129,133$.

should be adapted to depth of root, 123 .

r'upra-ammonia as light filter, 265.

Currant, aeid in, 315.

Curve of variation. See Variation, Curve of.

Cut, fever caused by, 262, 263.
I Cuticle, 197, $19 \%, 199, * 328,334 *$

effect of light on, 315 .

of water plants, 339.

Cuttings, correlation in, $\mathbf{3 5 9}$.

fever in, 292,203 .

propagation by, 433 .

regeneration in, 25.5 .

soil required by, 262, 263.

transpiration of. 282 .

treatment of, 26 ?.

Cydonia. Ser Quinco.

ro press, wood of, 230.

Cytisus, ;.:. $332 . *$

protection of, from drying, by sunken stomata, 21.5.

Sife, also, Broom.

Dahlia, root pressure, 24:3.

Daily morements of flowers, $295-298$.

- - leaves, 218*

Daisy, cross pollination of, 304.

Europe:tr, 12?.

Field, 42., 42\%.*

Jipanese. fies, $1 \pm 5$.

() $5-+$ ye, variation in, $417,41, *+19$.*

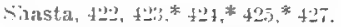

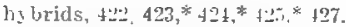

Dandelion, behavior of leaf of, $1 ;$.

disper sal of arerls of, 303.

effect of saturated atmosphere on, 341, $3+2 *$

flowers $c f$, arrangement of, $2 g$.

- - afferted by light, $-u$ s.

opening and closing of flowers of, afferted by light, 295.

protection of pollen by, 2.1.\%.

- - root by. 162 .

stalk - of, tissue ten-ions in, $269,273, *$

Darkness. See Light.

Darwis, on orchid pollination, 307.

- origin of species, $411,4+2$.

- self- vs. cross-pollination, 301.

- soil formation, 109.

Date, germination of, 180 .*

fruiting of, 350 .

seed-leaf of, 180 .

vitality of pollen of, 294.

Daucus. - Carrot.

Deras, $\sin 1-\sin$. 
Decomposition due to bacteria, $147,148,1.51$, $381-387$.

of curhon dioxide by leaf, 191,* 192.*

- rock by ehemical aetion, etc., 14,145 .

- starch by heat, $86, * 87$.

Deer-berry. See Partridge-lerry.

Deformity, 420, 421.

Delphinium. See Larkspur.

Deutzia, cross-pollination of, 303 .

Dew, formation of, 117.

Dextrin, changed to grape sugar, 168. in bread crust, 168. formation of, 167, 168 .

Diastase, 166, 167.

J)icotyledons, characterized, 22:6.

Digestion in animals, 166-172. - plants, 166-172.

Dikes, protected by plants, $\because 77$.

Dicecious plants, 302 .

Diphtheris, 376, 380 .

Directive action of air, $89,98,135,293$.

- - chemical substances, '293, 294.

- - gravity, $88,{ }^{*} 89{ }^{*}$ 90, 91,*92, 93**94, $95,98 * 99,264,277,308$.

- - light, 264, 346 .

- - water, $95, * 96, * 97,98$.

Diseases of plants, $397,398, * 399, * 400,401$, $402, * 403, * 404-407, * 408$.*

- - damage done by, 400, 401, 406 .

- - prevention of, $400,401,407,408$, 440 .

Disinfectant, 364 .

Dispersal of seeds, $320-32.5$.

Distilling, $137,{ }^{*} 138$.

Distribution of seerls, 33:0-;

Dog's Mereury, loves mild humu, 3.1.

Dronght. See Dryness and Water.

Drupes, protection agstinst drying of secul of, 317.

Drying, protection against, ree Protection ugainst drying.

Dryness, effect of, on plant, 82, 211 "217.

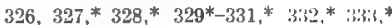
$334, * 335, * 336, * 337, * 3: 34_{1}^{*} 339, *: 340^{*}$ 342 * 343 * $^{*}$

Siet, also, Water

Ducts, 224, * $926,227, * 22 x, 2 y, 230,231$ * $232 * 233,234 *$

length of, 236,237 ,
Ducts, resin- 235,236 .*

water travels faster in, $2-28,299,230,237$.

Dung liquor, fixed by clay, 145.

Dust clogs stomata, 215 .

Dusty Miller, hairy covering of, 21:?,

- protection of, against drying, 333 .

- - - water, 214.

Earliness, 355, 411, 41:.

Earth. See Soll.

Earthworms bury seeds, 69.

Eau de Javeile, 23.

Eehinoeystis, See Cucumber, Squirting.

Echium, Rust on, 405.

Egg, food in, 176, 17\%.

of plants, 290.

preservation of. $38 \vec{i}$.

Elaborated food. See Food, Elaborated.

Elastieity of stem, 269.

Elder, flowers of, 298.

pith of, 269 .

stem of, $268,269$.

Electrie light, 346.

Elm, buds formed on roots of, 249 . cross-pollination of, :30:3.

Embryo. See Germ and Seed.

Embryo-sac, 290, 291,*

Endosperm, 2,*3,*4, i.,* 179, 180,*

absorption of, $57,+179,180 \%$

in Xenia, 311

Endosperm nucleus, 291,*311.

Energy absorbed from sumshine, 195, 1915, 201.

in foods, 173.

in starch, 196.

unes of, 173-175.

Environment, effect of, on the plaut, $320-$ 360.

Eosin, $2-24,66,161,224,225,228,230,242$, 251.

Eosin stains, how removed, 23.

Epidermis of fruit, : $: 17$. of leaf, $19 \vec{i}, 198,{ }^{*} 199,{ }^{*} 204,205,210,21:$, 214.

proterts against drying, $333,334^{*}$

Epilobium, dispersal of seeds, 323.

Equisetum. Sxe Horse-tail.

Erotium See Filaree.

Ether, test for futs and oils, 16.5. 
Etiolation, 144, 1 1-; : $: 34,45+$

Encalyptus, urotartion of, against drsing.

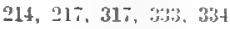

- - fruit of 320 .

Fupatorium. See Bonfset.

European Plum. Sis Plum, European.

Eraporation. See Soil, Evaporation from. and Transpiration.

Evening Primrose. See Primruse, Evening.

Erolution, 330, 41-453.

reontrol of. 4.53 .

indirated by variation curve, $41 b^{\text {s: }}$

Exrentric growth, : $: 4: 350, *$

Exiretions, nitrogen in, 1iti. poisonous character of, 3is.

Experimental morphology. see Plant, form of.

Exposure, effect of, on fruit production. IIO

External agent 326-361. see, alw, dir, Food, Grabity, Heat, Light, Water. Winl.

Eye, effect of light un, 190.

Fagopsrum. Ser Buckwheat.

Fall wood. 232, $236 *^{*}-4$;

Fascination, 4:4" 4 1.

Fats, changed to stareh. 259.

decomposition of, 381 .

emalsification of, 169, I,t.

energy from, 173 .

formation of, 170, 201.

in eges. 17.

- growing region,

- -

-trees. 250.

sayonification of, 170,171 .

tent for, 165,250 .

Set, also, "iil.

Feces contain wiste uitrogen. 176.

Fehling's so'ation, preparation of. $164,165$.

Feldspar, 106, 10 $\mathrm{i}$.

Fermentation by bacteria, 380 .

- Feast, 169.

Ferments, 166.

cause oxidation, 173 .

restore ritality of seeds, th.

Fernow, on forestry, 24.

Ferns as shate plants, 344 .
Ferns, protection against drying, 213.

rhizomes of, 27. .

soil needed by, 1ns.

unrolling of leaf of , $2, \%$.

Fertilization, $391, *$ *

after effect of, $30 \%, 360$.

Fertilizers, 139-160.

effect of, on fruit, :1:

- - - fruit production, ::1 .

Ferer caused by wounds. 262,$21 ; ;, ;, n$.

Fibrin. coagulation of. 1 i1.

for digestion experiment $, 1: 1,1: 2$.

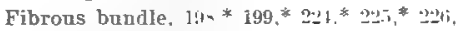

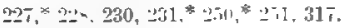

effect of water on, 335 .

Ficus. See Fig, Rubber Plant.

Fig, flower structure of, 310 . pollination of, 310,311 .

Filaree, seeds of, bory them 4 -15e, 70 , $; 1$.

Filbert, ahsorption of water by, 7 .

openings in cover of, 9 .

path of spater in cover of, 9. 24.

Filtration of water, $3 ;.$

Fire, protection ngainst, by bark, 256.

Fish, preservation of, $; ;$ i.

Fisher, on cookery, 17'.

Fire-finger. sme Cinquefoil.

Flaror. affected by external conditions, $31<, 319,2 \pm 2$

improvement of, by breeding, 41\%, 41 .

Flax, absorption of water by, i? seed-ever of, bolds water. 2".

Flesh-forming food *. 176 .

Fleur-de-lis. See Iris.

Flies carry disease, $;-1$. prefer yellow, 299.

Flinty texture proterts against animal, wa:;

Floods, relation of, to iorests. 11:.

Hloral eloek. See Clock, Horal.

Florida, forests of, 356 .

Flour. proteid in, 1T.

starch in, 17:.

Flower, attraction of insects for, $39--300$.

color-contrasts in, 29,

color of, affected by light, 34 .

donble, produced by breeding. $t_{-}^{-3 .}$ *

effert of heat on. 296, st:

- - light on, 295-298, ït. 
Flower, effect of water on, 496, 34".

fool needed by, $286,287$.

formation of, $286,287$.

improvement of, by breeding, 422,423 , $424, * 425, * 427$.

injury of, 288.

night blooming, 299, 300 .

opened by insects, 308 .

opening and closing of, $296,297$.

platforms of, 309.

production affected by heat, 347 .

- - - light, 347.

protection of, agaiust drying, 288.

- - - insects, 308.

- - - water, 294, 295.

position of, 307,308 .

respiration of, 287.

sets free heat, 287.

strueture of, 288 * 290,291 .*

work of, 286-311.

See, also, Anthers, Petals, Ovary and Orule.

Flower-buds, 286, 287.

Flowering, preparation for, 286, 28 ;.

Food, as source of energy, 173, 176.

- material for growth, 173.

crude, 201, 136-] 62.

digestion of, 166-172.

effect on plant, 349-351.

elaborated, 57,* 65,* 164, 169, 179, 180,* $183,253,2.44,260,278,286,287,313$. 314.

energy in, how measured, 173.

flesh-lorming, 176.

from the air, 200 .

- - soil, 201.

how conveyed to fruits, 313 .

in buds, 253.

- eggs, 176, 177.

- leaves, 181,

- seeds, $57, * 65, * 1$ tit $-180,{ }^{*}+37$.

- root, 122, 255, 260.

- stem, 169, 243, 250, 253, 254-260, 286, $287,313,314$.

-. vil, 146.

licck of, promotes fruit production, 350 . inate soluble, 166-172.

manufact nie of, 182-203, 253, 254, 278,

miner: $1,136-16^{2}$,
Food, muscle-forming, 176.

needed by fruits, 312-316.

- - plant, 326 .

organic, absorbed from soil, 150.

preservation of, $376,377,385-388,397$.

required for growth, 253.

storage of, in preparation for flowering. $260,286,287$.

stored, utilization of, 5 . $^{*} 164,179,180$, $183,260,286,287,313$.

plant, dissolved by caxbonic acid, 139-145.

- fixed by clay, 145.

- - humus, 145.

- set free by lime, 152.

- raw, 136-162, 201.

wandering of, $57, * 164,169,180,183,253$, $254-257,259,260,286,287,313,314$.

Forage crops, time for cutting, 314.

Forests, effect of heat on, 356 .

humus in, 107.

prevent floods, 11:.

remain naturally in good tilth, 129.

Forest, trees of, differ from isolated specimens, 261.

Form of plant, effect of external agents on. See Plant, form of.

Formalin, as disinfectant and preservative, $28,364,377,386,401$.

test for, in milk, $37 \pi$.

Foxtail, seeds of, bury themselves, 71 .

Fragaria. See Strawlerry.

Frankliu, on gypsum as fertilizer, 1 it.

Fraxinus. See Ash.

Freak, 420, 4:1, 440.*

Freezing. See Heat.

French Prune. See Prune, Freneh.

Frost. See Heat.

Fruits, acid in, 315.

air in, 317.

nir needed by, $31 \bar{i}$.

air, how conveyed tn, 31i.

attract animals, 324, 325.

benefited by ringing, 2.7.

effect of light on, 316, 347.

- - water on, 34'2.

- - wind on, 349.

defirition of, $4,312$.

fiut in, 314.

'yilermis of, 317. 
Fruits, fibrous bundle in, 317 .

flavor of, increased by dryness atid warmth, 315.

food needed by, 31?-316.

improrement of, by 1reeding, 409-411,* $412,413, * 414,{ }^{*} 415, * 416,{ }^{*}+17$.

oil in, 314.

path of food to, 313 .

- - water in, 24.

pectin compounds in, 315.

production of, methods of increasing, $31 \mathrm{~b}$, 319,342

protection of, $3: 30$.

respiration of, 317 .

ripening of, $315,316,324,325$.

starch in, 314.

struggle for existence of, 31:.

stomata of, 317 .

suceulent, require more water, 320 .

sugar in, $314,411$.

- - method of increasing. 315.

thinning of, 31 ?

transpiration of, 317 .

water needed by, 316,317 .

work of, 312-3y5.

Yeasts on, 390.

Fruit trees, bud - on roots of, 249.

- protection against drying, 213.

Fuel value of foods, $173,196$.

Fumigation of plants, 215.

Function determines iructure, $179,1 \times 5$, 186.*

Fungi, 361-408.

destroyed by lime, 1.52 .

- - rotation of crops, 1100 .

on roots of trees, 150 .

protection against by bark, 250.

- - - callus, 26:3.

Furrow-slice, 126,* 127.

Gaillardia, eross-yollination of, $303 . *$

flower structure of, 303.*

Galloway, on freezing, $3 \bar{s}^{4}$.

- soil, 129.

- plant diseases, 407 .

Galls, 359 .

Gardner, acknowledgment to, $x$.

Gardner on plant breediny. $4 \$ 1$.

Gases, fumigation with, $21 j$.
Gases. See, also, Air, Carbon dioxide, Nitrogen, Oxygen.

Gasolene, test for fats and oils, 165.

Gastric juice. 171.

Gaye, on soil, 109.

Gelatin for bacterial cultures, 368, 369 .

- mould cultures, 395

Generation, spont ineous, :36.5.

Geotropism, 88, ${ }^{*} 89, * 00,91, * 92,93, * 94,95$. $9 \times, * 99,264,308$

lipranium. See Herb Robert.

lipranium, air passages in, 280.

behaviour of seeds of, 71 .

flower of, pusition of, 307 .

stem of. 224 .

Geranium, Ivy, effect of cold on chlorophyll, $3 \tilde{5} \cdot$.

- leaf mosaic of, 219.

Germ, 1, ${ }^{*},{ }^{*} 3{ }^{*} 4,{ }^{*} 2 \varphi^{*} .506,58$.

montact of, with eover, 20.

osmotic action of, 17 .

See, also, Seed.

Germicide, 364.

Germination. See ireed.

Giant Prune. Ste Prune, Giant.

Gibson, on pollination, 307 .

Girder, 266.

Girdling increases fruit production, $25 \overline{\text { }}$. 318.

G]adiolus, leaf strueture of, 201.

protection of, against drying, 217.

Glauber's salt in soil, 158.

Gleditschia. See Illoney Locust.

Glueose. See Sugar.

Gluten, $17,178,437$.

Glycerine for shrinking eell 4,390 . a product of saponification, 170, 1i1.

Gnaphalium. See Immortelle.

Goodyera. See Plantain, Rattlesnake.

Gophers bury seeds, 69.

Gorse, 331, 343.*

effect of saturated atmosphere on, 341 , 343 *

Grafting, 248, 249, 433.

Grains, chaff of, holds water, 29. conveyance of food to seeds of, 313 , 314.

wrowth at nodes of, 250 .

proțeid in, 17. 
Grains, starch in, 177.

ovary of, 289.

pollen of, 289.

- - carried by wind, 300 .

stigma of, 289.

style of, 289.

time for cutting, 314 .

Grape attracts insects, 299.

fruit production of, increased by bending 318.

- - - - girdling, 257.

- of, stomata of, 317 .

pith of, 269 .

protection of pollen by, 295 .

- - root of, 162 .

self-sterility of, 309 .

stem of, 268.

- - rigidity of, 269.

tendrils of, $2 \%$ 2.

Grasses, are shallow-rooted, 134.

chaff of, holds water, 29.

germination of, 72 .

growth at nodes, 250.

leaf scar of, 212.

ovary of, 289.

pollen of, 289.

- - carried by wind, 300.

position of leaves of, 217.

protection of, against drying, 213, 334 .

- - - animals, 22a.

relation to light, 265 .

rhizome of, 277.

stigma of, $289,292$.

stomata of, 196.

style of, 389 .

Gravity, effect of, on direction of growth of root and stem, $88, *{ }^{*} 89{ }^{*} 90,91, * 92$, $93, * 94,95,98,99,26+276,277$.

effect of, on direction of growth of Hower and fruit, 308.

Gravel stops rise of water in soil, 115.

Gray, on mstivation, 213.

Green flowers, cause of, 349, 359 .

- manures, 150, 384.

- rays, partially cut out by potassium bichromate, 265.

- rays partially cut out by cupraammonia, 265.

Ground. Seo Soil.
Ground-squirrels bury seeus, 69.

Grow th at nodes, 249, 250.

correlations of, $79, * 359,360$.

effect of heat on, 252.

- - light on, 253.

- - water on, 116, *117, 252.

food required for, 253 .

foree of, in stem, $73,{ }^{*} 74,{ }^{*} 75, * 76$, $^{*}$

- - - root, $81,82, * 83,84, * 85$.

of leaves, inequalities of, 251.

oxygen necessary for, $5,6{ }^{*} 32,33,{ }^{*} 34^{*}$ $35,36,37, * 38,39, * 40,125,126,281$,* 283,326 .

region of differentiation, 229 .

- - in root, $85, * 86$.

- - - stem, 77,* 78."

relation of, to osmosis, $64-68$.

temporary vs. permanent, 67.

the three regions of, 249 .

Guano as a fertilizer, 148, 153.

Guard-cell, 197, 198,* 199,*200, 208,* 209,* 210 , ${ }^{*} 211$, *

artificial, 210,*211.*

Gums lessen transpiration, 214, 216, 333.

Gymnocladus. See Kentucky Coffee Tree.

Gypsum. See Lime sulphate.

Habit of plant, 264.

Hsamoglobin, 176.

Hairs, absenee of, from water plants, 339. effect of light on, 347.

- protect against animals, $221,256$.

- - drying, $213,214,333,334, * 3.5{ }^{*}$

- - water and dust, 215.

Hamamelis, See Hazel, Witch.

Hamburg, cholera epidemic of, 372,373 *

Hanging drop, 293, $395,405$.

Hardiness, 355, 412, 413 .

Hardpan, 106, 351.

alkali, 159.

$\mathrm{H}$ :uper, acknowledgement to, $\mathrm{x}$.

Hartley, on plant-breeding, $434,4+1$.

Harwood, on plant-breeding, 431.

Hawkweeds, behavior of seale leaves, 347 .

Hawthorn, food in buds of, 253.

protection of, 222 .

Hay, sweating of, 388.

time for cutting, 314 .

Hays, on plant-breeding, 433, 441. 
Hazel, pollen of, carried by wind, 300 . starch in, during winter, 259.

Hazel, Witch, dispersal of seets, 321.

Heart wood, 244, 245.

Heat, as preservative, 386 .

effect of. on absorption by root, 332 .

- - bacteria, 363, 364.

- - - direction of growth of stem and root, $88,89$.

- - evaporation, 115.

- - flora, 351, 356 .

- - Hower and fruit production, 347.

- - growth, 252.

- - leaf, 345.

- - Mould, 394.

- - opening and closing of flowers. 296.

effect of on plants, $352,353,354 * 355-358$.

- - transformation of fat into stareh, 259.

- - - transpiration, 207.

entrance of, into seed, $42, * 43$.

excessive, injurions, 35\%.

of respiration, $35,36^{*}, 287$.

lack of, kills plants, 352-354.

- - prevents ehlorophyll formation. $354 . *$

- - preserves foods, etc., 386.

- - produces rosette form, 357.

needed by plant, 326 .

- to awaken seed, $4,5,{ }^{*} 6$.

set free by flowers, 287 .

$---\operatorname{seeds}, 35, \div 6 . *$

Heath plants love sour humus, 351 .

protection of, against drying, 213,333 .

Helianthus. See Sunflower.

Heliotropism, 264, 346.

Hemizonia. See Tarweed.

Hen-and-chickens, protection of, against drying, 215.

storage of water by, 334 .

transpiration of, 216.

water reservoirs of, 215 .

Herb Robert, protection of pollen of, 295.

Hereditary pereentage, 436, 442.

Heredity, 411,* 413,* 416, $422,423, * 424, *$ $425^{*}, 426,{ }^{*} 42 \mathrm{i}^{*}{ }^{*} 428,429, * 434,436,442$.

Hickory, flower-buds of, 288.

path of water in, 226.
Hickory, preparation for flowering of, 286. seed-cover of, holds water, 29.

wood of, 230.

Hieracium. See Hawkweed.

Hilgard, acknowledgment to, $\mathbf{x}$.

- on soils, $126,{ }^{*} 160$.

Hilum, 1,*2.

as place for entrance of water, 10 .

Hippuris, 342 .

Histology of flower, $290, * 291$ *

- fungi, 395,* 396,* 397,* 399,* 402,* 403, * 404,* 407.*

- leaf, 196-198,* 199*-201,* 202,*208, $209, * 333,334, * 335, * 336, * 33 \tau_{*}^{*} 338_{1}^{*}$ $340, * 344,{ }^{*} 345, * 402$, , 403, ${ }^{*} 404$, *

- leaf-stalk. 212.

$-\operatorname{root}, 12 \theta_{1}^{*} 121$.

- seed, 65,*66,67, 177, 178.

- stem, $224^{*}-y 27$ * 203-230,*231, 232,*233, $234^{*}-236, * 267, * 268$, 328, 333,* 334,* 335.*

Holly, cuticle of, 334.*

protection of, against animals, 222 .

- - - drying, 333, 334.*

transpiration of, 204.

Hollyhock, rust of, 406 .

Holmes, on fertilizers, I53.

Honey. See Nectar.

Honey Locust, protection of, against animals, 222.

Honeysuckle family, cross-pollination of, 303.

flower, position of, 307 .

Hop, cross-pollination of, 302 .

dispersal of seeds of, $322-323$, *

twining of, 275 .

Hopkins, work of, 434-439.

Horehound, hairy covering of leaf, 213.

Hornblende, 107.

Hornwort, 339.

Horse-beau, germination of, $81,8^{* 2,}, * 86$.

micropyle of, 10.

seed of, structure of, $1, * 2$.

seed-leaf of, contrasted with foliage leaf, 180-186.

- - function of, $178,179$.

- - microscopic structure of, $65, * 66$.

Horse-chestnut, flower-buds of, 286.

hisiry covering of leaf of, 213. 
Horke-chestnut, preparation of, for flowering, 280.

Sinst, ílso, Buckeye.

Horse-tnil, protection of, against animals, 223.

rhizome of, 277.

House plants, care of, 13:, 136.

Honstonia, eross-pollination of, 305.

Howard, on mosquitoes, 380 .

on plant diseases, 407.

Hubreeht, on mutation, 453.

Hngging the ground as protection against unimals, 22:

Humulus. See Hop.

Humus, 104.

as fertilizer, 1 th.

colors soils, $10 \bar{r}$.

fixes plant-food, 145 .

of forest, 107 .

plant-food found in, $107,3.1$.

properties of, 107.

retains water in soil, 132, 133 .

test for, 155.

Hunn, on gardening, 249, 263.

Hunt, acknowledgment to, s.

Hyacinth, preparation of, for flowering, 286. stomata of, 196.

storage of food in, $286,313$.

witter, 340.

Hybrids, character of, $411, * 41\}, * 410, * 42-2$,

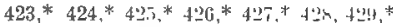
434.

defined, 421.

Hydrochloric acid. See Acid, Bydrochlurie.

Hydrogen, a produrt of decomposition of cellulose, 381 .

in foods, 175 ,

peroxide as disinfectant, 364 .

Hydrolysis, 167 .

of stareh, $16 \%-10 \mathrm{in}$.

Hydrotropism, 95,* $96,{ }^{*} 97,98$.

Ire, wethod of using, 5 ,* role in soil-formation, 109.

Iore Plant, protection of, agninst drying, 215.

witter reservoirs of, 216 .

Iles, on plant-breeding, 441.

Ilex. See Holly.
Illinois Experiment ittation, plant-hrestl.

ing at, 434-439.

river, sewage of, 382 .

Immature seeds, germination of, $4 . \%$.

Immortality of bacteria, 368 .

Immortelle, protection of, against drying. 334.

Immunity, 379 .

Impatiens. See Jewelweed.

Improved Beach Plum. See Plum, Improved Beach.

Inch Plant. See Wandering Jew.

India Ink, injection of wood with, $2: 7$.

Indigo rays eut out by potassium bichromate, 265.

Infectious diseases, 380 .

Injury, effect on the plant of, $79, * 86,263$.

Insects bury seeds, 69 .

destroyed by erop rotation, 160 .

- - lime, 152 .

how supplied with oxygen, 176.

method of alighting at fiower of, 307 .

open flowers, 308.

partial to certain colors, 298 .

protection against, by bark, aid.

- of flowors from, 308,309 .

- - fruits from, 320.

rôle of, in pollination, 289, 291، 297311 .

trapped by plants, 172

unwelcome, 308.

visual powers of, 300 .

Insectivorous plants, 172.

Iodine solution, preparation of, 164 .

test for starch, 164, 367.

Iodoform as disinfectant, 364 .

Ipomoetu. See Moonflower, Morning (xlory and Sweet Potato.

Iris, cross-pollination of, 304,"

flower of, platform of, 307 .

- - structure of, 304.*

leaf of, structure of, 199,201 .

protection of, agaiust drying, $217,333,334$.

- - - water, 214, 294.

- - pollen, 294

rhizome of, $27 \%$.

stomata of, 196, $199, * 208 * 209$,

sturage of food in, $260,313$.

Iron, needel by plants, 1:3!.

Iron chloride, 171. 
Irrigation, 130, 1:31, 135.

effect of, on fruit, 343 .

Iry, Boston. See Iry, Japanese.

Ivy, English, aërial roots of, 27..**

- attracts insects, 299.

- leaf-mosaic of, 219.

- starch in leaf of, 18: *

Ivy, Japanese, leaf-mosaic of, 219.

- tendrils of, 27 .

Iyy Geranium. See Geranium, Ivy.

Jam, process of making, $31 \%$.

Japanese Ivy. See Ivy, Japanese.

- Plum. See Plum, Japanes.

Jasmine, elimbing of, 270 .

Jasmine, Yellow, protertion of ront of, 161 , 162 .

Javelle water, 23.

Jelly, process of making, 31i.

Jewelweed, protertion of pollen by, 291.

Jimson Weed. See Thorn Apple.

Johnson, on bread, $] T$.

Johnson, on soil, 109, 133.

Juglans. See Walnut.

Juncus. See Rushes.

Jrniper, seed dispersal of, 325 .

wood of, 230.

Kentucky Coffee Tree, leaf scar, 212.

Kerner and Oliver, on pollination, 307. _ - - protection of pollen, 294.

King, on irrigation and soil, 109, 129, 133, 153.

Knot-grass. See Polygonum.

Laburnum, flower of, position of, $30 \%$.

Lnetic acid. Set Acid, Lactire.

Lactuca. See Lettuce.

Land. See Soil.

Land plants. See Plants, Land.

Land plaster. See Lime sulphate.

Landslides, experimental formation of, 111.

Lappa. See Burdock.

Larkspur needs light for germination, 47 .

Lateness, 412.

Lathyrus. See Pea, Sweet.

Luturel, air-passages of, 280 .

Leit absorbs light, 201.

air in, $187^{*}-190$.

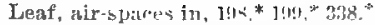

as absorbing organ, $2(4)$.

as muleh, 115.

arrangement of, $220, * 221$. $^{*}$

benefited by washing, 215 .

absorbs carbon dioxide, 200.

- oxygen, 194, 195.

autumn, 332.

bleaching of, with lye and alcohol, 22.7.

color of, in autumn, $3 ; 3$ 's.

compared to root, $200,201$.

decomposes carbon dioxite, 191, * 192,* $193, * 194,195$.

development of, 2.00, 251.

effect of cold on, 3.int*

- - Aryness on, 345.

- - freezing on, $3.5 \%$.

- - be:st on, 34.5.

-- light on, $184,185,344,345, * 346$, $34 \pi$.

- - water on, $341,342,{ }^{*} 343$.* $^{*}$

- - wind on, 345.

energy absorbed by, 196, 201.

evaporation from. SFE Leaf, transplration of.

fall of, 212, 332 .

- - caused by spraying, 215 .

foliage, contrasted with seed-leaf, 181 186.

follows sun, $217,218,34.5$

food in, 181.

function of, 181-223.

gives off carbon dioxide, 191.* 192,* 193,* $194,105$.

hinge-like joints of, $218,220$.

injured by fumigation and sprays, 215 .

internal structure of, $196-212$ ( $198, * 199, *$ $201,{ }^{*} 202, * 208, * 209, * 210, * 211$,*

microscopic structure of, 196-198,* $199 *$ $201,{ }^{*} 202,{ }^{*} 208, * 209,{ }^{*} 333, * 334, * 335, *$ $336,{ }^{*} 337,{ }^{*} 338, * 340,{ }^{*} 344, * 345, * 402, *$ $403,{ }^{*} 404 . *$

method of fixing air-tight in stopper, 205.*

movements of, $217,218,{ }^{*} 219,{ }^{*} 220,{ }^{*} 221$ * of water plants, $337,{ }^{*} 338$,

osmosis in, 24 ?.

position of, 216, 217,218 ,

propagation by, 433 . 
Leaf, motection of, against animals by ljit. ter taste, $222,223$.

---1 hairs, 221.

- - - - hugging the ground, 223.

- - - - poisonous substances, 222.

- - - - priekles, 221.

- - - - spines, 221, 334.

- - - - teeth, 222, 334 .

$-\cdots$ texture, 223

$--\cdots-$ thorns, 221 .

- - - - enwrapping, 251, 2131.

- - - trying, by hairs, 213, 333, 331,* 345.5.

---- position, 21i, 218.*

- - - reduction of surface. 215, $332,342 . *$

- - - - - in number of stomata $21,235,336 . *$

- - - - rolling. folding, ete. 2213, $3: 34$.

- - - - sunken stomati, 215, 33.5, 337.*

- - - thicker cuticle, 333, 334, ${ }^{*}$ $337, * 33 \times *$

- - - - water-proof substances, ㄴ. $14,2 \pi 1,333,334$ *

- - - - water - retaining substan ces, 216.

raises sap, $2+2$.

respiration of, 144. 195.

seale, 347 .

shade, $344, * 345, *$

sleep position of, 21\%*

starch formation in, 182-203 (182,* 184, * $186, * 191$, , 192,* 193, , 198 , ${ }^{*} 199, * 201$, * $202^{\text {*h) }}$.

stareh in, 181, 182, ${ }^{*} 183$.

storage of food in, 260 .

strength of, how secured, 207 .*

$\sin , 344, * 345$.*

transpiration of $203^{*} 208,{ }^{*} 207,208^{*}$

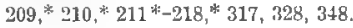

turns toward light, 217-219.

unequil growth of opposite sides of, 251.

rariegated, stareh in, 185.

veins of, 198, $199, * 2 * 25,267 . *$

water, $337, * 338, * 339{ }^{*} 340 . *$

withdrawal of nutriment from, in antumn, 332. 1.eaf, work of, 16?- 285

See, also, Seed-leaf and Stomati.

Luatf green. Sue Chlorophyll.

Leuf-mold, 107.

- capacity for holding water of, 132.

- test for humus in, 155.

Leaf-mosaic, 219.

Leaf'-sear, 212, 245, 332.

Lethery texture protects against anima]s, 223.

Isentiret, 232,*278, 279."

Leontodon. See Dandelion.

Lettuce, Prickly, sun- and shade-leaves of, 344 .*

Levees, protected by plants, 27.7 .

Life, length of, in plants, 286.

Light, absorbed by leaves, 201.

affects absorption of carbon dioxide, 207.

chemical action caused by, $182, * 1 \times 4, * 1 k i$, $195,196,201,316364,38$.

kills bacteria, 364,382 .

effect of, on chlorophyll, 184, 1 R.

$-\ldots$ color of fruit, 316.

- - direction of growtls of piant, 264,346 .

- - - evaporation from the soil, 11:

- - - eye, 196.

- - - flowers, 295, 290, 298, 308, 347, itis,

- - - form of plant, $184,{ }^{*} 1,7,261,127$, $328 * 329, * 344, * 345^{*}-348$.

- - fruit, $308,312,347$.

- - - fruit and flower production, 347.

- - - germination, $4^{-}$.

- - growth, 253.

- - leaves, $184,{ }^{*} 185,217-219$, : $34.4^{*}$ $345, * 346$.

- - Mould, 394.

portion of effective in heliotropism, 26 .

- - - stareh formation, 196.

relation of, to self-pruning of trees, ittr. stil.

- - - stareh formation, $182, * 184,{ }^{*} 145$ 201.

- - - stem, 264, 346

- - stomata, 207-209.

- - - trinspiration, 207 .

plectric, for growing plants, $: 346$.

neetherl by plants, 326 . 
Light filter, 265.

Lilac, food in buds of, 253.

Mildew of, 4140,407 ."

starch in, during winter, 259.

transpiration of, 204.

Lilium. See Lily.

Lily, embryo-sac of, 291 *

Jeaf-scar of, 212.

stomata of, 210 .

storage of food in, 313.

Lily, Pond. See Lily, Water.

Lily, Water, 282, 337. 330.

Lima Bean. See Bean, Jima.

Lime as fertilizer, 151, 153, 154.

benefits puddled soil, 129 .

destroys insects and fungi, 152.

effect of, on flora, 350 .

flocculates elay, 152.

for softening water, 152 .

how supplied to soil, 151.

needed by plants, 139 .

Iromotes decomposition, 152.

int s free plant-food, 152.

sweetens sour soil, 152 .

test for, 157.

Lime carbonate, dissolved by carbonir acid, $1+0$.

chloride as disinfectant, 364 .

(ralute, erystals, 232**at.

sulphate, as fertilizer, 151.

- etched by roots, 144.

- for casts, 76.

- - germination experiments, 44.

water, 34, 139.

Linden, change of fat to stareh in, 259.

dispersal of seeds of, 32:.*

fat of, in winter, 259.

protection of pollen of, 294.

Linnseus, floral elock of, 295.

Linum. See Flax.

Lipase, 170.

Liriodendron. See Tulip Tree.

Listerine as disinfectant, 364 .

Live-for-ever, protection of, against drying, 215.

storage of food in, 260.

- - water in, 334.

water reservoirs of, 216.

Loam, 108.
Loekjaw, 328, 380 .

Loeo weeds, 222.

Locust, protection against animals, 220.

Lodeman, on pruning, 264.

- spraying, 407.

Lonicora. See Honeysuckle.

Loughridge, acknowledgment to, $x$. on soil testing, 155, 160.

Lubbock, on pollination, 307 .

Lupine, dispersal of seeds of, 320 .

leaves of, follow sun, 218.

root-tubereles of, 149 ,

seed-covers of, hinder absorption, 25.

Lupine, Yellow, visited by bees, 299.

Lupinus. See Lupine.

Lye absorbs carbon dioxide, 34 .

and aleohol for blewehing leaf, 22.5.

softens bark, 248.

Lyle, on plant-breeding, 453 .

MaeDougal, on mutation, 453.

Madia. See Tar-meed.

Magnesium needed by plants. 139.

Magnolia, air-passages of, 280.

Mahonia, transpiration of, 204.

Maize. See Corn.

Malaria, 380.

Mallow, leaf of, follows sun, 218.

Rust of, 406.

Mallow family, cross-pollination of, 303.

Manure as general fertilizer, 148, 153.

as mulch, 115.

benefits puddled soils, 129 .

decomposition of, 383.

green, 150, 384.

nitrogen in, 147.

Maple, bird's-eye, 262.

dispersal of seeds of, $321,322,323, *$

flower-buds of, 286.

food in buds of, 253 .

preparation of, for flowering 286 .

protection of, against drying, 213.

Maple, Sugar, run of sap of, in spring, 243. 259.

Marble as fertilizer, 151.

dissolved by carbonic acid, 141.

etched by roots, 144.

Marking, apparatus for, 78 *

Marl as fertilizer, 151. 
Marrubium, See Horehound.

Marsh gas, 381.

Massee, on plant diserses, 407 .

Material, economy of, in construction, 265. 266.

MeKenny, on fertilizers, 153.

Meadows killed by flooding, 125. remain in good tilth, 129.

Meanders, experimental formation of, 111 , Means, on fertilizers, 153.

Meat, preservation of, 385,386 .

Medicago. See Alfalfa, Bur Clover.

Medullary rays, 232,* 233, 258.

Melampyrum. See Cow Whent.

Melilotus, leaves of, follow sun, 218.

Mentha. See Mint.

Mereurialis. See Dog's Mercury.

Mesembryanthemum. See Tee Plant.

Metabolism. See Chemical action in plantw.

Mexican Morning-Glory. See MorningFlory, Mexican.

Microseopie structure. See Histology

Mildew, 406, 407.*

Milk, action of ferments on, 172 .

as emulsion, 170 .

bacteria of, 372-378.

souring of, $37 \%$.

Mica, 107.

IIir ropyle, 8,*?

admits air, $30, * 31,32$.

funetion of, 10-24.

should be in contact with soil, $21, * 2 \cdot$.*

Mignonette attrarts inneets, 299.

Milling. 178.

Milner, on forkd, $17: 3$.

Mimulus. See Monkey Flower.

Nineral substances in soil, $136-160$.

Mint, rhizome of, 27 .

family, cross-pollination in, 30\%.

MLissing links, 443, 452 .

Mississippi, 382.

Mitehella. See Partringe-berry.

Moisture. See Water.

Molasses, 369, 389.

Molybdate of Ammonium. See Ammonium molybdate.

Monkey Flower, stigma of, 29 .

Monkshond, protection of pollen ut, 294.

- root, 161.
Monncolytedous are mostly shallow-rooted. 135.

hehavior of leaves of, in dark, 34\%.

characterized, 2020 .

have no cambium, $22 \mathrm{x}$.

Ionceeious plants, 302 .

Innstrosity, 420, 421, 449.*

Inon Flower, seed-cover of, hinders absorption, 25 .

Noor plants, protection against drying, 333.

Moors, absorption diffieult in, 336.

Moore, on bacteria, 384 .

Morphology, experimental. See Plinnt, form ot.

Morning-Glory, germination of, 81.

seed-cover of, hinders absorption, 25.

self- vs, cross-pollination of, 301, 302 .

twining of, 27.7 .

Ilexicin, seetl-rover of, hinders absorytion, 25.

Moss Rose. See Rose, Moss.

Ioths visit night-blooming flowers, 300 . visual powers of, 300 .

Mould, precautions against, 28, 72, 100, 102. 397.

bread, 391,* 392,*393,* 394,*395,* 396.*

green, $396,397 . *$

Movements of flowers, 296, 297.

- leaves, 217, 218,*219*220,*221.*

Mucor stolonifer, :49].

Mnleh for soil, 40,11.5, $116,{ }^{2} 117,125,1 \%$, $133,135,353$.

Mullein, hairy covering of leaf of, 213. protection of, against anima]s, 2n1.

- - drymess, 334, 335.*

Müller, on pollination, 307 .

Mushroom, power of growth of, 7 .

Iustard, effect of light on flowers of, ․ㅗ. germination of, 8.

Mustard family, cross-pollination in, 30:3.

Mustard, Yellow, structure of leaf of, 196. $197,198 * 200-202$.

Muscle-forming foods, 176.

Mutation, $330,442-444,{ }^{*} 445, * 446{ }^{*}{ }_{47}+-15:$,

Mycelium, 392, 402,

Nails used to promote fruit production, 319.

Nitreissus, pollen of', 293.

starch formation in, 183, 191, ${ }^{*} 193 .{ }^{*}$ 
Nareissus, stomata of, 196.

Nasturtiom, leaf-stalk of, as'ts as tendril, 270.

pollen of, 293.

Natural selection, 330, 331, 442-453.

Nectar attrats insects, 300 protection of, 245 .

Yectarine, origin of, 420 .

Needs of plant, 326.

Nepenthes, 1i:.

Nerium. See Oleander.

Vettle, pollen of, carried by wind, 300 . protection of, against animals, 2.1 .

Newman, on bacteria, 408.

Nicotiana. See Tobaren.

Nightshade family, rross-pollination of, 303.

Nitragin, 385.

Nitrates, produced by bacteria, 383-385.

Nitrate of potassium. See Potassium nitrate.

Nitrate of sibver. See Sllver nitrate.

Nitrate of soda. See Sodium nitrate.

Nitric acid. See Acid, Nitric

Nitrites produced by bacteria, $3 \times 3$ in:

Yitrogen combines with starch to form proteids, 253.

converved by plants, 176.

effect of, on plant, 349,350 .

escapes from soil, $148,149$.

how supplied to soil. 147, 14r, 149,* 1.in

in air, 149, 383-385.

- beans, 17 .

- eggs, 17 .

- peas, 17t.

- percolating water, 149.

needed by animals, 176.

- - plants, 139, 140,* 176.

prepared for plant by bacteria, $149,{ }^{*} 130$, $383-385$.

prepared for plant by fungi, $15 \%$.

produced by bacteria, "s

Jromotes leaf-, rather than frit-production, 318.

selected by plant, 161.

taken from air by bacteria, $383-5, x^{\prime}$

- - - some plants, 149 .

test for, in soils, 15.)

waste of, by animals, 176 .

Node, $32 \%$.
Node, growth at, 249, 250.

Sotching, to increase fruit production, "31\%.

Nucleus, 65." 66, $290,291, * 311$.

Nuphar. Ses Sunterdoek.

Nutrition. Siet Food.

Nuts, aburption of water by, $7,23, * 29$.

protection of, against drying, 31 .

- - seed of, 320.

Yymphra. Sef Lily, Water.

Oak, cambium of, $232, * 24 \rho$.

fibrous bundle of, 226 .

frod conreyed to fruit of, 313 .

latent buds of, 262.

path of water in, 226. 230, 29,* 233, 2\%, 235.

pollen of, carried by wind, 300 .

starch in, 259.

stem of, mieroscopic stracture of, sy... $233,234 . * 2 ;-\pi, 246$.

wood of, compared with wood of Pine, $235,238$.

Oat contains no pepsin, 172 .

germination of, 17 .

stomata of, 196.

orary of. $290 *$

pollen of, 290 .*

stigma of, 290 .*

style of, 290 .*

Oat, Wild, seeds of, bury themselves, $i l$.

Oat Rust, 404, 405.

Oat-smut. 400-401.

Odor attracts insects, 299,300 .

Enothera, See Primrose, Erening.

Oil, emnlsification of. $169,170$.

energy from. $17 \%$

formation of. 2 (1.

in eggs, 17i.

- fruits, 314.

- growing region, 253.

- seeds, 165, 177, 437 .

injures leaf, 215.

prodneed from starch, 314.

saponification of, 170,$1 ; 1$.

test for, 165, 259.

See, also, Fat.

Oil, Cocoanut, 169, 170.

Oil, Corn, 437.

Oil, Cottonseed, 147, 169, 170. 
Oil, Olive, 169, 170, 171.

Oily seeds, transformation of food in, 314 . Oleander, protection of, against drying, 215. 333, 337.*

transpiration of, 204.

Olive oil. See Oil, Olive.

Onion, germination of, $47,72,81$.

pollen of, 293 ,

roots of, 86.

storage of food in, 313 .

Opening and closing of flowers. See Flower.

Opium Poppy. See Poppy, Opium.

Opuntia. See Prickly Pear.

Orange rays eut out by cupra-ammonia, 265.

Orchids, cross-pollination of, 306, 307.

Orehis. See Orehids.

Oriental Poppy. See Poppy, Oriental.

Origin of species, 441-453.

Osmosis, 122, $123, * 124$.

generates pressure, 60, 61,*62.*

in seed, $60,63,64,67$.

makes stem rigid, 269.

of leaves, 242.

relation of, to growth, 64-68.

through seed-cover, $16, * 17,18,19, * 20$.

Osmotic pressure, measurement of $62, * 63$.

Ovary, $288, * 289,290$.*

correlation of, 360 .

Ovule, 288 ,* 312 .

Oxalate of ammonium. See Ammonium oxalate.

Oxalate of lime. See Lime oxalate.

Oxalic acid. See Acid, Oxalic.

Oxalis, dispersal of seeds of, 321.

opening and closing of flowers of, 29.5.

protection of, against water, 214.

sleep position of leaf of, 218.

(1) hows, experimental formation of , 111 .

Oxidation, as source of energy, 35, 173.

brought about by ferments, 173.

See, also, Combustion and Respiration.

Oxygen, absorption of, $33,31, * 35,36,175$, $194,195,200,287,317,388,390$.

given off by leaf, $191, * 192, * 193, * 194$, ] 11, . how suppiied to organisms, 176 .

useded for growth, $5,{ }^{*} 6,32,33, * 34, * 35$, $36,37, * 38,39, * 40,125,126,281, * 283$ 326.

See, also, Air.
Papaver. See Poppy.

Palisade cells, 198,* 199,* 200, 201.

effect of light on, 345 .

poorly developed in water-plants, 339.

Palms, pollen of, carried lig wind, 300 .

Pancreas, 169.

Pancreatic juice, 169-172.

Pansy hybrids, 428.

Parasitic bacteria, 380 .

Parenchyma of wounds, 319.

See, also, Cell parenchyma, Bast parenchyma and Wood parenchyma.

Parental characters. See Heredity.

Faris, plaster of. See Lime sulphate.

Parsley family, flowers of, 298.

Parsnip, flowers of, attract bees, 299.

storage of food in, 313.

sugar in, 122.

Partridge-berry, cross-pollination of, 304 , $305 . *$

Passiflora. See Passion Flower.

Passion Flower, 272.

calyx of, 288.

Pasteur's solution, formula of, 398 .

Pasteurization of milk, 377.

Pastintea. See Parsley.

Pastures, remain in good tilth, 1:9.

Paving, keeps air from roots, 126.

Pea, 89, 141-144.

absorption of water by seed of, 7 .

contains no pepsin, 172 .

eross-pollination of, 306 .

flower of, opened by bees, 308.

- - platform of 307 .

food in, 177.

germination of, 47 .

leaves of, follow sun, 21 ,

pocket of seed of, 20.

protection of fruit of, 320 .

P(ta, Sweet, pollen of, 292, 293.

Pea family, cross-pollination in, 303.

dispersal of seeds in, 321 .

protection of pollen iu, :94.

root-tubereles of, 149, 33't. 385 .

tendrils of, 272 .

l'eitbody, on foods, 173.

Peich, escilpe from seed-cover of, 54 . protection of, against drying, $21+, 317$. - fruit of, 320 . 
Peach, seed-cover of, 59.

- - hinders absorption, 25.

- - - path of water in, 9, 24.

sports of (Nectarine), 420.

Peanut, air-reservoir of, 42.

buries its seeds, 70 .

protection of fruit of, 320 .

strueture of fruit of, 3,4 . $^{*}$

Pear, epidermis of fruit of, 317.

hairy covering of leaf of, 213.

self-sterility of, 309 .

stomata of, 317 .

Pear, Prickly, cross-pollination of, 306 .

effect of moisture and darkness on, 329.

Pearl ash, 154.

Peat bogs, absorption difficult in, 217 .

Peat moss, kiljed by lime, 350 .

loves sour hunus, 351.

Pecan, escape from seed-covering of, 54 . opening in seed-cover of, $8,{ }^{*} 9$. path of water in seed-cover of, 9,24 .

Pectin compounds in fruits, 315.

Pelargonium, behavior of seeds of, $i 1$.

See Geranium.

Penicillium, 396, 397**

Pepsin, 171, 172.

Peptone, 369.

Perennials, flowering of, 286 .

Periwinkle, leaf-arrangement of, 220 , 221 .*

Petals, color of, $297-300$.

injury of, 288.

transformed into leaf-like bodies, 359 .

Petroselium. See Parsley.

Petunia, erossed with tobacco, 4;32.

Phaseolus. See Bean and Scarlet Runner.

Phleum. See Timothy.

Phoenix. See Date.

Phlox, protection of pollen of, 294.

Phosphorie acid. See Acid, Phosphoric.

Phosphorus, effect of, on production of flowers and fruit, 318,350 .

how supplied to soil, $150,151$.

needed by plants, $139,140 . *$

obtained from bones, 150 .

test for, in soils, 155, 156.

unites with starch in proteid formation, $25 \pm$.

Photosynthesis. See Starch-formation.

Phylloxera, 162.
Physiography, experiments in, 103-160.

Picea. See Spruce.

Pinchot, on forestry, 245.

Pine, cambium of, $236,{ }^{*} 246$.

correlation in, 339 .

eross-pollination of, 302.

dispersal of seeds of, 321,322 .

latent buds of, 262.

pollen of, carried by wind, 300,301 .

- - vesicles of, 301.

protection of, against drying, 333,334 .

- - fruit of, 320 .

wood of, compared with Oak wood, 235,

258.

- - mieroscopie structure of, 235, 236.*

Pine-apple, try psin in, 17:

Pink Bean. See Bean, Pink.

Pink family, eross-pollination of, 303 .

Pitcher Plant, pepsin in, $1 \%$.

Pith, I20,* 12l, 269.

Pits, $227 * 229,232, * 233,234, * 235$.

Plants, action of, in forming soil, 109.

alpine, 357,358 .

chemical action in, 166-177, 182-196, 253, $254,258,259,314-316$.

climbing, $270,271, * 272,273, * 274,275 . *$

decay of, 381.

dicotyledonous, 226.

diseases of, $397,398,{ }^{*} 399, * 400,401,402, *$ $403, * 404-407, * 408$.

- - darage done by, 400, 401, 406 .

- - prevention of, $400,401,407,408,440$.

engineering principles illustrated in struc. ture of, $266,267, * 268, * 269,270$.

forn of, effect of correlation on, 359 .

- - - furgi on, 359.

- - - light on, $184, * 185,261,327$, $328, * 329, * 344, * 34,5-348$

form of, effect of water on, $326, * 32-* *$ $328, * 329, * 330,331, * 332, * 333, * 334, *$ $335, * 336, * 337, * 338, * 339, * 340,{ }^{*} 341$, $342, * 343, * 344, *$

- - effect of wind on, $348, * 349, * 350$.*

food of, in soil, amount of, 146.

- - - dissolved by carbonic acid, $199-145$.

- - - - fixed by clay and humus, 145.

- - - - set free by lime, 152.

- needed by, 164-176. 
Plunts, habit of, 264.

has problems to solve, 6, 2y, 260 .

how supplied with air, $176,18 i^{*}-190,978$, $279, * 280, * 281, * 28,-285$

injury of, $79, * 86, * 26 \%$.

land $\mathrm{vs}$. water, $338,339, * 340,342$.

length of life of, 286.

monocotyledonous, $135,226,248,347$.

moncecious, 302 .

needs of, 6,326 .

poisonous, 222 .

selective action of, 161.

strength of, how secured, $266,267, * 268,{ }^{*}$ 269, 270 .

struggle of, for existence. See Struggle for existence.

supply carbon dioxide to aquaria, 285.

tendril beariug, 270-27t.

twining, 275, 276.

water, characteristics of, $337_{1}^{*} 33,0^{*} 339, *$ $340^{*}-342$.

weaving, 270 .

Plant-breeding, 331, 335, 409- $111, * 412-413, *$ $414,{ }^{*} 415, * 416, * 417,418, * 419, * 400-423, *$ $424,{ }^{*} 425, * 426, * 427, * 428,42 !, * 430$, $431^{*}-444_{1}{ }^{*} 445,{ }^{*} 446,{ }^{*} 447_{1}{ }^{*} 448^{*}, 449^{*}-$ 453.

Plant lice cause green flowers, 319.

Plantago. See Plantain.

Plantain, cross-pollination of, 303.

protection of pollen of, 295 .

Rattlesnake, prefers coniferous humus, 351.

Water, 34".

Planting stick, 40 .*

Plaster of Paris. See Lime sulphate.

Platinum wire, 366.

Plow sole, 126.*

Plowing, 126,* 127,* 128,* 1'u.

Plum, escape of , from seetl, 54.

flower of 431 ,*

improvement of, by breeding, $409-411,{ }^{*}$ $412,413,{ }^{*} 414, * 415,{ }^{*} 416,{ }^{*} 417$.

pollination of 430,431 .*

self'sterility of, 309 .

See, also, Prune.

Plum, American, 409, 410,411, $41 \%, 41:, *$

Apple, 410.

Sirtlett, 410,
Plum, Beach, 410.

European, 409, 411.

Improved Beach, 412, 41;,* 414.*

Japanese, 409, 410, 411.

Pond, 411.

Stoneless, $415,416, * 417$.

Plumeot, 415.*

Plumule, $1, * 2, *: ; * 4$,

protection of, $71, * 72,79 . *$

Pueumoniu, :imu.

Pocket around caulicle, $20, * 58 . *$

Pod, 3.

Poisonous plants, 222.

Pole Beaz. See Bear1, Pole.

Pollen, carried by insects, 289, 2911, 297-311.

- wind, 300, 301, 310, 311.

effect of, 309,311 .

exclusion of, 289.

germination of, $290, * 292,293, * 294$.

injured by raiu, 294.

protectinn of, 294, 295.

use of, 289 .

vitality of, 294 .

Pollen-tube, 290,*291*

attracted by stigma, 293, 294.

grows away from air, 298 .

Pollination, 289-311, 430-431,*435, 1jt.

cross-, 301 .

effect on ovary, etc., 309.

selt', 301.

Polygonatum. See Solomon's Seal,

Polygonum, protection of, aguinst mnimals, 223.

Water-, 335,*336,* 340.*

Pond Lily. See Lily, Water.

Pond Plnm, See Plum, Pond.

Pondweed, 339.

Poor-man's-weather-glass, Lehavior ot Hower's of, $295,296$.

protection of pollen of, 295 .

Pop corn, 7.

Poplar, buds formed on roots of, 249 .

cross-pollination of, 302.

flower-buds of, 286.

leaf of, hairy covering of, "213.

pollen of, "urried by wind, 300.

preparation of, for flowering, 286.

protection of, against drying, 214 .

- - water, 214. 
Poplar, transpiration of, 204.

Poplar, White, hairy covering, 213.

Poppy, needs light for germination, 47. position of tlowers of, 307 . protection of, against animals, 222.

Poppy, Opium, 427,* 428.

Poppy, Oriental, 427,* 428 .

Poppy hybrids, 427-429.*

Portulaca. See Purslane.

Potamogeton. See Pondweed.

Potash, as plant-food, 139,140 ,* how supplied to soil, 152 . increases fruit production, 318 . needed by plants, 139,140 ,* set free by lime, 1.52 .

Potassium, bichromate, as light filter, 265. chlorate, 235.

nitrate, 139, 148, 158 . permanganate, 364 .

Potato, correjation in, 360. cuticle of, 328.

effect of freezing on, 353 .

- - light on, 327, 328.*

- - water on, 326, 327,*328,* 329, 330. eyes of, 260.

for bacterial cultures, $365, * 366,36 \tau^{*}, 380$. protection of pollen by, 295 .

stareh in, 328.

stem nature of tuber of. 260 .

storage of food by, $260,297,31:$.

transpiration of, 328 .

Potato, Sweet, twining of, 275 .

Potato Vine, tendrils of, 270.

Potentilla. See Cinquefoil.

Powell, on pruning, 264.

Preservation of foods, $376,377,385-388,397$.

Priekles, effect of light on, 347 . protect against animals, 221 .

Priekly Lettuce. See Lettuce, Prickly.

Prickly Pear. See Pear, Prickly,

Primrose, cross-pollination of, 305. protection of pollen by, 294.

Primrose, Evening, Broad, 446,*447.* ।

- Dwarf, 445.*

- Lamarck's, mutations of, $443,444, *$ $445, * 446,447$;

- Pale, 447.*

Primula. See Primrose.

Propagation. See Reproductiou.
Protection against animals, etc., by luark, 256.

- - - bitter taste, 222, 260, 320 .

- - - coneealment, 260, 320.

- - - hairs, $221,256,260$.

- - - hugging the ground, 2y:

- - - - hard eoverings, 320.

--- poisonous substances, 162, 2202.

- - - prickles, 221.

- - - spines, 221, 256, 260, 320, 331,* 334.

- - - suspension, 320.

---1 teeth of leaf, 222, 394.

--- texture, 22s.

--- thorns, 221,260 .

- cold, 353,354 .

- drying by calyx, 288.

- - dispensing with leaves, $215,331, *$ $332, * 343 . *$

-- enwrapping leaves, $251,261$.

- - - hairy coverings, $213,333,334, *$ $335 . *$

- - - position of leaves, 217, 218.*

- - - reduction of leaf -surface, 21.7. $333,342 . *$

- - - - number of stomata, 21;, 335,336 .*

- - rolling and folding of leaf, 213 , 334.

- - - sinking of stomata, 215, 335, 337.*

- - - storage of water, $331, * 334$.

- - thicker cuticle, 333, 334,* 337,* $338 *$

- - water-proof substances, 214, 251, $333,334 . *$

- - water-retaining substances, 216.

- - - woody coverings, 317.

- dust by hairs, 214.

- fire by bark, 256.

- fungi by bark, 256.

- - callus, 263.

- water by callus, 263 .

- - - hairs, etc., 214.

- - wax, 214.

of plumule, $71,{ }^{*} 72, * 79 . *$

- root, $161,162$.

Proteids, decomposition of, 381 .

energy from, 173, 174 .

formation of, $201,253,254$. 
Proteisls, in animits, $171,172,176$.

- Beans, $17 \pi$.

- bran, 178.

- dietetics, 176.

- eggs, 176,17 .

- flour, 177 .

- fruits, :34.

- growing region, $2.73-2.4$.

- Peas, 17T.

- seeds, 165, 166, 314, 43í.

- Wheat, 1ir, 1ir.

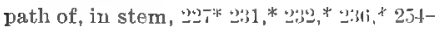
$2 \pi$.

tests for, $16,1,166$.

Protoplasm, 65,*66, ㄴ.11*

Prune. See Plum.

Prune, French, 411, 41 i, 416,*

Giant, 410, 411.

Stoneless, 415. 416,* 417 .

Sugar, 411.*

Prunier, sibs Noyau, $41.1,416 . *$

Pruning, 263, 346.

correlation in, 339 .

of roots to increase fruit-production, 319 . self-, 261.

Prunus, Stee Almond, Apricot, Cleerry, Peach, Plum and Prune.

Ptyalin, 167.

Puecinia. See Rust.

Pumpkiu, truit of, $31 \%$.

path of proteid in, 254.

tendrils of, $27^{2}$.

Purslane, protection of, from animals, 223 .

Pusley. See Purslane.

Putrefaction, 380.

Pyrus. See Apple, Pear.

Quaker Bonnets. See Houstonia,

Quaker Ladies. See Houstonia.

Quartz, 10.7. 107.

Quercus. See Oak.

Quince, absorption of water by seed of, $i$ 28.

brauches of, twisted in layering, 314.

seerl-fover of, holds water, 28.

Radish, absorption of water by sem of, 7 , 28.

germination of 47 ,
Radisli, relation of, to light, 265. root-hairs of, $100, * 101, * 121$. seed-cover of, holds witer, 29 .

Ragweed, protection of, against animals, 223.

Rain buries seeds, 69 .

percolation of, in soil, 111-118.

puddles soil, 129.

Ranunculus. See Buttercup.

Rape, 314.

Raphanus. See Radish.

Raspberry, acid in fruit of, 315.

climbing of, 270.

Rattlesuake Plantain. See Plantiliu, Ráttlesnake.

kaw Food. Sie Food, Raw.

Red rays cut ont by cupra ammoniil, 26.7.

Regeneration dependent on oxygen, $2 \mathrm{si}, *$ sx'

in stem, 257.

of root, siti.

- stem, $70^{\text {t }}$

Reproduction by seed, 291, ${ }^{*} 2 \mathrm{w}^{*}$ *

- spores, 362, $365,393,394, *$ in $39, * 396,{ }^{*}$ $397^{*}{ }^{*} 398,{ }^{*} 399, * 401,402,{ }^{*} 403,{ }^{*} 404$.* $^{*}$

- vegetative parts, $43{ }^{*}$.

Reseda. See Mignonette.

Resins absent from water-plants, ; 34 . proteet against drying, 214, 334 .

Resistance to disease, 440 .

Respiration defined, 17. .

increased by wounds, 3x,

measurement of, $34, * 17 \%$.

of animals, $35,176,104$.

- flowers, "28 7 .

- fruits, 317.

- leaves, 194, $19 \%$.

- Moulds, 394.

- seeds, 33, 34,*35, 36.*

- Yeast,

Reversion, $420,449, * 450$.

Rhamnus, Rust of, thi.

Rheum. See Rhubarb.

Rhizomes, function of, 277.

propagation by, 4:is

reximble roots, 27.

storige of fiuml in, von.

Rhizopus nigrieans, 391.

Rhubarb, bleaching of, 346 , 
Rlubarb, protection of root of, 162 ,

Ribes. See c'urrant.

Ricinus. See Castor-lean.

Riley on food of plant, 344.

Rind, function of, 25.

of root, $120, * 121$.

of stem, $224, * 225_{1}^{*} 232_{1}^{*} * 3 ;, 231 ; *$

starch in, 258 .

Ring, annual, $24 \vec{r}$.

bast-226, 246 .

cambium-246.

woody, 226, 246.

Ringing, 256, $257,31 \mathrm{~m}$

Ripening of fruits, 310.

- seeds, 314.

River water, plant-food in, 1 in

Rivers, self-purification of, ; 38.3 .38 .

Roberts, on fertilizers, 153 .

Robinia. See Loeust.

Rocks, decomposition of, $109,144,145$.

Roguing, 451.

Rogues, 451

Rolling of leaf protects it against drsiug, 213,334 .

Root, aëration of, $36,37,{ }^{*} 38,39, * 40,10: 3$, $119, * 120, * 124-126,128,130,132$.

aërial, $2-\bar{i} *$

absorption of water by, $88,102,10 \%, 119, *$ $120, * 121-123$ *

- - - affected by heat, 33:2.

- - - - - salts, 124, isti.

acid excreted by, 141-143,* 14, 145.

anchors plant in soil, $87^{*}$.

behavior of, to obstacles, $99 . *$

buds formed on, 249.

care of, 135, 136.

climbing, 275.*

contraction of, $x$

decomposes rocks, 144,145 .

depth of penetration of, 1;34, 135 .

direction of growth of, influenced by air, $89,98,135$.

- - - - centrifugal force, (1:9:2:* 94.

- - - - - food, 89,98 .

- - - - - grarity, 88,*89,*90,91,*

$92,93, * 94,95,98, * 99$.

- - - - heat, $89,9 \mathrm{k}$.

$=-\ldots-$ water, $89,95, * 96, * 97,4 \mathrm{~s}$
Root, elfect of heat on, $3: \%$.

- - water on the form of, $i+1$.

etehes marble and plaster of Paris, 14.

excretion by, $141-143, * 1+4,145$.

exploration of soil by, 133-135.

food in, 122, 125, 260.

fore $\theta$ of growth of, $81,82 * x^{*}, 3, \times 1, * 8.5$.

fungi ou, 150.

gives off earbonic acid, 141-14::, 144

growing region of, $85, * 86$.

mirroscopic structure of, $120 * 121$, , 5.5.

needs air, 12.5.

of water-plants, 339 .

osmotic action of, $123,1: 4$.

path of water in, $1200^{*}$ l's 1 .

penetration of soil by, $>1, * * 1, *$

propagation by, 4;.;.

protection of, 161,162 .

proteids in, 25 .

pruning of, 136 , $: 11 \%$.

regeneration of, 86 .

resemblance of rhizome to. 27.

selective action of, 161 .

shallow rs. deep, 87.

storage of food in 260 .

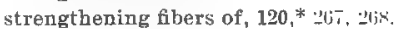

sugar in, 122.

tip of, how protected, 86 .

- - result of injury to, 86 .

treatment of, to promote fruit produetion, 34:.

tubercles of, $49 * 384,385$.

Root cap, 86.

Roothairs. absorb water by osmosis, 121$123, * 124,242$.

effect of water on growth of. 102.

method of obtaining, 100,*101.*

of radish, 100,* 101,*

of Wandering Jew, 102.*

relation to soil-particles, $119,120,121$.

turgidity of, 123.

Root-pressure, $243, * 244$.

Root-stock. See Rhizome.

Rosa. See Kose.

Rose, ealyx of, 288.

climbing of, $2 \vec{i} 0$.

protection of, against animals, 2.1. 1 .

Rose, Moss, origin of, by bud variation, 420. Rose, family, cross-pollination of, 303. 
Rosette form as protection against animals, 223 .

- of alpine plants, 357.

Rotation of crops, 160-161, 407, 408.

Roth, on forestry, 113, 245.

Rubber plant, 356 .

Rubus. See Blackberry, Raspberry.

Runoff, 113 .

Rushes, protection of, against animals, 223.

Russian Thistle, dispersal of seeds of, 322.

Rust, Black Stem, of Grain, 401, 402,*403,* $404, * 405$.

Crown, of Oats, $40 . \overline{\text {. }}$

Holly hock, 406.

Orange Leaf, of Wheat, 405.

Rye, germination of, 47 .

pepsin absent from, 172 .

Rust of, 405 ,

Smut of, 400,401 .

Saceharomyces. See Yeast.

Sage, cross-pollination of, 305-306.*

hairy covering of leaf of, 213.

structure of flower of, $306, * 307$.

brush, protection of against drying, 334.*

St. Lonis, water supply of, 382.

Sileratus, Iit.

Salicylic acid. See Acid, Salieylic.

Salix. See Willow.

Saliva, 166, 167.

Salt, 161 .

as preservative, 385,386 .

in osmosis, 18.

in soil, test for, 158 .

sets free potash, 152.

Salt Bush tolerates alkali, 350 .

Salt marshes, absorption difficult in, 217.

Saltpeter. See Potassinm nitrate.

Chili. See Sodium nitrate.

Salts in soil, 136-160.

- - fixation of, by soil, 145-147.

- - form crust, 127, 129.

- - hinder absorption, 18, 124, 217, 3366. needed by plant, 139, 140.*

protect plant against dryness, 216 .

Salvia. See Sitgre.

Sambucus. See Elder.

Sand, 104, 147.

bound together by plants, $27 \%$.
Sind, freed from plant-food, 155, 156.

microscopical examination of, 105.

percolation in, 113.

plant-food in, 105, 146.

power of, to lift water, 118.

properties of, 105.

water-holding capacity of, 132.

Sandy loam, 108

soil for cuttings, 262 .

Sap, rise of, 224-245, 259 (2) $24, * 225, * 227, *$ $231, * 232, * 234, * 236, * 237, * 238$, * $240, *$ $243 *)$.

Sap wood, 244, 245.

Saponification, $170,171$.

Saprophytic bacteria, 380 .

Saunders, on pruning, 264.

Scabiosa. See Scabious.

Scabious, protection of pollen of, 295.

Scale of boilers, 151.

Scale, bud. See Bud scale.

Scar. See Hilum.

Scarlet avoided by bees, 298.

Searlet fever, $329,376$.

Searlet Runner, 14.

absorption of water by soed of, 12 .

germination of, 59,60 .*

getting above ground of, 71 .

protection of tip of stem of, $71, * 79$.

transpiration of, 204 .

twining of, 275.

Scent. See Odor.

ven Schrenk, on woods, 24.5 .

- plant diseases, 407.

de Schweinitz, on milk, 377.

- plant diseases, 407.

Scion, 248.

Scirpus, strengthening filer's of, 267,*

Sclerenchyma. See Cell, Sclerenchyma.

Sea water, effect on germination of, 18 .

renders absorption difficult, 336 .

Seasoning of wood, 245.

Serale. See Ryo.

Sodges, protection of, against auimill4, 292.

s d dum. See Live-for-ever.

$\therefore$ sad, air-dry, contain water, 7.*

air needed by, $30, * 31,32, * 33,36,37, * 38$, $39,{ }^{*} 40$.

huritl of, in soil, 69,70 .

(2,1, ton dioxide given off by, $6,33,34,{ }^{*} 35$. 
Seeds, caulicle of, $1, * 2, * 3, * 4, * 20,7, ; *$ chaff of, holds water, 29.

diastase in, $168,169$.

dispersal of, by animals, $32 * 3, * 324, * 325$.

- - mechanieal contrivances, 320 , $321 . *$

- - water, $32 \%$.

- - wind, 321 , 322,** 323.*

affect of extremes of temperature on, $35^{2}$. embryo, 288, 312 .

embryo of, $1, * 2, * 3, * 4, * 20, * 56, * ;$, *

fat in, 165,437 .

fermonts in, 166-172.

food conveyed to, 313,314 .

- in, 65,* 164-180, 437.

- transformed in, 314 .

force exerted by swelling of, $\left\{x, 49^{*} 50\right.$, $51, * 32,53 * 54 *$

germ of. See Seeds Embryo of.

germination of, 1-86.

- - affeeted by air, $5, * 6$.

- - - alkali soils, 18.

- - - depth of planting, 38, 39,* 40,* 41.

- - - drying, 4 .

- - - heat, $5 * 6$.

-- light $4 \overline{\text {. }}$.

--- sea water, 18.

--- mater, 4,6 .

- - on surface of soil, 69.

- - quiekness of, 46.

getting above ground of, $71, * 72, * 73,{ }^{*}, t_{4}, *$ i5, ${ }^{*} 76,77, * 79 . *$

- down into ground of, $80,{ }^{*} 81,{ }^{*} 82,{ }^{*}$ x.i, $84, * 8 ., * 86$ *

heat set free by, 35,36 ,

hilum of, $1,2,10$.

immature, germination of, 43 .

lipase in, 170.

micropyle of, $8 * 9$.

mieroseopie structure of, $65, * 66,67,177$, 178.

needs of, 1 .

oil in, 165,437 .

osmotic action of, $17,18,60,63,64,67$.

path of water in, 22, 23,* 24 .

penetration of soil by, $80, * 81$.* pocket around caulicle of, $20, *$ in * preservation of $7,28,45,46,34$.
Seeds, proteid in, 437.

pepsin in, 172 ,

plumule of, $1,{ }^{*} 2{ }^{*} 3, * 4,20,{ }^{*} 58^{*} 59 *$

proteids in, $165,166$.

respiration of, $33,34,35,36$.*

resting period of, 43,44 .

restored by ferments, 44 .

ripening of, 314 .

starch in, 65, 164,435 .

structure of, $1, * 2, * 3, * 1, * 20,5 \pi, * 58, *$ $59, * 65, * 180$.*

struggle of, for existence, $31 \%$.

sugar in, 164, 165.

small, treatinent of, $41,42$.

testing of, 44,45 .

transportation of, 282.

trypsin in, 172.

vitality of, 44 .

water in, $T, * 4: T$.

- - how obtained, 6-50 $\left(7,{ }^{*} 8,{ }^{*} 9,{ }^{*} 15, *\right.$

$19 * 20 * 21, * 2, * 23 * 26 * 27 *$ ।

wrinkling of, in water, 8 *

Seed-beds, screens for, 41 .*

soil for, 41 .

Seed-case, $3, * 4, * 288, * 289, * 290,360$.

Seeil-corer, $1, * 2,{ }^{*} 3,{ }^{*} 4, * 20,21,23, * 24$.

eseape from, $48,49,{ }^{7} 50,51^{*}-54, * 5, i^{*} 57^{*}$ 58 , 59 , *60, * 61 , 62 , ${ }^{*} 63$, *

funetion of, 47,48 .

hinders absorption of air, $30,31,32$.

-- beat, $42, * 43$.

- - - water, $8,{ }^{*} 9^{*}-15,{ }^{*} 16^{*}-19, * 20,21, *$ $22 * 25 * 25$.

holds water, 28,29 .

openings in, $8, * 9^{*}-15, * 16^{*}-19, * 20,21, *$ $22, * 23 * 25$.

osmosis through, $16, * 17, * 18,19, * 20$.

place of rupture of, 54,58 .

Seed-leaves, $1{ }^{*}{ }^{*},{ }^{*} 3,{ }^{*} 4,{ }^{*} 178,17 !, 180 .{ }^{*}$

eontrasted with foliage-leaves, 180-186.

function of, 168, $164-179,180$.*

number of, 226 .

Seedlings. See Seed.

Selection, 331, 433-45̄3.

Self-pollination, 301, 302.

Self-sterility, 309.

Senecio. See Ragweed.

Septic tank, 382.

Serum, 171. 
Service berry, hairy covering of leaf of, 213 . Setchell, acknowledgement to, $x$.

Sewage, purification of, $381,382$.

Shade plants, 344 .

Shamel, work of, 434-439.

Shells as fertilizer, 151.

Shoot. See Stem.

Sidewalks exrlude air from roots, 126.

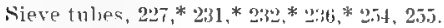

Silage, $38 \%, 38 \%$

Siliea, 145.

Silt, 118.

Silver grain. See Medullary rays.

Silver nitrate, 158.

Simple pits, 227,* 2:32.*

Size, increased by l,reeding, $410,411, * 411, *$ 416 , 422,423 ,

Sleep position of flowers, 291,295 .

- - leaves, $21 \%$.

Smallpox, 379.

Smut, 397-401.

Smut of Corn, 397, 398,*399,*400, 4411.

Smut of Grain, 400-401.

Smut, Stinking, 400 .

Snapdragon, flower of, opened by bees, ink. protection of pollen by, 294 .

Snow as muleh, 117.

Snyder, on fertilizers, $15 \%$.

- foods, 173, 178 .

Soap for softening bark, $24 \mathrm{k}$

Soda for softening water, 151.

in soils, test for, 158.

Soda-water dissolves marble, etc, , 141.

Sodium chloride. See Solt. nitrate as fertilizer, $148,153,1$ in.

- plant selects nitric acid from, 161.

sulphate in soills, 158.

- test for, 158.

Soil, absorption from, 103-16:.

affects the clistribution of plants, 351 .

action of rain on, 111-113, 129 .

aëration of, 126, 128.

air in, $36,37,{ }^{*} 3 \%, 39{ }^{*} 40,103,119, * 120, *$ $124-126,128,130,132$.

alkqli, 15i-15\%.

alluvial, 109.

as a labontory for prepuration of platrt-

fond, 140 .

as at innge, 1tij.
Soil as a storehouse of plant-forml, 116.

burial of seeds in, 69,70 .

capillary action of, 116.

ehemical action in, 14t-1533.

elassified, 108.

clayey, 106.

color of, 107, 108, 15i.

composition of, 104, 10. .

contact of, with seed, 21.

erust of, 116, 117, 125, 126, ${ }^{*} 127,130$.

drainage of, 40 .

drift, 109.

evaporation from, 115.

exploration of, by roots, 133-135.

formation of, $109,110$.

heart of, 107.

heat absorbed hy, tis.

- retained by, 4:3.

humus in, 104, 107, 1:2, 133, 14.5, 148, 3.1 .

- - test for, 15i.

injured by over-irrigation, 1:31.

- tilling at wrong time, 129.

lifts water, 114 .

lime supplied to, 1.i1.

- in, test for, 1.5

mechanical analysis of, 104 .

mellow, 107.

mineral substances in, $13 t \mathrm{j}-160$.

nitrogen supplied to, 147-150.

- in, test for, 1.5.

of arid regions, 146.

phosphorus supplied to, 150 .

- in, test for, 15. 150 .

physical condition of, 115,* $110, * 117^{*}$,

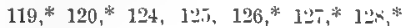

129-133, 384 .

potash supplied to, 1 i:.

plant-food in, 136-160, 201.

puddled, 125, 129.

requined by cuttings, ete., 108, 260. 26:\%.

salts in, 136-160.

sandy, 105 .

saturated, 118 .

sour, sweetened by lime, 1.iz.

temperature of, +3 .

lest $\times$ for, 1 ins-160

texture of. Shen Soil, Physieal andition wt.

tilth of. Sere Soil, Physical condition of. 
Soil, transported, 109.

washed away on slopes, 113.

water-holding capacity of, 13:.

water of, 103.

- - amount suited to plants, 130, 131.

- - how absorbed, 111-113, 129.

- - how regulated, 192, 133 .

Soil-erumbs, 124-127*, $128^{*}$.

Soil-floceules, $126,127,{ }^{*} 128$.

Soil-muleh, 115, ${ }^{*} 116,{ }^{*} 11 ;, * 12, ;,{ }^{*} 129,1 \ldots$.

Soil-particles, $119, * 120, * 128 *$

Solomon's seal, storage of form in, 313 .

Sorrel, wood. See Oxalis.

Spanish Bayonet, protection against animals, 2?1.

Spatterdoek, 337 .

Species, origin of, 441-453.

Sphagnum. See Peat Iloss.

Spines protect against animals, 221, 256, $260,320,331 . *$

Spiral tracheïds, 227,*229, 230, 231.*

Spongy tissue of leaf, 198,*199,*200.

Spontaneous generation, 365 .

Spores of bacteria, $302 . * 365$.

- Corn-Smut, 397, 398,* 399.*

- Mildew, 407.*

- Mould, 393, 394,* 395,*396, ${ }^{*} 39 \mathbf{7}^{*}{ }^{*}$

- Rusts, 401, 402,*403,*404.*

Sport. See Variation, sudden.

Spraying, 407.

with oil injures leaf, 215.

Spring, fat changed to starch in,

run of sap in, $243,259$.

sugar changed to starch in, 259.

Spring-wood, 232,*236, 247 .

Springs, formation of, 11 .

Spruce, protection against drying, 333. wood of, 230.

Squash, cross-pollination of, 302.

effeet of light on, $184, * 185$.

fibrous bundles of, $224, * 226,227$ *

fruit of, water conveyed to, 31\%.

germination of, $54 . * 55, * 56,81$.*

micropyle of, $8, * 9$.

path of proteid in, 224,*227,* 254-256.

- - water in, 224*-227,*228-230.

peg of $54^{*}-56$.

root-cap of, 86 ,

root pressure of, 243.
Ginush, sap of, forces which raise, 241 .

seed-cover of, holds water, thit

seedlings of, $184,{ }^{*} 185$.

sleep position of seed-leaf of, t21

stem of, microscopie structuro if, 224, $226,227, * 228,229,246$.

tendrils of, 272 .

transpiration of, 216.

Squash hybrids, 429.

squaw-vine. See Partridge-berry,

Squirrels, Ground, bury seeds, 69.

iquirting Cucumber. See Cucumber. Squirting.

Stannard, on soil, 133.

stareh, absorption of, from lears, $1 \times 2,25 \%$. as food, 164, 176.

changed to fat, $253,259$.

- - oil, $253,314$.

- - sugar, 167-169, 258, 314, 391.

eonveyed to wood, $232{ }^{*} 233$

decomposition of, $186,{ }^{*} 187$.

digestion of, 166-169.

disappears in darkness, 182,* 1 $4: 3$

energy from, 176, 196.

formation of, dependent on air supply, $191 . *$

$-\cdots-$ chlorophyll, $1 \times, 2$

- - - light, 182.

- - in variegated leaves, $1 \times i$.

- - - leaves, 182-203, (182,* 1int, 186 , $191, * 192, * 193, * 198, * 191, * 201$, * $202 *)$.

- - - stem, 278.

fuel value of, 176, 196.

in buds, 253.

- ehlorophyll gritins, 201, ${ }^{*} 202 . *$

- cortex, 258.

- flour, 177.

- fruits. 314.

- growing region, $253,254$.

- leaf-eells, 202.*

- medullary rays $232, * 233,258$.

- potato, 328.

- rind, 258 .

- seeds, $65 . * 164,314.437$.

- wheat, 17i, 178.

- wood, 232,*233, 257-25!

path of, in stem, 169, 2.it, 27. 2.is. 313. 314. 
Starch, rôle of, in proteid formation, 25.3. test for, 164.

wandering of, $169,183,253,254,313,314$.

Stareh-grains, 65, ${ }^{*} 66,201,{ }^{*} 202,{ }^{*} 367$, $^{*}$

Starch-trees, 259.

Steam pressure in boilers, 74.

Steapsin, 170.

Steel wire, 366.

Stem, air supply of, $278,279 * 280,281$, 282.

annual rings of, $232,{ }^{*} 236, * 24,262 . *$

bark of, $262 * 279$.

- - binding of 248 .

- - formation of, 256 .

- - function of, 256.

- - protects against dryness, 333 .

- - stretehing of, 247.

bast of, $120, * 224,{ }^{*} 225,227, * 231, * 292, *$ $233,236, * 254-257$.

behavior of, toward obstacles, $79 * 80$.

bending of, to increase fruit production, 318,342 .

binding of, 248 .

breaking, to increase fruit production, 318,342 .

buttresses of, 247. 248 .

cambium of, 227 ; 232 , * $236 * 246-248$.

ehlorophyll of, 278.

climbing, $270,271, * 272,273,274,275$, *

collenchyma of, 268.

correlation in, $79 * 257,359,360$.

direction of growth of, affected by cen. trifugal force, $92,93,{ }^{*}$ : 94 .

- - - - - gravity, 90, 91*, 92, 93*$95,264$.

$---\ldots-$ light, 261264,270 .

---- - wind, $348^{*} 349^{*}$ *

effect of frost on, 353 .

- - heat on, 346.

- - light on, 220, 261, 346, 350 .

elasticity of, 269.

epidermis of, 278 .

fat in, 253, 259.

fibrous bundles of, 224*, 225*, 226, 227*$231, * 232 *-234, * 235,236, * 240,2.44: 56$. food in, 169, 243, 250, 253,-260, 286, 287, 313,314 .

foree of growth of, $73, * 74, * 75,{ }^{*} 76$.* $^{*}$

function of, 163-285.
Stem, girdling, to increase fruit production, 257,318 .

method of fixing air-tight in stopper, 205. * microseopic structure of, $224, * 22^{*}-227^{*}$ $232 *-234 *, 235,236 *, 246,254-2,15,267$ * 268 , $328,333, * 334, * 335$.*

notehing, ta increase fruit production, 318 . one-sided development of, $349,350$. *

path of air in, $258,278,279 * 280, * 281, * 282$.

- - proteid in, 227, 231, 232, *236,* 2..44257.

- - starch in, $169,254,313,314$.

- - sugar in, 259.

- water in, $204^{*}, 225 * 226,227^{*}-231$, * $232 *-236, * 237, * 258$.

propagation by, 433 .

proteids in, 254 257.

pruning of, 261-264.

regeneration in, 257.

- of, 79 *

regions of growth of, 77 .* 78 .

rigidity of, due to osmosis, 269.

- - - strengthening tissues, $224_{1}^{*}$ $231, * 232, * 236, * 267, * 268-270$.

_- - - tissue tension, 268, 269.

rind of, $224, * 225, * 232, * 233,236, * 25,2,24$ ringing of, 244. 25", 318 .

self-pruning of, 261.

starch in, 169, 253, 254, 260,313, 311.

-formed in, 278.

storage of food in, $253,257-260,286,28$ -

strains of, due to wind, 20. .

strength of, how secured, 266, 267, 268 , * $269,270$.

strengthening fibers of, $224 * 231, * 232 *{ }^{*}$ $236, * 267, * 268$.

- - - effect of water on, 335 *

struggle among branches of, 261, 2li:.

sigar in, 243, 250, 2.54, 259.

sunseald of, 346 .

tendril-bearing, $270,271, * 272,273, * 2 \pi 4$

tip of, how protected, 79 .*

- - structure of, $226,250,{ }^{*} 251$.

twining, 275-277.

twisting, to increace fruit production, 318. underground, 260, 27 .

weaving, 270.

wood of, $224^{*}-227^{2}, 224-231^{*}, 232^{*}-234, *$ $235,230^{*}, 237^{*}, 216^{*}-240.4$ 
Stem, work of, 163-285.

See, also, Corm, Rhizome and Tuber.

Sterility, self-, 309 .

Sterilizer, 363.*

Stigma, 288*-290,* 291, 292.

Still, 137,*138.

Stinking Smut of Wheat, 400-401.

Stock, in grafting, 248.

Stomata, 196-198,* 199, * $203^{*}-206,{ }^{*} 207,208$, * 209 .

artificisl, 210,*211.*

effect of light on, 207-209, 345 .

function of, $207,208$.

mechanism of, 208, * 209,*210,*211,*

occur principally on under side of leaf, 215.

of fruit 317 .

- water-plants, 339.

protection of, against dust, 214.

- - - water, 214.

reduction in number of, as protection ngainst drying, $215,335,336$. *

sunken, as protection against drying, 215, 335,337 *

Stoneless Plum. See Plum, Stoneless.

Stoneless Prune. See Prune, Stoneless.

Stopper, method of fixing leaf or stem airtight in, 205.*

Storitge of food, See Food, Storage of.

- water. See Water, Storage of.

Strains in beams, 265.

- stem, 265.

Straw as mulch, 115.

benefits puddled soils, 129 .

Strawberry, effect of fertilization on, 309 . position of flower of, 307 .

protection of, from animals, 223.

Strength in relation to material, 265. 266.

Strengthening fibers. See Cell, Strengthen. ing.

Structure, Cellular. See Histology.

microscopic. See Histology.

Struggle for existence, 6, 46, 261, 262, 312 , $326,330$.

String Bean. See Bean, String.

Structure determined by function, 179 , 186 . *

Style, 288,* 289, 290,*

Sub-irrigation, 131.
Sublimate, corrosive, as disinfectant, 364.

Subsoil, 107, 146،

Suceulents, 215.

Sugar as preservative, 386 .

cane, 165 .

changed to stareh, 255 .

coagulates blood, 171.

decomposition of, 381 .

fermentation of, 390.

for yeast cultures, 389 .

formation of, 201.

in fruits, 314, 315, 411.

- growing region, 253, 254.

- osmosis experiments, $16,{ }^{*} 17,18,19$.*

- roots, 122.

- stems, 243, 250, 253, 254, 259.

- seeds, 164, 165.

- proteid test, $166,178$.

- stigma, 292.

produced from starch, 167-169, 258, 259, is $14,391$.

rôle of, in proteid formation, 253, 2.51.

test for, 164, 165 .

travels in cortex, $254,257$.

- - wood in spring, 259.

Sugar Beet. See Beet, Sugar.

Sugar Cane. See Cane, Sugar.

Sugar Corn. See Corn, Sugar.

Sugar Maple. See Maple, Sugar.

Sugar Prune. See Prune, Sugar.

Sulphate of ammonium. See Ammonium sulphate.

Sulphate of lime. See Lime sulphate.

Sulphate of sodinm. See Sodium sulphate.

Sulphur as disinfectant, 364 .

as remedy for plant diseases, 407.

in proteid formation, 253 .

needed by plants, 139, 140.*

Sulphuric acid. Seo Acid, Sulphuric.

Sundew loves sour humus, 351.

pepsin in, 172.

Sunflower, cross-pollination of, 304.

flowers of, 298.

- - effect of light on, 298.

germination of, 81 .

rise of sap in, 241.

root cap of, 86 .

root pressure of, 243.

seed of, $3 . *$ 
Sunflower, sted of, resting period of, $4 t$. seed-leaf of, sleep position of, 218 , stem of, $22+, 260$.

Sunlight. See Light.

Sunscald, 346.

Sinperphosphate, 139, 150, 153, 154.

Surface crust. See Soil, Crust of.

Surface mulch. See Soil muleh.

Sireet Pea. See Pea, Sweet.

Sireet Potato. See I'otato, Siwert

swingle, on Date Palm, 294.

- on Fig, 310.

- Smuts, 400.

- variation dne to enviromment, 421.

Switch Plants, 21., 331, 332,"343,*

Synergidæe, 291.*

Synclines, 111.

Syringa. See Lilite.

Taft, on soil, 133.

Tar excludes air from stems, 281.

Tirweed, dispersial of seeds of, :12t.

Teleutospores, 402."

T'emperature. Sere Heat.

Tendrils, $270,271 * 272,273 * 274$.

Terraces, experimentil formation of, 111.

Texture of soil. Ser Suil, Physical condition of.

Thigmotropism, 272, 2:-13, 274.

'Thinning of fruit. 312.

'Thistle, dispersal of seeds of, 321, :3:2

protection of, against animals, 221 .

Thurm apple, protection agitinst inimals, 222,320 .

Thorns protert against animills, ond.

'Thyme, visited lys hees, ans.

Thymus. See Thyme.

'Tilia. See Linden.

Ilillage. See Soil, Physical inndition nft.

Tilletia. See Smut, Stinking.

'Timothy, flower of', 280 .

'T'ilth. See Soil, Physieal condition of.

Tissue. Siee Cell and Histology.

l'nliteren crossed with Petunin, ti:2

fermentation of, 388.

'T'umatnes, canning of, 386.

immature sech of germinate, $4:$ :

improvement of, by breeding, 40!?,

T'onch-me-nut, Ses Jewelweed.
Toxins, 378, 379.

Tracheïl, 227, ${ }^{*} 929,230,231, * 233,234, * 235$, 236.*

Tradescantia. See Wandering Jew.

Transpiration, $203^{*}-205, * 206 *-208,209, *$ $210, * 11 *-218, * 317,328$.

affected by enwrapping leaves, 251, 261.

- - hairy coverings, 213, 233, 334, 335 ."

- - light, 206, 207.

- position of leaves, 217, 218.*

- - reduction of leaf-surface, 215, 331,* 3:;2* $33 \%, 342, * 343 *$

- - in number of stomata, 215, 335, 330 .

- - rolling and folding of leaf, $213,334$.

- - sinking of stomata, 215, 33., 337,*

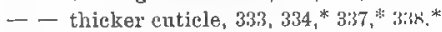

- - water-proof substances, 214, 느, $3 m, 334 . *$

- - water-retaining substances, 2lf.

- - wind, 208, 342 .

- - woody coverings, 31\%.

Transplanting, 135, 136, 220, 350.

Trees, buds on roots of, 249 .

offect of flooding on, 12.

- - frost on, 352, 33.

- - heat on, 346 .

- - light on, 220, 261, :340,359.

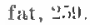

pruning of, 26 tis. 264.

rixts of, $87,1 \geq 5,136$.

- - fungi on, 150.

seed of, how preserved, 4 ti.

self-pruning of, 261.

stareh, 25t.

struggle among lyanelles of, "3i1, 262.

sunseald of 346 .

tritnsplanting of, $1: 1 ;, 2=0,: 34$.

treatment of, to increase frinit produc1ion, 315, 319, 342.

See, also, Forest ind stem.

Tree uf Heibren. Ëe Ailanthus

Triticum. See Whent.

Tropreolum. See Nasturtium.

Trypsin, 171, 1:2.

T'uber, propagation by, $4: 3$.

stem nitture of, 260 .

Tubercle biluteria, $149,351,385$.

Tubrerulosis, 366, 376, 380. 
Tulip, opening and closing of flowers of, 296. pollen of 293.

Tulip Tree, protection of, against dryness, 213.

transpiration of, 204.

Tumble weeds, 322.

Toumey, on forests, 113.

Turgidity, 123, 124, 209, 269.

Turnip, storage of food in, 260,313 .

Tuttle, acknow ledgement to, $x$.

Twinberry. See Partridge-berry.

Twining plants, $275,276,27$.

'Twisting to inerease fruit production, 318 , inis.

Type, $420,434,450$.

Typhoid fever, $371,376,379,380$.

llex. Seo Gorse.

Ulmus. See Elm.

Uredospores, 402.*

Urtica. See Nettle.

Urine, 48 ,

U. \&. Biological Survey, 356.

laboratory for plant-breeding, 441.

Dept. of Agriculture, publications of, 113 , $129,133,153,160,178,222,245,264,294$, $310,349,354,377,384,400,407,421,433$. 434,41 .

- - - soil surveys of, 351 .

forests of, 356 .

U'stilago. See Smut.

Vaceination, 379.

Variation, bud, 420 .

cause of, $421,4.50$.

curve of $417,418,{ }^{*} 419 . *$

due to crossing, $422,424,426, * 427^{*}-429$, $430,434$.

- - enviromment, 326-360.

fluetuating, 417, 418,* 419*-421, 44ㅇ, 443, $448, * 449,450$.

lack of, in vegetative propagation, 4.33 .

production of, 421 .

sudden, $420,421,442,443-145,{ }^{*} 446,{ }^{*} 44 i^{*}-$ $449, * 450-453$.

suppression of, $433-434$.

Varnish, absent from water-plants, 339 . protects against drying, 214, 333, 334.

Vegetable matter. See Humas.
Veins of animals, 17f.

- leaf, 225.

Verbascum. See Mullein.

Vernation as protection against drying. 213.

Vicis. See Horse Bean.

Vinca, leaf arrangement of, $220,{ }^{*} 221$.*

Vinegar as preservative, 386

manufacture of, 387.

Viola. See Violet.

Violet, dispersal of seeds of, 321.

protection of pollen of, 294 .

preferred by bees, 's. 48 .

Violet rays eut out potussium biehromate, 265.

Virginia Creeper attraks insects, sis. tendrils of, s-it.

Vitis. See Grape.

deVries, acknowledgement to, $x_{1}$, $n 9$, on origin of species, $442-4 ; \%$

Waite, on plant diseases, 407.

Walnut, cross-pollination of, 302 .

germination of. 59 .

leaf-scar of, 212.

seed of, path of water in, 23,* 24 .

- - structure of, $3,2 * * 24,59$.

seed-cover of, escape from, 54 .

- - holds water, 29.

- - openings in, $8,{ }^{*} 9,23, * 29$.

Wandering Jew, 102,* 138, 139, 110.* growth of, at nodes, 2.50.

root cap of, 86.

root-hairs of, 102.*

roots of, 102,"

stomata of, 196.

supplies carbon dioxide to aquaria, $2 R, 3$.

Ward, on plant diseases, 40T.

Wasp, power of scent of, 300 .

- - vision of, 300.

Water, absorption of, by root, 88, 102, 103, $119, * 120 *-123, * 332$ *

- - - seeds, $6,7^{*} 8, * 9^{*}-15, * 16-19$, $20, * 21 * 22, * 23, * 26, * 27$,

- - wood, 68 .

- - affected by heat, 332.

- - force required for, 121-123* 124.

- - hindered by dissolved salts, elr", 18, $124,217,336$.

- - - - seed.eover", 8-26. 
Yellow Lupin. See Lupin, Yellow. Yellow Mustard. See Mustard, Yellow. Yield increased by breeding, 414,* 435-437. Yueca. See Spanish Bayonet.
Zea. See Corn.

Zine, 161.

affects flora, 351 .

Zinnia, cross-pollination of, 304.

Zygospores, 396.* 


\title{
BOTANY
}

\section{An elementary text for schools}

\author{
By L. H. BAILEY \\ Professor of Horticulture in Cornell University
}

\section{With over 500 Illustrations. Half Leather. $12 \mathrm{mo}$. \$1.10, net}

"I have examined the book with much interest. It is easily seen that it is written with Professor Bailey's clearness and felicity of style; and I think it, as a whole, one of the most charmingly and appropriately illustrated of modern botanical text-books. I expect it to prove a stimulating and very useful work."-Professor W. F. Gaxisti, Smith College.

"It is the very best book that I have yet seen, and I shall take pleasure in using it in my class this year and in recommending it to others as occasion serves."-Herbert O. Clotgh, Albany Academy, Albany, N. Y.

"I note several features that appear to me worthy of special mention:-first, the illustrations that accompany the key; second, the introduction in a simple way of well-known facts of evolution as applied to plants as well as animals; third, the most important, the endeavor to have the student see the plant as a real live thing."-GilberT H. TrafTON, Normal School, Randolph, Vt.

"I consider it one of the best botanies on the market. Professor. Bailey is one of the best equipped men in the Lnited States to write on the subject of botany or horticulture. He expresses himself so elearly and writes so entertainingly that even the ordinary reader will find pleasure in perusing his botanies." - P. H. Mell, Director of state Experiment Station, Auburn, Ala.

\section{THE MACMILLAN COMPANY}

\author{
64-66 FIFTH AVENUE, NEW YORK \\ BQSTON \\ CHICAGO SAN FRANCISCO \\ ATLANTA
}




\title{
LESSONS WITH PLANTS
}

Suggestions for seeing and interpreting some of the common forms of vegetation

\author{
By L. H. BAILEY \\ Professor of Ho.ticulture in Cornell University
}

With delineations from nature by W. S. HOLDSWORTH, of the Agricultural College of Michigan

\section{Second Edition-446 illustrations-49 J pages \\ Half Leather. $12 \mathrm{mo}$. \$1.10, net}

"It is an admirable book, and eannot fail both to awaken interest in the subject and to serve as a helpful and reliable guide to young students of plant life. It will, I think, fill an important place in secondary schools, and comes at an opportune time when belps of this kind are needed and eagerly sought."- Professor V. M. SPALding, University of Michigan.

"I have spent some time in most delightful examination of it, and the longer I look, the better I like it. I find it not only full of interest, but eminently suggestive. I know of no book which begins to do so much to open the eyes of the student - whether pupil or teacher - to the wealth of meaning contained in simple plant forms. Above all else, it seems to be full of suggestions that help one to learn the language of plants, so they may talk to him."-DARWAN L. BARDWELL, Superintendent of Schools, Binghamton, N. Y.

\section{FIRST LESSONS WITH PLANTS}

The first twenty chapters of the larger work described above

IIT pages. II6 Illustrations. Cloth, 12 mo. 40 cents.

All of the illustrations of the original appear in these selected chapters, which are in no way abbreviated

"A remarkably well-printed and illustrated book, extremely original and unusually practical."-H.W. Foster, South Orange, N.J.

\section{THE MACMILLAN COMPANY}

\section{4-66 FIFTH AVENUE, NEW YORK}

BOSTQN CHICAGO SAN FRANCISCO ATLANTA




\section{WORKS ON BOTANY}

CAMPBELL. The Evolution of Plants. By Duvglas Hovghton CAMPBELL, Ph.D., Professor of Botany in Leland Stanford University.

Cloth, 12 mo. \$1.25

University Text-Book of Botany. By Douglas Houghton CAMPBell, Ph.D. With many illustrations.

Cloth, 8vo. \$4, net

GANONG.-The Teaching Botanist. A manual of information upon botanical instruction, together with outlines and direetions for a comprehensive elementary course. By Willian F. GaNONo, Ph.D., Smith College.

Cloth, 12 mo. Si. Io, net

MACDOUGAL.- The Nature and Work of Plants: An introduction to the study of botany. By D. T. MACDovGAL, Director of the Laboratories, New York Botanical Gardens. Cloth, 12 mo. 80 cents, net

SETCHELL.-Laboratory Practice for Beginners in Botany. By WILLIAMI A. Setchell, Ph.D., Professor in Botany in the University of California.

Cloth, I 2 mo. 90 cants, net

STRASBURGER. - Handbook of Practical Botany. For the botanical laboratory and private student. By Dr. E. Strasblrger, Professor of Botany in the University of Bonn. Translated and edited from the German, with many additional notes, by W. HillHodse, M.A., F.L.S., Professor of Botany in the Lniversity of Birminghan.

Fifth edition, rewritten and enlarged, with over 150 original illustrations.

Cloth, 8vo. \$2.60, net

STRASBURGER, NOLL, SCHENCK, and SCHIMPER_-A Text-Book of Botany. By EDWard Strasberger, Fritz Toll, Heivrich Schenck, and A. F. W. Schimper. Translated by H. C. Porter, Assistant Instructor of Botany, Cniversity of Pennsylvania. Tith 594 illustrations, in part colored.

Cloth, 8vo. \$4.50, net

VINES.-A Students' Text-Book of Botany. By S. H. VINES, Professor of Botany in the University of Oxford. With many illustrations.

Cloth, 8vo. \$3.75, net

An Elementary Text-Book of Botany. With 397 illustrations,

Cloth, 8vo. \$2.25, net

\section{THE MACMILLAN COMPANY}

\section{4-66 FIFTH AVENUE, NEW YORK}

BOSTON CHICAGO SAN FRANCISCO ATLANTA 




